\title{
Religion und Mobilität
}

Zum Verhältnis von raumbezogener

Mobilität und religiöser Identitätsbildung im frühneuzeitlichen Europa

Herausgegeben von

Henning P. Jürgens und Thomas Weller

Vandenhoeck $\&$ Ruprecht
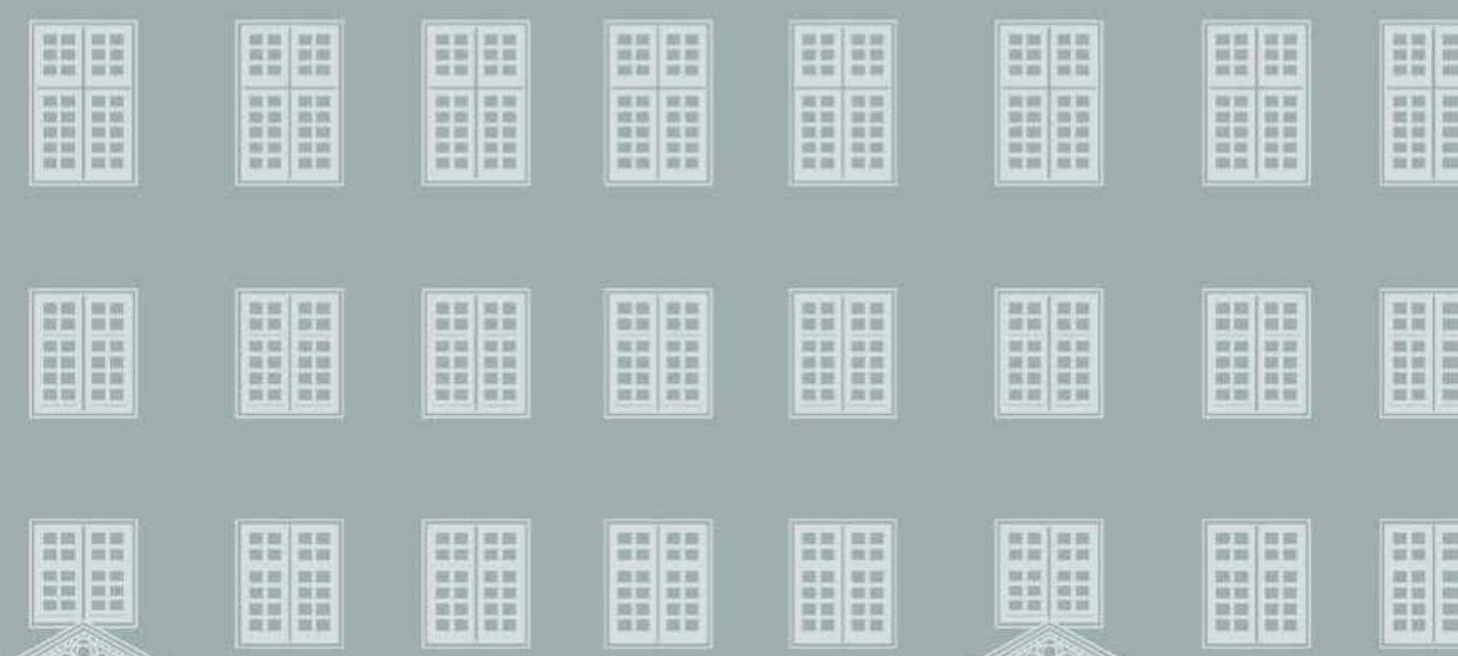
V\&R 


\title{
Veröffentlichungen des Instituts für Europäische Geschichte Mainz
}

\author{
Abteilung für Abendländische Religionsgeschichte \\ Abteilung für Universalgeschichte \\ Herausgegeben von Irene Dingel und Heinz Duchhardt
}

Beiheft 81

Vandenhoeck \& Ruprecht 


\title{
Religion und Mobilität
}

\section{Zum Verhältnis von raumbezogener Mobilität und religiöser Identitätsbildung im frühneuzeitlichen Europa}

\author{
Herausgegeben von \\ Henning P. Jürgens und Thomas Weller
}

Vandenhoeck \& Ruprecht 
Bibliografische Information der Deutschen Nationalbibliothek:

Die Deutsche Nationalbibliothek verzeichnet diese Publikation in der Deutschen Nationalbibliografie; detaillierte bibliografische Daten sind im Internet über https://dnb.de abrufbar.

(C) 2010, Vandenhoeck \& Ruprecht GmbH \& Co. KG, Theaterstraße 13, D-37073 Göttingen

Das Werk und seine Teile sind urheberrechtlich geschützt.

Die Beiträge sind als Open-Access-Publikation im Sinne der Creative-Commons-Linzenz BY-NC-ND International 4.0 (»Namensnennung - Nicht kommerziell - Keine Bearbeitung «) unter dem DOI 10.13109/9783666100949 abzurufen. Um eine Kopie dieser Lizenz zu sehen, besuchen Sie https://creativecommons.org/licenses/by-nc-nd/4.0/.

Jede Verwendung in anderen als den durch diese Lizenz erlaubten

Fällen bedarf der vorherigen schriftlichen Zustimmung des Verlages.

Satz und Redaktion: Vanessa Brabsche

Vandenhoeck \& Ruprecht Verlage | www.vandenhoeck-ruprecht-verlage.com

ISSN 2197-1056

ISBN 978-3-666-10094-9 


\section{Inhalt}

Henning P. Jürgens und Thomas Weller

Einleitung

Henning P. Jürgens

Die Vertreibung der reformierten Flüchtlingsgemeinden aus London.

Jan Utenhoves »Simplex et fidelis narratio«

Vera von der Osten-Sacken

Erzwungenes und selbstgewähltes Exil im Luthertum.

Bartholomäus Gernhards Schrift »De Exiliis« (1575)

Matthias Morgenstern

Unterwegs in symbolischen Räumen. Mobilität in der späten

jüdischen Vormoderne am Beispiel der Glückel von Hameln

Bettina Braun

Katholische Konfessionsmigration im Europa der Frühen Neuzeit -

Stand und Perspektiven der Forschung

Heinz Schilling

Die frühneuzeitliche Konfessionsmigration.

Calvinisten und sephardische Juden im Vergleich

Klaus Weber

Zwischen Religion und Ökonomie:

Sepharden und Hugenotten in Hamburg, 1580-1800

Susanne Lachenicht

Renaissance in der Diaspora?

Hugenottische Migration und Identität(en) im »Refuge«

Christian Windler

Katholische Mission und Diasporareligiosität.

Christen europäischer Herkunft im Safavidenreich

Felix Konrad

Soziale Mobilität europäischer Renegaten im

frühneuzeitlichen Osmanischen Reich 
Manuel F. Fernández Chaves and Rafael M. Pérez García

Mobility under suspicion. The Moriscos in early modern Spain

Margit Kern

Übersetzungsprozesse in der religiösen Kunst der Frühen Neuzeit:

Die Mission in Neuspanien

Thomas Weller

Vom Kaufmann zum protestantischen Märtyrer:

Johann Avontroot (1559-1633)

Almut Bues

»Altter gelaube« gegen »newerdachtten glauben« oder wen bewahrt Gott?

Martin Grunewegs interkonfessionelle Kontakte

Gesine Carl

»Ich beschlos zu fliehen. Aber wohin? das wust ich nicht«.

Konversionen von Juden zum Christentum und Mobilität

im 17. und 18. Jahrhundert

Marian Füssel

»Als Gefangener in ein ganz fremdes, abergläubisches

Land gebracht zu werden, stimmte meine Seele trübe«.

Kriegsgefangene in fremdkonfessionellem Umfeld und

militärische Migration während des Siebenjährigen Krieges

Matthias Asche

Von Konfessionseiden und gelehrten Glaubensflüchtlingen, von Konvertiten und heterodoxen Gelehrten.

Mobilitätsphänomene konfessionell devianter Professoren zwischen obrigkeitlicher Duldung, Landesverweis und freiwilligem Abzug

Autorenverzeichnis

Register 


\section{Henning P. Jürgens und Thomas Weller}

Einleitung

$\mathrm{Zu}$ den grundlegenden Neuerungen und Veränderungen am Beginn der Neuzeit gehört ein signifikanter Anstieg der Mobilität von Personen und Gütern. Im Zuge der bereits im 15. Jahrhundert einsetzenden europäischen Expansion drangen Abenteurer und Entdecker erstmals in entlegene Erdteile vor, ihnen folgten Kaufleute, europäische Siedler und Missionare, Soldaten und Sklavenhändler, die wiederum Waren und Menschen von einem Erdteil in den anderen und nicht zuletzt auch aus der >neuen< Welt nach Europa brachten $^{1}$. Zur gleichen Zeit sorgten die Verbesserung der Verkehrswege und technische Neuerungen aber auch innerhalb Europas für eine erhebliche Zunahme und Beschleunigung von Mobilitätsprozessen ${ }^{2}$. Doch spielten hier nicht allein technischer Fortschritt, Entdeckergeist oder Handelsinteressen eine Rolle, vielmehr stellte auch die Religion im Hinblick auf die angesprochenen Phänomene einen Faktor von nicht zu unterschätzender Bedeutung dar.

Zwischen Religion und Mobilität bestand wohl schon immer und besteht noch heute eine enge Wechselbeziehung. Die Mobilität von Gruppen und Individuen über territoriale und kulturelle Grenzen hinweg führt in der Regel auch zu einer Intensivierung des interreligiösen Kontakts. Dabei konnte sich der Faktor Religion einerseits als Mobilitätshindernis erweisen; so galten für Angehörige bestimmter Glaubensrichtungen zum Teil schon im Altertum strikte Aufenthaltsbeschränkungen ${ }^{3}$. Andererseits konnten und können religiöse Beweggründe raumbezogene Mobilität aber auch befördern, ja zum Teil überhaupt erst bewirken.

Von Beginn an war die Entstehung und Ausbreitung der großen monotheistischen Religionen untrennbar mit Prozessen raumbezogener Mobili-

1 Wolfgang Reinhard, Geschichte der europäischen Expansion, 4 Bde., Bonn 1983-1990; Frauke Gewecke, Wie die neue Welt in die alte kam, Stuttgart 1986; Nicholas Canny, Europeans on the Move. Studies on European Migration, 1500-1800, Oxford 1994.

2 Vgl. Wolfgang Behringer, Der Fahrplan der Welt. Anmerkungen zu den Anfängen der europäischen Verkehrsrevolution, in: Hellmut Trischler/Hans-Liudger Dienel (Hg.), Geschichte der Zukunft des Verkehrs. Verkehrskonzepte von der Frühen Neuzeit bis zum 21. Jahrhundert, Frankfurt am Main/New York 1997, S. 40-57; ders., Im Zeichen des Merkur. Reichspost und Kommunikationsrevolution in der Frühen Neuzeit, Göttingen 2002.

3 Zum Beispiel das Verbot für Juden, das als Aelia Capitolina wieder aufgebaute Jerusalem zu betreten; vgl. Christoph Markschiess, Zwischen den Welten wandern. Strukturen des antiken Christentums, Frankfurt am Main 1997, S. 15. 
tät verbunden ${ }^{4}$. Pilgerreisen und Wallfahrten; Heidenmission, reconquista und Kreuzzugsidee prägten das christliche Mittelalter ${ }^{5}$. Eine ganz spezifische Ausprägung und zuvor nicht gekannte Zuspitzung erfuhr das Verhältnis von Religion und Mobilität aber in der Frühen Neuzeit. Mehr noch als an die Ausbreitung des Christentums im Zuge der europäischen Expansion ist hier an die konfessionelle Spaltung der lateinischen Christenheit und die sich anschließende Konfessionalisierung in den Territorien zu denken, in deren Folge es zu Migrationsprozessen bisher ungekannter Größenordnung kam, bis hin zur Auswanderung ganzer Glaubensgemeinschaften nach Übersee ${ }^{6}$.

Dies darf freilich nicht darüber hinwegtäuschen, dass es in der Frühen Neuzeit auch noch ganz andere Motive für Mobilität gab: Wirtschaftliche Zwänge oder Interessenlagen, Kriege, Krisen und Hungersnöte, die Ausübung von Handel und bestimmten Gewerben, aber auch die akademische Ausbildung oder die adelige Standeserziehung konnten Menschen gleich welchen religiösen Bekenntnisses dazu veranlassen, sich auf Wanderschaft zu begeben ${ }^{7}$. Dabei sind zeitlich und/oder räumlich begrenzte Formen der Mobilität vom Phänomen der Migration zu unterscheiden. Migration ließe sich dann definieren als einmalige und dauerhafte oder aber periodische (saisonale) Wanderung von Individuen oder Gruppen über territoriale und kulturelle Grenzen hinweg ${ }^{8}$. Innerhalb der historischen Migrationsforschung ist allerdings die Überbewertung dauerhafter und die Vernachlässigung tem-

4 Die Motive der Mobilität sind in die grundlegenden Texte und religiösen Praktiken der drei monotheistischen Religionen eingeschrieben, von den Wanderungen des Volks Israel über die Missionsreisen des Paulus bis zum Hadsch nach Mekka.

5 Vgl. Arnold Angenendt, Geschichte der Religiosität im Mittelalter, Darmstadt 1997; Knut Schäferdiek (Hg.), Die Kirche des früheren Mittelalters, München 1978; Gillian R. Evans, The Church in the Early Middle Ages, London u.a. 2007; Diana WebB, Medieval European Pilgrimage c. 700-c. 1500, Basingstoke u.a. 2002; Nikolaus JASPERT, Die Kreuzzüge, in: Johannes Fried u.a. (Hg.), Weltdeutungen und Weltreligionen 600 bis 1500, Darmstadt 2010, S. 166-178.

6 Vgl. mit weiterer Literatur zuletzt Alexander SchunkA, Konfession und Migrationsregime in der Frühen Neuzeit, in: Ute Frevert/Jochen Oltmer (Hg.), Europäische Migrationsregime. Geschichte und Gesellschaft 35 (2009), S. 28-63; ders., Glaubensflucht als Migrationsoption. Konfessionell motivierte Migrationen in der Frühen Neuzeit, in: GWU 56 (2005), S. 547-564; Joachim BaHLcke (Hg.), Glaubensflüchtlinge. Ursachen, Formen und Auswirkungen frühneuzeitlicher Konfessionsmigration in Europa, Berlin 2008; ders./ Rainer BENDEL (Hg.), Migration und kirchliche Praxis. Das religiöse Leben frühneuzeitlicher Glaubensflüchtlinge in alltagsgeschichtlicher Perspektive, Köln / Weimar/Wien 2008.

7 Thomas Klingebiel, Migrationen im frühneuzeitlichen Europa. Anmerkungen und Überlegungen zur Typologiediskussion, in: Thomas Höpel/Katharina Midell (Hg.), Réfugiés und Emigrés. Migration zwischen Frankreich und Deutschland im 18. Jahrhundert, in: Comparativ 7 (1997), S. 23-38; CANNy, Europeans; Jochen Oltmer, Einführung: Europäische Migrationsverhältnisse und Migrationsregime in der Neuzeit, in: Oltmer / Frevert, Europäische Migrationsregime, S. 4-27.

8 Vgl. Dirk Hoerder/Jan Lucassen / Leo Lucassen, Terminologien und Konzepte in der Migrationsforschung, in: Klaus J. BADE u.a. (Hg.), Enzyklopädie Migration in Europa. Vom 17. Jahrhundert bis zur Gegenwart, Paderborn u.a. 2007, S. 28-53, hier: S. 36. 
porärer Migrationsformen zuletzt gerade als Defizit beklagt worden ${ }^{9}$. Unter dem weiter gefassten Begriff der Mobilität sollen im Folgenden Wanderungsbewegungen unterschiedlicher (zeitlicher und räumlicher) Reichweite in vergleichender Perspektive in den Blick genommen werden. Im Mittelpunkt steht dabei die Frage nach dem Verhältnis von Mobilität und religiöser Identitätsbildung.

Entscheidende Impulse für die Erforschung des Verhältnisses von Religion und Mobilität in der Frühen Neuzeit sind, ungeachtet aller Kritik, die zwischenzeitlich an diesem Forschungsparadigma geäußert worden ist ${ }^{10}$, nicht zuletzt von der Konfessionalisierungsforschung ausgegangen ${ }^{11}$. Religion ist dabei bislang jedoch vornehmlich als Impulsgeber für Mobilität wahrgenommen worden, obwohl einer der Hauptvertreter dieser Forschungsrichtung mit Recht darauf hingewiesen hat, dass es sich bei dem für das konfessionelle Zeitalter charakteristischen Typus der »Konfessionsmigration« lediglich um einen »besonders prominenten Teil eines viel weiter gespannten alteuropäischen Migrationsgeschehens « gehandelt habe ${ }^{12}$. Dass neben religiösen Motiven stets auch wirtschaftliche Interessen eine wichtige Rolle spielten, lässt sich am Beispiel der Sepharden ebenso gut erkennen wie an dem der calvinistischen Glaubensflüchtlinge: Auch wenn die religiöse Verfolgung oder gar Vertreibung in der Regel als Hauptgrund (Push-Faktor) für die Auswanderung anzusehen ist, spielte für die Wahl des Zufluchtsortes vielfach ganz andere, eben auch wirtschaftliche (Pull-)Faktoren eine Rolle ${ }^{13}$.

9 Ebd., S. 38.

10 Vgl. Heinrich Richard Sснміdт, Sozialdisziplinierung? Ein Plädoyer für das Ende des Etatismus in der Konfessionalisierungsforschung, in: HZ 265 (1997), S. 639-682; Luise ScHORNSchütте, Konfessionalisierung als wissenschaftliches Paradigma?, in: Joachim BAhlcke / Arno Strohmeyer (Hg.), Konfessionalisierung in Ostmitteleuropa. Wirkungen des religiösen Wandels im 16. und 17. Jahrhundert in Staat, Gesellschaft und Kultur, Stuttgart 1999, S. 63-77; Kaspar von Greyerz u.a. (Hg.), Interkonfessionalität - Transkonfessionalität - binnenkonfessionelle Pluralität. Neue Forschungen zur Konfessionalisierungsthese, Heidelberg 2003. Vgl. auch den Forschungsüberblick bei Stefan Ehrenpreis / Ute Lotz-Heumann, Reformation und konfessionelles Zeitalter, Darmstadt 2002, S. 67-71.

11 Vgl. insbesondere Heinz Schilling, Die niederländischen Exulanten des 16. Jahrhunderts. Ein Beitrag zum Typus der frühneuzeitlichen Konfessionsmigration, in: GWU 43 (1992), S. 6778; ders., Confessional Migration and Social Change. The Case of the Dutch Refugees of the Sixteenth Century, in: Paul Klep/Eddy van Cauwenberghe (Hg.), Entrepreneurship and the Transformation of the Economy $\left(10^{\text {th }}\right.$ and $20^{\text {th }}$ Centuries). Essays in Honour of Herman Van der Wee, Löwen 1994, S. 321-334; ders., Confessional Migration as a Distinct Type of Old European Longdistance Migration, in: Simonetta CAVACIOCCHI (Hg.), Le migrazioni in Europa, Secc. XIII-XVIII, Prato 1994, S. 175-189.

12 Heinz Schilling, Die frühneuzeitliche Konfessionsmigration, in: Klaus J. Bade (Hg.), Migration in der europäischen Geschichte seit dem späten Mittelalter. Vorträge auf dem deutschen Historikertag in Halle a.d. Saale, 11. September 2003 [2002], Osnabrück 2002, S. 67-89, hier: S. 68.

13 Vgl. dazu die Beiträge von Heinz Schilling, Klaus Weber und Susanne Lachenicht in diesem Band. 
Während es für die genannten Glaubensgemeinschaften nicht an monographischen Untersuchungen mangelt ${ }^{14}$, stellen sowohl die katholische Konfessionsmigration, die von der Forschung bislang noch kaum als eigenständiges Phänomen in den Blick genommen worden is $t^{15}$, als auch Vertreibung und Exil im Luthertum Forschungsdesiderate dar ${ }^{16}$.

Setzen die Forschungsbeiträge zur Konfessionsmigration die zentrale Bedeutung der Religion als Movens für die Mobilität von Gruppen und Individuen im frühneuzeitlichen Europa gewissermaßen immer schon voraus, so nimmt die traditionell sozialgeschichtlich dominierte historische Migrationsforschung religiöse Aspekte vielfach nur als einen Faktor unter vielen wahr ${ }^{17}$. Dies mag auch mit dem zeitlichen Zuschnitt vieler Darstellungen zu tun haben, die ihren Schwerpunkt auf die großen Wanderungsbewegungen des 19. und 20. Jahrhunderts legen ${ }^{18}$. Diese zeitliche Verengung des Blickwinkels erweist sich freilich schon bei oberflächlicher Betrachtung als willkürlich, ist doch zu Recht darauf hingewiesen worden, dass Mobilität und Migration schon im Spätmittelalter Massenphänomene waren ${ }^{19}$. Klaus J. Bade geht sogar noch weiter und erhebt das Phänomen der Mobilität gleichsam zur anthropologischen Konstante ${ }^{20}$.

14 Vgl. Heinz Schilling, Niederländische Exulanten im 16. Jahrhundert. Ihre Stellung im Sozialgefüge und im religiösen Leben deutscher und englischer Städte, Gütersloh 1972; Ulrich NiGGEMAnN, Immigrationspolitik zwischen Konflikt und Konsens. Die Hugenottenansiedlung in Deutschland und England (1681-1697), Köln 2008; Susanne LACHENICHT, Hugenotten in Europa und Nordamerika. Migration und Integration in der Frühen Neuzeit, Frankfurt am Main / New York 2010 [im Erscheinen]; Jonathan IsRael, European Jewery in the Age of Mercantilism (1550-1750), Oxford 1998; Yosef Kaplan, An Alternative Path to Modernity. The Sephardi Diaspora in Western Europe, Leiden 2000; ders., Between Christianity and Judaism in Early Modern Europe. The Confessionalization Process of the Western Sephardi Diaspora, erscheint in: Lothar Gall / Dietmar Willoweit (Hg.), Judaism, Christianity, and Islam in the Course of History: Exchange and Conflicts, München 2010.

15 Vgl. dazu den Beitrag von Bettina Braun in diesem Band.

16 Vgl. dazu den Beitrag von Vera von Der OSTEN-SACKen in diesem Band.

17 Vgl. aber zuletzt Susanne Lachenicht (Hg.), Religious Refugees in Europe, Asia and North America $\left(6^{\text {th }}-21^{\text {st }}\right.$ century), Münster 2007.

18 Zwei typische Beispiele: Leslie PAGE Moch, Moving Europeans. Migration in Western Europe since 1650, Bloomington u.a. ${ }^{2} 2003$; Klaus J. BADE, Europa in Bewegung. Migration vom späten 18. Jahrhundert bis zur Gegenwart, München 2000. Eine Überblicksdarstellung mit wahrhaft enzyklopädischem Anspruch, sowohl in zeitlicher wie räumlicher Hinsicht, ist hingegen vorgelegt worden von Dirk HoERder, Cultures in Contact. World Migrations in the Second Millenium, Durham/London 2002. Die der frühneuzeitlichen Konfessionsmigration zuzurechnenden Phänomene nehmen darin allerdings gerade einmal 26 von 779 Seiten ein, vgl. ebd., Kap. 4: The End of Intercivilizational Contact an the Economics of Religous Expulsions, S. 92-107.

19 Ernst Schubert, Latente Mobilität und bedingte Sesshaftigkeit im Spätmittelalter, in: Bade, Migration, S. 45-65.

20 »Den >homo migrans $<$ gibt es, seit es den >homo sapiens< gibt «, BADE, Europa in Bewegung, S. 11. Umso unverständlicher ist es, dass auch die von ihm federführend mitherausgegebene, umfänglichste Überblicksdarstellung in deutscher Sprache erst im 17. Jahrhundert einsetzt. Ironischerweise lautet auch dort gleich der erste Satz: »Migration gehört zur Condition huma- 
Jegliche Form von Mobilität innerhalb des seit der Mitte des 16. Jahrhunderts konfessionell gespaltenen und insbesondere an seinen Rändern schon seit dem Mittelalter multireligiösen Europa musste aber geradezu zwangsläufig Fragen des interkonfessionellen und interreligiösen Kontakts, des Neben-, Mit- oder Gegeneinanders von Religionen aufwerfen. Im Zuge der Konfessionalisierung und der Ausbildung frühmoderner Territorialstaaten, in denen die einheitliche Konfession der Untertanen vielfach als Klammer für einen politisch-rechtlich, häufig auch ethnisch heterogenen Untertanenverband diente, spitzten sich diese Fragen zu. Ob die »Flucht aus religiösen Gründen« am Ende des 17. Jahrhunderts wirklich bereits »an Bedeutung verloren « hat$\mathrm{te}^{21}$, wäre vor diesem Hintergrund zu diskutieren. Immerhin mangelt es auch für das 18. Jahrhundert nicht an Gegenbeispielen, wobei die Vertreibung der Protestanten aus Salzburg nur das prominenteste ist ${ }^{22}$. Aus Sicht der Zeitgenossen jedenfalls spielten religiöse Fragen im Zusammenhang mit Mobilität und Migration offenbar auch weiterhin eine zentrale Rolle, wie sich etwa an den Selbstzeugnissen von Kriegsgefangenen und Soldaten zur Zeit des Siebenjährigen Krieges erkennen lässt, die ihre von der jeweils anderen Konfession geprägte Umwelt als signifikant anders und fremd erlebten ${ }^{23}$.

Der vorliegende Band, der die Ergebnisse einer internationalen Tagung am Mainzer Institut für Europäische Geschichte dokumentiert ${ }^{24}$, hat sich zum Ziel gesetzt, die beiden vorstehend skizzierten Forschungsstränge zusammenzuführen, um auf diese Weise religions- und migrationsgeschichtliche Fragestellungen enger miteinander zu verzahnen. Religion gerät im Folgenden also einerseits als Movens für Mobilität in den Blick, wobei nicht nur die großen christlichen Konfessionen betrachtet werden, sondern auch das Judentum und der Islam. Andererseits richtet sich das Augenmerk auf den interreligiösen Kontakt als Konsequenz von anders motivierten Mobilitätsprozessen. Dabei treten Angehörige bestimmter sozialer Gruppen in den Vordergrund, die aufgrund ihrer spezifischen Tätigkeit besonders mobil waren, wie etwa Kaufleute oder Soldaten, aber auch Personen, die aus ganz an-

na wie Geburt, Vermehrung, Krankheit und Tod«, Klaus J. BADE u.a., Die Enzyklopädie: Idee - Konzept - Realisierung, in: Ders., Enzyklopädie, S. 19-27, hier: S. 19.

21 Hoerder, Terminologien und Konzepte, S. 29.

22 Vgl. Mack Walker, The Salzburg transaction. Expulsion and redemption in eighteenth-century Germany, Ithaca u.a. 1992; Charlotte E. HAver, Von Salzburg nach Amerika. Mobilität und Kultur einer Gruppe religiöser Emigranten, Göttingen 2005; Gabriele EMrICH, Die Emigration der Salzburger Protestanten 1731-1732. Reichsrechtliche und konfessionspolitische Aspekte, Münster 2002; Raymond Ditтrich, Die Lieder der Salzburger Emigranten von 1731 /32. Edition nach zeitgenössischen Textdrucken, Tübingen 2008.

23 Vgl. den Beitrag von Marian Füssel in diesem Band.

24 Vgl. »Religion und Mobilität, Wechselwirkungen und Interdependenzen zwischen raumbezogener Identität und religiöser Identitätsbildung«, Institut für Europäische Geschichte, Mainz, 12.02.-14.02.2009, Tagungsbericht von Carsten BRALL, Sina KALIPKE und Johannes WischmeyeR <http://hsozkult.geschichte.hu-berlin.de/tagungsberichte/id=2584>. 
deren, zum Teil individuellen Gründen religiöse Grenzen überschritten. Bei allen untersuchten Fallbeispielen soll es darum gehen, das Verhältnis von raumbezogener Mobilität und religiöser Identitätsbildung im frühneuzeitlichen Europa genauer zu bestimmen.

Religiöse Identitätsbildung wird dabei als ein Resultat von Selbst- und Fremdzuschreibungen der betroffenen Akteure verstanden ${ }^{25}$. Dieser Prozess lässt sich im Fall der dauerhaften Migration zum Teil über mehrere Generationen verfolgen. Die Ergebnisse konnten von der sozialen Akkomodation beziehungsweise Integration bis hin zur Assimilation an die Mehrheitskultur reichen, aber auch zur Bildung von Diasporen führen. Migration und Exil konnten die Ausbildung und Festigung einer entsprechenden (Gruppen-)Identität überhaupt erst ermöglichen oder befördern, ja sogar zur Ausformulierung einer entsprechenden Theologie führen ${ }^{26}$, umgekehrt konnte es aber unter den Bedingungen des Exils oder der Diaspora auch zu einer Aufgabe oder einem allmählichen Verlust religiöser Identität kommen $^{27}$.

In diesem Zusammenhang spielte es wohl generell eine bedeutende Rolle, ob sich die betreffenden Akteure dauerhaft oder nur temporär in der Fremde aufhielten, ob sich Individuen oder Gruppen, womöglich gar ganze Glaubensgemeinschaften auf Wanderschaft begaben und ob der Ortswechsel freiwillig oder unter Zwang vollzogen wurde, wie etwa bei den Morisken oder den christlichen Sklaven im Osmanischen Reich ${ }^{28}$. Schließlich dürfte auch der kulturelle >Abstand zwischen Ausgangs- und Zielkultur beziehungsweise die Existenz oder Nichtexistenz wechselseitiger Feindbilder den Prozess der religiösen Identitätsbildung in je unterschiedlicher Weise beeinflusst haben.

Offenbar beförderte die durch Mobilität vermittelte Erfahrung religiöser Pluralität häufig die Ausbildung multipler oder hybrider Identitäten ${ }^{29}$. In diesem Zusammenhang wäre darüber zu diskutieren, ob der Typus des religiö-

25 Vgl. Aleida Assmann/Heidrun Friese (Hg.), Identitäten, Frankfurt am Main 1998; Elisabeth Vogel (Hg.), Zwischen Ausgrenzung und Hybridisierung. Zur Konstruktion von Identitäten aus kulturwissenschaftlicher Perspektive, Würzburg 2003.

26 Nach Schilling, Niederländische Exulanten, S. 77, ein charakteristisches Merkmal frühneuzeitlicher Konfessionsmigration; vgl. dazu auch die Beiträge von dems., Vera vON DER OstenSACKen und Henning P. Jürgens in diesem Band.

27 Vgl. Robin Cohen, Global Diasporas. An Introduction, Seattle 1997, S. 172; sowie den Beitrag von Susanne LACHENICHT in diesem Band.

28 Vgl. die Beiträge von Manuel F. Fernández Chaves / Rafael M. Pérez García und Felix Konrad in diesem Band.

29 Vgl. dazu auch die Überlegungen von Dirk Hoerder, Transcultural States, Nations, and People, in: Ders. / Christiane Harzig / Adrian Shubert (Hg.), The Historical Practice of Diversity. Transcultural Interactions from the Early Modern Mediterranean to the Postcolonial World, New York 2003, S. 13-32, hier: S. 14; sowie den Beitrag von Margit Kern in diesem Band. 
sen Grenzgängers, wie er in einigen Beiträgen aufscheint ${ }^{30}$, nicht vielleicht ebenso charakteristisch für die frühneuzeitlichen Verhältnisse war wie die Markierung und Verfestigung konfessioneller Grenzen und Identitäten durch Kirchen- und Gemeindezucht ${ }^{31}$. Beide Phänomene stehen ganz offensichtlich in einem engen wechselseitigen Bedingungszusammenhang ${ }^{32}$.

Charakteristisch für den Umgang mit der Erfahrung religiöser Differenz im Zusammenhang mit frühneuzeitlichen Migrationsprozessen waren Reinheitsvorstellungen, wie sie sich auf Seiten der aufnehmenden Gesellschaften ebenso nachweisen lassen wie auf Seiten der Migranten ${ }^{33}$. Der Kontakt mit Andersgläubigen wurde von den Zeitgenossen vielfach als Bedrohung für die Reinheit des sozialen Körpers wahrgenommen. Dies lässt sich an der Furcht der spanischen Inquisition vor einer Infiltration der spanischen Gesellschaft durch konvertierte Juden, moriscos oder auch auswärtige Protestanten ebenso zeigen ${ }^{34}$ wie an den Bemühungen von Flüchtlingsgemeinden, zentrifugalen Kräften innerhalb der eigenen Gruppe oder schädlichen Einflüssen von außen durch identitätsstiftende und disziplinierende Maßnahmen Einhalt zu gebieten.

Binnen- und Außenwahrnehmung einer Gruppe konnten dabei mithin erheblich voneinander abweichen, häufig trifft man auch auf konträre $\mathrm{Zu}$ schreibungen innerhalb der Ausgangs- und der Zielkultur. Galten etwa die emigrierenden Hugenotten in Frankreich als Protestanten, so wurden sie in den Aufnahmeländern oft in erster Linie als Franzosen betrachtet. Hier markierten also nicht mehr religiöse, sondern regionale bzw. sprachliche oder ethnische Zuschreibungen die Differenz ${ }^{35}$. Analoge Vorgänge lassen sich bei vielen anderen Gruppen beobachten.

Dies wirft allgemein die Frage nach dem Stellenwert von Religion im Verhältnis zu anderen Unterscheidungsmerkmalen wie Ethnie, Geschlecht oder

30 Vgl. die Beiträge von Almut Bues, Gesine CARL und Thomas Weller in diesem Band; dazu auch Monika Fludernik (Hg.), Grenzgänger zwischen Kulturen, Würzburg 1999.

31 Heinrich Richard Schmidt, Kirchenordnung und Kirchenzucht im reformierten Europa, in: Ansgar Reiss / Sabine WitT (Hg.), Calvinismus: Die Reformierten in Deutschland und Europa, Katalog zur Ausstellung des DHM Berlin 2009, S. 351-356; ders., Gemeinde und Sittenzucht im protestantischen Europa der Frühen Neuzeit, in: Peter BliCKLE (Hg.), Theorien kommunaler Ordnung in Europa, München 1996, S. 181-214; Judith BECKER, Gemeindeordnung und Kirchenzucht. Johannes a Lascos Kirchenordnung für London (1555) und die reformierte Konfessionsbildung, Leiden 2007; Heinz Schilling (Hg.), Kirchenzucht und Sozialdisziplinierung im frühneuzeitlichen Europa, Berlin 1994.

32 Vgl. die Beiträge des Sammelbandes Ute Lotz-Heumann u.a. (Hg.), Konversion und Konfession in der Frühen Neuzeit, Gütersloh 2007.

33 Vgl. dazu allgemein Peter Burschel/Christoph Marx (Hg.), Reinheit, Wien/Köln/Weimar 2010 (im Erscheinen).

34 Max Sebastián Hering Torres, Rassismus in der Vormoderne. Die Reinheit des Blutes im Spanien der Frühen Neuzeit, Frankfurt am Main / New York 2006.

35 Vgl. die Nachweise bei Lachenicht (S. 172, Anm. 13-15, und S. 176) in diesem Band. 
sozialer Standeszugehörigkeit auf. Generell wird man unterstellen dürfen, dass die Identität einer Gruppe dann besonders stabil war, wenn mehrere Differenzen, etwa religiöse, sprachliche und ethnische, miteinander korrelierten und sich wechselseitig verstärkten. Unter den besonderen Bedingungen von Flucht und Diaspora konnte die Zugehörigkeit zu einer Religionsgemeinschaft andere Unterschiede zwischen den Mitgliedern der Gemeinschaft aber auch zeitweise überlagern. Dies gilt bemerkenswerterweise auch für religiöse Binnendifferenzierungen. So lässt sich etwa am Beispiel der europäischen Christen im Safavidenreich erkennen, wie die Unterschiede zwischen den christlichen Konfessionen unter den spezifischen Bedingungen der Diaspora an Bedeutung verloren - zu einer Zeit, als innerhalb Europas von einer Abschwächung der konfessionellen Gegensätze noch keineswegs die Rede sein konnte ${ }^{36}$. Neben der räumlichen Distanz zu den Zentren der konfessionellen Auseinandersetzungen spielte hier wohl vor allem der Umstand eine Rolle, dass die Differenz zur nichtchristlichen Umwelt die innerchristlichen Gegensätze zurücktreten ließ. In anderen Kontexten konnte sich die religiöse Differenz zur Mehrheitskultur mit der Zeit aber auch verflüssigen. Am Beispiel des hugenottischen Refuge wird etwa das Problem der Weitergabe konfessioneller Identität an die nächste Generation unter den Bedingungen des Exils greifbar, ein Problem, das sich offenbar besonders dann stellte, wenn ganze Gemeinden auswanderten, die sich über ihren Status als Flüchtlinge definierten, zugleich aber einem hohen Assimilationsdruck seitens der aufnehmenden Gesellschaft ausgesetzt waren ${ }^{37}$.

Wenn im Titel des Bandes von raumbezogener Mobilität die Rede ist, so ist damit der physisch-geographische, in Abgrenzung vom sozialen Raum gemeint. Dass horizontale (raumbezogene) und vertikale (soziale) Mobilität einander indes durchaus bedingen können, zeigen gleich mehrere der hier versammelten Beiträge: So versprachen sich die irischen Migranten, die in die Dienste auswärtiger Armeen traten, davon häufig ebenso einen sozialen Aufstieg, wie viele zum Islam übergetretene Christen, die sich dem osmanischen Sultan andienten ${ }^{38}$. Doch auch der physisch-geographische Raum trat den Akteuren stets als ein sozial und religiös angeeigneter Raum entgegen ${ }^{39}$, raumbezogene Mobilität implizierte daher häufig das Überschreiten religiö-

36 Vgl. den Beitrag von Christian WindLeR in diesem Band.

37 Vgl. dazu den Beitrag von Susanne Lachenicht (S. 169-182) in diesem Band.

38 Vgl. die Beiträge von Marian Füssel und Felix Konrad in diesem Band; Matthias Asche, Krieg, Militär und Migration in der Frühen Neuzeit. Einleitende Beobachtungen zum Verhältnis von horizontaler und vertikaler Mobilität in der kriegsgeprägten Gesellschaft Alteuropas im 17. Jahrhundert, in: Ders. u.a. (Hg.), Krieg, Militär und Migration in der Frühen Neuzeit, Münster 2008, S. 11-36.

39 Vgl. Pierre Bourdieu, Physischer, sozialer und angeeigneter physischer Raum, in: Martin Wentz (Hg.), Stadt-Räume. Die Zukunft des Städtischen, Frankfurt am Main / New York 1991, S. 26-34; Martina Löw, Raumsoziologie, Frankfurt am Main 2001; zum Verhältnis von Religi- 
ser oder konfessioneller Grenzen ${ }^{40}$. Dazu mussten die Zeitgenossen freilich oft gar keine weiten Reisen unternehmen. Unterschiedliche konfessionelle Räume konnten, in unmittelbarer räumlicher Nachbarschaft oder, wie etwa im Falle der im Heiligen Römischen Reich verbreiteten Simultaneen, sogar an ein und demselben Ort entstehen ${ }^{41}$. Es gilt also im Einzelfall zu klären, ob und inwieweit die zeitgenössischen Akteure durch ihre Mobilität selbst Anteil an der Konstruktion religiöser Räume hatten.

Von besonderem Interesse ist dabei auch das Verhältnis von Innen- und Außenräumen. Bei dem von Almut Bues untersuchten Martin Gruneweg etwa bedingen einander offenbar innere Ruhelosigkeit, Identitätssuche und Mobilität im physischen Raum. ${ }^{42}$ In anderen Fällen ging dem Wechsel des Aufenthaltsortes aus religiösen Gründen eine Phase der sinneren Emigration< voraus, so zu beobachten bei vielen späteren Konvertiten ${ }^{43}$; umgekehrt kam es häufig zum Rückzug in >innere Räume<, wenn die offene Ausübung der eigenen Religion in der Fremde nicht möglich war.

Religiöse Räume bedurften stets einer symbolischen Markierung, um als solche überhaupt wahrgenommen zu werden. Religiöse Gruppenzugehörigkeit manifestiert sich noch heute nicht zuletzt im individuellen oder kollektiven Vollzug religiöser Riten und Zeremonien. Letztere fungieren dabei oftmals als die einzigen nach außen hin sichtbaren Zeichen der Zusammengehörigkeit einer Glaubensgemeinschaft und der Abgrenzung gegenüber anderen Religionen oder Konfessionen. Es ist wohl kein Zufall, dass im Zuge von Reformation und Konfessionalisierung immer wieder gerade über diese Fragen gestritten wurde ${ }^{44}$. Und welcher Stellenwert religiösen Symbolen noch heute

on und Raum Susanne Rau / Gerd Schwerhoff (Hg.), Topographien des Sakralen. Religion und Raumordnung in der Vormoderne, München / Hamburg 2008.

40 Vgl. Eszter Andor/István György Tо́тн (Hg.), Frontiers of Faith. Religious Exchange and the Constitution of Religious Identities, 1400-1700, Budapest 2001; Benjamin J. Kaplan, Divided by faith. Religious conflict and the practice of toleration in early modern Europe, Cambridge, Mass u.a. 2007.

41 Vgl. Gerd Schwerhoff, Sakralitätsmanagement. Zur Analyse religiöser Räume im späten Mittelalter und in der Frühen Neuzeit, in: Susanne Rau / ders., Topographien des Sakralen, S. 3867, hier: S. 55-59; Étienne FrançoIs, Die unsichtbare Grenze. Protestanten und Katholiken in Augsburg 1648-1806, Sigmaringen 1991; Natalie Zemon DAvis, Das Heilige und der gesellschaftliche Körper. Wie widerstreitende Glaubensformen den städtischen Raum im Lyon des 16. Jahrhunderts prägten, in: Dies., Frauen und Gesellschaft am Beginn der Neuzeit. Studien über Familie, Religion und die Wandlungsfähigkeit des sozialen Körpers, Frankfurt am Main 1989, S. 64-92.

42 Vgl. den Beitrag von Almut Bues in diesem Band.

43 Vgl. den Beitrag von Gesine CARL in diesem Band.

44 So lagen etwa die entscheidenden Hindernisse für eine Einigung zwischen Katholiken und Protestanten auf dem Augsburger Reichstag vornehmlich in den Passagen der Confessio Augustana, die die Riten der alten Kirche betrafen, vgl. Herbert ImmEnKöTter, Der Reichstag zu Augsburg und die Confutatio, Münster ${ }^{2} 1980$, S. 37; allgemein Carlos M. Eire, War Against the Idols. The Reformation of Worship from Erasmus to Calvin, Cambridge 1986; Robert W. Scribner, Ritual and Reformation, in: Ders., Popular Culture and Popular Movements in Ref- 
zukommt, zeigt sich in letzter Zeit immer wieder vor allem im Kontakt von Christen und Muslimen.

Im Hinblick auf das Thema des vorliegenden Bandes stellt sich vor allem die Frage, in welchem Verhältnis der - in der Fremde oft nur unter Einschränkungen oder im Geheimen mögliche - Vollzug religiöser Riten und die inneren Überzeugungen der Beteiligten standen. Welche Konsequenzen hatte der weitgehende Verzicht auf die kollektive Ausübung der eigenen Religion? Wie wirkten sich demgegenüber unter Zwang - und oft nur zum Schein vollzogene fremdreligiöse Handlungen oder gar erzwungene Konversionen aus ${ }^{25}$ Fast alle christlichen Konfessionen setzten sich mit dem Problem des Nikodemismus auseinander. Schon Augustinus ließ in solchen Fällen eine reservatio mentalis gelten, und auch Erasmus stellte in diesem Zusammenhang fest: »Die Augen des Herrn sehen nicht auf das Öffentliche, sondern auf das Verborgene ${ }^{46}$. Dieser Linie folgten auch Reformatoren wie Bucer, wohingegen etwa Calvin den Nikodemismus auf das Schärfste verurteilte ${ }^{47}$. $\mathrm{Zu}$ fragen wäre, ob die individuelle Migrationserfahrung, wie bei Calvin, die Haltung in dieser Frage beeinflusste ${ }^{48}$.

Wenn eingangs von der Zunahme von Mobilität als Kennzeichen des frühneuzeitlichen Europas die Rede war, so darf darüber nicht vergessen werden, dass der Beginn der Moderne zugleich durch eine Medienrevolution einge-

ormation Germany, London / Ronceverte, WV 1987, S 103-122; Susan C. Karant-Nunn, The Reformation of Ritual. An Interpretation of Early Modern Germany, London / New York 1997; Edward Muir, Ritual in Early Modern Europe, Cambridge 1997, S. 202-251; Bernhard JusSEN/Craig Koslofsky (Hg.), Kulturelle Reformation. Sinnformationen im Umbruch 14001600, Göttingen 1999.

45 Vgl. dazu Kim Siebenhüner, Conversion, Mobility and the Roman Inquisition in Italy around 1600, in: Past \& Present 200 (2008), S. 5-35; Alexander SchunKa, Konfessionelle Liminalität. Kryptokatholiken im lutherischen Territorialstaat des 17. Jahrhunderts, in: BAHLCKE/BendeL, Migration, S. 113-131.

$46 \gg$ Oculi domini non vident in manifesto, sed in oculto, neque secundum visionem oculorum iudicat«, Erasmus von RotTerdam, Enchiridion militis Christiani. Handbüchlein eines christlichen Streiters, in: Ders., Ausgewählte Schriften, hg. v. Werner WelzIG, Bd. 1, Darmstadt 1968, S. $231 f$.

47 Carlos M. N. Eire, Prelude to Sedition? Calvin's Attack on Nicodemism and Religous Compromites, in: ARG 76 (1985), S. 120-145; Francis Higman, Bucer et les Nicodemistes, in: Christian Krieger / Marc Lienhard (Hg.), Martin Bucer and Sixteenth Century Europe, Bd. 2, Leiden / New York / Köln 1993, S. 645-658; Peter Zagorin, Ways of Lying. Dissimulation, Persecution and Conformity in Early Modern Europe, Cambridge/London 1990; Carlo GinzBurG, Il nicodemismo. Simulazione e dissimulazione religiosa nell'Europa del '500, Turin 1970.

48 Vgl. Johannes Calvin, Epistolae duae, ... Prior de fugiendis impiorum illicitis sacris, et puritate Christianae religionis obseruanda, altera de Christiani hominis officio in sacerdotijs Papalis ecclesiae uel administrandis uel abijciendis, Basel 1537; VD 16 C 305; CR 33 (OC 5), Sp. 233312. Zur individuellen Erfahrung vgl. Herman J. Selderhuis, Singende Asylanten: Calvins Theologie der Psalmen, in: Eckhard Grunewald u.a. (Hg.), Der Genfer Psalter und seine Rezeption in Deutschland, der Schweiz und den Niederlanden. 16.-18. Jahrhundert, Tübingen 2004, S. 79-95, bes. S. 90f. 
läutet wurde ${ }^{49}$. Welchen herausragenden Stellenwert die Erfindung des Buchdrucks für die Ausbreitung der Reformation hatte, ist hinlänglich bekannt ${ }^{50}$. Der zunehmende Gebrauch der Schrift als Distanzmedium war ein wesentliches Charakteristikum der Moderne, andererseits war die frühneuzeitliche Gesellschaft noch lange durch das besonders für die Städte charakteristische Phänomen der »Kommunikation unter Anwesenden« geprägt ${ }^{51}$. Es wäre daher zu fragen, welche Rolle neben der raumbezogenen Mobilität von Personen die Zirkulation von Texten spielte und ob es einen Unterschied machte, ob religiöse Ideen primär durch Texte in Umlauf gebracht wurden oder durch Personen. Von ebenso großem Interesse ist die Frage nach der Bedeutung von Schrift und Druck als Gedächtnisspeicher. Die Erfahrung von religiöser Verfolgung, Flucht und Vertreibung, aber auch die Konversion oder ganz allgemein das Bereisen fremder Länder fanden ihren Niederschlag in einer Vielzahl von unterschiedlichen Texten: theologischen Traktaten, Martyrologien, Konversionserzählungen, Reiseberichten, Tagebüchern und anderen autobiographischen Texten, die vielfach auch gedruckt wurden, um sie, nicht selten in propagandistischer oder konfessionspolemischer $\mathrm{Absicht}^{52}$, einem größeren Publikum zugänglich zu machen.

Für den Historiker erweisen sich solche Texte oft als besonders aufschlussreich, weil sie unmittelbare Einblicke in die Wahrnehmung der zeitgenössischen Akteure geben. Von besonderem Interesse sind dabei zum einen die Begrifflichkeiten und Konzepte, mit denen Mobilitätsprozesse beschrieben werden, und zum anderen die Art und Weise, wie die Erfahrung von Fremdheit und religiöser Differenz verarbeit wird. Bei den Verfassern von Konversionserzählungen etwa korrespondierte die religiöse Identitätssuche nicht selten mit einer scheinbar ziellosen Bewegung im Raum. Bei der im weitesten Sinne theologischen Reflexion der (eigenen) Wanderung wurde vielfach auf das biblische Vorbild der Vertreibung des Volkes Israel zurückgegriffen, die Bewegung im Raum wird dabei teils als Wanderschaft, teils als zielgerichtete Bewegung mit dem Exil als Endpunkt beschrieben ${ }^{53}$. Schließlich wäre danach zu fragen, inwieweit die Verbreitung solcher Texte geeignet

49 Vgl. nur Johannes Burkhardt, Das Reformationsjahrhundert. Deutsche Geschichte zwischen Medienrevolution und Institutionenbildung 1517-1617, Stuttgart 2002.

50 Vgl. Berndt Hамм, Die Reformation als Medienereignis, in: JBTh 11 (1996), S. 138-166; HansJoachim KöHLER (Hg.), Flugschriften als Massenmedium der Reformationszeit. Beiträge zum Tübinger Symposion 1980, Stuttgart 1981.

51 Rudolf Schlögl, Kommunikation und Gesellschaft unter Anwesenden. Formen des Sozialen und ihre Transformation in der Frühen Neuzeit, in: Geschichte und Gesellschaft 34 (2008), S. 155-224; André Kieserling, Kommunikation unter Anwesenden. Studien über Interaktionssysteme, Frankfurt am Main 1999.

52 Vgl. den Beitrag von Henning P. Jürgens in diesem Band.

53 Vgl. zu diesem Motiv die Beiträge von Gesine CARL und Vera vON DER Osten-Sacken in diesem Band. 
war, die Identität einer Religionsgemeinschaft zu stabilisieren und die Erfahrung der Flucht und Vertreibung an künftige Generationen weiterzugeben, die keine persönliche Erinnerung an die geschilderten Vorgänge mehr hatte.

Abschließende Antworten auf die genannten Fragen können die hier versammelten Beiträge nicht bieten, wohl aber erste Ergebnisse und weiterführende Überlegungen zu einem Forschungsfeld, das noch viel Raum für weitere Untersuchungen bietet. So muss etwa hier die Frage offen bleiben, ob die durch Mobilitätsprozesse begünstigte Zunahme interreligiöser Kontakte in der Frühen Neuzeit möglicherweise langfristig zu einer Ablösung der Religion von anderen gesellschaftlichen Handlungsfeldern wie Politik oder Wirtschaft beitrug und damit einer zunehmenden Säkularisierung und religiösen Toleranz den Weg ebnete. Der Blick auf die Gegenwart nährt freilich eher die Skepsis gegenüber solchen modernisierungstheoretischen Interpretamenten; gewinnt man doch angesichts von Kriegen und internationalem Terrorismus zur Zeit eher den Eindruck, dass die aus dem Spannungsverhältnis von Religion und Mobilität resultierenden Konflikte sich im Zuge der Globalisierung vielerorts dramatisch zuspitzen und die Menschheit von einem friedlichen Zusammenleben der Religionen vielleicht weiter denn je entfernt ist.

Die Herausgeber danken der Fritz Thyssen Stiftung, die die Konferenz im Februar 2009 großzügig gefördert hat. Viele helfende Hände haben für einen reibungslosen Ablauf des Kolloquiums gesorgt, Esther Verwold hat sich um die Erstellung des Registers verdient gemacht. Auch dafür möchten wir uns bedanken. Unser besonderer Dank aber gilt den Autorinnen und Autoren der hier versammelten Beiträge ${ }^{54}$ sowie allen Teilnehmerinnen und Teilnehmern an der Tagung, die mit ihren anregenden Diskussionsbeiträgen ebenfalls zum Gelingen des Bandes beigetragen haben.

Mainz, im Mai 2010

Henning P. Jürgens

Thomas Weller

54 Der Vortrag von Sabine Meine, Hannover, ist an anderer Stelle veröffentlicht worden: Sabine Meine, Musikalische Spuren konfessioneller Spannungen an den Höfen von Renée de Valois und Ercole II d'Este im Ferrara des 16. Jahrhunderts, in: Katharina Hottmann / Christine SieGERT (Hg.), Feste - Opern - Prozessionen. Musik als kulturelle Präsentation, Hildesheim 2008, S. $27-43$. 


\title{
Henning P. Jürgens \\ Die Vertreibung der reformierten Flüchtlingsgemeinden aus London
}

\author{
Jan Utenhoves »Simplex et fidelis narratio $\ll^{1}$
}

\begin{abstract}
Am 17. September 1553 stachen zwei dänische Frachtschiffe, der »Mohr« und die »Kleine Krähe«, in Gravesend auf der Themse in See. An Bord befand sich allerdings kein portugiesisches Salz, sondern eine Fracht, die in Dänemark nicht erwartet wurde: eine Gruppe von 175 Glaubensmigranten, meist Flamen und Wallonen, unter der Leitung des Superintendenten, zweier Prediger und mehrerer Ältester der Londoner Flüchtlingsgemeinden. Begleitet wurde ihr Abschied von einer Schar zurückbleibender Gemeindeglieder. Der Chronist berichtet:
\end{abstract}

Als nun die Ancker aufgehaben/vnd die Schiff abgestoßen waren/vnd wir dahin fuhren/da stiegen dieselbige brüder (darunter ich auch die Weiber verstehe) auf den nehesten berg/von welchem sie uns von fernen sahen dahin fahren. Als sie aber vns nicht mehr sehen konnten/fiengen sie an zu beten/vnd sich vndereinander zur wahren

1 Jan Utenhove, SIMPLEX ET fidelis narratio de INSTITVTA AC DEMVM DISsipata Belgarum, aliorumq[ue] peregrinorum in Anglia, Ecclesia. \& potissimum de susceptis posteà illius nomine itineribus quaeq[ue] eis in illis euenerunt. In qua multa de Coena Dominicae negocio alijsq[ue] rebus lectu dignissimis tractantur [...], [Basel] 1560. VD 16 U 389. Moderne Edition in: Frederik PIJPER (Hg.), Geschriften van gemengden aard (van Utenhove, Cooltuyn e.a.), s-Gravenhage 1912. Nach dieser Ausgabe wird der Text zitiert als »Narratio«; die Seitenzahlen bei Pijper werden zusätzlich in eckigen Klammern angegeben. Die deutschsprachigen Zitate folgen der Ausgabe Jan Utenhove, Kurtzer/einfeltiger Vnd wahrhafter Historischer Bericht / wie die Christliche Kirche oder Gemeine auß Niderland vnd andern außlendischen örtern/erstlich in Engelland angefangen vnd aufkomen/wie auch endlich sie widerumb zerstört worden. vnd fürnemlich was sie für reisen sie deßwegen haben auf sich nemen vnd thun muessen: auch wie es jhnen auf denselbigen ergangen sey. Darin zugleich vil vom Abendmal des Herren gelehrt und gehandelt wird/wie auch von andern sachen mehr/die sonderlich wol lesens werth seind. Geschehen im jar nach Christi geburt 1553. vnd 1554: vnd anfänglich durch Johann Vtenhoven von Gendt im Latein beschrieben/vnd zu Basel gedruckt durch Iohannem Oporinum im jar 1560: Jetzt aber auß dem Latein ins Teutsch gebracht/durch Bartholomaeum Rhodingum/Dienern am wort Gottes zu Dillenburg, Herborn 1603, VD 17 3:308218B. Verwendet wurde das Mikrofiche-Exemplar der Bibliotheca Palatina, Fiche Nr. F 3821-3824. Zitiert als Bericht. 
Gottesfurcht zu ermahnen/vnd psalmen zu singen mit vilen threnen/auch ihren armen zur aufenthaltung ein stewr vnder sich aufzuheben ${ }^{2}$.

Abgesehen davon, dass diese Szene einige konstitutive Elemente reformierter Flüchtlingsgemeinden, nämlich die besondere Rolle der Diakonie und das Psalmensingen, en passant einfängt, markiert sie auch den Beginn einer umfangreich dokumentierten religiös motivierten Auswanderung oder Konfessionsmigration ${ }^{3}$. Denn sie steht am Beginn einer langen Erzählung, die Jan Utenhove, ein Ältester der Londoner Flämischen Gemeinde ${ }^{4}$, veröffentlicht hat. Seine Schrift, die Simplex et fidelis narratio de instituta ac demum dissipata Belgarum aliorumque peregrinorum in Anglia Ecclesia soll im Mittelpunkt der folgenden Untersuchung stehen. Dabei soll zuerst ein Überblick über die Geschichte der Londoner Gemeinden und die Ereignisse auf der abenteuerlichen Reise der Flüchtlinge geboten werden. In einem zweiten Schritt soll das theologische Umfeld zur Zeit der Ereignisse und die Einbindung in den so genannten Zweiten Abendmahlsstreit beleuchtet werden, bevor der Inhalt der Schrift Utenhoves näher betrachtet werden soll. Sie ermöglicht Einblicke sowohl in die theologische Motivation der Flüchtlinge wie auch in die Alltagserfahrungen von Glaubensmigranten in der Frühen Neuzeit. In ihrer Gesamtheit trug die Narratio zur Ausprägung dessen bei, was man als »Exulantentheologie« bezeichnet hat ${ }^{5}$. Sie formuliert die

2 »Dumque sublatis anchoris uela uentis damus, illi ipsi fratres (quorum nomine et foeminas comprehendo) montem proximum conscendunt, unde nos nauigantes eminus oculis sequuntur: et ubi nos amplius non conspiciunt, se precibus, pijs exhortationibus et cantioni Psalmorum multis cum lachrymis dedunt, atque in usum pauperum suorum eleemosynas inter sese colligunt«. Utenhove, Narratio, S. 21 [40]; ders., Bericht, S. 26.

3 Zum Begriff vgl. Heinz Schilling, Die frühneuzeitliche Konfessionsmigration, in: Klaus J. BADE (Hg.), Migration in der europäischen Geschichte seit dem späten Mittelalter, Osnabrück 2002, S. 67-89.

4 Jan Utenhove war adeliger Herkunft und stammte aus Gent. Er erhielt eine humanistische Erziehung bei Georg Cassander, studierte in Löwen und wurde 1545 wegen eines von ihm verfassten Theaterstücks aus Flandern verbannt. Utenhove wandte sich nach Straßburg, von wo aus er in die Zentren der Reformation der Schweiz reiste und deren führende Theologen kennenlernte. 1548 reiste er erstmals zu Cranmer nach London, war an der Gründung der Flüchtlingsgemeinden beteiligt und übernahm 1550 das Amt eines Ältesten der flämischen Gemeinde. Nach der Vertreibung begleitete er einige Jahre Johannes a Lasco bis nach Polen, kehrte 1559 nach London zurück, wo er 1566 starb. Zu Utenhove, seinem faszinierenden Lebenslauf und seinen Werken fehlt eine aktuelle Untersuchung. Vgl. immer noch Fredrik PiJPER, Jan Utenhove, zijn leven en zijne werken, Leiden 1883, sowie zu Utenhoves Psalmkompositionen Hans BeElen, »Als een kindt des lichts in een nyeuwigheyt des leuens«. Die eigenwilligen Psalmen Jan Utenhoves, in: Eckhard Grunewald u.a. (Hg.), Der Genfer Psalter und seine Rezeption in Deutschland, der Schweiz und den Niederlanden, Tübingen 2004, S. 411-420. Der Artikel von Raingard Esser, Utenhove, Jan, in: BBKL XII (1997), S. 990-993, enthält trotz guter Literaturangaben mehrere Fehler.

5 So der Begriff bei Heinz Schilling, Die niederländischen Exulanten des 16. Jahrhunderts. Ein Beitrag zum Typus der frühneuzeitlichen Konfessionsmigration, in: GWU 43 (1992), S. 67-78 unter Berufung auf Heiko A. Oberman, Die Reformation als theologische Revolution, in: Peter 
theologische Grundlage und dokumentiert die praktische Erfahrung einer der ersten großen Wellen von konfessionell motivierter Migration in der Frühen Neuzeit. Insofern kann man die Narratio geradezu als Programmschrift einer zwar erzwungenen, gleichwohl aber planmäßig vollzogenen und theologisch verantworteten Konfessionsmigration betrachten.

\section{I.1 Überblick über die Geschichte der Londoner Gemeinden}

In den vierziger Jahren des 16. Jahrhunderts nahm die Zahl der Flüchtlinge aus den habsburgischen Niederlanden, die aus Glaubensgründen nach England, vor allem in die Metropole London übersiedelten, sprunghaft zu. Besonders nach dem Schmalkaldischen Krieg und dem Augsburger Reichstag von 1548, der Kaiser Karl V. auf dem Höhepunkt seiner Macht sah, entzogen sich zahlreiche Niederländer der zunehmenden religiösen Unterdrückung in ihrer Heimat ${ }^{6}$. $\mathrm{Zu}$ den in England Eintreffenden zählten auch führende protestantische Theologen wie Martin Bucer ${ }^{7}$, Pietro Martyr Vermigli und Johannes a Lasco ${ }^{8}$, die wegen des Augsburger Interims 1548 den Kontinent verlassen mussten. Unter dem englischen König Edward VI., der als »Boy King 1547 im Alter von knapp zehn Jahren auf den Thron kam ${ }^{9}$ und maßgeblich von einem Thronrat unter Führung des Duke of Somerset und des Erzbischofs Thomas Cranmer ${ }^{10}$ begleitet wurde, kam es zu Bemühungen um eine weitergehende theologische und praktische Umgestaltung der englischen Kirche. In Beratungen mit den geflohenen Theologen entstand darüber hinaus der Plan, für die zahlreichen Migranten niederdeutscher, französischer und italienischer Sprache in London Flüchtlingsgemeinden einzurichten ${ }^{11}$. Sie sollten einerseits den >Fremdlingen< eine Gemeinschaft bieten

Blickle/ Anton Schindler (Hg.), Zwingli und Europa, Zürich 1985, S. 11-26. Zur Problematisierung des Begriffs siehe unten.

6 Allgemein zur niederländischen Reformation und Exilbewegung vgl. Andrew Pettegree, Emden and the Dutch revolt. Exile and the development of reformed Protestantism, Oxford 1992, S. 1-25, zu den protestantischen Flüchtlingen in London vgl. Andrew Pettegree, Foreign Protestant communities in sixteenth-century London, Oxford 1986.

7 Vgl. Martin Greschat, Martin Bucer. Ein Reformator und seine Zeit. 1491-1551, München 1990, S. 233-256.

8 Vgl. Henning P. JÜrgens, Johannes a Lasco. Ein Leben in Büchern und Briefen, Eine Ausstellung der Johannes a Lasco Bibliothek vom 15.10. bis 28.11.1999, Wuppertal 1999, S. 60-71. Zur Vorgeschichte der Londoner Tätigkeit a Lascos vgl. auch Henning P. JÜRGENs, Johannes a Lasco in Ostfriesland. Der Werdegang eines europäischen Reformators, Tübingen 2002, S. 326-344.

9 Vgl. Diarmaid MacCulloch, The boy king. Edward VI and the protestant reformation, Berkeley/London 2002.

$10 \mathrm{Zu}$ ihm vgl. die umfassende Biographie von Diarmaid MaCCulloch, Thomas Cranmer. A life, New Haven 1996.

11 Vgl. Pettegree, Foreign Protestant communities, Kap. II: The Foundation of the Stranger Churches, S. 23-45. 
und den Einfluss täuferischen Gedankenguts zurückdrängen, zugleich aber auch als eine Art Modellgemeinden das Beispiel einer >nach Gottes Wort reformierten Kirche< ohne Residuen der alten Kirche vorleben ${ }^{12}$. Die Gemeinden wurden als Freiwilligkeitsgemeinden organisiert: Wer Mitglied werden wollte, musste eine Glaubensprüfung ablegen und das Bekenntnis der Gemeinde unterschreiben. Die Flüchtlingsgemeinden erhielten ein königliches Privileg $^{13}$, das ehemalige Augustinerkloster als Gottesdienstraum und gaben sich eine Leitungsstruktur mit Predigern, Ältesten und Diakonen, an deren Spitze Johannes a Lasco als Superintendent stand. In den ersten drei Jahren ihrer Existenz formulierten und veröffentlichten die Gemeinden Glaubensbekenntnisse, Katechismen und Gemeinde- und Gottesdienstordnungen in verschiedenen Sprachen ${ }^{14}$. Sie bildeten eine Einheit in weitgehender Unabhängigkeit von der englischen Kirche und standen in engem Austausch mit der Schweiz, vor allem mit dem Zürcher Antistes Heinrich Bullinger.

Der rasante Gemeindeaufbau - nach Schätzungen ${ }^{15}$ zählten rund 4000 Personen zum Umfeld der Gemeinden - wurde jäh abgebrochen, als Edward VI. am 6. Juli 1553 starb. Nach einigen Wirren gelangte seine katholisch gebliebene Halbschwester Mary auf den Thron, die umgehend eine Aufhebung des Sonderstatus der Gemeinden und ein Verbot der Predigt befah $1^{16}$. Durch die Hinrichtung von Protestanten, unter ihnen später auch Erzbischof Thomas Cranmer, erwarb sich die Königin den Beinamen »Bloody Mary«. Schon vorher aber war deutlich geworden, dass Mitglieder der Flüchtlingsgemeinden, die an ihrem Bekenntnis festhalten wollten, nicht im Land bleiben konnten. Die denkwürdige, eingangs geschilderte Einschiffung von 175 Gemeindegliedern war nur die erste Welle der Auswanderung ${ }^{17}$. Zwar blieb auch eine gewisse Zahl von Flüchtlingen heimlich in England, die Mehrheit aber muss-

12 Zur Geschichte und zu Kirchenordnung und Kirchenzucht der Gemeinden, vor allem in der elisabethanischen Zeit vgl. die detaillierte Studie von Judith BECKER, Gemeindeordnung und Kirchenzucht. Johannes a Lascos Kirchenordnung für London (1555) und die reformierte Konfessionsbildung, Leiden 2007; zur Gründung der Gemeinden bes. S. 259-268 und 403f.

13 Text und Abbildung bei Jürgens, Johannes a Lasco, S. 63-66. Den Text der Charta gibt auch Utenhove in seiner »Narratio« wieder: Utenhove, Narratio, S. 13-19 [35-38]; ders., Bericht, S. $18-23$.

14 Überblick und Abbildungen bei JürgEns, Johannes a Lasco, S. 67-69. Zu den Kirchenordnungen und Katechismen in der Gemeindepraxis BECKER, Gemeindeordnung und Kirchenzucht, S. 278-292. Auch die ersten Psalmbereimungen Jan Utenhoves wurden in dieser Zeit veröffentlicht, vgl. BEELEN, »Als een kindt des lichts [...]«, S. 412-414. Sie waren die ersten niederländischen Psalmen, die nachweislich im Gottesdienst gesungen wurden.

15 Vgl. Pettegree, Foreign Protestant communities, S. 78, 118. Becker, Gemeindeordnung und Kirchenzucht, S. 260 mit Anm. 4 und 5, referiert Gerüchte über eine Größe von bis zu 5000 Flüchtlingen, die aber übertrieben gewesen seien.

$16 \mathrm{Zu}$ den Ereignissen unter der Herrschaft Königin Marys vgl. Pettegree, Foreign Protestant communities, S. 113-131.

17 Der Befehl zur Ausweisung aller Ausländer, die kein Bürgerrecht erworben hatten, erging am 17.2.1554, vgl. Pettegree, Foreign Protestant communities, S. 117f. Auch die Prediger der Ge- 
te in der Folgezeit das Land verlassen. Einige kehrten zurück in ihre niederländischen Heimatorte, andere fanden in deutschen Städten Aufnahme.

\section{I.2 Die Flucht der Londoner Gemeinden 1553}

In der Gruppe derer, die sich schon wenige Wochen nach der Thronbesteigung Marys einschifften, befanden sich neben Johannes a Lasco und Jan Utenhove auch der Prediger dieser Gemeinde, Marten Micron, sowie die Drucker Nicolaus von den Berghe und Gellius van der Erve, die als Produzenten protestantischer Bücher besonders gefährdet waren (und ihre Druckbetriebe auf die Reise mitnahmen $)^{18}$. Auch einige Engländer und Schotten schlossen sich der Gruppe $a^{19}$. Die Fahrt ging Richtung Dänemark. Während der Reise wurden die Schiffe getrennt, das kleinere erreichte Helsingborg am 13. Oktober 1553, das größere, mit Utenhove und den Predigern an Bord, wurde in Herbststürmen vom Kurs abgebracht, musste in norwegischen Häfen im Skagerrak und Kattegat anlanden und kam erst am 29. Oktober 1553 in Helsingborg an.

Während die Mehrzahl der Flüchtlinge nach Kopenhagen weiterreiste, wandten sich a Lasco, Micron und Utenhove nach Kolding in Jütland, den Aufenthaltsort des dänischen Königs Christian III., wo sie am 8. November eintrafen. Ihr erklärtes Ziel war es, für die Londoner Gemeindeglieder eine ebensolche Aufnahme und Privilegierung zu erreichen, wie sie sie in London genossen hatten - das Privileg Edwards VI. führten sie mit sich ${ }^{20}$. Doch ehe sie beim König eine Audienz erhielten, wurden sie aufgefordert, einem Gottesdienst beizuwohnen, in dessen Verlauf der Hofprediger Paul Noviomagus in scharfem Tonfall gegen »Sakramentierer « wetterte, also den Schimpfnamen verwendete, mit dem schon Luther die Vertreter einer schweizerischen Abendmahlslehre belegt hatte. Damit war offensichtlich, dass die Ankömmlinge mit keiner positiven Aufnahme rechnen konnten.

Zwar bemühten sich die drei Theologen, in ausführlichen Suppliken und mehreren Gesprächen mit den Hofpredigern ihre Wünsche zu begründen, doch fanden sie kein Gehör. Vielmehr erging der königliche Befehl, dass alle Flüchtlinge umgehend aus Dänemark auszuweisen seien. A Lasco, Utenhove

meinden, die zur Betreuung der Zurückbleibenden noch in London waren, verließen anschlieBend das Land.

$18 \mathrm{Zu}$ ihnen und dem mit ihnen einsetzenden exportorientierten Emder Buchdruck vgl. PetteGREE, Emden and the Dutch revolt, S. 87-108.

19 Utenhove, Narratio, S. 22 [40]; ders., Bericht, S. 27.

20 Ebd., S. 29 [43]; ders., Bericht, S. 34: »[...] sondern hat [sc. Edward] auch dasselbig allmiteinander/wie jetzt erzehlt/mit offentlichen königlichen gewaltsbrieffen vnd sigill (so wir bey vns haben) bekräftigt«. Das Dokument kehrte später mit Utenhove aus Polen nach London zurück und wird heute im Archiv der Dutch Church in London aufbewahrt. 
und Micron durften nicht nach Kopenhagen zurückkehren. Sie reisten über Jütland und Hamburg weiter nach Emden. Dort erhielten sie von der Regentin Ostfrieslands, Gräfin Anna von Oldenburg, die Erlaubnis für die Niederlassung der Gemeinde unter der Voraussetzung, dass eine eigenständige Diakonie sicherstellte, dass die Neuankömmlinge nicht der dortigen Gemeinde zur Last fielen.

Die übrigen, in Kopenhagen gebliebenen Londoner Migranten wurden nach dem königlichen Ausweisungsedikt binnen weniger Tage trotz des strengen Winters zur Weiterfahrt gezwungen. Sie teilten sich in verschiedene Gruppen auf und reisten auf dem See- und Landweg nach Wismar, Rostock, Lübeck und Hamburg. Nach zum Teil dramatischen Überfahrten über die zugefrorene Ostsee wurden sie in den Hansestädten meist nur für kurze Zeit an Land gelassen. In keiner dieser Städte konnten sie ein Bleiberecht erwirken und mussten weiterziehen. Letztlich trafen bis zum Sommer 1554 alle in Emden ein. Die Flämischsprachigen schlossen sich in Emden der dortigen Gemeinde an, in der a Lasco vor seinem Weggang nach England als Superintendent Ostfrieslands tätig gewesen war; die Wallonen gründeten eine eigene, französischsprachige Gemeinde mit nochmals eigener Diakonie, die mehrere Jahrhunderte lang bestand ${ }^{21}$.

\section{II.1 Der theologiegeschichtliche Hintergrund - Der Zweite Abendmahlsstreit}

Die winterliche Reise der Londoner Flüchtlinge nach Dänemark und zu den wendischen Hansestädten war also Teil der großen Migrationsbewegung niederländischer protestantischer Glaubensmigranten, die nach 1553 in einigen deutschen Städten, etwa Wesel und Frankfurt am Main und darüber hinaus vor allem in Ostfriesland zeitweilige oder dauerhafte Aufnahme fanden. Was die Londoner Migranten auf ihrer Reise erlebten und erlitten, unterscheidet sich wohl nur wenig von dem, was andere, weniger prominente Migranten in diesen Jahren durchmachen mussten. Herausgehoben ist ihre Reise vor allem durch die ausführliche Dokumentation, die sie durch die Schrift Utenhoves erfahren hat, und durch die Verquickung mit der großen theologischen Auseinandersetzung im europäischen Protestantismus dieser Zeit, dem so genannten Zweiten Abendmahlsstreit ${ }^{22}$.

21 Zur Diakonie in Emden vgl. Timothy G. FeHLER, Poor relief and protestantism. The evolution of social welfare in sixteenth-century Emden, Aldershot 1999.

22 Diesem Zusammenhang widmet sich explizit der Aufsatz von Andrew Pettegree, The London Exile Community and the Second Sacramentarian Controversy, in: ARG 78 (1987), S. 223-252. 
Die neuentbrannte Auseinandersetzung zwischen den Protestanten Wittenberger Prägung und den schweizerischen Theologen Zürichs und Genfs und ihrer Anhänger stand im größeren Zusammenhang einer Reihe weiterer theologischer Kontroversen, die nach dem Tod Luthers 1546 und dem Augsburger Interim 1548 für drei Jahrzehnte unter den reformatorischen Theologen ausgetragen wurden und zur Herausbildung der konfessionellen Trennung führten, die in den jeweiligen Bekenntnisdokumenten der Formula Concordiae oder der Confessio Helvetica Posterior ihre Formulierung fand ${ }^{23}$. Wichtigste Streitgegenstände zwischen den Theologen in der Nachfolge Luthers und den Schweizern um Bullinger und Calvin, die sich gerade 1549 im Consensus Tigurinus ${ }^{24}$ untereinander auf eine Konsensformel geeinigt hatten, waren die Frage nach der realen Gegenwart der menschlichen Natur Christi im Abendmahl und die damit verbundenen christologischen Implikationen $^{25}$.

Die Londoner Flüchtlingsgemeinden hatten sich in dieser Frage schon vor ihrer Vertreibung ganz auf die Seite der Schweizer Theologie gestellt, den Consensus Tigurinus rezipiert und in London gedruckt ${ }^{26}$. Damit war Johannes a Lasco mit seinen Werken auch in das Visier eines der führenden Vertreter der lutherischen Theologie in Norddeutschland geraten. Der Hamburger Pastor Joachim Westphal ${ }^{27}$ veröffentlichte 1552 in Magdeburg seine Farrago confusanearum et inter se dissidentium opinionum de coena Domini, ex Sacramentarioru $[m]$ libris congesta ${ }^{28}$, wörtlich $\gg$ das Mischmasch der ver-

$23 \mathrm{Zu}$ den Streitigkeiten vgl. den Überblick von Irene DingeL, The Culture of Conflict in the Controversies Leading to the Formula of Concord (1548-1580), in: Robert KolB (Hg.), Lutheran ecclesiastical culture, 1550-1675, Leiden 2008, S. 15-64. Eine Edition der wichtigsten Quellentexte erscheint seit 2008 in der Reihe »Controversia et Confessio « des gleichnamigen Mainzer Forschungsprojekts, herausgegeben von Irene Dingel bei Vandenhoeck und Ruprecht in Göttingen.

24 Vgl. Eberhard Busch (Bearb.), Consensus Tigurinus 1549, in: Heiner FaulenBaCh/Eberhard Busch (Hg.), Reformierte Bekenntnisschriften, Bd. 1/2, Nr. 35, Neukirchen 2006, S. 467-480 (Einleitung), 481-490 (Edition).

25 Ein knapper Überblick über den Verlauf der zweiten Abendmahlskontroverse in Kapitel VII: Der zweite Abendmahlsstreit, in: Wilhelm H. Neuser, Dogma und Bekenntnis in der Reformation. Von Zwingli und Calvin bis zur Synode von Westminster, in: Carl Andresen (Hg.), Handbuch der Dogmen- und Theologiegeschichte 2: Die Lehrentwicklung im Rahmen der Konfessionalität, Göttingen ${ }^{2} 1999$, S. 167-352, hier: S. 272-285.

26 A Lasco veröffentlichte den Consensus Tigurinus zusammen mit Auszügen aus Werken Calvins, Bullingers und anderer im Rahmen einer eigenen Schrift: Johannes a LASCO, BREVIS ET DILVCIDA DE SACRAmentis Ecclesiae Christi tractatio, in qua \& fons ipse, \& ratio, totius Sacramentatiæ nostri temporis co[n]trouersiæ paucis exponitur: naturáq[ue] ac uis Sacramentorum compendio \& perspicuè explicatur [...], London, Stephen Mierdmann, 1552. Edition: Abraham KUYPER (Hg.), Joannis a Lasco opera tam edita quam inedita, Bd. I, Amstelodami 1866, S. 97-232.

$27 \mathrm{Zu}$ ihm vgl. Irene Dingel, Westphal, Joachim, in: TRE 35 (2003), S. 712-715.

28 Joachim WeSTPHAL, FARRAGO CONFVSANEARVM ET INTER SE DISSIDENTIVM OPINIOnum De Coena Domini, ex Sacramentarioru[m] libris congesta [...], [Magdeburg: Chris- 
worrenen und unter einander widersprüchlichen Meinungen vom Abendmahl, aus den Büchern der Sakramentierer gezogen«. In dem Werk wurden auch Passagen aus Schriften a Lascos angeführt und scharf kritisiert ${ }^{29}$. Westphal eröffnete mit dieser Schrift nicht nur erneut die Abendmahlskontroverse, sondern griff auch die Londoner Gemeinde gezielt als Sakramentierer an.

So war die Stimmung vorgegeben, mit der die Londoner Ankömmlinge in Dänemark und den wendischen Hansestädten empfangen wurden ${ }^{30}$. Den dänischen Hofpredigern, den Predigern und Superintendenten der wendischen Hansestädte, die alle durch die Kirchenordnungen und Theologie des Wittenbergers Johannes Bugenhagen geprägt waren, waren die Londoner damit von vornherein suspekt - und die Flüchtlinge ihrerseits taten nichts, um ihre abweichende Abendmahlsauffassung zu verhehlen. Im Gegenteil, sie suchten sogar die öffentliche Auseinandersetzung darüber, mit der Folge, dass sie überall ausgewiesen wurden.

Auch nach der Aufnahme der Londoner in Emden ging die Abendmahlskontroverse in publizistischer Form weiter. Wie alle theologischen Streitschriften dieser Zeit waren auch die hierbei gewechselten Schriften und Argumente auf beiden Seiten durch scharfe Polemik, persönliche Invektiven und unerbittliche Gegnerschaft gekennzeichnet - dieselbe Unerbittlichkeit, mit der die Migranten außer Landes gewiesen wurden.

tian Rödinger, 1552]. VD 16 W 2287. Zur Abfassung dieser Schrift wurde Westphal durch ein Schreiben des Antwerpeners Alexander Bruchsal veranlasst, der die Gefahr einer Ausbreitung des Calvinismus beschwor und Westphal, Flacius und andere besonders auf a Lasco hinwies. Dem Schreiben legte er unter anderem a Lascos Londoner Veröffentlichung des Consensus Tigurinus bei, vgl., Carl H. W. Sillem (Hg.), Briefsammlung des Hamburgischen Superintendenten Joachim Westphal aus den Jahren 1530 bis 1575, Bd. I, Hamburg 1903, S. 127f.

29 Die Passagen zu a Lasco finden sich auf fol. D 8r-E 3r. In einer weiteren Schrift, der RECTA FIDES DE COENA DOmini, ex uerbis Apostoli Pauli, \& Euangelistarum demonstrata ac communita, per Magistrum Ioachimum VVestphalum Ecclesiae Hamburgensis pastorem [...], [Magdeburg, Michael Lotter, 1553]. VD 16 W 2308, hatte Westphal eine Formulierung der Abendmahlslehre in der Tradition Luthers geliefert.

30 Gegen die Annahme von Pettegree, Second Sacramentarian Controversy, der aus dem Umstand, dass a Lasco die Schriften Westphals erst in Emden Ende 1553 in die Hände bekam, schließt: »It was the sufferings of the London exiles at the hands of the northern Lutheran ministers which brought the works [sc. Westphals] belatedly into the public eye and gave them a dramatic contemporary relevance«. Westphals Schrift war in Magdeburg erschienen und Westphal war einer der wichtigsten Wortführer der norddeutschen Theologen, die sich gegen das Interim gestellt hatten - seine Schrift war sicherlich schon vor der Ankunft der Flüchtlinge in Dänemark und Norddeutschland der Öffentlichkeit bekannt geworden. Zu Magdeburg als Druckzentrum in dieser Zeit vgl. die Untersuchung von Thomas KaufmanN, Das Ende der Reformation. Magdeburgs »Herrgotts Kanzlei« (1548-1551/2), Tübingen 2003. Auch Calvin ging davon aus, dass der dänische König durch die Schriften Westphals in seinem Verhalten beeinflusst worden sei, vgl. den Brief Calvins an Bullinger, Genf, 3.5.1554, CR 43 (OC XV), Nr. 1947, Sp. 123-126, hier: Sp. 124: »Nam etsi libello boni illius Westphali nihil insulsius fingi potest, quia tamen videmus principum animos talibus calumniis corrumpi et nuper triste eius rei exemplum in rege Daniae apparuit, officii nostri esse videtur quibuscunque licebit modis occurrere $\ll$. 


\section{II.2 Der Entstehungskontext von Utenhoves »Narratio« - Die Migranten in Wesel und Frankfurt}

Der theologiegeschichtliche Zusammenhang des Zweiten Abendmahlsstreits setzt nicht nur für das Verständnis der Erlebnisse der Flüchtlinge in der Ostsee den Rahmen. Auch Utenhoves Narratio ist nur in diesem Kontext zu verstehen, weil der Text selbst einen Beitrag zu der Kontroverse darstellt. Die Narratio ist zugleich ein Bericht über die Ereignisse und ein Beitrag in der Auseinandersetzung mit Westphal, genauer: sie steht an deren Ende.

Eine erste - verlorene - Schilderung der Ereignisse am dänischen Hof hatte a Lasco schon Anfang März 1554, noch vor dem Eintreffen der übrigen Londoner Gemeindeglieder, aus Emden an die Zürcher und an Calvin gesandt ${ }^{31}$. Zugleich hatte er die Schriften Westphals beigelegt und die Adressaten zur Widerlegung der Recta fides aufgefordert ${ }^{32}$. In den folgenden Monaten verfasste Calvin daraufhin in Absprache mit Bullinger eine Verteidigungsschrift des Consensus Tigurinus gegen Westphal, die Defensio doctrinae de Sacramenti S $^{33}$, die im Dezember abgeschlossen war und in der er den Hamburger, ohne ihn beim Namen zu nennen, scharf angriff.

Auch im weiteren Verlauf der Debatte setzte sich die unmittelbare Verbindung zwischen der Diskussion über die Abendmahlslehre und der Frage der Aufnahme der englischen und niederländischen Migranten in deutschen Städten fort. Ein erster Konflikt brach schon kurze Zeit nach Eintreffen der aus London Kommenden im niederrheinischen Wesel aus, wo seit 1545 wallonische Leineweber Zuflucht gefunden hatten und Gottesdienste in französischer Sprache halten durften. Der ehemalige Prediger der französischen Gemeinde in London, François Perussel, hatte Anfang 1554 ähnlich wie

31 Vgl. den Brief a Lascos an die Zürcher Prediger, Emden, 3.3.1554, in: CR 43 (OC XV), Nr. 1919, Sp. 63-65: »Mitto autem vobis silvam itineris nostri, usque dum a rege Dania dimitteremur, nec dicam propelleremur, in qua videbitis ad quem modum nobiscum egerint antagonistae nostri in doctrina de sacramentis, et facile intelligetis quod sit ipsorum ingenium, quae integritas, et quid ab illis sit piis omnibus exspectandum«. Vgl. auch Brief a Lascos an Calvin, Emden, 13.3.1554, in: CR 43 (OC XV), Nr. 1930, Sp. 81-84. Es scheint, als habe Marten Micron auch eine deutsche Fassung dieses Berichts erstellt, vgl. PiJPER, Geschriften van gemengden aard, Einleitung, S. 7.

32 Er selbst erklärte, auf die »Farrago« antworten zu wollen, vgl. ebd., S. 64, 83f.

33 Johannes CALvin, DEPENSIO SANAE ET ORTHODOXAE DOCTRINAE DE SAcramentis, eorum[que] natura, ui, fine, usu, \& fructu: quam pastores \& ministri Tigurinae Ecclesiae \& Geneuensis antehac breui Consensionis mutuae formula complexi sunt: unà cum refutatione probrorum quibus eam indocti \& clamosi homines infamant, Zürich, Christoph Froschauer, 1555. VD 16 C 301. Zu den Werken Calvins in der Kontroverse vgl. Rodolphe PetER/Jean-François Gilmont, Bibliotheca Calviniana. Les œvres de Jean Calvin publiées au XVIe siècle, Écrits théologiques, littéraires et juridiques 1555-1564, Genève 1994, hier: Nr. 55/6 und 7. Zur theologischen Einordnung der Kontroverse in die Reihe der Abendmahlsstreitigkeiten insgesamt vgl. Ernst BizER, Studien zur Geschichte des Abendmahlsstreits im 16. Jahrhundert, Darmstadt ${ }^{2} 1962$, passim, bes. S. 275-299. 
die Londoner in Dänemark beim Stadtrat um die Erlaubnis gebeten, eigene Abendmahlsfeiern abhalten zu dürfen, nicht nur wegen der sprachlichen Barriere, sondern auch, weil die Mitglieder seiner Gemeinde mit den in Wesel üblichen Riten nicht einverstanden waren. Diese Bitte wurde ihm abgeschlagen $^{34}$. Noch während der Überlegungen, ob die Gemeinde deshalb anderswo Aufnahme suchen sollte, trafen zwei gegenläufige Gutachten zu dieser Frage ein: Die um Rat gebetenen Genfer Prediger um Calvin empfahlen brieflich, soweit nur Fragen der Gebräuche, also Adiaphora betroffen seien, die Unterschiede zu tolerieren und in Wesel zu bleiben ${ }^{35}$.

Nach seiner Meinung zu dieser Stellungnahme befragt, votierte a Lasco von Emden aus genau entgegengesetzt: Er vermutete, die Genfer seien nicht ausreichend über die Verhältnisse in Wesel informiert und nähmen fälschlich an, dass es keine Lehrunterschiede zwischen den Weseler Theologen und den Wallonen in der Abendmahlsfrage gebe. Er sah die Gemeinschaft der Londoner Flüchtlinge in Wesel als Wiedereinrichtung der Londoner Gemeinde an. Mit deutlichem Bezug auf die Erfahrungen in Dänemark argumentierte er: Solange die Gemeinde nicht in einem öffentlichen Gespräch ihre abweichende Lehre verteidigen könne, werde man sie für Häretiker halten, wenn sie den lokalen Riten nicht zustimmten. Deswegen könnten sie, ohne die Freiheit ihres Gewissens und ihres Bekenntnisses zu gefährden, nicht in Wesel bleiben ${ }^{36}$. Auch hier plädierte a Lasco also für ein beständiges Festhalten an der eigenen Lehre, eine öffentliche Auseinandersetzung darüber und notfalls eine weitere Migration ${ }^{37}$ - also genau das Verhalten, das schon die Gemeindegruppen in Dänemark und den wendischen Hansestädten an den Tag gelegt hatten ${ }^{38}$.

34 Wilhelm H. Neuser, Die Aufnahme der Flüchtlinge aus England in Wesel (1553) und ihre Ausweisung trotz der Vermittlung Calvins und Melanchthons (1556/57), in: Weseler Konvent 1568-1968. Eine Jubiläumsschrift, Düsseldorf 1968, S. 28-49, hier: S. 31, schreibt dazu ohne Erklärung und genaue Quellenangabe: »Von den Flüchtlingen wurde die Stadt nicht mit ihrem späteren Ehrennamen >Vesalia hospitalis<, sondern in Erinnerung an trübe Erfahrungen >Kopenhagen $<$ genannt $\ll$.

35 Brief der Genfer Prediger an die Brüder in Wesel, Genf, 13.3.1554, in: CR 43 (OC XV), Nr. 1929, Sp. 78-81. Vgl. die widerstreitende Interpretation dieses Briefs bei NEusER, Die Aufnahme der Flüchtlinge, S. 32, und Walter Hollweg, Calvins Beziehungen zu den Rheinlanden, in: Josef Bohatec (Hg.), Calvinstudien, Leipzig 1909, S. 126-186, hier: S. 156.

36 Brief a Lascos, Utenhoves und Pierre du Vals an die Weseler Gemeinde, ca. April 1554; KuYPER, Opera, II, Nr. 102, S. 703-707.

37 Vgl. zum Konflikt in Wesel die Passage bei Pettegree, Second Sacramentarian Controversy, S. 232-236, der die Situation vor allem unter dem Blickwinkel der Frage diskutiert, ob die Weseler Gemeinde als Teil der Londoner anzusehen sei. A Lascos Haltung verurteilt NeusER, Die Aufnahme der Flüchtlinge, S. 33, folgendermaßen: »Der polnische Edelmann verwechselt hier den Anspruch mit der rechtlichen Lage. Er geht von der irrtümlichen Voraussetzung aus, in Deutschland könnten an einem Ort zwei Gemeinden mit verschiedenem Bekenntnis bestehen. Auch spricht er von >Toleranz<, die das 16. Jahrhundert nicht übte. Darin sah Calvin klar und konnte deshalb den Weselern wirklich raten«. 
Zwar entschloss sich die wallonische Gemeinde, vorerst in Wesel zu bleiben und sich weiter um die Genehmigung für die eigene Sakramentsverwaltung zu bemühen, doch erhielt sie diese nicht. Immerhin konnte man - unter dem Einfluss des katholischen Vermittlungstheologen Georg Cassander - erreichen, dass sie ihre eigene Kirche zur Nutzung zugewiesen bekam und für kurze Zeit unbehelligt Predigtgottesdienste halten konnte. Nach Abschluss des Augsburger Religionsfriedens aber wuchs der Druck auf die Migranten, sich zur Confessio Augustana zu bekennen. Eine Vermittlung durch ein Gutachten Melanchthons scheiterte. Im Frühjahr 1557 mussten die Londoner auf Beschluss des Weseler Rats die Stadt verlassen, wofür das Abendmahlsverständnis ausschlaggebend war ${ }^{39}$.

Parallel zu den Vorgängen in Wesel entspann sich auch in Frankfurt am Main nach der Ansiedelung von Glaubensmigranten und ihren Gemeinden eine Auseinandersetzung um die Abendmahlslehre. In Frankfurt hatten im Frühjahr 1554 wallonische Leinenweber der Flüchtlingsgemeinde in Glastonbury unter der Leitung von Valerand Poullain Aufnahme gefunden ${ }^{40}$. Zahlreiche weitere Flüchtlinge aus England und den Niederlanden folgten in den nächsten Monaten. Auch Johannes a Lasco kam, nachdem er Emden im April 1555 verlassen hatte, nach Frankfurt und bemühte sich um die Gründung einer Gemeinde für die flämischsprachigen Flüchtlinge. Zeitweilig waren die Migranten in der Stadt in drei nach Sprachen unterschiedenen Gemeinden organisiert.

Kurz nach seinem Eintreffen wurde Frankfurt zum Schauplatz der Fortsetzung des Abendmahlsstreits: Joachim Westphal, der schon mehrfach bei dem Frankfurter Drucker Peter Braubach Schriften hatte drucken lassen und mit ihm und dem Frankfurter Pfarrer Hartmann Beyer in engem Kontakt stand $^{41}$, veröffentlichte hier im Juli 1555 seine Justa Defensio als Antwort

38 Im Bezug auf die Vorgänge in Wesel kann man die spätere Veröffentlichung der »Narratio« auch als nochmalige Betonung dieser Prinzipien gegenüber Calvin und den Genfer und Lausanner Theologen verstehen, die im Fall Wesel anfangs anders votiert hatten.

39 Vgl. zu den Ereignissen in Wesel Neuser, Die Aufnahme der Flüchtlinge, bes. S. 34-45; Heinz Schilling, Niederländische Exulanten im 16. Jahrhundert. Ihre Stellung im Sozialgefüge und im religiösen Leben deutscher und englischer Städte, Gütersloh 1972, S. 88f., und HoLlwEG, Calvins Beziehungen zu den Rheinlanden, S. 144-163. Der in mancher Hinsicht problematische Aufsatz von Jesse A. Sponholz, Multiconfessional celebration of the Eucharist in sixteenth-century Wesel, in: SCJ 39 (2008), S. 705-729, berücksichtigt die Auseinandersetzungen um die Londoner Gemeinde praktisch nicht.

40 Vgl. den Beitrag von Irene Dingel, Entstehung der Evangelischen Französisch-reformierten Gemeinde Frankfurt. Theologische und ekklesiologische Aspekte, in: Georg Altrock (Hg.), Migration und Modernisierung. 450-jähriges Bestehen der Evangelischen Französisch-reformierten Gemeinde Frankfurt am Main, Frankfurt am Main 2006, S. 53-72, und die übrigen Beiträge dieses Sammelbands.

$41 \mathrm{Zu}$ Westphals Schriften und der Rolle Frankfurts als Druckort in dieser Kontroverse vgl. Herwarth von Schade, Joachim Westphal und Peter Braubach. Briefwechsel zwischen dem Ham- 
auf Calvins Defensio ${ }^{42}$. In diesem Text wurden die Flüchtlinge und a Lasco erneut heftig attackiert. Auch in einem weiteren Werk aus der Presse Braubachs, der Farrago des Bremer Predigers Johann Timann ${ }^{43}$, erschienen unter anderem Briefe Westphals, des dänischen Hofpredigers Heinrich Buscoducensis und Bugenhagens mit zahlreichen Invektiven gegen die Flüchtlinge ${ }^{44}$. A Lasco reagierte darauf in der Vorrede zu seinem Hauptwerk, der Kirchenordnung der Londoner Flüchtlingsgemeinden ${ }^{45}$. Die Ordnung unter dem Titel Forma ac ratio tota ecclesiastici ministerii war schon in London konzipiert und praktiziert worden; ein großer Teil der Druckfassung entstand in Emden bei Gellius van der Erve. Die letzten Bögen druckte die Druckerei von Christian Egenolff in Frankfurt. In seiner Widmungsvorrede, gerichtet an den polnischen König Zygmunt II. August, wies a Lasco die in der Farrago erhobenen Vorwürfe gegen die Flüchtlingsgemeinden zurück und griff seinerseits Timann und Westphal $\mathrm{an}^{46}$. Er verteidigte sich und seine Gemeinde: Sie hätten nicht vorgehabt, in die wendischen Hansestädte zu kommen, sondern hätten in Dänemark bleiben wollen, aber der dänische König sei durch unwürdige Sykophanten in die Irre geführt worden ${ }^{47}$. Auf die weiteren Um-

burger Hauptpastor, seinem Drucker-Verleger und ihrem Freund Hartmann Beyer in Frankfurt am Main über die Lage der Kirche und die Verbreitung von Büchern, Hamburg 1981, bes. S. $28-48$.

42 Joachim Westphal, Aduersus cuiusdam SacramenTARII FALSAM CRIMINATIONEM, IVSTA DEFENsio [...] in qua \& Eucharistię causa agitur [...], Frankfurt, Peter Braubach, 1555. VD 16 W 2260.

43 Johann Timann, Farrago SenTENTIARVM CONSENTIENTIVM IN VERA ET CAtholica doctrina, de Coena Domini, quam firma assensione, \& uno spiritu, iuxta diuinam uocem, Ecclesiae Augustanae confessionis amplexae sunt, sonant \& profitentur: Ex Apostolicis scriptis: Praeterea ex Orthodoxorum tam ueterum, quâm recentium perspicuis testimonijs, contra Sacramentariorum dissidentes inter se opiniones, diligenter \& bona fide collecta, Frankfurt, Peter Braubach, 1555. VD 16 T 1313. Die »Farrago« Timanns ist eine mehr als 600 Seiten umfassend Kompilation verschiedener Stellungnahmen lutherischer Theologen zum Abendmahl.

44 Bugenhagen bezeichnete die Flüchtlinge als Sakramentsverderber und Glieder des Satans, Westphal nennt sie nicht »peregrini«, sondern »errones«, vgl. die Darstellung der Rolle a Lascos im Abendmahlsstreit aus konfessionell-lutherischer Perspektive bei Richard KRUSKE, Johannes a Lasco und der Sacramentsstreit. Ein Beitrag zur Geschichte der Reformationszeit, Leipzig 1901, zur »Farrago« bes. S. 106-109.

45 Johannes a LASCO, FORMA AC RATIO TOTA ECCLEsiastici Ministerij, in peregrinorum, potißimùm uerò Germanorum Ecclesia: instituta Londini in Anglia, per [...] Regem EDVARDVM [...] Cum breui etiam (in Epistola nuncupatoria) calumniarum quarundam refutatione: quae falsò aduersus ipsum, in Martiniani cuiusdam apud Bremen[ses] Pastoris farragine inspersae habentur, Emden, Gellius Ctematius; Frankfurt, Christian Egenolff, 1555. VD 16 L 591. Edition: KuYPER, Opera, II, S. 1-283. Zu der Ordnung vgl. die jüngst erschienenen Untersuchungen von Becker, Gemeindeordnung und Kirchenzucht; Michael S. Springer, Restoring Christ's church. John a Lasco and the Forma ac ratio, Aldershot 2007.

46 A Lasco bezeichnet die Autoren der beiden »Farragines« als fartores (Wurstmacher, Geflügelstopfer), verwendet dabei nicht ihre Namen, sondern nennt sie Catones und wirft Timann Trunkenheit bei der Abfassung seiner Schriften vor. Vgl. a LAsco, Forma ac ratio, Epistola nuncupatoria, fol. $\gamma$ 8r-v. KUYPER, Opera, II, S. $20 \mathrm{f}$.

47 Ebd., fol. $\delta$ 4r; Kuyper, Opera, II, S. $23 \mathrm{f}$. 
stände der Flucht der Londoner Gemeinden ging er nicht näher ein, formulierte aber noch einmal in scharfer Form seine Position im Abendmahlsstreit und verwarf die seiner Gegner. Die Vorrede a Lascos datiert vom 6. September 1555; wenige Wochen später lag das Werk gedruckt vor. Darüber hinaus ließ a Lasco noch drei begleitende Briefe an den polnischen König und die Stände drucken, die am 31.12.1555 abgeschlossen waren ${ }^{48}$.

Als Reaktion auf die derart öffentlich ausgetragene Kontroverse um die Flüchtlingsgemeinden erließ der Rat der Stadt Frankfurt am 14. November 1555 einen Beschluss, dass in der Stadt keine Schriften mehr zum Abendmahlsstreit gedruckt werden dürften ${ }^{49}$. Dies hatte aber nur zur Folge, dass a Lasco von nun an bei Johannes Oporinus in Basel drucken ließ, während Westphal nach Oberursel oder Straßburg auswich, zu Druckereien, mit denen Braubach kooperierte. Die Kontroverse ließ sich durch solche Maßnahmen nicht unterbinden.

Im Januar 1556 ergriff auch Calvin, darin von Bullinger und Farel bestärkt, noch einmal die Feder und veröffentlichte seine Secunda defensio gegen Westphal ${ }^{50}$. Darin nahm er erneut Bezug auf die Lage der reformierten Migranten und warf Westphal vor, er habe diese noch verhöhnt, als sie am Boden lagen. Mit seiner Widmung an die Prediger »in Saxonicis Ecclesiis et Germania inferiore $\aleph^{51}$ hoffte Calvin auf Unterstützung durch die deutschen Protestanten etwa in Wittenberg, die er nicht auf Seiten Westphals vermutete. Auch Bullinger und Ochino veröffentlichten weitere Schriften gegen Westphal.

In der Zwischenzeit wurde die Lage der zahlreichen, in drei Gemeinden organisierten Migranten durch äußere und innere Faktoren erschwert: Die

48 Johannes a LASCO, EPISTOLAE tres lectu dignissimae, DE RECTA ET LEGITIMA ECCLESIARVM BEnè instituendarum ratione ac modo: AD POTENTISS. REGEM Poloniae, Senatum, reliquos[que] Ordines, Basel, Johannes Oporinus, 1556. VD 16 L 587. KuYPER, Opera, I, S. 347-388.

49 »Desgleichen ist auch beratslagt, das den Predicaten, haimischen und frembden, ainem tail sol wol als dem andern zu undersagen, das sy alhie nichts in trugkh geben noch verteutschen lassen oder auspraiten solten, sonderlich sovil den stritt des Nachtmals des Herrn belangt, dann ain E. Rat wisste Inen das auß besondern wichtigen bedencklichen ursachen mit nicht zu gestatten«. Hermann Meinert (Hg.), Die Eingliederung der niederländischen Glaubensflüchtlinge in die Frankfurter Bürgerschaft 1554-1596. Auszüge aus den Frankfurter Ratsprotokollen, Frankfurt am Main 1981, S. 20.

50 Johannes CAlvin, SECVNDA DEFENSIO PIAE ET ORTHODOXAE DE SACRAMENTIS FIDEI, Contra Ioachimi Westphali calumnias [...], Genf, Jean Crespin, 1556. Peter/Gilmont, Bibliotheca Calviniana, Nr. 56/4. Zur Auseinandersetzung zwischen Westphal und Calvin vgl. jetzt die Neubewertung der Kontroverse bei Wim JANSE, Joachim Westphal's Sacramentology, in: LuthQ 22 (2008), S. 137-160. Janse zeigt überzeugend, dass Westphal mit dem frühen Calvin gegen dessen spätere Position nach dem Consensus Tigurinus zu argumentieren vermag und dass sich seine Gegnerschaft vor allem gegen Zwinglis und Bullingers Auffassungen richtete, die den äußeren Elementen keine Heilswirkung zuerkennen.

51 Ebd., fol. a 2r. 
Stadt Frankfurt nahm im September 1555 die Beschlüsse des Augsburger Religionsfriedens formal an, dessen Regelungen sich nur auf die Verwandten der Confessio Augustana erstreckten. Die Flüchtlingsgemeinden gerieten so unter Druck ihre Zugehörigkeit zur Confessio Augustana zu belegen, die ihnen von den Anhängern der lutherischen Prediger um Hartmann Beyer bestritten wurde. Im Mai 1556 versuchte a Lasco deshalb, in einem Gespräch mit dem württembergischen Hofprediger Johannes Brenz in Stuttgart die Übereinstimmung seiner Abendmahlslehre mit der CA zu erweisen, wobei er sich auf die Variata von 1540 berief, doch Brenz brach das Gespräch nach dem ersten Tag $a b^{52}$.

Zudem kam es zu heftigen internen Streitigkeiten, sowohl innerhalb der Gemeinde der englischen Flüchtlinge als auch unter den französischsprachigen Niederländern ${ }^{53}$. Die Streitigkeiten eskalierten so weit, dass sie nicht nur öffentliche Aufmerksamkeit erregten, sondern den Verbleib der Migrantengruppen in der Stadt gefährdeten. Deshalb kam Calvin, von verschiedenen Seiten dazu aufgefordert, im August 1556 zur Schlichtung in die Stadt ${ }^{54}$. Doch sein Aufenthalt konnte weder innerhalb der Gemeinden eine dauerhafte Beruhigung des Streits herbeiführen, noch das Verhältnis zu den Frankfurter Predigern verbessern. Dazu trug auch bei, dass Westphal erneut gegen die Flüchtlinge und speziell gegen a Lasco einen scharfen Angriff veröffentlichte, den er mit einer Widmung an den Frankfurter Rat versah ${ }^{55}$. In der Widmungsvorrede ${ }^{56}$, die zudem noch in einer hochdeutschen Übersetzung in Oberursel als Separatdruck erschien ${ }^{57}$, warnte Westphal vor den »Sakramen-

52 Vgl. die knappe Darstellung bei KRuSKe, a Lasco und der Sacramentsstreit, S. 126-129. Eine Darstellung des Gesprächs in einem Brief von Brenz erschien im Rahmen eines Beitrags Westphals zur Abendmahlskontroverse: Clarissimi Viri Philippi Melanthonis sententia de Coena Domini. ex scriptis eius collecta a Joachimo Westphalo Ministro Ecclesię Hamburgensis [...], Hamburg, Johannes Wickradt Junior, 1557. VD 16 W 2271. Darin: Epistola de colloquio habito cum D. Johanne a Lasco, Stutgardiae 2.9.1556, fol. C 3v-C 5r. Vgl. dazu JürgEns, Johannes a Lasco, S. 82f.

53 Vgl. hierzu in Zukunft: Judith BeCKer, Reformierte Konfessionsmigration. Die Frankfurter Fremdengemeinden 1554-1561 und ihre Bedeutung für die Verbreitung reformierter Gemeindeordnung, Basiseinheit im Internetportal Europäische Geschichte Online, www.ieg-ego.de, Freischaltung 2010. Für die Erlaubnis zur vorzeitigen Lektüre und zahlreiche Hinweise sei der Autorin herzlich gedankt.

$54 \mathrm{Zu}$ Calvins Rolle in den Auseinandersetzungen innerhalb der Frankfurter englischen und der wallonischen Gemeinde vgl. Karl BAuer, Die Beziehungen Calvins zu Frankfurt a. M., Leipzig 1920, S. 33-52, dessen Darstellung von deutlicher Parteinahme für die Reformierten geprägt ist.

55 Vgl. Joachim Westphal, IVSTA DEFENSIO, ADVERSVS insignia mendacia Ioannis á Lasco que in Epistola ad Sereniss. Poloniae Regem, \&c. contra Saxonicas Ecclesias sparsit [...], Straßburg, Jakob Fabricius, 1557. VD 16 W 2296. Westphal bezog sich ausdrücklich auf die Widmung der »Forma ac ratio« an den polnischen König, wobei er zur Verbreitung der Texte a Lascos beitrug, indem er dessen Brief in seiner Gegenschrift noch einmal abdruckte.

56 Ebd., fol. *2r-7v.

57 Joachim Westphal, Ein Christliche vnd trewliche Warnung [...] die Sacramentirer belangend / 
tierern «, die er mit Dieben und Räubern verglich ${ }^{58}$. In der Schrift selbst fiel auch das Wort, die Flüchtlinge aus England seien »Teufels-Märtyrer«, das auch bei Melanchthon auf Kritik stie $\beta^{59}$.

Im Zuge der öffentlichen Auseinandersetzungen veröffentlichte a Lasco eine weitere Schrift, die ursprünglich als ein Privatbekenntnis gemeint war, dann aber am 23.9.1556 als Stellungnahme der Prediger der Flüchtlingsgemeinden dem Rat überreicht wurde. Darin versuchte a Lasco noch einmal die Übereinstimmung der Frankfurter Gemeinden mit der Confessio Augustana in der Fassung von $1540 \mathrm{zu}$ belegen. Auch dieser Text wurde gedruckt, durfte aber ebenfalls nicht in Frankfurt erscheinen ${ }^{60}$. Die öffentliche Debatte um das Abendmahl erreichte mit weiteren Schriften zwischen Calvin und Westphal ${ }^{61}$ sowie scharfen Stellungnahmen des wallonischen Predigers Valerand Poullain ${ }^{62}$ im Jahr 1557 ihren Höhepunkt. Calvins Hoffnung, die Unterstützung Melanchthons für seine Position zu gewinnen ${ }^{63}$, wurde jedoch

geschrieben an die Erbarn Herrn/die Burgermeister vnd Rath zu Franckfurt am Meyn. [...] Oberursel, Nikolaus Heinrich, 1557, VD 16 W 2270.

58 Vgl. Westrhal, IVSTA DEFENSIO, fol. * 5v: »Saepius commendat scriptura hospitalitatem, praecipit opera misericordiae et Charitatis exercere erga exules \& peregrinos: Verum ita ne fides uioletur, \& ne aduersus multos laedatur charitas. Vt enim charitatis est hospitio recipere peregrinos, \& his benigne facere, si pro hospitalitate $\&$ beneficijs non malefacta rependant, si quieti non turbent Ecclesiam \& Rempublicam: ita charitati maxime repugnat, praebere hospitium ingratis, inquietis, \& noxijs communitati, his parcere, hos fouere, non piae charitatis obsequium, sed impiae peruersitatis exitiale nocumentum, non misericordia est sed crudelitas «.

59 Vgl. den Brief Philipp Melanchthons an Philipp von Hessen vom 20.3.1559, CR 9, Nr. 6710, Sp. 779; MBW Nr. 8898.

60 A Lasco, Johannes, PURGATIO MINISTRORUM IN ECCLESIIS PEREGRIN[ORUM] FRANCOFVRTI, aduersus eorum calumnias, qui ipsorum doctrinam, de CHRISTI, Domini in Coena sua praesentia, dissensionis accusant ab AVGVSTANA Confessione, Basel, Johannes Oporinus, [1556]. VD 16 L 601. Edition: KuYPER, Opera, I, S. 243-268. Zum Inhalt KruSKe, A Lasco und der Sacramentsstreit, S. 121-125.

61 Gegen a Lascos »Purgatio« und Calvins »Secunda Defensio« verfasste Westphal eine im August 1557 erscheinende Entgegnung: Joachim WeSTPHAL, EPISTOLA, qua breuiter respondet ad conuicia Iohannis Caluini. ITEM, RESPONSIO [...] ad scriptum Iohannis à Lasco, in quo Augustanam Confessionem in Cinglianismum transformat, Oberursel, Nikolaus Heinrich, 1557. VD $16 \mathrm{~W}$ 2283. Im selben Jahr veröffentlichte Johannes Calvin noch eine dritte und letzte Schrift in der Debatte mit Westphal, die VLTIMA ADMONITIO [...] Ad Ioachimum Westphalu[m], cui nisi obtemperet, eo loco posthac habendus erit, quo pertinaces haereticos haberi iubet Paulus [...], Genf, Jean Crespin, 1557. Peter/Gilmont, Bibliotheca Calviniana, Nr. 57/11, S. 652-657. Die umfangreiche Schrift richtete sich in einem zweiten Teil auch gegen die Magdeburger Theologen.

62 Valerand Poullain, ANTIDOtus [...] ADuersus Ioachimi Vuestphali nomine pestilens Consiliu[m], nuper scriptum ad Magnificum Senatum inclytae ciuitatis Francofordiae [...], o. O. 1557. VD $16 \mathrm{P}$ 4517. Poullain reagierte damit auf Westphals »Iusta Defensio« und seine Widmung an der Frankfurter Rat. Westphal replizierte mit seiner APOLOGIA ADVERSVS VENENATVM ANTIDOTVM VALERANDI POLLANI SACRAMENTARII, [...]. Oberursel, Nikolaus Heinrich, 1557. VD 16 W 2263.

63 Calvin sandte seine »Ultima admonitio« an Melanchthon nach Worms, vgl. den Brief Calvins an Melanchthon vom 3.8.1557, CR 44 COC XVI, Nr. 2677, Sp. 556-558, MBW Nr. 8293. 
enttäuscht. Auf dem Kolloquium in Worms im Herbst 1557 trat Melanchthon der Verurteilung der Lehre Zwinglis nicht entgegen. Im folgenden Jahr 1558 veröffentlichte Westphal noch vier weitere Schriften, darunter Sammlungen seiner bisherigen Beiträge in der Debatte und neue Antworten auf Calvin, die alle in Oberursel erschienen ${ }^{64}$. Anschließend verloren jedoch sowohl Calvin als auch Westphal das Interesse an der Fortführung der Auseinandersetzung ${ }^{65}$.

Noch während die Diskussion andauerte, konnte a Lasco, was er lange erhofft hatte, Ende 1556 nach Polen zurückkehren. Bei seiner Reise, die ihn über Wittenberg führte, wo er mit Melanchthon zusammentraf, wurde er von Jan Utenhove begleitet. Auch für seine Tätigkeit in Polen, auf die hier nicht näher eingegangen werden $\mathrm{kann}^{66}$, war es für a Lasco entscheidend, die Übereinstimmung seiner Theologie mit der Confessio Augustana in Anspruch nehmen zu können. Die Umstände seiner Tätigkeit und die Druckmöglichkeiten in Polen erschwerten allerdings die Fortführung der Debatte mit Westphal. So erschien a Lascos letzte Schrift und zugleich die letzte Schrift in diesem Diskussionszusammenhang, die Responsio gegen Westphals Angriff auf seine Purgatio ${ }^{67}$ erst nach seinem Tod, im Frühjahr 1560 in Basel. Die Auseinandersetzungen zwischen den Frankfurter Flüchtlingsgemeinden und den Predigern der Stadt fand in dem Verbot der öffentlichen Religionsausübung der niederländischen Gemeinde 1561 ein vorläufiges Ende ${ }^{68}$.

Die Kontroversen über die Abendmahlslehre zwischen den Schweizern und den Nachfolgern Luthers, die letztlich zur Herausbildung zweier getrennter Konfessionen führten, hatten also nicht nur anfangs die Ausweisung der niederländischen Glaubensflüchtlinge aus England in Dänemark und einigen norddeutschen Städten zur Folge. Auch die Fortsetzung der Diskussion, vor allem zwischen Johannes Calvin und Joachim Westphal, blieb aufs Engste

64 Vgl. die Aufstellung bei von Schade, Joachim Westphal und Peter Braubach, S. 45f. Aus Platzgründen seien hier nur die Nummern im VD 16 genannt: W 2262, W 2264, W 2269, W 2278. Die fünfte bei von Schade unter Berufung auf die Literatur des 18. Jahrhunderts aufgeführte Schrift ist im VD 16 und im Karlsruher Virtuellen Katalog nicht nachzuweisen.

65 Westphal schrieb am 28.4.1558 an seinen Frankfurter Drucker Braubach bei Übersendung seiner »Apologia contra corruptelas et calumnias Calvini«: »Valedicam hoc scripto Sacramentariis, nihil responsurus post hac, nisi inevitabilis aliqua necessitas exigat «. Von ScHADE, Joachim Westphal und Peter Braubach, S. 127, 238.

66 Vgl. Halina Kowalska, Działalność reformatorska Jana Łaskiego w Polsce 1556-1560, ND der Ausgabe Wrocław 1969, Warszawa 1999; Henning P. Jürgens, Johannes a Lasco 1499-1560. Ein Europäer des Reformationszeitalters, Wuppertal 1999, S. 40-45.

67 Johannes A LASCO, RESPONSIO ad uirule[n]tam, calumNIISQVE AC MENDACIIS CONsarcinatam hominis furiosi IOACHIMI VVESTPHALI Epistola[m] quandam, qua Purgationem Ecclesiaru[m] Peregrinarum Francoforti conuellere conatur [...], Basel, Johannes Oporinus, 1560. VD 16 L 603. Edition: KUYPER, Opera, I, S. 271-344.

68 Vgl. Schilling, Niederländische Exulanten im 16. Jahrhundert, S. 130. Schilling sieht in Frankfurt anders als in Wesel ökonomische Gründe den religiösen Gegensatz verstärken. 
mit der Frage der Aufnahme von Glaubensmigranten verknüpft. Frankfurt als wichtigste Aufnahmestadt bildete trotz Druckverbots den Schauplatz für die zahlreichen Veröffentlichungen; in gewisser Weise waren viele Schriften an den Frankfurter Rat adressiert und bezogen Partei für oder gegen die Flüchtlingsgemeinden. Bei aller überregionalen und theologiegeschichtlich weitreichenden Bedeutung der Kontroverse trafen ihre praktischen Auswirkungen zuallererst die niederländischen Glaubensflüchtlinge.

\section{II.3 Die Veröffentlichung der »Narratio«}

In diesen komplexen Entstehungszusammenhang mit seiner jahrelangen Vorgeschichte ist Utenhoves Narratio bei ihrer Veröffentlichung im Frühjahr 1560 einzuordnen, zu einem Zeitpunkt, als schon mehr als fünf Jahre seit der Flucht aus London vergangen waren ${ }^{69}$. Vorausgegangen waren nicht nur die Vertreibung durch die Rekatholisierungsversuche in England, deren Ende bei der Abfassung der Vorreden der Schrift den Autoren schon bekannt war, sondern vor allem die Behandlung der Migranten in protestantisch geprägter Umgebung und die erhitzte Diskussion über ihre Lehre. Entsprechend formulierte a Lasco die Motivation für die Veröffentlichung und ihren späten Zeitpunkt in einer Vorrede an die Leser:

Wir haben bisher keinen bericht in offentlichen druck außgehen lassen/von vnserm außzug vnnd reiß auß Engelland/nach dem vnser Christliche kirche vnd gemeinde daselbst/durch das wider eyngeführte Bapstumb zerstört vnd verjagt/vnd derwegen sie jhr fürgenommen hatte/anderswo eine wohnung vnd aufenthaltung zu suchen. Vnd zwar dasselbige haben wir gethan/dieweil wir (so viel es möglich gewesen) mit jederman friden zu haben vnd zu halten vns beflissen: wiewol man allenthalben gegen vns vnd vnsere in Christo brüder vnd schwester/welche mit vns auf diser reiß gewesen/so vil beschwerlich ding wider alle billichkeit fürgenomen vnd gehandelt/daß wir hoch von nöten vnd gantz billiche gnugsame vrsach gehabt hetten/jederman offentlich davon zu berichten vnd vns zu beklagen.

Man habe alles ertragen

vnd alles weiter gezänck vnnd vnruhe mit vnserm stillschweigen verhüten wollen. [...] Demnach wir aber sehen/daß vnser gegentheil vnd widersacher durch diß vnser

69 Die eigentliche Schrift war schon am 29. Juli 1557 fertig, vgl. Utenhove, Narratio, S. 238 [151] (die Datierung fehlt in der Übersetzung). Die Vorrede Johannes a Lascos ist datiert »Calissiae, in maiore Polonia. 26. Martij, Anno 1558«, also Kalisz, die Vorrede Utenhoves datiert vom 1. Februar 1559 aus Krakau. 
stillschweigen/gedult vnd sanftmut/sich so gar nichts (wie wir doch sonsten gehoffet hatten) haben erweichen vnd bewegen lassen/daß sie vns etwas geneigter würden [...] Dieweil auch alle guthertzigen es darfür halten/daß diß vnser stillschweigen vns vnd vnsern Gemeinden nachtheilig vnd verweslich sey [...] Als haben wir endlich/doch vngern/vnd wider vnsern willen nicht lenger stillschweigen können noch sollen/damit wir nicht möchten dafür angesehen werden/wir hetten vmb all das böß vnd vbel / das vnsere widersacher von vnd wider vns hin vnd wider geredt/wol gewußt/aber nichts darzu sagen noch vns verantworten können ${ }^{70}$.

Allerdings war man in Genf anderer Meinung als »alle Guthertzigen«: Das fertige Manuskript, noch ohne die Vorrede Utenhoves, sandten Utenhove und a Lasco im August 1558 nach Genf, um es in der Druckerei Jean Crespins drucken zu lassen, und baten Calvin um eine Vorrede ${ }^{71}$. Doch Calvin antwortete Utenhove, er und seine Kollegen hielten eine Veröffentlichung der Narratio nicht für nützlich: sie würde alte Wunden wieder aufreißen und Westphal zu neuen Angriffen anstacheln. Glücklicherweise sei das Buch durch das Fortschreiten der Ereignisse inzwischen obsolet geworden ${ }^{72}$. Das Manuskript blieb so monatelang ungedruckt in Genf liegen, bis ein Beauftragter a Lascos, Sebastian Pech, es im Dezember 1559 bei Crespin abholte und nach Basel brachte, wo es im März 1560 bei Johannes Oporinus veröffentlicht wurde. Mindestens 600 Exemplare wurden gedruckt, 40 davon gin-

70 Johannes a Lasco, Vorred an den Leser, Bericht, S. 7f.; Utenhove, Narratio, S. 3-5 [31f.]. Vgl. den Brief Utenhoves an Calvin CR 45 (OC XVII), Nr. 2924, Sp. 268: »Mittimus nunc D. Crispino excudendam historiam peregrinationis nostrae anglicae in Daniam, dignam sane quae toti mundo innotescat. Eam vero vel ab invitis nobis extorsit nimia adversariorum impudentia, quae tanta fuit, post ipsos alioqui casus illos nostros plane miserandos, ut sine summo passim fratrum dolore maximaque ecclesiae nostrae nostrique item ministerii contumelia, causaeque demum ipsius gratia, suspicione eam premere diutius non licuerit. Neque suadet ipse Phil. Melanchthon ut eam premamus diutius, praesertim quum adeo multis calumniis nos cum suis gravarit Westphalus, qui denuo nunc adversum te nescio quid scripsisse fertur. Porro Westphalus vere ex istac historia qualis sit facile innotescet«. Ein entsprechender Brief Melanchthons ist nicht bekannt, aber er könnte diese Ansicht bei der Begegnung in Wittenberg geäußert haben.

71 Brief Utenhoves an Calvin aus der Nähe von Krakau, 30.7.1558, CR 45 (OC XVII), Nr. 2924, Sp. 266-269; vgl. Brief a Lascos an Calvin aus Osseco (heute Osiek an der Weichsel nahe Baranów), 5.8.1558, CR 45 (OC XVII), Nr. 2931, Sp. 283-285: »Praeter responsionem porro meam adversus Westphalum mittimus istuc excudendam historiam nostrae profectionis ex Anglia in Daniam, descriptam ad nostram omnium postulationem a D. Utenhovio. Ea autem ut excudatur, ecclesiae christianae omnino esse videtur. Si tu quoquoe epistolam quantumvis parvam ei historiae posses praemittere, quo maior fides historiae concilietur, faceres certe operae pretium. Porro fides ac perpetua animi D. Utenhovii constantia, ab eo tempore quo primo religionis nomine est eiectus, ita tibi est nota ut nihil opus sit ulla ipsius apud te commendatione «.

72 Brief Calvins an Utenhove, 19.11.1558, CR 45 (OC XVII), Nr. 2982, Sp. 379: »Historiam reditus vestri hoc tempore excudi collegae mei utile esse non putarunt. Vides enim quam exulcerata sint omnia et quo amentiae praecipites ruant Westphalici, etiamsi nemo eos lacessat. Turbulentos quidem eorum impetus repellere, nobis moderati etiam homines concedent, sed vulnera renovare quae odia semisepulta iterum accendant non videtur esse consultum. Adde quod libri gratia iam temporis progresso obsolevit«. 
gen als Autorenbelegexemplare nach London, wohin Utenhove inzwischen zurückgekehrt war. 150 Exemplare nahm Pech mit nach Polen, 400 weitere sollte Oporinus an a Lasco senden. Diese erreichten ihn jedoch nicht mehr, er war am 8. Januar 1560 verstorben.

\section{III.1 Die »Narratio« als Beitrag in der Abendmahlsdebatte}

Entsprechend ihrer Entstehungsgeschichte changiert auch der Inhalt der Narratio. Von den dreihundert Oktavseiten (inkl. Register) nehmen die Wiedergabe von Petitionen, Denkschriften, Briefen und Diskussionsprotokollen zur Abendmahlsfrage mindestens drei Viertel ein. Die wenigen erzählenden Passagen bilden meist lediglich die Überleitung zwischen den zum Teil seitenlangen Dokumenten. Dieser Doppelcharakter der Schrift kommt auch in ihrem Titel zum Ausdruck: zwar verspricht die Titelzeile, es werde »fürnemlich [...] was sie für reisen haben auf sich nemen vnd thun müssen« behandelt, doch behält der Untertitel sehr viel mehr Recht: »Darin zugleich vil vom Abendmal des Herrn vnd vom heutigen gegenwärtigen Streit desselbigen gelert vnd gehandelt wird $\aleph^{73}$.

Die abweisende Behandlung der aus London Kommenden in Dänemark und ihre Fahrt über die winterliche Ostsee hatten in Europa Aufsehen erregt und waren durchaus geeignet, im Streit um das Abendmahl die lutherische Seite zu diskreditieren und die Flüchtlinge zu Verfolgten zu stilisieren ${ }^{74}$. Tatsächlich finden sich auch Passagen in der Schrift, die die Herausbildung eines Märtyrerbilds hätten befördern können, aber sie treten gegenüber den abendmahlstheologischen Debatten eindeutig in den Hintergrund. Als Beleg für Vorwürfe gegen die katholische Seite wurde das Schicksal der aus England vertriebenen Protestanten fast nicht mehr verwendet, wozu wohl auch der inzwischen wieder eingetretene Umschwung durch den Regierungsantritt

73 Vgl. Utenhove, Narratio, S. 1 [29]: "potissimum de susceptis posteà illius nomine itineribus, quaeque eis in illis euenerunt. In qua multa de Coenae Dominicae negocio, aliisque rebus lectu dignissimis tractantur .

74 Einen späten Nachhall dieser Wirkung findet man auch in der Beschreibung der Geschichte der Reformierten in Frankfurt, die Abraham Mangon Anfang des 18. Jahrhunderts verfasste. Im Rahmen der Schilderung von Calvins Aufenthalt in Frankfurt schreibt Mangon die Verantwortung für die Vertreibung der Flüchtlinge aus Dänemark und den Hansestädten ganz Westphal zu: »Es kame auch ein boshafftes Warnungschreiben von einem Joachim Westphalo an E.E. Rath durch Beförderung M. Hartmann Bayers an das Licht, in welchem die Frembden ärger als Zauberer und Mordbrenner zu seyn taxiert wurden [...]. Calvinus schriebe damahln auch ein Tractätgen wieder obgedachten Westphalum, als welcher der christlichen Liebe zuwieder durch sein Schreiben verursachet hatte, daß die umb der Religion willen Vertriebene weder in Holstein, noch Dänemarck, noch in der Graffschaft Oldenburg sich haben sezen können, ausser zu Embden und Bremen«. Abraham MAngon, Kurze doch wahrhafftige Beschreibung der Geschichte der Reformierten in Frankfurt. 1554-1712, hg. von Irene Dingel, Leipzig 2004, S. 61. 
Königin Elisabeths I. beigetragen haben mag ${ }^{75}$. Dagegen wird es zum Hauptanliegen der Schrift, den Vorwürfen gegen die Gemeinde und ihre Lehre entgegenzutreten, sich also mit der lutherischen Seite auseinanderzusetzen.

Eine Rezeption als Märtyrerbericht erfuhr Utenhoves Schrift in späterer Zeit: Eine ausgesprochen wortgetreue deutsche Übersetzung der Narratio erschien 1603 in Herborn. Sie stammte aus der Feder des reformierten Predigers in Dillenburg, Bartholomäus Rhoding, und wurde vom Drucker Christoph Rab zusammengebunden mit einer Übersetzung des Märtyrerbuchs Jean Crespins $^{76}$. Der Übersetzer nimmt keine Straffung oder gar Bearbeitung vor und hebt auch die Aspekte der Standhaftigkeit in seiner Widmungsvorrede nicht besonders hervor; nur der vom Drucker hergestellte Veröffentlichungskontext stellt die Londoner Flüchtlinge in eine Reihe mit denen, die »um der göttlichen warheit willen jämmerlichen verfolget/gemartet/vnd endlich auf allerley weise entleibet seyn worden $\ll^{77}$.

Die Behandlung der Londoner Flüchtlingsgemeinde blieb ein kontroverses Thema. Noch zweihundert Jahre nach den Ereignissen erfuhr die Narratio eine Art Gegendarstellung von dänischer Seite: Der jütländische Bischof Ludwig Harboe verfasste 1754 die kurz darauf auch ins Deutsche übertragenen Zuverlässige[n] Nachrichten von dem Schicksale des Johann von Lasco und seiner aus England vertriebenen reformirten Gemeinde in Dänemark, in denen er eine Ehrenrettung des dänischen Verhaltens versuchte ${ }^{78}$. Und bis heute erfahren die Narratio und die darin geschilderten Ereignisse auch in der wissenschaftlichen Literatur Wertungen mit eindeutig konfessioneller Perspektive ${ }^{79}$.

75 Auch in einem langen Schreiben a Lascos an Königin Elisabeth, das dieser wenige Monate vor seinem Tod dem nach London zurückkehrenden Utenhove mitgab, lobte a Lasco zwar ausführlich Edward VI. und ermahnte die Königin zur Wahrnehmung ihrer Pflicht, die wahre Religion zu fördern, bezog sich aber auf die Vertreibung durch Maria nur in Andeutungen, vgl. den Brief a Lascos an Königin Elisabeth, 1.9.1559, KUYPER, Opera, Bd. II, Nr. 134, S. 758-765.

76 Jean CRespin/Simon Goulart, Märtyrbuch. Darin[n]en erstlich merckliche denckwürdige Reden vnd Thaten viler heiligen Märtyrer beschrieben werden/welche nach den zeiten der Aposteln/bis aufs jar Christi M. D. LXXIIII. hin vnd wider in Teutschland/Engelland/Schotland / Niderland/Jtalien/Hispanien etc. vmb der götllichn warheit willen jämmerlich verfolget/gemartert/vnd endlich auf allerley weise entleibet seyn worden: Auß den Frantzösischen Geschichten der Märtyrern außgezogen, [Herborn] 1603, VD 17 3:308218B. Der genaue Titel der Übersetzung Rhodings vgl. oben, Anm. 1.

77 So die Formulierung auf dem Titel, ebd., fol. A 1r.

78 Ludvig Harboe, [...] Zuverlässige Nachrichten von dem Schicksale des Johann a Lasco und seiner aus England vertriebenen reformirten Gemeinde in Dännemark [...], Kopenhagen, 1758.

79 Z.B. dargestellt als Märtyrergeschichte etwa bei dem Hamburger Rudolf KAYSER, Johannes a Lasco und die Londoner Flüchtlingsgemeinde in Hamburg, in: ZVHaG 37 (1938), S. 1-15, in abgeschwächter Form bei Frederick A. Norwood, The Reformation Refugees as an Economic Force, Chicago 1942, dagegen aus Sicht Westphals bei Carl MönCKEBERG, Die Ausweisung der Englischen Exulanten aus Hamburg im Jahre 1553. Ein Vortrag, im Vereine gehalten im Januar 1863, in: ZVHaG 5 (1866), S. 186-201; aus Perspektive der Schweizer bei Bizer, Studien zur Geschichte des Abendmahlsstreits, S. 275-299; mit Verständnis für die dänische Haltung bei 


\section{III.2 Die »Narratio« als Bericht über die Erlebnisse der Migranten}

Der Doppelcharakter, den die Narratio Utenhoves als Beitrag in der Zweiten Abendmahlskontroverse und als Bericht über die Auswanderung der Londoner Migranten trägt, findet auch in der Darstellung der Ereignisse in Dänemark ihre Entsprechung. Den weitaus größeren Teil der »Erzählung« nehmen eben gerade keine erzählenden, sondern dokumentierende Passagen ein, beginnend mit der knappen Schilderung des Aufbruchs aus London ${ }^{80}$. Den ersten Schwerpunkt der Dokumentation bilden die Erlebnisse der drei Unterhändler a Lasco, Utenhove und Micron am Königshof in Kolding ${ }^{81}$. Sie verhandelten auf höchster Ebene und ihre Bitte um Aufnahme zeigte ein erhebliches Selbst-, wenn nicht Sendungsbewusstsein. Sie verlangten nichts weniger als die Gewährung derselben Privilegien, die sie in London genossen hatten, also eine eigenständige Gemeindegründung mit eigenen Gottesdienstformen und eigener Theologie. Dabei signalisierten sie, dass auch Dänemark von ihrer reinen, allein auf biblische Prinzipien gegründeten und von allen papistischen Überresten gereinigten Kirchenordnung profitieren würde. Von dänischer Seite wurde dagegen die Unterordnung der niederländischen Glaubensflüchtlinge unter die Bugenhagensche Kirchenordnung verlangt. Dabei ist eine besondere Pointe, dass die beiden als Kontrahenten auftretenden Hofprediger Paul Noviomagus und Heinrich Buscoducensis ihrerseits niederländische Glaubensmigranten waren, die - wie ihre Namen ausweisen - aus Nijmegen und s'Hertogenbosch stammten, aber eben in Wittenberg studiert hatten. Die Einordnung in eine lutherisch geprägte Ordnung war wiederum für die reformierten Theologen nicht akzeptabel. Sie beharrten auf ihrer Abendmahlstheologie, boten wiederholt an, diese in öffentlichen Disputationen zu verteidigen und nahmen lieber die Ausweisung in Kauf, als in diesem Punkt Abstriche zu machen. Eine Einigung war bei der Konfrontation dieser beiden Positionen nicht möglich und nicht zu erwarten.

Durch die erzwungene direkte Weiterreise a Lascos, Microns und Utenhoves nach Emden blieben die übrigen rund 160 Gemeindeglieder für mehr

Ole Peter Grell, Exile and Tolerance, in: Ders./Bob Scribner (Hg.), Tolerance and intolerance in the European reformation, Cambridge 2002, S. 164-181, bis hin zu Martin Schwarz Lausten, Die Reformation in Dänemark, Gütersloh 2008, S. 138f., der davon ausgeht, es drohte durch die 175 Flüchtlinge die Gefahr, dass ganz Nordeuropa an die calvinistische Abendmahlslehre verloren gehen könnte.

80 Vgl. das Textverhältnis in Kapitel 1, »Qua occasione peregrinorum ecclesiae Londini, per Eduardum Regem sint institutae, ac demum post eius mortem dissipatae : Von den knapp zehn Seiten Text entfallen allein sieben Seiten auf den vollständigen Abdruck der Einsetzungsurkunde der Gemeinde: Utenhove, Narratio, S. 12-21 [35-39]; ders., Bericht, S. 17-26.

81 Das zweite Kapitel, in dem die Einschiffung und abenteuerliche Überfahrt beschrieben werden, nimmt vier Seiten ein; Kapitel 3 zu den Ereignissen am Königshof umfasst dagegen 76 Seiten und enthält die vollständige Wiedergabe mehrerer Denkschriften und Gesprächsprotokolle. Vgl. ebd., S. 21-24, 24-100 [39-41, 41-77]; ders., Bericht, S. 26-28, 29-108. 
als zwei Monate ohne ihre theologischen Leiter. Hier zeigte sich, dass die theologischen Überzeugungen ihrer Pastoren und Ältesten auch von der Gemeinde geteilt und verteidigt wurden. Der Bericht über diese Phase der Reise hat noch am ehesten erzählenden Charakter und gewährt, obwohl der Verfasser Utenhove ja kein Augenzeuge war, interessante Einblicke in den Alltag der Glaubensmigranten. So wurden die Ankömmlinge in Kopenhagen Anfang November durchaus nicht unfreundlich empfangen. Sie wurden nach Name, Beruf und Bekenntnis befragt und mussten einen heiligen Eid schwören, keine Wiedertäufer oder Aufrührer zu sein. Dann wurde ihnen, in Erwartung einer positiven Beantwortung der Bitte um Aufnahme durch den König, gestattet, Häuser zu mieten und den Handwerken nachzugehen, die nicht einer Zunftbeschränkung unterlagen. Außerdem wurden sie von Pflichten und Abgaben befreit ${ }^{82}$. Als sich jedoch die Nachrichten aus Kolding verdichteten, dass die Verhandlungen mit dem König scheitern würden, wurden der Lehrer Hermen Backereel und ein schottischer Prediger aus der Gruppe von Bischof Peder Palladius vorgeladen und einem Glaubensverhör unterzogen, das speziell die Themen Kindertaufe, Inkarnations- und Abendmahlslehre zum Inhalt hatte. Die dabei zutage tretenden Differenzen in der Realpräsenzlehre bezeichnete Palladius »so groß nicht/ daß darumb das band der christlichen brüderlichen lieb zwischen uns soll zerrissen werden ${ }^{83}$.

Direkt nach diesem Gespräch wurde jedoch eine Delegation der Londoner erneut einbestellt, diesmal vor die lokale weltliche Obrigkeit ins Rathaus. Ihnen wurde befohlen, sofort auszureisen, wenn sie nicht »die lehr vnd meinung des Königs vom Sakrament des heiligen Abendmals billigen vnd annemen $\ll^{84}$ wollten. Als sie dies ablehnten, wurden sie erneut durch Palladius befragt, ob denn

auch die andere all miteinander/darin einer lehr vnd meinung mit jhnen seyen. Sie sprachen/sie hieltens zwar dafür: doch wolten sie nicht vermessen von allen vnd jeder [sic] wegen dasselbige für gewiß sagen/sintemal ein jeder für sich selbst vnd seines glaubens rechenschaft zu wissen vnd zu geben schuldig were ${ }^{85}$.

Unter der expliziten Androhung der sofortigen Ausweisung kam es nun zur Einzelbefragung der Flüchtlinge, die alle bezeugten,

daß sie der lehr/welche wir bekennen/von hertzen zugethan seyen/vnd vnderschreyben [...] außgenommen ein schneider/welcher sagte, zu was für einer lehr vnd mei-

82 Ebd., S. 100f. [77-81]; ders., Bericht, S. 108f.

83 Utenhove, Bericht, S. 113; vgl. ders., Narratio, S. 104 [82].

84 Ebd., S. 114; vgl. ders., Narratio, S. 105 [83].

85 Ebd., S. 115; vgl. ders., Narratio, S. 106 [84]. 
nung er sich bekennen solte, das wolte er zuvor mit seinem weib berathschlagen/welche schon vorlangst solches reisens zu wasser vnd zu land/vnd erlittener gefähr- vnd beschwerlichkeiten war müde vnd überdrüssig worden ${ }^{86}$.

Hier zeigt sich an der Ausnahme des Schneiders wie an den Beispielen der übrigen Befragten die hohe theologisch-konfessionelle Motivierung der Londoner Gemeinde, deren Mitglieder sich über die Theologumena, für die sie diese Migration auf sich nahmen, durchaus im Klaren waren, diese in Einzelbefragung bekannten und die Haltung ihrer Theologen mit trugen. Sie verkörpern beispielhaft die, wie Heinz Schilling es genannt hat, »entschiedene Bejahung einer konfessionell bestimmten Religiosität « bei den Konfessionsmigranten $^{87}$.

Die sofortige Ausweisung, die ihre Erklärung nach sich ziehen sollte, versuchte die Gruppe angesichts des strengen Winters zu vermeiden. Ihre Bitte, wenigstens überwintern zu dürfen, wurde ihnen abgeschlagen. Der Bericht zeugt davon, wie sie um immer kürzere Fristen anhielten, um zwei Monate, einen, zwei Wochen, schließlich wurden ihnen selbst die erbetenen acht Tage nicht gewährt. Dabei argumentierten die Flüchtlinge nicht nur mit der widrigen Witterung ${ }^{88}$ und dem Appell an christliche Nächstenliebe oder mit dem Vers über die Aufnahme des Fremden nach Mt 25,35, sondern auch mit ökonomischen und praktischen Überlegungen:

So lasset euch doch erbitten/vnd gebt uns viertzehen tag zeit: dann wir biß auf Ostern häuser gedingt haben/deßgleichen mit holtz vnd anderer notturft vns auf den winter versorget/vnd darüber schulden in der statt gemacht/damit wir dieselbige vnsere sachen all richtig vnd auf ein end machen/vnd nicht jemand vnter vns mit seinem schaden noch nachtheil ausziehen möge ${ }^{89}$.

Der Verdacht liegt nahe, dass der Rat der Stadt Kopenhagen die sofortige Umsetzung des königlichen Ausweisungsedikts, auf die selbst der Bischof nicht bestand, unter anderem aus solchen ökonomischen Motiven exekutierte. Selbst ein Abzug als Einzelne über einen gewissen Zeitraum hinweg wurde ihnen untersagt. Darum hatten die Migranten in dem Bewusstsein gebeten, dass eine so große Gruppe anderswo ebenfalls nur schwer aufgenommen

86 Ebd., S. 117; vgl. ders., Narratio, S. 107f. [84]. Der Fall des Schneiders, der als einziger in Dänemark bleiben wollte, ist auch auf dänischer Seite dokumentiert durch einen Bericht von Peter Godske, einem dänischen Beamten, der wiedergegeben ist bei HARBOE, Zuverlässige Nachrichten, S. 60f. Dort ist allerdings von einem Schuster die Rede.

87 Schilling, Die niederländischen Exulanten des 16. Jahrhunderts, S. 77.

88 Utenhove, Bericht, S. 122: »Es sey doch niemands so vnbarmhertzig vnd vnmenschlich gesinnet/der bey solchem wetter auch ein irrenden hund nicht in sein hauß neme«. Vgl. ders., Narratio, S. 112 [87].

89 Ebd., S. 120; vgl. ders., Narratio, S. 111 [86]. 
würde und sich notwendig verdächtig machen müsste ${ }^{90}$. Doch letztlich wurden alle bis auf vier Kranke und Schwangere gleichzeitig zum Verlassen der Stadt gezwungen, teilten sich aber in vier Gruppen auf, die an verschiedenen Orten um Aufnahme baten ${ }^{91}$.

Den nach Rostock Gereisten gelang es, mehrere Wochen ohne größeres Aufsehen in der Stadt zu bleiben, was vom Rat stillschweigend toleriert wurde. In Wismar, wohin die Flüchtlinge nur über das Packeis der zugefrorenen See gelangten, erfuhren sie sogar eine freundliche Aufnahme. Unter denen, die ihnen mit »Wegg und Wein« entgegen kamen ${ }^{92}$, waren auch Leute,

die man Westerlinge nennet/dieselbige selbsten theten gleichfals auch anfenglich den vnsern vil guts: Aber durch die gelegenheit vnderstunden sie sich die gewissen der vnsern/vnd insonderheit der schwachgläubigen vnd einfeltigen/zu verwirren vnd zu verfüren/vnd von der Gemein abwendig zu machen/in dem sie sie auf etliche fragen führten/von der menschwerdung des Herrn Christi/von der kindertauf/von der widertauf/vom aidschwur/vom brauch des weltlichen schwerts oder gewalt der weltlichen Oberkeit/vnd dergleichen ding mehr ${ }^{93}$.

Die Londoner Gemeinde geriet in Wismar also noch von einer anderen, unerwarteten Seite in Bedrängnis. Galt es sonst, gegenüber den lutherischen Predigern und der Obrigkeit glaubhaft zu machen, keine Täufer zu sein ${ }^{94}$, um nicht unter die kaiserlichen und lokalen Täuferverdikte zu fallen, mussten sie nun befürchten, Gemeindeglieder an die taufgesinnten Landsleute zu verlieren. Der Leiter der Gemeinde, der Lehrer Backereel, suchte daraufhin das Gespräch mit Menno Simons, der sich unerkannt in Wismar aufhielt. Doch

90 Vgl. ebd., S. 121: »Vnd nach dem ein jeder hauf volcks/sonderlich fremder vnbekanter leut/in bösen argwohn vnd verdacht heimlicher zusammenrottung/tumults vnd aufrhur/leichtlich komme/so würde man sie/insonderheit weil sie der gestalt vom König in Dennemarck/vnd bey solchem vngewitter/verjagt/auch anderswo allenthalben für vbelthäter vnd aufrührische leut halten vnd vertreiben. Zu dem könne man auf den dörffern/für einen solchen hauffen volcks nicht bald zu essen gnug bekommen: dieweil auch zu Kappenhagen die Pestilenz regier/so würde man sie mit einem solchen hauffen daher kommende auch allein derselbigen vrsachen halben an keinem ort aufnehmen«. Vgl. ders., Narratio, S. 111f. [86].

91 Vgl. ebd., S. 124f.; ders., Narratio, S. 115 [88].

92 Im Bericht von Menno Simons, den dieser über das Gespräch mit Micron veröffentlichte (siehe Fn 95), heißt es: »Sy [sc. die Wismarer Täufer] sijnse met weggen ende wijn en tegen gegaen, so daer eninge crancken ofte swacken onder haer geweest waren, dat sy de selfde daermeede verquicken ende weinich hadden stercken mogen«. Zitiert nach PIJPER, Geschriften van gemengden aard, S. 94, Fn 1.

93 Utenhove, Bericht, S. 131f.; ders., Narratio, S. 122f. [93f.].

94 In Wismar etwa schürten Prediger die Angst vor den Flüchtlingen folgendermaßen: »Vnder anderm schemten vnd scheuten sich etlich nit von jnen zu sagen/[...] daß sie [sc. die Londoner] des nachts jhre zusammenkunft hielten/darin sie ohne lichter die weiber ohn allen vnderscheid gemein hetten vnd vnzucht trieben«. UtenHove, Bericht, S. 135. Hier wirkten offensichtlich die Gerüchte über die Vielweiberei der Münsterschen Täufer nach. 
scheint dieses Gespräch nicht nach Wunsch verlaufen sein, denn anschließend riefen die Londoner ihren Prediger Marten Micron zur Hilfe.

Micron eilte aus Emden herbei und führte mit Menno Simons ein Gespräch, über das später beide noch Flugschriften veröffentlichten, in denen sie jeweils den Sieg für sich reklamierten ${ }^{95}$. Micron revanchierte sich zudem, indem er andere Täufer in Wismar aufsuchte, die Menno aus seiner Gemeinde ausgeschlossen hatte,

$\mathrm{zu}$ erforschen/was doch die vrsach wer [...] vnd verstund, daß es darumb allein geschehen wer/dieweil sie neben den Widertäuferischen Predigern/auch andere auß den Evangelischen höreten/vnd daß sie meinten/es stünde ihnen frey dieselbige zu hören ${ }^{96}$.

Sowohl die reformierte als auch die täuferische Migrantengemeinde hatten also mit dem Phänomen zu kämpfen, dass ihnen einzelne Mitglieder von der Fahne gingen beziehungsweise die konfessionelle Abgrenzung im Alltag nicht ausreichend gelang.

Mit dem Eintreffen Microns in Wismar endet der kurze Teil der Narratio, der über die Erlebnisse der Gemeinde ohne Leitung eines Theologen berichtet und wirklich eine Erzählung bietet. In den folgenden Wochen von Microns Rückkunft an dominieren wieder die Gesprächsprotokolle und Briefe die Schrift. Die anschließend geschilderten Ereignisse wiederholten sich in Wismar, Rostock, Lübeck und Hamburg fast stereotyp: Die Londoner Flüchtlinge lebten anfangs ruhig und mit Duldung der weltlichen Obrigkeit in den Städten, bis es zu Angriffen auf sie durch die lutherischen Prediger von der Kanzel herab kam. Micron suchte daraufhin das Gespräch mit den Predigern, bestand aber immer darauf, die Debatte über die Abendmahlslehre, um die es in jedem Fall ging, solle in Anwesenheit aller Prediger, einiger Bürger und der weltlichen Obrigkeit stattfinden. Die lutherischen Kontrahenten wiesen vor allem die Beteiligung der Obrigkeit zurück, verlangten stattdessen eine Disputation vor der Universität Rostock, auf die Micron sich aber nicht

95 Vgl. Marten Micron, Een waerachtigh verhaal der ṫzamensprekinghe[n] tusschen Menno Simons ende Martinus Mikron va[n] der Menschwerdinghe Jesu Christi. Mit einer kleyner verklaringhe op den zelven end anderen twistighen artikelen [...] ghetrauwelick en naerstlick in aller eenvoldigheit beschreven, Emden, Gellius Ctematius, 1556. VD 16 M 5179. [Menno Simons], Een gans duytlijck, ende bescheyden antwoordt. An[n]o 1556. wt waerheyt ende cracht der heylighen godlicken schrift grondlijcken veruaetet, op Martini Mikrons Antichristissche leere ende onwaerachtighe valsche verhael van den handel ofte bispreck. An[n]o .53. minder ghetal, tusschen hem ende my van die alderheylichste menschwerdinghe onses Heeren Iesu Christi voor veele getuyghen gheschien, o.O. u. J. [Fresenburg 1556]. Im VD 16 nicht nachgewiesen, vgl. Irvin Buckwalter Horst, A bibliography of Menno Simons, Nieuwkoop 1962, Nr. 59.

96 Utenhove, Bericht, S. 134; vgl. ders., Narratio, S. 124 [96]. 
einlie ${ }^{97}$. Im Anschluss an die in der Narratio ausführlich protokollierten Gespräche - aus denen Micron natürlich in seiner Schilderung immer als Sieger hervorgeht, während die lutherischen Prediger manchmal eine recht traurige Figur machen - änderte sich die vorher tolerante Haltung der Obrigkeiten und die Londoner wurden ausgewiesen.

Pointiert könnte man formulieren, dass der Zug der Londoner Glaubensmigranten von Wismar über Rostock, Lübeck und Hamburg in Richtung Ostfriesland, wo ihnen ihre Aufnahme schon zugesagt war, geradezu als performativer Teil der Abendmahlsdebatte anzusehen ist. Bei den in allen wendischen Hansestädten abgehaltenen Abendmahlsgesprächen suchte Micron regelrecht eine Bühne, um mit größtmöglicher Öffentlichkeit seine Lehre vertreten zu können. Und auch in Hamburg, der Stadt des Hauptopponenten, ging er gezielt in die Bekenntnissituation im Gespräch mit Westphal - mit der Konsequenz, dass auch die direkt aus London gekommenen Flüchtlinge, die sich zum Teil seit einem halben Jahr in der Stadt aufhielten, hier ebenfalls ausgewiesen wurden.

\section{Zusammenfassung}

Die Lektüre der Simplex et fidelis narratio Jan Utenhoves bietet einen Einblick sowohl in theologische Motivationen wie praktische Probleme der niederländischen Konfessionsmigration in der Mitte des 16. Jahrhunderts ${ }^{98}$. In ihrer eigentümlichen Mischung von konfessionspolemischen Dokumenten und zum Teil tief berührenden Schicksalsberichten ist sie ein Text, in dem theologische Argumentation, konfessorische und apologetische Texte und der Bericht über das standhafte Bekennen zusammengefasst sind. Damit ist die Narratio eine frühe und beispielhafte Formulierung der Theologie der niederländischen Glaubensmigranten, die von Heinz Schilling im Anschluss an Heiko A. Oberman als »Exulantentheologie « bezeichnet worden ist ${ }^{99}$. Doch scheint dieser Begriff dem Anliegen der Exulanten nicht genau genug zu entsprechen. Auch wenn sie für die Beibehaltung ihrer Glaubensüberzeugungen mehrfache Vertreibungen oder Umsiedelungen in Kauf nahmen, vertraten sie

97 So etwa in der Debatte mit Heinrich Schmedenstede in Wismar, in der dieser sagt: »Was? solle die Oberkeit darin richter seyn? vil eher der Teufel. Was weiß vnd versteht die Oberkeit von der Religion? Lasset vns gen Rostock ziehen/zu den Doctorn vnd Superintendenten, welche recht von dem gesprech vrtheilen können«. Ebd., S. 155f.; vgl. ders., Narratio, S. 146 [107].

98 Der Text steht, folgt man Heinz Schilling, am Beginn der »erste[n] Welle der alteuropäischen Konfessionsmigration«, vgl. Schilling, Die niederländischen Exulanten des 16. Jahrhunderts, S. 67, und damit auch am Anfang der publizistischen Formulierung und Verbreitung des Phänomens Konfessionsmigration.

99 Vgl. Schilling, Die niederländischen Exulanten des 16. Jahrhunderts, S. 67-78. 
in den dogmatischen Fragen, an denen sich der Konflikt mit den Theologen der Aufnahmeländer und -städte entzündete, keine eigenständige Theologie, die womöglich das Sein als Exulanten oder Glaubensmigranten in den Mittelpunkt stellte. Vielmehr blieben ihre theologischen Argumentationen vor allem bei der Debatte um die Abendmahlslehre wenig originell und hielten sich theologisch auf der Linie Calvins und Bullingers ${ }^{100}$. Sie alleine rechtfertigen nicht, den Flüchtlingen eine besondere Theologie zuzuschreiben.

Das besondere Moment dieser Theologie der Migranten, das in der Narratio deutlich zum Ausdruck kommt, liegt vielmehr in der Verbindung des Selbst- wenn nicht Sendungsbewusstseins der von ihnen vertretenen Theologie als einer allein nach Gottes Wort geordneten und aus der Schrift begründeten Lehre mit der Erfahrung der Migration. Die konfessionelle Identität der Gemeinden manifestierte sich in der Migration: Indem die Flüchtlinge an allen Stationen ihrer Reise ihre Theologie nicht nur verteidigten, sondern zum Teil sogar offensiv vorbrachten und dafür die Konsequenzen auf sich nahmen, bezeugten sie ihr Bekenntnis mit Worten und Taten und sind im wörtlichen Sinn als Konfessions-Migranten anzusehen.

Bezeichnenderweise wird die vollzogene Migration in dem Text zwar auch »peregrinatio«, häufig aber auch »iter« genannt, was in der deutschen Übersetzung zum Teil einfach als »Reise« wiedergegeben wird: Nicht das Moment der gewaltsamen Vertreibung oder der Flucht vor Verfolgung steht im Selbstverständnis der Migranten im Vordergrund, sondern der bewusst vollzogene Ortswechsel, um an den Glaubensüberzeugungen festhalten zu können, auch wenn die zum Teil lebensbedrohlichen Umstände durchaus als Kreuz, als auferlegte Probe, verstanden werden ${ }^{101}$.

Genau zur Zeit der reichsrechtlichen Formulierung des »ius emigrandi« nahmen die Londoner Flüchtlinge eine konfessionell motivierte Emigration auf sich. Sie stellten dabei das »ius reformandi« der aufnehmenden Obrigkeiten nicht in Frage, sondern appellierten vielmehr an den dänischen König, die Räte und Bürgerschaften der wendischen Städte, dieses »ius« in ihrem Sinne einer weiteren Reformation von Leben und Lehre in Anspruch zu nehmen. Dadurch, dass sie keine Dissimulation betrieben, blieb die Möglichkeit einer stillschweigenden Duldung für die Obrigkeiten ausgeschlossen: Durch ihr offenes Auftreten in Dänemark und Norddeutschland warfen sie die Frage auf, wie die lokalen Autoritäten auf ihre Ankunft reagieren sollten, denn sie stell-

100 Wie weit Calvins Theologie durch sein eigenes Schicksal als Exulant geprägt gewesen ist, wird immer wieder, namentlich im laufenden »Calvin-Jahr«, ausgiebig diskutiert. Für die Utenhove, Micron und a Lasco noch näher stehende Theologie Heinrich Bullingers lässt sich dieses Moment aber wohl nicht besonders betonen.

101 Vgl. nur die Formulierungen der beiden Vorreden a Lascos und Utenhoves, UtEnHove, Narratio, S. 3-11 [31-35]; ders., Bericht, S. 7-17. 
ten bewusst das Prinzip der religiösen Einheitlichkeit der lutherisch geprägten Aufnahmeorte in Frage. Die in Dänemark und den Hansestädten letztlich einhellig vollzogene Ausweisung der Flüchtlingsgruppen erscheint so als Phänomen der Konfessionalisierung - und zeigt zugleich deren Grenzen auf. 


\title{
Vera von der Osten-Sacken
}

\section{Erzwungenes und selbstgewähltes Exil im Luthertum}

\author{
Bartholomäus Gernhards Schrift »De Exiliis« (1575)
}

Bei der Erforschung des Phänomens der »frühneuzeitlichen Konfessionsmigration $\ll^{1}$ galt das Hauptinteresse bisher den Migrationen calvinistischer Flüchtlingsgemeinden und ihren Auswirkungen im Bereich von Gesellschaft und Politik. Relativ wenig bekannt und erforscht sind dagegen die Exile innerhalb des Luthertums.

In der zweiten Hälfte des 16. Jahrhunderts gab es im ernestinischen und albertinischen Sachsen mehrere Veränderungen der Herrschaftssituation, die kirchenpolitische Maßnahmen und schließlich Absetzungen und Vertreibungen nach sich zogen und eng mit theologischen Kontroversen der Zeit verbunden waren. In den Kontext dieser Vertreibungen gehört auch die hier zu untersuchende Quelle: Bartholomaeus Gernhards im Jahre 1575 bei Urban Gaubisch in Eisleben gedruckte Schrift De exiliis ${ }^{2}$ reflektiert die Situation evangelischer Theologen in der Tradition Luthers, die sich im Exil befanden oder Exile erlebt hatten. Sie zeigt die besondere Weise, in der sich Exil und Vertreibung in der theologischen Selbstwahrnehmung der Anhänger Luthers spiegelten.

In De exiliis thematisiert Gernhard die Exilserfahrungen der vertriebenen Theologen. Dabei schreibt er aus einer Binnenperspektive ${ }^{3}$, schildert

1 Vgl. dazu: Heinz Schilling, Die frühneuzeitliche Konfessionsmigration, in: Klaus J. Bade (Hg.), Migration in der europäischen Geschichte seit dem späten Mittelalter. Vorträge auf dem deutschen Historikertag in Halle a.d. Saale, 11. September 2003 [2002], Osnabrück 2002, S. 67-89.

2 Bartholomaeus Gernhard, De exiliis, Christliche Erinnerungen aus Gottes Wort. In etlichen furnemen Artickeln zu ende der Vorrede verzeichnet. An die Enturlaubten und Vertriebenen Prediger aus Düringen/Francken/und Meissen/der unmündigen Herzogen zu Sachsen und Fürstentumb. bey Ausspendung der contribuirten Stewer gehalten. Durch M. Bartholome Gernharden exulem Christi Anno 1575, Eisleben: Urban Gaubisch [VD 16 G 1592].

3 Bartholomaeus Gernhard musste im Jahre 1573 sein Amt als Hofprediger Dorothea Susannas von Sachsen-Weimar aufgeben. Er blieb bis 1575 im Exil. 1574 entstand sein aus zwei Predigten bestehendes Werk »De exiliis« in Gera. Eine weiter im Sinne einer systematischen Lehre ausgearbeitete, allerdings nicht mehr in der Situation des eigenen Exils verfasste Darstellung der »Exilia« bietet Johannes Wigand, der ebenfalls 1573 sein Amt verlassen musste, mit seinem Werk »De persecutione piorum« (1580). Vgl. Johannes WigAnd, De Persecutione piorum. Exiliis piorum. Exiliis facinorosorum. Martyriis piorum. Pseudomartyriis. Fuga ministrorum verbi. Constantia. Apostasia. Patientia. per Iohannem Wigandvm, D. Episcopum Pomezaniensem, Frankfurt am Main: Georg Rab 1580 [VD 16 W 2822]. 
aber keine Einzelschicksale. Vielmehr entfaltet er eine theologische Reflexion über die Situation der Exilierten. Indem er die Zwangslage der Exilanten, entweder einer bestimmten dogmatischen Entscheidung zuzustimmen oder das eigene Amt aufzugeben, als »status confessionis « deutet ${ }^{4}$, macht er ihnen zugleich ein Identifikationsangebot. Ihre Entscheidung für das Exil wertet Gernhard als Ausweis aufrechten Bekennertums und reiht sie damit in die kleine Schar der verfolgten Kinder Gottes ein, deren Weg er durch die Heilsgeschichte bis zu seiner - als Endzeit gedeuteten - Gegenwart verfolgt und einer übermächtigen feindlich gesinnten Welt gegenüberstellt. Gernhard ist gewiss, gemeinsam mit den anderen Exilierten zu diesen Bekennern zu zählen. Wie schon Nikolaus von Amsdorf ${ }^{5}$ und eine Reihe anderer Theologen verwendet er die Selbstbezeichnung »Exul«, um seine Zugehörigkeit zu dieser Gruppe zu verdeutlichen.

$\mathrm{Zu}$ Absetzung und Vertreibung Gernhards und seiner Gesinnungsgenossen hatten innerevangelische Konflikte zwischen den Theologen und ihren protestantischen Fürsten geführt. Daher möchte ich zunächst die Situationen kurz umreißen, die die Theologen ins Exil trieben, um dann auf Gernhards Schrift De exiliis einzugehen und näher zu betrachten, welche Identifikationsangebote er seinen exilierten Gesinnungsgenossen macht.

Diejenigen Theologen, die sich in der zweiten Hälfte des 16. Jahrhunderts zur Confessio Augustana bekannten, genossen innerhalb der Territorien CAverwandter Fürsten Schutz und Unterstützung. Sie wirkten mit obrigkeitlicher Billigung oder sogar in fürstlichem Dienst. Als Professoren, Prediger oder Träger kirchlicher Ämter ${ }^{6}$ bezogen sie meist ein regelmäßiges Einkommen und befanden sich zunächst nicht in einer Verfolgungssituation mit direkter Gefahr für Leib und Leben. Dennoch gab es in der zweiten Hälfte des 16. Jahrhunderts Verfolgungen und Exile im Luthertum. Allerdings unterscheiden sie sich von der Gefahr, der die Anhänger Luthers in der ersten Hälfte des 16. Jahrhunderts ausgesetzt waren oder die zum Beispiel Calvi-

4 Schon der Prolog zu Gernhards Werk beginnt mit einem Hinweis auf die Unterscheidung zwischen Er- und Bekennen Christi. »Gnade vnd friede von Gott dem Vater/durch seinen lieben Son sampt reichem trost vnd krafft des heiligen Geistes/Christus nicht allein zuerkennen und lieben/sondern auch seinen heiligen Namen warhafftig bis zu seligem ende zu bekennen und preisen/auch mitler weile/allerley vngemach mit jme willig vnd geduldig zu leiden [...]«.

5 Vgl. Irene Dingel, Die Kultivierung des Exulantentums im Luthertum am Beispiel des Nikolaus von Amsdorf, in: Dies. (Hg.), Nikolaus von Amsdorf (1483-1565) zwischen Reformation und Politik, Leipzig 2008, S. 153-175.

6 Inhaber eines Pfarramtes waren nicht immer akademisch gebildete Theologen. Aus den Visitationsprotokollen von 1554/55 im Ernestinischen Sachsen geht hervor, dass nicht nur die Bildung der Pfarrer zu wünschen übrig ließ, sondern eine Anzahl gar keine universitäre Ausbildung genossen hatte, sondern zuvor als Kirchner, Altarleute oder Handwerker gearbeitet hatten. Siehe dazu Rudolf Herrmann, Die Generalvisitationen in den Ernestinischen Landen zur Zeit der Lehrstreitigkeiten des 16. Jahrhunderts (1554/55, 1562, 1569/70, 1573), in: ZVThG 22 (1915), S. 73-187, hier: S. 94f. 
nisten oder Juden erlebten. Betroffen waren vor allem Gnesiolutheraner ${ }^{7}$. Sie wurden in der Regel als Einzelpersonen ihrer Ämter entsetzt und mit ihren Familien vertrieben. Ihre Gemeinden verließen das Land jedoch nicht. Aus Perspektive der Gemeinden wechselte lediglich der Amtsinhaber ${ }^{8}$. Die Exile der Theologen waren häufig befristet. Viele konnten nach einer bestimmten Zeit zurückkehren oder fanden anderweitig Aufnahme in ein Amt ${ }^{9}$.

Gernhard spricht in seiner Schrift von drei »Verfolgungen« im ernestinischen Sachsen innerhalb von zwölf Jahren vor und nach der Regierungszeit des den Gnesiolutheranern zugetanen Herzogs Johann Wilhelm (1530, $1572-1573)^{10}$. Auf welche Vorgänge bezieht er sich dabei?

Zwischen 1561 und 1573 mussten mehr als 200 Theologen im herzoglichen Sachsen ihr Amt verlassen. Die meisten davon wurden im Verlauf von drei Kirchenvisitationen 1562, 1569/70 und 1573 entlassen. In allen drei Visitationen spielte der Konflikt zwischen politischer Raison des jeweiligen Landesherren und religiöser Überzeugung, vor allem in Hinsicht auf das Amtsverständnis der Pfarrer, eine wichtige Rolle ${ }^{11}$. Allerdings fällt die zweite Visitation in die Regierungszeit Johann Wilhelms, die Gernhard nicht als Verfolgungszeit deutet. Die Konsequenzen dieser Visitation waren im Sinne der Gnesiolutheraner. Die Ereignisse des Jahres 1561 um die Jenaer Professoren oder auch die Absetzungen von Pfarrern in Weida, Arnshaugk, Ziegenrück und Sachsenburg, als diese Ämter 1571 an Kurfürst August von Sachsen fielen, könnte Gernhard als dritte Verfolgung gezählt haben.

Nicht erst, seitdem 1547 die Kurwürde auf Moritz von Sachsen übergegangen war, hatten sich der albertinische und der ernestinische Zweig des

7 Als »Gnesiolutheraner« sollen im Folgenden diejenigen evangelischen Theologen bezeichnet werden, die die Schriften Melanchthons zwar gelten ließen, sie im Zweifelsfall aber durch Luther interpretiert wissen wollten. Zu unterscheiden sind »Gnesiolutheraner« von »Flacianern«, also solchen evangelischen Theologen, die die 1560 von Flacius in Weimar geäußerte Auffassung bejahten, dass die Erbsünde zur Substanz des Menschen gehöre und ihm nicht nur als ein Akzidens zukomme. Vgl. Rudolf KELLER, Art. Gnesiolutheraner, in: TRE 13 (1984), S. 512-519, hier: 513.

8 Argumentationen, die auf ein kollektives Gemeindeexil zielten, gab es auch im Luthertum: WigAnD, De persecutione piorum, S. 99f., begegnet der Frage, ob eine Gemeinde, deren Pfarrer exiliert worden sei, als Ganze ihre Ämter niederlegen müsse (»Iam tota recipit ministrum verbi. Ergo tota etiam ecclesia functionem resignare debebat «). Wigand argumentiert pragmatisch mit der kräftemäßigen Unterlegenheit einer Kirchengemeinde gegenüber der »Magistratus tyrannidi « und mahnt den frommen Lehrer, der Gemeinde, so sie mit ihren Gebeten nichts habe erreichen können, nicht noch mehr Ungemach zuzumuten, sondern lieber zu gehen.

9 Dass es sich bei diesen Vertreibungen nicht immer um einen Abschied ohne Wiederkehr handeln musste, war vielen der betroffenen Pfarrer bewusst. GERnHARD, De exiliis, fol. 20v betet etwa: »Hilff uns auch HERR mit gnaden/ists dein wille/wider in das Ampt/das du uns befohlen hast [...]«. Ähnlich auch ebd., fol. 36r, 46v.

10 Vgl. ebd., fol. 28v-29r.

11 Vgl. Daniel Gehrt, Pfarrer im Dilemma. Die ernestinischen Kirchenvisitationen von 1562 , 1569/70 und 1573, in: HerChr 25 (2001), S. 45-71, hier: 45. 
sächsischen Wettinerhauses einander entfremdet. Dem Gegensatz der beiden Territorien korrespondierte eine theologische Opposition, »deren politische Instrumentalisierung auf beiden Seiten unverkennbar war ${ }^{12}$.

Die 1548 gegründete Universität Jena entwickelte sich unter Beteiligung des Matthias Flacius in dezidierter Konkurrenz zu Wittenberg und sollte das Erbe Luthers gegen Verfälschungen, die man Melanchthon und den Wittenberger Theologen unterstellte, hochhalten und bewahren ${ }^{13}$.

Herzog Johann Friedrich der Mittlere unterstütze die Theologen seiner Universität in ihrer scharfen Kritik an den Wittenbergern und verfolgte eine Politik, die den Gegensatz mit Kursachsen auch auf theologischer Ebene herausstellte. Mit der Einführung des Konfutationsbuchs ${ }^{14}$, das nach dem Willen des Matthias Flacius »wider allerley Secten und Corruptelen [...] eine Bekenntnus $\aleph^{15}$ enthalten sollte, verband Johann Friedrich der Mittlere die Bekenntnisfrage sichtbar mit der herzoglichen Staatsraison. Der Jenaer Professor Victorinus Strigel wurde mit seinem Kollegen Erhard Schnepf und dem Jenaer Superintendenten Andreas Hügel beauftragt, einen entsprechenden Entwurf zu verfassen, was dieser wohl nur ungern übernahm. Die Arbeit am Konfutationsbuch entwickelte sich durch Änderungsvorschläge der ernestinischen Superintendenten und Jenaer Theologen in einer Weise, dass Strigel sie nicht mehr befürworten konnte ${ }^{16}$. Johann Friedrich erhob das Buch zum Landesgesetz und verpflichtenden Bekenntnisstand für alle seine Unterta-

12 Thomas Klein, Ernestinisches Sachsen, kleinere thüringische Gebiete, in: Anton SchindLInG / Walter Ziegler (Hg.), Die Territorien des Reiches im Zeitalter der Reformation und Konfessionalisierung. Land und Konfession 1500-1650, Bd. 4: Mittleres Deutschland, S. 8-39, hier: S. 19.

13 Vgl. Thomas Kaufmann, Die Anfänge der Theologischen Fakultät Jena im Kontext der >innerlutherischen< Kontroversen zwischen 1548 und 1561, in: Volker LePPIN (Hg.), Johann Friedrich I. - der lutherische Kurfürst, S. 209-258, hier: S. 222f., sowie Volker LePpIn, Bekenntnisbildung als Katastrophenverarbeitung. Das Konfutationsbuch als ernestinische Ortsbestimmung nach dem Tode Johann Friedrichs I., in: ebd., S. 295-306, hier: S. 296f.

14 Des Durchleuchtigen || Hochgebornen Fürsten vnd Herren/Herrn || Johans Friderichen des Mittlern/Hertzogen zu Sachs\|sen ... $\|$ für sich selbs/Vnd von wegen seiner F.G.Brüdere / || Hertzog Johans Wilhelmen/vnd Hertzog Johans Friderichen \|| des Jngern zu Sachssen etc. in Gottes wort/Prophetischer \| vnd Apostolischer schrifft/gegründete Confutationes/Wider=||legungen vnd verdamnung etlicher einzeit her/zuwider demsel=| ben Gottes wort/und heiliger Schrifft/auch der Augspurgi=| schen Confession Apologien/und den Schmalkaldischen Ar=|tickeln... || zu Fürderung ... des Antichri=\|stischen Bapstumbs eingeschlichenen ... Corru=\|ptelen/Secten vnd Jrrthumen ... $\|$ An jhrer F.G. $\|$ getrewe Landstende/Vnterthanen vnd Verwanten ausgangen/\| ... \|, Jena: Thomas Rebart 1559, [VD 16: 1097-1099]. Zum Inhalt des Konfutationsbuchs vgl. LePpin, Bekenntnisbildung, S. 299-304.

15 Der Vorschlag dazu dürfte von Flacius stammen, zumindest beansprucht er die Urheberschaft dieses Gedankens. Das Zitat stammt aus Matthias Flacius Illyricus, Erzehlunge der Handlungen/oder Religionsstreiten und Sachen Matthiae Fl: Illyrici/von jm selbs trewlich und warhafftiglich/auf Beger der Prediger zu Strasburg/beschrieben/Anno 1568. zu Strasburg, Aa 4v, zitiert nach Kaufmann, Anfänge, S. 252, Anm. 158.

16 Strigel stieß sich daran, dass Flacius für Artikel 6 des Konfutationsbuchs eine scharfe Verurteilung des Synergismus Melanchthons verlangte. Vgl. August BECK, Johann Friedrich der 
nen $^{17}$. Da Strigel seine Unterschrift unter das Konfutationsbuch verweigerte, wurde er inhaftiert.

Der Landesherr hatte also seine obrigkeitliche Gewalt in einer Bekenntnisfrage eingesetzt, wofür ihn Flacius, eigentlich ein Befürworter des Konfutationsbuchs in seiner vorliegenden Form und Widerpart Strigels, allerdings kritisierte. Er appellierte an den Herzog, er müsse »seine Sache in einer öffentlichen Disputation aus der Schrift verteidigen $\aleph^{18}$.

$\mathrm{Zu}$ expliziten Auseinandersetzungen zwischen Landesherrn und Theologen kam es, als Jenaer Theologen Kirchenzuchtmaßnahmen gegenüber Predigern, Professoren anderer Fakultäten und anderen Bürgern durchzusetzen versuchten. Im Vorgehen des Superintendenten Balthasar Winter, der Flacius nahestand, erkannte der Herzog gar inquisitorische Züge.

Winter war nicht bereit gewesen, den Juraprofessor Matthias Wesenbeck als Taufpaten zu akzeptieren, weil Letzterer sich weigerte, sich auf das Konfutationsbuch verpflichten zu lassen. Wesenbeck beschwerte sich und verlangte Winters Entlassung. Herzog Johann Friedrich der Mittlere lud Winter nach Weimar vor, untersagte ihm sein rigoroses Vorgehen und verwarnte ihn.

Am 28. August sandte Winter in der Sache Wesenbeck ein weiteres Rechtfertigungsschreiben an den Herzog. Darauf antwortete dieser mit einem scharfen Reskript, in dem er das Vorgehen Winters »auch zum Theil einer hispanischen Inquisition nicht ungleich $\ll^{19}$ nannte und auf den Unterschied zwischen Kirchenamt und weltlichem Regiment verwies. Er werde sich an die Mahnung Martin Luthers halten:

[...] als da etliche hochmüthige und vermessene Theologen, die, weltlichen Richteramts und Gewalt begierig, sich hervorbrechen und der weltlichen Obrigkeit nach dem Zügel greifen wollten, daß man alsdann dawider sein und ihnen solches nicht gestatten sollte $[\ldots]^{20}$.

Die Jenaer Theologen antworteten mit Berufung auf ihr Gewissen, dass sie den Bann gegen Strigel und diejenigen, die das Konfutationsbuch nicht unterschreiben wollten, nicht länger aufhalten könnten.

Der Herzog wollte ein derartiges Vorgehen nicht dulden und setzte Winter ab. Nikolaus von Amsdorf plädierte in einem Gutachten zu diesem Fall deut-

Mittlere, Herzog zu Sachsen. Ein Beitrag zur Geschichte des sechzehnten Jahrhunderts, Weimar 1858, S. 311.

17 Beck, Johann Friedrich, S. 309 sowie Kaufmann, Anfänge, S. 253.

18 Flacius, Erzehlunge der Handlungen, Bb f. 2r, zitiert nach Kaufmann, Anfänge, S. 253.

19 Zitat bei BECK, Johann Friedrich, S. 324.

20 Zitat ebd. mit Hinweis auf Johann Joachim Müller, Entdecktes Staats=Cabinet, I, Cap. 3, S. 128 sowie Karl Adolf Menzel, Neuere Geschichte der Deutschen seit der Reformation, Breslau 1854, Bd. IV, S. 178. 
lich für den Vorrang des »ministerium verbi« gegenüber jeder weltlichen Gewalt ${ }^{21}$. Der erste evangelische Theologe, der die Selbstbezeichnung »Exul « für sich in Anspruch genommen hatte ${ }^{22}$, die auch Gernhard und seine exilierten Gesinnungsgenossen benutzten, erhob also einen ganz ähnlichen Vorwurf gegen den Herzog, wie dieser ihn den Theologen gemacht hatte. Die weltliche Obrigkeit maßte sich nach Amsdorfs Urteil Zuständigkeiten der Pfarrer an, ohne dazu berufen zu sein.

Der Konflikt erhielt hier Züge eines Kompetenzstreits. Wo der Herzog von den Theologen als seinen Untertanen Gehorsam verlangte, beanspruchten diese als Diener des »ministerium verbi«, in Lehrfragen einzig dem »regnum Christi« zu unterstehen.

Als Herzog Johann Friedrich eine Konsistorialordnung ${ }^{23}$ erließ, die dem Konsistorium das alleinige Bannrecht und die Zensur über geistliche und weltliche Publikationen übertrug, beschwerten sich die Jenaer Theologen mit einem scharfen Protestschreiben, das einer Strafpredigt ähnelt und Gerichtsandrohungen enthält. Sie warfen dem Herzog vor, neben der weltlichen nun auch noch die geistliche Gewalt zu beanspruchen. Die Absetzung Winters nannten sie eine Verfolgung gottseliger Lehrer. Winter werde gegen sein $\mathrm{Ge}-$ wissen gezwungen, einem Unbußfertigen, nämlich Wesenbeck, das Abendmahl zu reichen.

Nach diesem scharfen Protest richteten Flacius und Johannes Wigand ein Schreiben an Johann Stössel, durch das dieser sich beleidigt sah. Stössel und der akademische Senat erhoben Klage gegen sie. Eine Disputation zwischen Flacius und Strigel im August 1560 war nicht über Fragen der Erbsündenlehre hinausgekommen und hatte nach dreizehn Sitzungen und einem Privatge-

$21 \gg[\ldots]$ so sollten sie auch wissen, daß kein König noch Kaiser über das ministerium verbi Macht und Gewalt habe, sondern das ministerium verbi hat Macht und Gewalt nicht allein über Kaiser und Könige, dieselben zu strafen und zu bannen, sondern auch über die Pforten der Hölle, ihnen zu steuern und zu wehren, daß sie nicht thun noch ausrichten können, was sie gern wollten. Derohalben Kaiser, Könige und vielmehr ihre trunkene und gottlose Räthe von dem ministerio verbi Macht und Gewalt haben, den Predigern und Pfarrern zu gebieten, daß sie absolviren und zum Sacramente zulassen sollen, wen sie wollten, so erheben sie sich nicht allein über das ministerium Christi und sein Reich, sondern auch über Christum und Gott selbst. [...] « Zitat nach BECK, Johann Friedrich, S. 325, Anm. 64.

22 Zur Verwendung der Selbstbezeichnung »Exul« bei Nikolaus von Amsdorf vgl. Dingel, Kultivierung, S. 156-162.

23 Bereits 1542 hatte es eine Konsistorialordnung in den ernestinischen Landen gegeben. Luther hatte daran entscheidend mitgewirkt. Mit dem Übergang Wittenbergs an Moritz von Sachsen wurde sie allerdings hinfällig. Im Juli 1561 ließ Johann Friedrich der Mittlere eine neue Konsistorialordnung entwerfen, in der für die Jenaer Theologen keine aktive Rolle vorgesehen war. Johann Friedrich oder einer seiner Brüder sollten den Vorsitz haben, dazu kamen ein weltlicher und ein geistlicher Assessor sowie vier Superintendenten, unter denen sich kein Jenaer Theologe befand, und vier weltliche Räte. Die herzogliche Stimme sollte im Zweifelsfalle den Ausschlag geben. Allerdings ist unklar, ob diese Ordnung jemals umgesetzt wurde. Vgl. HerRMANN, Generalvisitationen, S. 113f. 
spräch zu keinem Ausgleich geführt. Flacius und seine Anhänger mussten ihre Ämter am 10. Dezember 1561 nach längerem Streit verlassen. Matthäus Iudex hatte schon im Oktober weichen müssen und Simon Musaeus war auf eigenen Wunsch bereits im September desselben Jahres gegangen ${ }^{24}$. Victorinus Strigel kehrte auf seine Professur zurück.

Um die Einigung mit Strigel im Lande durchzusetzen, nutzte Johann Friedrich der Mittlere die aus einem »Bekenntnis Strigelii« hervorgegangene »Declaratio Victorini « ${ }^{25}$, zum freien Willen in der Erbsündenlehre als Kriterium einer Kirchenvisitation im Jahre 1562. Die Visitatoren Maximilian Mörlin und Johann Stössel stießen auf erheblichen Widerstand. Eine »Superdeclaratio« Stössels sollte strittige Punkte annehmbarer machen; Deutungen, Erklärungen und persönliche Bekenntnisse wurden zugelassen, schließlich den Pfarrern, die nicht bereit waren, die »Declaratio Victorini $\ll$ zu unterschreiben, eine Frist gesetzt. Als letztes Mittel griff Johann Friedrich zu einer Gewaltmaßnahme und setzte eine große Zahl der Widerständigen $a^{26}$.

Die Abgesetzten formulierten eine Protestschrift, auf deren Titelblatt sie sich ausdrücklich als »exules« aus dem Raum des Exils heraus artikulieren ${ }^{27}$.

Gründe, die Unterschrift unter die »Declaratio Victorini« zu verweigern, nennen zum Beispiel Superintendent Melchior Weideman und Diakon Johann Messerschmidt aus Gotha: Selbst wenn man noch so einig sei, könne man nicht unterschreiben,

weil in streitigen Fragen nicht eines oder mehrerer Menschen Gutachten als Norm und Regel gelten dürfe, sondern allein Gottes Wort in der Heiligen Schrift, dessen Erklärung und Sinn durch Luther klar und deutlich geoffenbart worden

sei. Überdies argumentierten sie, »daß eine christliche Obrigkeit nicht über, sondern in der Kirche wäre ${ }^{28}$. Auch gegen Strigels Person hatten sie Bedenken, weil er erst wegen falscher Lehre abgesetzt, dann ohne reuige Absage und öffentliche Abbitte wieder ins Amt gekommen war, und viele ihn des Synergismus verdächtigten. Pfarrer, die sich gefügt und die »Declaratio Victorini« unterschrieben hatten, trugen nach Meinung der Widerständigen die Schuld an deren Entlassungen, da der Widerstand nicht geschlossen gewesen $\operatorname{sei}^{29}$.

24 BECK, Johann Friedrich, S. 378-381.

25 Zur Declaratio Victorini (3. März bzw. 4. Mai 1562) vgl. ebd., S. 382f. sowie, Herrmann, Generalvisitationen, S. 114-117.

26 Ebd., S. 116 spricht von 40, nach anderen Quellen 42, abgesetzten Theologen.

27 RESPONSIO \| EXVLVM TVRIN=\|GICORVM AD INVECTIVAM $\|$ D. IOHANNIS STOSSELII, QVAM || MENSE OCTOBRI ANNO || M.D.LXV. EMI=||SIT, Eisleben: Urban Gaubisch 1567 [VD 16 R 1191f.].

28 Beide Zitate nach BECK, Johann Friedrich, S. 385f.

29 Gernhard, De exiliis, fol. 29v-30r bezeichnet Theologen, die Anpassungsstrategien an Vorga- 
Nachdem über Herzog Johann Friedrich als Folge der so genannten »Grumbachschen Händel« die Reichsacht verhängt und diese 1567 durch den sächsischen Kurfürsten vollzogen worden war, übernahm sein jüngerer Bruder Johann Wilhelm die Regierung im Herzogtum Sachsen. Johann Wilhelm unterstützte die streng an Luther orientierten Theologen und gestaltete die Kirche in seinem Herrschaftsgebiet entsprechend um. Gernhard lobt den Herzog als frommen, christlichen Fürsten und nimmt seine Regierungszeit ausdrücklich aus, wenn er davon spricht, dass es in den letzten zwölf Jahren drei große Verfolgungen gegeben habe ${ }^{30}$. Allerdings ließ auch Johann Wilhelm eine Kirchenvisitation durchführen. Sie war bereits für 1567 avisiert und kam 1569 zustande ${ }^{31}$.

Bei der konkreten Durchführung der Visitation setzte sich die radikale Forderung nach öffentlicher Abbitte für die Unterzeichner der »Declaratio Victorini« gegenüber dem milderen Vorgehen, sie nur gegenüber den Visitatoren widerrufen zu lassen, durch. Dahinter standen wohl auch personalpolitische Erwägungen, da Herzog Friedrich Wilhelm offenbar plante, aus Kursachsen ausgewiesene gnesiolutherische Prediger mit vakanten Stellen in seinem Land $\mathrm{zu}$ versorgen ${ }^{32}$.

Neunzig Prozent der Pfarrer, die die mittlerweile kassierte »Declaratio Victorini« unterschrieben hatten, widerriefen ihre Unterschrift. Zehn Prozent zogen ihre Entlassung vor. Glaubensüberzeugungen waren hier wohl weniger leitend als der Wunsch, im Amt zu bleiben ${ }^{33}$.

Als im Jahre 1571 die vier ernestinischen Ämter Weida, Arnshaugk, Ziegenrück und Sachsenburg durch kaiserlichen Schiedsspruch an den Kurfürsten August von Sachsen fielen, ersetzte dieser einen großen Teil der gnesiolutherischen Pfarrerschaft, die gegen ihn und seine Theologen polemisiert hatten. Am weitesten reichten seine Maßnahmen in Weida. Dort mussten 23 von 24 Pfarrern und Diakonen ihr Amt verlassen ${ }^{34}$.

ben der Obrigkeit entwickelt hatten, um in ihren Ämtern zu bleiben, als »creuzflüchtige Manenten«, ebd., fol. 11r spricht er von »Manenten/Conuiuenten/Tacenten«. Beispiele für erfolgreichen Widerstand gab es z.B. in Weimar, wo die Visitation ergebnislos abgebrochen wurde, oder auch in Altenburg, wo viele Pfarrer ihre Unterschriften nachträglich widerriefen, vgl. GehrT, Pfarrer, S. 55.

30 Vgl. Gernhard, De exiliis, fol. 28v-29r: »Da allein in diesem Fürstenthumb/vor vnd nach vnserm Christlichen seligen frommen Fürsten/H. Johans Wilhelm Hertzogen zu Sachsen etc. innerhalb zwölff jahren/drey grosser verfolgunge frommer bestendiger Christlicher Lerer/sich begeben vnd zugetragen haben $[\ldots] \ll$.

31 Vgl. Rudolf Herrmann, Thüringische Kirchengeschichte, Weimar 1947, S. 165. Zur Instruktion der Visitatoren vom 31. Oktober 1569 vgl. ders., Generalvisitationen, S. 121-125.

32 Darauf deutet die folgende Bemerkung seines Kanzlers hin: »wo wollte man auch den edlen Weizen, den unser Herrgott aus Meißen und anderen Landen E. F. Gn. zu feilem Markt schickt, aufschütten und versorgen«. Zitat nach ders., Kirchengeschichte, S. 166.

33 Vgl. Gehrt, Pfarrer, S. 60.

34 Vgl. Herrmann, Kirchengeschichte, S. 171. 
Zwei Jahre später, am 2. März 1573, starb Herzog Johann Wilhelm. Nach Johann Wilhelms Tod gelang es Kurfürst August von Sachsen, der bereits Vormund der Söhne Johann Friedrichs des Mittleren war, auch die Vormundschaft über die unmündigen Erben Johann Wilhelms an sich zu bringen. Zu diesem Zwecke erreichte er beim Kaiser die Aufhebung von Johann Wilhelms Testament, mit dem der Verstorbene diese Entwicklung hatte verhindern wollen. Gleich nachdem er das ernestinische Gebiet unter seine Kontrolle gebracht hatte, setzte Kurfürst August von Sachsen die Jenaer Professoren Johannes Wigand und Tilemann Heshusius ab. Auch viele Superintendenten und der Hofprediger, Bartholomäus Gernhard, mussten ihre Ämter verlassen. Vom 8. Juli bis zum 4. Oktober 1573 visitierte eine Kommission aus zwei albertinischen und zwei neu eingesetzten ernestinischen Superintendenten sowie einigen weltlichen Räten die nun dem Regiment Kurfürst Augusts von Sachsen unterstehende Kirche.

Alle Pfarrer und Diakone sahen sich während der Visitation mit drei Forderungen konfrontiert, nämlich erstens Melanchthons Schriften als Lehrautorität neben denen Luthers anzuerkennen, zweitens die polemische Predigt gegen kursächsische Theologen zu unterlassen, und schließlich drittens die Nachfolger der abgesetzten Professoren und kirchlichen Amtsträger anzuerkennen $^{35}$.

Im Zuge der Visitation von 1573 wurden gut 100 Pfarrer sowie sämtliche aus Herzog Johann Wilhelms Zeit stammenden Superintendenten entlassen, mit Ausnahme derer von Heldburg und Eisfeld ${ }^{36}$. Unter den 1573 entlassenen und vertriebenen Theologen gibt es Pfarrer, die bereits Exilantenkarrieren mit mehrfacher Absetzung, Neueinsetzung und erneuter Vertreibung durchlebt hatten.

Bartholomäus Gernhards Schrift De exiliis reflektiert die Exile dieser Theologen und deutet sie vor einem heilsgeschichtlichen Horizont. Gernhard selbst war bereits zum zweiten Male im Exil, als er De exiliis verfasste ${ }^{37}$. Nach seiner Absetzung begab er sich nach Zeulenroda, 1574 reiste er weiter nach Gera. Hier entstand De exiliis aus gegebenem Anlass: Für die ernesti-

$35 »[\ldots]$ das sie wollen den Christlichen Consens der lehr nach gottes wort, der Bibel, prophetischer vnd apostolischer schrifft, augsburgischer Confession, vnd büchern Lutheri vnd Philippi, mitt andern kirchen in Churfurstenthumb Sachsen eintrechtig halten [...] sich des vnbillichen Condemnirens, schmehens vnd lesterns, wolverdienter vnschuldiger persohnen, kirchen und schulen, hinfort gentzlich eussern« und »den geordneten Superintendenten (jedes orts) vnd Consistorio zu Jhena sich vnterwerffen vnd demselben geburlichen gehorsam leisten «. Zitiert nach Gehrt, Pfarrer, S. 62, Anm. 76.

36 Vgl. Herrmann, Generalvisitationen, S. 145f.

37 Seine erste Amtsenthebung erfuhr er im sog. Rudolstädter Wucherstreit (1565), die zweite im Jahre 1573. Weitere Absetzungen erlebte er 1581 und 1590. Vgl. Johann Matthias Gross, Art. Gernhard (Bartholomaeus), in: Historisches Lexicon evangelischer Jubel-Priester 3 (1746), S. 156-159, als elektronische Ressource in Wold Biographical Information System Online unter: http://db.saur.de/WBIS/basicTextDocument.jsf (zuletzt aufgerufen am 31. März 2009). 
nischen Exiltheologen hatte es Spendensammlungen gegeben; das Werk besteht aus zwei Predigten, die Gernhard anlässlich der Verteilung der Spendengelder im Jahre 1574 gehalten haben soll. Im Vorwort zu De exiliis beschreibt er ein territorienübergreifendes Versorgungsnetzwerk, an dessen unterschiedlichen Aktivitäten in prominenter Weise vor allem die Witwe Johann Wilhelms von Sachsen, Herzogin Dorothea Susanna von SachsenWeimar sowie Tilemann Heshusius und der Kriegsoberste Johann von Hildesheim, dem Gernhard die Vorrede zu De exiliis widmet, beteiligt waren ${ }^{38}$.

Das gedruckte Werk war sicherlich nicht nur für die Förderer bestimmt, die Gernhard in diesem Zusammenhang explizit als Adressaten nennt, sondern sollte einen weiteren Rezipientenkreis ansprechen. Die Vorrede zu De exiliis hatte Gernhard der Herzoginwitwe zugesandt, die sie von Martin Chemnit $^{39}$ und Hieronymus Menzel ${ }^{40}$ begutachten lassen wollte ${ }^{41}$.

Auf dem Titelblatt seines Werkes verwendet Gernhard die Selbstbezeichnung »Exul Christi«, mit der er auf seine Exilierung hinweist und die er wie einen Titel oder eine Amtsbezeichnung führt. Damit beansprucht Gernhard die Zugehörigkeit zu einem besonderen Stand innerhalb der evangelischen Christenheit, dessen theologische Grundlegung er in seinem Werk entfaltet. Allerdings gehen weder die Selbstbezeichnung als »Exul Christi« noch deren Verwendung in der Art eines Titels ursprünglich auf Gernhard zurück. Eher scheint er sich damit als Mitglied einer bestehenden Gruppe oder eines Netzwerks beziehungsweise als Träger einer allgemein bekannten Funktion zu erkennen zu geben. Schon Nikolaus von Amsdorf benutzte den Titel »Exul« auf den Titelblättern seiner Schriften ${ }^{42}$. Wie Amsdorf ${ }^{43}$ verwendet auch Gernhard die Selbstbezeichnung »Exul« als Ausweis seiner Bekennersituation, wobei legitimatorische Zwecke und inhaltliche Anliegen im Vordergrund stehen.

Gernhard nannte sich, soweit ich sehen kann, nur in der Zeit »Exul Christi«, in der er tatsächlich seines Amtes enthoben war. Bereits im Zusammenhang seiner ersten Absetzung im so genannten Rudolstädter Wucherstreit $(1565)^{44}$

38 Vgl. Gernhard, De exiliis, fol. 13r sowie »Vorrede von Danckbarkeit« (unpaginiert).

39 Martin Chemnitz (1522-1586) befand seit 1568 auf Wunsch des Herzogs Julius in BraunschweigWolfenbüttel, um dort die Reformation einzuführen. Im Jahre 1576 verfasste er das »Corpus Doctrinae Julium«, und war an der Gründung der Universität Helmstedt beteiligt.

40 Hieronymus Menzel (1527-1590) war seit 1560 Generalsuperintendent in Mansfeld und hatte sich als Gegner der Flacianischen Erbsündenlehre hervorgetan.

41 Vgl. den Brief der Susanna Dorothea von Sachsen-Weimar an Bartholomäus Gernhard vom 1.11.1574, aus dessen Nachlass, Forschungsbibliothek Gotha, Chart. A 105, fol. 335r-v.

42 Vgl. Dingel, Kultivierung, S. 166. Amsdorf verwendet den Titel »Exul«, nicht aber »Exul Christi«, bei dem es sich um eine spätere Form handeln muss, vgl. ebd., S. 171f.

43 Vgl. ebd., S. 157.

44 Dieser Streit, der sich zwischen Bartholomäus Gernhard mit einigen anderen Rudolstädter Prädikanten und zwei Rudolstädter Edelleuten abspielte, betraf die Rechtmäßigkeit von Zinsen ausgeliehener Gelder. Er wurde sehr heftig ausgetragen und führte dazu, dass die Theologen, 
und auch in seiner Korrespondenz zwischen 1573 und 1575 verwendet Gernhard diese Selbstbezeichnung; allerdings tut er es nicht konsequent und nur ein einziges Mal, nämlich im Falle von De exiliis, in einem Werktitel.

Bezeichnungen mit erklärenden Zusätzen, die auf den angenommenen oder proklamierten Grund von Gernhards Exilierung, nämlich sein Eintreten für das Wort Gottes beziehungsweise das »Bekenntnis der Wahrheit« hindeuten, verwenden einige seiner Korrespondenzpartner ${ }^{45}$. Die Bezeichnung »Exul« wurde also auch als Anrede unter Gleichgesinnten gebraucht. Gernhard verwendet »Exules« oder »Exules Christi« auch als Gruppenbezeichnung für die 1573 abgesetzten Pfarrer, mit denen er das Exilantenschicksal teilte ${ }^{46}$. Die Vorrede zu De exiliis ist im Namen der Abgesetzten unterzeichnet mit »IHESV CHRISTI EXVLES ${ }^{47}$. Gernhards Mitexilanten geben Gernhard in der Vorrede zu De exiliis den Titel »Exul« in Kombination mit dem Amt, aus dem er vertrieben wurde ${ }^{48}$. Vor ihnen hatten sich bereits die 1562 in Thüringen abgesetzten Pfarrer als gemeinsam agierende Gruppe von »Exules« zu Wort gemeldet $^{49}$. Sowohl aus Vorrede und Widmung, als auch aus den beiden

die sich weigerten, den Bann gegen die Edelleute zurückzunehmen, ihrer Ämter enthoben wurden. Vgl. Thüringisches Staatsarchiv Rudolstadt, A VIIIb Nr. 15, S. 571-582: Streit zwischen dem Prädikanten zu Rudolstadt und den Edelleuten Georg von Schönberg und Georg von Schönfeld, 1564 (Wucherstreit), aus einem Manuskript in der Hofbibliothek, sowie L.[udwig] F.[riedrich] Hesse, Rudolstadt und Schwarzburg nebst ihren Umgebungen, historisch und topographisch dargestellt, Rudolstadt 1816, S. 59 und Bernhard ANEMüLLER, M. Bartholomäus Gernhard und der Rudolstädter Wucherstreit im 16. Jahrhundert. Zugleich ein Beitrag zur Geschichte der Gräfin Katharina, »der Heldenmüthigen«, nebst einigen noch nicht veröffentlichten Briefen derselben, Rudolstadt 1861.

45 Wolrad II. Graf von Waldeck-Eisenberg nennt ihn in einem Brief vom 4.12.1565 »propter verbum DEI Exul(i)«, Philipp Caesar schreibt ihm als einem »Exulanti ob veritatis confessione [m]« (13.11.1656), Cyriacus Spangenberg adressiert sein Schreiben an »Reuerendo et pio [...] D. M. Bartholomaeo Gernhardo Ecclesiae Rudelstadianae Pastori vero: nunc exulanti« (13.12.1656). Alle Briefe aus dem Nachlass Gernhards, Forschungsbibliothek Gotha, Chart. A 103 (Akten zum Rudolstädter Wucherstreit, Gernhards Nachlass, fol. 372r-439v). In seiner Korrespondenz mit Herzogin Dorothea Susanna von Sachsen-Weimar bezeichnet Gernhard sich gelegentlich, jedoch nicht konsequent als »Exul«. Die Herzogin redet Gernhard gar nicht als »Exul« an.

46 Als »Exul« bezeichnet Gernhard zunächst jeden, der »extra solum natale oder patrium« ist, das lateinische »exilium« übersetzt er mit »elend umherziehen, Fremdling sein«. Alle drei Zitate aus Gernhard, De exiliis, fol. 23r. Dabei unterscheidet er zwei Arten von Exil. Dem Exil als Ergebnis einer Strafmaßnahme, die auf Fehlverhalten des Exilierten zurückzuführen sei, stellt er die frommen Exile gegenüber, denen er einen göttlichen Befehl (Abraham), Not (Jakob), Vertreibung (Lot) oder Verfolgung durch »Gottlose Regenten« als Ursachen zuordnet. Vgl. ebd., fol. $24 \mathrm{v}$.

47 Vgl. die Unterschrift der unpaginierten »Vorrede von Danckbarkeit«zu De exiliis: »E.G.E. Allezeit Dienstwillige/Enturlaubte Diener des Euangelij IHESV CHRISTI EXVLES , in Dueringen/Francken vnd Meissen $\ll$.

48 Vgl. Gernhard, De exiliis, »Vorrede von Danckbarkeit«, unpaginiert, »[...] haben wir hierauff den Ehrnwirdigen vnd Wolgelarten Herrn Bartholome Gernharden/F. Sechsischen Hoffpredigern Exulem/vnsern geliebten Herrn vnd Brudern in Christo/bruederlich erinnert vnd gebeten / [...]«.

49 Vgl. RESPONSIO || EXVLVM TVRIN=||GICORVM AD INVECTIVAM 
Predigten, aus denen die Schrift De exiliis besteht, geht hervor, dass Gernhard fest davon überzeugt war, dass er und die vertriebenen Theologen sich in vollem Recht befanden und nicht nur unschuldig, sondern gerade wegen ihres vorbildlichen Verhaltens ins Exil geraten ${ }^{50}$ waren.

Obwohl Gernhard das Exil, im Sinne der »peregrinatio« im zeitlichen Leben der Menschen, grundsätzlich auf den Sündenfall zurückführt, unterscheidet er die Exile der Frommen und der Gottlosen »in fine et effectu« hinsichtlich der jeweils unterschiedlichen Auswirkungen, indem das Exil den Frommen als Übung dienen, den anderen eine schwere Strafe sein soll ${ }^{51}$.

Sich selbst und die anderen »exules « grenzt er gegen Vorwürfe ab, die seiner Ansicht nach legitime Exilierungsgründe darstellen, indem er etwa betont, dass es sich bei den abgesetzten Pfarrern weder um Anhänger der Flacianischen Erbsündenlehre noch um Synergisten handele ${ }^{52}$. In Abgrenzung gegen die Maßnahmen Kurfürst Augusts von Sachsen und zur Legitimierung seiner eigenen Lehrmeinung hält Gernhard sich explizit zum Corpus Doctrinae Thuringicum (1571) ${ }^{53}$. Zusätzlich bietet er ein positiv formuliertes Bekenntnis zum Thema der Erbsünde, für das er sich auf Luther beruft ${ }^{54}$.

Die Situationen, in denen seine Gesinnungsgenossen sich lieber ihrer Ämter entheben ließen, als sich den Forderungen ihrer weltlichen Herrscher zu beugen, deutet Gernhard als »actus confessionis«, Anlässe bei denen es galt, trotz der drohenden Absetzung an der als wahr erkannten Lehre festzuhal-

STOSSELII, QVAM || MENSE OCTOBRI ANNO || M.D.LXV. EMI=||SIT, Eisleben: Urban Gaubisch 1567 [VD 16 R 1191f.].

50 Vgl. Gernhard, De exiliis, Die erste Erinnerunge An die versamleten Pfarherren/Diacon/Kirch und Schulendiener/Exules CHRISTI, fol. 3r: »Dieses hohen herrlichen Guts koennen wir vns ja/was die vrsach vnsers Elendes furnemlich anlanget/alle sampt/hoffe ich/kuenlich troesten/denn wir ja nicht vmb vbelthat/sondern vmb trewlicher verrichtung vnsers Ampts willen/vnd das wir vnsere wahre Bekentnis reiner Lere nicht begeben/noch in andere vnreine Lere bewilligen können noch wollen/vnserer Kirchen vnd Schulendienste entsetzet/vnd ins Elende verjaget/vnd ausgestossen sind $[\ldots] \ll$.

51 Vgl. Gernhard, De exiliis, Die Andere Erinnerung/den 8. tag Decemb., fol. 23r-V.

52 Vgl. ebd., »Vorrede von Danckbarkeit«, unpaginiert: »Vnd dieweil gleublich berichtet worden/Das etliche verdechtige Personen (mit allerley Corruptelen/vnd sonderlich mit dem abschewlichen Manicheischem Schwarm/de Substantia peccati Originalis, Das ist/Das die Wesen/Seele/Hertz etc. selbs/die Erbsünde sein sol) sich auff vns beruffen/oder in vnsere anzal mengen/vnd gleichsam mit vns verkeuffen wollen/So haben wir dessen auch eben an diesem Orte zu gedencken nicht vmbgehen können/nicht alleine Christliche Gemeinden zuuor warnen/sondern vns selbs zugleich vnbillicher nachrede vnd verdachts hiemit zu entschütten. [...] haben wir ein hertzliche abschew [...] sonderlich an beyden/dem Pelagianischen vnd dem Manicheischem Schwarm von der Erbsünde«.

53 Ebd.

54 Vgl.: »[...] halten doch endtlich vnd gentzlich dafur/Das zwischen der Natur vnd jrer verderbunge/in allwege vleissig zu vnterscheiden/Vnd sey die Erbsuende eigentlich/nach der gewissen vnd Schrifftmessigen beschreibunge des Mans Gotes D. Luthers/so gar eine böese Verderbunge der Natur/das sie keine Vernunfft nicht kennet/sondern muss aus der Schrifft offenbarunge gegleubet werden/Psal. 51 Rom. 5. Exod. am 33. Gene. 3. Dabey wirs auch lassen wenden«. 
ten $^{55}$. Die Vertreibungen seiner Gesinnungsgenossen betrachtet er als Verfolgung und sieht darin das Kennzeichen einer Bekennerelite. Zu bekennen - und sich nicht durch die scheinbare Nichtigkeit des Anlasses davon abbringen zu lassen, auch wenn diplomatisches Nachgeben opportuner erscheint - war für Gernhard nichts Geringeres als die wahre Lehre ${ }^{56}$, die er im Evangelium und den Schriften Luthers niedergelegt und durch Irrlehren bedroht sah. Damit schließt er an Nikolaus von Amsdorf an, dessen »Gedanke, als Exul in einer Verfolgungssituation zu stehen, die sich aus der endzeitlichen Konfrontation zwischen Christ und Antichrist ergab $\ll^{57}$ auch in Gernhards Werk vorkommt ${ }^{58}$.

Allerdings führt auch Gernhard keine Lehrgründe an, weswegen er und die anderen »exules« vertrieben worden seien, sondern betont im Gegenteil die Unangefochtenheit der Lehre, zu der sie sich bekannten. Ein Lehrstreit mit der weltlichen Obrigkeit als vertreibender Instanz lag nicht vor. In der Hauptsache hatten sich die Gnesiolutheraner von Seiten der Obrigkeit wohl den Vorwurf zugezogen, Unruhestifter und Querulanten zu sein ${ }^{59}$. Dabei handelte es sich bei den Theologen, die Exil und Vertreibung auf sich nahmen, jedoch kaum um eine sektiererische in sich geschlossene Winkelgruppe, die sich hartnäckig jedem Konsens verschlossen hätte. Sowohl Bartholo-

55 Ebd., Die erste Erinnerunge, fol. 10r: »Und dieweil wir jetzt nach GOTTES gnedigem willen / gleich eben in ipso Actu Confessionis, hafften/vnd gegenwertiges vnser Elende/vber der Bekentnis Goettlichs Namens und Warheit dulden/[...]«. Von einem casus confessionis spricht Matthias Flacius im Zusammenhang des adiaphoristischen Streits. »Es sollen aber die Leut wissen/daß in casu confessionis/Scandali etc. cum necessitas seruandi adiuncta est/[...] gar nichts ein Adiaphoron ist «. Flacius, Mitteldinge, A 1b. Zitat bei Hans Christoph von Hase, Die Gestalt der Kirche Luthers - Der casus confessionis im Kampf des Matthias Flacius gegen das Interim von 1548, Göttingen 1940.

56 Gernhard spricht beispielsweise in De exiliis, Die erste Erinnerunge, fol. 10r vom »Bekentnis Goettlichs Namens vnd Wahrheit « und dem »feste halten vber dem Bekentnis Christlicher Lere / darueber wir in diß Elend vertrieben/[...]«, in ebd., fol. 10v von der »norma«.

57 Dingel, Kultivierung, S. 169.

58 Vgl. Gernhard, De exiliis, Vorrede von Danckbarkeit, unpaginiert: »Die vierde vrsache/dieser in Druck vbergebenen einfeltigen Christlichen Erinnerungen ist/die Gefehrligkeit/der gegenwertigen vnd noch mehr zukünftigen zeiten/gegen welche es sich nach der heiligen Schrifft/vnd Doct. Luthers weissagungen/leider greifflich anlesset/das jmmer je lenger je mehr schwerre Confusiones vnd Verwirrungen/vnd denen nach auch mehr Exilia vnd verstossungen frommer Gottfürchtiger Lerer vnd Christen/sich zutragen vnd begeben möchten«. Ein eschatologischen Hintergrund lässt sich noch deutlicher in Johannes Wigands 1580 erschienenem Werk »De persecutione piorum« finden. Vgl. Wigand, De persecutione piorum, Epistola dedicatoria, S. 4-6, bes. S. 4: »Docet autem nos vox diuina, in postrema huius mundi aetate, in Ecclesia praesertim, omnia fore asperiora \& turbulentiora, idque propter collisiones \& mutationes regnorum, \& quia Diabolus animadvertit suam abiectionem in aeternos cruciatus haud procul abesse $\ll$.

59 Vgl. Gernhard, De exiliis, Die Andere Erinnerung, fol. 36r: »Wir haben uns vertreiben und verjagen lassen muessen/als Friedehessige/unruhige/zenckische Leute/die wir auch Christliche einigkeit und gleicheit in der Lere/nicht mit andern halten wollten«. 
mäus Gernhard als auch Johannes Wigand gehören zu den Unterzeichnern der Konkordienformel.

Die abgesetzten Pfarrer assoziiert Gernhard mit den von der Welt verachteten, bei Gott jedoch geehrten Armen Christi. In ihre klassische Referenz in Mt 25 fügt er die »exules« explizit ein: »[...] Ich bin ein Exul, Fremdling und Gast gewesen, und ihr habt mich beherbergt $[\ldots] \ll^{60}$.

Mit einem Hinweis auf Joh 16,2 reiht Gernhard die »exules« auch unter die Märtyrer ein ${ }^{61}$. An ihrem Exilantentum erkennt er die Zugehörigkeit der »exules « zu den Kindern Gottes ${ }^{62}$, denen göttlicher Beistand sicher sei ${ }^{63}$. Dennoch propagiert er das Exil nicht im Sinne einer Leidensnachfolge Christi als anzustrebende Größe, sondern beschreibt es als Leidensschicksal, das die kleine Elite der Bekenner als solche identifiziert und das es mit Gottes Hilfe auszuhalten gilt.

Gleichzeitig verwendet Gernhard das Exil als Identifikationsmerkmal der verfolgten Kirche, sodass er Verfolgung und Exil miteinander verklammern und als Deutungsschlüssel in einem Durchgang durch die Heilsgeschichte verwenden kann $^{64}$. An biblischen und kirchengeschichtlichen Beispielen führt er das Exil, das er auch als Pilgerstand bezeichnet, von der Vertreibung der Ureltern aus dem Paradies bis in seine Gegenwart vor. In leidenden und verfolgten Christen erkennt er die Kinder Gottes, die als zerstreutes und angefochtenes Häuflein (»caetus dispersus «) ${ }^{65}$ unter ständiger Verfolgung existieren.

Aus der Verfolgung durch die weltliche Obrigkeit leitet Gernhard also eine besondere Würde der Verfolgten innerhalb der Christenheit her, die er durch die Verwendung des Titels »Pilger« oder »Exul« kennzeichnet ${ }^{66}$. Die abge-

60 Vgl. ebd., Die erste Erinnerunge, fol. 15v. Im selben Zusammenhang spricht er ihnen Teilhabe an der göttlichen Natur als höchste Ehre zu, jedoch nicht »unione naturae hypostatica« (das komme nur Christus zu), sondern »per assistentiam gratiae, sanctificative«.

61 Vgl. ebd., Die Andere Erinnerung, fol. 31r: »Das/wenn sie die vnschueldigen armen kinder GOTTES/jagen/plagen/vnd wo nicht mit dem Schwerd/doch mit kuemmernis im Elende wuergen/sie meinen/sie thun GOtt einen dienst daran/[...]«. Ähnlich auch fol. 46v.

62 Vgl. ebd., fol. 42v und 56r.

63 Vgl. ebd., fol. 50b.

64 Eine geschichtstheologische Einordnung - allerdings seiner selbst, nicht eines Gesamtphänomens - bietet schon Nikolaus von Amsdorf, Vom Bapst und seiner Kirchen/das sie des Teufels / vnd nicht Christi vnseres lieben Herrn Kirche sey. Nicolaus von Amsdorff. EXUL, Magdeburg: Christian Rödinger 1551, [VD 16 A 2406]. Vgl. Dingel, Kultivierung, S. 172: Amsdorf sah sich »als >Exuk in ein historisch gewachsenes Kontinuum eingebunden und damit in Strukturen, deren antithetische Ausrichtung schon in biblischer Zeit begründet war«.

65 Vgl. Gernhard, De exiliis, Die Andere Erinnerung, fol. 27v. Nach Robert Kolb, Nikolaus von Amsdorf 1483-1565. Popular polemics in the preservation of Luther's legacy, Nieuwkoop 1978, S. 76, schließt sich Amsdorf mit seiner Wertung der »true church of God as a persecuted remnant $\ll$ bereits an Luther an.

66 Vgl. Gernhard, De exiliis, Die Andere Erinnerung, fol. 34r-v: »Daher scheinet/das die Gleubigen im Alten und Newen Testament/gleich zum gedechtnis nützlicher vbunge/den Titel gern 
setzten Pfarrer identifiziert er als Teil dieser Gruppe, indem er sie, und auch sich selbst, als »Exules« anspricht.

Zwar knüpft Gernhard deutlich an Gedanken Amsdorfs an, er findet jedoch eine veränderte Situation vor, die sich in seiner heilsgeschichtlichen Deutung der Exile spiegelt. Als Gegenspieler sieht Gernhard nicht mehr nur eine verfolgende Kirche gegenüber den »Kindern Gottes« am Werk. Er versteht die Situation vielmehr im Sinne eines aus dem Johannesevangelium geschöpften Dualismus als Gegenüber von wahrer Kirche und Welt ${ }^{67}$. Die Verfolgungssituation, die Gernhards gleichgesinnten Zeitgenossen ihre Exile eintrug, spielte sich also in dessen Sicht nicht ausschließlich innerhalb der »ecclesia «, sondern unter Beteiligung von »ecclesia « und »politia

Mit Berufung auf eine Psalmenexegese Luthers entwickelt Gernhard die Vorstellung einer sich steigernden dreistufigen Verfolgung der Christenheit in ihrer Geschichte ${ }^{68}$. Die erste Stufe erblickt er in gewaltsamer Verfolgung durch weltliche Herren, die zweite nennt er »tückisch« und identifiziert sie mit den abweichenden Lehren der Häretiker. Eine dritte und letzte Verfolgungswelle sieht er im Schicksal der »exules « gegeben, indem falsche Lehrer sich hier die weltliche Gewalt der Fürsten gegen die Theologen zunutze machten. Nach der anfänglichen Bedrohung durch das Papsttum erkennt Gernhard die gefährlichen Irrlehrer nun auch in den Reihen der Evangelischen ${ }^{69}$. Vor allem die Wittenberger Theologen um Phillip Melanchthon verdächtigt er, die Macht der Fürsten zu instrumentalisieren, sodass die sichtbare Kirche durch Häretiker unterwandert und die weltlichen Machtmittel ihrer Mitglieder gegen die Bekenner der wahren Lehre mobilisiert werden konnten.

Die »exules« stellt Gernhard als aufrechte Bekenner einer zur Irrlehre verführten Obrigkeit gegenüber ${ }^{70}$. Darin konnte er sich besonders bestätigt

geführet haben/das sie sich Exules, Peregrinos, Frembdlinge/jhr leben/Exilium, peregrinationem, eine Walfahrt/Pilgramschaft/wanderung genant haben/[...] ob sie wol die Welt Titulos Oneris achtet und verlacht/als/Schmachtitel [...]«.

67 Z.B. den Hinweis auf Joh. 15,19 bei Gernhard, De exiliis, Die Andere Erinnerung, fol. 47r: »Als / inwendiges werden die lieben Christen/dadurch bey sich selbs gewis/das sie nicht von dieser Welt sein/denn sonst köndte und würde sie die Welt wol dulden/ja lieb und wird haben/wie der HERR spricht im Johanne: Weret jr von diser Welt/so hette die Welt das jre lieb/[...]«.

68 Vgl. ebd., fol. 30v.

69 Vgl. ebd.: »Zwar vom Bapsthumb anher/ists also gegangen/wider das Euangelium/Aber jetzt koempts eben starck auch an die/so sich des Euangelij rhuemen/haben aber darbey auch grobe grewliche Corruptelen und falsche Leren/doch koennen solche Corruptelisten/jhre Irrthuemb mit geschwinder list und schoenen farben listiglich schmuecken/hengen darneben an sich weltliche gewalt/welche sie aber/mit jren Tuecken/bezaubern/also/das sie mit gewalt verfolgen/jagen und plagen/alle die so in jhre Corruptelen und falsche Leren nicht willigen koennen noch wollen $[\ldots] \ll$.

70 Dass Gernhard den weltlichen Herrschern eine derart passive Rolle zuweist, ist bemerkenswert. Gerade diejenigen Herzöge Sachsens, deren Religionspolitik er lobt, also Johann Friedrich der Mittlere (1529-1595), aber vor allem Johann Wilhelm (1530-1573), nahmen die Rolle des Herrschers als »custos utriusque tabulae« durchaus ein. Vgl. LePPIN, Bekenntnisbildung, S. $300 f$. 
fühlen, als die kurfürstlichen Theologen kaum ein Jahr nach Gernhards Vertreibung der Vorwurf des Kryptocalvinismus traf ${ }^{71}$. In drastischem Ton fordert Gernhard die weltliche Obrigkeit auf, die Häretiker als solche zu erkennen, die seiner Meinung nach die Kirche in Thüringen zerrütteten und die Absetzung der »exules « verursacht hatten: »die unordentliche eingedrungene Mietling/vnd Sacramentirische Gezichte/solten sich packen/und die ordentlichen Kirchendiener/so one alle schuld vnd vrsach ausgetrieben/solten widerumb in jre Empter gesetzt werden $\ll^{72}$.

Die Opposition zu den Wittenbergern ist, auch in Verbindung mit dem Vorwurf, das Exil der Gnesiolutheraner auf die eine oder andere Weise mitverursacht zu haben, kein Proprium Gernhards. Sie begegnet schon bei Nikolaus von Amsdorf und lässt sich fünf Jahre nach Gernhard auch bei Johannes Wigand finden ${ }^{73}$. Durch den gegebenen Anlass des aktuellen Exils kommt in Gernhards Schrift jedoch als wichtiges und von Gernhard mehrfach wiederholtes Interesse hinzu, die abgesetzten Pfarrer wieder ins Amt zu bringen.

Die Ämter, die die »exules« verlassen mussten, erachtet Gernhard als von Christus verliehen ${ }^{74}$, die Absetzung als durch weltliche Kräfte herbeigeführtes Unrecht. Exiliert zu sein, bedeutete für Gernhard also neben materieller Not die Trennung vom durch Christus gegebenen Wirkungsfeld, nicht aber eine Entbindung von der pfarramtlichen Verantwortung. An mehreren Stellen in De exiliis bittet er Christus, die »exules« wieder in ihre Ämter zu füh$\mathrm{ren}^{75}$. Mit dem Titel »Exul«, der hin und wieder in Verbindung mit dem Amt erscheint, aus dem der Abgesetzte hatte weichen müssen, weist Gernhard also auch auf die Unrechtmäßigkeit der Absetzungen hin. »Exul« transportiert in dieser Verwendung nicht nur die Autorität des Bekenners, sondern auch den Protest des Abgesetzten, der sich als der rechtmäßige und zu unrecht vertriebene Inhaber seines Amtes verstand.

Irene Dingel ${ }^{76}$ hat am Beispiel der Einsprüche gegen die Konkordienformel gezeigt, dass die Selbstbezeichnung »Exul« oder »Exul Christi« als »Er-

71 Gernhard, De exiliis, Die Andere Erinnerung, fol. 36r: »Ehe wir ein jahr im Exilio gewesen / bringets GOTT ans liecht/(mit waserley Lere und Lerern/wir einigkeit und gleicheit haben willigen und halten sollen) eben in deme /das unsere Visitatores und Reformatores selbs / halstarrige Ketzer/Caluinisten/vnd Sacramentirer sind/sind drueber in vielen andern vnfertigen Hendeln begriffen/vberweiset/und selbs in hafften kommen«.

72 Ebd., fol. 40v-41r.

73 Vgl. Wigand, De persecutione piorum, S. 5: »Obsurdescunt, obstupescunt, obmutescunt non pauci vigiles Ecclesiae Dei, absterriti scilicet periculis, vt feminaria falsorum dogmatum, imo manifestos errores, non inclament, non damnent, vti debebant, imo conciliationes concinnae mendacij \& veritatis, Christi \& Belial, miris artibus quaeruntur. Saltem specta quantum operae sumatur in Sacramentariorum erroribus palliandis atque ornandis, vt de caeteris in praesentia non dicam «.

$74 \mathrm{Vgl}$. Gernhard, De exiliis, fol. 20v.

75 Vgl. ebd., fol. 20v, 36r, 46v, sowie o. Anm. 9.

76 Vgl. Dingel, Kultivierung, S. 161. 
kennungszeichen für Gleichgesinnte « gedient habe. Als Erkennungszeichen hatte der Titel »Exul« für diejenigen, die ihn führten, eine nach innen gewandte und eine nach außen gerichtete Funktion. Für die im Exil befindlichen oder mit aktuellen Exilierungen konfrontierten Gesinnungsgenossen Gernhards stand wahrscheinlich mehr das Erkanntwerden durch Außenstehende als das gegenseitige Erkennen der »exules« untereinander im Vordergrund. Sie dürften voneinander gewusst und Publikationen Gleichgesinnter verfolgt haben. Entsprechend wählten sie die Selbstbezeichnung »Exul«, häufig auch das stärkere »Exul Christi« oder »Exul« mit erläuternden Zusätzen, wahrscheinlich weniger mit informatorischer als mit deklaratorischer Absicht. Sie artikuliert ein Bekenntnis zu der mit ihr assoziierten Lehre ${ }^{77}$ und dem Anspruch, Glied der wahren Kirche Christi zu sein.

In seinem fünf Jahre nach Gernhards De exiliis erschienenen Werk De persecutione piorum (1580) spricht Johannes Wigand von dem »strahlenden Titel eines Exul Christi«, der um 1580 offenbar schon so eingeführt war, dass Wigand Gelegenheit hatte, über seinen häufigen Missbrauch zu klagen ${ }^{78}$.

Durch kirchenpolitische Maßnahmen der weltlichen Obrigkeit, die zu den Exilen der streng an Luther orientierten Theologen führten, sahen die Theologen sich in den »status confessionis « gebracht. Sie verhielten sich streitbar und selbstbewusst. Die exilierten Theologen waren sich sicher, zu unrecht zum Verlassen ihrer Ämter gezwungen worden zu sein.

Gernhard identifiziert die abgesetzten Pfarrer als unschuldig verfolgte Bekenner der rechten evangelischen und in Luthers Schriften niedergelegten Lehre und ordnet sie innerhalb einer Dichotomie zwischen Welt und wahrer Kirche Christi der wahren Kirche Christi zu. Dabei deutet er die Schicksale der abgesetzten Pfarrer als Ausweis ihrer Rechtgläubigkeit.

Durch seine Darstellung konstituiert Gernhard die »exules« als Gruppe. Er bietet ihnen einen Platz in einer geschichtstheologisch herausgearbeiteten Traditionslinie an und verleiht dem Begriff des Exils damit mehrere Dimensionen. Neben das zeitlich begrenzte Exil der Theologen, das mit Vertreibung und Verlust des Amtes einherging, tritt die "peregrinatio «, die das zeitliche Leben eines jeden Christen bestimmt, den Kindern Gottes aber im Gegensatz zu anderen Menschen zum Nutzen gereicht. Als dritte Dimension kommt schließlich das Exil als ortsunabhängiger Raum und Ort hinzu, aus dem herkommend es möglich ist, sich als »exul« im Diskurs zu artikulieren ${ }^{79}$.

77 Anhänger der flacianischen Erbsündenlehre benutzten die Selbstbezeichnung »Exul« ebenfalls. Gegen sie grenzt sich Gernhard allerdings ab. Er bestreitet die Rechtmäßigkeit ihrer Lehre und also auch ihren Anspruch auf den Titel »Exul«. Vgl. GERnHARD, De exiliis, »Vorrede von Danckbarkeit«, unpaginiert.

78 Wigand, De persecutione piorum, S. 97: »Itaque multi hoc splendidißimo titulo abutuntur, quod sint Exules Christi, ut suo loco repetendum erit «.

79 Den Gedanken, das Exil der Gnesiolutheraner als einen ortsunabhängigen Raum des Diskurses 
Mit De exiliis will Gernhard eine Lehre über die »exules« bieten $^{80}$. Er entwirft aber keine neue, ganz von den Schicksalen der abgesetzten oder vertriebenen Theologen her entwickelte Anschauung, sondern ordnet die Exile seiner Gesinnungsgenossen in die Gedankenwelt des Luthertums ein ${ }^{81}$.

De exiliis trägt insofern zur Kultivierung des Exils im Luthertum bei, als Gernhard die Exile seiner Glaubens- und Zeitgenossen theologisch reflektiert, als Ausweis der Zugehörigkeit zur Gemeinschaft der Kinder Gottes in eine Geschichtstheologie einbindet und als Identifikationsmerkmal in das Selbstverständnis der »exules« als Bekennerelite und Verfechter der wahren Lehre Luthers integriert.

zu betrachten, verdanke ich einem mündlichen Hinweis von Prof. Dr. Peter Burschel, Professor für Geschichte der Frühen Neuzeit an der Universität Rostock.

80 Gernhard, De exiliis, Die Andere Erinnerung, fol. 22v. Gernhard behandelt in drei Kapiteln zunächst die Einordnung der Exilanten in eine heilsgeschichtliche Gesamtschau, dann die heilsgeschichtliche Funktion der Exile und schließlich Trost und Erbauung für die Exilanten: »1. Von den Exilijs, das ist/von dem elenden Irreziehen/sonderlich der lieben Kinder Gottes / in dieser argen Welt. 2. Von den vrsachen solches Elendes/Warumb dann Gott die seinen/in dieser Welt/also elende jrreziehen vnd verstossen lasse. 3. Vom Trost/damit sich fromme Christen/in jrem Elende/auffrichten/vnd zu frieden stellen sollen«. Ebd.

81 Damit begegnete er einem vorhandenen Klärungsbedarf. Auch Johannes Wigand sah hier ein Desiderat und wollte eine Unterscheidungslehre bieten, vgl. WIGAND, De persecutione piorum, S. 7: »Cum autem multi non satis dextre afflictiones Ecclesiae Dei norint discernere, ac nonnulli pietatis \& Martyrum nomina sibi perperam arrogent, vtile est, doctrinam de hisce rebus, plane \& dilucide explicatam extare $\ll$. 


\title{
Matthias Morgenstern
}

\section{Unterwegs in symbolischen Räumen}

\author{
Mobilität in der späten jüdischen Vormoderne \\ am Beispiel der Glückel von Hameln
}

$\mathrm{Zu}$ den grundlegenden Vorstellungen der Theologie des rabbinischen Judentums in den Jahrhunderten vor dem Einbruch der Moderne gehört eine Konstruktion des geographisch-historischen Raumes, die sich an der heilsgeschichtlichen Begrifflichkeit von Exil und Erlösung (hebräisch: galut und ge'ula) orientiert. In dieser Begriffswelt war das durch Leiden und Verfolgung gekennzeichnete Exil mit den Ländern der Diaspora und die Erlösungshoffnung mit der Erwartung der messianischen Heimführung nach Zion verbunden ${ }^{1}$. Diese symbolische Raumkonstruktion brachte es mit sich, dass die in den Jahrhunderten der späten jüdischen Vormoderne häufigen Wanderungsbewegungen von Juden - gleich ob es sich nun um Fluchtbewegungen oder um andere Phänomene des Reisens, etwa aus wirtschaftlichen oder familiären Gründen handelte - jedenfalls eines gemeinsam hatten: Sie wurden als eine Mobilität innerhalb des Exils wahrgenommen, die von dem für die messianische Zukunft erwarteten Ausbruch aus dem Raum des Exils und der Rückkehr ins Gelobte Land deutlich zu unterscheiden war.

Das den folgenden Überlegungen zugrundeliegende Buch ist für das Verständnis dieser jüdischen Konstruktion vom Raum und Mobilität, aber auch für das Verständnis derjenigen Vorgänge, die in der Moderne zur Zerstörung dieser traditionellen Konzeption führten, besonders aufschlussreich. Die in westjiddischer Sprache geschriebenen Memoiren der Glückel (Glikl) von Hameln (1646/47-1724) - es handelt sich ohne Übertreibung wohl um das wichtigste in jiddischer Sprache geschriebene Buch dieser Epoche - erzählen die Geschichte einer Frau, die als Kauffrau und Angehörige der jüdischen Oberschicht ihrer Zeit viel reisen mußte. Glückel gehörte einerseits noch ganz der vormodernen Welt des aschkenasischen Judentums an, für das die Exilszeit

1 Vgl. Jakob Katz, Aus dem Ghetto in die bürgerliche Gesellschaft. Jüdische Emanzipation 1770-1870, Frankfurt am Main 1986, S. 16; zum Einbruch der Moderne in die traditionelle jüdische Gesellschaft mit den ersten Vorzeichen der beginnenden Emanzipation im späten 18. Jahrhundert vgl. ebd., S. 39-54. Im Kontext der jüdischen Geschichte sollte man den im Folgenden zu behandelnden Zeitraum nicht als Frühe Neuzeit, sondern eher als späte Vormoderne bezeichnen. 
eine von Gott für die Sünden der Juden verhängte Strafe war; andererseits sind ihrem Bericht erste Andeutungen der grundstürzenden Veränderungen zu entnehmen, die das europäische Judentum in den folgenden Jahrzehnten erfahren sollte.

Wie grundlegend diese Veränderungen waren, wird in prägnanter Weise am Beispiel des Lebensweges von Bertha Pappenheim deutlich, der ersten Übersetzerin dieser Memoiren ins Deutsche. Denn die Biographie dieser Übersetzerin lässt sich vor dem Hintergrund einer Wanderungsbewegung verstehen - jener für das europäische Judentum des 19. und frühen 20. Jahrhunderts typischen Bewegung, die den Vater Bertha Pappenheims, Wolf Pappenheim, aus dem Preßburger jüdischen Ghetto in die österreichische Hauptstadt Wien führte ${ }^{2}-$, die über das Geographische hinaus vor allem eine geistige Dimension hatte und mit der altjüdischen Exilsmentalität zugleich die traditionelle Konstruktion des Raumes sprengte. Es wird deutlich werden, dass die Übersetzerin das von Glückel von Hameln beschriebene UnterwegsSein in eine besondere Perspektive rückt und so die Symbolik dieser Mobilität zu verstehen hilft.

Bertha Pappenheim war es, die im Jahre 1896 die von David Kaufmann, einem Professor an der Landesrabbinerschule in Budapest, veröffentlichten jiddischen Memoiren der Glückel von Hameln in die Hände bekam. Sie fand heraus, dass sie selbst eine Nachfahrin der Familie dieser jüdischen Frau aus dem 17. und frühen 18. Jahrhundert war $^{3}$ und übersetzte den Text 1910 ins Deutsche. Die Übersetzung erschien zunächst im Verlag ihres Bruders als Privatdruck, der aber keine größere Resonanz fand. Es war der Historiker Alfred Feilchenfeld, der Glückels Memoiren 1913 in einer gekürzten Fassung unter dem Titel Die Denkwürdigkeiten der Glückel von Hameln bekannt machte. Es ist vermutet worden, dass Feilchenfeld in den Besitz der Übersetzung von Bertha Pappenheim gekommen war und diesen Vorgänger-

2 Wolf Pappenheim, der Vater der Übersetzerin, blieb in Wien zunächst noch den jüdisch-orthodoxen Glaubensvorschriften treu; dieses geistige Erbe geriet aber fortschreitend in Kollision mit dem von der Emanzipation der Juden und ihrer Assimilation geprägten Zeitgeist. Die Konflikte, die vor allem in der folgenden Generation entstanden, lassen sich in mehrfacher Hinsicht am Beispiel der Biographie seiner Tochter studieren, wobei der psychologische Aspekt - als »Anna $\mathrm{O}$ « Siegmund Freuds ist der Name Bertha Pappenheims untrennbar mit der Entstehungsgeschichte der Psychoanalyse verbunden - besonders bekannt geworden ist; vgl. dazu Albrecht Koschorke, Nachwort, in: Lena Kugler/Albrecht Koschorke (Hg.), Bertha Pappenheim. Literarische und Publizistische Texte, Wien 2002, S. 299. Vgl. auch Daniel Boyarin, Unheroic Conduct. The Rise of Heterosexuality and the Invention of the Jewish Man, Berkeley 1997, S. 180-184. Zur Verortung der Psychoanalyse in der jüdischen Geistesgeschichte vgl. Matthias Morgenstern, Theater und zionistischer Mythos. Eine Studie zum zeitgenössischen hebräischen Theater unter besonderer Berücksichtigung des Werkes von Joshua Sobol, Tübingen 2002, S. 301-317.

3 Vgl. die genealogischen Tafeln in: Bertha PAppenheim, Die Memoiren der Glückel von Hameln. Aus dem Jüdisch-Deutschen übersetzt, Weinheim 2005, S. 321-327. 
text benutzte. Bertha Pappenheims Werk fiel jedenfalls zunächst einmal in Vergessenheit. Ihre Übersetzung wurde erst 1994 nachgedruckt ${ }^{4}$.

Dieses Buch weist in seiner Bedeutung weit über die norddeutsche Heimat der Autorin hinaus. Dies weniger, weil die »Glückel von Hameln« dem Historiker zunächst als weibliche Ausnahmegestalt erscheint, sondern vor allem deshalb, weil ihr Schicksal, wie auf den zweiten Blick deutlich wird, allgemeinere Rückschlüsse auf den Status und die Wirkungsmöglichkeiten jüdischer Frauen in der Vormoderne zulässt. »Glikl bas Juda Leib« - David Kaufmann nannte sie nach der Sitte des 19. Jahrhunderts kurzerhand nach ihrem Ehemann Chajim Hameln, obgleich jüdische Frauen des 17. Jahrhunderts nicht ihren Ehemann, sondern ihren Vater im Namen führten - war Perlenund Juwelenhändlerin, handelte eigenständig an der Börse und stand in familiären und wirtschaftlichen Beziehungen zu Juden in ganz Mitteleuropa. Um die für eine jüdische Frau ihrer Zeit außergewöhnliche Bildung im weltlichen wie in gewisser Hinsicht auch im religiösen Bereich charakterisieren zu können, muss man freilich die geschlechtsspezifische Arbeitsteilung des traditionellen Judentums in Aschkenas in Rechnung stellen, in dem das »Lernen « der Tora, also die Auseinandersetzung mit den Überlieferungen des rabbinischen Schrifttums, den Männern vorbehalten war. In der Tat zitiert Glückel immer wieder aus der Bibel, den Gebetstexten und der jiddischen Volksliteratur, weniger jedoch aus dem Talmud und dem sonstigen religionsgesetzlichen Schrifttum, in dem sie offensichtlich weniger bewandert war ${ }^{5}-$ das in hohem Maße anspruchsvolle Studium der rabbinischen Literatur war Männern vorbehalten ${ }^{6}$. Ihre religiösen Äußerungen sind demnach vor dem Hintergrund der rabbinischen Genderkonstruktion zu interpretieren.

Die Färbung ihres Textes mag nichtjüdischen Nachgeborenen als besonders »fromm« erscheinen. Ständiges Thema ist etwa die Frage, warum Gott Unglück und Elend in dieser Welt zuläßt; es handelt sich hier aber nicht um einen Diskurs, wie er im traditionellen jüdischen »Lernen« in der Welt der Talmudgelehrsamkeit üblich war. Auch die bei Glückel häufigen und etwas stereotypen Reflexionen über die Notwendigkeit der Gesetzesobservanz und der Wohltätigkeit entsprechen nicht unbedingt dem traditionellen jüdischgelehrten Frömmigkeitsdiskurs der Männer; sie erscheinen eher als Ausdruck einer spezifisch weiblichen Religiosität. Dementsprechend sind auch

4 Monika Richarz, Einleitung, in: Dies. (Hg.), Die Hamburger Kauffrau Glikl. Jüdische Existenz in der frühen Neuzeit, Hamburg 2001, S. 9-26, hier: S. 11.

5 Zu den Talmudzitaten bei Glückel, die offensichtlich nicht auf eigene und direkte Talmudlektüre zurückgehen (die Verfasserin gibt selbst an, dass ihr die Originaltexte nicht zur Verfügung standen) und zudem ungenau sind, vgl. Alfred FeILchenfeld, Denkwürdigkeiten der Glückel von Hameln. Aus dem Jüdisch-Deutschen übersetzt, mit Erläuterungen versehen und herausgegeben, Königstein 1980, S. 314-316.

6 Gegen Richarz, Einleitung, S. 9. 
die häufigen Erwähnungen der eigenen Sündhaftigkeit und der von Gott für die Sünden verhängten Strafen weder ein Reflex pietistischer Zerknirschung noch gar Indiz einer theologisch-philosophischen Auseinandersetzung mit der Theodizeefrage, sondern Hinweis auf das Bewusstsein, nach jahrhundertelangem Herkommen weiterhin im vom Gott Israels als Strafe für die »Sünden des jüdischen Volkes« verhängten exilischen Zustand zu leben, in einem nach heilsgeschichtlichen Dimensionen zugeschnittenen Raum also, den Glückel - in ihrem Klagelied um Zion ${ }^{7}$ - letztlich auch für ihre persönlichen Unglückslagen verantwortlich macht ${ }^{8}$.

Nach dem Tod ihres Ehemannes Chajim übernahm die Memoirenschreiberin das Geschäft der Familie und führte es selbstständig weiter. Sie stellte in Hamburg Strümpfe her, handelte mit Perlen, Wertpapieren und importierten Waren, besuchte mit ihrem ältesten Sohn auswärtige Messen und verfolgte ihre wirtschaftlichen Interessen über weite Entfernungen hinweg ${ }^{9}$. In ihren Erinnerungen schildert sie mit großem Selbstbewusstsein ihre Aktivitäten. Im Laufe ihres Lebens spielten Handelsbeziehungen und entsprechende Reisen »über ganz Mitteleuropa von Kopenhagen bis Wien und von Lissa bis Metz « ${ }^{10}$ eine Rolle. Sogar von Handels- und Finanzbeziehungen bis London, Amsterdam, Berlin, Wien und Paris und selbst von verstreuten kolonialen Interessen in Übersee ist die Rede ${ }^{11}$.

Mobilität war auch in familiären Belangen wichtig. Noch vor seinem Tod hatte ihr Ehemann Verhandlungen über eine Ehe seiner ältesten Tochter Zippora mit dem Sohn des berühmten Elias Gomperz von Kleve geführt, dem Bankier des großen Kurfürsten ${ }^{12}$. Die Familie verfolgte die Strategie, einige ihrer Söhne und Töchter in der näheren Umgebung, einige aber in weiter entfernten Städten zu verheiraten - nach Kopenhagen, Amsterdam, Berlin. Die Tochter Esther heiratete gar in das unmittelbar an der Grenze gelegene Metz im Königreich Frankreich ${ }^{13}$. Die Ausdehnung des jüdischen Heiratsnetzes über so viele politische Grenzen hinweg machte entsprechende Reisen notwendig. Nach dem Tod ihres Ehemannes war es Glückel selbst, die diese Reisen unternahm.

»Zu Glikls Zeit heirateten nur Angehörige von Königs- oder Herzogshäusern oder vielleicht auch Angehörige der zerstreuten französischen Hugenot-

7 Pappenheim, Die Memoiren, S. 182.

8 Vgl. ebd., S. 69, 74, 115, 192, 198, 309f.

9 Vgl. Natalie Zemon Davis, Glikl bas Juda Leib - ein jüdisches, ein europäisches Leben, in: Richarz (Hg.), Die Hamburger Kauffrau Glikl, S. 27-48, hier: S. 30.

10 Richarz, Einleitung, S. 9.

11 Vgl. Michael Toch, Jüdische Unternehmerinnen im 16. und 17. Jahrhundert: Wirtschaft und Familienstruktur, in: Richarz (Hg.), Die Hamburger Kauffrau Glikl, S. 255.

12 Vgl. Davis, Glikl bas Juda Leib, S. 35.

13 Vgl. ebd., S. 30. 
tengemeinden quer durch Europa, wie es diese Juden taten $\aleph^{14} .1700$ heiratete sie selbst ein zweites Mal: einen Bankier in Metz, der aber ebenfalls einige Jahre später starb. Ihre sieben Bücher umfassenden Memoiren begann sie 1690 nach dem Tode des ersten Mannes zu schreiben. Ihre Schilderungen sind aufgrund vieler Einzelheiten zur jüdischen Geschichte, insbesondere der jüdischen Gemeinden in Hamburg, Altona und Metz bedeutsam. Sie sind Zeugnis einer Zeit, in der Juden durch rechtliche Einschränkungen auf den Handel mit Waren und Geld beschränkt waren.

Bei diesem Handel mussten jüdische Frauen aus wirtschaftlichen Gründen mithelfen und waren im Familiengeschäft aktiv, das meist von den Eheleuten gemeinsam betrieben wurde. Wenn die Männer auf Handelsreisen unterwegs waren, wurde das Geschäft daheim von den Frauen weitergeführt, die als vollwertige Arbeitskräfte angesehen wurden. Dabei konnte es vorkommen, dass die Frauen auch über Hilfskräfte verfügten, denen sie vorstanden. Auffallend häufig waren Frauen in der Geldleihe tätig.

Wenn in diesem Zusammenhang überhaupt von einer geschlechtsspezifischen Arbeitsteilung die Rede sein kann, so funktionierte diese Teilung ganz anders als es der spätneuzeitlichen Vermutung entspricht - wir werden später auf die Gründe zurückkommen. Wie alle jüdischen Berufe der Vormoderne, mit Ausnahme des Rabbiners und des studierten Arztes, erforderte die Geldleihe keine formale Ausbildung, sondern wurde im Familiengeschäft praktisch erlernt; es bestanden daher keine Zugangsbarrieren für Frauen. Will man entsprechenden Untersuchungen Glauben schenken, so waren ein Drittel der im Spätmittelalter im Geschäftsleben tätigen Juden weiblich - eine Zahl, die sich in anderen Bevölkerungsgruppen nicht finden läßt $\mathrm{t}^{15}$.

Eine Folge dieser besonderen Wirtschaftsstruktur bestand in der geographischen Mobilität, deren volles Ausmaß für modernes Denken nur schwer zu begreifen ist. Trotz der Vielzahl von Einschränkungen und der eklatanten Gewalt, denen sie unterwegs immer wieder ausgesetzt waren, unternahmen Juden im Zuge ihrer Geschäfte häufig Reisen: auf das Land, um Schuldner ausfindig zu machen und Bezahlung in Waren, zumeist in Form von Korn, Wein, Rindern und Pelzen, in Empfang zu nehmen, nach Frankfurt oder zu anderen Messen, wo sie Waren kauften und verkauften, zu den unterschiedlichen Gerichtshöfen der Region, wo sie Prozesse anstrengten und endlosen Folgen von Gerichtssitzungen beiwohnten ${ }^{16}$.

Wie weit die Erwartungen im Hinblick auf das wirtschaftliche Handeln von jüdischen Frauen verbreitet waren, zeigt eine Äußerung des im 18. Jahrhun-

14 Ebd.

15 Tосн, Jüdische Unternehmerinnen, S. 257.

16 Ebd., S. 263. 
dert führenden Rabbiners Jacob Emden (1697-1776). Emden tadelte seine zweite Ehefrau, weil sie - anders als seine erste Gattin - über keinen Geschäftssinn verfügt habe ${ }^{17}$. Wirtschaftliches Denken und Handeln wurde von Frauen also erwartet. Um Frauen die Erwerbstätigkeit, etwa den Trödelhandel, zu ermöglichen, wurde sogar das religionsgesetzliche Verbot aufgehoben, das es Frauen ansonsten untersagt, sich mit einem anderen Mann als ihrem Ehemann allein in einem Zimmer aufzuhalten (אור יחור berichtet in ihren Erinnerungen, dass sie ihren Mann oft in Geschäftsdingen beraten habe und nichts ohne sie entschieden worden $\operatorname{sei}^{19}$.

Wenn wir ihre Biographie und die in ihrer Biographie zutage tretende Mobilität deuten wollen, so ist zunächst ein Blick auf das Frauenbild nötig, das uns in den Texten der jüdischen Tradition entgegentritt. Ein immer wieder zitierter Grundtext steht in Prv 31, 10-22, dem Lied von der »tüchtigen Frau « (eshet hayyil), in dem der Ehemann und seine Söhne die Mutter in den höchsten Tönen loben. Dieser Text wird von orthodoxen jüdischen Ehemännern bis heute zu Beginn des Sabbat rezitiert. Er läßt die Frau als Ehefrau und Mutter den Mittelpunkt des Hauses sein, zeigt aber zugleich eine Frau, die selbständig ökonomisch agiert und in keiner Weise auf ihren Mann angewiesen zu sein scheint. Es heißt dort im Hinblick auf ihre Handelstätigkeit und Mobilität: »Sie ist wie ein Kaufmannsschiff; ihren Unterhalt bringt sie von ferne [...] Sie trachtet nach einem Acker und kauft ihn und pflanzt einen Weinberg vom Ertrag ihrer Hände« (V. 14.16). Moderne Exegetinnen haben zu Recht darauf aufmerksam gemacht, dass die traditionelle Überschrift des Abschnitts (eshet hayyil) im Hebräischen gerade nicht von einer »tüchtigen Hausfrau«, sondern von einer »starken« Frau spricht ${ }^{20}$ - das hebräische hayyil heißt neben »Tugend « vor allem »Stärke«.

Was die rabbinische Literatur anbelangt, so ist das auffälligste Merkmal der Genderkonstruktion die Tatsache, dass das Recht (freilich auch die Pflicht) zum Studium der Tora den Männern vorbehalten ist. Begründet wird der Ausschluss von Frauen mit dem Bibelvers Dtn 11,19 »ihr sollt sie (die

17 Vgl. Monika Richarz, Geschlechterhierarchie und Frauenarbeit seit der Vormoderne, in: Kirsten Heinsohn/Stefanie Schüler-Springorum (Hg.), Deutsch-jüdische Geschichte als Geschlechtergeschichte. Studien zum 19. und 20. Jahrhundert, Göttingen 2006, S. 87-104, hier: S $91 f$.

18 Nach dem babylonischen Talmud [Traktat Sanhedrin 21ab (vgl. Lazarus Goldschmidt, Der Babylonische Talmud neu übertragen, Bd. 8, Darmstadt ${ }^{4} 1996$, S. 538f.)] ist das Alleinsein von zwei gegengeschlechtlichen Personen generell verboten, wenn diese beiden Personen nicht miteinander verheiratet sind; vgl. Ernst MüLLER, Art. JICHUD (זידו ״Einung «), in: JL 3 (1927), Sp. 267; vgl. auch Eduard BANETH, Art. ISSUR WEHETTER (אסור והתר ״Verbot und Erlaubnis «), in: JL 3 (1927), Sp. 86f.

19 Pappenheim, Die Memoiren, S. 69.

20 Vgl. Christl Maier, Das Buch der Sprichwörter. Wie weibliche Weisheit entsteht ..., in: Luise Schottroff / Marie-Theres Wacker (Hg.), Kompendium feministische Bibelauslegung, Gütersloh ${ }^{3} 2007$, S. 217-219. 
Tora) lehren euren Söhnen«, der nach traditionell-rabbinischem Verständnis den Ausschluss der Töchter vom Torastudium rechtfertigt und fordert ${ }^{21}$.

Dies bedeutet erstens: Wer nicht selbst lernt, hat einen geringeren gesellschaftlichen Status und kann auch nicht lehren. Spuren vorbildlicher Frauen finden sich daher, von wenigen Ausnahmen abgesehen, nicht in den religionsgesetzlichen Diskussionen, sondern vor allem in den erzählenden Texten des Talmuds ${ }^{22}$. Da die Beobachtung der religionsgesetzlichen Gebote ein hohes Maß an religiösen Wissen erfordert - im Talmud heißt es: »Ein Unwissender kann kein frommer Mensch sein ${ }^{23}{ }^{23}$, sind die religiösen Möglichkeiten für Frauen daher von vornherein eingegrenzt.

Dies bedeutet aber nun umgekehrt zweitens, dass die ökonomischen Betätigungsmöglichkeiten der Frauen größer sind, da sie nicht Tora lernen müssen oder dürfen. In der traditionellen Talmudfrömmigkeit führt das dazu, dass das Idealbild des frommen Mannes das eines Stubengelehrten ist, der Tag und Nacht nicht von seinem Schreibtisch aufsteht und sein Leben der Tora widmet ${ }^{24}$. Im rabbinischen Schrifttum ist geradezu von den »vier Ellen der Halakha«, den »vier Wänden der Tora $\aleph^{25}$ die Rede, in denen der Mann

21 Vgl. Sifre Devarim, § 46 (= Hans Bietenhard, Der tannaitische Midrasch Sifre Deuteronomium übersetzt und erläutert, Bern 1984, S. 165). Es ist in der Forschung umstritten, inwiefern das rabbinische Frauenbild an das biblische Frauenbild anschließt, inwieweit es späteren griechisch-römischen Einflüssen unterliegt und, wenn ja, ob und in welchem Maße diese griechisch-römischen Einflüsse gegenüber der Bibel eine Verbesserung oder Verschlechterung der Lage der Frau mit sich gebracht haben; zur Diskussion vgl. Miriam Peskowitz, Spinning Fantasies. Rabbis, Gender and History, Berkeley 1991.

22 Neuere Überlegungen im Umkreis der feministisch-jüdischen Theologie, Frauen könnten in talmudischer Zeit in höherem Umfang an der rabbinischen Lehre beteiligt gewesen sein, bleiben weitgehend im Hypothetischen; vgl. dazu Tal Ilan, Jewish Women in Greco-Roman Palestine. An Inquiry into Image and Status, Tübingen 1995, S. 194.

23 Sprüche der Väter 2,6 (Goldschmidt, Der Babylonische Talmud, Bd. 9, S. 668); bezeichnenderweise heißt es an der zitierten Stelle weiter: »Und wer viel Handel treibt, wird nicht weise «.

24 Der hebräische Schriftsteller Chaim Nachman Bialik (1873-1934) hat diese Raumkonstruktion des Talmudlernens von Männern im Ghetto in seinem kulturkritischen Gedicht »Bei meiner Rückkehr« beschrieben: »Wieder seh’ ich dich, du Alter/ Dein Gesicht vergilbt und trocken/ Unstet wie ein müder Falter/ Über deinen Büchern hocken [...] Und wie damals Spinnennetze/ Ziehen sich von Wand zur Decke/ Toter Fliegen Ruheplätze/ In dem Dunkel jener Ecke« (zitiert nach: Amos Oz, Im Lande Israel. Herbst 1982, Frankfurt am Main 1984, S. 11).

25 Dieses Ideal bezieht sich auf das rabbinische Raummaß sowie die Fiktion, dass jeder Jude mindestens vier Elen Land in Palästina besitze; vgl. Marcus CoHn, Art. ARBA AMMOT (ארבע אמות $»$ vier Ellen«), in: JL 1 (1927), Sp. 430. Im Jerusalemer Talmud sagt ein Toragelehrter von sich selbst: »In meinem Leben ging niemand vor mir in die Synagoge (d.h. in das Lehrhaus, MM). Ich ließ auch niemanden jemals in der Synagoge zurück, bevor ich sie verließ. Weder ging ich je (mehr als) vier Ellen, ohne (ein Wort aus der) Tora (zu erwähnen) noch erwähnte ich Worte der Tora an einem unangemessenen Ort« (Andreas LEHNARDT, Ta’aniyot. Fasten, Übersetzung des Talmud Yerushalmi, Bd. II/9, Tübingen 2008, S. 98); vgl. auch GoldschmidT, Der Babylonische Talmud, Bd. 3, S. 704 (Traktat Taanith 20b: »nie ging ich vier Ellen ohne Tora und Tephillin«) und Bd. 5, S. 360 (Traktat Kethuboth 111a: »Wer vier Ellen im Jisraéllande wandelt, ist dessen sicher, daß er der zukünftigen Welt teilhaftig wird «). Der Aufenthalt in den 
sich aufhalten soll. Das Idealbild der Mobilität von Männern bestand darin, dass sie entweder als junge Männer unterwegs zu einer Stätte der Talmudgelehrsamkeit sein oder als bereits erwachsene und im »Lernen« selbständige Ehemänner die »vier Wände« ihrer persönlichen Lernstube sozusagen an jedem Ort neu konstituieren konnten ${ }^{26}$. Im Talmud werden in diesem Zusammenhang auch die Gefahren beschrieben, die auf den Mann lauern, wenn er seine Lernstube verläßt und das Torastudium vernachlässigt. Wenn die wirtschaftlichen Realitäten das vollzeitliche »Lernen« - »Tag und Nacht« nach Ps 1,2 - für die jüdischen Männer häufig auch nicht zuließen und ihre Frauen natürlich nicht nur auf den Märkten und Plätzen, sondern ebenso im häuslichen Bereich tätig waren, so entsprach es doch eher dem weiblichen Stereotyp, das Betätigungsfeld im Draußen, in der ökonomischen Realität, im wirtschaftlichen Leben, zu finden. Bei jüdischen Frauen lauerten die Gefahren, wenn sie unbefugterweise in die Studierstube eindrangen, die nicht für sie bestimmt war $^{27}$. Wenn Glückel ihre schriftstellerische Tätigkeit rechtfertigen will und betont, selbst keine Schriftgelehrte zu sein, so scheint es sich um eine Kautele zu handeln, die unter diesem Gesichtspunkt zu verstehen ist ${ }^{28}$.

Erst im späten 18. und frühen 19. Jahrhundert begannen die jüdischen Bürger des Westens und auch die Aufklärer des Ostens, die Erwerbsarbeit von Frauen abzulehnen und ihre Beschränkung auf das Heim zu befürworten, wo ihnen die bildungsbewusste Kindererziehung, die Schaffung eines kultivierten Heims und die Reproduktion der männlichen Arbeitskraft zur Aufgabe gemacht wurde. Das erste und wichtigste Gegenbild zur traditionellen familiären Ökonomie waren in dieser frühbürgerlichen Zeit die Salons der Berliner Oberschicht des späten 18. Jahrhunderts, die - nach dem Vorbild französischer Salons im 17. Jahrhundert - großenteils von Frauen geleitet wurden. Es handelte sich hier um einen politisch-kulturellen Freiraum der

»vier Ellen der Tora« lässt sich in diesem Zusammenhang als symbolische Konstruktion von Heimat interpretieren.

26 Das jüdische Verhältnis zum Raum ist gelegentlich (etwa bei Franz RosenzweIG, Der Stern der Erlösung, Frankfurt am Main 1988, z.B. S. 397 und 415 sowie passim) Gegenstand religions-, kultur- und kunstphilosophischer Überlegungen gewesen, was freilich auch zu Überzeichnungen Anlass gegeben hat. Im Zusammenhang mit Glückel von Hameln geht es in der hier vorgetragenen Skizze nur um den Nachweis der entsprechenden stereotypen Vorstellungen in der Literatur. Auf einem anderen Blatt steht die Frage, inwieweit das theoretische Verhältnis zu Raum und Mobilität einen Niederschlag in der historischen Realität gefunden hat.

$27 \mathrm{Zu}$ den (offensichtlich in erster Linie sexuellen) Gefahren, denen Frauen sich aussetzen, wenn sie in den Innenbereich des Talmudstudiums eindringen, am Beispiel der Erzählungen über das Schicksal der gelehrten Frau Berurja, der Ehefrau des rabbinischen Gelehrten Rabbi Meir, vgl. Tal Ilan, Folgenreiche Lektüren. Gender in Raschis Kommentar zum babylonischen Talmud, in: Christiane E. MülleR / Andrea Schatz (Hg.), Der Differenz auf der Spur. Frauen und Gender in Aschkenas, Berlin 2004, S. 21-50, hier: S. $48 f$.

28 Vgl. Pappenheim, Die Memoiren, S. 3 und 112: Ihr Buch sei geschrieben worden, »um meine müßigen melancholischen Gedanken damit zu verbringen, wenn mich die betrübten Gedanken so geplagt $\ll$. 
Begegnung von jüdischen mit nichtjüdischen Frauen und Männern, der zugleich Ort weiblicher Selbstverwirklichung war. Erst in dieser Zeit begann die Transformation des traditionellen Judentums in ein bürgerlich-liberales Judentum, und es kam zu einer Übernahme des Konzepts der Dichotomie der Geschlechter mit dem Bild von der Frau als Hüterin von Heim und Familie und dem Mann als Ernährer und Beschützer mitsamt der Übernahme des bürgerlichen Wertekanons und der entsprechenden symbolischen Konstruktion von Räumlichkeit, die dem Mann das »Draußen« und der Frau das »Drinnen « zuweis $^{29}$. In Glückels Memoiren haben wir einen Text vor uns, der gewissermaßen noch vor dem Wechsel vom vormodern-halachischen zum bürgerlichen Patriarchat steht und der uns deshalb Einblick gibt in eine versunkene Welt.

Gleich zu Beginn ihres Textes macht Glückel darauf aufmerksam, dass das Besondere ihrer Person nicht in ihrer wirtschaftlichen Aktivität und Mobilität liegt, sondern darin, dass sie angefangen hat zu schreiben: »Meine lieben Kinder, ich gehe nicht darauf aus, euch ein Moralbuch zu machen und zu schreiben, ich bin nicht kapabel dazu, dazu sind unsere Weisen da, die viele Bücher darüber geschrieben haben $[\ldots]^{30} \ll$. Ihr Ort war nicht die Schreib- und Studierstube, und es scheint, dass sie sich bei ihrer schriftstellerischen Tätigkeit einer gewissen »Grenzüberschreitung « bewusst gewesen ist. Umgekehrt finden wir in ihrem Bericht immer wieder, gelegentlich geradezu komisch anmutende Situationen von Männern, die ihre Bet- und Lernstube verlassen - sei es gezwungernaßen oder aus eigenem Antrieb - und dadurch in Gefahr geraten.

Das spektakulärste Beispiel dafür hängt mit der messianischen Naherwartung in Folge der Bewegung um den Pseudomessias Sabbatai Zwi (1626-1676) zusammen, jener Bewegung, die nach der Deutung Gershom Scholems das Zerbrechen der traditionellen jüdischen Welt vorwegnahm und als Vorbote eines neuen Zeitalters zu verstehen is $\mathrm{t}^{31}$. Glückel berichtet, wie ihr Schwiegervater in Hameln infolge der messianischen Begeisterung Haus und Hof aufgab, seine Wohnung und seine sonstige Habe stehenließ und nach Hildesheim zog - ein durch messianisches Engagement veranlaßter Ortswechsel, der für Glückels Familie im Desaster endete. In der Meinung, sich demnächst von Hamburg aus in das Heilige Land einschiffen zu können, schickte der fromme Mann zwei große Fässer in die Hansestadt »mit allerhand Leinenzeug «, wie die Autorin schreibt: »Und darin ist gewesen allerhand Essenspeis, wie Erbsen, Bohnen, Dörrfleisch [...], alles, was sich aufbewahren läßt.

29 Vgl. Richarz, Geschlechterhierarchie, S. 94-98; zu Glückel von Hameln vgl. ebd., S. $92 f$.

30 Pappenheim, Die Memoiren, S. 3.

31 Gershom Scholem, Die Metamorphose des häretischen Messianismus der Sabbatianer in religiösen Nihilismus im 18. Jahrhundert, in: Ders., Judaica 3. Studien zur jüdischen Mystik, Frankfurt am Main 1987, S. 198-217, hier: S. 217. 
Diese Fässer sind wohl mehr als ein Jahr in meinem Hause gestanden. Endlich haben sie gefürchtet, daß das Fleisch und andere Sachen verderben ${ }^{32}$.

Später erzählt Glückel von ihrer Tochter Zippora, die in den Verdacht gerät, von der Pest befallen zu sein, während die Familie das Laubhüttenfest in Hannover verbringen will. Um keinen Skandal zu verursachen und die ganze Judenschaft der Stadt in Gefahr zu bringen (vor allem der Herzog darf nichts davon erfahren), soll das Kind mit einer Magd, einer »Polakin «, in ein benachbartes Dorf geschickt werden. Dort sollen die beiden einstweilen anonym bei einem Bauern Unterschlupf suchen und abwarten, wie sich die Krankheit entwickelt.

In Hannover ist ein alter Mann, ein Polak, gewesen, ein Bettler, den haben sie gedungen, und auch die betreffende alte Polakin; diese beiden sollten einige Tage bei ihnen bleiben, bis man sieht, wie es abläuft. Die beiden haben aber nicht von der Stelle weichen wollen, wenn man ihnen nicht dreißig Reichstaler Geld gibt dafür, daß sie sich in Gefahr begeben. Also hat sich mein Schwager Reb Abraham und mein Schwager Reb Lipmann und mein Schwager Reb Loeb ins Konsilium gesetzt und der Lehrer von Hannover, welcher auch ein großer Schriftgelehrter gewesen, die haben studiert, ob man den Feiertag damit verletzen darf, daß man Geld gibt. Also haben sie zusammen zugestimmt, man soll ihnen das Geld geben, denn sie haben gesagt, es ist in der Stunde der Gefahr, geradezu Lebensgefahr ${ }^{33}$.

Eine für die altjüdische Konstruktion von Raum und Gender charakteristische Szene: die Männer sitzen drinnen und »lernen« die Situation, während die Frauen im Draußen sind und sich praktisch um das Kind kümmern. Die Unbeholfenheit der Männer und ihre Gefährdung im Draußen tritt auch auf einer Reise zutage, die Glückel von Hannover aus zusammen mit ihrem Boten Jakob unternimmt. Jakob ist dem Alkohol zugeneigt und macht sich

32 Pappenheim, Die Memoiren, S. 76; vgl. auch Gershom Scholem, Sabbatai Zwi. Der mystische Messias, Frankfurt am Main 1992, S. 645, 842. Bemerkenswerterweise beschreibt Glückel die Aufregung um den Messiasprätendenten Sabbatai Zwi mit Hilfe der unter Gendergesichtspunkten aufschlussreichen biblischen Metapher der »Wehen des Messias«: »Wir haben gehofft wie eine Frau, die da sitzt auf dem Gewinnstuhl und mit großen Schmerzen ihren Wehtag verbringt, und meint, nach all ihrem Schmerz und Wehtag wird sie mit ihrem Kind erfreut werden; aber nach all ihrem Schmerz und Wehtag kommt nichts anderes, als daß sie einen Wind gehört. Also, mein großer Gott und König, ist uns auch geschehen. Wir haben gehört, und alle deine lieben Knechte und Kinder haben sich sehr gemüht mit Gebet, Buße und Almosen durch die ganze Welt. Und dein liebes Volk Israel ist auf dem Gewinnstuhl gesessen und hat gehofft, [...] und es ist nichts als Wind herausgekommen« (PAPPEnHeIM, Die Memoiren, S. 74f).

33 Ebd., S. 81f.; angespielt wird auf das religionsgesetzliche Verbot, am Sabbat finanzielle Transaktionen vorzunehmen; diese Vorschrift kann nach dem Talmud im Falle einer Lebensgefahr (pikkuah nefesh) aber außer Kraft gesetzt werden; die Frage, ob hier ein solcher Fall vorlag, war Gegenstand der religionsgesetzlichen Prüfung der am »Konsilium« beteiligten gelehrten Männer. 
unterwegs selbstständig, um mit einem Kollegen die Nacht durchzuzechen. Während der Nacht muss Glickl dann zusammen mit Dorfleuten zurückreiten und ihren Jakob aus dem Graben ziehen - sein Geld und sein schöner Mantel sind ihm in seiner Besoffenheit gestohlen worden ${ }^{34}$.

Von den Aktivitäten ihres Mannes berichtet Glückel, dass er immer wieder von Unglück verfolgt wurde; man gewinnt den Eindruck, dass er im Handel nicht eigentlich in seinem Element war ${ }^{35}$ - es ist ihr wichtig zu betonen, dass er sich auch immer wieder die Zeit nahm zum »Lernen ${ }^{36}$ :

Auch weiß ich wohl, daß, wenn er - er ruhe in Frieden - in seinem Zimmer gewesen ist und sein Gebet getan hat und jemand gekommen ist und ihn wegrufen wollte, daß irgendwo ein billiger Kauf gewesen wäre, dann hätte weder ich noch mein ganzes Hausgesinde das Herz haben können, zu ihm zu gehen und ihm davon zu sagen ${ }^{37}$.

Weil sie »mit dem Reisen allezeit große Sorgen und Schrecken« gehabt hätten und wohl auch um der Priorität des Talmudstudiums willen betont die Autorin, dass sie es »gern gesehen hätte«, wenn ihr Ehemann »hätte zu Hause bleiben können ${ }^{38}$. Einmal berichtet Glückel davon, dass ihr Mann, von dem es heißt, er sei »kein starker Mann« gewesen, auf einer Handelsreise nach Leipzig krank wird ${ }^{39} .1689$ fiel er schließlich auf dem Weg zu einem Geschäftstermin mit einem Hamburger Christen auf einen »spitzigen« Stein - einige Tage später war er tot. Glückel war nun allein für ihre Familie verantwortlich ${ }^{40}$.

Dass Mobilität auch mit imaginären Räumen zu tun hat und Räume symbolisch besetzt sind, zeigt schließlich eine von Glückel erzählte Geschichte, die eine weibliche Hauptperson auf eine Reise schickt - eine Reise, die uns

34 Ebd., S. 96.

35 Glückel berichtet davon, ihr Ehemann habe ihr nach von ihm zu verantwortenden fehlgeschlagenen Handelsaktionen und anderen ökonomischen Misserfolgen immer wieder »eitel Trost« (ebd., S. 155) gespendet und gut zugeredet, es sei »ja nun nicht zu ändern« (ebd., S. 154); offensichtlich war sie in wirtschaftlichen Dingen die treibende Kraft, die insistierte und den Erfolg suchte.

36 Ebd., S. 62. Zum Typus des gelehrten »meist als blass und zart, zuweilen auch kränklich beschriebenen« Talmudjüngers vgl. Simone LÄssıg, Religiöse Modernisierung, Geschlechterdiskurs und kulturelle Verbürgerlichung. Das deutsche Judentum im 19. Jahrhundert, in: Kirsten Heinsohn/Stefanie Schüler-Springorum (Hg.), Deutsch-jüdische Geschichte als Geschlechtergeschichte. Studien zum 19. und 20. Jahrhundert, Göttingen 2006, S. 46-84, hier: S. 63.

37 Pappenheim, Die Memoiren, S. 62f.

38 Ebd., S. 101; vgl. auch ebd., S. 130: »Also macht das göttliche Gericht die Armen dafür verantwortlich, wenn sie keine Thora lernen und nichts Gutes tun «.

39 Ebd., S. 98 (jiddisch: ער וואר קיין שטרקיר מאן); vgl. David Kaufmann (Hg.), זכרונות מרת גליקל המיל (Zikhronot Marat Glikl Hamil), Frankfurt am Main 1896; vgl. auch ebd., S. 181: »(M)ein Mann [...] ist kein starker Mann gewesen (איזט קין שטרקיר מאן גיוועזין. An Anspielung auf Prv 31,10 liegt auf der Hand.

40 Vgl. Pappenheim, Die Memoiren, S. 185; Davis, Glikl bas Juda Leib, S. 30. 
zudem an das Kaufmannsschiff der biblischen Proverbien erinnert ${ }^{41}$. Natalie Davis hat in diesem Zusammenhang von der jüdischen Liebe »zum Geschichtenerzählen « gesprochen ${ }^{42}$. Des Weiteren glaubt Davis, anhand dieser Geschichte ihre These von einem gemeinsamen europäischen Kulturerbe von Juden und Christen veranschaulichen zu können, da es hier um Motive gehe, die sich »in weltweiten Überlieferungen von Indien bis zum mittelalterlichen Christentum finden $^{43}$. Es muss aber darauf hingewiesen werden, dass die Quelle dieser Geschichte das Maassebuch ist - eine in jiddischer Sprache verfasste Erzählungsammlung für Frauen, die 1723 in Amsterdam im Druck erschien und 1929 ebenfalls von Bertha Pappenheim übersetzt und veröffentlicht wurde. Entscheidend für das Verständnis dieser Geschichte ist bei Glückel der Anfangsteil, der über die Vorlage hinausgeht und auch bei Davis unkommentiert bleibt. In der Vorlage ist von einem frommen Mann die Rede, der von seinem Vater das Vermächtnis erhalten hatte, er solle in seinem Leben auf Eidesleistungen verzichten. Diesen letzten Wunsch seines Vaters wollte der fromme Mann erfüllen und auf Schwüre verzichten. So wurde er aber erpressbar und fiel in Armut:

Nun, es hat viel böse Schälke in der Stadt, die waren es gewahr, wie ihm der Vater hat seinen Zwoe (Willen) gesagt, daß er keinen Schwue (Schwur) tun sollt. Da kam einer un sprach den Sohn um tausend Gulden an, die ihm der Vater schuldig wär. Der Sohn leugnet, es wär Scheker (Lüge). Da nahm er ihn vor. Nun schließlich kam es auf einen Schwur, daß er keine Wissenschaft davon hätt. Der Sohn gedacht. Schwör ich, so brech ich meines Vaters Zwoe, es ist besser, ich schwör nit, un geb ihm das Geld un will meines Vaters Zwoe nit brechen ${ }^{44}$.

Während der Plot sich in der Vorlage an einem religionsgesetzlich motivierten Konflikt entzündet, wird die Armut des Mannes bei Glückel damit begründet, dass er keiner Erwerbsarbeit nachgeht, sondern sich Tag und Nacht mit dem Torastudium beschäftigt:

Es war einmal ein frommer Mann, derselbe hatte zwei kleine Söhne und ein frommes Weib. Er hatte auch etwas Geld, davon er zehrte, aber er wußte keinen Handel zu treiben, nichts anderes als Talmud zu lernen. Und der fromme Mann wollte sich mit

41 Ebd., S. 45.

42 Ebd., S. 40.

43 Zur Analyse dieser Erzählung, die Davis dem Erzähltypus »Placidas oder Der Mann, der nie einen Eid schwor« zuordnet (ebd., S. 43), vgl. auch ebd., S. 41-45.

44 Bertha Pappenheim, Allerlei Geschichten. Maasse-Buch. Buch der Sagen und Legenden aus Talmud und Midrasch nebst Volkserzählungen in jüdisch-deutscher Sprache. Nach der Ausgabe des Maasse-Buches Amsterdam 1723, Frankfurt am Main 1929, S. 286. 
Gewalt gern ernähren, damit er sein Weib und seine Kinder ohne anderer Leute Gift und Gabe ernähren könnte. Aber das Glück wollte ihm nicht wohl [... $]^{45}$.

In ihrer Not lässt sich die Frau von einem alten Mann trösten: »Derweil dein Mann die Thora lernet, wird Gott deiner nicht vergessen, denn Gott läßt keinen Schriftgelehrten verfallen $\ll^{46}$. Glückel, die sich ebenso wie ihre Heldin offensichtlich als von ihrem Mann »vergessen « empfindet, geht es mit ihrer Geschichte nicht nur um die Gottergebenheit - »daß man alles mit Geduld und für gut annehmen soll $\ll^{47}$, sondern um eine Hoffnung, die die traditionelle Konstruktion von Raum und Gender im jüdischen Exil überwindet: »Dann wird Gott auch zum Guten sein gedenken und ihn vor allem Bösen behüten, uns aus unserer langen schweren Verbannung erlösen und in das heiligen Land hineinbringen $\ll^{48}$.

Im weiteren Verlauf der Erzählung gerät der fromme Mann erst einmal in Verzug beim Bezahlen seiner Schulden und muss, in Schuldhaft geraten, seine Lernstube mit dem Gefängnis vertauschen. In dieser Zeit wird seine Frau von einem Schiffer entführt, während sie am Meer steht und ihre Wäsche wäscht ${ }^{49}$. Ziel der Erzählung ist nun zu zeigen, wie der fromme Mann und seine Frau am Ende wieder zusammenkommen und wie - das ist das utopische Element der Geschichte - die nun doch in gewisser Hinsicht als defizitär empfundene Toragelehrsamkeit des Mannes sich mit den Tugenden seiner Frau vereint.

Auf der Suche nach seiner entführten Frau begibt sich der Fromme nach seiner Freilassung selbst auf eine Schiffsreise; nach etlichen Verwicklungen und Abenteuern stößt er auf einen Schiffer, der zwei Ehefrauen hat - eine an Land gebliebene Hausfrau und eine Frau, mit der er nie Verkehr gehabt hat, die aber an Bord die Geschäfte für ihn erledigt. Diese Frau hat dem fremden Schiffer gesagt, dass sie den ehelichen Verkehr nur einem Manne gestatten könne, der ihrem ehemaligen Ehemann ebenbürtig sei. Dies habe er zu beweisen, indem er ein Rätsel löse, dass ihr frommer Ehemann ihr beigebracht habe. Dies ist das Rätsel:

Die Frau gibt an, wie ein Vogel war vom Himmel auf die Erde geflogen, ohne Flügel, und setzt sich auf ein kleines Bäumlein, gar hübsch und gar fein. Er wendet und kehrt das Bäumlein hin und her, man sieht den Vogel nimmermehr $[\ldots]^{50}$.

\footnotetext{
45 Pappenheim, Die Memoiren, S. 37.

46 Ebd., S. 37.

47 Ebd., S. 50.

48 Ebd.

49 DAvis, Glikl bas Juda Leib, S. 44.

50 Pappenheim, Die Memoiren, S. 45.
} 
Und dies die Deutung:

Der Vogel, der da fliegt vom Himmel auf die Erde, das ist die Seele des Menschen. Sie setzt sich auf ein Bäumlein, das ist der Körper des Menschen. Der ist verglichen mit einem Baum, der aufwächst, hübsch grün und zweighaftig. Das ist die Jugend, die ist verglichen mit einem hübschen Lustgarten, in den der Vogel kommt und wendet den Baum. Das ist die Seele, die regiert, kehrt und wendet, macht gelenkig alle Glieder; aber keiner sieht den Vogel, denn die Seele ist im Körper verborgen. Daß der Baum alle Kräfte in sich zieht und dadurch verdorrt, das ist, weil sich der Mensch an dem Seinigen nicht begnügen läßt und alles an sich ziehen will, und verliert oft das Seinige darüber. Das Unrechte frißt das Rechte. Unversehens stirbt der Mensch und läßt alles hinter sich. So fliegt der Vogel in die Luft. Das ist die Seele, die den Körper an$\operatorname{klagt}^{51}$.

Der Leser vernimmt das Rätsel aus dem Mund der gefangenen Frau, die es von ihrem toragelehrten Mann gehört, gelernt und während ihrer langen Reise memoriert und bewahrt hat und nun in der Stunde der Gefahr anzuwenden weiß. Die Deutung hören wir von ihrem Ehemann, der endlich die vier Wände des Lehrhauses verlassen und sich auf die Suche nach seiner Frau begeben hat. Erst jetzt erweist er sich als ihrer würdig, indem er sie aus der Gefangenschaft des fremden Schiffers befreien kann. Erst durch das Zusammenwirken der auf ihre Weise gelehrten Frau und des auf seine Weise aktiv und mobil gewordenen Mannes können die Eheleute wieder zusammenkommen und empfängt der Leser Belehrung - vielleicht eine Allegorie auf das Aufeinander-bezogen-Sein von mündlicher und schriftlicher Tora, von Bibel und Talmud, durch das die jüdische Lehre entsteht, sicherlich aber auch eine Anspielung auf das von Gott erwartete Erbarmen am Ende der Exilszeit, die die Autorin mit ihrem eigenen Leiden in eins setzt ${ }^{52}$.

Es ist wohl kein Zufall, dass der Historiker Alfred Feilchenfeld in seiner Übersetzung diese Geschichte fortgelassen, während Bertha Pappenheim den vollen Wortlaut bewahrt hat ${ }^{53}$. Die Annahme liegt nicht fern, dass die Übersetzerin an dieser Stelle eine Spur von eigener innerer Verwandtschaft mit der außergewöhnlichen Memoirenschreiberin wahrgenommen hat, die mit ihrem schriftstellerischen Talent, aber auch ihrer Herzensbildung und ihrem Interesse an theologischen Fragen, entgegen den Genderklischees ihrer Zeit,

51 Ebd., S. 46f.

52 An anderer Stelle bezieht Glückel das Bild des wegfliegenden Seelenvogels direkt auf den Tod ihres Ehemannes Chajim Hameln (vgl. ebd., S. 191: »Wie seine Seele weggeflogen ist, ist meine Herrlichkeit, mein Reichtum und meine Ehre weggeflogen«).

53 Vgl. aber den Anhang bei Feilchenfeld, Denkwürdigkeiten, S. 307-317. Diese Geschichte fehlt auch in der englischen Übertragung von Marvin Lowenthal, The Memoirs of Glückel of Hameln, New York 1932. 
auf ihre eigene Art und Weise eben doch auch eine gelehrte Jüdin war. Bertha Pappenheim litt zeit ihres Lebens darunter, dass ihr kein Universitätsstudium möglich war; abgesehen von der Frage des Zugangs zu weltlicher, nichtjüdischer Bildung wollte sie aber auch die Begrenzungen der traditionell-jüdischen Geschlechterrollen überwinden und in jüdischer Hinsicht in den »Innenraum der Lehre« eindringen. In einer Zeit, in der die sabbatianische Versuchung, dem Ghettoraum des Lehrhauses zu entfliehen und im verheißenen Land neuen Boden zu gewinnen, im Rahmen der zionistischen Bewegung zu einer realen Möglichkeit geworden war, wollte sie weder selbstmächtig nach Palästina ausweichen noch sich einstweilen passiv auf die messianische Zeit vertrösten lassen, sondern den Raum der Diaspora im Hier und Heute neu gestalten. Sie suchte ihre Verwirklichung nicht durch Auswanderung, sondern im Bereich der Bildung und mithilfe der von ihr gegründeten und wesentlich mitgeprägten jüdischen Frauenbewegung in Deutschland. Diese Aktivitäten, zu denen offenbar auch ihre Übersetzungen aus dem Jiddischen gehörten, waren für sie ein Instrument der gesellschaftlichen Neugestaltung des Judentums, durch die - so lässt sich interpretieren - nicht zuletzt die Einseitigkeiten der rabbinischen Geschlechterrollen beseitigt werden sollten. So eröffnet uns die erste Übersetzerin der Memoiren der Glückel von Hameln zugleich eine Möglichkeit zum Verständnis der symbolischen Konstruktion von Raum und Mobilität in diesem außergewöhnlichen Text. 


\title{
Bettina Braun
}

\section{Katholische Konfessionsmigration im Europa der Frühen Neuzeit - Stand und Perspektiven der Forschung}

\section{Konfessionsmigration - ein protestantisches Phänomen?}

\begin{abstract}
Noch vor wenigen Jahren wäre eine Tagung zu Religion und Mobilität in der Frühen Neuzeit eher ungewöhnlich gewesen, wurde die Epoche doch verstanden als Vorstufe der Moderne, geprägt von Modernisierung, Bürokratisierung und Säkularisierung. Inzwischen gilt Konfessionsmigration ${ }^{1}$ geradezu als ein Signum der frühneuzeitlichen Geschichte Europas ${ }^{2}$. Nach Ausweis der diversen Überblicke und Typologien sowie der jüngst erschienenen monumentalen Enzyklopädie Migration in Europa ${ }^{3}$ scheint es sich dabei um ein protestantisches Phänomen gehandelt zu haben. Auch wenn nicht expli-
\end{abstract}

1 Konfessionsmigration soll im Folgenden verstanden werden als ein Vorgang, der erstens die Existenz von einigermaßen klar umrissenen Konfessionen voraussetzt. Die zahlreichen Wanderungen, die im Gefolge einer Entscheidung für oder gegen die neue Lehre zu Beginn der Reformationsepoche angetreten wurden, werden mithin nicht als Konfessionsmigration verstanden. Der Student der Theologie, der Wittenberg verließ, weil ihm die von Luther und Melanchthon gelehrte Theologie nicht zusagte, wäre also ebenso wenig ein Konfessionsmigrant wie die Nonne, die in ein anderes Kloster ihres Ordens umsiedelte, weil sich ihr bisheriges Kloster aufgelöst hatte. Zweitens folgt Konfessionsmigration aus dem Willen und der Fähigkeit der Obrigkeiten, auf einer einheitlichen Konfession ihrer Untertanen zu bestehen, so dass den Andersgläubigen nur die Alternative Anpassung oder Auswanderung bleibt. Drittens bildet bei diesen Migrationsvorgängen Konfession nicht nur das entscheidende Motiv für den Aufbruch in die Fremde, sondern sie prägt die Migration und vor allem das Selbstverständnis der Migranten auch weiterhin entscheidend. Aufgrund dieser definitorischen Vorentscheidungen ist Konfessionsmigration regelmäßig eine Erscheinung vor allem der zweiten Hälfte des 16. und der ersten Hälfte des 17. Jahrhunderts.

2 Thomas Klingebiel, Migrationen im frühneuzeitlichen Europa. Anmerkungen und Überlegungen zur Typologiediskussion, in: Thomas HöPel/Katharina Midell (Hg.), Réfugiés und Emigrés. Migration zwischen Frankreich und Deutschland im 18. Jahrhundert, in: Comparativ 7 (1997), S. 23-38, hier: S. 29f.; Alexander SchunKa, Glaubensflucht als Migrationsoption. Konfessionell motivierte Migrationen in der Frühen Neuzeit, in: GWU 56 (2005), S. 547-564, hier: S. 547: »Konfessionell motivierte Migrationen sind geradezu eine Besonderheit der Frühen Neuzeit und der konfessionellen Spaltung Europas«.

3 Klaus J. BAdE u.a. (Hg.), Enzyklopädie Migration in Europa. Vom 17. Jahrhundert bis zur Gegenwart, Paderborn ${ }^{2} 2008$. 
zit behauptet wird, dass nur Protestanten aus religiösen Gründen sich auf die Reise begeben hatten, so vermitteln die angeführten Beispiele - Hugenotten, Waldenser, Salzburger Protestanten, niederländische Calvinisten, protestantische Böhmen - genau diesen Eindruck ${ }^{4}$. Allein Heinz Schilling wies bereits in seinem Vortrag über Konfessionsmigration auf dem Historikertag in Halle 2002 darauf hin, dass es »aber auch eine - noch kaum erforschte - katholische Glaubensmigration [gegeben habe] «; ohne jedoch Beispiele zu nennen.

Es spricht schon die reine Plausibilität dagegen, dass es keine katholische Konfessionsmigration gegeben haben soll. Denn in der Überzeugung, dass die Bevölkerung ihres Territoriums nur einem Bekenntnis angehören sollte, waren sich protestantische und katholische Obrigkeiten prinzipiell einig und handelten entsprechend. Protestantische Landesherren waren also grundsätzlich genauso wenig bereit, konfessionelle Minderheiten in ihrem Territorium zu dulden, wie dies die katholischen Herrscher waren. Dass es keine katholische Konfessionsmigration gegeben hätte, hieße dann aber vorauszusetzen, dass katholische Untertanen - anders als protestantische - grundsätzlich die Konversion einer Migration vorzogen. Auch diese Annahme erscheint in dieser Ausschließlichkeit unwahrscheinlich.

Selbstverständlich hat es also katholische Konfessionsmigration gegeben, und insbesondere über die Migration von Katholiken von den britischen Inseln auf den Kontinent ist in den letzten Jahren auch verstärkt gearbeitet worden. Aber selbst über die vielleicht am besten erforschte irische Migration wissen wir noch lange nicht so genau Bescheid wie zum Beispiel über die Migration der Hugenotten oder der niederländischen Calvinisten. Diese Forschungen sind zudem bisher zumeist nur einem kleinen Kreis von Spezialisten bekannt und haben noch keinen Eingang in die einschlägigen Überblicke zur frühneuzeitlichen Migration gefunden. Von anderen Gruppen katholischer Glaubensflüchtlinge ist ohnehin kaum mehr bekannt, als dass es sie gegeben hat.

Angesichts dieser rudimentären und äußerst disparaten Forschungslage ist es im Moment noch viel zu früh, einen fundierten Vergleich über katholische

4 In den Gruppenartikeln der Enzyklopädie findet sich mit den »Jesuiten in Europa seit der Frühen Neuzeit« nur eine katholische Gruppe. Allerdings stellen die Jesuiten sicherlich einen eher untypischen Fall dar, der durch die Subsumierung unter Konfessionsmigration nur unzureichend erfasst werden kann. Selbstverständlich steht außer Frage, dass die Jesuiten immer wieder Opfer von Ausweisung und Vertreibung wurden, und zwar lange vor der Auflösung des Ordens 1773. Dabei handelte es sich jedoch häufig um spezifisch antijesuitische Maßnahmen, die nicht den Katholiken im Allgemeinen, sondern eben speziell den Jesuiten galten und deshalb immer wieder auch von katholischen Obrigkeiten durchgeführt wurden.

5 Heinz Schilling, Die frühneuzeitliche Konfessionsmigration, in: Klaus J. BADE (Hg.), Migration in der europäischen Geschichte seit dem späten Mittelalter. Vorträge auf dem deutschen Historikertag in Halle a.d. Saale, 11. September 2003 [2002], Osnabrück 2002, S. 67-89, hier: S. 69. 
Konfessionsmigration in verschiedenen Ländern des frühneuzeitlichen Europa vorzulegen. Das Ziel dieses Aufsatzes ist denn auch viel bescheidener. Im Anschluss an einen knappen Überblick über verschiedene Gruppen katholischer Glaubensflüchtlinge werde ich einige Forschungsdesiderate formulieren, die mir für die Erforschung katholischer Konfessionsmigration zentral zu sein scheinen. Diese Fragen decken sich selbstverständlich zu einem erheblichen Teil mit den Fragestellungen, die für die Migration protestantischer Gruppen bereits bearbeitet worden sind. Allerdings zeichnet sich schon jetzt ab, dass es daneben auch Komplexe gibt, die für die katholische Migration - und eben nur für sie - signifikant waren: Ihre Analyse wird es erlauben, die katholische Konfessionsmigration im Unterschied zur protestantischen genauer zu konturieren und ihre spezifische Ausformung zu beschreiben. In einem dritten Teil soll anhand eines Fallbeispiels - nämlich anhand der englischen Katholiken in den Niederlanden - aufgezeigt werden, wie das aufgestellte Forschungsprogramm umgesetzt werden könnte und wo bereits jetzt auf der Grundlage vorliegender Literatur erste Antworten gegeben werden können.

\section{Katholische Konfessionsmigration im Europa der Frühen Neuzeit - ein Überblick}

Die folgende knappe Auflistung verschiedener Fälle katholischer Konfessionsmigration erfasst Gruppen sehr unterschiedlicher Größe und Bedeutung, deren Migrationsschicksale sehr unterschiedlich gelagert sein können und deren Geschichte zudem sehr unterschiedlich gut erforscht ist. Auch wenn hier kaum mehr als eine kurze Aufzählung geleistet werden kann, erscheint diese doch angesichts des Fehlens jeglicher Überblicke sinnvoll, ja notwendig.

In den Kerngebieten des Reichs dürfte es in der Tat kaum katholische Konfessionsmigranten gegeben haben ${ }^{6}$. Der Übergang der meisten protes-

6 Völlig anderer Ansicht ist Georg MAY, Zum >Ius emigrandi< am Beginn des konfessionellen Zeitalters, in: AKathKR 155 (1986), S. 92-125, der die »Übung «, »andersgläubige Untertanen zur Auswanderung zu zwingen« für eine protestantische Erfindung hält (S. 92), ohne beispielsweise auch nur mit einem Wort auf die rigorose Durchführung des Wormser Edikts in den burgundischen Erblanden Kaiser Karls V. einzugehen, die Dissentierende nicht nur mit Ausweisung, sondern mit der Todesstrafe bedrohte. Die von May angeführten Beispiele der Vertreibung katholischer Geistlicher, insbesondere aus Sachsen und Hessen im Zusammenhang mit den ersten Visitationen (S. 96-100), sind zu sehen als Ausfluss des von allen Obrigkeiten selbstverständlich in Anspruch genommenen Rechts, die Ausgestaltung des Kirchenregiments in ihren Territorien nach ihrem Verständnis zu regeln. Diese Vorgänge sind noch kaum mit den Kategorien konfessioneller Politik zu erfassen. Allein die Diktion des Aufsatzes, in dem von der »sogenannte[n] Reformation« (S. 96) und dem »sogenannte[n] Augsburger Religionsfrieden « (S. 102) die Rede ist und in dem den evangelischen Glaubensflüchtlingen überwiegend 
tantischen Territorien und Städte zur Reformation vollzog sich frühzeitig und mehrheitlich lange vor der Formierung klar abgegrenzter Konfessionen. Die Bevölkerung dieser Gebiete spielte häufig gegenüber den Obrigkeiten eine Vorreiterrolle oder folgte zumindest der obrigkeitlichen Entscheidung zur Reformation in ganz überwiegendem Maße, so dass es sicherlich weit weniger katholische $» I n s e l n \ll$ in protestantischen Territorien gegeben hat als umgekehrt?

In der Eidgenossenschaft waren die konfessionellen Verhältnisse in ihren Grundzügen bereits mit dem Zweiten Kappeler Landfrieden von 1531 festgeschrieben worden. Danach kam es in den dreizehn Orten nur noch zu marginalen Änderungen. Ein solcher Fall betraf die katholische Grafschaft Greyerz. Als der Graf von Greyerz Ende 1553 Konkurs anmelden musste, wurde die Grafschaft zwischen Bern und Freiburg aufgeteilt. Im Obergreyerz, der so genannten Landschaft Saanen ${ }^{8}$, führte Bern sodann gegen den Willen der Einwohner die Reformation ein. Die katholischen Geistlichen, die an ihrem Glauben festhalten wollten, wurden des Landes verwiesen. Aber auch ganze Familien verließen das Tal. Bevorzugtes Ziel der Flüchtlinge war das Untergreyerz, das bei der Teilung des Landes an Freiburg gekommen und damit katholisch geblieben war'.

niedere Beweggründe [zerrüttete Familienverhältnisse, ökonomische Motive, Hoffnung auf die »Erleichterungen und Freiheiten, welche das protestantische System verheißt«, das eben deshalb »bequemer und begehrenswerter als die Forderungen und Gebote des katholischen Glaubens « erschien (S. 111)] für ihre Flucht unterstellt werden, verbietet eigentlich eine ernsthafte Auseinandersetzung mit dem Vorgebrachten. Zudem halten die wenigen von May aufgeführten Fälle, in denen es zur Ausweisung oder Auswanderung von Katholiken innerhalb des Reichs gekommen sein soll, einer Überprüfung nicht stand. Nur zwei Beispiele: May hat sich offenbar auf die Behauptung von Götz von Pölnitz in seiner Biographie über den Würzburger Bischof Julius Echter von Mespelbrunn verlassen, wonach Julius Echter katholische Einwanderer aus Sachsen in seinem Hochstift aufgenommen hatte (S. 124). Pölnitz selbst gibt keinen Beleg an, Anfragen an das Bayerische Hauptstaatsarchiv Würzburg und das Diözesanarchiv Würzburg ergaben, dass man dort jedenfalls keine Bestände kennt, die auf eine solche Migrantengruppe hindeuten. Und die Erwähnung eines »landesherrlichen Treibjagens auf alles, was für katholisch galt« und die daraus folgende Vertreibung der Katholiken aus der Pfalz in der Abhandlung Johannes Geissels über »Die religiöse Erziehung der Kinder aus gemischten Ehen«, also in einem Text, den der spätere Kölner Erzbischof im Zusammenhang mit dem Kölner Mischehenstreit geschrieben hat, kann wohl kaum den Rang eines seriösen Quellenbelegs beanspruchen, muss bei May aber als solcher herhalten (S. 124).

7 Zur Ausweisung anderskonfessioneller Minderheiten aus Reichsterritorien siehe Matthias Asche, Auswanderungsrecht und Migration aus Glaubensgründen - Kenntnisstand und Forschungsperspektiven zur ius emigrandi Regelung des Augsburger Religionsfriedens, in: Heinz Schilling/Heribert Smolinsky (Hg.), Der Augsburger Religionsfrieden 1555, Gütersloh 2007 und Münster 2007, S. 75-104. Asche weist darauf hin, dass bis jetzt fast nur Fälle der Ausweisung protestantischer Minderheiten durch katholische Landesherren bekannt sind, muss aber angesichts der insgesamt unbefriedigenden Forschungslage die Frage offen lassen, ob dies einer asymmetrischen Erforschung der Ausweisungspraxis geschuldet ist oder ob protestantische Obrigkeiten tatsächlich kaum zu diesem Rechtsmittel gegriffen haben.

8 Sie umfasst die Gemeinden Saanen, Rougemont, Château d'Oex und Rossinière. 
Die Niederlande waren in der Frühen Neuzeit ein Raum, der von vielen Migrationsvorgängen geprägt wurde. Bekannt und gut erforscht ist die Flucht von Calvinisten aus den südlichen Niederlanden, die infolge der streng katholischen Religionspolitik der habsburgischen und spanischen Herrschaft das Land verließen und vor allem nach Deutschland und England flohen ${ }^{10}$. Aber auch katholische Niederländer wurden in den unruhigen Zeiten des niederländischen Aufstands zu Glaubensflüchtlingen.

Hier sind vor allem zwei Gruppen zu unterscheiden: In den nordniederländischen Provinzen Holland und Seeland wurde der Katholizismus 1573 verboten. Hier wie an anderen Orten der aufständischen Provinzen war die Einführung des Calvinismus regelmäßig mit einer Ausweisung der katholischen Geistlichen, weniger wohl der katholischen Laien, verbunden ${ }^{11}$. Die bevorzugten Ziele der Ausgewiesenen waren die südlichen Niederlande und die benachbarten deutschen Gebiete. In den südlichen Niederlanden wiederum übernahmen 1577 in Gent, Antwerpen, Brügge, Ypern und Brüssel radikale Calvinisten die Herrschaft ${ }^{12}$. Daraufhin verließen zahlreiche Katholiken diese südniederländischen Städte und gingen unter anderem nach Köln, wo sie aufgrund ihrer Konfession bereitwillig Aufnahme fanden ${ }^{13}$. Nachdem Antwerpen 1585 als letzte dieser Calvinisten-Hochburgen durch die Truppen des Generalstatthalters der spanischen Niederlande, Alessandro Farnese, wiedererobert worden war, kehrten die Niederländer in ihre Heimatstädte zurück. Für diese Exulantengruppe stellte das Exil also nur eine vorübergehende Episode von nicht einmal zehn Jahren Dauer dar.

9 Josef GunTERn, Die Protestantisierung der Landschaft Saanen 1555/56, Freiburg i.Ü. 1961, S. 81f.

10 Die Forschung zu den niederländischen calvinistischen Flüchtlingen ist inzwischen sehr reichhaltig und differenziert. Genannt seien deshalb hier nur wenige Überblicksdarstellungen, die zudem weiterführende Literaturhinweise enthalten: Dagmar FrEIST, Südniederländische calvinistische Flüchtlinge in Europa seit der Frühen Neuzeit, in: BADE, Enzyklopädie Migration, S. 1019-1029; Raingard EsSER, Niederländische Exulanten im England des 16. und frühen 17. Jahrhunderts, Berlin 1996; Heinz Schilling, Niederländische Exulanten im 16. Jahrhundert. Ihre Stellung im Sozialgefüge und im religiösen Leben deutscher und englischer Städte, Gütersloh 1972.

11 Jonathan Israel, The Dutch Republic. Its Rise, Greatness, and Fall 1477-1806, Oxford 1995, S. 193 und 206f. Zuletzt: Charles H. PArker, Cooperative confessionalisation: lay-clerical collaboration in Dutch Catholic communities during the Golden Age, in: Benjamin KaPlan u.a. (Hg.), Catholic communities in Protestant States. Britain and the Netherlands c. 1570-1720, Manchester/New York 2009, S. 18-32, hier: S. 20f.; Judith PollmanN, Burying the dead; reliving the past: ritual, resentment and sacred space in the Dutch Republic, in: Ebd., S. 84-102, hier: S. 89-91.

12 In der »klassischen« Abfolge von Angriffen auf Kirchen und Klöster, Bildersturm und Ausweisung der katholischen Geistlichen liefen die Ereignisse im Jahre 1578 in Kortrijk, Arras, Ypern und Brügge ab. Israel, Dutch Republic, S. 194.

13 Fernand Donnet, Les Exilés anversois à Cologne (1582-1585), in: Bulletin de l'Academie Royale d'Archéologie de Belgique 1898, S. 288-355. 
Wahrscheinlich die bekannteste katholische Konfessionsmigrantin der Frühen Neuzeit dürfte Königin Christina von Schweden sein. Sie verließ nach Abdankung und Konversion zur katholischen Kirche 1654 Schweden und siedelte nach Rom über ${ }^{14}$. Aber - und das mag vielleicht erstaunen - sie war nicht die einzige Schwedin, die sich wegen ihres katholischen Glaubens außer Landes begab. Schweden hatte sich relativ früh der Reformation zugewandt, aber die noch im Land verbliebenen Katholiken wurden bis in die 1580er Jahre in Ruhe gelassen. Das änderte sich grundlegend, als in der Auseinandersetzung um den schwedischen Thron der lutherische Herzog Karl von Södermannland über seinen katholischen Neffen Sigismund siegte, der seit 1587 als König in Polen regierte. 1595 wurden alle Katholiken des Landes verwiesen. Diejenigen, die dann tatsächlich das Land verließen, gingen nach Polen, in der Hoffnung, mit Sigismund als König nach Schweden zurückkehren zu können. Das galt für die Adligen ebenso wie beispielsweise für die Nonnen des Mutterklosters des Birgittenordens, die im Danziger Birgittenkloster Marienbrunn Zuflucht fanden ${ }^{15}$. Dass sich diese Hoffnung nicht erfüllte, ist bekannt; nichts wissen wir jedoch über das Leben der schwedischen Katholiken in Polen.

Die mit Abstand größte Zahl katholischer Konfessionsmigranten kam von den Britischen Inseln. Gemeinsam ist ihnen die Migration als Reaktion auf die staatliche Religionspolitik, ansonsten aber handelte es sich bei der englischen, irischen und schottischen Migration um klar voneinander abzugrenzende Wanderungsbewegungen, die sich auch in ihrer spezifischen Ausprägung, ihren zeitlichen Schwerpunkten und in ihren Zielen deutlich unterschieden.

In England wurde nach dem kurzen katholischen Intermezzo unter Maria (1553-1558) mit dem Regierungsantritt Elisabeths I. die Anglikanische Staatskirche wiederhergestellt. Diejenigen, die ein kirchliches oder weltliches Amt übernehmen wollten, mussten nun einen Eid auf die Königin als Supreme Governor der Kirche ablegen (Act of Supremacy, 1559) ${ }^{16}$. Die katholische Kirche wurde nicht direkt verboten, die einfachen Gläubigen nicht verfolgt, aber der verlangte Eid hatte zur Folge, dass die Eidverweigerer von der Teilhabe am öffentlichen und politischen Leben ausgeschlossen waren; hin-

$14 \mathrm{Zu}$ Christina von Schweden siehe den Ausstellungskatalog Christina. Königin von Schweden, Bramsche 1997; darin vor allem den Beitrag von Gabriele HART, Die Konfession der Königin Christina von Schweden, S. 151-165, dort auch die ältere Literatur.

15 Werner Buchнolz, Schweden mit Finnland, in: Matthias Asche/Anton Schindling (Hg.), Dänemark, Norwegen und Schweden im Zeitalter der Reformation und Konfessionalisierung. Nordische Königreiche und Konfession 1500-1660, Münster 2003, S. 107-243.

$16 \mathrm{Zu}$ den Bemühungen, den Klerus zur Unterschrift unter den Suprematseid zu bewegen, siehe Christopher Haigh, English Reformations. Religion, Politics, and Society under the Tudors, Oxford 1993, S. 243f. 
zu kam die Pflicht, den sonntäglichen Gottesdienst in der Anglikanischen Kirche zu besuchen. Diese Regelungen ermöglichten immerhin katholische Glaubenspraxis im privaten Rahmen ${ }^{17}$. Auch wenn die Gesetzgebung im Laufe der Regierungszeit Elisabeths erheblich verschärft wurde ${ }^{18}$, kam es nicht zu einer systematischen Katholikenverfolgung. Deshalb setzte auch kein Massenexodus von der Insel ein. Zwar verließ eine sicherlich kleine Minderheit der englischen Katholiken die Insel, doch ist über die englische Laienmigration bisher kaum etwas bekannt ${ }^{19}$. Die katholischen Geistlichen sowie diejenigen, die einen Dienst in der katholischen Kirche anstrebten oder in ein Kloster eintreten wollten, hatten hingegen keine andere Möglichkeit, als das Land zu verlassen ${ }^{20}$. Ziel dieser Emigranten waren vor allem die spanischen Niederlande, die von nun an für Jahrhunderte das Zentrum der katholischen englischen Emigration bilden sollten. In Douai wurde 1568 ein Priesterseminar gegründet ${ }^{21}$, ein Benediktiner- und ein Franziskanerkloster folgten. Ein zweites Ziel der englischen katholischen Emigration bildete Spanien $^{22}$, wo ebenfalls Priesterseminare gegründet wurden ${ }^{23}$.

Auch in Irland wurden katholische Laien lange Zeit nicht verfolgt, hinzu kam, dass eine deutliche Ausdifferenzierung der Konfessionen hier erst rela-

17 Arnold Oskar Meyer, England und die katholische Kirche unter Elisabeth und den Stuarts, Bd. 1: England und die katholische Kirche unter Elisabeth, Rom 1911, S. $103 \mathrm{f}$.

18 Ebd., S. 124f.; HaIGH, English Reformations, S. 202f. Eine wesentlich kritischere Darstellung der Religionspolitik Elisabeths aus katholischer Sicht bei Peter GuILDAY, The English Catholic Refugees on the Continent 1558-1795, Bd. 1: The English Colleges and Convents in the Catholic Low Countries, 1558-1795, London 1914, S. 3f., 11f., 24-26; zur Religionspolitik unter Jakob I. ebd., S. 27f.

19 Eine systematische Forschung zur englischen Laienmigration fehlt. Man ist daher angewiesen auf verstreute Nachrichten aus dem Umkreis der Priesterseminare oder im Zusammenhang vor allem der spanisch-englischen Auseinandersetzungen, in denen die englischen Katholiken häufig genug zwischen alle Fronten gerieten. Hin und wieder stößt man auf Einzelschicksale: Dr. John Story war aus England geflohen und in den Niederlanden als Revisor des Büchermarkts in spanische Dienste getreten. Im Jahre 1570 geriet er in eine Falle der Engländer, wurde verhaftet und hingerichtet; Meyer, England und die katholische Kirche, S. 210. Zu dem Schriftsteller und Verleger Richard Verstegan siehe S. $273 \mathrm{f}$.

20 Edward Norman, Roman Catholicism in England from the Elizabethan Settlement to the Second Vatican Council, Oxford 1985; GulLDAY, English Catholic Refugees, S. 3-28.

21 Thomas Francis Knox (Hg.), The First and Second Diaries of the English College, Douay, London 1878. Treibende Kraft der Seminargründung war William Allen. Zu ihm siehe Eamon Duffy, William, Cardinal Allen, 1532-1594, in: ReH 22 (1995), S. 265-290; Thomas Francis Knox (Hg.), The Letters and Memorials of William Cardinal Allen, London 1882; Alphons Bellesheim, Wilhelm Cardinal Allen (1532-1594) und die englischen Seminare auf dem Festland, Mainz 1885.

22 Albert J. Loomie S.J., The Spanish Elizabethans. The English Exiles at the court of Philip II, New York 1963.

23 Auf Initiative des Jesuiten Robert Persons wurde 1589 ein Kolleg in Valladolid gegründet, das den Namen des frühchristlichen englischen Märtyrers St. Alban erhielt. Bereits 1592 wurde ein zweites Kolleg in Sevilla eröffnet, das jedoch nie auch nur annähernd die Bedeutung und die Absolventenzahlen von Valladolid erreichte; Loomie, Spanish Elizabethans, S. 187-193. 
tiv spät, in den 1580 er Jahren, einsetzte ${ }^{24}$. Auch aus Irland gingen vor allem diejenigen Katholiken außer Landes, die einen geistlichen Beruf anstrebten. Das wichtigste Zentrum der irischen Emigration war Spanien ${ }^{25} .1590$ entstand in Lissabon das erste irische Priesterseminar auf der Iberischen Halbinsel, fünf weitere folgten in Spanien bis Mitte des 17. Jahrhunderts ${ }^{26}$. Insbesondere infolge der rigoros antikatholischen Politik Cromwells um 1650 schwoll die Zahl der Studenten an, außerdem flohen in diesen Jahren rund 1000 katholische Geistliche aus Irland. Daneben ließen sich aber auch zahlreiche irische Kaufleute in Spanien nieder, Iren dienten in den spanischen Armeen in den Niederlanden und auf der Iberischen Halbinsel ${ }^{27}$. Diese Iren in Spanien waren selbstverständlich katholisch. Ob die Hauptmotivation ihrer Emigration konfessioneller Natur war, lässt sich nur schwer feststellen; in vielen Fällen dürften sich konfessionelle und ökonomische Beweggründe überlagert haben.

In Schottland konnte reformatorisches Gedankengut erst relativ spät Fuß fassen; entscheidende Bedeutung kam dabei dem Auftreten John Knox' ab 1559 zu. Nachdem 1560 in Schottland das Bekenntnis zur katholischen Kirche unter Strafe gestellt worden war, setzte auch hier die Emigration auf den Kontinent $e^{28}{ }^{28}$. Sie erfolgte in Wellen, abhängig von der Rigidität der staatlichen Religionspolitik. Aufgrund der engen Verbindungen der Stuarts zu den Guises lag das Zentrum der schottischen Emigration in Frankreich. Diese Konzentration auf Frankreich erfuhr eine weitere Verstärkung nach der

24 Ute Lotz-Heumann, Die doppelte Konfessionalisierung in Irland: Konflikt und Koexistenz im 16. und in der ersten Hälfte des 17. Jahrhunderts, Tübingen 2000.

25 Karin Schüller, Die Beziehungen zwischen Spanien und Irland im 16. und 17. Jahrhundert. Diplomatie, Handel und die soziale Integration katholischer Exulanten, Münster 1999; Louis Cullen, The Irish Diaspora of the Seventeenth and Eighteenth Centuries, in: Nicholas Canny (Hg.), Europeans on the Move. Studies on European Migration, 1500-1800, Oxford 1984, S. 113-149; Thomas O’Connor/Mary Ann Lyons (Hg.), Irish Migrants in Europe after Kinsale, 1602-1820, Dublin 2003; dies. (Hg.), Irish Communities in Early-Modern Europe, Dublin 2006; Declan M. Downey/Julio Crespo MacLennan (Hg.), Spanish-Irish relations through the ages. New historical perspectives, Dublin 2006; Igor PÉrez Tostado, Irish Influence at the Court of Spain in the Seventeenth Century, Dublin 2008.

26 Patricia O'Connell, The early modern Irish college network in Iberia, 1590-1800, in: Thomas O’Connor (Hg.), The Irish in Europe, 1580-1815, Dublin 2001, S. 49-64; dies., The Irish College at Santiago de Compostela 1605-1769, Dublin 2007.

27 John McGurk, Wild Geese. The Irish in European armies (sixteenth to eighteenth centuries), in: Patrick O’Sullivan (Hg.), Patterns of migration, London 1992, S. 36-62; Gráinne Henry, The Irish Military Community in Spanish Flanders, 1586-1621, Dublin 1992; Thomas BARTLETT, Last flight of the Wild Geese? Bonapartes's Irish Legion, 1803-1815, in: O'ConNor / Lyons, Irish Communities, S. 160-171; Maria Begoña Villar GARCIA, Irish migration and exiles in Spain. Refugees, soldiers, traders and statesmen, in: ebd., S. 172-199.

28 Christopher Thomas Smout, Scots as Emigrants in Europe 1400-1700, in: Simonetta CAvaciocchi (Hg.), Le migrazioni in Europa secc. XIII-XVIII, Prato 1994, S. 659-669, geht trotz des umfassendes Titels - nicht auf die Konfessionsmigranten ein, sondern konzentriert sich auf Kaufleute und Söldner. 
Glorious Revolution von 1688, als die Stuarts ihren Exilhof in St.-Germainen-Laye aufschlugen ${ }^{29}$. Während bei den Iren offenbar mehr die wirtschaftlichen Kontakte die Wege der Glaubensflüchtlinge vorprägten, war es im Fall der Schotten die politisch-dynastische Verbindung nach Frankreich. Ansonsten waren die Muster aber ähnlich: Auch bei den Schotten sollte die Gründung von Kollegs für die Aufnahme der exilierten Mönche und die Ausbildung von Missionaren für den Dienst in der Heimat sorgen. So verfügten die schottischen Benediktiner über Kollegs in Douai ${ }^{30}$, Paris ${ }^{31}$, Madrid und Regensburg, wobei freilich dem Pariser Kolleg mit Abstand die größte Bedeutung zukam. Die Migration der Laien jedoch ist für die Schotten - anders als für die Iren - noch weitgehend unerforscht.

\section{Katholische Konfessionsmigration - Perspektiven der Forschung}

Der vorstehende Überblick erhebt keinen Anspruch auf Vollständigkeit, dürfte aber doch die wesentlichen Gruppen erfasst haben. Deutlich geworden sein dürfte auch, dass es katholische Konfessionsmigration in durchaus nennenswertem Umfang im Europa der Frühen Neuzeit gegeben hat. Wenn man nach Gemeinsamkeiten dieser Migrationsvorgänge fragt, ergibt sich folgende allererste Typologie:

- Aufgrund des obrigkeitlichen Drucks auf Angehörige anderer als der herrschenden Konfession musste die katholische Konfessionsmigration wie jede Konfessionsmigration territoriale Grenzen überschreiten.

- Katholische Konfessionsmigration war Zwangsmigration. Wenn die Katholiken ihren Glauben öffentlich praktizieren wollten, blieb ihnen keine andere Wahl als die Emigration ${ }^{32}$. Dieser Zwang zur Emigration galt für Geistliche in besonderem Maße.

- Katholische Konfessionsmigration war Fernmigration: von Schweden nach Polen, von England in die Spanischen Niederlande, von Irland nach Spanien, von Schottland nach Frankreich. Nur in kleinräumigen Verhältnissen wie in der Eidgenossenschaft fanden die Katholiken bereits nach einer kurzen Wanderung ein Gebiet katholischer Konfession.

29 Geoffrey Sсотт, The court as a centre of Catholicism, in: Edward Corp (Hg.), A court in Exile. The Stuarts in France, 1689-1718, Cambridge 2004, S. 235-256.

30 J.H. Boxter, The Scots College at Douai, in: ScHR 24 (1927), S. 251-257; Hubert S.J. CHADwICK, The Scots College Douai, 1580-1613, in: EHR 56 (1941), S. 571-585.

31 Brian M. Halloran, The Scots College Paris 1603-1792, Edinburgh 1997.

32 Dass ökonomische Überlegungen eventuell in dieselbe Richtung weisen konnten, steht der Charakterisierung als Zwangsmigration nicht entgegen. 
- Katholische Konfessionsmigration war Migration auf Dauer. Die einzige Ausnahme bildeten die Katholiken aus den südniederländischen Städten, die nach 10 Jahren in ihre Heimatorte zurückkehren konnten. In keinem der anderen hier behandelten Ursprungsgebiete der katholischen Glaubensflüchtlinge wurde der Katholizismus im Verlauf der Frühen Neuzeit erneut zur herrschenden Konfession oder wurde den Katholiken Religionsfreiheit gewährt.

Diese Typologie ermöglicht indessen nur eine äußerst grobe Annäherung an die katholische Konfessionsmigration. Denn erstens vermögen ihre Kriterien, die der sozialwissenschaftlich ausgerichteten Migrationsforschung entnommen $\operatorname{sind}^{33}$, nur sehr unzureichend die Spezifika konfessioneller Migration zu erfassen. Und zweitens trifft diese Typologie weitgehend auch auf die protestantische Migration zu, ist also bezüglich der Besonderheiten katholischer Konfessionsmigration wenig aussagekräftig. Und diese Besonderheiten gab es durchaus. Unabdingbar ist deshalb die Einbeziehung kirchenhistorischer Fragestellungen. Eine solche Verschränkung von sozialwissenschaftlich geprägter historischer Migrationsforschung und Kirchengeschichte findet bisher für die katholische Konfessionsmigration kaum statt. Am ehesten sind solche Ansätze für die Erforschung der irischen Migration zu beobachten. Besonders gut lässt sich die Sprachlosigkeit, ja völlige Missachtung der jeweils anderen Seite am englischen Beispiel beobachten. Der totalen oder doch jedenfalls fast vollständigen Ausblendung konfessioneller Migration durch die Historische Migrationsforschung ${ }^{34}$ steht eine von Katholiken, im Speziellen häufig von Jesuiten, getragene - zumeist ältere - (Kirchen-)Geschichtsschreibung mit mehr oder weniger deutlichen apologetischen Tendenzen gegenüber ${ }^{35}$. Die Forderung nach Methodenvielfalt und Interdisziplinarität bei der Erforschung katholischer Konfessionsmigration ist also keineswegs als Zugeständnis an omnipräsente und wohlfeile Forderungen des modernen Wissenschaftsbetriebes zu verstehen; sie wird vielmehr vom Gegenstand geradezu vorgegeben, und die bisherige Forschungsgeschichte untermauert diese Forderung auf eindrückliche Weise. Unabdingbar ist deshalb ein weiter Forschungsansatz, der nach meinem Verständnis vor allem folgende Fragenkomplexe einbeziehen sollte:

33 Siehe z.B. die Typologien in Klingebiel, Migrationen; Dirk Hoerder/Jan Lucassen/Leo LuCAssen, Terminologien und Konzepte in der Migrationsforschung, in: BADE, Enzyklopädie Migration, S. 28-53, hier: S. 37.

34 So erwähnt die für Studenten konzipierte Einführung von Ian D. Whyte, Migration and Society in Britain 1550-1830, London 2000, konfessionellen Druck als Migrationsgrund nur an wenigen Stellen, ohne jedoch näher darauf einzugehen.

35 So z.B. in dem Bemühen Peter Guildays, die englischen Katholiken von dem Vorwurf mangelnden Patriotismus' zu befreien; GuILday, English Catholic Refugees, S. XXII. 


\section{Aufbruch ins Exil und Zusammensetzung der Migrantengruppen}

Hier ist zunächst der Ausgangspunkt der Migration in den Blick zu nehmen. $\mathrm{Zu}$ fragen ist also nach den Bedingungen für das religiöse Leben der Katholiken im Ursprungsland, nach den Maßnahmen, die die Katholiken veranlassten, ihre Heimat zu verlassen. Diese Rahmenbedingungen wirkten sich nämlich bestimmend auf die Struktur der Wanderungsbewegung aus: Handelte es sich eher um Migrationsschübe infolge plötzlicher staatlicher Repression, die dazu führte, dass ganze Glaubensgemeinschaften oder jedenfalls große Gruppen sich auf den Weg machten? Wanderten vielleicht wie bei den Waldensern ganze Gemeinden zusammen mit ihrem Pfarrer aus, die sich dann auch in dieser Zusammensetzung an einem anderen Ort wieder niederließen? Dies scheint eher nicht der Fall gewesen zu sein. Eher handelte es sich bei den Katholiken um einen kontinuierlichen Strom von Auswanderern, der je nach staatlicher Politik anschwellen konnte oder gelegentlich auch nahezu verebbte. Spektakuläre Ereignisse wie der Widerruf des Edikts von Nantes oder die Ausweisung der Protestanten aus Salzburg fehlen, was mit zu dem geringeren Bekanntheitsgrad katholischer Migration beigetragen haben dürfte.

Völlig unklar ist bis jetzt auch die quantitative Dimension der katholischen Migration. Selbstverständlich sind solche Angaben im vorstatistischen Zeitalter stets mit vielen Unwägbarkeiten behaftet. Dennoch wäre es wünschenswert, aufgrund des ja durchaus vorhandenen Datenmaterials wenigstens eine Vorstellung von der Größenordnung katholischer Migration zu erhalten und damit auch ihren Anteil an den frühneuzeitlichen Konfessionsmigranten insgesamt bestimmen zu können, die Heinz Schilling mit einer Million Menschen veranschlagt ${ }^{36}$.

Über die zahlenmäßige Dimension hinaus ist nach der inneren Differenzierung der Migrantengruppen zu fragen, zum Beispiel nach der sozialen Zusammensetzung oder nach dem Anteil von Frauen und Kindern. Wenn die Forschung über solche Angaben verfügte, wäre damit nicht allein ein statistisches Interesse befriedigt. Die Binnendifferenzierung einer Gruppe blieb nicht ohne Auswirkungen auf das Leben der Gruppe und ihre Integration in die Umwelt. So hatte eine Gruppe, in der alle sozialen Schichten vertreten waren, ganz andere Chancen ein eigenes Gemeinschaftsleben aufzubauen als eine Gruppe, die sich vor allem aus den unteren Schichten der Gesellschaft rekrutierte. Und eine Gruppe, die fast nur aus Männern bestand, war unbedingt auf das Konnubium mit Frauen außerhalb der eigenen Grup-

36 Heinz Schilling, Peregrini und Schiffchen Gottes. Flüchtlingserfahrung und Exulantentheologie des frühneuzeitlichen Calvinismus, in: Calvinismus. Die Reformierten in Deutschland und Europa. Ausstellungskatalog, Dresden 2009, S. 160-168, hier: S. 162. 
pe angewiesen, was sich wiederum auf die Integration der Gruppe in die Aufnahmegesellschaft auswirkte. Aber auch an andere Differenzierungen ist zu denken: So führte bei den Iren die gemeinsame Erfahrung des Exils um des Glaubens Willen keineswegs dazu, dass man die Unterscheidung in Iren gälischer Herkunft und Anglo-Normannen auf der Insel zurückgelassen hätte. Vielmehr lassen sich in der Bretagne deutliche Siedlungsschwerpunkte der beiden Bevölkerungsgruppen beobachten: Während die gälischen Iren sich häufig in kleineren Städten niederließen, siedelten die Anglo-Normannen, die überwiegend als Kaufleute tätig waren, bevorzugt in den groBen Hafenstädten ${ }^{37}$.

\section{Leben im Exil}

Hier sind die klassischen Fragen der Migrationsforschung nach der Integration der Flüchtlinge zu untersuchen. Dabei muss es zunächst um eine wertneutrale Beschreibung gehen und nicht um eine vorschnelle Qualifizierung der verschiedenen Migrationsvorgänge, die Assimilierung mit »Erfolg « gleichsetzt, wie dies ausgehend von moderner Arbeitsmigration häufig geschieht. Hier dürfte es von Bedeutung sein, ob die Flüchtlinge ihre Existenz als temporären Zufluchtsort oder als dauerhaftes Exil verstanden haben. In den meisten Fällen gingen die Flüchtlinge wohl zunächst von einer baldigen Rückkehr aus, da ihre Flucht im Zusammenhang mit kriegerischen Auseinandersetzungen oder dynastischen Umwälzungen erfolgt war, bei denen das Pendel leicht bald wieder in die andere Richtung ausschlagen konnte. Für die Katholiken aus den südniederländischen Städten erfüllte sich diese Hoffnung nach knapp zehn Jahren. Auch der englische Jesuit Joseph Creswell rechnete noch 1595 mit einer Rückkehr in einem Zeitraum von ungefähr zehn Jahren ${ }^{38}$ - eine Annahme, die sich angesichts der zahlreichen überraschenden Wendungen der englischen Politik der vergangenen Jahrzehnte als durchaus wahrscheinlich ausnahm, die sich aber bekanntlich als Fehlkalkulation erweisen sollte. Dasselbe gilt für die schwedischen Katholiken, die hofften, mit einem siegreichen König Sigismund nach Schweden zurückkehren zu können. Sobald sich die Hoffnung auf baldige Rückkehr als illusorisch erwiesen hatte, mussten sich die Flüchtlinge auf einen längerfristigen Aufenthalt in der Fremde einrichten. Damit stellten sich die typischen Fragen nach der Organisation des Lebens in der Fremde, wie sie sich allen Migranten stets stellen: Sollten sie eigene Gemeinschaften bilden und weitgehend unter sich bleiben oder sich so weit

37 Éamon Ó'Ciosáin, A hundred years of Irish migration to France, 1590-1688, in: O'ConnoR, Irish in Europe, S. 93-106, hier: S. 95.

38 Siehe S. 272. 
integrieren, dass sie bereits nach wenigen Jahren in der Gesellschaft des Ziellandes aufgingen?

In diesem Zusammenhang interessiert vor allem die Organisation des kirchlichen Lebens der Migranten. Da die Katholiken stets in katholische Länder flohen, fanden sie an ihren Zufluchtsorten überall katholische Gemeinden vor, in die sie sich integrieren konnten. Sie waren also nicht auf die Gründung eigener Gemeinden angewiesen, um ihren Glauben praktizieren zu können, wie vielfach die protestantischen Flüchtlinge, die zumeist in eine anderskonfessionelle Umgebung kamen. $\mathrm{Zu}$ fragen ist also, ob die katholischen Glaubensflüchtlinge eigene Kirchengemeinden gründeten und ob sie religiöse Eigenheiten bewahrten, die sich auch nach Generationen noch von der kirchlichen Praxis der Umgebung unterschieden.

Auch wenn dazu noch keinerlei Forschungen vorliegen, so ist doch zunächst - jedenfalls bis zum Beweis des Gegenteils - davon auszugehen, dass die geistlichen Exilinstitutionen, also vor allem Priesterseminare, Klöster und Schulen, eine wichtige Rolle für die Exilgemeinden spielten. Die Klöster und Kollegs dürften häufig Kristallisationspunkte für die Gemeinden gebildet haben; umgekehrt dürften die geistlichen Institutionen häufig gerade dort errichtet worden sein, wo sich die Flüchtlinge aufgrund schon bestehender Verbindungen bevorzugt niederließen. Dafür sprechen zum Beispiel die irischen Niederlassungen im Norden Spaniens und an der französischen Küste.

\section{Die zentrale Rolle des Klerus}

Das Amts- und Kirchenverständnis der katholischen Kirche, das sich grundsätzlich von demjenigen der protestantischen Kirchen unterschied, hatte vielfältige Auswirkungen auf die Migration von Katholiken und ihr Leben in der Diaspora. Hier dürfte ein fundamentaler Unterschied zu den Wanderungsbewegungen evangelischer Gruppen liegen, die unter ganz anderen Bedingungen in der Fremde lebten. Denn während jede calvinistische Gemeinde für sich allein eine vollgültige Kirche darstellte, die einen Prediger und weitere Älteste wählte ${ }^{39}$, und die mennonitischen Gemeinden lange Zeit nicht einmal bestallte Geistliche hatten, sondern jeweils Älteste das Predigtamt ausübten, konnte eine katholische Gemeinde nicht ohne einen geweihten Geistlichen und ohne Einbindung in die kirchliche Hierarchie existieren. Denn nur ein Priester durfte Sakramente spenden, nur ein Bischof durfte Priesterweihe und Firmung vornehmen, die Heiligen Öle konsekrieren und liturgische Ge-

39 Zum Zusammenhang zwischen der die Calvinisten prägenden Flüchtlingsexistenz und ihrer Kirchenlehre und Theologie siehe jetzt Schilling, Peregrini, S. 166f. 
räte weihen. Eine katholische Gemeinde in völliger Isolation wäre damit jedenfalls auf längere Dauer nicht denkbar gewesen, da sie nicht hätte gewährleisten können, katholische Kirche in einem vollgültigen Sinne zu sein. Diese ekklesiologischen Voraussetzungen hatten damit massive Auswirkungen auf das Leben in der Diaspora, aber auch zum Beispiel im Untergrund ${ }^{40}$.

Für die katholischen Glaubensflüchtlinge stellte die Versorgung mit kirchlichen Dienstleistungen allerdings nirgends ein Problem dar, da sie sich selbstverständlich in katholischen Territorien niederließen. Anders als die protestantischen Flüchtlinge, die häufig in einer anderskonfessionellen Umgebung leben mussten, fanden die Katholiken an ihren Zufluchtsorten also stets eine ausgebaute kirchliche Infrastruktur ihrer Konfession vor. Damit stellte sich für sie aber die Frage nach Assimilation und Integration in verschärfter Weise: Wenn sie sich in die bestehenden Strukturen und Gemeinden eingliederten und also keine eigenen Gemeinden bildeten, konnten sie zwar ihren katholischen Glauben ungehindert praktizieren, existierten aber wahrscheinlich nicht lange als klar zu unterscheidende landsmannschaftliche, nationale oder sprachliche Gemeinschaft. Zugespitzt formuliert hätten sie also die religiöse Freiheit mit der Preisgabe der »nationalen« Identität »bezahlt«.

Ein ähnlicher Zusammenhang zwischen der Einbindung in die umfassenden kirchlichen Strukturen und der Ausbildung spezieller Exilinstitutionen lässt sich für die Orden beobachten. Die Angehörigen der Orden konnten bei ihrer Flucht das die ganze europäische Christenheit umspannende Netzwerk ihrer Orden nutzen. Dennoch gingen zum Beispiel die Mönche von den Britischen Inseln nicht einfach in der internationalen Gemeinschaft ihrer Orden auf, sondern gründeten irische, englische und schottische Ableger auf dem Kontinent, so dass zum Beispiel in Douai ein englisches Benediktiner- und ein englisches Franziskanerkloster bestanden. In diesen Zusammenhanggehören beispielsweise auch die so genannten Schottenklöster in Regensburg $^{41}$, Erfurt und Würzburg, die schottischen Mönchen Zuflucht boten; ja im Falle von Würzburg 1595 von den Schotten überhaupt erst wieder besetzt wurden.

40 So stellte beispielsweise das Fehlen eines Bischofs in England seit der Regierungszeit Elisabeths I. ein lange kaum zu überwindendes Problem dar, das die englischen Katholiken und die römische Kurie jahrzehntelang beschäftigte. Erst im Jahre 1623 ernannte die Kurie William Bishop zum Bischof von Chalcedon mit Jurisdiktionsbefugnis für England und Schottland. Allerdings starb Bishop bereits im darauffolgenden Jahr, und sein Nachfolger ging 1631 ins Exil. Erst 1685 wurde erneut ein Apostolischer Vikar für England ernannt; GuILDAY, English Catholic Refugees, S. 245 und 250. Bereits 1598 war ein Erzpriester für England bestellt worden, der den in England tätigen Priestern vorstehen sollte, ohne jedoch besondere Jurisdiktionsgewalt oder die bischöfliche Weihe zu besitzen.

41 Zum Regensburger Schottenkloster siehe Scoti Peregrini in St. Jakob. 800 Jahre irisch-schottische Kultur in Regensburg, Ausstellung [...] im Priesterseminar St. Wolfgang, Regensburg, 16. November 2005 bis 2. Februar 2006, Regensburg 2005, v.a. den Beitrag von Ludwig HAMmERMEYER, Die schottischen Benediktiner zu St. Jakob in Regensburg (1515-1862), in: Ebd., S. 25-35. 
Außerdem errichteten die Orden spezielle Kollegs für die Ausbildung des Nachwuchses aus den Fluchtländern. Damit wurde die Fortexistenz »nationaler « Ordenszweige über Generationen hinweg gesichert. Besonders beeindruckend ist das Netz irischer Kollegs, das fast das gesamte katholische Europa umspannte: von Spanien über Frankreich, die spanischen Niederlande und Polen bis nach Italien ${ }^{42}$. So entstanden irische Franziskanerkollegs in Löwen, Prag, Wielun (Polen) und Capranica (Italien), die irischen Dominikaner unterhielten ebenfalls ein Kolleg in Löwen, außerdem eines in Lissabon; die irischen Kapuziner bildeten ihren Nachwuchs in Charleville aus und die Karmeliter in La Rochelle und in Aachen. Eine typische Erscheinung sind auch die Kollegs in Rom: So waren die irischen Franziskaner, Dominikaner und Augustiner mit einer solchen Einrichtung am Tiber vertreten.

Überhaupt ist die Rolle der geistlichen Exilinstitutionen genau zu analysieren. Denn ihre Funktion war eine doppelte: Sie waren Institutionen des Exils, denen für das Leben auch der katholischen Laien erhebliche Bedeutung zukam. Vor allem die Priesterseminare waren aber auch und wohl in erster Linie Instrumente der Mission, d.h. sie dienten primär dem Erhalt des Katholizismus im Heimatland.

\section{Die Rolle der Kurie und der kirchlichen Hierarchie}

Noch völlig ungeklärt ist die Rolle der Kurie im Zusammenhang mit der katholischen Konfessionsmigration. Das dürfte auch daran liegen, dass es sich hier um eine Einflussgröße handelt, die in vergleichbarer Form bei keinem anderen Migrationsvorgang vorkommt und die deshalb - anders als staatliche Politik - auch keinerlei Berücksichtigung findet unter den Faktoren, die gemeinhin für die Steuerung von Migrationsvorgängen verantwortlich gemacht werden ${ }^{43}$. Mit der Dichotomie von Push- und Pull-Faktoren, die vor allem bei ökonomisch motivierten Migrationen in Ansatz gebracht werden, dürfte man der Rolle der Kurie kaum gerecht werden. Ebenso einleuchtend dürfte aber sein, dass die katholische Konfessionsmigration in ihrer spezifischen Ausprägung kaum adäquat zu erfassen sein dürfte, wenn man die Kurie und die katholische Hierarchie ausblendet.

Dies wird besonders deutlich, wenn man zum Vergleich die Bedingungen calvinistischer Konfessionsmigration heranzieht. Die calvinistische Migration war gekennzeichnet durch ein europaweites Netz von Flüchtlings-, Untergrund-, Minderheits- und Sonderkirchen. Innerhalb dieses Netzwerkes

42 O'Connell, Irish college network.

43 Siehe z.B. Typologie Migrationsregime in: Hoerder/LuCassen/Lucassen, Terminologien und Konzepte, Abschnitt über Migrationsregime, S. 39-42. 
wurden Spenden für Flüchtlinge gesammelt, das Geld direkt an diese oder an finanziell überforderte Aufnahme- oder Transitgemeinden ausgezahlt, es wurden Transportmöglichkeiten organisiert, Ansiedlungsbedingungen in aufnahmewilligen Ländern und Städten ausgelotet und Aufnahmeprivilegien ausgehandel $t^{44}$. Es war also ein durchaus beeindruckendes Netzwerk, das hier seit der Mitte des 16. Jahrhunderts entstanden war und das den internationalen Calvinismus auch jenseits der Migration prägte. Die Calvinisten hatten sich diese Organisationsform freilich nicht bewusst ausgesucht, sie war aus der Not geboren, aber sie konnte wohl auch deshalb so erfolgreich sein, weil sie ideal zum calvinistischen Kirchenverständnis passte ${ }^{45}$.

Die kirchenorganisatorischen Rahmenbedingungen, innerhalb derer sich katholische Glaubensflüchtlinge bewegten, sahen dagegen gänzlich anders aus. Diese Exulanten waren nicht darauf angewiesen, sich erst ein Netzwerk zu schaffen, denn ein solches existierte bereits, zwar nicht in der Form eines flachen Netzwerks wie bei den Calvinisten, sondern in der Form der Hierarchie der römisch-katholischen Kirche, die wie keine andere frühneuzeitliche Organisation das ganze katholische Europa umspannte. Im Verhältnis von kirchlicher Organisation und Migration dürfte demnach ein fundamentaler Unterschied zwischen der calvinistischen und der katholischen Konfessionsmigration liegen. Diesen gilt es zu untersuchen, um so den Spezifika katholischer Konfessionsmigration näherzukommen. Dabei stellen sich vielfältige Fragen. Wie stellte sich die Kurie auf die Tatsache ein, dass es nun auch katholische Glaubensflüchtlinge gab? Wo waren die Belange der Flüchtlinge organisatorisch angesiedelt, gab es dafür überhaupt eine spezialisierte Stelle in der Behördenstruktur? Erfuhren die Flüchtlinge besondere Beachtung und eine spezielle Unterstützung, sei es monetärer, sei es politischer Art? Zumindest für eine direkte finanzielle Unterstützung von Glaubensflüchtlingen durch die Kurie finden sich vereinzelt Hinweise. So stellte Papst Innocenz XII. 169937.500 livres für arme katholische Flüchtlinge in Frankreich zur Verfügung, wobei der Löwenanteil an die Iren ging ${ }^{46}$. Bei der Untersuchung dieser Fragen ist besonders darauf zu achten, dass das Ergebnis nicht dadurch präjudiziert wird, dass nur alle Indizien für eine besondere Unterstützung der Glaubensflüchtlinge erfasst werden. Ernst genommen werden müssen auch die Hinweise, die darauf hindeuten, dass die Exulanten keine spezifische Beachtung erfuhren, sondern - wenigstens aus kurialer Sicht - in den bestehenden kirchlichen Gemeinschaften aufgingen.

44 Siehe z.B. für die Hugenotten Barbara Dölemeyer, Die Hugenotten, Stuttgart 2006, S. 34-36.

45 Schilling, Peregrini, S. 163.

46 Edward Corp, The Irish at the jacobite court of Saint-Germain-en-Laye, in: O'ConNor, Irish in Europe, S. 152. 
Zugespitzt könnten die Fragen nach dem spezifischen Zusammenhang von Kirchenorganisation und Konfessionsmigration in Bezug auf die Katholiken also folgendermaßen formuliert werden: Stellte die Organisation der römisch-katholischen Kirche eine Infrastruktur dar, die in ihrer Funktion für die Exulanten dem calvinistischen Netzwerk entsprach? Falls diese Frage bejaht werden kann, wäre genau nach möglichen Unterschieden in den Reaktionen auf die Herausforderung Konfessionsmigration zu suchen. Denkbar ist aber auch, dass die allumfassende Struktur der katholischen Kirche eine spezialisierte Behandlung des Problems »Konfessionsmigration« geradezu verhinderte, weil die Flüchtlinge von der bestehenden Organisation aufgesogen wurden und damit praktisch unsichtbar wurden.

Erst wenn Fragen dieser Art wenigstens für einige der angeführten katholischen Konfessionsmigrationen geklärt sind, kann auch die weitergehende Frage angegangen werden, ob und inwieweit sich die katholische von calvinistischer und lutherischer Konfessionsmigration in ihren grundsätzlichen Ausprägungen unterschied oder ob die typologischen Gemeinsamkeiten überwogen.

\section{Die englischen Katholiken in den Niederlanden - eine erste Annäherung}

Das vorgestellte Forschungsprogramm soll im Folgenden anhand der englischen Katholiken in den spanischen Niederlanden konkretisiert werden ${ }^{47}$. Damit soll gezeigt werden, dass die aufgeführten Fragestellungen ergiebig sind und wichtige neue Aufschlüsse über die Struktur des Exils der englischen Katholiken in Flandern wie der katholischen Konfessionsmigration im Allgemeinen versprechen ${ }^{48}$.

47 Diese Gruppe bietet sich für eine solche Annäherung an, da sie vergleichsweise überschaubar und außerdem durch Quelleneditionen und Literatur immerhin so weit erschlossen ist, dass die gestellten Fragen wenigstens in Ansätzen zu beantworten sind und dass aufgezeigt werden kann, in welche Richtung deren weitere Erforschung gehen müsste und könnte. Die Darstellung folgt weitgehend der Literatur; Quelleneditionen wurden nur in Einzelfällen herangezogen, archivalische Quellen überhaupt nicht.

48 Bewusst wird dabei auf die Verwendung des Diaspora-Begriffs bzw. der unterschiedlichen Diaspora-Konzepte verzichtet. Siehe dazu zuletzt Nina Clara TiEsLer, Diaspora ohne Religion? Zur Konjunktur des Diaspora-Konzepts in den Sozialwissenschaften, in: ZRGG 61 (2009), S. 157-170. Der traditionelle christentumsgeschichtliche Diaspora-Begriff, der eine Minderheiten-Kirche in einem anderskonfessionellen Umfeld bezeichnet, kommt nicht in Frage, da die englischen Katholiken sich in anderen katholischen Gesellschaften niederließen, also keine konfessionelle Diaspora bildeten. Von den äußeren Rahmenbedingungen ausgehend wird die Situation der englischen Katholiken eher vom jüdischen Diasporabegriff abgedeckt, der das Leben in der Fremde und den zwangsweisen Verlust der Heimat einschließt; ebd., S. 159. Allerdings ist auch für den jüdischen Diasporabegriff das Leben im andersreligiösen Umfeld 


\section{Aufbruch ins Exil und Zusammensetzung der Migrantengruppe}

Die Politik Königin Elisabeths I. gegenüber den sich nicht der Anglikanischen Kirche unterwerfenden Gruppen begann eher vorsichtig und keineswegs mit einem Paukenschlag (wie bei der Ausweisung der Salzburger Protestanten), der einen sofortigen und massenweisen Aufbruch nach sich gezogen hätte. Hinzu kam, dass die Engländer in den Jahrzehnten zuvor so viele religionspolitische Kehrtwendungen erlebt hatten, dass es durchaus wahrscheinlich war, dass die Maßnahmen der Jahre nach 1558 alsbald wieder revidiert würden. Erst einmal abzuwarten schien aufgrund der jüngsten Erfahrungen also eine durchaus vernünftige Entscheidung. Dass das später so genannte Elizabethan settlement mit dem Ausbau der Anglikanischen Kirche zur Staatskirche tatsächlich von Dauer sein würde, war um 1560 keineswegs ausgemacht. Außerdem wurden weder der Act of Supremacy ${ }^{49}$ noch der Act of Uniformity überall oder überall gleich konsequent durchgesetzt. Zwar mussten diejenigen, die ein öffentliches Amt anstrebten, den Eid auf die Königin als Supreme Governor der Kirche ablegen, und dies galt umso mehr, je höher das angestrebte Amt angesiedelt war, aber von einer flächendeckenden Anwendung konnte keine Rede $\operatorname{sein}^{50}$. Selbstverständlich wurden beispielsweise die Bischöfe, die den Eid verweigerten, ihres Amtes enthoben, aber die einfachen Laien mussten zunächst kaum Einschränkungen bei der Ausübung ihres Glaubens hinnehmen. Hinzu kam, dass auch die katholischen Theologen lange uneins waren, wie auf die königlichen Vorschriften zu re-

konstitutiv, ganz abgesehen von den theologischen Implikationen, die mit der Hoffnung auf Rückkehr verbunden sind; zwei Punkte, die eine einfache Übertragung auf die Situation der englischen Katholiken ausschließen. Der Diaspora-Begriff wurde in den letzten beiden Jahrzehnten von den Sozialwissenschaften übernommen und adaptiert und dabei weitgehend seiner religiösen Bezüge entkleidet. Diese Ausweitungen gingen jedoch einher mit einem teilweisen Verlust der analytischen Schärfe der Konzepte. In einem weiten Verständnis von Diaspora, das die Existenz von Gruppen beschreibt, die Beziehungen unterschiedlichster Art zu Räumen, die sie nicht mehr bewohnen, unterhalten (ebd., S. 166), fehlt das für die Konfessionsmigration konstitutive Element, dass religiöser Zwang die Gruppe zum Verlassen der Heimat veranlasst hat und ihre Rückkehr unmöglich machte - dieses Element wird von dem Begriff »Exil« besser erfasst. Durchaus problematisch erscheint auch die vorgängige Anwendung des Diasporabegriffs als Bewusstseinskategorie, der die Erfahrungen von Fremdheit, hybrider Identität und eines doppelten oder multiplen Bewusstseins zum Ausdruck bringt. Denn zum einen handelte es sich dabei möglicherweise eher um eine Elitenkonzeption, vor allem aber kann die Zuschreibung eines solchen Diasporabewusstseins zu einer Gruppe erst am Ende einer Untersuchung stehen, sollte diese aber nicht von vornherein präjudizieren.

49 Geoffrey R. Elton (Hg.), The Tudor Constitution. Documents and Commentary, Cambridge 1960, Nr. 184.

50 So waren die Katholiken im ersten Jahrzehnt der Regierung Elisabeths noch im House of Commons vertreten, erst im Parlament des Jahres 1571 saßen im House of Commons keine Katholiken mehr, da nunmehr der Suprematseid streng eingefordert wurde; Adrian Morey, The Catholic Subjects of Elizabeth I, London 1978, S. 60 und 139. Dem House of Lords gehörten jedoch weiterhin auch Katholiken an; ebd., S. 139. 
agieren sei. Viele hielten es für akzeptabel, wenn die katholischen Gläubigen sonntags pro forma und das heißt: ohne innere Anteilnahme, dem anglikanischen Gottesdienst beiwohnten und damit der vom Gesetz vorgeschriebenen Pflicht genügten, daneben aber den katholischen Gottesdienst besuchten $^{51}$. Und selbst viele Geistliche hielten es nicht für verwerflich, den Eid auf die Königin zu schwören und offiziell als Geistliche der Anglikanischen Kirche zu dienen, heimlich aber katholische Messe zu feiern sowie die anderen katholischen Sakramente zu spenden. Von denjenigen, die bereits früh ins Exil gegangen waren, wurde dieses Lavieren zwischen der Treue zur katholischen Kirche und der Unterwerfung unter die Königin als rechtmäßige Obrigkeit äußerst kritisch gesehen; sie verlangten von ihren Glaubensgenossen, die Teilnahme am anglikanischen Gottesdienst zu verweigern, also: to recuse. Bereits 1564 hatten überdies der Papst und die römische Inquisition eine Anfrage englischer Laien dahingehend beantwortet, dass die Teilnahme am Gottesdienst der Anglikanischen Kirche nicht erlaubt sei ${ }^{52}$. Im Jahre 1566 verbot Papst Pius V. dann offiziell die Teilnahme ${ }^{53}$. Offensichtlich führten schon diese Klärungen zu einer Zunahme der Rekusanten ${ }^{54}$. Es war also nicht erst die Exkommunikation Elisabeths durch Papst Pius V. im Jahre $1570^{55}$, die einer wachsenden Zahl von Katholiken klar vor Augen führte, dass sie sich entscheiden mussten, und die sich dann für eine Verweigerung entschieden $^{56}$. Freilich, eine Massenbewegung waren die Rekusanten nicht ${ }^{57}$,

51 Morey, Catholic Subjects, S. 45.

52 Haigh, English Reformations, S. 259; Anne Dillon, The Construction of Martyrdom in the English Catholic Community, 1535-1603, Aldershot 2002, S. 11. Es wurden sogar eigens vier Priester mit Fakultäten ausgestattet, um diejenigen, die dem Schisma verfallen waren, d.h. die anglikanische Gottesdienste besucht hatten, wieder mit der römischen Kirche zu versöhnen; Meyer, England und die katholische Kirche, S. 412-414; Ludwig von PAstor, Geschichte der Päpste seit dem Ausgang des Mittelalters, Bd. 8: Geschichte der Päpste im Zeitalter der katholischen Reformation und Restauration: Pius V. (1566-1572), Freiburg i. Br. 1920, S. 427.

53 Morey, Catholic Subjects, S. 46.

54 Haigh nennt Zahlen für einzelne Bezirke sowie einige Einzelfälle, die eine solche Tendenz andeuten; Haigh, English Reformations, S. 259. Diese sind freilich allzu punktuell, um Rückschlüsse auf eine allgemeine Richtung für das ganze Königreich zu erlauben.

55 Bulle »Regnans in excelsis« vom 27. April 1570, gedr. bei Elton, Tudor Constitution, Nr. 197.

56 Auch von staatlicher Seite wurde die Grenze erst jetzt klar gezogen. Der Treasons Act von 1571 erklärte Zweifel an der Rechtmäßigkeit der Herrschaft Elisabeths oder ihre Bezeichnung als häretisch, schismatisch oder Usurpatorin zu Hochverrat. Ein weiterer Act verbot die Einfuhr päpstlicher Bullen oder katholischer Devotionalartikel und erklärte es zu einem Akt des Verrats, jemanden mit dem Heiligen Stuhl zu versöhnen, oder eine solche Absolution oder ein sonstiges päpstliches Schreiben zu erhalten; Elton, Tudor Constitution, Nr. 198; Morey, Catholic Subjects, S. 60.

57 Die Forschung ist sich einig, dass die Katholiken am Ende der Regierungszeit Elisabeths eine kleine Minderheit bildeten, über deren Größe dann allerdings die Schätzungen auseinander gehen. Unstrittig ist auch, dass es erhebliche regionale Unterschiede gab: Im Norden war der Anteil der Katholiken dauerhaft erheblich höher als in anderen Landesteilen. Für Yorkshire liegen genauere Schätzungen vor: Danach waren dort $2 \%$ der Bevölkerung katholisch, immerhin $20 \%$ der dortigen Gentry wurden 1580-1582 beschuldigt, zu den Rekusanten oder 
und eine größere Zahl von Auswanderungen erwuchs daraus schon gar nicht. Denn das Risiko für die Rekusanten war lange Zeit gering. Auf die Weigerung, dem anglikanischen Gottesdienst beizuwohnen, stand eine vergleichsweise geringe Geldbuße, und selbst diese wurde offenbar vielerorts nur sehr nachlässig eingetrieben ${ }^{58}$.

Es waren also immer nur Einzelne, die das Land verließen, in keinem Fall ganze Gemeinden, wohl nicht einmal ganze Familienverbände. Denn zum Beispiel bei den Adligen blieb schon aus ökonomischen Gründen häufig ein Teil der Familie in England, um den Erhalt des Familienbesitzes nicht zu gefährden. So holte Sir William Stanley, der bereits seit der Mitte der 1580er Jahre in der spanischen Armee in den Niederlanden diente, seine Familie erst 1606 nach Mecheln nach ${ }^{59}$. Es steht also zu erwarten, dass die Auswanderung katholischer Laien aus England ein kontinuierliches Rinnsaal darstellte, das in Reaktion auf die staatliche Politik auch einmal anschwellen konnte, das aber nie die Dimensionen eines größeren Flusses erreichte ${ }^{60}$. Auch nur einigermaßen zuverlässige Schätzungen über die Zahl englischer Migranten in den Niederlanden oder auf dem Kontinent insgesamt liegen nicht vor. Guilday schätzt, dass die Zahl der englischen Migranten auf dem Kontinent (also vor allem in den spanischen Niederlanden und in Spanien) zu keinem Zeitpunkt mehr als 3.000 betrug $^{61}$. Selbst aus dieser Zahl, so sie denn stimmen

den Nichtkommunikanten zu gehören, bis 1603/04 war dieser Anteil auf 33 \% gestiegen; Morey, Catholic Subjects, S. 212f. Zu den methodischen Schwierigkeiten, die Zahl der Katholiken zu bestimmen, siehe John Bossy, The English Catholic Community 1570-1850, London 1975, S. 182-194. Bossy errechnet für die Zeit um 1603 eine Zahl von 40.000 Katholiken, für 164160.000 Katholiken und für 1770 ungefähr 80.000 Katholiken, ohne diese Zahlen allerdings in Relation zur Gesamtbevölkerung zu setzen. Er korrigiert damit z.B. die Berechnungen Meyers (1585: 120.000 Katholiken, 1603: 120-130.000, 1635: 150.000, 1670: 200.000, was jeweils knapp $3 \%$ der Bevölkerung ausmachte; MeYER, England und die katholische Kirche, S. 48-53) erheblich nach unten, was zumindest teilweise auch an Bossys definitorischen Vorannahmen, was ein Katholik sei, liegt.

58 Die Geldbuße für Abwesenheit vom anglikanischen Gottesdienst betrug zunächst nur $12 \mathrm{~d}$. Härter bestraft wurde dagegen die Teilnahme an der katholischen Messe; Morey, Catholic Subjects, S. 26.

59 Zur Biographie Stanleys siehe Loomie, Spanish Elizabethans, S. 129-181. Ob 1606 dann ein anderer Verwandter den Familienbesitz übernommen hat, geht aus den Angaben Loomies nicht hervor.

$60 \mathrm{Zu}$ untersuchen wäre, ob die Verschärfung der Katholiken-Gesetzgebung in den Jahren 1571, 1581 und 1585 zu einer spürbaren Erhöhung der Zahl der Emigranten führte. Zu den Maßnahmen von 1571 siehe Anm. 56 in diesem Beitrag. 1581 wurde die Strafe bei Nichtbesuch des anglikanischen Gottesdienstes von $12 \mathrm{~d}$ auf die ruinöse Höhe von $20 £$ pro Monat erhöht. Jemanden von seiner natürlichen Obrigkeit wegzuführen oder zum Katholizismus zu bekehren, wurde als Hochverrat angesehen und entsprechend bestraft. Das Zelebrieren der Messe wurde mit einem Jahr Gefängnis und 200 Mark Geldbuße geahndet, Messe hören mit einem Jahr Gefängnis und 100 Mark Geldbuße; Elton, Tudor Constitution, Nr. 199. 1585 wurde die Gesetzgebung gegen die nach England zurückkehrenden Priester verschärft; ebd., Nr. 200.

61 Guilday, English Catholic Refugees, S. XX. Leider gibt er nicht an, wie er zu dieser Schätzung kommt. 
sollte, ist aber keine Hochrechnung auf die Zahl der Emigranten möglich. Auch über die Ziele, die die englischen Katholiken ansteuerten, lässt sich kaum mehr sagen, als dass sie vor allem in die spanischen Niederlande gingen, wobei Löwen zunächst ein bevorzugtes Ziel war, und zu einem wesentlich geringeren Teil nach Spanien.

Weitgehend im Dunkeln blieb bisher auch die soziale Zusammensetzung der englischen katholischen Migranten. Es zeichnen sich jedoch deutlich zwei Tendenzen ab: Zum einen kamen die Glaubensflüchtlinge offenbar aus allen Schichten der Bevölkerung, zum anderen war der Adel überproportional stark vertreten ${ }^{62}$. So finden sich in den Darstellungen über einzelne Exilinstitutionen zahlreiche Hinweise auf adlige Familien. Beispielsweise wurde das Benediktinerinnenkloster Brüssel von Lady Mary Percy, der Tochter des Herzogs von Northumberland, gegründet ${ }^{63}$. Und das Klarissenkloster in Gravelines galt geradezu als Refuge für die Töchter der am Gunpowder-Plot Beteiligten ${ }^{64}$. Gleichzeitig zeigt aber das Engagement führender englischer Exilkatholiken wie Sir Francis Englefields für in Not geratene Landsleute, dass sich bei weitem nicht alle Exulanten in einer komfortablen ökonomischen Situation befanden. Im Jahre 1570 organisierte Englefield die Verteilung von 4.000 escudos, die von Spanien zur Verfügung gestellt worden waren, an bedürftige englische Exulanten ${ }^{65}$. Offenbar waren etliche englische ebenso wie schottische und irische Exulanten auf spanische Pensionszahlungen angewiesen. Diese allerdings trafen nicht immer pünktlich ein, so dass die Not seiner Landsleute den Jesuiten Robert Persons zu einem Schreiben an Philipp II. veranlasste, in dem er dem König die Folgen der ausbleibenden Zahlungen drastisch vor Augen führte: Einige Exulanten seien bereits verhungert, andere seien kurz davor, wieder andere hätten sich entschieden, nach England zurückzukehren und sich der Gnade der Häretiker zu unterwerfen ${ }^{66}$. Auch wenn Persons hier möglicherweise übertrieben hat, um den gewünschten Effekt zu erzielen, so kann doch kein Zweifel daran bestehen, dass etliche der Exulanten in ziemlich bescheidenen Verhältnissen lebten.

Von diesen Exulanten verdiente ein nicht unerheblicher Teil seinen Lebensunterhalt im englischen Regiment in der spanischen Flandernarmee. Die Stärke des Regiments schwankte erheblich: Während 1595 nur 318 Mann

62 Während der Regierungszeit Elisabeths entstammte ungefähr die Hälfte der katholischen Priester der Gentry, im 17. Jahrhundert stieg dieser Anteil weiter an. Selbstverständlich kann dieses Zahlenverhältnis nicht auf die Rekusanten insgesamt übertragen werden, aber es stellt doch ein wichtiges Indiz für den überproportionalen Anteil des Adels an den Rekusanten dar; Bossy, English Catholic Community, S. 198f. und 415.

63 Guilday, English Catholic Refugees, S. 257.

64 Ebd., S. 297.

65 Loomie, Spanish Elizabethans, S. 20.

66 Ebd., S. 30. 
gezählt wurden, stieg die Zahl der Soldaten um 1605 bis auf 1500 Mann. Nach dem spanisch-niederländischen Waffenstillstand 1609 wurde das Regiment aufgelöst, ohne dass etwas über das Schicksal der Soldaten bekannt wäre. Doch selbst solange das Regiment bestand, bedeutete der Militärdienst nicht unbedingt eine finanziell gesicherte Existenz. Denn angesichts der notorischen Finanzprobleme Spaniens mussten die Söldner oft genug auf ihren Sold warten. Deshalb baten fünf englische Frauen den spanischen Statthalter in den Niederlanden, Erzherzog Albrecht, 1598 um sicheres Geleit für ihre Rückkehr von Antwerpen nach England. Zur Begründung für ihr ungewöhnliches Anliegen führten sie an, dass sie zu diesem Schritt gezwungen seien, da ihre Männer für ihren Dienst in der spanischen Armee seit zwanzig Monaten keinen Sold mehr bekommen hätten ${ }^{67}$. Mögen solche Streiflichter das Dunkel über dem Leben der Exulanten auch an manchen Stellen etwas erhellen, so können sie selbstverständlich nicht eine sozialhistorische Analyse der Exilgemeinden ersetzen ${ }^{68}$.

Während die katholische englische Laienmigration also weitgehend eine terra incognita darstellt, ist über die englischen Kleriker sowie über die Mönche und Nonnen auf dem Kontinent, die sich ebenfalls in den spanischen Niederlanden konzentrierten, weit mehr bekannt. Dies liegt zum einen an der Quellenlage, die schon deshalb viel besser ist, weil die Institutionen selbst Klöster und Kollegs - entsprechende Quellen produzierten, aber auch daran, dass die englischen Behörden sich in erster Linie für die Kleriker interessierten, da diese für den Fortbestand oder Untergang des englischen Katholizismus verantwortlich waren ${ }^{69}$. Zum anderen hat sich auch die englische katho-

67 Ebd., S. 11.

68 Sozialhistorische Untersuchungen, wie sie z.B. für die irischen Emigranten in Spanien vorliegen, die in den Archiven der niederländischen Städte z.B. in Kirchenbüchern oder Ratsprotokollen nach Spuren der englischen Katholiken gesucht hätten, gibt es bisher nicht. Lediglich für Douai konnte ich durch eigene Archivrecherchen feststellen, dass in den Archives communales de Douai keine Bestände vorhanden sind, die derartige Untersuchungen erlauben würden. Für das 18. Jahrhundert immerhin: Edward Hughes, Les Britanniques dans les registres paroisseaux à Douai au XVIIIe siècles, in: Mémoires de la Société agriculture, sciences et arts de Douai $5^{\text {e }}$ série, 2000-2005, S. 15-76.

69 Berichte englischer Informanten geben Auskunft über die Zahl, teilweise auch über die Namen der Männer und Frauen in den geistlichen Institutionen. Siehe z.B. die Listen bei GuILDAY, English Catholic Refugees, S. 14-18: »A catalogue of certayn english catholicks, religious, preests, jesuites \& others dispersed in divers places«; S. 28f.: »A list of the Semminaryes, Monasteries, Cloisters, and Colledges of his $\mathrm{Ma}^{\mathrm{ts}}$ Subiects in the Provinces of the Netherlands, under the King of Spaines obedience and the Dioces of the Bishopp of Lige«. Über die Methoden, Spione in die katholischen Kreise einzuschleusen, siehe die Hinweise bei Morey, Catholic Subjects, S. 130f. Die englische Regierung bemühte sich systematisch um Informationen über die katholischen Exulanten. Dabei war der Regierung klar, dass Insider-Informationen nur von Personen zu erhalten waren, die den Exulanten als vertrauenswürdig galten. Als conditio sine qua non galt hier ganz offensichtlich das (zumindest vorgebliche) katholische Bekenntnis. Verhältnismäßig einfach zu bewerkstelligen war es, sich als Pilger nach Santiago de Compostela auszugeben (Loomie, Spanish Elizabethans, S. 60), der Wert der von solchen »Pilgern« eruierten Informa- 
lische Kirchengeschichtsschreibung vor allem für die geistlichen Institutionen im Exil und die bei der Mission in England ums Leben gekommenen Märtyrer interessiert. Von dieser Seite liegen eine Reihe allerdings zumeist älterer und in ihrem Ansatz traditioneller Darstellungen der Geschichte einzelner Institutionen vor, die eine äußere Rekonstruktion dieser Institutionen bieten, aber kaum sozialgeschichtlich verwertbares Material aufbereiten, beispielsweise über die soziale Zusammensetzung der Kollegs und Konvente oder ihre Einbindung in ihre Umgebung ${ }^{70}$. Immerhin liefern diese Darstellungen aber ein Bild von dem Netz von Einrichtungen des englischen katholischen Exils, das innerhalb weniger Jahrzehnte in den Niederlanden entstand. Den Anfang machte das Priesterseminar in Douai 1568. Noch im selben Jahre wurde in Brügge eine englische Kartause eröffnet ${ }^{71}$. Die englischen Benediktiner gründeten 1611 in Douai das Kloster St. Gregory ${ }^{72}$, der weibliche Zweig des Ordens unterhielt englische Konvente in Brüssel, Gent, Cambrai sowie kurze Zeit in Ypern ${ }^{73}$. Die englischen Franziskaner wählten als Ort für ihr Kloster ebenfalls Douai ${ }^{74}$. Bevor sie ihre eigene Gemeinschaft begründete, hatte Mary Ward 1609 in Gravelines ein Klarissenkloster ge-

tionen dürfte allerdings begrenzt gewesen sein. Für die Exulanten wesentlich gefährlicher war es, wenn junge Männer in den Priesterseminaren ihre Kommilitonen ausspionierten und dann ohne ihr Studium abgeschlossen zu haben - nach England zurückgingen und ihr Wissen preisgaben. Unklar ist, ob diese Männer von vornherein als Spione in die Seminare eintraten oder ob sie während ihres Studiums angeworben wurden; ebd., S. 76. Selbstverständlich versuchte die Regierung auch, aus inhaftierten Priestern unter Folter Informationen herauszupressen und in einigen Fällen gelang ihr dies auch; ebd., S. 73f. Außerdem Pastor, Geschichte der Päpste, Bd. 9: Geschichte der Päpste im Zeitalter der katholischen Reformation und Restauration: Gregor XIII., Freiburg i. Br. 1923, S. $336 f$.

70 Guilday, English Catholic Refugees enthält eine Sammlung solcher Institutionengeschichten für die englischen Klöster und Konvente in den spanischen Niederlanden, die sich allerdings auf die organisatorische Entwicklung sowie die Streitigkeiten innerhalb der englischen Diaspora konzentriert und für die einzelnen Institutionen eine Kombination aus Erfolgs- und Leidensgeschichte bietet. Außerdem Frédérich FABRE, The English College at Eu 1582-1592, in: The CHR 37 (1951), S. 257-280. Eine neuere, sehr ausführliche Darstellung einer Exil-Institution liegt für das Kloster Lamspringe bei Hildesheim vor, das von 1643 bis 1803 von englischen Benediktinern genutzt wurde; Anselm CRAMER (Hg.), Lamspringe - an English abbey in Germany 1643-1803, Ampleforthe 2004.

71 Guilday, English Catholic Refugees, S. 43. Bereits 1578 wurden die Kartäuser jedoch von den Spaniern vertrieben. Nach diversen Irrwegen konnten sie 1623 eine Kartause in Nieuport (westlich von Ostende) gründen, die bis zur Aufhebung des Klosters durch Joseph II. 1783 bestand; ebd., S. 45f.

72 Weitere englische Benediktinerklöster bestanden in Dieulouard (bei Nancy), St. Malo, Paris und Lamspringe; GuILDAY, English Catholic Refugees, S. 216-224.

73 Das Genter Kloster unterhielt Ableger in Boulogne, Pontoise und Dünkirchen. Das Kloster in Ypern wurde aber bald von Irinnen dominiert und hatte ab 1682 eindeutig irischen Charakter. Außerdem gab es ein Benediktinerinnenkloster in Paris; GuILday, English Catholic Refugees, S. 256.

74 Ebd., S. 287. 
gründet. Der Konvent erfreute sich regen Zuspruchs, so dass bald Filialen in Aire, Rouen und Dünkirchen eingerichtet wurden ${ }^{75}$.

Lässt sich über die Zahl der Exilinstitutionen noch recht einfach Klarheit gewinnen, so ist es schon wesentlich schwieriger anzugeben, wie viele Männer und Frauen in diesen geistlichen Häusern auf dem Kontinent lebten. Grundsätzlich gibt es darüber zwei Überlieferungsstränge: die Kloster- bzw. Kollegchronistik und die Berichte der im Dienst der englischen Krone stehenden Spione. Dass die Angaben der Spione nicht immer zuverlässig ausfielen, liegt auf der Hand. So zählt eine Liste für 1598 immerhin 182 englische Priester, Mönche und Nonnen im Exil, ist aber schon deshalb mit Sicherheit nicht vollständig, weil sie Spanien völlig ausspart ${ }^{76}$. Die Zahl der Studenten, die für Douai mit 34, für Rom mit sieben »und viele weitere« angegeben wird, dürfte außerdem zu niedrig gegriffen $\operatorname{sein}^{77}$. Eine andere Liste aus der Regierungszeit Karls I. kommt allein für die Niederlande auf eine Zahl von 889 Priestern, Mönchen, Nonnen und Studenten ${ }^{78}$. Dagegen werden in der Überlieferung der Institutionen selbst zumeist Jahr für Jahr die Professe angegeben, diese aber nicht zu Gesamtzahlen addiert ${ }^{79}$. Versucht man aus den vorliegenden Zahlen eine Summe zu ermitteln, so kommt man für die Hochzeit des englischen katholischen Exils in der ersten Hälfte des 17. Jahrhunderts auf die Zahl von ungefähr 400 Ordensangehörigen in den englischen Exilinstitutionen in den Niederlanden. Die Zahl der von ihnen unterrichteten

75 Ebd., S. 297-300.

76 Auch für die genannten Orte ist die Liste nicht vollständig, für Antwerpen gibt der Informant zwei Priester namentlich an und fügt hinzu »\& many other priests «; »A catalogue of certayn english catholicks, religious, preests, jesuites \& others dispersed in divers places «, in: GuILDAY, English Catholic Refugees, S. 14-18, hier: S. 16.

77 Auch in dieser Liste sind übrigens die Angaben über die Laien noch wesentlich diffuser; erkennbar werden vor allem sozial höher stehende Personen genannt, nicht selten dürfte sich hinter einem Namen auch ein kompletter Haushalt verbergen, was durch den gelegentlichen Zusatz »Frau und Kinder « angedeutet wird. Die angegebenen 59 Nonnen (+ 200 Soldaten in Arras) erfassen die englischen Exulanten mit Sicherheit nur sehr unvollständig, zumal z.B. für Löwen und Antwerpen überhaupt nur eine Person genannt ist, obwohl sich hier bekanntermaBen englische Exilgemeinden befanden - von dem völligen Fehlen Spaniens auch hier ganz abgesehen.

$78 \gg$ A list of the Semminaryes, Monasteries, Cloisters, and Colledges of his Mat ${ }^{\text {ts }}$ Subiects in the Provinces of the Netherlands, under the King of Spaines obedience and the Dioces of the Bishopp of Lige «, in: Guilday, English Catholic Refugees, S. 28f. Von der in der Liste genannten Gesamtzahl von 1103 Personen sind die 204 Schotten und Iren abzuziehen. Diese Liste veranschlagt übrigens für das Seminar in Douai 120 Personen.

79 Für die englischen Nonnen im Exil soll diese Überlieferung nunmehr durch das im September 2008 an der Queen Mary University of London eingerichtete Forschungsprojekt »Who were the nuns? « erfasst und ausgewertet werden. Zum gegenwärtigen Zeitpunkt sind erst einige gedruckt bereits vorliegende Quellen online zugänglich gemacht worden; http:wwtn.history. qmul.ac.uk (letzter Zugriff: 23.7.2009). Zu den englischen Frauenklöstern auf dem Kontinent zuletzt: Claire WaLKer, Gender and Politics in Early Modern Europe. English Convents in France and the Low Countries, Basingstoke 2003. 
Schülerinnen und Schüler sowie der Studenten und Priesteramtskandidaten dürfte mindestens ebenso hoch liegen.

\section{Leben im Exil}

Die englischen Katholiken, die nach 1558 die Insel Richtung Kontinent verließen, rechneten fest damit, bald zurückkehren zu können - daran kann kein Zweifel bestehen. Sie glaubten zurückkehren zu können, so wie sie 1553/54 zurückgekehrt waren. Denn es war ja nicht die führende Macht des Kontinents, die sie zur Flucht gezwungen hatte, wie Spanien die niederländischen Calvinisten. Nein, es war eine in den Augen der Katholiken illegitime Königin, noch unverheiratet und ohne Nachkommen, die sich bestimmt nicht lange auf dem Thron würde halten können.

Doch mit den Jahren wich der Optimismus. Ein Indiz dafür, dass die Exulanten sich nun doch auf längere Zeit in ihrem Exil einzurichten begannen, ist die Gründung von geistlichen Einrichtungen im Exil, die nach ungefähr zehn Jahren einsetzte, mit der Gründung des Priesterseminars in Douai 1568 als deutlichem Zeichen. Die Signalwirkung war eine doppelte: Man begann, die Exilsituation aktiv zu gestalten und hielt zugleich an der engen Verbindung zum Heimatland fest. Man gab also die Hoffnung auf Rückkehr nicht auf, aber rechnete nun doch damit, dass es vielleicht noch ein paar Jahre dauern könnte. In diesen Zusammenhang gehören auch die in Exulantenkreisen immer wieder ventilierten Projekte einer militärischen Invasion Spaniens in England - kurz als the enterprise bezeichnet -, die eine Rückkehr der Flüchtlinge und eine Rekatholisierung des Königsreichs ermöglichen sollte ${ }^{80}$. Die spanische Regierung ließ sich jedoch von den in regelmäßigen Abständen eingereichten Plänen nicht zu irgendwelchen riskanten militärischen Operationen hinreißen, da für sie die Sicherung der Niederlande eindeutig oberste Priorität besaß. Die Niederlage der spanischen Armada 1588 war deshalb für die Exulanten ein schwerer Schlag, der ihre Hoffnungen weiter dämpfte - zumal sie bereits ein Jahr zuvor mit dem Tod Maria Stuarts auch ihre Thronprätendentin verloren hatten. Dennoch glaubten wohl immer noch viele der Exulanten an eine Rückkehr in absehbarer Zeit, zum Beispiel nach dem Tod Königin Elisabeths ${ }^{81}$. Wenn der Jesuiten-

80 Loomie, Spanish Elizabethans, S. 22-25, 157; Philip Hughes, The Reformation in England, Bd. 3: True Religion now established, London 1954, S. 315-329.

81 Ein Produkt dieser Hoffnungen auf die Zeit nach Elisabeth bilden die im Kreise der englischen Exulanten entstandenen Schriften über die Nachfolge auf dem englischen Thron, z.B. R. DoLEMAN [Pseud.], A Conference about the Next Succession to the Crowne of Ingland, [Antwerpen 1595]; Paul Arblaster, Antwerp \& the World. Richard Verstegan and the International Culture of Catholic Reformation, Löwen 2004, S. 61-63. 
pater Joseph Creswell 1595 in seinem Bericht über die Errichtung und die ersten Jahre der Priesterseminare in Spanien nach Rom schrieb, dass die Finanzierung der Kollegs für die sieben bis zehn Jahre, die die Verfolgung noch dauern würde, gesichert sei ${ }^{82}$, so verlieh er damit wohl auch der Überzeugung mancher Exulanten in den Niederlanden Ausdruck. Diese Hoffnung der Exulanten zerstob dann endgültig, als sich die an den Regierungsantritt Jakobs I. geknüpften Erwartungen auf eine tolerantere Politik nicht erfüllten. Wohl nicht zufällig brachten die Jahre nach 1610 eine ganze Gründungswelle geistlicher Institutionen im Exil.

Nach England zurückgekehrt sind wenigstens die englischen Mönche und Nonnen schließlich doch, aber erst in der Zeit um 1800, als ihre Klöster in den Zufluchtsländern aufgelöst wurden: in den seit 1714 österreichischen Niederlanden durch die Klosteraufhebungen Josephs II., in Frankreich infolge der Enteignung der Kirchengüter im Zuge der Französischen Revolution und im Reich durch die Säkularisation Anfang des 19. Jahrhunderts ${ }^{83}$. Ermöglicht wurde die Rückkehr durch die veränderte Gesetzeslage in England. Im ersten Relief Act von 1778 wurde der Eid auf den König so formuliert, dass er nun auch für die Katholiken akzeptabel war, gleichzeitig distanzierten sich die Katholiken vom Thronanspruch der Stuarts und verneinten eine päpstliche Jurisdiktionsgewalt in England sowie ein Recht der Kurie, Katholiken von ihrem Loyalitätseid zu entbinden. Die Denunziation und Inhaftierung von Priestern wurde verboten ${ }^{84}$. Mit dem Gesetz von 1778 begann die katholische Emanzipation in England, die den Katholiken allmählich wieder die volle Teilhabe am politischen, gesellschaftlichen und wirtschaftlichen Leben ermöglichte. Welche Bedeutung das Exil für die englischen Katholiken über zwei Jahrhunderte lang gehabt hatte, erhellt noch einmal schlaglichtartig die Tatsache, dass führende Köpfe der ersten Generation der katho-

82 Loomie, Spanish Elizabethans, S. 202.

83 Einige Beispiele mögen genügen: Die Benediktiner verließen nach längerem Hausarrest Douai im März 1795 und setzten nach England über; nach einigen Zwischenstationen wurden Kloster und Schule 1814 in Downside angesiedelt; GuILDAY, English Catholic Refugees, S. 229f. Die Benediktiner von St. Lawrence in Dieulouard waren bereits 1793 in England eingetroffen, 1802 bezogen sie ein Kloster in Ampleforth; ebd., S. 234. Die Benediktinerinnen aus Brüssel ließen sich bald nach ihrer Flucht 1794 in Winchester nieder, wo sie auch ihre Schule weiterhin betrieben; ebd., S. 264f. Die Benediktinerinnen aus Dünkirchen waren 1793 gefangen genommen worden, 1795 flohen sie nach England und ließen sich in Teignmouth nieder; ebd., S. 273. Die Franziskaner verlegten ihre Residenz angesichts der die kirchlichen Einrichtungen bedrohenden Gesetze des revolutionären Frankreich bereits 1790 nach Brügge, die noch in Douai verbliebenen zehn Mönche flohen 1793 nach London; ebd., S. 294. Die Klarissen aus den verschiedenen Exilklöstern vereinigten sich nach ihrer Rückkehr nach England zu einem gemeinsamen Kloster in Darlington, ebd., S. 301. Siehe auch die Übersicht, ebd., S. 40.

84 Norman, Roman Catholicism, S. 55. 
lischen Emanzipationsbewegung wie Charles Butler ${ }^{85}$, John Milner ${ }^{86}$ und Dr. William Poynter ${ }^{87}$ in Douai studiert hatten ${ }^{88}$.

Die Ansiedlungsschwerpunkte der Exulanten deckten sich wohl weitgehend mit den Standorten der Exilinstitutionen. Da die Mehrzahl der Klöster erst zu Beginn des 17. Jahrhunderts gegründet wurde, spricht manches dafür, dass die Mönche und Nonnen sich an den Orten ansiedelten, in denen bereits zahlreiche Engländer wohnten. Unklar ist jedoch, nach welchen Kriterien die ersten Exulanten ihren Zufluchtsort wählten. Dass die ungefähr hundert Gelehrten, die bald nach dem Regierungsantritt Elisabeths die Universitäten Oxford und Cambridge verlassen hatten, sich mit Löwen für die einzige Universitätsstadt in den Niederlanden entschieden, war naheliegend ${ }^{89}$. Dort scheinen auch bereits Engländer ansässig gewesen zu sein ${ }^{90}$. Weitere Kolonien englischer Exulanten bildeten sich in Douai, Antwerpen, Brüssel, St. Omer und Brügge.

Über die kirchliche Organisation der englischen Katholiken an ihren Exilorten wissen wir nichts. So ist völlig unbekannt, ob sie eigene Gottesdienste abhielten, gar eigene Gemeinden bildeten oder ob sie nach der Gründung geistlicher englischer Institutionen von deren Seelsorgern mit betreut wurden. Für die englischen Soldaten in spanischen Diensten bemühte man sich jedenfalls um englische Priester, und dies auch bereits zu einem Zeitpunkt, als die Engländer noch nicht in einem speziellen englischen Regiment zusammengefasst waren ${ }^{91}$.

Allerdings bedurften nicht nur die Laien der Kleriker, die Abhängigkeit war durchaus gegenseitig, und sie legte beiden Gruppen eine enge Zusammenarbeit nahe. Denn die geistlichen Institutionen waren in vielfältiger Weise auf die Unterstützung durch die Laien angewiesen. Dies sei am Beispiel des Druckers und Verlegers Richard Verstegan erläutert. Verstegan, um 1548

85 Charles Butler (1750-1832) studierte nach der Rückkehr aus Douai Jura, konnte aber wegen seiner katholischen Konfession nicht Rechtsanwalt (barrister) werden; führender Vertreter der katholischen Laienbewegung gegen die penal laws.

86 John Milner (1752-1826), 1764-1776 Studium in Douai, 1777 Ordination, ab 1779 in Winchester, unterstützte dort die aus Brüssel geflohenen Benediktinerinnen und die Franziskaner aus Brügge, 1803 Bischof von Castabala und Apostolischer Vikar für den Bezirk Midlands, als Vertreter ultramontaner Positionen sehr umstritten.

87 William Poynter (1762-1827), Studium in Douai, anschließend dort als Professor tätig, nach der Aufhebung des Kollegs infolge der Französischen Revolution Rückkehr nach England, 1803 Koadjutor und 1812 Apostolischer Vikar des Distrikts London.

88 Norman, Roman Catholicism, S. 58f.

89 Haigh, English Reformations, S. 253; Bossy, English Catholic Community, S. 12. Die Universität Douai wurde erst 1562 gegründet.

90 Loomie, Spanish Elizabethans, S. 17.

911582 fragte der Herzog von Parma bei Robert Persons an wegen Kaplänen für die englischen Soldaten; Loомie, Spanish Elizabethans, S. 132f. 1596 wurde das englische Regiment von drei Kaplänen betreut, die in Douai lebten und auf Anforderung zu den Truppen kamen; ebd., S. 156. 
in London als Richard Rowlands geboren, hatte wegen des Drucks eines katholischen Buchs aus England fliehen müssen. Nach Stationen in Rouen, Paris, Reims und Rom ließ er sich nach der spanischen Rückeroberung der Stadt 1586 dauerhaft in Antwerpen nieder und änderte seinen Nachnamen in Verstegan. Dort druckte und verlegte er nicht nur weiterhin katholische Schriften ${ }^{92}$, sondern kümmerte sich auch um deren Schmuggel nach England und versorgte als Buchhändler die englischen Seminare mit Literatur. Daneben - oder hauptsächlich? - fungierte er als eine Art Nachrichtenzentrale für die führenden englischen Geistlichen im Exil: Wöchentlich schrieb er Berichte an Robert Persons nach Spanien und William Allen nach Rom und leitete deren Botschaften nach England weiter. Missionare, die ihren Dienst in England antreten sollten, versorgte er mit Papieren ${ }^{93}$. Es ist anzunehmen, dass er sich dabei seine ökonomischen Kontakte und die Verbindungen anderer englischer Kaufleute zunutze machte. Dass die englischen Katholiken im Exil wohl auch bei ihren wirtschaftlichen Aktivitäten Landsleute als Geschäftspartner bevorzugten, erhellt eine weitere Episode aus dem Leben Verstegans. 1612 erhielt er nämlich ein Monopol zum Import ungefärbter englischer Stoffe. Dieses Geschäft betrieb er mit einem Konsortium englischer Kaufleute in Antwerpen. Das gemeinsame ökonomische und religiöse Interesse dürfte es erleichtert haben, die Handelsverbindungen auch für den Transport ganz und gar nichtkommerzieller »Waren« zu nutzen. Einige Details aus dem Leben der Geschäftspartner Verstegans beleuchten die enge Verbundenheit der Laien mit den geistlichen Institutionen. So wurde Verstegans Kompagnon Gabriel Colford später Laienprokurator des englischen Kollegs in St. Omer. Seine Tochter trat in das Benediktinerinnenkloster in Brüssel ein. Von den fünf Söhnen eines anderen Konsortiumsmitglieds stiegen zwei in das Familiengeschäft ein und drei wurden Jesuiten. Der Vater wiederum, nachdem er alle seine Söhne solchermaßen versorgt wusste, vermachte englischen religiösen Stiftungen in Flandern $1.000 £$. Die Tochter eines dritten Geschäftspartners war Priorin der englischen Theresianerinnen in Antwerpen ${ }^{94}$. Solche Details stützen die These Heinz Schillings, dass Konfession nicht nur als Movens am Beginn jeder Konfessionsmigration steht, sondern auch im Verlauf des Exils eine entscheidende Rolle spielt ${ }^{95}$. Die Beispiele machen es vertretbar, grundsätzlich von konfessionellen Motivationen

92 Seine Tätigkeit als Verleger katholischer Schriften endete dann weitgehend mit der Errichtung einer Druckerpresse am Jesuitenkolleg in St. Omer 1604; Arblaster, Antwerp \& the World, S. 64.

93 Ebd., S. 49.

94 Ebd., S. 98f. »The English merchant community should not be seen as too sharply distinct from the exile community«.

95 Heinz Schilling, Confessional Migration as a Distinct Type of Old European Longdistance Migration, in: CAVACIOCCHI, Migrazioni in Europa, S. 175-189, hier: S. 176. 
auszugehen, auch wenn nicht in jedem Einzelfall das Überwiegen einer konfessionellen Motivation nachgewiesen werden kann. Die Integration der Migranten in die sich nicht zuletzt durch ihre enge Anbindung an die geistlichen Institutionen definierenden Exilgemeinden erlaubt ihre Subsumierung unter Konfessionsmigration.

Für das konfessionell bestimmte Selbstverständnis der katholischen englischen Exulanten spricht auch der Aufbau und dauerhafte Unterhalt katholischer englischer Bildungseinrichtungen im Exil. Dieses Bildungssystem umfasste alle Stufen, und es beinhaltete Angebote für Jungen wie für Mädchen. Die englischen Katholiken reagierten damit auf Maßnahmen der englischen Regierung, jegliche katholische Erziehung und Ausbildung im Königreich zu unterbinden. Den Höhepunkt dieser Bestrebungen bildete 1593 ein Gesetzentwurf, der vorsah, den Katholiken ihre Kinder wegzunehmen und sie protestantisch erziehen zu lassen ${ }^{96}$. Obwohl der Entwurf nicht realisiert wurde, führte er den Katholiken nochmals deutlich vor Augen, was sie ohnehin längst wussten, dass nämlich eine katholische Ausbildung für ihre Kinder nur außerhalb des englischen Königreichs möglich war.

Deshalb wurde das Priesterseminar in Douai bald um Schulen für englische Jungen ergänzt, denn je länger die elisabethanische Regierung dauerte, desto weniger brachten die Jungen die für ein Studium in Douai nötige Vorbildung mit. Auf Betreiben Robert Persons' war bereits 1582 in Eu bei Rouen eine Schule für englische Jungen gegründet worden, die aber nach der Ermordung ihres Protektors, des Herzogs von Guise, im Jahre 1588 in ihrer Existenz gefährdet war ${ }^{97}$. Die Gründung einer Schule in St. Omer 1592 ersetzte dann diese erste englische Schule ${ }^{98}$. St. Omer wurde rasch die bedeutendste englische Schule auf dem Kontinent. Bereits 1598 lernten hier über einhundert Schüler, und ihre Zahl stieg weiter. Mit Ausnahme der Endphase des Dreißigjährigen Krieges blieb die Schülerzahl dauerhaft bei über hundert. Nicht das Desinteresse der englischen Katholiken, sondern das Verbot der Gesellschaft Jesu durch die französische Regierung brachte dann im Jahre 1762 das Ende des Kollegs in St. Omer ${ }^{99}$. Die Bedeutung der Schule in St. Omer und ihrer Vorgängerin in Eu lässt sich auch daran ablesen, dass die Schulgründung die englische Regierung $1585 \mathrm{zu}$ einer scharfen Gesetzgebung gegen die Ausbildung von englischen Kindern im Ausland veranlass$\mathrm{te}^{100}$. Aber auch die Orden unterhielten zahlreiche Schulen: So wurde am Be-

96 Morey, Catholic Subjects, S. 70.

97 FABre, English College, S. 257-280.

98 Leo Hicks, The Foundation of the College of St. Omers, in: AHSJ 19 (1950), S. 146-180.

99 Das Kolleg zog nach Brügge um, wo ihm aber wegen der Aufhebung des Jesuitenordens 1773 keine lange Wirksamkeit beschieden war; GuILDAY, English Catholic Refugees, S. 145f.

100 Eltern, die ihre Kinder in eine katholische Schule auf dem Kontinent schickten, wurden mit einer Geldstrafe von $100 £$ belegt. Und 1616 forderte ein königliches Edikt die sofortige Rück- 
nediktinerkloster St. Gregory in Douai bereits 1608 eine Schule gegründet, die bis zur Französischen Revolution von 1100 Schülern besucht wurde ${ }^{101}$. Auch die katholischen Mädchen sollten eine angemessene Ausbildung erhalten. Neben den bekannten Bemühungen Mary Wards wäre hier zum Beispiel das Benediktinerinnenkloster in Brüssel zu nennen, das ebenfalls eine Schule unterhielt ${ }^{102}$.

Der Impetus für die Schul- und Seminargründungen war es also gewesen, den in England geborenen katholischen Kindern eine katholische Ausbildung zu ermöglichen. Aber selbstverständlich wurden die Bildungseinrichtungen auch von den Kindern englischer Exulanten frequentiert: Allerdings liegen über ihren Anteil an den Schüler- und Studentenzahlen keine Informationen vor, sondern es sind eher zufällige Hinweise, die diese naheliegende Annahme untermauern. So hatte James Thompson, Sohn des gleichnamigen Geschäftspartners Verstegans in Antwerpen, die Schule in St. Omer besucht und sollte nun, 1595, mit einigen anderen englischen Schülern zur Fortsetzung der Studien an eines der neuen Kollegs nach Spanien gebracht werden, als ihr Schiff von Engländern aufgebracht und die Schüler gefangen genommen wurden - womit ihr Schulbesuch aktenkundig wurde ${ }^{103}$. In jedem Fall dürfte es für das Selbstbewusstsein der englischen Exilgemeinschaften von großer Bedeutung gewesen sein, dass ihnen über Jahrhunderte hinweg Schulen ihrer Konfession und Sprache zur Verfügung standen. Dadurch, dass diese zugleich von Schülern und Studenten aus England besucht wurden, riss der Kontakt zum Heimatland nie ab. Diese Ausbildung von Exilinstitutionen mit permanentem Kontakt zum Herkunftsland dürfte eine der wesentlichen Voraussetzungen dafür gewesen sein, dass die englischen Gemeinschaften offenbar über Generationen hinweg ihre Identität bewahren konnten.

\section{Die zentrale Rolle des Klerus}

Die englischen Katholiken, die sich in den südlichen Niederlanden niederließen, kamen in ein katholisches Land mit ausgebauter kirchlicher Infrastruktur, mussten sich also über die Versorgung mit Gottesdiensten, Sakramenten und sonstigen kirchlichen Dienstleistungen keine Sorgen machen. Die englischen Katholiken konnten sich in die bestehenden Gemeinden integrieren -

kehr aller englischen Schüler im Ausland, wobei die Schule von St. Omer explizit genannt wurde - bei Strafandrohung der Güterkonfiskation; Guilday, English Catholic Refugees, S. 142.

101 Ebd., S. 227.

$102 \mathrm{Zu}$ den an Frauenklöster angeschlossenen Mädchenschulen siehe WaLkeR, Gender and Politics, S. 92f.

103 Arblaster, Antwerp \& the World, S. 98f. 
ob und in welchem Maße sie dies taten, wissen wir nicht. Aber in jedem Fall war die Wahrscheinlichkeit, dass die Engländer in der niederländischen Gesellschaft aufgingen, groß.

Dass man dennoch bis zum Ende des 18. Jahrhunderts Zentren des englischen - wie auch des irischen und schottischen - Katholizismus auf dem Kontinent identifizieren kann, dürfte eng mit dem katholischen Amtsverständnis zusammenhängen. Denn um auf den britischen Inseln wenigstens ein Mindestmaß an katholischem Leben aufrechtzuerhalten, waren die dortigen Katholiken auf katholische Priester angewiesen. Deren Ausbildung und Weihe war aber auf den britischen Inseln nicht möglich ${ }^{104}$. Und so generierte das katholische Amtsverständnis eine fortwährende Migration von jungen Menschen, die eine katholische Ausbildung oder gar einen geistlichen Beruf anstrebten, auf den Kontinent und eine Wanderung der Geistlichen zurück in ihre Heimatländer. Auf diese Weise bildete sich die spezifische Struktur des britischen Exilkatholizismus mit einer Vielzahl geistlicher Exilinstitutionen und dem fortwährenden Kontakt der Exulanten mit ihren Heimatländern heraus. Dabei kam die größte Bedeutung sicherlich den Priesterseminaren zu. Vorbildcharakter nicht nur für die späteren englischen Gründungen, sondern auch für Iren und Schotten hatte das 1568 von William Allen in Douai gegründete Priesterseminar, 1578 entstand ein Englisches Kolleg in Rom, 1590 eines in Valladolid, dem kurz darauf noch eines in Sevilla folgte. Diese Kollegs waren nicht gedacht, um die Exilgemeinden mit Geistlichen $\mathrm{zu}$ versorgen ${ }^{105}$ und damit die Existenz klar abgegrenzter Exilgemeinden zu gewährleisten, sondern sie sollten das Überleben des Katholizismus in England sichern. Allein schon durch ihre Existenz dürften die Kollegs bei den Exulanten der Umgebung, unabhängig davon, ob sie in eigenen Kirchengemeinden organisiert waren oder nicht, zur Bewahrung einer jeweiligen nationalen Identität beigetragen haben.

Die existentielle Bedeutung der Missionspriester für den Fortbestand des englischen Katholizismus erkannte niemand besser als die englische Regierung. Als ab Mitte der 1570er Jahre die ersten Priester aus Douai auf der Insel eintrafen, musste sich die Regierung eingestehen, dass ihre Rechnung, durch das allmähliche Aussterben der Priester würde der Katholizismus nach und nach verschwinden, nicht aufgehen würde ${ }^{106}$. Denn auf die vier Priester, die 1574 in England eintrafen, folgten weitere. Die Zahlen stiegen in einem

104 In dieser Pauschalität gilt diese Aussage vor allem für England, während es in Irland weiterhin in gewissem Umfang katholische Lateinschulen gab und dort auch stets einige katholische Bischöfe amtierten.

105 Die Kollegiaten verpflichteten sich beim Eintritt in das Kolleg zum Missionsdienst, d.h. zum Dienst in der Heimat. Ob und wie viele dieser Verpflichtung nicht nachkamen und stattdessen als Geistliche in Exilgemeinden arbeiteten, ist nicht bekannt.

106 Pastor, Geschichte der Päpste 9, S. 334; Haigh, English Reformations, S. 262. 
$\mathrm{Ma} ß$ an, das der englischen Regierung wie eine Invasion vorgekommen sein mochte ${ }^{107}$. Angesichts dieser Entwicklung konnte die Regierung nicht untätig bleiben und beschloss, die Sanktionen gegen die Priester zu verschärfen - in der richtigen Einschätzung, welche Bedeutung dem Zustrom von Priestern zukam.

Von den zwischen 1577 und 1603 nach England entsandten Priestern bezahlten 123 ihren Missionsdienst mit dem Leben, d.h. ungefähr jeder zweite bis dritte der Missionspriester ${ }^{108}$. Von den 314 katholischen englischen Märtyrern zwischen 1535 und 1680 waren die meisten, nämlich 185, Priester ${ }^{109}$. Der erste dieser Märtyrer war Cuthbert Mayne im November 1577. Von da an riss die Reihe nicht mehr ab. Der letzte Priester, der wegen seines Missionsdienstes in England zum Tode verurteilt wurde, war Oliver Plunket. Er wurde am 11. Juli 1681 hingerichtet ${ }^{110}$.

Auch über ihren Tod hinaus erwiesen diese Priester den englischen Katholiken einen wertvollen Dienst. Anne Dillon hat jüngst herausgearbeitet, wie aus den Toten mit Hilfe von Text und Bild Märtyrer wurden, die für die englischen Katholiken weitreichende Funktionen übernehmen konnten. Dillon hat in diesem Zusammenhang darauf hingewiesen, dass die Konstruktion dieses Märtyrernarrativs ein Produkt des englischen Exilkatholizismus war. Die Bilder und Texte entstanden im Exil auf dem Kontinent, produziert von Männern, die vielfach beeinflusst waren von den Institutionen des Exils, v.a. den Seminaren, und die die Doktrin des Trienter Konzils in ihren Texten und Bildern umsetzten ${ }^{111}$. Adressaten der Werke waren nicht nur die Katholiken in England, die durch die Lektüre in ihrem Glauben und in ihrem Widerstand gegen die englische Regierung gestärkt werden sollten

107 1574-1578: 52 Priester aus Douai nach England; 1579-1585: 216; 1586-1603: 170, d.h. bis zum Tod Elisabeths insgesamt 438; dazu kamen ab 1579 bzw. 1589 Priester aus den englischen Kollegs in Rom und Valladolid, deren Zahl aber nie annähernd an die der Absolventen aus Douai heranreichte; HugHEs, Reformation in England 3, S. 293.

108 Meyer, England und die katholische Kirche, S. 138; Hughes, Reformation in England 3, S. 338. Außerdem wurden 60 Laien hingerichtet.

109 Geoffrey F. NutTall, The English Martyrs 1535-1680: a statistical review, in: JEH 22 (1971), S. 191-198, hier: S. 192f. 1535-1544 (Heinrich VIII.): 50 Märtyrer; 1570-1603 (Elisabeth I.): 189; 1604-1618 (Jakob I.): 25; 1641-1646 (Karl I.): 24; 1651-1654 (Commonwealth und Protektorat): 2; 1678-1680 (Karl II.): 24.

110 Da Plunket Ire und in Irland als Priester tätig war, wird er teilweise nicht zu den englischen Märtyrern gezählt. Er war aber in jedem Fall der letzte in England wegen seines Glaubens hingerichtete Katholik. Unabhängig von dieser letztlich irrelevanten Zuordnungsfrage bleibt die Tatsache, dass die Hinrichtungen von Katholiken 1678-1680 nochmals einen Höhepunkt erreichten, um dann endgültig aufzuhören. Posthum wurde Plunket jedenfalls von den englischen Katholiken vereinnahmt. Denn Plunkets Gebeine wurden teilweise von einem Mithäftling, der später Abt des Benediktinerklosters Lamspringe wurde, auf den Kontinent mitgenommen und in Lamspringe beigesetzt. Nach der Auflösung Lamspringes überführten die Benediktiner die Reliquien Plunkets 1883 in ihr neues Kloster Downside.

$111 \mathrm{Zu}$ den Details siehe Dillon, Construction of Martyrdom, S. 9, 116 und passim. 
und die insbesondere durch die Unterstützung und Beherbergung der Priester teil hatten am Martyrium und damit an der Erlösung. Die Publikationen richteten sich auch an die englischen Katholiken im Exil, die auf diese Weise zu Solidarität und tatkräftiger Unterstützung der Missionspriester aufgefordert wurden ${ }^{112}$. Da Dillon sich vor allem für die Konstruktion des Märtyrertums interessiert, bleibt die Rezeption der Werke durch die englischen Katholiken diesseits und jenseits des Kanals außerhalb ihres Fokus. Es scheint jedoch naheliegend, dass die Märtyrerdarstellungen die Bindungen zwischen den Katholiken in England und auf dem Kontinent verstärkten. Der Katholizismus in England war nur überlebensfähig, wenn Priester dort die Sakramente verwalteten - die Märtyrer hatten in der Ausübung dieses Dienstes ihr Leben verloren. Die Bedeutung des Priestertums für die Aufrechterhaltung des katholischen Kirchenwesens bestimmte also das Dasein der englischen Katholiken im Exil entscheidend, obwohl die Exulanten selbst keinen Mangel an priesterlicher Versorgung litten. Entscheidend war die Versorgung der Katholiken auf der Insel mit Priestern. Deshalb bildeten Priesterseminare die zentralen Institutionen des Exils, deshalb wurde das Martyrium der Priester, aber auch der Laien, die sie unterstützten, breit dargestellt. Mit der Unterstützung der Priester erhielt die englische Exilgemeinschaft eine Aufgabe, die ihre Identität gestärkt haben dürfte.

Zugleich weisen die englischen katholischen Märtyrer aber weit über die Gemeinschaft der englischen Katholiken hinaus. Denn sie starben für die Einheit der von Christus eingesetzten und von Petrus begründeten Kirche, weil sie den König bzw. die Königin als Oberhaupt der Kirche ablehnten. Damit bildeten sie einen völlig neuen Typ von Märtyrern, der nicht für eine bestimmte Glaubensüberzeugung starb, sondern für die kirchliche Einheit und Universalität mit dem Papst an der Spitze ${ }^{113}$. Ihr Tod war damit zugleich ein Appell an die internationale Gemeinschaft, den Katholizismus in England zu unterstützen - sei es durch Unterstützung der Priester auf der Insel, sei es durch eine Politik, die die Herrschaft Elisabeths und ihrer Nachfolger schwächte. Die englischen katholischen Märtyrer hatten aber auch deshalb eine weit über die englische Gemeinschaft hinausgehende Bedeutung, weil sie die einzigen zeitgenössischen katholischen Märtyrer in Europa waren. Märtyrererzählungen boten die Möglichkeit, doktrinäre Positionen pointiert darzustellen, und in diesem theologischen Diskurs konnten die katholischen Autoren auf die verschiedenen protestantischen Märtyrererzählungen nur mit den Märtyrern der englischen Katholiken antworten.

112 Daneben hatte diese Märtyrerliteratur selbstverständlich die Funktion, der europäischen Öffentlichkeit die Brutalität der englischen Religionspolitik vor Augen zu führen.

113 Dillon, Construction of Martyrdom, S. 27 und 38 am Beispiel Thomas Morus', S. 94 allgemein. 


\section{Die Rolle der Kurie und der kirchlichen Hierarchie}

Während für die ersten drei Fragekomplexe aufgrund der vorliegenden Literatur immerhin einige Tendenzen aufgezeigt werden konnten, ist für die Frage nach dem Verhältnis zwischen der kirchlichen Hierarchie und den englischen Katholiken im Exil nicht einmal dies möglich, sondern es können kaum mehr als äußere Voraussetzungen benannt werden.

Organisatorisch gehörten die Niederlande und auch England ${ }^{114}$ in die $\mathrm{Zu}$ ständigkeit erst der Kölner Nuntiatur ab 1596, dann der neugegründeten Nuntiatur in Brüssel ${ }^{115}$. Erster Nuntius in Brüssel war Ottavio Mirto Frangipani, der bisherige Kölner Nuntius. Dass er auch für die Belange der englischen Katholiken zuständig war, macht der ihm verliehene Titel eines Vizeprotektors für England deutlich ${ }^{116}$. In der Korrespondenz Frangipanis als Nuntius in Flandern zwischen 1596 und 1606 nehmen die englischen Angelegenheiten breiten Raum ein, doch geht es dabei überwiegend um den Katholizismus in England selbst, so zum Beispiel um die Frage eines katholischen Nachfolgers für Elisabeth I. ${ }^{117}$. Dagegen lässt sich die Existenz eng-

114 Nicht ganz klar ist die Abgrenzung von den Kompetenzen des Nuntius in Frankreich, der auch mit der Beobachtung der englischen Angelegenheiten betraut war; Bernard BARBICHE, La nonciature de France et les affaires d'Angleterre au début du XVII ${ }^{\mathrm{e}}$ siècle, in: Ders., Bulla, Legatus, Nuntius. Études de diplomatique et de diplomatie pontificales (XIII ${ }^{\mathrm{e}}-\mathrm{XVII}^{\mathrm{e}}$ siècles), Paris 2007, S. 477-507 [1967].

115 Die Einrichtung der Nuntiatur in Brüssel verlief ungewöhnlich. Papst Clemens VIII. kündigte dem neuen Statthalter der Niederlande, Erzherzog Albrecht, an, dass er den bisherigen Kölner Nuntius Ottavio Mirto Frangipani zum Nuntius der neu einzurichtenden Nuntiatur in Brüssel ernannt habe. Wenige Tage später informierte der päpstliche Staatssekretär Pietro Aldobrandini Frangipani über sein neues Amt. Eine Instruktion, aus der die Aufgaben der neuen Nuntiatur ersichtlich würden, erhielt Frangipani nicht. Offenbar war man in Rom überzeugt, dass der Nuntius nach neun Jahren in Köln mit den Gegebenheiten in den Niederlanden ausreichend vertraut sei; Léon van der Essen/Armand Louant (Hg.), Correspondance d'Ottavio Mirto Frangipani 1596-1606, 3 Bde., Brüssel/Rom 1924-1942, Bd. 1, S. LIIf. Zur Einrichtung der Brüsseler Nuntiatur siehe allgemein: Pierre BLET, Histoire de la Représentation Diplomatique du Saint Siège des origines à l'aube du XIX ${ }^{\text {e }}$ siècle, Vatikanstadt 1982, S. 317-320. Das Breve an Erzherzog Albrecht, in: Essen/Louant, Correspondance Frangipani, Bd. 1, Anhang II, S. 385f.; das Schreiben an Frangipani, ebd., Nr. 1. Zur Gründung der Nuntiatur siehe auch die Einleitung zu Bd. 3, S. IXXX-XIV. Der Band Alexander Koller (Hg.), Kurie und Politik, Stand und Perspektiven der Nuntiaturberichtsforschung, Tübingen 1998, der einen Überblick über die Nuntiaturforschung gibt, enthält keinen Beitrag über die Nuntiatur in Flandern. Dass diese als einzige frühneuzeitliche Nuntiatur nicht vertreten ist, ist bezeichnend für die Forschungslage.

116 Das Datum der Ernennung und die mit dem Titel verbundenen Kompetenzen sind nicht bekannt; Essen/Louant, Correspondance Frangipani 3/1, S. CLX. Laut Pastor erhielt der Vizeprotektor die Vollmacht, alle kirchlichen Rechtsstreite in England zu entscheiden; PASTOR, Geschichte der Päpste, Bd. 11: Geschichte der Päpste im Zeitalter der katholischen Reformation und Restauration: Klemens VIII. (1592-1605), Freiburg i. Br. 1927, S. 331.

117 Essen/Louant, Correspondance Frangipani 3/1, Einleitung, S. LXXVII-LXXXVI, CLCLXIV und Quellen passim; Alfred CAUCHIE, Relations générales des nonces de Flandre Ottavio Mirto Frangipani et Fabio della Lionessa en 1605 et 1634, in: AHEB 32 (1906), S. 241-265, hier: S. 244 und 253-262. Die englischen Angelegenheiten traten damit wesentlich stärker in 
lischer Katholiken in den Niederlanden in der Korrespondenz fast nur erahnen, obwohl Engländer sogar zum Haushalt des Nuntius gehörten ${ }^{118}$. In der Instruktion für Giovanni Francesco Guidi di Bagno, der 1621 die Brüsseler Nuntiatur übernahm, wurden die englischen Angelegenheiten dann explizit erwähnt. Der Nuntius wurde angewiesen, über die Lage in England zu informieren und mit dem Erzpriester in England Kontakt zu halten. Außerdem wurden die Priesterseminare seiner besonderen Sorge anempfohlen ${ }^{119}$.

Die 1622 gegründete Congregatio de Propaganda fide, die mit der Mission in den häretischen Ländern Europas sowie unter den Ungläubigen in den anderen Kontinenten betraut war, beauftragte verschiedene Nuntiaturen mit der Beobachtung benachbarter häretischer Gebiete. In die Zuständigkeit des Brüsseler Nuntius fielen die protestantischen Niederlande, England, Schottland, Irland, Dänemark und Norwegen ${ }^{120}$. Damit wurde nochmals bekräftigt, dass der Nuntius in Flandern die Kurie mit Informationen über die Britischen Inseln versorgen sollte. Für die spanischen Niederlande und damit auch für die dort lebenden Engländer war die Kongregation nicht zuständig, da Flandern ja ein katholisches Land war und damit kein Missionsgebiet darstellte. Allerdings ließ sich das nicht immer genau trennen, denn die so genannten Missionsseminare, also auch die englischen, gehörten ausdrücklich zum Aufgabenbereich der Kongregation.

Um über die Lage der englischen Katholiken auf dem Laufenden zu bleiben, war die Kurie aber nicht allein auf die Berichte ihrer Nuntien angewiesen. In Rom hielten sich stets etliche Engländer auf, die die Kurie mit ihren Angelegenheiten bedrängten, auf deren Expertise man aber in allen englischen Belangen auch gern zurückgriff. Dabei handelte es sich natürlich vor allem um Männer aus dem Umkreis des englischen Priesterseminars. Nachdem er sich 1585 dauerhaft in Rom niedergelassen hatte, war selbstverständlich William Allen, der Gründer des Priesterseminars in Douai, bevorzugter Ansprechpartner der Kurie; seine Ernennung zum Kardinal 1587 demonstrierte dann öffentlich, dass der Papst ihn für den legitimen Vertreter der eng-

das Blickfeld der Kurie als in den Berichten der Kölner Nuntiatur. Dass dies offenbar strukturelle Ursachen hatte und nicht den speziellen Interessen Frangipanis geschuldet war, zeigt der Vergleich mit den Berichten Frangipanis aus seiner Kölner Zeit: In seinen Kölner Berichten geht er nicht auf die Lage des Katholizismus in England oder die englische (Innen-)Politik ein; England kommt nur als Faktor in den internationalen Beziehungen vor. Dies gilt entsprechend für die Nuntiaturberichte der Kölner Nuntiatur vor und nach Frangipani; Nuntiaturberichte aus Deutschland. Die Kölner Nuntiatur, passim.

118 Essen/Louant, Correspondance Frangipani 3/1, S. XXXXVII. Einer dieser Engländer dürfte Frangipanis Kaplan George Chamberlain gewesen sein, ein in Gent geborener englischer Adliger, der an den englischen Kollegs in Rom und Spanien studiert hatte; ebd., Nr. 774.

119 Klaus Jaitner (Hg.), Die Hauptinstruktionen Gregors XV. für die Nuntien und Gesandten an den europäischen Fürstenhöfen 1621-1623, 2 Bde., Tübingen 1997, Bd. 2, Nr. 8, S. 657f.

120 Essen/Louant, Correspondance Frangipani 3/1, Einleitung, S. XV; Barbiche, Nonciature de France, S. 478. 
lischen Katholiken hielt. Nach dem Tod Allens 1594 fand sich freilich niemand, der gleichermaßen die Rolle als Vertreter der englischen Katholiken hätte ausfüllen können. Sowohl das Priesterseminar als auch die englische Gemeinde in Rom zerfleischten sich in den folgenden Jahren in tiefgreifenden Streitigkeiten, bei denen die Rolle der Jesuiten im Mittelpunkt stand. Die Lage war damit nicht nur für die Päpste unübersichtlicher geworden, es gab nun verschiedene Parteien mit durchaus unterschiedlichen Meinungen. Auf alle Fälle befanden sich stets genügend Engländer in Rom, die schon aufgrund ihrer Nationalität für Experten in englischen Angelegenheiten galten und sich auch selbst dafür hielten ${ }^{121}$. Zumindest der Realität auf der Insel waren manche nach teilweise jahrzehntelangem Aufenthalt im Exil aber doch schon ziemlich fern gerückt, weshalb die Exulanten - und in der Folge auch der Papst - sich über die problemlose Thronfolge Jakobs I. wunderten ${ }^{122}$.

Diese Engländer lebten in Rom, sie waren aber nicht Angehörige der Kurie. Engländer in päpstlichem Dienst scheint es nur in Ausnahmefällen gegeben zu haben. Eine solche Ausnahme war Owen Lewis, der als Archidiakon von Cambrai in einer Rechtsangelegenheit von seinem Erzbischof nach Rom geschickt worden war und dann in Rom blieb. Er wurde unter Gregor XIII. Apostolischer Referendar und war zuständig für alle englischen Angelegenheiten ${ }^{123}$. Dass es gerade unter diesem Papst also offenbar eine institutionalisierte Zuständigkeit für England gegeben hat, deckt sich mit den sonstigen Beobachtungen, dass Gregor XIII. sich überdurchschnittlich für die englischen Angelegenheiten interessierte.

Dürfte die Kurie also insgesamt über die Lage der Katholiken in England recht gut informiert gewesen sein, so lässt sich bis jetzt nicht abschätzen, inwieweit damit auch die - mit den Verhältnissen in England ja in engem $\mathrm{Zu}-$ sammenhang stehende - Situation der englischen Katholiken im Exil an der Kurie Beachtung fand. Die Exil-Institutionen werden immer dann erwähnt, wenn es dort zu Problemen kam, die ein Eingreifen des Nuntius oder der Kurie erforderlich machten. Die Tatsache, dass auch die Katholiken im Exil für ihren Glauben Opfer brachten, nicht nur durch den Verlust der Heimat und das Abbrechen persönlicher Verbindungen, sondern in sehr vielen Fällen eben auch durch erhebliche ökonomische Einbußen, wird in der durchgesehenen Korrespondenz nicht thematisiert: Exil und Migration als Probleme sui generis tauchen nicht auf.

Immerhin ließ die Kurie den Exulanten gelegentlich Geld zukommen. So konnten Institutionen des Exils, wie die Priesterseminare, durchaus mit fi-

121 Pastor, Geschichte der Päpste, Bd. 10: Geschichte der Päpste im Zeitalter der katholischen Reformation und Restauration: Sixtus V., Urban VII., Gregor XIV. und Innozenz IX. (15851591), Freiburg i. Br. 1926, S. 306.

122 Blet, Histoire de la Représentation Diplomatique, S. 325.

123 Pastor, Geschichte der Päpste 9, S. 278f. 
nanzieller Unterstützung durch die Kurie rechnen ${ }^{124}$. Mehr noch als für die anderen Kollegs galt das für die direkt unter den Augen des Papstes in Rom arbeitenden Kollegs, also auch für das Englische Kolleg. Papst Gregor XIII. wies 1579 das alte englische Priesterhospiz dem neuen Englischen Kolleg als Unterkunft zu, verlieh ihm die Einkünfte einer Abtei und wies ihm eine Jahresrente von 3600 Goldscudi an ${ }^{125}$. Daneben bemühte sich der Papst um Spenden für das Kolleg in Douai, indem er zum Beispiel 1582 eine Kollekte für das Kolleg ausschrieb ${ }^{126}$. Offenbar hatte Gregor XIII. nicht nur mehr als die anderen Päpste die Lage der Katholiken in England im Blick, sondern auch ein besonders offenes Ohr für die Anliegen ihrer Landsleute auf dem Kontinent. Er veranlasste beispielsweise auch die Überweisung von Almosen an das Kloster der englischen Birgitten in Mecheln, die englische Kartause und an englische Priester, die in den Niederlanden tätig waren ${ }^{127}$. Clemens VIII. dagegen bat zwar den spanischen König Philipp II., den englischen Flüchtlingen ihre seit Monaten ausstehenden Pensionen zu bezahlen, zog aber offenbar nicht in Betracht, an Stelle des spanischen Königs den Flüchtlingen finanziell unter die Arme zu greifen ${ }^{128}$. Dass etliche der englischen Exilkatholiken spanische Pensionen erhielten, ist bekannt. Ob und in welchem Umfang auch die Kurie einzelne englische Katholiken oder Gemeinden unterstützte, ist hingegen völlig unklar. Bereits 1568 sollen die englischen Katholiken in Löwen ein jährliches Almosen von Papst Pius V. erhalten haben ${ }^{129}$. Als Richard Verstegan, der nach dem Druck katholischer Schriften in Frankreich gefangen genommen worden und auf Betreiben des Nuntius frei gekommen und nach Rom geflohen war, dort um päpstliche Unterstützung bat, wurde ihm diese mit dem Kommentar verweigert, der Papst könne schließlich nicht jeden nach Rom kommenden Engländer finanziell unterstützen ${ }^{130}$, woraus umgekehrt immerhin auch der Schluss zu ziehen wäre, dass manche doch Geld bekamen. Auch Verstegan erhielt letztlich eine päpstliche Pension, aber erst nach dem Druck eines weiteren katholischen Buches. All dies sind freilich nur einzelne Hinweise. Erst eine umfassende Auswertung päpstlicher Finanzregister könnte hier größere Klarheit bringen, und zwar sowohl über

124 Das Priesterseminar in Douai erhielt seit 1575 eine päpstliche Pension von 2100 Kronen, die bis 1793 gezahlt wurde; Guilday, English Catholic Refugees, S. 70; PAstor, Geschichte der Päpste 9, S. 177. Gregors XIII. Nachfolger Sixtus V. hatte die Zahlungen zunächst eingestellt und William Allen damit 1585 zu der Reise nach Rom veranlasst, die zu seiner dauernden Berufung in die Ewige Stadt führte. Offenbar konnte Allen den Papst überzeugen, die Zahlungen wieder aufzunehmen; PAstor, Geschichte der Päpste 10, S. 303.

125 Pastor, Geschichte der Päpste 9, S. 177.

126 Ebd., S. 278 und 342.

127 Ebd., S. 342.

128 Pastor, Geschichte der Päpste 11, S. 345.

129 Pastor, Geschichte der Päpste 8, S. 427.

130 Arblaster, Antwerp \& the World, S. 34 
den Umfang der päpstlichen Zahlungen, als auch über die Frage, ob die Kurie jeweils auf konkrete Anfragen reagierte oder eine bestimmte Strategie verfolgte, indem zum Beispiel bestimmte Empfänger bevorzugt wurden.

Wenn damit am Schluss dieser kurzen Annäherung an das Leben der englischen Katholiken in den Niederlanden erneut eine Frage steht, so ist dies symptomatisch für die Forschungslage. Denn über diese Migrantengruppe ist eben weit weniger bekannt als über manche andere, nur wenige Jahre existierende oder wesentlich kleinere Gruppen wie zum Beispiel die so genannten Marian Exiles, also die Protestanten, die während der Regierungszeit Maria Tudors England verlassen hatten ${ }^{131}$. Dies ist erstaunlich - immerhin handelt es sich bei den englischen Katholiken in den Niederlanden um eine Gruppe von Konfessionsmigranten, die dort fast zweieinhalb Jahrhunderte lang eine ganze Reihe geistlicher Institutionen unterhielt, was für eine deutlich fassbare Gruppenidentität spricht. Wie diese genau aussah, wie die englischen Katholiken in den Niederlanden lebten, wie sie sich in den katholischen Gemeinden im Exil einrichteten, wie sie ihre Position innerhalb der katholischen Kirche verstanden, ob und wie sie von Rom aus wahrgenommen wurden, können erst zukünftige Forschungen zeigen. Diese Forschungen können nicht nur an und für sich Interesse beanspruchen, sie versprechen auch weiterführende und aufschlussreiche Erkenntnisse über die Strukturen der katholischen Konfessionsmigration im Allgemeinen - idealerweise ergänzt um entsprechende Untersuchungen zu anderen Gruppen katholischer Glaubensflüchtlinge.

131 Dan D. Danner, Pilgrimage to Puritanism. History and Theology of the Marian Exiles at Geneva 1555 to 1560, New York 1999; Christina Hallowell Garrett, The Marian Exiles. A study in the Origins of Elizabethan Puritanism, Cambridge 1938, ND Cambridge 1966; Rudolf JunG, Die englische Flüchtlingsgemeinde in Frankfurt am Main: 1554-1559, Frankfurt am Main 1910; George T. Washburn, A Study of the Marian Exiles at Geneva and their Contributions to the Rise of Elizabethan Puritanism, Ann Arbor 1991; Andrew Pettegree, Marian Protestantism. Six Studies, Aldershot 1996. 


\title{
Heinz Schilling \\ Die frühneuzeitliche Konfessionsmigration
}

\author{
Calvinisten und sephardische Juden im Vergleich
}

I.

Die Konjunktur, der sich gegenwärtig die Migrationsgeschichte erfreuen kann $^{1}$, ist das Resultat des ungebremsten Zustroms von Migranten nach Europa, der im letzten Viertel des vorigen Jahrhunderts scheinbar unvermittelt einsetzte und bis heute sozial wie kulturell nicht bewältigt ist ${ }^{2}$. Die europäischen Gesellschaften, die sich seit dem 19. Jahrhundert überwiegend als Nationalstaaten organisiert und gegen Fremde abgeschottet hatten, waren durch diese Entwicklung zutiefst verunsichert, hatten sie doch über Generationen hinweg Migration vornehmlich als Krisenphänomen am geographischen und sozialen Rand erfahren. Unter den politischen und ideologischen Prämissen des Nationalstaates musste den Europäern massenhafte Zuwanderung als ein Phänomen erscheinen, das die »normale« Ordnung störte, ja zerstörte. Doch nicht nur die Bevölkerungsbewegung als solche ist das Beunruhigende. Nicht weniger einschüchternd war und ist die prinzipielle kulturelle Fremdheit der außerhalb Europas beheimateten Migranten - symbolisch verdichtet in ihrer nicht-christlichen Religion, die in Riten und Gebäuden zunehmend auch real erfahrbar wird. Unmittelbar nach dem Zweiten Weltkrieg hatte das Christentum als Identitätskern des »freien Europa« in der Debatte um die Abgrenzung des »christlichen Abendlands« (Friedrich Heer) von dem atheistischen Osten eine Renaissance erfahren. Vor dieser in Deutschland auch über die engere Adenauer-Ära hinaus wirksamen Identifizierung von freiem Westen und Christentum - »Western Civilization « in der US-amerikanischen Variante - musste die dauerhafte Anwesenheit fremder, nichtchristlicher Religionen als etwas unerhört Neues erscheinen. Das wurde erlebt als die Wiederkehr einer fundamentalen Gefahr, die Europa in seiner Konstituierungsphase schon einmal gebannt hatte und deren Überwindung im Zentrum der frühen

1 Zum Abdruck gelangt der um die nötigen Anmerkungen ergänzte Vortragstext. Eine erweiterte Fassung, die weitere, erst nach der Mainzer Tagung zugängliche Informationen zur SephardenDiaspora einarbeitet, ist in der Zeitschrift für Historische Forschung erscheinen: Heinz ScHILLING, Christliche und jüdische Minderheitengemeinden im Vergleich. Calvinistische Exulanten und westliche Diaspora der Sephardim im 16. und 17. Jahrhunder, in: ZHF 36 (2009), S. 407-444.

2 Das bestätigt die Ende Januar 2009 veröffentlichte Studie des »Berlin-Instituts für Bevölkerung und Entwicklung . 
Erinnerungskultur des sich vereinenden Europa stand - memorialpolitisch verdichtet im Sieg Karl Martells am 29. Mai 732 bei Tours, den das Internet heute wieder als »Rettung des Abendlandes « feiert ${ }^{3}$, sowie in der Lechfeldschlacht von 955, deren tausendster Jahrestag 1955 genutzt wurde, den Widerstand des christlichen Abendlandes gegen Überfremdung zu beschwören ${ }^{4}$.

In einer längerfristigen Perspektive wird allerdings sogleich deutlich, dass transkontinentale Migrationen und Minderheiten von Anfang an die Geschichte Europas mit geprägt haben und dass auch die Verbindung von Migration und religiöser Andersartigkeit in Europa keineswegs ungewöhnlich ist. Es lässt sich sogar die These vertreten, dass gerade die Existenz von religiösen Minderheiten als Ergebnis transkontinentaler Migrationsbewegungen einen wesentlichen Charakterzug des lateinisch-christlichen Zivilisationstyps ausmachte und dass religiöse Minderheiten entscheidend zu der exzeptionellen Dynamisierung beitrugen, die das neuzeitliche Europa vor anderen Weltzivilisationen charakterisierte ${ }^{5}$. Diese Zusammenhänge lassen sich bereits an der jüdischen und islamischen Migration des frühen und hohen Mittelalters beobachten ${ }^{6}$. Ihre besondere gesellschaftliche und kulturelle Dynamik entfaltete die Verbindung von Migration und religiöser Differenzierung aber vor allem im späten Mittelalter und in der ersten Phase der Frühen Neuzeit.

In dieser rund zwei Jahrhunderte umfassenden Epoche von Mitte des 15. bis Mitte des 17. Jahrhunderts, die im Zentrum der folgenden Überlegungen steht, haben auch das Migrationsgeschehen und die religiösen Minderheiten eine neue, neuzeitliche Gestalt angenommen, und zwar in innerer zeitlicher und sachlicher Verschränkung. Seinen Höhepunkt erreichte das früh-

3 Jan von Flocken, Art. Wie Karl Martell das Abendland rettete, in: Welt Online, URL: http:// www.welt.de/wissenschaft/history/article902832 (eingesehen am 31.7.2009).

4 Nicht ganz unähnlich stilisierte sie Guido Knopp in der im Herbst 2008 ausgestrahlten ZDFSerie »Die Deutschen « zu einem ersten wesentlichen Schritt der Selbstfindung der Deutschen, mit der unbeabsichtigten ironischen Pointe, dass ein Großteil der heutigen Deutschen, um deren »nationale « Integration es zu Beginn des 21. Jahrhunderts geht, ihrer langfristigen historischen Herkunft nach eher den vor Augsburg unterlegenen Angreifern als den dort siegreichen Sachsen zuzurechnen wäre.

5 Näher entwickelt als globalhistorischer Ansatz bei Heinz SchiLling, Early modern European Civilisation and its political and cultural dynamics. The Menahem Stern Jerusalem Lectures 2006, Hanover 2008.

6 Michael Borgolte, Christen, Juden, Muselmanen. Die Erben der Antike und der Aufstieg des Abendlandes 300 bis 1400 n. Chr., Berlin 2006. Im Unterschied zu der dort konstitutiven nivellierenden Tendenz, Europa mit drei gleichgewichtigen Monotheismen zu identifizieren, wird im Folgenden mit der Typisierung [»lateinisch-christliche(r) Zivilisationstypus «] gearbeitet, und zwar nicht zuletzt, um die Stellung der jüdischen und islamischen Minderheiten in den europäischen Gesellschaften tiefenscharf beschreiben und analysieren zu können. Näheres dazu in dem Folgeband in der Siedler Geschichte Europas: Heinz Schilling, Die neue Zeit. Vom Christenheitseuropa zum Europa der Staaten. 1250 bis 1750, Berlin 1999, sowie ders., European Civilisation. 
neuzeitliche Migrationsgeschehen in der so genannten Konfessionalisierung, also in der zu Mitte des Reformationsjahrhunderts einsetzenden Herausbildung der drei großen lateinisch-christlichen Weltanschauungssysteme, die für die nächsten Generationen das kulturelle, gesellschaftliche und politische Leben Europas und der europäisch durchdrungenen Welt maßgeblich mitprägten. Von dieser Formierung ihrer christlichen Umwelt waren auch die nicht-christlichen Minderheiten betroffen - so namentlich die nur formell christianisierten islamischen Morisken und die jüdischen conversos auf der Iberischen Halbinsel, die auf dem Höhepunkt der katholischen Konfessionalisierung Spaniens und Portugals Verfolgungen und Vertreibungen ausgesetzt waren. Während die Morisken - insgesamt rund 270.000 - Europa verließen und sich im islamischen Nordafrika ansiedelten ${ }^{7}$, richtete sich die große transkontinentale Migration sephardischer Juden nicht nur nach Nordafrika und in den Vorderen Orient, sondern auch nach Nordwest- und Südeuropa. Die Sephardenmigration lässt sich somit auch hinsichtlich ihrer Zufluchtsorte innerhalb des lateinisch-christlichen Europa der frühmodernen Konfessionsmigration zurechnen.

Diese Beobachtung berechtigt $\mathrm{zu}$ dem Versuch eines vergleichenden Blicks auf die christliche und jüdische Migration. Zuvor gilt es aber die Konfessionsmigration genauer zu umreißen (Teil II), um dann in einem längeren Hauptteil (Teil III) an einzelnen Beispielen die konkreten Abläufe, Institutionen und Bewältigungsstrategien den jüdischen und christlichen Teil der Konfessionsmigration zu vergleichen. Abschließend lassen sich einige längerfristige Konsequenzen der frühmodernen Migrations- und Minderheitenerfahrung erörtern (Teil IV).

\section{II.}

Konfessionalisierung - das sei hier nur in Erinnerung gerufen ${ }^{8}-$ meint den mit allen politischen und kirchlichen Mitteln der Kontrolle und Repression

7 Horst Pietschmann, Spanien und Portugal, in: Klaus J. Bade (Hg.), Enzyklopädie Migration in Europa. Vom 17. Jahrhundert bis zur Gegenwart, Paderborn 2007, S. 220-242, hier: S. 229. Vgl. auch den Beitrag von Manuel F. Fernández Chaves und Rafael M. Pérez García, in diesem Band, S. 235-264.

8 Zuletzt als Überblick zu Inhalt und Historiographie des Konfessionalisierungsansatzes: Ute Lotz-Heumann, Confessionalization, in: David M. Whitford, Reformation and Early Modern Europe, a guide to research, Kirksville/MO 2008, S. 136-157; Stefan Ehrenpreis/Ute LotzHeumann, Reformation und konfessionelles Zeitalter, Darmstadt 2002, S. 62ff. Vgl. auch die diesbezüglichen Aufsätze in Wolfgang Reinhard, Ausgewählte Abhandlungen, Abt. 2: Konfessionen, Berlin 1997, S. 77-151; Heinz SchiLling, Ausgewählte Abhandlungen zur europäischen Reformations- und Konfessionsgeschichte, Teil IV: Konfessionalisierung und nationale Identitäten, Berlin 2002, S. 433-700. 
vorangetriebenen Versuch der politischen, gesellschaftlichen, kulturellen und religiösen Vereinheitlichung eines Untertanenverbandes oder eines Staates im Zeichen der aus der Reformation hervorgegangenen beziehungsweise als Antwort auf sie entstandenen Weltanschauungssysteme des Katholizismus, Luthertums, Calvinismus oder Anglikanismus. Zentraler Teil dieses staatlich-politischen und religiös-kirchlichen Formierungsprogramms war die religiös-weltanschauliche Vereinheitlichung der Untertanen, die nötigenfalls mit Zwang und drastischen Strafen bis hin zu Vermögensentzug und Hinrichtung durchgesetzt wurde und in der andersgläubigen Bevölkerung eine mehr oder weniger lang anhaltende Fluchtbewegung auslöste. Der Auftakt dieses transkontinentalen Migrationsgeschehens aus religiösen beziehungsweise konfessionellen Gründen war in gewisser Weise bereits vorreformatorisch auf der Iberischen Halbinsel erfolgt: Präludiert von dem Pogrom des Jahres 1391, das die erste antisemitische Großkampagne des Erzdiakons von Écija Fernando Martínez ausgelöst hatte, erzwang dort bekanntlich die Reconquista eine umfangreiche Moslem- und Judenmigration, der ein gutes Jahrhundert später mit der gewaltsamen Verfolgung der formell christianisierten Morisken und conversos eine zweite Welle folgte.

Diese Repressalien gegen Andersgläubige brachten dem lateinischen Europa zwischen dem ausgehenden 15. und der Mitte des 18. Jahrhunderts einen beträchtlichen transkontinentalen Bevölkerungsaustausch, eine so genannte »frühmoderne Konfessionsmigration « - wegen des genannten Auslösungsfaktors, aber auch wegen der spezifischen Bedingungen der Ansiedlung ${ }^{9}$. Denn auch das gesellschaftliche und kirchliche Leben der Zufluchtsorte war mindestens bis Mitte des 17. Jahrhunderts durch den Konfessionalismus und seine Zwänge geprägt, wenn auch in unterschiedlicher Intensität, am stärksten in den katholischen und lutherischen Städten und Territo-

9 Begriff und Sache »Konfessionsmigration « genauer entwickelt auf der Basis meiner Dissertation (Heinz Schilling, Niederländische Exulanten im 16. Jahrhundert. Ihre Stellung im Sozialgefüge und im religiösen Leben deutscher und englischer Städte, Gütersloh 1972) in Heinz Schilling, Innovation through Migration. The Settlements of Calvinistic Netherlanders in Sixteenth- and Seventeenth-Century Central and Western Europe, in: Histoire sociale - Social History 16 (1983), S. 7-33; ders., Confessional Migration as a Distinct Type of Old European Long-distance Migration, in: Simonetta CAVACIOCCHI (Hg.), Le migrazioni in Europa, Secc. XIII-XVIII, Prato 1994, S. 175-189; ders., Confessional Migration and Social Change. The Case of the Dutch Refugees of the Sixteenth Century, in: Paul KLEP/Eddy van CAuwENBERGHE (Hg.), Entrepreneurship and the Transformation of the Economy (10th bis 20th Centuries). Essays in Honour of Herman Van der Wee, Löwen 1994, S. 321-334; ders., Die frühneuzeitliche Konfessionsmigration, in: Klaus J. BADE (Hg.), Migration in der europäischen Geschichte seit dem späten Mittelalter. Vorträge auf dem Deutschen Historikertag in Halle a.d. Saale, 11. Sept. 2002, Osnabrück 2002, S. 67-89. - Um Missverständnissen vorzubeugen, sei nochmals explizit betont, dass, anders als vor allem von Wirtschaftshistorikern gelegentlich unterstellt, der Begriff »Konfessionsmigration« weder in Bezug auf die christlichen noch auf die jüdischen Migranten wirtschaftliche Motive und Konsequenzen ausschließt, sondern sie theoretisch-methodisch als mit den religiösen Momenten zu einem Syndrom verbunden integriert. 
rien Deutschlands, weniger ausgeprägt in Skandinavien oder England, am schwächsten in der notorisch libertären Nordniederländischen Republik. Bezeichnenderweise waren es auch die für den christlichen Dissens relativ offenen Gesellschaften, die sephardische Migranten aufnahmen. Konfessionelle Erwägungen spielten auch dort eine Rolle, wo sich die Glaubensflüchtlinge des Schutzes und der Privilegierung durch eine glaubensverwandte Obrigkeit erfreuen konnten - so besonders deutlich bei der Aufnahme der Hugenotten in Brandenburg, die nicht nur der Wirtschaft und dem allgemeinen Landesausbau dienen, sondern den reformierten Glauben der Hohenzollerndynastie stärken und damit gleichzeitig helfen sollte, die Widersetzlichkeit der lutherischen Untertanen zu brechen. Ein einprägsames Fallbeispiel bietet das lutherische Magdeburg, wo nach der Herrschaftsübernahme durch die calvinistischen Hohenzollern 1680 die Aufnahme Pfälzer und französischer Reformierter die landesherrliche Kirchenhoheit und die Abschaffung der politischen wie stadtkirchlichen Unabhängigkeit der Stadtrepublik besiegelte ${ }^{10}$.

Die religiös bedingte Auswanderung von englischen Puritanern nach Amerika mitgerechnet, erfasste die Konfessionsmigration über die drei Jahrhunderte der Frühen Neuzeit hinweg insgesamt rund eine Million Menschen. Betroffen waren nahezu alle Konfessionen, Religionen und Denominationen der lateinischen Christenheit. Im 16. Jahrhundert waren es vor allem die Reformierten aus den Niederlanden und Frankreich, daneben Täufer, die abgesehen von den wenigen Monaten ihres Neuen Jerusalems in Münster und einigen ostmitteleuropäischen Regionen allenthalben vertrieben wurden und nur im Untergrund leben konnten sowie zu Mitte des Jahrhunderts eine relativ kleine Gruppe von Lutheranern - einerseits Philippisten, anderseits Gnesiolutheraner. Im 17. Jahrhundert waren es Protestanten aus Österreich und Böhmen (Reformierte, Lutheraner und Böhmische Brüder) sowie englische Puritaner, die nach Amerika auswichen. Im 18. Jahrhundert folgte als letzte große Welle der Konfessionsmigration die Auswanderung von Lutheranern aus dem Erzstift Salzburg. Über die ganze Periode hin erstreckte sich die Migration der Waldenser vor allem aus den Alpentälern. Schließlich migrierten, wenn auch in geringerem Umfang, auch Katholiken, namentlich in den 1570er und 1580er Jahren aus den Calvinistenrepubliken in Gent, Antwerpen und anderen südniederländischen Städten, später aus England, Irland und Skandinavien.

Indirekt von den konfessionalistischen Formierungsprozessen der christlichen Mehrheitsgesellschaft betroffen waren - wie bereits erwähnt - auch die im lateinischen Europa lebenden Juden, die daher auch Anteil an der

10 Matthias Puhle (Hg.), Magdeburg 1200. Mittelalterliche Metropole, preußische Festung, Landeshauptstadt, Darmstadt 2005, S. 206ff.; ders. / Peter Petsch (Hg.), Magdeburg. Die Geschichte der Stadt 805 bis 2005, Dosse (Saalkreis) 2005, S. 460ff. 
Konfessionsmigration hatten. Konkret geht es um denjenigen Teil der sephardischen Migration, der sich auf mehr oder weniger konfessionalisierte Städte und Länder West- und Mitteleuropas richtete.

Jede einzelne Welle dieser Konfessionsmigration hatte ihr eigenes Sozialund Religionsprofil. Im Folgenden stehen zwei Gruppen im Blickpunkt, die in ihrem Migrationsprofil sowie in den Ordnungsprinzipien und Verhaltensweisen als religiöse Minderheiten manche Parallele erkennen lassen, nämlich auf die viel beachteten calvinistischen Exulanten vornehmlich aus den Niederlanden und auf die sephardischen Migranten, deren Geschichte in der Regel isoliert von derjenigen der christlichen Mehrheitsgesellschaft behandelt wird. Dieser Vergleich ist ein kleiner Mosaikstein für eine integrative Geschichte von Juden und Christen in der werdenden Neuzeit.

Unter den christlichen Migranten stellten die Reformierten oder Calvinisten zweifellos den Löwenanteil - im 16. und frühen 17. Jahrhundert zwischen 100.000 und 150.000 Niederländer oder Wallonen; seit Mitte des 16. Jahrhunderts Engländer, zunächst eine kleine Gruppe, die vor der katholischen Reaktion unter Maria Tudor auf den Kontinent flohen, ein halbes Jahrhundert später ein kontinuierlicher Strom von Puritanern, deren calvinistische Gesinnung sie den Anglikanismus fliehen ließ, insgesamt einige 10.000; eine Gruppe Italiener, vor allem aus Lucca; zu Beginn des Dreißigjährigen Krieges die Pfälzer sowie ein Teil der böhmischen und österreichischen Exulanten; im späten 17. Jahrhundert mit rund $150.000^{11}$ dann nochmals eine quantitativ größere Welle aus Frankreich, die Hugenotten, die aufgrund ihrer ausgeprägten Gedächtniskultur und Geschichtspolitik bis heute das Bild des protestantischen refuge bestimmen - sehr zu unrecht, wenn man die skizzierte Konfessionsmigration insgesamt und insbesondere die frühe, in vielem prägende Dominanz der Niederländer ins Auge fasst. Für die Sephardenmigration sind quantitative Angaben noch schwieriger zu erlangen, da auch sie durch Sekundärwanderungen vor allem über Portugal und Frankreich gekennzeichnet war, vor allem aber wegen der converso-Problematik. Ein einigermaßen verlässlicher Weg ist die statistische Hochrechnung der Zahlen zu den einzelnen Ansiedlungsorten. Danach ist die früher in der Regel angesetzte Zahl von insgesamt 300.000 Flüchtlingen wohl zu hoch und auf rund 200.000 zu korrigieren -80.000 bis 110.00 aus der Krone Kastilien, gut 10.000 aus Aragonien, 70.000 aus Portugal. Wanderungsziele waren ${ }^{12}$ zunächst Handelsorte in Nordafrika, in der Levante und in den nichthabsburgischen Territorien Italiens (darunter auch Rom und der Kirchenstaat) so-

11 Zahlen nach Matthias Asche, Hugenotten in Europa seit dem 16. Jahrhundert, in: BADE, Enzyklopädie Migration, S. 635-642, hier: S. 636.

12 Georg Bossong, Die Sepharden. Geschichte und Kultur der spanischen Juden, München 2008, S. 57f., 70ff.; vgl. Karte ebd., S. 129. 
wie im Osmanischen Reich, vor allem Saloniki, weil man aus den arabischen Herrschaften des mittelalterlichen Spanien die Toleranz des Islam in Erinnerung hatte. Die Hafen- und Handelsstädte Nordwesteuropas wurden im wesentlichen von späteren Migrationswellen des späten 16. und des 17. Jahrhunderts aufgesucht, die durch die katholische Konfessionalisierung der spanischen Königreiche und des seit 1580 mit diesen in Personalunion vereinigten Portugal ausgelöst wurde: In Amsterdam stieg die Zahl der Mitglieder der Sephardenkolonie von einem guten Dutzend Familien ausgangs des 16. Jahrhunderts auf eine Gemeindestärke von 500 bis 700 Mitglieder im Jahr 1612, 1.000 bis $1.500 \mathrm{im}$ Jahr 1620 und rund 2.000 bis $2.500 \mathrm{zu}$ Ende des 17. Jahrhunderts ${ }^{13}$. Die Hamburger Gemeinde, zu der zeitweilig auch diejenige in der benachbarten schauenburgisch-pinnebergischen Landstadt Altona zu zählen ist, wuchs von rund 100 Personen insgesamt zu Anfang auf $500 \mathrm{zu}$ Mitte und rund $1.000 \mathrm{zu}$ Ende des 17. Jahrhunderts, wobei die Gemeinde selbst nie mehr als 600 bis 650 Mitglieder zählte ${ }^{14}$.

III.

Vergleicht man nun den christlich-calvinistischen und den jüdisch-sephardischen Zweig der frühneuzeitlichen Konfessionsmigration, so lassen sich folgende, in einem Aufsatz nur holzschnittartig charakterisierbare Züge festhalten ${ }^{15}$ :

Erstens: Beide Gruppen stammten aus ökonomisch und kulturell fortschrittlichen Ländern und sorgten daher in vielen ihrer Gaststädte oder Gastländer für einen gewaltigen Innovationsschub. Im Falle der Reformierten

13 Hiltrud Wallenborn, Bekehrungseifer, Judenangst und Handelsinteresse. Amsterdam, Hamburg und London als Ziele sefardischer Migration im 17. Jahrhunderts, Hildesheim 2003, S. 335ff. - Es ist bezeichnend, dass diese wichtige und gründliche Arbeit zur jüdischen Ansiedlung in Hamburg so gut wie nicht wahrnimmt, dass sich zur gleichen Zeit eine calvinistische Minderheit in der Hansestadt befand, deren Schicksal in vielem dieselben Züge aufweist wie dasjenige der jüdischen Minderheit.

14 Ebd., S. 11, 152, 337; Hermann Kellenbenz, Sephardim an der unteren Elbe. Ihre wirtschaftliche und politische Bedeutung vom Ende des 16. bis zum Beginn des 18. Jahrhunderts, Wiesbaden 1958, S. 27ff. Vgl. auch den Beitrag von Klaus WeBer, in diesem Band, S. 137-168.

15 Daten und Informationen zu den calvinistischen Minderheitengemeinden sind in der Regel folgenden Arbeiten entnommen: Schilling, Innovation through Migration; ders., Confessional Migration as a Distinct Type; ders., Confessional Migration and Social Change; ders., Die frühneuzeitliche Konfessionsmigration. Grundlegend zu den Strukturen und Vorgängen in den sephardischen Ansiedlungen die Arbeiten von Yosef Kaplan, Between Christianity and Judaism in Early Modern Europe. The Confessionalization Process of the Western Sephardi Diaspora, in: Lothar GALL / Dietmar WilloweIT (Hg.), Judaism, Christianity, and Islam in the Course of History: Exchange and Conflicts, München 2010; ders., From Christianity to Judaism. The story of Isaac Orobio de Castro, Oxford 1989; ders, An Alternative Path to Modernity. The Sephardi Diaspora in Western Europe, Leiden 2000. 
wird ein solcher ökonomischer und kulturell-wissenschaftlicher Aufschwung insbesondere mit den späteren Hugenotten in Verbindung gebracht. Doch bereits die frühe Welle niederländischer und - nicht selten fälschlicherweise als Franzosen verrechnet - wallonischer Exulanten brachte einen tiefgreifenden sozio-ökonomischen und kulturellen Wandel auf den Weg: In ihren deutschen, englischen oder skandinavischen Gastgesellschaften sorgten sie für die Ansiedlung neuer Gewerbezweige und die Einführung neuer Techniken beim Seidefärben oder beim Bleichen, im Handel, bei der Geldschöpfung, im Versicherungswesen sowie bei den Betriebsverfassungsformen. Insbesondere die Textilproduktion - Mischgewebe, Nouvelle Draperie - und die Manufaktur von Luxusgütern - so Zuckersieden, Edelsteinschleifen, Tapisserie, Kunstgewerbe und Malerei, namentlich im pfälzischen Frankenthal erfuhren einen raschen Aufschwung. Von all dem profitierten Städte wie London, Norwich, Frankfurt, Köln und Hamburg, die zu Wirtschafszentren des 17. Jahrhunderts aufblühten. Vor allem aber ließ die von den Calvinisten mit Nachdruck verfolgte Durchsetzung des Verlagswesens, der Akkordund Lohnarbeit oder ähnlicher neuer Betriebsformen in Territorialstädten auf dem platten Land ganz neue, modernere Formen des Wirtschaftens und ein aus den traditionellen »feudalen « Strukturen ausbrechendes frühmodernes Wirtschaftsbürgertum entstehen, so vor allem am Niederrhein in Stolberg, Monschau und Krefeld. Das wohl imposanteste Beispiel umstürzender Entwicklungshilfe durch die calvinistische Migration bieten jedoch Schweden und der dortige Aufbau eines frühmodernen Montan- und Metallverarbeitungsgewerbes durch die wallonischen Unternehmer Louis de Geer und die Brüder Trippen zusammen mit einer calvinistischen Arbeiterschaft, die teilweise über eine Sekundärmigration aus dem Aachener Raum nach Skandinavien kam. Umstürzend war diese Entwicklung vor allem auch in politischer Hinsicht, weil erst sie die ökonomischen und fiskalischen Grundlagen für die kurz nach Beginn der niederländischen Einwanderung einsetzende schwedische Großmachtpolitik legte.

Da die wirtschaftliche Oberschicht der Sepharden zunächst kaum im Gewerbe, sondern ganz überwiegend im Fernhandel tätig war, ergaben sich kaum vergleichbare Konsequenzen für die Organisation und Verfassung der Stadtwirtschaft der Gastgesellschaften. Gleichwohl haben die »Portugiesen « entscheidend zum Aufschwung Amsterdams und Hamburgs, später auch Londons beigetragen - indem sie diese nordwesteuropäischen Städte in einem Moment, als sie noch weitgehend von ihren mittelalterlichen Handelsverbindungen - im Falle Hamburgs der Hanse - lebten, an das Verkehrs- und Handelsnetz Südwesteuropas und des Überseehandels anschlossen - an den Spanien- und Portugalhandel, an den Kolonialwarenimport, vor allem brasilianischen Zuckers und asiatischer Gewürze, an den Handel mit Diamanten und anderen Luxusgütern. Auf dem Gewerbesektor waren sephardische Ju- 
den als Unternehmer von Zuckerraffinerien, in der Diamantenschleiferei und der Tabakverarbeitung tätig. Also Manufakturbetriebe außerhalb der traditionellen städtischen Zunftverfassung, womit sie in Hamburg allerdings wenig reüssierten ${ }^{16}$. Umso größer waren die Erfolge der sephardischen Finanziers, die in Hamburg entscheidend dazu beitrugen, dass die Stadt während des Dreißigjährigen Krieges zur finanziellen Schaltstelle im Nordwesten des Reiches und hinauf nach Skandinavien aufstieg. Namentlich Diego Teixeira und sein Sohn Manuel fungierten als Finanziers der skandinavischen Kronen, zeitweilig auch als persönliche Berater Königin Christinas von Schweden ${ }^{17}$.

Die technischen und betriebsverfassungsmäßigen Innovationen der calvinistischen Migranten aus den Niederlanden, aber auch die neuen, den frühmodernen Welthandel in die Gaststädte lenkenden Unternehmungen der Sephardenkolonie veränderten vor allem in Hamburg und London das traditionelle Wirtschafts- und Sozialgefüge der Gastgesellschaft tiefgreifend und riefen daher bei den Einheimischen Ängste und Fremdenfeindschaft hervor. In den deutschen Städten, anfangs auch in London, kaum aber in dem früh multikonfessionellen Amsterdam, kamen die offenkundigen religiösen Unterschiede hinzu, die innerchristlich hauptsächlich mit den rationalen Abendmahlsriten der Calvinisten ins Auge fielen. Die einheimische Geistlichkeit, insbesondere die lutherische und die katholische in Deutschland, trug zur Verschärfung der Fremdenfeindschaft bei, indem sie in der zeitüblichen Weise gegen die Andersgläubigen polemisierte - gegen die Juden ebenso wie gegen die konfessionell abweichenden Christen, und zwar - in unserem Zusammenhang bemerkenswert - häufig zur selben Zeit, gleichsam im selben Atemzug. So sehr der Antijudaismus in allen christlichen Konfessionen verbreitet war, war er in den vorliegenden Fällen kaum handlungsleitend. Der Stadtgeistlichkeit ging es vielmehr um die konfessionelle Glaubenseinheit ihrer Kommunen, die sie durch den christlichen Dissens ebenso bedroht sah wie durch die Juden. In Deutschland und England kam es daher immer wieder zu Ausschreitungen gegen die Eingewanderten und ihre Kirchen beziehungsweise Synagogen sowie zu Ausweisungen durch die Obrigkeiten - im

16 Kellenbenz, ebd.; ders., Unternehmerkräfte im Hamburger Portugal. Spanienhandel 15901625, Hamburg 1954. Jüngere Überblicksdarstellungen mit Spezialliteratur: Klaus WeBER, Were Merchants More Tolerant? Godless Patrons of the Jews' and the Decline of Sephardi Community in Late Seventeenth-Century Hamburg, in: David CESARINI/Gemma Romain (Hg.), Jews and Port Cities, 1590-1990. Commerce, Community and Cosmopolitanism, London 2004, S. 77-92 (mit einer Bemerkung zur historiographischen Einordnung der judengeschichtlichen Arbeiten von Hermann Kellenbenz, Sephardim an der unteren Elbe, S. 90 und Pietschmann, Spanien und Portugal). Ausführlich dazu die Untersuchungen von Jonathan Israel, insbesondere Jonathan IsRaEL, European Jewery in the Age of Mercantilism (1550-1750), Oxford 1998; ders., Empires and entrepots, London 1990, S. 425ff.; WALLENBorn, Bekehrungseifer, S. 398ff.

17 Vgl. Isidore Singer/Meyer Kayserling, Art. Teixeira, in: Jewish Encyclopedia.com, URL: http://jewishencyclopedia.com (eingesehen am 31.7.2009). 
katholischen Köln und Aachen ebenso wie im lutherischen Frankfurt (mit Verlagerung der calvinistischen Fremdenkolonien nach Bockenheim beziehungsweise in die Neustadt Hanau) und in Hamburg, wo Calvinisten wie Juden wiederholt in die benachbarten Landstädte Stade im Hochstift Bremen oder Altona im Territorium Schauenburg-Pinneberg ausweichen mussten. Wegen des ökonomischen Schadens, der regelmäßig mit der Verlagerung der Wirtschaftsaktivitäten der Religionsmigranten eintrat, wurden die religiösen und sozialen Sanktionen in der Regel aber bald wieder aufgehoben; so auch in der katholischen Metropole Köln.

Ohne die prinzipiellen Unterschiede zwischen konfessionell-christlicher und jüdischer Minderheit zu verkennen, lässt sich doch für beide ein auf Generationen hin unveränderbarer Sonderstatus ausmachen - am deutlichsten natürlich bei den Juden, aber auch bei den Reformierten, die in vielen Gaststädten über Generationen hinweg wenn nicht Fremdkörper, so doch eine sozial wie kulturell segregierte Sondergruppe blieben. Neben ihrer abweichenden Konfession beziehungsweise Religion war das ihrem ökonomischen Erfolg und einem neuzeitlichen »Sozialprestige « geschuldet, das im Gegensatz zum ständischen, auf Geburt und gesellschaftskonformer Ehre basierenden Sozialstatus ihrer Gastgesellschaft auf Vermögen und Kapital basierte, die teils zur ostentativen Repräsentation der Vermögensüberlegenheit eingesetzt wurden. Für Frankfurt und die dorthin eingewanderte reformierte Minderheit hat das noch Goethe in der zweiten Hälfte des 18. Jahrhunderts beobachtet: »Die sogenannten Reformierten«, so notiert er im siebzehnten Buch von »Dichtung und Wahrheit«, »bildeten (in Frankfurt) wie auch an anderen Orten die Refugiés, eine ausgezeichnete Klasse $\ll^{18}$. Und während die einheimischen Lutheraner das Recht hätten, sonntags bei Wind und Wetter zu Fuß in die städtischen Pfarrkirchen zu gehen, leisteten sich die zugewanderten Reformierten, denen öffentliche Gottesdienste in der Stadt versagt waren, demonstrativ und zum Ärger der Altfrankfurter den Luxus, mit der Kutsche ins nicht weit vor den Toren gelegene Bockenheim zur Kirche zu fahren. Und ihre ebenfalls außerhalb der Stadt gelegenen Grabplätze schmückten sie mit pompösen Epitaphen und Statuen aus, wie sie auch ihre Häuser und Villen mit erlesenen Kunstwerken versahen - wie sie uns heute noch in der Kunstund Luxusproduktion der Exulantenstadt Frankenthal oder dem prächtigen Porträt des Frankfurter Bankiers Johann von Bodeck vor Augen stehen ${ }^{19}$.

18 Johann Wolfgang GoEthe, Dichtung und Wahrheit. Vierter Teil, Siebzehntes Buch, in: Ders., Werke Hamburger Ausgabe X, Autobiographische Schriften II, München 1982, S. 120.

19 Vgl. den Katalog: Edgar HürkeY (Hg.), Kunst, Kommerz, Glaubenskampf. Frankenthal um 1600, Worms 1995; Wim Blockmans u.a., Republiek tussen Vorsten. Oranje, Opstand, Vrijheid, Geloof, Zutphen 1984, S. 132. 
Ähnlich die Sephardenkolonien. In Amsterdam zeugt bis heute die portugiesische Synagoge vom Reichtum der Gemeinde und ihrer Überlegenheitsrepräsentation, und zwar auch und gerade gegenüber den Aschkenasim, deren bescheidene Synagoge keinen Steinwurf weit entfernt liegt (heute jüdisches Museum). Die Hamburger Kolonie besaß zwar eine breite Mittel- und Unterschicht ${ }^{20}$; umso auffallender und von den Einheimischen nur zu gerne als Vermögensdarstellung der Juden bewertet war die Statusrepräsentation der extrem reichen Oberschicht. Allen voran stand die der Familie Teixeira (Diego und Sohn Manuel), die ganz wie die von Goethe beschriebenen reformierten Unternehmer Frankfurts in Prachtkutschen mit livrierter Dienerschaft durch die Stadt fuhr, in ihrer Residenz am Jungfernstieg die Kostbarkeiten der Welt sammelte und dort mehrmals - 1661 sogar für etwa ein Jahr Königin Christina von Schweden beherbergte, womit sie die Überlegenheit ihrer Villa und ihrer Gastfreundschaft über die Möglichkeiten des Gästehauses des Magistrats demonstrierte ${ }^{21}$.

Zweitens: Vergleichbar sind sephardisch-jüdische und calvinistisch-christliche Migranten des weiteren in der Organisation ihrer Gemeinden und des religiösen Lebens: Der Calvinismus erscheint im öffentlichen Geschichtsbild der Gegenwart weitgehend im Licht der religionssoziologischen beziehungsweise machtpolitischen Interpretationen von Max Weber, Georg Jellinek oder Otto Hintze. Das sind aber - wie viele unserer Geschichtsbilder - Produkte des 19. Jahrhunderts. In der Frühen Neuzeit waren es nicht Kapitalismus-, Parlamentarismus- oder Machtstaatsaffinität, sondern die frühneuzeitliche Existenz als Flüchtlings- und in ihrem Rechtsstatus stets labile Minderheitengemeinden, die in mannigfacher Weise das konfessionskulturelle Profil des Calvinismus bestimmten ${ }^{22}$ : Das Kirchenwesen der Exulanten entwickelte sich in enger Wechselwirkung mit ihrer sozialen Flüchtlings- und Minderheitenexistenz. Das gilt als erstes für Verfassung und Organisation der Gemeinden, aber auch für die Frömmigkeit und die Spiritualität, ja selbst für die

20 Detaillierte Angaben bei WallenBorn, Bekehrungseifer.

21 Vgl. Singer/Kayserling, Art. Teixeira, in: Jewish Encyclopedia.com, URL: http://jewishency clopedia.com (eingesehen am 31.7.2009).

22 Näheres dazu bei Heinz Schilling, Peregrini und Schiffchen Gottes, Flüchtlingserfahrung und Exulantentheologie des frühneuzeitlichen Calvinismus, in: Ansgar ReIss/Sabine WiTT (Hg.), Calvinismus. Die Reformierten in Deutschland und Europa, Dresden 2009, S. 160-168; ausführlicher ders., Calvin und Calvinismus in europageschichtlicher Perspektive, in: Anton Schinding/Márta Fata (Hg.), Calvin und Reformiertentum in Ungarn und Siebenbürgen. Helvetisches Bekenntnis, Ethnie und Politik vom 16. Jahrhundert bis 1918, Münster 2010, S. 1-21; sowie in: GWU 60 (2009), S. 372-386. Grundlegend zum kirchlichen Leben der Flüchtlingsgemeinden weiterhin Aart Arnout van Schelven, De Nederduitsche Vluchtelingenkerken der 16e eeuw in Engeland en Duitsland, Den Haag 1909; Owe Boersma, Vluchtig Voorbeeld. De nederlands, franse en italiaanse Vluchtelingenkerken in Londen 1568-1585, Diss. Theologische Akademie, Kampen 1994 und Philippe Denis, Les églises d'étrangers en pays rhénans (1538-1564), Paris 1984. 
Theologie im engeren Sinne. Die Erfahrung von Verbannung und Flucht sowie die spezifischen Bedingungen von Fremdenkirchen prägten bereits das Kirchenverständnis und die Ordnungslehre der reformierten »Kirchenväter « Johannes Calvin ebenso wie Johannes a Lasco.

Umgekehrt war die in Calvins Ordonnances ecclésiastiques von 1541 und den verschiedenen Ausgaben der Institutio zwischen 1536 und 1559 systematisch entwickelte Ämter- und Ordnungslehre wie keine zweite geeignet, Flüchtlingskirchen unter fremder oder gar feindlicher Obrigkeit Schutz und Funktionsfähigkeit zu garantieren: Nicht Landes- oder Nationalkirchen wie bei den Lutheranern, Katholiken und Anglikanern machten den institutionellen und geistigen Kern des Calvinismus aus, sondern ein Netz von Flüchtlings-, Untergrund-, Minderheiten- oder Sonderkirchen, das seit Mitte des 16. Jahrhunderts den Kontinent überspannte.

Jede Einzelgemeinde war Kirche im vollen Sinne und konnte entsprechend legitim und umfassend handeln - theologisch wie kirchenpolitisch. Sie regierte und verwaltete sich durch unabhängig und selbsttätig arbeitende Selbstverwaltungsgremien, die von den vier evangelischen Ämtern Prediger und Älteste im Presbyterium oder Kirchenrat sowie Diakone für die Armenund Altenfürsorge und Lehrer für die religiöse und allgemeine Bildung der Jugend getragen wurde. Der Zusammenhalt dieser autonomen Ortsgemeinden und der Austausch zwischen ihnen erfolgte anfangs durch eine intensive transkontinentale Reisetätigkeit führender Prädikanten und Ältesten, letztere häufig im Zusammenhang mit Geschäftsreisen. Seit den 1560er Jahren entwickelte sich dann das Konzept eines förmlichen Synodalsystems, das die Fremdenkirchen zu Regional- und Nationalsynoden sowie einer internationalen Generalsynode zusammenfassen sollte. Richtungweisend wurden die Synoden der niederländischen Flüchtlingskirchen des Jahres 1571 im rheinischen Bedburg und insbesondere im ostfriesischen Emden, von der längerfristig Impulse auch für einheimische reformierte Kirchen außerhalb des Flüchtlingsnetzes ausgingen. Auf Dauer funktionsfähig erwies sich das Synodalsystem jedoch nur auf territorialer oder regionaler Ebene, während wegen starker Widerstände von Seiten der Obrigkeiten »Nationalsynoden « nur ausnahmsweise und eine internationale Generalsynode nur einmal stattfinden konnte, nämlich 1618/19 im holländischen Dordrecht.

Die jüdischen Fremdenkolonien hatten ihren Gottesdienst und ihr gesamtes religiöses Leben ganz ähnlich zu organisieren ${ }^{23}$. Das gilt insbesondere für das lutherische Hamburg unter dem konfessionalistischen cuius-regio-eiusreligio-Prinzip und der religio-vinculum-societatis-Maxime. Der Kontrakt, den der Magistrat 1612 mit der Sephardenkolonie abschloss, hatte eine rein wirtschaftsgeschichtliche Zielsetzung. Das Recht auf jüdische Gottesdienste

23 Ausführlich bei WaLlEnBorn, Bekehrungseifer, S. 427ff. 
war damit nicht verbunden, und zwar auch nicht in Privathäusern, wie es die Stadt etwa den Residenten katholischer Mächte zugestand, voran den Vertretern des Kaisers. Die Juden waren somit auf klandestine Gottesdienste angewiesen, deren Duldung oder Verfolgung je nach den politischen Machtverhältnissen innerhalb der Gastgesellschaft schwankte - ganz ähnlich wie im Falle der calvinistischen »Kirchen unter dem Kreuz« unter katholischer oder lutherischer Obrigkeit. Seit Mitte des 17. Jahrhunderts unternahm die Gemeindeleitung wiederholt Versuche, die Betstuben in jüdischen Privathäusern zu einer öffentlichen Synagoge zusammenzuführen, scheiterte damit aber stets am Widerstand des Geistlichen Ministeriums der lutherischen Stadtkirche. In Amsterdam und London wurden von Anfang an Privatgottesdienste formell beziehungsweise informell geduldet, nicht aber der Bau einer Synagoge. Die Amsterdamer Judenverordnungen von 1612 und 1616 verboten sogar ausdrücklich öffentliche Gottesdienste; wie beim christlichen Dissens, hier konkret der Katholiken, duldete der Magistrat aber die allseits bekannten katholischen schuil-kerken und schuil-synagogen, wie sie bereits seit 1612 an der Houtgracht, später auch andernorts bestanden (also verborgene/klandestine Kirchen und Synagogen). Ab 1629 wurde die schuil-synagoge an der Houtgracht zur Gesamtsynagoge aller Amsterdamer Sepharden und zu einem als solchem auch erkennbaren Gottesdienstgebäude ausgebaut; 1671 bis 1675 wurde die heute noch vorhandene Prachtsynagoge für über hundert Gottesdienstteilnehmer errichtet.

Religiöses Leben im Geheimen war den Sepharden als conversos auf der Iberischen Halbinsel durchaus vertraut. In ihren außeriberischen Zufluchtsstätten organisierten sie nun aber ein geheimes Gemeindeleben, und zwar mit Institutionen und Modalitäten, die denjenigen des klandestinen Calvinismus durchaus ähnlich waren: An der Spitze der Gemeinde und zugleich der Fremdenkolonie - auch das der Situation bei den Calvinisten ähnlich - stand ein Gemeinderat, der Maamad ${ }^{24}$, mit weitreichenden Befugnissen, wie dem Protokollbuch der Hamburger Sephardengemeinde zu entnehmen ist:

Dieser Vorstand der sieben Gewählten und die, welche ihnen im Amte folgen, sollen volle Befugnis haben und absolute Gewalt zur Leitung dieser Nation (nação) haben, sowohl für Angelegenheiten mit dem Senat wie auch bezüglich der Ausgabe aus der allgemeinen Kasse, zur Ausstellung und zur Absetzung von Amtsträgern, nebst allen übrigen dieselben angehenden Dinge ${ }^{25}$.

24 Ausführlich am Beispiel Hamburgs: Ben-Zion Ornan Pinkus, Die Portugiesische Gemeinde in Hamburg und ihre Führung im 17. Jahrhundert, in: Michael Studemund-Halévy (Hg.), Die Sefarden in Hamburg, 2 Bde., Hamburg 1994, hier: Teil I, S. 3-36.

25 Zitiert nach Pinkus, Die Portugiesische Gemeinde, S. 14. 
Auch im Wahlverfahren und in der sozialen Zusammensetzung zeigen calvinistisches und sephardisches Leitungsgremium Ähnlichkeiten, und zwar bereits bei der Diskrepanz zwischen Norm und Realität: Wie die calvinistischen Presbyterien ungeachtet aller gemeindepartizipatorischen Normen sich weitgehend aus den vermögenden Honoratioren der Fremdenkolonien rekrutierten ${ }^{26}$, so wich die Realität des Wahlvorgangs auch bei den Sephardengemeinden immer wieder von der Norm ab. In Hamburg zum Beispiel sollte der Maamad von allen Vorstehern der großen Familien gewählt werden, der Maamad neigte aber wiederholt zur Selbstergänzung ${ }^{27}$ und damit ähnlich wie zahlreiche Presbyterien zur realpolitischen Abschaffung der Gemeindepartizipation, die man gleichwohl theoretisch und theologisch zur Grundlage der eigenen Legitimität machte. In Hamburg kam es zu einem jahrzehntelangen Ringen zwischen Oligarchisierungs- und Demokratisierungstendenzen. Für den Maamad ebenso wie für das Presbyterium galt im Prinzip die Pflicht, das Amt ohne Wenn und Aber anzunehmen. Dennoch kam es immer wieder zu Verweigerungen oder Rücktritten, die das Plenum jeweils mit kirchlichen Buß- und empfindlich hohen Geldstrafen ahndete - in London zum Beispiel mit 10 Pfund Sterling und einem mehrjährigen Ausschluss von hervorgehobenen zeremoniellen Diensten (Aufruf zum Sefer; Erlaubnis zur guten Tat) ${ }^{28}$.

Ein formelles System übergemeindlicher Versammlungen nach Art des calvinistischen Synodalsystems gab es zwar nicht; es existierte aber ein informelles Netzwerk, das die sephardische Diaspora nicht nur zum Austausch beziehungsweise zur Abstimmung theologisch-dogmatischer Positionen befähigte, sondern auch zur institutionellen Vereinheitlichung, etwa bei der Zusammensetzung und Funktionsweise des Maamad ${ }^{29}$. Eine Schlüsselrolle scheint dabei die portugiesisch-spanische Gemeinde in Venedig eingenommen zu haben ${ }^{30}$, wie die Lagunenstadt überhaupt einen Zentralknoten im Kommunikationsnetz der Sephardendiaspora bildete.

Drittens: Auch im Aufgabenbereich und in der Legitimationsgrundlage weisen beide Leitungsinstitutionen Ähnlichkeiten auf. So erfasste ihre Tä-

26 Ausführliche prosopographische Analysen hierzu Heinz Schilung, Calvinistische Presbyterien in Städten der Frühneuzeit - eine kirchliche Alternativform zur bürgerlichen Repräsentation?, in: Wilfried Ehbrecht (Hg.), Städtische Führungsgruppen und Gemeinden in der werdenden Neuzeit, Köln 1980, S. 385-444; ders., Das calvinistische Presbyterium in der Stadt Groningen während der frühen Neuzeit und im ersten Viertel des 19. Jahrhunderts. Verfassung und Sozialprofil, in: Ders./Herman DiederiKs (Hg.), Bürgerliche Eliten in den Niederlanden und in Nordwestdeutschland, Köln 1985, S. 195-273. Englische Fassung: Calvinism and Urban Elites, in: Heinz Schilling (Hg.), Civic Calvinism in Northwestern Germany and the Netherlands, Sixteenth to Nineteenth Centuries, Kirksville/MO 1991, S. 105-162.

27 Pinkus, Die Portugiesische Gemeinde, S. 9ff.

28 Ebd., S. 8.

29 Ebd.

30 Ebd., S. 4. 
tigkeit neben den Angelegenheiten des Gottesdienstes und der Gemeindeverwaltung im engeren Sinne das breite Überschneidungsfeld religiöser und weltlicher Dinge, im Christentum res mixtae genannt - Schwangeren- und Geburtenbetreuung, Taufe/Beschneidung, Ehe und Familie, Schule und Erziehung, Begräbnis und Begräbnisstätten. Daneben war der Maamad ebenso wie das Presbyterium für die Regelung der Kontakte mit der fremdkonfessionellen Obrigkeit und deren Untertanenverband verantwortlich beziehungsweise für die Vorkehrungen gegen Reibungspunkte und Grundsatzkonflikte mit der Stadtbevölkerung und ihrer Obrigkeit ${ }^{31}$.

Einen weiteren Schwerpunkt der Rats- und allgemein der Gemeindeaktivitäten bildete die Sozial-, Kranken- und Altenfürsorge. Prägend war dabei die Erfahrung der Vertreibung, der Flucht, die Erfahrung in der Fremde und der Diaspora. Die Calvinistengemeinden bauten dafür eine eigene Institution, die Diakonie, aus. Sie war primär ortsgebunden, also für die Armen und bedürftigen Alten und Kranken der eigenen Gemeinde zuständig. In den Zeiten starker Fluchtbewegungen agierte sie aber durchweg überregional und international. Die Flüchtlingsgemeinden und ihre Diakonie spielten daher für die Logistik von Aufbruch und Wanderung, für die Orientierung über mögliche Zufluchtsorte, für die Versorgung während der Migration und die erste Unterbringung am Zufluchtsort eine existentielle Rolle, häufig auch noch länger danach, wenn es darauf ankam, beruflich und sozial in der Gastgesellschaft Fuß zu fassen. War man etabliert und liefen Gewerbe oder Handelsgeschäfte reibungslos, gehörte es zu der - nötigenfalls von der Gemeindeleitung eingeklagten - Christenpflicht, selbst ein Gemeindeamt zu übernehmen, so dass die meisten der Ältesten und Diakone auf eigene Erfahrung mit Flucht und Ansiedlung zurückgreifen und entsprechend kompetent raten und helfen konnten. - Im Falle der sephardischen Migranten war diese Hilfe bei der Logistik der Wanderung und bei der Ansiedlung um so wichtiger, als die Flucht aus den katholischen Königreichen heimlich und möglichst unauffällig vorbereitet werden musste und meist nur von Einzelnen oder kleinen Gruppen, selten in ganzen Familienverbänden unternommen werden konnte, ganz anders als in den 1580er Jahren der offen planbare Fortzug und die Geschäftsverlagerung calvinistischer Exulanten aus Antwerpen. Nach Überschreitung der Grenze hatte man sich zunächst bei nahegelegenen Gemeinden - etwa Bordeaux - zu orientieren, bevor über weitere Stationen die Niederlassung in den größeren Zufluchtsorten Nordwest- oder Südeuropas erfolgen konnte.

Viertens: Zentraler noch als die soziale Betreuung von Migranten und Gemeindemitgliedern war die moralisch-sittliche Beaufsichtigung der jeweiligen Minderheitenkommunität durch die Gemeindevorstände. Für die calvinistische Kirchenzucht ist das im Rahmen der Diskussion um die Sozialdis-

31 WallenBorn, Bekehrungseifer, S. 428, $431 \mathrm{ff}$. 
ziplinierung oder Sozialkontrolle der Frühen Neuzeit ausführlich dargestellt worden. Die Ergebnisse dieser Forschungen seien daher nur stichpunktartig in Erinnerung gerufen: so die grundlegende Komplementarität von kirchlicher »Sünden-« und staatlicher Kriminalzucht ${ }^{32}$; dann die in der letzten Generation von Forschern der Sozialdisziplinierung, Kriminal- und Kirchenzucht vorgenommene quantitative wie qualitative Auswertung der jeweiligen Aktenüberlieferung, der Kirchenratsprotokolle der calvinistischen Presbyterien einerseits, die zum ganz überwiegenden Teil die Verhandlungen über die Kirchenzucht wiedergeben, und der Verhandlungs- und Urteilsbücher weltlicher Gerichte und Policeybehörden andererseits. Die quantitative Auswertung dieser Quellen hat zu einem detaillierten und differenzierten Bild von der kirchlichen wie der staatlichen Seite des frühmodernen Disziplinierungsprozesses einschließlich der Selbstdisziplinierungstendenzen frühneuzeitlicher Gruppen und Individuen geführt ${ }^{33}$. Innerhalb dieses Spektrums erscheint die Kirchenzucht der calvinistischen Diasporagemeinden als besonders ausgeprägt und allgegenwärtig: Jedes Gemeindemitglied war einer permanenten und engmaschigen Kontrolle und Disziplinierung ausgesetzt - durch die Nachbarn, den für den Wohnbezirk zuständigen Ältesten, durch die Diakone, sofern man soziale Hilfen in Anspruch nehmen musste. Die Kirchenzucht, die man heute eher zur Schattenseite des frühneuzeitlichen Gemeindechristentums zu rechnen geneigt ist, gehörte zum - hier nicht im Einzelnen zu behandelnden - theologischen Kern reformierter Konfessionskultur $^{34}$. Allgemein gesprochen ging es dabei um die Sicherstellung der reformierten Konfessionsorthodoxie im Glauben ebenso wie im Verhalten jedes einzelnen Gemeindemitgliedes. Für die Flüchtlingskirchen war das besonders wichtig, da ihr Status als Fremden-, Sonder- oder gar Untergrundgemeinde sie zur Wachsamkeit nach außen gegenüber der anderskonfessionellen Gastgesellschaft und zu erhöhten Integrationsanstrengungen im Inneren zwang. So achteten die Presbyterien streng auf friedliches Verhalten in der Ehe, in den Familien zwischen Eltern und Kindern, in der Nachbarschaft und natürlich auch in der Kirchengemeinde selbst. Wer im Streit mit Eltern, Kindern oder Nachbarn lebte, musste sich des Abendmahls enthalten. Dahinter stand die Vorstellung, dass Streit in Familien, Nachbarschaft oder Gemeinde, aber auch abweichendes religiöses und theologisches Denken sowie

32 Heinz Schilling, »History of Crime« or »History of Sin«? Some Reflections on the Social History of Early Modern Church Discipline, in: Erkki I. Kouri/Tom ScotT (Hg.), Politics and Society in Reformation Europe. Essays for Sir Geoffrey Elton on his 65th Birthday, London 1987, S. 289-310.

33 Aus der Flut von Publikationen seien nur genannt Heinrich Richard ScHмIDT, Dorf und Religion. Reformierte Sittenzucht in Berner Landgemeinden der Frühen Neuzeit, Stuttgart 1995; Wolfgang DoBras, Ratsregiment, Sittenpolizei und Kirchenzucht in der Reichsstadt Konstanz 1531 bis 1548, Gütersloh 1993; Herman Roodenburg/Pieter Spierenburg (Hg.), Social Control in Europe 1500-1800, Columbus 2004. 
insbesondere sexuelle Verfehlungen, also Ehebruch, uneheliche Verbindungen oder gar Homosexualität und Sodomie, die Reinheit der Abendmahlsgemeinschaft und der Gemeinde insgesamt in Frage stellten. Das waren zwar allgemeinchristliche Vorstellungen des konfessionellen Zeitalters; in der ausgesetzten Situation der Flüchtlingskirchen erhielten sie aber gesteigerte Bedeutung - weil man sich der Gastgesellschaft gegenüber keine Blöße geben durfte - daher das Verbot, bei Streitigkeiten zwischen Gemeindemitgliedern die öffentlichen Gerichte anzurufen -, häufig auch, weil man sich in Idealkonkurrenz mit der konfessionellen Dominanz oder anderen Gemeinden am Ort wusste, so etwa die reformierte Flüchtlingsgemeinde Emdens mit den ebenfalls zum großen Teil niederländischen Täufergemeinden, die sich wiederholt abfällig über die angeblich zu nachlässige Kirchenzucht der Calvinisten äußerten.

Die Zuchttätigkeit jüdischer Gemeinden wird in die ansonsten umfassende Diskussion um die frühmoderne Sozialdisziplinierung kaum einbezogen, und auch quantifizierende Langzeitanalysen, wie sie für eine Reihe calvinistischer Gemeinden - Emden zumal, aber auch einzelne schottische Gemeinden - vorliegen, gibt es kaum, obgleich mit den Protokollen des Maamad durchaus vergleichbares Quellenmaterial vorzuliegen scheint. Angesichts dieser Forschungslage ist augenblicklich ein systematischer und erschöpfender Vergleich nicht möglich. Im Folgenden werden deshalb einzelne Beobachtungen geschildert, hinter denen die Hypothese steht, dass gerade in diesen Ordnungs- und Zuchtfragen die frühneuzeitliche Geschichte von Juden und Christen als Teil eines übergreifenden gemeinsamen Entwicklungsprozesses zu begreifen ist. Detaillierte Aussagen wären aber nur durch sprachkompetente Interdisziplinarität zu erreichen:

Bereits Ursprung und Grundlage der Zuchttätigkeit erscheinen vergleichbar. Bei den Calvinisten ging es - jedenfalls anfangs in Emden - im Kern um

34 Auch hier lässt sich nur eine Auswahl nennen: Zuletzt zusammenfassend Heinrich Richard ScнміDт, Kirchenordnung und Kirchenzucht im reformierten Europa, in: Ansgar ReIss / Sabine Witт (Hg), Calvinismus: Die Reformierten in Deutschland und Europa, Katalog zur Ausstellung des DHM Berlin 2009, S. 351-356; ders., Gemeinde und Sittenzucht im protestantischen Europa der Frühen Neuzeit, in: Peter BliCkLE (Hg.), Theorien kommunaler Ordnung in Europa, München 1996, S. 181-214; Judith BECKER, Gemeindeordnung und Kirchenzucht. Johannes a Lascos Kirchenordnung für London (1555) und die reformierte Konfessionsbildung, Leiden 2007; Heinz Schilling (Hg.), Kirchenzucht und Sozialdisziplinierung im frühneuzeitlichen Europa, Berlin 1994; ders./Lars BeHRISCH (Hg.), Institutionen, Instrumente und Akteure sozialer Kontrolle und Disziplinierung im frühneuzeitlichen Europa, Frankfurt am Main 1999; ders., Frühneuzeitliche Formierung und Disziplinierung von Ehe, Familie und Erziehung im Spiegel calvinistischer Kirchenratsprotokolle, in: Paolo Prodi (Hg.), Glaube und Eid. Treueformeln, Glaubensbekenntnisse und Sozialdisziplinierung zwischen Mittelalter und Neuzeit, München 1993, S. 199-235; ders., Reform and Supervision of Family Life in Germany and the Netherlands, in: Raymond A. Mentzer (Hg.), Sin and the Calvinists. Morals Control and the Consistory in the Reformed Tradition, Kirksville/MO 1994, S. 15-61. 
die Reinheit der Abendmahlsgemeinde, deren Verletzung durch Sünder der Gemeinde, und damit auch der Stadt als Heilsgemeinschaft, Verderben bringen würde ${ }^{35}$. Ob beziehungsweise wieweit die Kategorie $\gg$ dogmatische und moralische Reinheit« für die Judengemeinden eine Rolle spielte, ließe sich nur theologiegeschichtlich klären. Deutlich ist aber, dass der Maamad eine ebenso entschiedene Ordnungspolitik und Zucht betrieb wie die Presbyterien und dass sich dies in gleicher Weise aus der Flüchtlings- und Minderheitensituation speiste. So ging der Maamad entschieden gegen Gemeindemitglieder vor, die sein Monopol bei »Angelegenheiten mit dem Senat $\aleph^{36}$ oder seine Schiedsfunktion bei innergemeindlichen Streitigkeiten nicht achteten. Gemeindemitglieder, die ihre Konflikte vor die öffentlichen Gerichte der Gastgesellschaft brachten, hatten in der jüdischen nicht anders als bei den calvinistischen Minderheitengemeinden mit Bann und Ausschluss zu rechnen ${ }^{37}$.

Wie die Presbyterien der calvinistischen Minderheitengemeinden, so wirkte auch der Maamad generell für ein friedvolles, reibungsloses Zusammenleben der Gemeinde, und zwar nicht zuletzt wiederum, um den kirchlichen oder weltlichen Führern der Gastgesellschaft beziehungsweise der konfessionellen Dominanz keine Angriffsfläche zu bieten. Das gilt für wirtschaftliche Auseinandersetzungen ebenso wie für Erbstreitigkeiten oder Streit in den Familien zwischen Ehepartnern oder Eltern und Kindern. Der Zuchttätigkeit in Matrimonialangelegenheiten, die die Calvinisten teilweise in Konkurrenz zu der »staatlichen « Matrimonialgerichtsbarkeit ausübten, entsprach der Anspruch des Maamad, dass Ehescheidungen innerhalb seiner Gemeinde nur nach seiner formellen Genehmigung durchgeführt werden durften ${ }^{38}$. In ähnlicher Weise diente auch die Lehrzucht dem inneren Frieden und der Ausschaltung von äußeren Angriffsflächen - so die vom Maamad besonders ernsthaft durchgeführte Zensur dogmatisch oder sittlicher anstößiger Bücher, die er nötigenfalls verbrennen ließ, oder auch der berühmte Prozess der Amsterdamer Sephardengemeinde gegen den Philosophen Baruch de Spinoza, vergleichbar dem Ausschluss Adrian von Haemstedes wegen heterodoxer Lehren durch den Emdener Kirchenrat ein Jahrhundert zuvor ${ }^{39}$.

35 Eine vergleichenden Betrachtungen über die Kirchenräte in Groningen und Leiden sowie mit einem Ausblick ins 17. Jahrhundert vgl. Heinz Schilling, Reformierte Kirchenzucht als Sozialdisziplinierung? - Die Tätigkeit des Emder Presbyteriums in den Jahren 1557-1562 (Mit vergleichenden Betrachtungen über die Kirchenräte in Groningen und Leiden sowie mit einem Ausblick ins 17. Jahrhundert), in: Wilfried Ehbrecht / Heinz Schilling (Hg.), Niederlande und Nordwestdeutschland, Köln 1983 (Städteforschung A 15), S. 261-327.

36 Vgl. Pinkus, Die Portugiesische Gemeinde, S. 14.

37 Beispiel Wallenborn, Bekehrungseifer, S. 353 Anm. 78.

38 Zusammenstellung für Hamburg bei Pinkus, Die Portugiesische Gemeinde. 
Angesichts dieser Parallelität bei den Ordnungs- und Zuchtmaßnahmen zur sozialen Integration und zum inneren Frieden zwischen Nachbarn und Geschäftsleuten, vor allem aber innerhalb der Familie (zwischen Mann und Frau, Eltern und Kindern, Hausherrschaft und Dienerschaft), zur Sicherung der reinen Lehre und des rechten Gottesdienstes einschließlich des dazu notwendigen Schulunterrichts und der Erziehung allgemein stellt sich die Frage nach Osmose beziehungsweise nach der Möglichkeit eines kulturellen Transfers zwischen den häufig an demselben Ort ansässigen christlichen und jüdischen Migrationsgemeinden. Auf einer allgemeineren Ebene wäre zu diskutieren, ob der Prozess frühneuzeitlicher Sozialdisziplinierung und Sozialkontrolle, der bislang aus der christlich-antiken Tradition hergeleitet und weitgehend auf das christliche Milieu beschränkt wurde, nicht auch die jüdische Minorität mit erfasste - sei es durch die Partizipation an einer allgemeinen Zeittendenz, sei es durch Osmose oder Anpassung an die christliche Dominanz. Einzelne Beobachtungen, die sich den Arbeiten Yosef Kaplans zu der Amsterdamer Sepharden-Minorität entnehmen lassen, deuten jedenfalls darauf hin, dass eine solche Osmose ausgangs des 17. Jahrhunderts und im 18. Jahrhundert vorhanden war. So zeigt zum Beispiel die Ehe- und Sexualzucht der Amsterdamer Sephardengemeinde auffällige Ähnlichkeiten mit der calvinistischen, wie man sie über einen Zeitraum von gut 300 Jahren anhand des Emder Presbyteriums beschreiben kann - Ähnlichkeiten sowohl in der Begründung (Reinheit der Gemeinde) als auch in der historischen Entwicklung, etwa der seit Mitte des 17. Jahrhunderts in der jüdischen wie in der calvinistischen Gemeinde rasch zunehmenden Stigmatisierung unehelicher Mütter ${ }^{40}$.

\section{IV.}

Fragt man abschließend nach den langfristigen Folgen der christlichen und jüdischen Konfessionsmigration, so erscheinen zwei Zusammenhänge besonders wichtig:

Erstens, die Dialektik von Traditionalismus und Innovation: Bereits die knappe Skizze der wirtschaftlichen, gesellschaftlichen und religiösen Verhältnisse hat gezeigt, dass die Konfessionsminoritäten - die christlichen

39 Zum »Häresiefall« Haemstede, den sowohl das Presbyterium der Fremdengemeinden in London als auch dasjenige Emdens behandelte, vgl. Jan Hendrik Hessels, Ecclesiae Londino-Bataviae Archivum, Bd. 1, Canterbury 1889 sowie Heinz Schilling (Hg.), Die Kirchenratsprotokolle der reformierten Gemeinde Emden, 1557-1620, Teil 1: 1557-1574, Köln 1989, hier bes. S. 147f., 152; Wilhelm GoETERs, Dokumenten van Adrian van Hemstede, in: NAKG N.S. 5 (1908), S. 1-67.

40 Yosef Kaplan, The Threat of Eros in eighteenth Century Sephardi Amsterdam, in: Ders., An Alternative, S. 280-300; zur calvinistischen Sexualzucht: SchilLing, Formierung und Disziplinierung von Ehe; ders., Family Life. 
nicht anders als die jüdischen - unzweifelhaft Teil der vormodernen Gesellschaft waren. Das gilt für die Institutionen und Funktionsweisen der Gemeinden ebenso wie für ihre kulturellen Repräsentationen, ihre Mentalitäten und insbesondere für die allgemeine Zentrierung auf das Religiöse und die religiös abgeleiteten Denk- und Verhaltensnormen. Die Minderheitengemeinden waren bestimmt von dem traditionalen Ideal nahezu totaler interner Integration unter dem Gebot der »Reinheit« des Denkens und Handelns, ihrer Hochschätzung von Familie, Ehe, guter Nachbarschaft etc. - Dennoch ist Yosef Kaplans Feststellung zur Amsterdamer Sephardengemeinde zuzustimmen: Mentalität, Theologie und Institutionen der Sephardengemeinde waren, so resümiert er, keineswegs »based in an universalist, rationalist ideology, which legitimised the neutralisation of religious differences «. Angesichts der dialektischen Natur des alteuropäischen Wandels zeige das Amsterdamer Beispiel aber dessen ungeachtet, »how far traditionalism and modernism are from being uni-dimensional, and it demonstrates how simplistic it would be to see the distinction between traditional and modern societies as a dichotomy $\ll^{41}$.

Diese Dialektik lässt sich auch bei den anderen Zweigen der frühneuzeitlichen Konfessionsmigration beobachten: Der Traditionalismus der Fremdengemeinden führte nicht zu Stagnation, Rückständigkeit oder Ressentiments von Verlierern oder Underdogs. Im Gegenteil, es waren gerade die Selbstisolation, der Wille zur dogmatischen und moralischen Exklusivität sowie der entschiedene Rückbezug auf Familie, Nachbarschaft und Gemeinde, die die Fremdenkolonien in die Lage versetzten, eine außergewöhnliche ökonomische, soziale und kulturelle Dynamik zu entfalten und damit entscheidend zur fundamentalen Transformation der alteuropäischen Gesellschaften in den modernen Liberalismus der Wirtschaftsgesellschaft des 19. Jahrhunderts beizutragen.

Wirtschaftlicher Erfolg und sozioökonomisches Innovationspotential waren Ausdruck einer alltäglich wirksamen Migranten- und Minderheitenidentität, die alle Mitglieder der Fremdenkirchen auszeichnete, gleich welcher sozialen Schicht und welchen intellektuellen Profils. Wie sich am Beispiel der eingangs erwähnten niederrheinischen Textil- und Metallgroßgewerbe (im Monschauer Tal, im Wuppertal, in Burtscheid, Stolberg oder Krefeld) zeigen lässt, beruhte der ökonomische Erfolg der Calvinisten in der Frühen Neuzeit und im Übergang zur modernen Wirtschaftsgesellschaft wesentlich auf diesen Flüchtlings- und Minderheitenstrukturen sowie auf einem Gemeindeleben und einer sozialen Solidarität, die weit über den kirchlichen Raum hinaus Unternehmer und Arbeiter auch im alltäglichen Leben, insbesondere

41 Kaplan, An Alternative Path, S. 26. 
in der Wirtschaft zusammenband ${ }^{42}$. Die wichtigsten Züge dieses alteuropäischen Unternehmertums zwischen städtischem Zunfthandwerk und modernem Wirtschaftsbürgertum waren: die fehlende Einbindung in die alteuropäischen Herrschaftsstrukturen der Städte oder der Territorien; die daraus resultierende Konzentration, ja Beschränkung dieser neuen, stadtfernen Bürgerelite auf das wirtschaftliche Handeln statt auf Politik im alteuropäischen Sinne; schließlich die soziale, institutionelle, kulturelle und emotionale Basis dieses von alteuropäischer Herrschaft ausgeschlossenen Unternehmertums im Dreieck Familie, Kirchengemeinde und Wirtschaftsbetrieb. Angesichts der patriarchalisch-korporativen Strukturen und der starken, existentiellen religiös-weltanschaulichen Bindungen waren die Wurzeln dieses calvinistischen Bürgertums (dem sich die mennonitische Seidenunternehmerschaft Krefelds oder die bergische Variante der Wuppertaler Leinenverleger zur Seiten stellen lassen) zweifellos nicht individualistisch, säkular modern, sondern intellektuell-sozial traditional. Dennoch waren es, der Beobachtung Yosef Kaplans zur Sephardengemeinde Amsterdams entsprechend, gerade diese traditionalen Elemente, die eine geeignete und zuverlässige Basis für die Überwindung oder das Sprengen der traditionellen Beschränkungen der alteuropäischen Gesellschaften in Kirche/Glauben, Handel und Gewerbe, zwischen Individuum und Gruppe bildeten.

Gegenüber diesen der Migrations- und Minderheitensituation geschuldeten Faktoren spielte die von Max Weber in seiner berühmten Calvinismus-Kapitalismus-These in den Vordergrund gerückte calvinistische Prädestinationslehre, wenn überhaupt, eine geringe Rolle. Das belegt auch der vergleichende Blick auf die jüdischen Minderheiten, deren ökonomischer Erfolg demjenigen der Calvinisten ganz ähnlich war, ohne dass sich das auf eine jüdische Prädestinationslehre zurückführen ließe: Da die ökonomische Elite der sephardischen Juden in Amsterdam, Hamburg oder London ein ganz ähnliches Profil wie diejenige der calvinistischen Minderheiten entwickelte (Ausschluss von öffentlichen Ämtern, Führungspositionen in der Gemeinde, starke Familienbande, soziales Engagement etc.), war auch die jüdische Elite im 18. Jahrhundert im Prinzip in der Lage, denselben Weg in die Modernität zu beschreiten. Im Gegensatz aber zu den calvinistischen Eliten, denen sich nach der Beseitigung religiöser Begrenzungen im Zuge der Aufklärung und der Französischen Revolution ein neuer, weiter Horizont politischer, sozialer und kultureller Betätigungen öffnete, sahen sich die jüdischen Unternehmer und Finanziers sogleich mit neuen Hindernissen und Animositäten konfrontiert, die ihnen das Leben keineswegs einfacher als in der alteuropäischen Epoche machten.

42 Für die Calvinisten näher beschrieben bei Schilling, Frühneuzeitliche Konfessionsmigration. 
Die zweite Beobachtung zu den langfristigen Folgen bezieht sich auf eine mentalitätsgeschichtliche Parallelität von migrationsbedingter jüdischer und calvinistischer Konfessions- bzw. Religionskultur, die über die Frühe Neuzeit hinaus auch für die Gegenwart relevant erscheint: Nachdem über Jahrhunderte hinweg die jüdischen Gemeinden durch Wanderung, Umherziehen und Fremdsein in der christlichen Dominanz geprägt waren, brachte die Konfessionsmigration des 16. und 17. Jahrhunderts erstmals größeren christlichen Gruppen die nämliche Erfahrung. Für den Calvinismus wurde das nachgerade zum Kern seiner Konfessionskultur ${ }^{43}$. Denn Hunderttausende calvinistische Migranten erlebten existentiell, was es heißt, in einem fundamentalen Sinne fremd zu sein und ohne erreichbare Heimat durch die Welt zu pilgern - eine Erfahrung, wie sie bislang nur die Juden in der ihnen grundsätzlich fremden christianitas hatten machen müssen. Besonders bitter und daher prägend für Mentalität und Habitus war die Fremdheitserfahrung für die calvinistischen Exulanten des 16. Jahrhunderts, als die konfessionelle Feindschaft noch fundamental, nicht selten sogar fundamentalistisch war: Das erfuhr etwa die kleine Flüchtlingsgruppe, die nach der Thronbesteigung der gegenreformatorischen Mary Tudor unter Führung des bereits erwähnten polnischen Reformators Jan Łaski mitten im Winter London verlassen musste und nach einer stürmischen Überquerung der Nordsee eine wahre Odyssee die dänische und norddeutsche Küste entlang durchlitt. Denn sie fanden allenthalben die Stadttore verschlossen, weil die ihnen feindlich gesinnten lutherischen Pastoren die Magistrate gegen sie einzunehmen gewusst hatten. Erst in dem glaubensverwandten Emden und später in Frankfurt am Main, wo kurzfristig eine liberale Ratsmehrheit der konfessionalistischen Feindseligkeit der Theologen die Stirn bot, fanden sie dann endlich für einige Jahre Unterschlupf ${ }^{44}$.

Angesichts dieser Erfahrungen entwickelten die calvinistischen Flüchtlinge - darauf hat insbesondere der niederländische reformierte Reformationshistoriker Heiko Augustinus Oberman aufmerksam gemacht - eine spezifische »Exulantentheologie«, die abgesehen von spezifischen kirchen- und politikgeschichtlichen Besonderheiten (wie dem Kirchenbegriff, der von der Einzelgemeinde ausgeht, dem Widerstandsrecht, dem Volk-Gottes-/Neues-Israel-Bewusstsein) bestimmt sei durch das Wissen und Erleben, dass irdisches Dasein peregrinatio, Unterwegs-Sein in der Fremde, ist und dass Menschsein In-der-Welt-fremd-Sein bedeutet. Aus dem Bewusstsein irdischer Depravation resultierte aber zugleich das unerschütterbare Vertrauen, mitten in den politischen Umbrüchen und den Zurückweisungen durch die Menschen in der Hand Gottes und damit unangreifbar geschützt zu sein - symbolisch

43 Das Folgende näher entwickelt bei Schilling, Calvinismus in europageschichtlicher Perspektive. 44 Vgl. hierzu den Beitrag von Henning P. Jürgens, in diesem Band, S. 13-40. 
repräsentiert und jedermann vor Augen gestellt in der peregrinus-Figur und dem Schiffchen-Gottes-Symbol, dem kleinen Schiff, das die Herde des Herrn in Sturm und schwerer See sicher trägt. Johannes a Lasco wusste, wovon und wofür sein Siegel Zeugnis ablegte: Ein Kahn mit der christlichen Gemeinde unter dem Motto in portu navigo - nach Sturm umtobter Fahrt segle ich sicher im (himmlischen) Hafen ${ }^{45}$.

Das emphatische Bewusstsein, Fremder und Migrant zu sein, prägte die Mentalität und Kultur der Flüchtlingskirchen und später auch des calvinistischen Teils der niederländischen, in gewisser Hinsicht auch der englischen Gesellschaft tief. So spricht einiges für die von Oberman vertretene Annahme, dass dieses Fremden- und Peregrini-Bewusstsein nicht ohne Einfluss auf die Haltung und die Beziehungsgeschichte der Calvinisten zu der anderen zeitgenössischen Peregrini-Gruppe, also den Juden, blieb. Die »dritte Reformation « der Exulanten habe, so Oberman, aufgrund ihrer exul-Theologie Herz und Seele für ein tieferes Verständnis der jüdischen Situation innerhalb der christlichen Dominanz geöffnet ${ }^{46}$. Doch auch unabhängig von solchen theologischen Überlegungen erscheint es plausibel, dass Gesellschaften und Kulturen mit Flüchtlings- und Minoritätenerfahrungen eine andere und offenere (liberale) Einstellung gegenüber Fremden und Minoritäten entwickeln, und folglich auch gegenüber Juden, als solche Gesellschaften, denen eine derartige Erfahrung unbekannt ist. In dieser Perspektive war die Konfessionskultur des »kontinentalen « Luthertums, in gewisser Weise auch des Katholizismus, deutlich anders als diejenige des westeuropäischen, maritimen Calvinismus. Abgesehen von den kleinen Gruppen der Gnesiolutheraner oder Flacianer, die in den Jahren nach Luthers Tod ihre Heimat verlassen mussten, aber nie eine Chance hatten, die Identität des Luthertums entscheidend zu prägen, war die politische und religiöse Kultur des deutschen Luthertums von Stabilität, Rechtssicherheit im Schutz des Augsburger Religionsfriedens bestimmt. Sie war charakterisiert vom kontinentalen Parochialismus der Landeskirchen, der sich um die geistige und soziale Wohlfahrt

45 Vgl. Henning P. JüRgEns, In portu navigo - Nulla piis patria in terris superna quaerentibus. Zwei Wahlsprüche - Ein Leben, in: Ders., Johannes a Lasco. Ein Leben in Büchern und Briefen. Eine Ausstellung der Johannes-a-Lasco-Bibliothek, Wuppertal 1999, S. 7-14.

46 Heiko A. Oberman, Die Reformation als theologische Revolution, in: Peter Blickle u.a. (Hg.), Zwingli und Europa, Zürich 1985, S. 11-26, bes. S. 24f.; ders., Die Reformation: Von Wittenberg nach Genf, Göttingen 1986, S. 283-300, bes. S. 296f.; siehe auch seine Heineken Lecture: Ders., The Devil and the Devious Historian: Reaching for the Roots of Modernity, in: Heineken Lectures 1996, Amsterdam 1997, S. 33-44. - Zu den Kontakten zwischen Reformierten und Juden speziell: Howard Hotson, Antisemitismus, Philosemitismus und Chiliasmus im neuzeitlichen Europa, in: Werkstatt Geschichte 24 (1999), S. 7-35; von jüdischer Seite: Yosef Kaplan, Jews and Judaism in the Hartlib Circle, in: Irene ZwIEP u.a. (Hg.), Omnia in eo. Studies on Jewish books and libraries in honour of Adri Offenberg, Löwen 2006, S. 186-215; David Katz, Philo-Semitism and the Readmission of the Jews to England, 1603-1655, Oxford 1982. 
der Landeskinder bemühte und Fremde tendenziell als Eindringlinge und Störenfriede begriff. Diese parochiale Kultur der Verantwortlichkeit und der sozialen wie kulturellen Stabilität war eine vorzügliche Basis für den wohlgeordneten Staat und seine Verantwortung für das dies- und jenseitige Wohl der Untertanen als Vorläufer des modernen Sozialstaates. Dagegen konnte sich auf dieser intellektuellen wie sozialen Basis kaum eine Peregrinus-Mentalität mit korrespondierendem Verständnis und Verantwortlichkeit für die Fremden und die anderen entwickeln.

Mit einiger Plausibilität lässt sich daher argumentieren, dass auch die bereits im 16. und 17. Jahrhundert greifbaren Unterschiede zwischen Lutheranern und Calvinisten nicht in der theoretisch-theologischen Beurteilung der Juden und im konkreten Verhältnis zu den jüdischen Minderheiten in der unterschiedlichen Theologie Luthers und Calvins begründet waren, sondern in der skizzierten Erfahrung des Fremdseins in der Welt, die die Reformierten aufgrund der prägenden Konfessionsmigration mit den sephardischen, aber auch mit den anderen jüdischen Minderheiten teilten, während sie dem kontinentalen, dominant von der Erfahrung einheitlich konfessioneller Landeskirchen geprägten Luthertum weitgehend fehlte. 


\section{Klaus Weber \\ Zwischen Religion und Ökonomie: Sepharden und Hugenotten in Hamburg, 1580-1800}

Es ist sicher keine ganz unzulässige Verallgemeinerung, wenn man feststellt, dass die Öffentlichkeit dem religiös oder politisch Verfolgten wohlwollender begegnet als dem »Wirtschaftsflüchtling«. Während Ersterer vor allem als Opfer von Willkür und Despotie gesehen wird, steht Letzterer häufig unter dem Verdacht, aus rein materiellen Gründen in ein Land zu ziehen, das ihm Vorteile bietet, die ihm in seiner Heimat unerreichbar wären - und die er, wie dabei gerne unterstellt wird, auf Kosten der Gesellschaft des Gastlandes in Anspruch nimmt. Die Bundesrepublik Deutschland, in der man sich lange der Einsicht versperrt hat, dass auch sie nolens volens längst ein Einwanderungsland geworden ist, bietet vielleicht ein besonders plastisches Beispiel für diese überzogene Polarisierung zwischen politisch und wirtschaftlich motivierter Einwanderung. Nach den Erfahrungen, die vor dem NS-Regime geflüchtete Deutsche mit den Ländern gemacht hatten, die ihnen Zuflucht (oder eben keine Zuflucht) gewährten, wurde 1949 in Artikel 16 des Grundgesetzes ein Rechtsanspruch auf politisches Asyl festgeschrieben - in seiner Generosität »ein Unikat im internationalen Verfassungsvergleich«. Dazu gehörte in der Regel die Einbürgerung, die dagegen den Wirtschaftsmigranten prinzipiell vorenthalten blieb, obwohl es doch einen fließenden Übergang zwischen den beiden Gruppen gibt ${ }^{1}$. Der schlechtere Ruf des Wirtschaftsflüchtlings reicht weit zurück und hat mit dazu geführt, dass die ökonomischen Aspekte der Migration religiöser Gruppen oftmals übersehen wurden. So hat sich zum Beispiel die »deutsche Hugenottengeschichtsschreibung [...] lange Zeit gesträubt, in den französischen Réfugiés nicht nur Glaubenszeugen« zu sehen und bemühte sich immer, sie abzusetzen von »gewöhnlichen Migranten, die etwa aus ökonomischen Gründen ihre Heimat verlassen $\ll^{2}$. Dadurch konnten die Hugenotten als besonders wertvolle Zuwanderer geschätzt werden, vom

1 Klaus J. BADE, »Politisch verfolgte genießen ...«: Asyl bei den Deutschen - Idee und Wirklichkeit, in: Klaus J. BADE (Hg.), Deutsche im Ausland - Fremde in Deutschland. Migration in Geschichte und Gegenwart, München 1992, S. 411-422, hier: S. 411f.; siehe auch Dieter Gosewinkel, Einbürgern und Ausschließen. Die Nationalisierung der Staatsangehörigkeit vom Deutschen Bund bis zur Bundesrepublik Deutschland, Göttingen 2001.

2 Thomas Klingebiel, Die Hugenotten in der frühmodernen Migrationsgeschichte, in: Sabine Beneke/Hans Otтomeyer (Hg.), Zuwanderungsland Deutschland. Die Hugenotten, Wolfratshausen 2005, S. 11-16, hier: S. 13. 
18. und 19. Jahrhundert über die NS-Zeit bis hin zu den beiden deutschen Staaten der Nachkriegszeit ${ }^{3}$. Umgekehrt war die erste umfangreiche Studie zu den Geschäften der Hamburger Sepharden wohl nicht als unvoreingenommen-nüchterne Darstellung geplant. Hermann Kellenbenz schloss sie 1944 unter dem Titel Das Hamburger Finanzjudentum im 17. Jahrhundert und seine Kreise ab, und zwar als Mitarbeiter am Reichsinstitut für die Geschichte des neuen Deutschlands ${ }^{4}$.

Das Problem der Abgrenzung und Bewertung von wirtschaftlichen und religiösen Motiven kann man an vielen Beispielen aufzeigen, wie etwa an der Emigration von vielen Hunderttausenden russischer Juden aus dem Zarenreich. Selbst in diesem Fall lässt sich die Auswanderung nicht allein durch die 1881 einsetzenden Pogrome erklären. Die meisten Emigranten kamen nicht aus den Gebieten, in denen die Ausschreitungen am blutigsten waren, sondern aus anderen, viel ärmeren Regionen, in denen wirtschaftliche Not ein weiterer wichtiger Antriebsfaktor war. Einige Orte in den südlichen Gouvernements, wo die schlimmsten Pogrome stattfanden, erlebten in der unmittelbaren Folgezeit sogar eine jüdische Zuwanderung. Es ist verständlich, dass die internationalen jüdischen Hilfsorganisationen - deren Vertreter die komplizierte Gemengelage selbst nicht immer überblicken konnten - bei ihren Hilfeaufrufen vor allem den Antisemitismus in der Bevölkerung und die ungenügende Reaktion der Staatsmacht hervorhoben, zumal in den westlichen Exilländern Vorurteile gegen ostjüdische Einwanderer weit verbreitet waren $^{5}$. Das Beispiel zeigt jedenfalls, dass auch bei schweren Einschränkungen der religiösen und politischen Freiheit und sogar bei lebensbedrohlichen Risiken die existentielle Entscheidung zum Bleiben oder Auswandern meist noch von weiteren Faktoren bestimmt wird. Dazu gehört in erster Linie die Abwägung der wirtschaftlichen Aussichten in den möglichen Zielländern. Das ist auch im Europa der Frühneuzeit nicht anders gewesen, als große Be-

3 Etienne François, Vom preußischen Patrioten zum besten Deutschen, in: Rudolf von Thadden / Michelle Magdelaine (Hg.), Die Hugenotten 1685-1985, München 1985, S. 198-212.

4 Walter Frank, der Leiter des Instituts, war einer der prononciertesten Antisemiten unter den damaligen deutschen Historikern. Das Originalmanuskript von Kellenbenz ist nicht erhalten; 1958 erschien eine überarbeitete Version als Habilitationsschrift: Hermann KeLLenBEnz, Sephardim an der unteren Elbe. Ihre wirtschaftliche und politische Bedeutung vom Ende des 16. bis zum Beginn des 17. Jahrhunderts, Wiesbaden 1958. Zu den Hintergründen siehe Helmut Heiber, Walter Frank und sein Reichsinstitut für die Geschichte des neuen Deutschlands, Stuttgart 1966, S. 452-457, 1189.

5 Simon Kuznets, Immigration of Russian Jews to the United States. Background and Structure, in: Perspectives in American History 9 (1975), S. 35-124; John D. KLIER, Emigration Mania in Late-Imperial Russia. Legend and Reality, in: Aubrey Newman/Stephen W. MassiL (Hg.), Patterns of Emigration, 1850-1914, London 1996, S. 21-30; Alexander Orbach, The Development of the Russian Jewish Community, 1881-1903, in: John D. KLIER/Shlomo LambrozA (Hg.), Pogroms: Anti-Jewish Violence in Modern Russian History, Cambridge 1992, S. 137163, hier: S. 138-140. 
völkerungsgruppen vor religiöser Unterdrückung und Verfolgung in andere, teils benachbarte, teils weit entfernte Territorien flohen. Der Entscheidungsprozess verläuft - bildlich gesprochen - unter dem Einfluss von mindestens zwei sich überlagernden Kraftfeldern: dem politischen beziehungsweise konfessionellen und dem ökonomischen. Die Wirkungen der beiden Felder auf die betroffenen Individuen sind in der Analyse oft kaum mehr voneinander $\mathrm{zu}$ isolieren, müssen aber beide berücksichtigt werden. Dabei ist das ökonomische Kraftfeld mit seinen Pull-Faktoren insbesondere für die Wahl des Ziellandes von Bedeutung.

Diese beiden Felder sollen besser sichtbar gemacht werden im vergleichenden Blick auf zwei eindeutig religiös beziehungsweise konfessionell definierte Minderheiten, die im frühneuzeitlichen Hamburg von großer wirtschaftlicher Bedeutung waren: die um 1600 zugewanderten sephardischen Juden und die nach der Widerrufung des Ediktes von Nantes (1685) angekommenen reformierten Franzosen. Die Vertreibung der Juden von der Iberischen Halbinsel und die Flucht der Hugenotten waren die größten kurzfristigen Migrationsbewegungen im frühneuzeitlichen Europa. Die Geschichte beider Gruppen ist auch für den Zufluchtsort Hamburg mittlerweile recht gut erforscht, aber sie sind kaum direkt miteinander verglichen worden ${ }^{6}$. Dass sie trotz unterschiedlicher Herkunft auffallende Gemeinsamkeiten im wirtschaftlichen Profil aufwiesen, legt die Vermutung nahe, dass ähnliche ökonomische Faktoren die Migration beider Gruppen nach Hamburg begünstigten. Um dieser Frage nachzugehen, werden hier zunächst die jüdische und dann die hugenottische Gruppe vorgestellt und dann die Gründe für Aufstieg und Niedergang beider Minderheiten miteinander verglichen. Zum besseren Verständnis der vor allem im Fernhandel tätigen Gruppen müssen dabei auch Entwicklungen in den überseeischen Kolonialgebieten einbezogen werden, die in bisherigen Untersuchungen wenig Beachtung gefunden haben ${ }^{7}$. Dabei wird deutlich, wie sehr selbst relativ überschaubare Gruppen wie die Huge-

6 Jutta Braden, Hamburger Judenpolitik im Zeitalter der lutherischen Orthodoxie 1590-1710, Hamburg 2001; Michaël Studemund-Halévy/Jorun Poettering, Étrangers universels: les réseaux séfarades à Hambourg, in: Arquivos do Centro Cultural Calouste Gulbenkian XLVIII (2004), S. 117-150; Joachim Whaley, Religiöse Toleranz und sozialer Wandel in Hamburg: 1529-1819, Hamburg 1992; Franklin Kopitzsch, Franzosen in den Hansestädten und in Altona zwischen 1685 und 1789, in: Jean Mondot/Jean-Marie Valentin/Jürgen Voss (Hg.), Deutsche in Frankreich, Franzosen in Deutschland 1715-1789, Sigmaringen 1992, S. 283-295; Klaus Weber, Were Merchants More Tolerant? >Godless Patrons of the Jews< and the Disappearance of the Sephardi Community in Late $17^{\text {th }}$ Century Hamburg, in: David Cesarani/Gemma RoMAIN (Hg.), Jews and Port Cities, 1590-1990. Commerce, Community and Cosmopolitanism, London 2005, S. 79-92.

7 Der vorliegende Beitrag baut zum Teil auf folgenden Aufsätzen auf: Klaus WeBer, La migration huguenote dans le contexte de l'économique atlantique: l'exemple de Hambourg, in: Guido Braun/Susanne Lachenicht (Hg.), Les états allemands et les huguenots, München 2007, S. 125-136; Klaus Weber, The Hamburg Sephardic Community in the Context of the Atlantic 
notten nach sozialer und regionaler Herkunft differenziert waren, und dass diese Unterschiede sich sowohl auf die Intensität des Verfolgungsdrucks in der Heimat als auch auf die Wahl der Fluchtorte auswirkten.

\section{Die Hamburger »Portugiesen«}

Als gegen 1590 die ersten Sepharden in Hamburg ankamen, hatten ihre Familien bereits eine Odyssee hinter sich. Viele Juden waren schon seit der 1492 einsetzenden Vertreibung aus Spanien in den östlichen Mittelmeerraum ausgewichen sowie nach Portugal, wo die Inquisition erst ab 1536 verschärften Druck auf sie ausübte. Von dort flohen dann Zehntausende nach Livorno, Saloniki und in andere Städte des Osmanischen Reiches, auch in Nordafrika.

Ein wichtiges Exilland waren auch die habsburgischen Niederlande, mit dem Schwerpunkt Antwerpen, einem wichtigen Umschlagplatz für portugiesische und spanische Kolonialwaren. Da die Juden in Portugal schon 1497 summarisch zu Christen erklärt und Zwangstaufen ausgesetzt worden waren, kamen viele als conversos beziehungsweise Neuchristen in den Norden. Sie behielten aber neben den neuen christlichen ihre alten hebräischen Namen, für den privaten Bereich und die im Geheimen weiter geübte Religion. Nach der Eroberung Antwerpens durch spanische Truppen (1585) und dem anschließenden Zusammenbruch des Handels dieser Stadt flohen die überwiegend im Seehandel tätigen Juden von dort nach Amsterdam, Hamburg und in andere Nordseehäfen ${ }^{8}$. Nur wenige dieser frühen sephardischen $\mathrm{Zu}$ wanderer kamen direkt aus Portugal. Die »Portugiesen«, wie man sie trotzdem in der Hansestadt nannte, hätte man dort - und insbesondere wohl beim Senat - »zuerst gerne für Katholiken gehalten«, bis aus der Bürgerschaft Beschwerden an die Senatoren gingen, dass diese Fremden »der jüdischen $\mathrm{Su}-$ perstition zugethan « seien ${ }^{9}$. Aber noch in den Entwürfen zum 1612 geschlossenen »Niederlassungskontrakt«, der die Rechte und Pflichten der Portugiesen sowie die Abgaben regelte, ihnen obrigkeitlichen Schutz zusagte und die öffentliche Religionsausübung nur im benachbarten Altona erlaubte, wurde

Economy, in: Michaël Studemund-Halévy (Hg.), Coming and Going. Proceedings from the Conference on the History of the Portuguese Jews in $17^{\text {th }}$ Century Hamburg, Hamburg 2010 [im Druck].

8 Jessica V. Roitman, Sephardische Juden im Europa der frühen Neuzeit, in: Klaus J. BadE u.a. (Hg.), Enzyklopädie Migration in Europa. Vom 17. Jahrhundert bis zur Gegenwart, Paderborn 2007, S. 975-981.

9 Wanda Kampmann, Deutsche und Juden. Die Geschichte der Juden in Deutschland vom Mittelalter bis zum Beginn des Ersten Weltkrieges, Frankfurt am Main ${ }^{2}$ 1994, S. 85; Günter BöHM, Die Sephardim in Hamburg, in: Arno HerzIG/Saskia Rohde (Hg.), Juden in Hamburg, Hamburg 1991, S. 21-40, hier: S. 22, auch Anm. 9. 
an keiner Stelle erwähnt, welcher Religion die Neuankömmlinge eigentlich angehörten ${ }^{10}$.

So oder so wurden sie schnell zu einer kaufmännischen Elite mit ganz eigenem Profil: Aus Antwerpen brachten sie ihre bereits in Häfen wie Sevilla und Lissabon entwickelten Verbindungen zu den iberoamerikanischen Kolonien mit, die ihnen bei der Einfuhr von Kolonialwaren zugute kamen. Zugleich lieferten sie mitteleuropäische Gewerbeprodukte nach Spanien und Portugal, von denen ein Teil nach Afrika und in die Neue Welt reexportiert wurde. Besonders bei der Einfuhr und der Verarbeitung von Kolonialwaren, unter denen der Zucker eine besondere Rolle spielte, bewegten sich die Sepharden auf einem für die Hamburger Wirtschaft völlig neuen Gebiet und gerieten deshalb zumindest in den ersten Jahrzehnten ihrer Präsenz nicht in direkte Konkurrenz oder in Konflikt mit den Zünften ${ }^{11}$.

Laut Jonathan Israel kontrollierten die Portugiesen während des größten Teils ihrer Präsenz in der Hansestadt bis zu 20 Prozent des Hamburger Handels mit Portugal und Spanien. In der Zeit des Dreißigjährigen Krieges

machte der Iberienhandel wenigstens ein Fünftel der Tonnage des hamburgischen Seehandels aus und einen viel höheren Anteil seines Wertumschlages. Ein großer Teil dieses Handels wurde mit Portugal betrieben, und etwa die Hälfte davon lag in der Hand von Hamburgs portugiesischen Juden ${ }^{12}$.

Im Vergleich mit den alteingesessenen Kaufleuten waren sie also zweifellos überrepräsentiert. Im hamburgischen Seehandel insgesamt galt das zwar in noch größerem Maße für die eingewanderten lutherischen und reformierten Niederländer. Die Niederländer waren zum Beispiel im Holz- und Getreidehandel mit dem Ostseeraum sehr stark, aber bei den viel hochwertigeren Kolonialwaren hielten die Sepharden eine beherrschende Stellung. Das lag unter anderem an der von 1570 bis in die Mitte des folgenden Jahrhunderts währenden Dominanz des brasilianischen Zuckers auf den europäischen Märkten, und an den guten Verbindungen der Sepharden nach Bahia ${ }^{13}$. Die günstigen Bedingungen in der portugiesischen Kolonie und die spanisch-niederländische Friedensphase von 1609 bis 1621 führten zu einem größeren Zuckerangebot und damit zu niedrigeren Preisen, was erstmals breiteren Schichten den Konsum der vormaligen Luxusware erlaubte, auch in Mitteleuropa. So-

10 Braden, Hamburger Judenpolitik, S. 103-115.

11 Studemund-Halévy/Poettering, Étrangers universels, S. 119.

12 Jonathan I. Israel, European Jewry in the Age of Mercantilism (1550-1750), Oxford 1985, S. 91. Für diese Quantifizierung nutzte Israel die Admiralitätszollbücher, Serie F4/1-15, die im Staatsarchiv Hamburg erhalten sind.

13 Im Jahre 1630 stammten z.B. 80 Prozent des in London gehandelten Zuckers von dort. KeLLENBENZ, Sephardim an der unteren Elbe, S. 111f. 
gar von Hamburg aus liefen ab 1590 Schiffe direkt die brasilianischen Häfen an, woran auch Hamburger Sepharden beteiligt waren, wie etwa die Familie von Ximenes und Manoel Alvares. Viele ihrer Glaubensgenossen waren von der portugiesischen Inquisition nach Brasilien verbannt worden, wo sie sich beim Aufbau der Kolonie nützlich machen sollten. Krypto-Juden oder solche, die man dafür hielt, stellten mehr als die Hälfte aller dorthin Deportierten, und viele stiegen mit der Zeit in wirtschaftlich bedeutende Positionen auf. Das erleichterte auch den Hamburger Portugiesen direkte Geschäfte mit diesem entfernten Gebiet ${ }^{14}$.

Sepharden gehörten nicht nur zu den großen Zuckerimporteuren Hamburgs, sondern - neben niederländischen Zuwanderern - auch zu den ersten Gründern von Zuckerraffinerien in der Stadt ${ }^{15}$. Außerdem betrieben sie Tabakmanufakturen, in denen sie übrigens viele aschkenasische Arbeiter beschäftigten, was ganz dem zwischen den beiden Gruppen bestehenden sozialen Gefälle entsprach ${ }^{16}$. Wie die Niederländer waren die portugiesischen Juden auch an der Gründung der Hamburger Bank beteiligt (1619), die bis zur Eröffnung der Bank of England im Jahr 1694 der einzige nennenswerte Widerpart zur 1609 geschaffenen Amsterdamer Wechselbank blieb. Noch viel gewichtiger soll der Anteil der Juden an den Geschäften im Wechselverkehr gewesen sein. Die Bedeutung des Standortes an der Elbe wird auch durch den Vergleich mit Amsterdam ersichtlich: Während die Zahl der Bankkonten von Sepharden dort in den Jahren 1620 bis 1625 von 114 auf 76 fiel, stieg sie in Hamburg zwischen 1619 und 1623 von 28 auf 43 an ${ }^{17}$. Die Entwicklung war von der hansischen Neutralität begünstigt, während der Amsterdamer Handel unter dem 1621 wieder ausgebrochenen Krieg litt, denn bis in die 1640er Jahre blieben die Niederlande vom direkten Handel mit Spanien und Portugal ausgeschlossen.

Zugleich profitierten neutrale Plätze wie Hamburg aber auch vom 1624 einsetzenden Vordringen der niederländischen Westindien-Kompanie in Brasilien, wo die Gesellschaft es vor allem auf die Zuckerproduktion abgesehen hatte, damals die bedeutendste weltweit. Bis 1654 hielt sie die Häfen Bahia (heute Salvador) und Recife sowie die Plantagengebiete des Hinterlandes besetzt. Nach der Eroberung gewann die Kompanie Sepharden aus Amsterdam

14 Geraldo Pieroni, Outcasts from the Kingdom: The Inquisition and the Banishment of New Christians to Brazil, in: Paolo Bernardini/Norman Fiering (Hg.), The Jews and the Expansion of Europe to the West, 1450 to 1800, New York 2001, S. 242-251, hier: S. 245; BöHм, Sephardim in Hamburg, S. 26.

15 Ebd., S. 27f.

16 Die soziale Kluft zwischen beiden Gruppen war besonders ausgeprägt in Städten wie London und Hamburg, wo die Sephardengemeinden kleiner und homogener waren. Yosef KAPLAN, An Alternative Path to Modernity. The Sephardi Diaspora in Western Europe, Leiden 2000, S. 63, 173.

17 Kellenbenz, Sephardim an der unteren Elbe, S. 255-258; Israel, European Jewry, S. 92. 
dafür, sich am Wiederaufbau der Region zu beteiligen und auch christlichportugiesische Plantagenbesitzer zum Bleiben unter den neuen Herren zu bewegen. So vermittelten sie technisches und kaufmännisches Wissen und Kapital zwischen allen Gruppen. Einige wurden selbst zu Pflanzern und noch mehr von ihnen zu Großhändlern und Finanziers der kapitalintensiven Plantagenwirtschaft, vor allem im Hafen Recife. Auf dem Zenit ihrer Präsenz im niederländischen Brasilien, in den 1640er Jahren, stellten die Sepharden mit 1.420 Köpfen knapp die Hälfte der gesamten weißen Bevölkerung der Region, die - Soldaten ausgenommen - etwa 3.000 Menschen zählte ${ }^{18}$.

Die 1621 einsetzende Schwäche Amsterdams hatte unterdessen zu einer weiteren Zuwanderung von Sepharden an die Elbe geführt, dieses Mal vor allem aus Holland. Sie verbanden Hamburg nun auch mit dem niederländischbrasilianischen Kolonialhandel. Wenigstens bis in die frühen 1630er Jahre, als in Amsterdam eine Erholung einsetzte, sah es so aus, als ob Hamburgs sephardische Gemeinde zur größten im nördlichen Europa werden würde. Schätzungen zufolge könnte bis zu einem Viertel der Amsterdamer Portugiesen in norddeutsche Städte ausgewichen sein, wobei Hamburg der bedeutendste Zielort war. Unter den Migranten befanden sich Großkaufleute wie Duarte Nunes da Costa (alias Jacob Curiel), der zunächst ins dänische Glückstadt und 1627 nach Hamburg ging. Bis zur Ankunft der noch wohlhabenderen Familie des Diego Texeira im Jahr 1646 war da Costa der reichste der Hamburger Portugiesen. Übrigens war auch Texeira als Neuchrist angekommen und bekannte sich mit seinen Söhnen erst im folgenden Jahr zum Judentum. In den fünfziger bis siebziger Jahren, in denen die Gemeinde in demographischer und wirtschaftlicher Hinsicht am stärksten gewesen sein dürfte, lebten etwa 120 sephardische und 40 bis 50 aschkenasische Familien in der Stadt. Man schätzt, dass es damit insgesamt rund 800 bis 900 Juden waren (davon etwa 200 Aschkenasen). Das entsprach einem Hundertstel der damaligen Gesamtbevölkerung, die zwischen 50.000 und 75.000 lag $^{19}$. Damit beherbergte Hamburg - dicht vor London liegend - für einige Zeit die zweitgrößte der westlichen Diasporagemeinden. Langfristig blieb aber Amsterdam die führende Stadt der westlichen Diaspora, trotz des vorübergehenden Niedergangs in den zwanziger Jahren. Um 1680, als die Hamburger Gemeinde schon wieder schrumpfte, lebten dort wenigstens um die 3.000 Sepharden, mit stark steigender Tendenz ${ }^{20}$.

18 Jonathan I. Israel, The Jews of Dutch America, in: Bernardini/Fiering (Hg.), The Jews and the Expansion of Europe, S. 336-349, hier: S. 341f.

19 Kaplan, Alternative Path, S. 169; Israel, European Jewry, S. 164. Schätzungen zu Hamburgs Bevölkerungszahlen bei Hans MAuersBerg, Wirtschafts- und Sozialgeschichte zentraleuropäischer Städte in neuerer Zeit dargestellt an den Beispielen von Basel, Frankfurt a.M., Hamburg, Hannover und München, Göttingen 1961, S. 30-48.

$20 \mathrm{Zu}$ Amsterdam: Miriam Bodian, Hebrews of Portuguese Nation. Conversos and Community in 
Aufgrund ihres Wohlstandes konnten die Hamburger Portugiesen auch andere jüdische Gemeinden finanziell oder sogar politisch unterstützen. So versuchte Manoel Texeira (ein Sohn Diego Texeiras), der auch als Resident der Königin Christina von Schweden fungierte, auf Bitte der Wiener Juden gegen deren 1670 verfügte Ausweisung aus Wien und den Österreichischen Erblanden zu vermitteln ${ }^{21}$. Politischen Einfluss besaßen auch die anderen großen portugiesischen Kaufleute, wie Duarte Nunes da Costa, ab 1644 Agent der portugiesischen Krone, oder Jacob Rosales, in den vierziger und fünfziger Jahren Ministerresident des spanischen Königs. Dass die Blütezeit der Gemeinde sich ungefähr deckt mit den Jahren des portugiesischen Unabhängigkeitskrieges (1640-1668), in dem das Land sich aus einer spanisch dominierten Personalunion löste, ist vielleicht kein Zufall. Beide Seiten bezogen den Materialnachschub für ihre Marinewerften und Kriegsflotten zu einem großen Teil über das neutrale Hamburg, das auch auf diesem Sektor einer der wichtigsten europäischen Handelsplätze war. Waldarme Länder wie Spanien und Portugal waren in besonderem Maße auf die überwiegend aus dem Ostseeraum stammenden Baumaterialen Holz, Pech und Teer angewiesen und kauften in Hamburg auch ganze Schiffsneubauten. Das verlieh den Vermittlern des Kriegsmaterials sowohl bei den westlichen Seemächten als auch in der Hansestadt besonderes Gewicht. Dabei standen Nunes da Costa und Rosales in direkter Konkurrenz, so dass Rosales bei einer Gelegenheit sogar versuchte, zwei bereits dem portugiesischen König zugesagte Kriegsschiffe für Spanien zu sichern. Da Costa spielte auch eine wichtige Rolle bei der Schaffung der portugiesischen Brasilien-Kompanie, für die er ebenfalls mehrere Kriegsschiffe kaufte und ausrüsten lie $\beta^{22}$. Diese Situation illustriert in plastischer Weise das Dilemma, in das sich die iberischen Monarchien manövriert hatten: Sie benötigten die Dienste einer kaufmännischen Elite, die sie selbst außer Landes getrieben hatten. Deren Netzwerke ergänzten sich mit denen der in Spanien gebliebenen conversos, wie etwa den in Madrid ansässigen de Fonseca Piña, die in den vierziger Jahren zu den wichtigsten asentistas der Krone gehörten und auch in Sevilla, Lissabon, Antwerpen, Amsterdam und Hamburg vertreten waren ${ }^{23}$.

Early Modern Amsterdam, Bloomington 1997, S. 156. Nach einer weniger konservativen Schätzung sollen es in den achtziger Jahren etwa 4.500 gewesen sein; siehe Hubertus P.H. NusTELING, The Jews in the Republic of the United Provinces. Origins, Numbers and Dispersion, in: Jonathan Israel/Reiner SAlverda (Hg.), Dutch Jewry. Its History and Secular Culture, Leiden 2002, S. 43-62, hier: S. 51-53.

21 Die Bemühungen waren allerdings vergeblich; siehe Kampmann, Deutsche und Juden, S. 59.

22 Michaël Studemund-Halévy/Sandra Neves Silva, Tortured Memories. Jacob Rosales alias Imanuel Bocarro Francês. A Life from the Files of the Inquisition, in: Stephan Wendehorst (Hg.), The Roman Inquisition, the Index and the Jews. Contexts, Sources and Perspectives, Leiden 2004, S. 107-151, hier: S. 147; IsRAEL, European Jewry, S. 108 f.

23 Markus Schreiber, Marranen in Madrid 1600-1670, Stuttgart 1994, S. 232. 
Die Gemeinde in der Hansestadt bestand nicht nur aus Großkaufleuten und ihren Bediensteten, sondern bot auch ein für die relativ kleine Gruppe erstaunlich produktives kulturelles Leben, das sich nicht zuletzt im Reichtum der Privatbibliotheken von vielseitig interessierten, polyglotten Händlern wie Manoel Texeira und der Zahl der in Hamburg gedruckten Bücher spiegelte $^{24}$. Zu den prominentesten der in Hamburg lebenden Autoren gehörte der schon um 1591 angekommene Arzt Dr. Rodrigo (Ruy) de Castro, der dort 1614 das Buch Medicus politicus veröffentlichte, mit einer Widmung an den Senat der Stadt. Er war übrigens einer der ganz wenigen Juden, denen der Besitz eines Hauses im Zentrum, an der Wallstraße, gestattet war. Zu seinen Patienten zählten der König von Dänemark, der Erzbischof von Bremen und der Herzog von Holstein. Sein Sohn Benedikt (alias Baruch Nehemias) wurde Leibarzt von Christina von Schweden ${ }^{25}$. Sowohl die in Hamburg gedruckten als auch die aus Amsterdam importierten Bücher unterstanden der Zensur durch den Mahamad der Gemeinde, der auch darüber wachen musste, dass insbesondere die von den Pastoren misstrauisch begutachteten theologischen Traktate in spanischer und portugiesischer Sprache keinen Anstoß erregten. Zum besseren Verständnis der jüdischen Religion las auch der Senior des Geistlichen Ministeriums und Hauptpastor an St. Petri, Johannes Müller, diese Werke und suchte sogar das Gespräch mit dem Rabbi David Cohen de Lara - auch wenn dieser daraufhin Ärger mit seinen Gemeindevorstehern bekam und Müllers Ziel nicht der interreligiöse Dialog, sondern die Ausweisung oder Konversion der Minderheit war $^{26}$. Aber sogar in Müllers Äußerungen mischen sich negative Urteile mit einer widerstrebenden Anerkennung mancher Leistungen der Juden. Diese Ambivalenz war vermutlich kennzeichnend für die Haltung der meisten Lutheraner in der Stadt. Für sie mussten »Gelehrsamkeit, Selbstbewusstsein, Wohlstand und hoher Sozialstatus [der Sepharden] in eklatantem Widerspruch zur [...] orthodoxen Theologie« stehen, die für die Juden doch den niedrigsten Rang in der Gesellschaft vorgesehen hatte ${ }^{27}$.

24 Michaël Studemund-Halévy, Sephardischer Buchdruck in Hamburg, Teil 1 in: Lusorama 32 (1997) S. 85-101, Teil 2 in: Lusorama 33 (1997) S. 41-72.

25 Wilfried Schleiner, The Contribution of the Exiled Portuguese Jews in Renaissance Medical Ethics, in: Raymond A. Waddington/ Arthur H. Williamson (Hg.), The Expulsion of the Jews. 1492 and After, New York 1994, S. 147-159, hier: S. 148f., 153f.

26 Michaël Studemund-Halévy, Codices Gentium. Semuel de Isaac Abas, coleccionista de libros hamburgués, in: Jaime Contreras/Bernardo J. García García/Ignacio Pulido (Hg.), Familia, religión y negocio. El sefardismo en las relaciones entre el mundo ibérico y los Paises Bajos en la Edad Monderna, Madrid 2003, S. 287-319, hier: S. 289-292. 1644 hatte Müller die Schrift »Judaismus und Judentum, d.i. ausführlicher Bericht von des jüdischen Volkes Unglauben, Blindheit und Verstockung « veröffentlicht, so Kampmann, Deutsche und Juden, S. 88.

27 Braden, Hamburger Judenpolitik, S. 187-189. 
Unterstützung erhielten die sephardischen Migranten in Hamburg vor allem vom Senat, dessen Mitglieder sich seit Beginn der Zuwanderung der wirtschaftlichen Bedeutung dieser Gruppe bewusst waren. Das ging so weit, dass die Senatoren sie nicht nur gegen die wachsende Kritik von Seiten der Zünfte, sondern auch von Seiten des lutherischen Klerus in Schutz nahmen auch als schon lange offensichtlich geworden war, dass es sich bei ihnen nicht um portugiesische oder spanische Katholiken, sondern um Juden handelte. Der Senat bemühte sich sogar, ihnen das Recht auf den Bau einer Synagoge zu gewähren, denn, wie es in einer Senatsakte heißt, »die Juden können doch nicht wie das dumme Vieh ohne allen Gottesdienst und Religion in der Welt leben $\ll^{28}$. Solche Initiativen wurden jedoch immer wieder von Seiten der Bürgerschaft und der Geistlichkeit torpediert. Deshalb konnten für die Gottesdienste nur Beträume in Privathäusern genutzt werden. Ein solcher war letztlich auch die »Hauptsynagoge « am so genannten Dreckwall, aber schon diese Gotteshäuser und die dort abgehaltenen religiösen und privaten Festlichkeiten der Gemeinde erregten Ärgernis. Im Jahr 1649 äußerte sich Johannes Müller darüber mit folgenden Worten:

Sie speisen auf ihren Hochzeiten aus silbernen Gefäßen und setzen dabei eine große Menge Schüsseln und Confecte auf und endlich fahren sie in solchen Carossen, die nur hohen Standespersonen zustehen, und gebrauchen bei solchen Gelegenheiten noch oben darein Vorreuter und ein großes Comitat. [...] Es werden ihre Synagogen allhie mit silbernen, köstlichen Lampen gezieret, auf etliche 1000 Rthlr. an Werth [... ${ }^{29}$.

Gegen 1670 schließlich erhielt Manoel Texeira nach Unterredungen mit dem Bürgermeister und dem Syndikus die Genehmigung für den Bau einer Synagoge, allerdings unter der unverfänglichen Bezeichnung »Versammlungsort « und hinter einem Wohnhaus am Alten Wall verborgen. Die Erweiterung bis zur Straße hin scheiterte allerdings am Widerstand der evangelischen Geistlichen, so dass die halbfertige »Satansschule« (so der Pastor Johann Friedrich Mayer) im November 1672 wieder abgebrochen werden musste ${ }^{30}$. Für ihre Begräbnisse waren die Hamburger Juden auf den bis heute erhaltenen Friedhof im dänischen Altona angewiesen ${ }^{31}$. Es muss hervorgehoben werden, dass nicht alle Geistlichen Demagogen vom Schlage Müllers oder Mayers

28 Вӧнм, Sephardim in Hamburg, S. 26.

29 Ebd., S. 25, dort zitiert nach den »Bedenken des Herrn Mülleri, Theol. Dr. et Senioris Minist. Hamb., die Juden betreffend «, vom 15.10.1649.

30 Ebd., S. 30-32.

31 Braden, Hamburger Judenpolitik, S. 105, 112. Der Friedhof ist heute für die prosopographische Forschung von größter Bedeutung. Michaël Studemund-Halévy, Biographisches Lexikon der Hamburger Sepharden. Die Grabinschriften des Portugiesenfriedhofs an der Königstraße in Hamburg-Altona, Hamburg 2000. 
waren. Besonders Johannes Volckmar (St. Katharinen) und Johann Winckler (St. Michaelis) setzten sich für die Respektierung des den Juden einmal gewährten Status ein. Pastor Johann Heinrich Horb forderte überdies die Tolerierung von Katholiken und Calvinisten.

Die Auseinandersetzungen um die Präsenz der Sepharden, die zwischen dem Senat auf der einen und den Zünften, der Bürgerschaft und militanten Pastoren auf der anderen Seite ausgetragen wurden, kulminierten im letzten Drittel des 17. Jahrhunderts, einer Zeit heftiger innerstädtischer Konflikte um die Machtverteilung zwischen Senat und Bürgerschaft. Seit 1666 gab es immer wieder heftige Proteste gegen Vetternwirtschaft und Korruption unter den Senatoren, die 1685 sogar zur vorübergehenden Festnahme eines Bürgermeisters führten. Der lange anhaltende Streit um die Verfassung, der auf seinem Höhepunkt zu fast bürgerkriegsähnlichen Konfrontationen führte, konnte erst 1712 nach Vermittlungen von kaiserlicher Seite beigelegt werden und endete mit einem Machtzuwachs für die Bürgerschaft. Bereits im Verlauf des Konflikts war die Position des Senats geschwächt worden, was für die Portugiesen einschneidende Folgen hatte. So waren die Senatoren und die in der Commerzdeputation (Vorläufer der Handelskammer) organisierten Großkaufleute schon 1697 in einem Streit um die von den Juden zu leistenden Abgaben unterlegen. Die Kaufleute argumentierten, dass die Nähe Altonas die Wirksamkeit einer Erhöhung der Abgaben schwächen werde:

Es will das Ansehen gewinnen, ob wolten die hiesigen Jüdischen Kaufleute, wegen ihrem Vorgeben nach einige harte Conditiones, so ihnen anitzo angemahnet würden, aus dieser Stadt entweichen: da uns diese Entweichung vermuthlich geschehen solte, würde dieselbe gewisslich mit großem Abbruch hiesiger gantzen Kauffmanschaft verbunden seÿn. Nicht reden wir solches als Juden Patronen, sondern als ehrliche Patrioten, die wohl sehen, daß die Juden nicht über die Alpes oder das Pireneische Gebirge hinüber ziehen, sondern sobald sie aus dieser Stadt sind, ihren Fuß alsoforth wieder auff diese Grentzen niederlassen, zu Altona ihr Commercium anfangen, und daselbsten eine große Handlung, zum großen Nachtheil dieser Stadt stabiliren werden, woselbsten sie sonder Zweifel der Zollfreÿheit und anderer Privilegien mehr genießen werden. Mit was vor Schaden der hiesigen Handlung solches wird verbunden seÿn, siehet ein jeder leichtlich ein, der nur derselben in etwas kundig is ${ }^{32}$.

Die Bürgerschaft, dieses Mal besonders von der Zunft der Goldschmiede angespornt, setzte aber noch im selben Jahr eine empfindliche Erhöhung durch. Die Sepharden sollten jährlich 20.000 Mark, die Aschkenasen sogar 30.000 Mark mehr abführen. Wie von den Kaufleuten in der Commerzdepu-

32 Commerzbibliothek (Archiv der Handelskammer Hamburg), Protokolle der Commerzdeputation, Sign. S/599, Bd. F (1697-1700), fol. 6. 
tation vorhergesehen, verließ die Familie Texeira schon im folgenden Jahr die Hansestadt, um sich in Altona niederzulassen. Sie blieben allerdings nicht lange dort, sondern zogen bald nach Amsterdam, von wo ja auch viele der Hamburger Portugiesen gekommen waren. Andere wohlhabende Familien, wie die Nunes Henriques, Soares und Bravo, folgten binnen weniger Jahre diesem Beispiel, und gegen 1700 war die vormals so wohlhabende sephardische Gemeinde auf eine Handvoll kleiner und mittlerer Makler geschrumpft ${ }^{33}$.

\section{Die Hamburger »Franzosen«}

In den letzten Dekaden des 17. Jahrhunderts erlebte Hamburg nicht nur den Niedergang der sephardischen Gemeinde, sondern auch die Ankunft einer Gruppe von hugenottischen Seehändlern, die im atlantischen Raum ebenso gut vernetzt waren wie die Portugiesen. Auch ihre Zuwanderung stand unter dem Zeichen von religiöser Verfolgung. Im zahlenmäßigen Vergleich mit den übrigen Ländern des Refuge war Hamburg allerdings von untergeordneter Bedeutung: Von den insgesamt etwa 43.000 Franzosen, die in deutschen Territorien Zuflucht fanden, gingen rund 20.000 nach Brandenburg-Preußen, während Länder wie Hessen und Sachsen zwischen drei- und viertausend aufnahmen. Nur etwa 1.500 entschieden sich für die Hansestädte. Es sollen rund 920 Hugenotten nach Hamburg, etwa 470 nach Bremen und gut 80 nach Lübeck gegangen $\operatorname{sein}^{34}$. Die meisten von ihnen dürften von dort allerdings schon bald weiter gezogen sein, denn die Hamburger Gemeinde zählte im 18. Jahrhundert kaum über 200 Seelen; mit den in Altona lebenden Franzosen könnten es insgesamt 300 bis 400 gewesen sein ${ }^{35}$. Im Verhältnis zu der in dieser Zeit auf 100.000 Einwohner ansteigenden Gesamtbevölkerung Hamburgs war ihr proportionaler Anteil noch geringer als jener der Sepharden im 17. Jahrhundert. Umso mehr fiel die Wirtschaftskraft dieser

33 Braden, Hamburger Judenpolitik, S. 301, 314f., 322-325, 331-334.

34 Wilhelm Beuleke, Die landsmannschaftliche Gliederung der drei hansestädtischen Réfugiésgemeinden, in: Hans W. Wagner (Hg.), Hugenotten in Hamburg - Stade - Altona. Tagungsschrift zum Deutschen Hugenottentag in Hamburg, 23. bis 26. April 1976, Obersickte 1976, S. 22-28, hier: S. 22.

35 In den 1770er Jahren sollen es in Hamburg selbst 200 gewesen sein, daneben (nach einer Zählung vom Anfang der 1760er Jahre) 51 Familien mit 122 Kommunikanten in Altona. Otto WEDEKIND, Die Réfugié's. Blätter zur Erinnerung an den zweihundertjährigen Jahrestag der Aufhebung des Edicts von Nantes, Hamburg 1885, S. 39-42. Da der hamburgisch-französische Handel sich in den siebziger und achtziger Jahren auf seinem Höhepunkt befand, ist eine gröBere Stärke der Gemeinde für die erste Hälfte des Jahrhunderts unwahrscheinlich. Genauere Angaben zur Entwicklung liegen für Bremen vor, wo man in den ersten Jahren nach der Widerrufung 300 bis 500 Mitglieder und gegen Mitte des 18. Jahrhundert nur noch etwa 150 zählte. Otto VEECK, Geschichte der reformierten Kirche Bremens, Berlin 1917, S. $240 \mathrm{f}$. 
kleinen Gruppe ins Gewicht. Obwohl einige französische Händler bereits in den 1670er Jahren in Hamburg eingetroffen waren, formierte sich ihre Gruppe eigentlich erst in den beiden Dekaden nach der Widerrufung des Ediktes von Nantes. Aber nicht nur die inneren Konflikte in der Hansestadt und die in dieser Zeit besonders intolerante Geistlichkeit machten ihre offizielle Anerkennung als religiöse Minderheit und die Gewährung des Rechts auf eigene Gottesdienste unmöglich. Reichsrechtlich war Hamburg entsprechend dem Westfälischen Frieden als rein lutherische Stadt definiert, und außerdem bestand ein enger Konnex zwischen kirchlicher und politischer Verfassung. Es gab insofern keinen großen Spielraum. Religiöse Minderheiten konnten nur geduldet wurden, solange ihr Verhalten die Obrigkeit nicht zwang, von ihrer Existenz offiziell Kenntnis zu haben ${ }^{36}$. Dass der Senat wenigstens private Zusammenkünfte duldete, war nicht zuletzt den Eingaben einiger Fürsten geschuldet, die selbst dem reformierten Glauben anhingen. Wie schon den »Portugiesen « kam auch den »Franzosen « - die wie die Sepharden nicht nach ihrer Religion, sondern nach der nationalen Herkunft bezeichnet wurden - die Nähe Altonas zugute: Da die Senatoren die Zuwanderer in der Stadt halten wollten, aber auch in diesem Fall Zugeständnisse an die Bürger machen und die Religionsfreiheit der Hugenotten einschränken mussten, wurde ihnen entsprechend den Toleranzartikeln des Westfälischen Friedens die Religionsausübung in der Nachbarschaft gestattet. Dort gab es seit 1602 eine reformierte Gemeinde. Die dänischen Religionsprivilegien Altonas erleichterten also Kompromisslösungen in der Hansestadt. Schon 1682 hatte man in Altona einen französischer Prediger berufen, den aus der Normandie vertriebenen Pierre Emerence de la Conseilleire ${ }^{37}$. Außerdem konnten die Hamburger Franzosen seit 1689 in der Hansestadt selbst an den Gottesdiensten in der Kapelle der niederländischen und ab 1744 auch in der preußischen Gesandtschaft teilnehmen ${ }^{38}$.

36 Frank Hatje, Zwischen Repräsentation und Konfession: Konflikte um Bedeutung, Nutzung und Architektur eines hamburgischen Stadtpalais im 18. Jahrhundert, in: Susanne RAu/Gerd Schwerhoff (Hg.), Zwischen Taverne und Gotteshaus. Öffentliche Räume in Spätmittelalter und früher Neuzeit, Köln 2001, S. 155-181, hier: S. 161-163.

37 Elisabeth Bütfering, Niederländische Exulanten in Frankenthal, Neu-Hanau und Altona. Herkunftsgebiete, Migrationswege und Ansiedlungsorte, in: Heinz Schilling/Wilfried EhBrecht (Hg.), Niederlande und Nordwestdeutschland. Studien zur Regional- und Stadtgeschichte Nordwestkontinentaleuropas im Mittelalter und in der Neuzeit (Franz Petri zum 80. Geburtstag), Köln 1983, S. 347-417; Franklin Kopitzsch/Ursula Stephan-Kopitzsch, Franzosen in den Hansestädten und in Altona zwischen 1685 und 1789, in: Jean Mondot/Jean-Marie VAlENTIN/Jürgen Voss (Hg.), Deutsche in Frankreich, Franzosen in Deutschland 1715-1789, Sigmaringen 1992, S. 283-295, hier: S. 286f.

38 Staatsarchiv Hamburg (StAH), Bestand 521-4 (Deutsche evangelisch-reformierte Gemeinde), Sign. IC 49, Festschrift »Zur Feier des 300-jährigen Bestehens der evangelisch-reformierten Gemeinde in Hamburg«, Hamburg 1902, S. 12. 
Trotzdem kann Hamburg nicht als ein Refuge angesehen werden, vergleichbar dem in Brandenburg-Preußen, Hessen oder anderen deutschen Territorien, wo den Flüchtlingen nicht nur Kultusfreiheit, sondern meist auch das Recht auf die Bildung weitgehend autonomer Personalgemeinden mit eigener Rechtssprechung gewährt wurde. Hinzu kamen dort Steuerfreijahre, Zunftfreiheit, Zollprivilegien, unentgeltliche Ressourcen wie Baumaterial und ähnliche Starthilfen ${ }^{39}$. In Hamburg gab es kein öffentliches Einladungsdekret, und es gab auch kein rechtliches Entgegenkommen. Die Calvinisten waren und blieben hier ebenso benachteiligt wie die Katholiken. Sie konnten kein Bürgerrecht erwerben und waren deshalb auf den minderen Status des Fremdenkontrakts verwiesen. Das bedeutete, dass jeder von ihnen sich nur mit einer individuell gewährten Konzession niederlassen durfte und dass sie beim Handel den Vollbürgern gegenüber durch höhere Zollabgaben benachteiligt waren ${ }^{40}$. Als religiöse Minderheit waren sie allenfalls geduldet, mussten aber »als Einwohner Hamburgs [...] die iura stolae an die lutherische Geistlichkeit entrichten«. Ein Recht auf eigene Gotteshäuser erlangten Katholiken und Reformierte erst 1785. Die Zubilligung bürgerlicher Rechte ließ bis 1819 auf sich warten ${ }^{41}$.

Es trifft wohl zu, dass die Gegnerschaft der lokalen Pastoren keine Hamburger Besonderheit war. Auch an anderen Orten opponierten die »führenden Angehörigen und Institutionen der lutherischen Geistlichkeit « gegen die Ansiedlung von Hugenotten. Ein Beispiel wäre Frankfurt am Main, wo die Franzosen sich in einer ganz ähnlichen Lage befanden wie in der Hansestadt: Nur einige wenige, die als reiche Kaufleute oder wegen ihrer handwerklichen Fähigkeiten für nützlich angesehen wurden, durften sich in der Messe- und Finanzstadt niederlassen, aber ihre Gemeinde durfte - wie in Hamburg - erst in den 1780er Jahren eine eigene Kirche errichten. Die Ablehnung der Hugenotten durch die autochthone Bevölkerung war in den Territorien des Hinterlands vielleicht sogar ausgeprägter als in den großen Städten. Die dortigen Konflikte entzündeten sich meist an konkreten Versorgungsproblemen, wie

39 Heinz Duchhardt, Glaubensflüchtlinge und Entwicklungshelfer. Niederländer, Hugenotten, Waldenser, Salzburger, in: Klaus BADE (Hg.), Deutsche im Ausland - Fremde in Deutschland, München 1992, S. 278-287, hier: S. 282; Susanne Lachenicht, Die Freiheitskonzessionen des Landgrafen von Hessen-Kassel, das Edikt von Potsdam und die Ansiedlung von Hugenotten in Brandenburg-Preußen und Hessen-Kassel, in: Braun/Lachenicht (Hg.), Les états allemands, S. 71-83. Lachenicht weist darauf hin, dass die Privilegien auch ihren Preis hatten: In Brandenburg-Preußen etwa war damit keinesfalls ein Bleiberecht, sondern vielmehr ein Bleibezwang verbunden; ebd., S. 82.

40 Thomas Klingebiel, Aspekte zur Ansiedlung von Hugenotten in den norddeutschen Territorien, in: Frédéric Hartweg/Stefi Jersch-Wenzel (Hg.), Hugenotten und das Refuge. Deutschland und Europa, Berlin 1990, S. 67-79, hier: S. 69.

41 Whaley, Religiöse Toleranz, S. 161 (Zitat), 178-191; siehe auch Franklin KopItzsch, Minderheiten und Fremde in nordwestdeutschen Städten in der frühen Neuzeit, in: NSJ 69 (1997), S. 45-59, hier: S. 48f. 
sie in der Frühneuzeit häufig vorkamen, zum Beispiel wenn die ohnehin gegebene Brennholzknappheit durch die Bevölkerungsverdichtung noch verschärft wurde. Mit der Lösung solcher Anfangsprobleme nahmen die Spannungen aber meist »schon wenige Jahre nach Beginn der Niederlassung schnell $\mathrm{ab} \ll{ }^{42}$.

In einer Großstadt wie Hamburg konnte der Zuzug einer sehr kleinen und zudem sehr wohlhabenden Gruppe keine Verknappung von Ressourcen wie Brenn- oder Bauholz bewirken. Die Ursachen für die Ablehnung der Hugenotten lagen hier mehr als anderswo bei den lutherischen Geistlichen, von denen einige so weit gingen, mit feindseligen Predigten die Ressentiments gerade bei den unteren und mittleren Schichten zu schüren, wo sozialer Neid womöglich ausgeprägter war als bei wohlhabenden Kaufleuten. Den Höhepunkt erreichten die Kampagnen um 1720, als die Kirchgänger wiederholt zu Tumulten vor der Kapelle der niederländischen Gesandtschaft aufgewiegelt wurden. Die Androhung physischer Gewalt, und sei es auch nur gegen Sachen, musste durchaus ernst genommen werden, denn katholische Kapellen waren in der Stadt bereits zweimal zerstört worden, und beide Male hatten Pastoren die Menge dazu ermutigt: 1667 traf es den Andachtsraum im Haus der konvertierten Christina von Schweden, während eines Festes, das sie während eines ihrer Aufenthalte in der Stadt gab. 1719 wurde die Kapelle in der kaiserlichen Gesandtschaft vollständig zerstört, weil man es als schweren Affront auffasste, dass das Gebäude eine größere Kapelle mit Eingang von der Straße erhalten sollte. Es war übrigens dasselbe Haus am Krayenkamp, gegenüber der St. Michaeliskirche, in dem zuvor schon die Königin Christina und die Texeiras residiert hatten. Der zweite Vorfall führte zu einem Prozess gegen die Stadt, die ihrer Aufsichtspflicht nicht nachgekommen sei und damit die Friedensvereinbarungen von Münster verletzt habe. Es drohte eine Einquartierung von Truppen, und nur mit Mühe gelang es dem Senat 1721, eine Halbierung des von einer kaiserlichen Kommission verhängten Strafgeldes von 400.000 Gulden auszuhandeln. Als Ersatz für das verwüstete Gebäude musste der Gesandtschaft zudem ein repräsentatives Stadtpalais überlassen werden ${ }^{43}$.

42 Andreas ReINKe, »Man fügt ihnen unendliche Schmach zu«. Proteste und Widerstände gegen die Hugenotten in den deutschen Staaten, in: Beneke/OttomeYer (Hg.), Zuwanderungsland Deutschland, S. 65-72, Zitate von S. 68, 72; Ulrich NigGEMANN, Immigrationspolitik zwischen Konflikt und Konsens. Die Hugenottenansiedlung in Deutschland und England (1681-1697), Köln 2008, S. 247-272; siehe auch Willi Stubenvoll, Die deutschen Hugenottenstädte, Frankfurt am Main 1990, S. 185f.; Michelle Magdelaine, Francfort-sur-le-Main et les réfugiées huguenots, in: Braun/Lachenicht (Hg.), Les états allemands, S. 35-49, hier: S. 43, 48.

43 Frank Hatje, Repräsentationen der Staatsgewalt. Herrschaftsstrukturen und Selbstdarstellung in Hamburg 1700-1900, Basel 1997, S. 113-125; siehe auch WhaLEY, Religiöse Toleranz, S. 66f., 71-77. 
Man darf den Pastoren zugestehen, dass sie aus ihrer Sicht sowohl das Fest der schwedischen Königin, das sie zu Ehren des neu gewählten Papstes Clemens IX. gab, als auch die Erweiterung der Kapelle als Provokation werten und eben im Interesse eines dauerhaften Friedens genau so handeln mussten. Hauptpastor Erdmann Neumeister forderte aber wiederholt, dass nicht nur das Karthago der Papisten, sondern auch das der Calvinisten vernichtet werden müsse, obwohl die Reformierten in der Stadt sich keine derartigen Provokationen erlaubten. Dennoch schritt der Senat auch bei der Agitation gegen die niederländisch-reformierte Kapelle nicht gleich energisch ein, sodass die Angelegenheit auch in der ausländischen Presse Wellen schlug, besonders in den Niederlanden, der Schutzmacht der Hamburger Reformierten. Wie schon beim Konflikt um die Sepharden mussten die Senatoren wieder zwischen den Interessengruppen lavieren. Erst nachdem die Regierung in Den Haag sie 1722 öffentlich darauf gestoßen hatte, dass »die Geistlichen in [... der] Stadt [...] sich scheinen vorgesetzt zu haben, das Feuer der Verachtung und Uneinigkeit [...] mehr und mehr aufzublasen, und den Pöbel wider die Reformirten aufzuhetzen « und Neumeister als einen »geschworenen Feind [...] aller Verträglichkeit und Friedens « benannte, schritten sie entschiedener gegen die Predigten und Schriften der Pastoren ein ${ }^{44}$.

Nicht nur wegen dieser Vorfälle konnten sich die Franzosen an der Elbe nicht sonderlich willkommen fühlen. Nicht einmal die reformierte Gemeinde in Altona war ihnen wohl gesonnen. Die Literatur erwähnt gelegentlich, dass der dänische König Christian V. eine Trennung der zunächst unter einem Dach vereinten deutschen, niederländischen und französischen Calvinisten anordnete ${ }^{45}$, verschweigt aber die Hintergründe: Die deutschen Mitglieder sperrten sich gegen eine Zusammenarbeit mit den seit etwa 1680 ankommenden Hugenotten und verweigerten ihnen Plätze im Konsistorium. Auch Vermittlungsversuche der Königin waren erfolglos geblieben, so dass die Krone die Bildung einer französischen Gemeinde ab März 1686 verfügte. Sie war der deutschen Gemeinde rechtlich gleichgestellt ${ }^{46}$.

Während die lutherischen Prediger Hamburgs durch ihre Agitation den internationalen Ruf der Stadt schädigten, waren die Franzosen in der Oberschicht gern gesehene Geschäftspartner. Familiäre Verbindungen mit deutschen Kaufmannsfamilien blieben jedoch eine Seltenheit. Von den bis ins

44 StAH, Bestand 521-4, Sign. IC: »Schreiben Derer Herren General=Staaten der Vereinigten Niederlande, An den Rath zu Hamburg, Der Geistlichkeit daselbst, Straffbares Unternehmen wider die Reformirten, und sonderlich Die von Herrn Erdmann Neumeister [...] in Druck gegebene Ärgerliche Schriften, auch allerseits Ahnd= und Bestraffung betreffend [...] d. d. Haag den 3 Januarii 1722 «. In dem Brief wird auch das abwiegelnde Verhalten kritisiert, mit dem der Senat schon 1719 monierte Vorkommnisse dem niederländischen Residenten selbst zuschrieb.

45 Stubenvoll, Die deutschen Hugenottenstädte, S. 185.

46 StAH, Bestand 521-3 (Französisch Reformierte Gemeinde), Sign. 1, Protocole du Secrétariat commencé le mois d'avril 1686. 
frühe 19. Jahrhundert verzeichneten 36 Ehen der männlichen und weiblichen Mitglieder der aus Bordeaux stammenden Familie Boué - neben den His die erfolgreichsten und wohlhabendsten der Hamburger Franzosen - sind 28 mit reformierten Partnern französischer Herkunft geschlossen worden. Die Glaubensgenossen in Hamburg und Altona stellten die weitaus größte Zahl von Ehepartnern, doch zählten zu besagten 28 Ehen auch Verbindungen mit den großen calvinistischen Familien in Frankreich ${ }^{47}$. Wie Fred Schrader gezeigt hat, lagen die Gründe für das endogame Verhalten kaum in sozialen Abschließungstendenzen der Hugenotten selbst, sondern vielmehr in der Geschlossenheit des monokonfessionellen Hamburger Bürgertums. Die multikonfessionelle Gesellschaft von Bordeaux, in der auch zahlreiche Hamburger etabliert waren, war weitaus offener gegenüber Fremden als die der Hansestadt $^{48}$.

Wieso aber hatten diese Hugenotten überhaupt einen so wenig gastlichen Ort wie Hamburg gewählt? Verweigerung der Religionsfreiheit, politische und wirtschaftliche Benachteiligung, Feindseligkeiten von Seiten der anderen Glaubensgruppe - dafür mussten sie nicht an die Elbe gehen, das gab es auch in Bordeaux oder La Rochelle. Natürlich kann man die Situation in Hamburg nicht mit der rücksichtslosen und nach 1685 immer blutigeren Unterdrückung der Reformierten in den Cevennen, im Vivarais oder im Languedoc vergleichen ${ }^{49}$. Eine solche Eskalation des Konflikts gab es aber auch nicht in den westfranzösischen Hafenstädten, aus denen die Hamburger Franzosen ganz überwiegend kamen. Warren Scoville hat gezeigt, dass Ludwig XIV. und Colbert sogar Anweisungen gaben, den Konflikt in den wichtigen maritimen Handelszentren nicht anzufachen und besonders die wirt-

$47 \mathrm{Zu}$ nennen ist besonders die 1746 in Hamburg geschlossene Ehe von Pierre Boués Tochter Anne-Marie mit Guillaume Nairac. Ihre in der Heimat gebliebene Tante Jeanne hatte bereits 1707 in Bordeaux Isaac Balguerie geheiratet. Die Balgueries und die Nairacs zählten zu den führenden Reedern in Bordeaux. Henriette, eine Tochter von Jean-Alexandre Boué (17061781), heiratete 1768 den Reeder Pierre Samuel de Meschinet in La Rochelle. In den 1790er Jahren, als die Grundlagen der französischen Kolonialmacht ins Wanken gerieten, schlossen die Boués erste Heiratsverträge mit britischen Familien, darunter die überaus wohlhabenden Parish. Hamburgisches Geschlechterbuch 13 (1996), S. 53-132. Das Ergebnis dieser Stichprobe zur Familie Boué wird von anderer Seite bestätigt; siehe Richard HerTz, Das Seehandelshaus J.C. Godeffroy und Sohn 1766-1879, Hamburg 1922, S. 6, zum Heiratsverhalten der Franzosen: »Sie hatten mit verschwindenden Ausnahmen kein Konnubium mit den Alteingesessenen«.

48 Fred E. Schrader, Handel und Aufklärungssoziabilität in Hamburg und Bordeaux, 17501820, in: Jean Mondot / Catherine LARRÈre (Hg.), Lumières et commerce. L'exemple bordelais, Frankfurt am Main 2000, S. 67-87. Auch in Berlin wurde das Heiratsverhalten der Hugenotten im Verlauf des 18. Jahrhunderts zunehmend exogam. Hierzu Eckart BiRnstiel/Andreas ReINKe, Hugenotten in Berlin, in: Stefi Jersch-Wenzel/Barbara John (Hg.), Von Zuwanderern zu Einheimischen. Hugenotten, Juden, Böhmen und Polen in Berlin, Berlin 1990, S. 13-152, hier: S. 94-97

49 Hierzu z.B. Roy L. McCullough, Coercion, Conversion and Counterinsurgency in Louis XIV's France, Leiden 2007. 
schaftlich bedeutungsvollen Seehändler und die Betreiber der Zuckerraffinerien mit großer Nachsicht zu behandeln. Denn - wie der Marineminister Seignelay im September 1685 schrieb - es waren hugenottische Reeder, die fast den gesamten Verkehr zwischen dem Mutterland und den karibischen Inselkolonien bestritten, und sie kontrollierten auch fast den gesamten Weinund Salzexport aus Bordeaux und La Rochelle. Das lag nicht zuletzt an ihren ausgezeichneten Verbindungen zu den für die Region lebenswichtigen Handelspartnern im Nord- und Ostseeraum, die durch die Abwanderung von Hugenotten nach Norden noch verbessert wurden. Aus dieser Position heraus konnten sie auch Druck auf katholische Standesgenossen und auf Konvertiten üben. Der Intendant in Bordeaux wagte bisweilen nicht einmal, Kaufleute festzunehmen, die gegen das Edikt von Fontainebleau verstießen, weil solche Eingriffe den Handel empfindlich gestört hätten. Hinzu kommt die militärische Bedeutung der Reformierten: Sie belieferten auch die Marinehäfen mit Nachschub, und auf den Kriegsschiffen stellten sie ein Drittel der Mannschaften und die Hälfte der Offiziere ${ }^{50}$.

Wenn dies auch etwas verkürzt scheinen mag, so könnte man doch sagen, dass die hier betrachteten Händler zu den in Frankreich am wenigsten bedrängten Reformierten gehörten, dass sie in Deutschland aber einen der in politisch-konfessioneller Hinsicht unvorteilhaftesten Plätze wählten. Oder anders formuliert: Der religiöse Push-Faktor in der Heimat war in diesem Fall ebenso schwach wie der religiöse Pull-Faktor am Zielort. Gerade bei einer solchen Konstellation muss daran erinnert werden, dass die härteste der in der Révocation angedrohten Strafen - Verlust allen Besitzes, Galeere für die Männer, Gefängnis oder Kloster für die Frauen - nicht auf Verweigerung der Konversion stand, sondern auf Flucht aus dem Lande ${ }^{51}$. Es muss also gute Gründe gegeben haben, sich diesem Risiko auszusetzen. Selbst der mit der Mission in La Rochelle beauftragte Abbé François de Fénelon befand, dass für viele Hugenotten »kommerziell-ökonomische Schwierigkeiten der Hauptgrund seien, das Land zu verlassen, nicht so sehr religiöse Gründe ${ }^{42}$. Das traf kaum für die von Dragonaden und zunehmendem Terror getroffene Landbevölkerung im Landesinneren zu. Für die Seehändler jedoch hatten wirtschaftliche Gründe sicherlich großes Gewicht. Wenn man trotzdem die

50 Warren Scoville, The Persecution of the Huguenots and French Economic Development 16801720, Berkeley/Los Angeles 1960, S. 134-137, 241f., 252.

51 Vollständige Wiedergabe des Edikts von Fontainebleau in Dieter Mempel, Gewissensfreiheit und Wirtschaftspolitik. Hugenotten- und Waldenserprivilegien 1681-1699, Trier 1986, S. 2631, siehe Artikel X. Die Galeerenstrafe drohte auch den Predigern, die weder konvertieren noch sich außer Landes begeben wollten, siehe Artikel IV.

52 Der Abbé fügte hinzu, man möge ihnen deshalb die Handelsbedingungen etwas erleichtern. Heinz Duchiardt, Die Konfessionspolitik Ludwigs XIV., in: Ders. (Hg.), Der Exodus der Hugenotten. Die Aufhebung des Edikts von Nantes 1685 als europäisches Ereignis, Köln 1985, S. 29-52, hier: S. 49. 
Unterdrückung als einen der Hauptgründe für ihre Flucht annehmen will, dann erklärt dieses Motiv aber noch nicht die Wahl des Zielortes Hamburg. Dafür müssen die ökonomischen Aspekte hinzugezogen werden. Orte wie das pfälzische Frankenthal oder das hessische Karlshafen kamen als $\mathrm{Zu}$ fluchtsort für sie ebenso wenig in Frage wie die Kolonien in Brandenburg, nicht einmal eine Stadt wie Berlin - obwohl sie dort sicher willkommen gewesen wären. Ihren Geschäften konnten sie nur in den größeren Seehäfen nachgehen. Unter denen wiederum boten sich aber freundlichere Orte als Hamburg an - zum Beispiel Amsterdam oder London, wo ihr Glaube als bevorzugte Öffentlichkeitskirche etabliert war oder zumindest weit weniger angefeindet wurde als in der Hansestadt, und wo sich ja bereits Tausende ihrer reformierten Landsleute niedergelassen hatten.

Zum besseren Verständnis der Anziehungskraft, die Hamburg trotzdem auf diese Gruppe übte, soll Bertrand Van Ruymbekes Konzept der hugenottischen Diaspora herangezogen werden. Er hat das Refuge in eine atlantische und eine kontinentale Diaspora geteilt, wobei der atlantische etwa 80.000 und der kontinentaleuropäische Raum rund 100.000 Auswanderer aufnahm ${ }^{53}$. Zum Raum des atlantischen Refuge gehörten demnach die Britischen Inseln, die Küstenstädte Hollands, die Karibik, das britische Nordamerika und die Kapkolonie. Auch Hamburg müsste aufgrund seiner geographischen Lage und der ökonomischen Ausrichtung seiner reformierten Minderheit diesem Raum zugeordnet werden. Bei den Hamburger Hugenotten handelte es sich in der Mehrzahl um wohl etablierte und erfolgreiche Seehändler aus westfranzösischen Hafenstädten wie Bordeaux, La Rochelle und Rouen, die im Handel mit französischen Kolonialwaren und Erzeugnissen des Mutterlandes aktiv waren, also vor allem mit Zucker, Kaffee, Baumwolle, Indigo und Farbhölzern sowie Wein, Branntwein, Olivenöl und Trockenfrüchten. Binnen kurzer Zeit erarbeiteten sie sich an der Elbe eine überragende Stellung im Handel mit den karibischen Plantagenerzeugnissen.

Schon in ihren französischen Heimatstädten war ihr Erfolg eng mit dem Aufstieg Frankreichs zu einer der führenden Kolonialmächte verbunden gewesen. Mit seinen karibischen Erwerbungen war Frankreich gewissermaßen ein Nachzügler in dem Rennen um profitable Überseegebiete, hinter Spanien, Portugal, den Niederlanden und England. Erst die in den 1650er Jahren erfolgte französische Besetzung von Saint-Domingue, dem westlichen Teil der spanischen Insel Hispaniola, sowie der Erwerb von Martinique und Guadeloupe machten Frankreich zu einem ernstzunehmenden Konkurrenten der etablierten Kolonialmächte. Im Frieden von Rijswijk wurden diese

53 Bertrand Van Ruymbene, Minority Survival. The Huguenot Paradigm in France and the Diaspora, in: Bertrand Van Ruymbeke/Randy J. Sparks (Hg.), Memory and Identity. The Huguenots and the Atlantic Diaspora, Columbia (SC) 2003, S. 1-25, hier: S. 12f. 
Erwerbungen auch international anerkannt. Besonders Saint-Domingue erwies sich als höchst gewinnbringend. Die außerordentlich fruchtbaren Böden dieser Kolonie, mit Jahreserträgen von bis zu 3,5 Tonnen pro Hektar, machten sie zum weltweit größten Zuckerproduzenten des 18. Jahrhunderts. Die Insel löste also Brasilien in dieser Position ab und lieferte bald zwei Drittel bis drei Viertel des gesamten in der westlichen Welt konsumierten Zuckers. Während die spanischen Kolonien weit davon entfernt waren, den Bedarf des Mutterlandes zu decken und selbst England mit den Erträgen aus Jamaika und Barbados vor allem die eigene Nachfrage stillte, konnte der Großteil des Zuckers aus der französischen Karibik reexportiert werden, vor allem nach Spanien und in die expandierenden Märkte in Mitteleuropa und im Ostseeraum. Die enorme Bedeutung der französischen Karibik lässt sich schon an einem Vergleich der Einwohnerzahlen mit dem flächenmäßig ungleich größeren Kanada ablesen: Auf den etwa 1 Million Quadratkilometern Kanadas, die Frankreich bis 1763 mehr oder weniger effektiv kontrollierte, hatten nie mehr als 10.000 Siedler gelebt. Dagegen zählten Saint-Domingue, Martinique und Guadeloupe - zusammengenommen nur 30.000 Quadratkilometer groß - schon gegen 1680 ca. 50.000 Bewohner, und hundert Jahre später waren es 730.000. Die meisten von ihnen waren afrikanische Sklaven ${ }^{54}$.

Obwohl sich unter Ludwig XIV. weder Hugenotten noch Juden in den überseeischen Territorien niederlassen durften, stellten Protestanten einen hohen Anteil der Kolonisten. Schon auf Saint-Christophe, dem seit 1625 französischen Teil der Insel St. Kitts, gab es um 1630 eine reformierte Gemeinde, die dort vor allem Tabakanbau betrieb. Als die Niederländer 1654 aus Brasilien ausgewiesen wurden (wobei sie ihren Besitz mitnehmen durften, auch die Sklaven und die sehr kostspielige technische Ausrüstung der Zuckermühlen), fanden sie nicht nur auf Curaçao und den englischen Karibikinseln Aufnahme. Eine Gruppe von etwa tausend Personen ließ sich auf Guadeloupe nieder, dessen Gouverneur sich von diesen Experten eine Verbesserung der dort noch in den Anfängen steckenden Zuckerwirtschaft versprach. Unter den Flüchtlingen waren 300 wallonische und flämische Soldaten, 200 Frauen und 300 Sklaven. Nur die übrigen 100 bis 200 waren Pflanzer, die dort aber mit ihren Familien und dem Personal das in Bewegung setzten, was gemeinhin als Sugar Revolution beschrieben wird: die Verdrängung aller anderen Feldfrüchte durch das Zuckerrohr, die mit Landkonzentration einhergehende Verdrängung der kleineren Pflanzer (petits blancs) durch kapitalkräftigere Investoren und die zunehmende Verdrängung europäischer Vertragsarbeiter

54 Jean Meyer, Histoire de la France coloniale, Bd. 1: Des origines à 1914, Paris 1991, S. 72, 75; siehe auch Herbert KLeIn, African Slavery in Latin America and the Caribbean, Oxford 1986, S. 56-58. 
durch afrikanische Sklaven ${ }^{55}$. Im Verlauf dieses Prozesses gingen die Niederländer viele familiäre Verbindungen mit den bereits auf den Inseln lebenden reformierten Franzosen ein, die übrigens unter den Vertragsarbeitern stark überrepräsentiert waren. So ergaben sich weit gespannte Verwandtschaftsverbindungen. Die in den 1660er Jahren geschaffene Compagnie des Indes Occidentales sollte die Holländer aus der französischen Karibik verdrängen, und jede Teilnahme von Nichtkatholiken an dem Unternehmen war untersagt. Die Vorgaben wurden jedoch weitgehend missachtet. Schon die ersten Generalagenten der Kompanie auf Martinique, Guadeloupe und SaintChristophe waren Hugenotten. Zudem erhielten viele der Zuckerplantagen, die wegen der hohen Kosten für Sklaven und technische Ausrüstung als sehr kapitalintensive Unternehmen gelten müssen, ihre Kredite über die familiären Netzwerke calvinistischer Familien: aus Handelsstädten wie »Rotterdam, Vlissingen, Leiden und Hamburg, die schon Mittel zur Entwicklung des niederländischen Brasilien aufgebracht hatten«. Du Lion, Gouverneur von Guadeloupe, schrieb 1665: »Die Mehrheit der schönen Plantagen auf dieser Insel wurde mit Darlehen von diesen Fremden aufgebaut $\aleph^{56}$.

Bis in die frühen 1680er Jahre gingen die Inselbewohner mit der Konfessionsverschiedenheit relativ entspannt um. Katholische Priester tauften die Kinder der Calvinisten ohne viel Aufhebens und gegen ein vages Versprechen der Eltern, die Kinder im römischen Glauben zu erziehen. Dass Protestanten ihre Ehen in den benachbarten englischen Kolonien schlossen, wurde stillschweigend geduldet. Und diese akzeptierten es, dass sie ihre Toten ohne religiöses Zeremoniell begraben mussten. Erst nach dem Tod des pragmatischen Colbert (1683), dem es vor allem an der Prosperität der überseeischen Gebiete gelegen war, nahm der Konversionsdruck auch dort zu. Was im Mutterland mit der Révocation durchgesetzt wurde, erreichte man auf den Inseln durch den ebenfalls 1685 erlassenen Code noir, der im wesentlichen die Verhältnisse zwischen Sklaven und ihren Herren regelte, in seinem ersten Artikel aber jede Form des Protestantismus in den Kolonien untersagte. Durch empfindliche Geldstrafen wurde ein Großteil der auf den Inseln lebenden Reformierten zur Konversion gebracht, die übrigen entkamen in niederländische oder britische Gebiete, häufig mitsamt den Sklaven und Maschinen. Die Flucht ließ sich dort noch weniger verhindern als im Mutterland ${ }^{57}$. Freilich zerrissen die erzwungenen Konversionen in der Regel nicht die familiären und geschäftlichen Netzwerke, die sich

55 Die Erfahrung der niederländischen Fachleute wurde genauso auf den englischen Inseln genutzt.

56 Gérard Lafleur/Lucien Abénon, The Protestants and the Colonization of the French West Indies, in: Van Ruymbeke/Sparks (Hg.), Memory and Identity, S. 267-284, hier: S. 268-272, Zitate auf S. 271f.

57 Ebd, S. 273-280. 
über die Jahrzehnte zwischen den Inseln und Europa entwickelt hatten. Die Bedeutung der »calvinistischen Internationale« für den gesamten französischen Karibikhandel erkennt man zum Beispiel daran, dass vor 1680 zwischen 20 und 35 Prozent der Zuckerproduktion auf den Inseln Guadeloupe, Martinique und Marie-Galante in der Hand von Hugenotten $\operatorname{lag}^{58}$. In dieser Zeit dehnten sich die Netzwerke auch auf die Britischen Inseln und nach Nordamerika aus ${ }^{59}$.

Die Gruppe der Hugenotten in Hamburg und Altona muss als ein integraler Bestandteil dieser stark auf reformierten Unternehmern aufbauenden französischen Kolonialwirtschaft verstanden werden. Das kann durch ihre Bedeutung im Hamburger Zuckerhandel illustriert werden. Im Jahr 1753 wurden 36 Prozent der vom Admiralitätszoll erfassten Zuckerimporte - es handelte sich dabei ausschließlich um französischen Zucker - von nur drei der großen französischen Handelshäuser getätigt: His, Boué und Bosanquet. Weitere 30 Prozent verteilten sich auf ein Dutzend weniger potente Hugenotten, die aber immer noch die ganz große Mehrzahl der eingesessenen Importeure in den Schatten stellten. Bei den Franzosen kamen zum Zucker andere hochwertige Waren wie Indigo, Kaffee, Baumwolle, Gummi, Wein und Branntwein dazu. Stichproben ergaben, dass bei ihren Geschäften der Anteil der profitablen Kolonialwaren über 90 Prozent betrug, bei den gröBeren eingesessenen Kaufleuten waren es allenfalls ein Drittel ${ }^{60}$. Die Admiralitätszollbücher erfassten für das genannte Jahr französische Einfuhren in Höhe von knapp 6,5 Millionen Mark banco; der französische Gesandte in der Stadt schätzte die französischen Gesamtlieferungen in dieser Zeit auf einen Wert von etwa 14,25 Millionen Mark, die Seeimporte Hamburgs insgesamt auf etwa 77 Millionen ${ }^{61}$. Da der Handel der Vollbürger weitgehend von den Abgaben befreit war, dürften sie einen großen Teil des unverzollten Frankreichhandels in Höhe von fast 8 Millionen bestritten haben. Doch selbst vor diesem Hintergrund ist allein das Einfuhrvolumen von Pierre François His und Pierre Boué (jr.) beeindruckend: His verzollte 1753 Waren im Wert von

58 Ebd, S. 273. Im zitierten Beitrag werden nicht die Verhältnisse auf Saint-Domingue untersucht. Dort könnte der Anteil der Protestanten niedriger gewesen sein.

59 David William Voorhees, Jacob Leisler and the Huguenot Network in the English Atlantic World, in: Randolph Vigne/Charles Littleton (Hg.), From Strangers to Citizens. The Integration of Immigrant Communities in Britain, Ireland and Colonial America, 1550-1750, Brighton 2001, S. 322-331; Robert C. NAsh, Huguenot Merchants and the Development of South Carolina's Slave Plantation and Atlantic Trading Economy, 1680-1775, in: VAN RuYmBEKE/Sparks (Hg.), Memory and Identity, S. 208-240.

60 StAH, Admiralitätskollegium, F6, Bd. 18 (1753). Dazu auch Klaus WeBER, Die Admiralitätszoll- und Convoygeld-Einnahmebücher. Eine wichtige Quelle für Hamburgs Wirtschaftsgeschichte im 18. Jahrhundert, in: Hamburger Wirtschafts-Chronik N.F. 1 (2000), S. 83-112, hier: S. 98-102.

61 Archives du Ministère des Affaires Étrangères, Paris, Mémoires et documents, Allemagne, vol. 138, fol. 255, Bericht des Gesandten Champeaux an Minister Rouillé vom 25.2.1752. 
gut 1,8 Millionen Mark (davon 1 Million für Zucker), und Boué lag nicht weit darunter ${ }^{62}$.

Damit trugen die Hugenotten entscheidend zum Wachstum des wohl wichtigsten Gewerbezweigs im Hamburg des 18. Jahrhunderts bei: der Raffinierung von Zucker. Zwar ist keine einzige von den Franzosen selbst betriebene Siederei bekannt, aber sie hatten indirekt großen Einfluss auf den Sektor, da die überwiegend kleinen Betriebe (solche mit mehr als 10 Beschäftigten waren eher selten) ganz von Krediten und Warenvorschüssen der großen $\mathrm{Zu}$ ckerhändler abhängig waren ${ }^{63}$. Unter den französischen Zulieferhäfen ragte Bordeaux als wichtigster französischer Umschlagplatz im Reexport von Kolonialwaren besonders heraus. Bis zur Revolution lagen die Hamburger Einfuhren (nach Warenwert) allein aus diesem Hafen um ein Vielfaches über denen aus allen englischen Häfen zusammen, wozu vor allem Zucker, Kaffee, Baumwolle und Farbstoffe von den französischen Antillen beitrugen ${ }^{64}$. Schon im Jahr 1727 lag die Zahl der Zuckersiedereien an der Elbe bei 200, um die Jahrhundertmitte bei 300 und in den Jahren um 1780 über 350. Die Bedeutung Hamburgs auf diesem Sektor wird auch im Vergleich mit den Niederlanden deutlich: Für Amsterdam sind für die Zeit um 1750 nur 90, für Rotterdam nur 30 Raffinerien bekannt ${ }^{65}$. An der gesamten französischen Atlantikküste soll es in den 1710er Jahren kaum 40 dieser Betriebe gegeben haben ${ }^{66}$. Im Standortwettbewerb um die expandierende Zuckerindustrie hatte Hamburg einige unschlagbare Vorteile aufzuweisen, und die dürften zu den wesentlichen Gründen für die Zuwanderung der Hugenotten gehört haben. Über die Jahrzehnte hinweg beklagten Beamte und die Handelskammer von Bordeaux immer wieder die ungünstigeren Bedingungen in Frankreich. Ein Bericht von 1781 fasst die Gründe für die Stagnation der dortigen Industrie kurz zusammen:

62 WeBEr, Admiralitätszoll- und Convoygeld-Einnahmebücher, S. 105.

63 Astrid Petersson, Zuckersiedergewerbe und Zuckerhandel in Hamburg. Von den Anfängen bis zum Ende der Kontinentalsperre, in: Hamburger Wirtschafts-Chronik N.F. 1 (2000), S. 53-81, hier: S. 74-77.

64 Archives Nationales, Paris, Commerce et industrie, départements hanséatiques, Sign. $F^{12}$ 566595, »Etat comparatif des importations des ports de France dans le port de Hambourg \& toutes les autres puissances en 1788«. Danach erhielt Hamburg in dem Jahr aus Bordeaux Waren im Wert von über 35 Millionen Livres, gegenüber knapp 12 Millionen aus England. Da das Dokument aus einer vom Juni 1807 datierenden, im Namen der Hansestädte verfassten Denkschrift stammt, welche die hamburgischen Handelsverluste seit Beginn der Kontinentalsperre deutlich machen sollte, könnten die Zahlen für Frankreich übertrieben sein. Die Tendenz trifft allerdings zu. Zum Wachstum Bordeauxs im frühen 18. Jahrhundert siehe Paul Butel, Les négociants bordelais, l'Europe et les îles au $18^{\text {e }}$ siècle, Paris 1974, S. 17, 20f., 31-30.

65 Petersson, Zuckersiedergewerbe, S. 58; Jonathan Israel, Dutch Primacy in World Trade, 1585-1740, Oxford 1989, S. 265.

66 Scoville, The Persecution of the Huguenots, S. 241. 
Wir zweifeln indessen, ob sich unser Wettbewerb an Hamburg, Fiume und Triest wird messen können; nicht weil wir weniger arbeitsam sind, sondern wegen unserer Entfernung [von den Märkten], wegen der hohen Preise für die Arbeit, für die Kohle und für alle in den Zuckersiedereien notwendigen Dinge. Die ausländischen Raffinerien versorgen sich zu niedrigeren Preisen damit, und wir werden ihnen deshalb immer nachstehen $^{67}$.

Neben niedrigen Lohnkosten bot die Hansestadt dem energieintensiven Gewerbe auch eine sichere Versorgung mit hochwertiger nordenglischer Kohle, während dieser Brennstoff in Frankreich knapp und von minderer Qualität war. Hinzu kam der neutrale Status der Hansestadt, die im Gegensatz zu den französischen Häfen auch in Kriegszeiten aus England beliefert wurde ${ }^{68}$.

Scoville betonte zwar, dass die französische Zuckerindustrie während der Abwanderung von Hugenotten allenfalls stagniert, aber nicht weiter gelitten habe ${ }^{69}$. Im Vergleich mit dem enormen, ganz auf französischem Rohzucker gegründeten Wachstum in Hamburg durchlief die Branche in Frankreich allerdings einen relativen Schrumpfungsprozess, und der hatte weniger mit der Unterdrückung zu tun als mit makroökonomischen Nachteilen. Eine der Ursachen für die niedrigeren Lohnkosten an der Elbe war die frühneuzeitliche Preisrevolution. Durch die aus dem spanischen Amerika nach Europa strömenden Silbermengen war ein von West nach Ost sich erstreckendes Lohn- und Preisgefälle entstanden, das die lohnintensiven Gewerbe bei den östlicheren Nachbarn der Seemächte begünstigte ${ }^{70}$. Das war auch einer der Gründe dafür, dass die holländischen Zuckerstandorte nach 1700 hinter Hamburg zurückfielen. Man darf deshalb annehmen, dass sich in Hamburg auch ohne die Religionspolitik Ludwigs XIV. eine bedeutende französische Kaufmannskolonie entwickelt hätte.

67 Archives départmentales de la Gironde (ADG), Bordeaux, C 4265, fol. 169, Memorandum der Handelskammer von Bordeaux an den französischen Gesandten für Venedig und die Levante, vom 3.4.1781; meine Übersetzung (K.W.). Ein ähnliches Schreiben vom 28.3.1778 auf fol. 82.

68 ADG, C 4473, $\mathrm{N}^{\circ}$ 46, »Memoire sur le Charbon de Terre« vom 10.4.1764.

69 Scoville, The Persecution of the Huguenots, S. 439.

70 Earl J. Hamilton, American Treasure and the Price Revolution in Spain, 1501-1650, Cambridge (Mass.) 1934; ders., War and Prices in Spain, 1651-1800, Cambridge (Mass.) 1947. Mittlerweile hat sich in der Diskussion um die Preisrevolution ein multikausaler Erklärungsansatz durchgesetzt, der neben der zunehmenden Münzgeldmenge weitere Parameter wie das Bevölkerungswachstum, die Zunahme des Buchgeldes und der Umlaufgeschwindigkeit berücksichtigt. Auf solche zweifellos wichtigen Differenzierungen muss aber an dieser Stelle nicht näher eingegangen werden, denn hier interessieren nicht die Ursachen der Preisrevolution, sondern ihre Folgen. Renate PIEPER, Die Preisrevolution in Spanien (1500-1650), Wiesbaden 1985; dies., The Volume of African and American Exports of Precious Metals and its Effects in Europe, 15001800, in: Hans PoHL (Hg.), The European Discovery of the World and its Economic Effects on Pre-Industrial Society, 1500-1800, Stuttgart 1990, S. 97-117. 
Die Hugenotten nutzten diese Vorteile auch in der entgegengesetzten Richtung, indem sie große Mengen arbeitsintensiver Güter, vor allem deutsche Leinenstoffe, in den atlantischen Raum exportierten. Eine Korrespondenz, die der gegen 1700 nach Hamburg gekommene Pierre Boué (1677-1745) Mitte der 1730er Jahre im Zusammenhang mit Lieferungen an die im spanischen Amerikahandel tätige Caracas-Kompanie führte, benennt die Preisvorteile:

Die Ladung, die wir für die Kompanie von Caracas zusammengestellt haben, ist expediert, und das Schiff muss bereits auf See sein. Sie ist bedeutender als wir uns vorgestellt haben, denn sie hat einen Wert von mehr als 40 Tausend Ecus. Niemals ist auf unserem Fluss ein Schiff mit so günstig eingekaufter Leinwand ausgelaufen; hätte die Kompanie diese Ladung in Amsterdam gemacht, so hätte sie 15 Hundert Pistolen [eine zeitgenössische Goldmünze] mehr gekostet, und sie hätte keine so schöne Ware erhalten. Wir lassen für besagte Kompanie zwei weitere Ladungen vorbereiten, eine Ladung von Teer in Stockholm, eine andere von Hanf in Riga, zur direkten Verschiffung nach $S^{t}$ Sebastien. Da die Kompanie uns die Ehre macht, sich uns anzuvertrauen, führen wir sie an die Quellen, so dass sie die Waren zum niedrigsten Preis erhält $[\ldots]^{71}$.

An der Beladung der für Spanien gecharterten Schiffe waren auch die Hugenotten Bernard Texier, Pierre His, Jean Boyer und Alexandre Bruguier beteiligt sowie eingesessene Hamburger Kaufleute, darunter Stenglin und Sohn, Zimbert Amsinck sowie Johann und Rudolf Berenberg, um nur einige der bekannteren zu nennen ${ }^{72}$. Der Standort Hamburg zog freilich nicht nur Protestanten an. Für den Wareneinkauf unterhielt zum Beispiel auch die große Sklavenhandelsfirma der Katholiken Michel \& Grou aus Nantes eine Filiale in Hamburg ${ }^{73}$.

Es ist bislang noch nicht genauer untersucht worden, welche Geschäftsverbindungen zwischen den Hamburger Franzosen und ihren nach Schlesien, Hessen oder Braunschweig gegangenen Glaubensgenossen bestanden. Unter denen waren Textilfachleute stark vertreten. In den deutschen Leinenregionen produzierten sie weiter ihre Stoffe bretonischer, normannischer und schweizerischer Machart, die als »Bretannies«, »Rouanes« oder »Sangallas « (benannt nach St. Gallen) im gesamten atlantischen Raum nachgefragt wurden. Ergänzt wurden die Sortimente durch genuin deutsche Sorten, die un-

71 ADG, 7 B 1784, Brief Boués an Jean Pellet (Bordeaux) vom 27. Mai 1735; Übersetzung von K.W.

72 ADG, 7 B 1784, Briefe Boués an Jean Pellet vom 6., 10., und 17.6., vom 11.7., vom 8.8., vom 23.9., vom 21., 24., 28. und 31.10., und vom 4., 11., 14. und 18.11.1735. Die Amsincks und die Berenbergs waren niederländischer Herkunft - ein weiterer Beleg für die überdurchschnittliche Präsenz der Immigranten in Hamburgs großem Überseehandel.

73 Olivier Pétré-Grenoullleau, L'argent de la traite. Milieu négrier, capitalisme et développement. Un modèle, Paris 1996, S. 22. 
ter Bezeichnungen wie »Osnabrughs«, »Tecklenburghs« oder »Brunswicks« vermarktet wurden. Schon der Hamburger Gelehrte und Wirtschaftsexperte Johann Georg Büsch (1728-1800) beschrieb den Erfolg dieser Gewebe auf den westlichen Märkten, auch als Tauschware für den Sklavenhandel:

Wie schnell sie sich beliebt gemacht, davon giebt schon Desmarchais in der Beschreibung seiner im Jahre 1720 nach Guinea angetretenen Reise einen Beweis, da er erzählt, daß das Französische Schiff, mit welchem er von L'Orient abreiste, in seiner Ladung nur Hamburgische Leinen gehabt habe ${ }^{74}$.

Mit den niedrigeren Produktionskosten bot Mitteleuropa dem Textilgewerbe der Hugenotten bessere Bedingungen als die französische Heimat, wo die Leinenweberei im 17. Jahrhundert einen stetigen Niedergang erlebte und dann vom Exodus der Protestanten nochmals schwer getroffen wurde ${ }^{75}$. Die Franzosen in den Leinenexporthäfen Hamburg und Bremen konnten für die Textilproduzenten im Refuge den Absatz auf denselben Märkten organisieren, die sie schon von Frankreich aus beliefert hatten. Insofern waren die Händlerkolonien in den Hansestädten ein Bindeglied zwischen der kontinentalen und der atlantischen Diaspora, von existentieller Bedeutung für beide Seiten. Bis zu welchem Grad die Textilkrise in Frankreich und die besseren Bedingungen in Deutschland als ökonomische Push- und Pull-Faktoren auch zur Migration der protestantischen Textilexperten beitrugen, wäre eine andere Frage. Immerhin kam es vor, dass katholische Franzosen sich als angebliche Calvinisten dem Exodus anschlossen, weil sie sich davon eine Verbesserung ihrer wirtschaftlichen Lage versprachen.

Ein weiterer Sektor, auf dem die Hugenotten von den niedrigeren Lohnund Rohstoffkosten profitierten, war der Schiffbau. Im Jahr 1719 gründeten die Brüder Boué in Altona eine Werft, die der Hamburger Senat schon 1723 durch die Überlassung eines am Oberhafen gelegenen, bestens geeigneten Grundstücks in seine Stadt ziehen konnte. Unter dem Namen »Französische Schiffbauerei« war sie im ganzen Jahrhundert die bedeutendste Hamburger Werft. Wichtigster Kunde war die im bretonischen Lorient ansässige und sowohl im Indien- als auch im atlantischen Sklavenhandel aktive Compagnie de l'Inde, an die Pierre und Jacques Boué von 1719 bis 1732 wenigstens 23 Schiffe lieferten, darunter vier Kriegsschiffe der größten Klasse, die mit je 50 Kanonen bestückt waren ${ }^{76}$. Jean Meyer, der auch schon auf diese Geschäf-

74 Johann Georg Büsch, Versuch einer Geschichte der Hamburgischen Handlung nebst zwei kleineren Schriften verwandten Inhalts, Hamburg 1797, S. 88f.

75 Jean TAnguy, Quand la toile va. L'industrie toilière bretonne du $16^{\mathrm{e}}$ au $18^{\mathrm{e}}$ siècle, Rennes 1994.

76 Weber, La migration huguenote, S. 131f. Das Grundstück auf dem Grasbrook wurde als Fideikommiss übereignet. Ich danke Herrn Peter Boué für eine Kopie des Vertrags mit der Stadt, der auch im Staatsarchiv Hamburg erhalten ist. 
te eingegangen ist, sah in Pierre Boué ein typisches Beispiel für die bedeutende Gruppe hugenottischer Seehändler, die wesentlich zu dem unter dem Sonnenkönig gelingenden Aufstieg Frankreichs zur großen Seemacht beitrugen ${ }^{77}$.

Ebenso herausragend war Pierre François His (1692-1760) aus Rouen, dessen Präsenz in Hamburg ab 1717 nachweisbar ist. Neben dem Warenhandel betrieb er umfangreiche Bankgeschäfte, vor allem im Zahlungs- und Wechselverkehr. Er vermittelte Frankreichs Subsidienzahlungen an Dänemark und Preußen, und seit 1745 diente er dem dänischen König als diplomatischer Vertreter in der Hansestadt. In der Catharinenstraße ließ er sich 1742 eine barocke Stadtresidenz errichten, in der Großen Reichenstraße unterhielt er ein Geschäftshaus und vor den Toren der Stadt ein Landgut mit Gärten, die sich bis zum Elbufer erstreckten. Die Tochter Louise Madeleine His heiratete 1750 den aus einer reformierten Baseler Kaufmannsfamilie stammenden Albrecht Ochs, der die Firma bis zu seinem Tod (1780) weiterführte ${ }^{78}$.

Die Bedeutung der Franzosen in Hamburg litt auch nicht unter den Folgen des Siebenjährigen Krieges. Ab den fünfziger Jahren nahm die Menge der in Hamburg umgeschlagenen und verarbeiteten Plantagenerzeugnisse von den französischen Antillen sogar noch zu, vor allem seit man dort auch den Kaffeeanbau intensivierte. Den Höhepunkt erreichte diese Entwicklung in den 1780er Jahren. Erst die Französische Revolution und der folgende Sklavenaufstand auf Saint-Domingue, die in die Haitianische Revolution und 1804 in die Unabhängigkeit der Kolonie mündeten, setzten auch den über das ganze Jahrhundert so erfolgreichen Hamburger Hugenotten schwer zu. Mit der schon während der Kontinentalkriege einsetzenden Konzentration des Welthandels in London verloren die über Frankreich gespannten Netzwerke ihre Funktion. Auch diese Verlagerung ist am Zuckerhandel gut verfolgbar: Nach dem Ende der Kontinentalsperre bezog die Hansestadt ihren Rohzucker überwiegend aus Brasilien, Kuba und den britischen Kolonien ${ }^{79}$.

Damit ging die große Zeit der Hamburger Franzosen zu Ende. Die Godeffroys, die einzige bedeutende Kaufmanns- und Reederfamilie des 19. Jahrhunderts, die man noch der französischen Gemeinde zuordnen kann, waren eigentlich schweizerischer Herkunft. Aber wie die übrigen wohlhabenderen Franzosen wechselten auch sie 1871 unter dem Druck des neuen Nationalismus zur lutherischen Kirche. Damit wurde die französisch-reformierte Gemeinde Hamburgs, die immer eine Unterstützerin ärmerer Konsistorien -

77 Jean Meyer, Marchands et négociants allemands dans la France de l'ouest aux XVII ${ }^{\mathrm{e}}$ et XVIII siècles, in: Etudes Germaniques 37 (1982), S. 187-210, hier: S. 200.

78 Eduard His, Chronik der Familie Ochs, genannt His, Basel 1943, S. 122, 155-160.

79 Astrid Petersson, Zuckersiedergewerbe und Zuckerhandel in Hamburg im Zeitraum von 1814 bis 1834. Entwicklung und Struktur zweier wichtiger Hamburger Wirtschaftszweige des vorindustriellen Zeitalters, Stuttgart 1998, S. 295 f. 
etwa in Brandenburg - gewesen war, selbst von der finanziellen Hilfe von außerhalb abhängig.

\section{Zusammenfassender Vergleich}

Die Migration von Sepharden wie von Hugenotten nach Hamburg erscheint auf den ersten Blick als ein Ausweichen vor der Unterdrückung, denen die Migranten an ihren Herkunftsorten ausgesetzt waren: die Juden auf der iberischen Halbinsel und dann auch in den spanischen Niederlanden, die $\mathrm{Hu}-$ genotten in Frankreich. Wie Michael Studemund-Halévy konstatierte, sind die Gründe für die sephardische Migration an die Elbe allerdings noch nicht befriedigend geklärt ${ }^{80}$, und das ließe sich auch von den rund 100 Jahre nach ihnen angekommenen Franzosen sagen. Hugenotten wie Juden hätten vor den katholischen Verfolgern auch an Orte ausweichen können, die ihnen eine bessere Rechtsstellung gewährten als die Hansestadt und ihnen zugleich eine Betätigung im großen Überseehandel erlaubten. Diese Vorteile boten vor allem Amsterdam und London, wo sich ja auch viele ihrer Glaubensgenossen niederließen. In Amsterdam zum Beispiel konnten Juden sogar das Bürgerrecht kaufen, auch wenn es nicht auf die Kinder übertragbar war, und in England verlief die Integration der Sepharden in die Mehrheitsgesellschaft von Beginn an so mühelos, dass die hohe Zahl von Konversionen und Ehen mit christlichen Partnern sogar die Identität der Gemeinde bedrohten ${ }^{81}$. Die Hamburger Senatoren waren sich bewusst, dass ihre Stadt mit diesen Orten um den Zuzug der wirtschaftlich potenten Migranten konkurrierte. Doch obwohl der Senat sich kontinuierlich gegen den Widerstand einer einflussreichen Gruppe von Geistlichen und der Mehrheit der Bürgerschaft darum bemühte, konnte er weder für die Portugiesen noch für die Franzosen ein freundlicheres Klima oder eine bessere Rechtsstellung erreichen.

Die Verfolgung als Push-Faktor steht besonders für die jüdische Gruppe außer Frage. Die calvinistischen Geschäftsleute in den französischen Atlantikhäfen - und von dort kamen die Hamburger Hugenotten ganz überwiegend - waren dagegen einem geringeren Konversions- und Verfolgungsdruck ausgesetzt, als ihre Glaubensgenossen in den ländlichen Gebieten Südund Westfrankreichs. Wegen ihres überragenden Gewichts in der maritimen Wirtschaft und damit auch für die ehrgeizigen Kolonialprojekte des Landes dekretierten Ludwig XIV. und Colbert eine mildere Behandlung der Mitglieder dieser Elite. Schon die Zeitgenossen befanden, dass deren Flucht aus Frankreich weniger konfessionelle als ökonomische Hintergründe habe. Auf

80 Studemund-Halévy / Poettering, Ètrangers universels, S. 124.

81 Roitman, Sephardische Juden, S. 978, 981. 
der anderen Seite war Hamburg möglicherweise der ungastlichste Ort, den Hugenotten sich im protestantischen Teil des Alten Reich hätten aussuchen können. Nachdem die Unduldsamkeit in der Hansestadt sich von den 1660er bis in die 1710er Jahre vor allem gegen die katholische und die jüdische Minderheit gerichtet hatte, waren dann die Calvinisten besonders bedroht. Das kulminierte um 1720 in Tumulten, die von einigen Pastoren orchestriert wurden und auf eine Zerstörung der reformierten Kapelle in der niederländischen Gesandtschaft zielten. Nicht einmal in der reformierten Gemeinde Altonas waren die Franzosen sonderlich willkommen, sondern mussten sich dort, privilegiert vom wohlwollenden dänischen König, mit einem separaten Konsistorium etablieren. Da also für ihre kleine Gruppe nicht nur der konfessionelle Push-Faktor in der Heimat relativ schwach war, sondern auch ein konfessioneller Pull-Faktor in Hamburg fehlte, müssen wirtschaftliche Gründe bei der Entscheidung zur Migration eine große Rolle gespielt haben.

Aus der Hamburger Perspektive und unter Berücksichtigung der Entwicklung des französischen Kolonialimperiums lassen sich diese Gründe genauer identifizieren: Das enorme Wachstum der Plantagenwirtschaft auf den französischen Antillen setzte bereits vor der Widerrufung des Ediktes von Nantes ein und stellte insbesondere bei der Zuckerproduktion die bis dato führenden Gebiete in Brasilien und in der britischen Karibik bald in den Schatten. So wurde Frankreich im frühen 18. Jahrhundert zum weltweit größten Zuckerexporteur, mit den wichtigsten Absatzmärkten in Nord- und Mittelosteuropa. Da die Ware ohnehin in den Nordseeraum transportiert werden musste, verlagerten französische Unternehmer die Raffinierung des Rohzuckers zunehmend an die Elbmündung, wo niedrigere Lohn- und Brennstoffkosten winkten. Auch in umgekehrter Richtung profitierten sie vom niedrigeren Lohn- und Preisniveau Mitteleuropas: beim Export arbeitsintensiver Textilien und Metallwaren in den atlantischen Raum, beim Bau von Frachtund Kriegsschiffen für Frankreich oder bei der Belieferung französischer und spanischer Werften mit Schiffbaumaterial. Wie die Geschäftskorrespondenz bedeutender hugenottischer Kaufleute belegt, schlugen die Standortvorteile Hamburgs sogar Amsterdam aus dem Feld, und das muss der Hauptgrund dafür gewesen sein, dass zumindest eine kleine Gruppe die Hansestadt bevorzugte.

Besonders der Aspekt der Marinerüstung unterstreicht die Bedeutung der kleinen Kolonie an der Elbmündung. Gegen 1700 begann erstmals eine systematische Modernisierung der bisher bunt zusammengewürfelten Kriegsflotten Englands, Frankreichs und Spaniens. Die Schiffe wurden in nur noch drei untereinander bauähnliche Größenklassen unterschieden: Linienschiffe ersten, zweiten und dritten Ranges. Erst diese Standardisierung stellte eine gemeinsame Manövrierfähigkeit der Fahrzeuge her. Diese einheitlich gefertigten Flotten gehörten »eigentlich zu den ersten Großserien der Industriellen 
Revolution: serienmäßige Herstellung am laufenden Band, mit allen Problemen der Materialbereitstellung $\ll^{82}$. Unbedingt notwendig waren zum Beispiel hochwertiges Eichenholz aus Böhmen, Ostpreußen und den Häfen Rostock und Danzig sowie aus schwedischen und russischen Häfen, oder die langen Tannenmasten, Teer, Pech und Hanf aus Skandinavien und Russland. Mit seinen Rohstoffen, »für die damalige Zeit das Gegenstück zum heutigen Öl aus dem Mittelorient «, erhielt der Ostseeraum strategische Bedeutung ${ }^{83}$. Als Frankreich unter Ludwig XIV. begann, seine Flotte aufzubauen, waren niederländische und britische Kaufleute dort bereits fest etabliert, so dass französische Einkäufer weitgehend von ihnen abhängig waren. Colberts Compagnie du Nord und Versuche einer Intensivierung der heimischen Produktion genannter Rohstoffe hatten sich als wenig effizient erwiesen ${ }^{84}$. Umso wichtiger war es also, wenigstens im neutralen Hamburg über bessere Verbindungen in diese Peripherie des atlantischen Raums zu verfügen. Und wer wäre für den Aufbau entsprechender Netzwerke besser geeignet gewesen als protestantische Franzosen?

Beim Vergleich mit den Sepharden fallen die Ähnlichkeiten im Wirtschaftsprofil beider Gruppen auf: Kolonialwarenhandel, Zuckerverarbeitung, Export von deutschen Textilien in Richtung Westen, Belieferung der Herkunftsländer mit Rüstungsgütern und internationale Finanzgeschäfte waren die wichtigsten Sparten, in denen die Portugiesen wie die Franzosen aktiv waren. Beide erfüllten eine Scharnierfunktion, in der sie die atlantischen Imperien Spaniens, Portugals und schließlich Frankreichs mit dem mitteleuropäischen Binnenraum und der Ostsee verbanden. Dabei ist es nicht ohne Ironie, dass diese drei Monarchien auf die Unterstützung derselben Kaufleute angewiesen waren, deren Religion sie unterdrückten, und dass Sepharden und Hugenotten durch ihre Rüstungslieferungen die Macht der Regime stärkten, die ihre ärmeren und weniger gut vernetzten Glaubensgenossen blutig verfolgten. Während die dichtere Quellenlage für die Hamburger Hugenotten den Nachweis zulässt, dass das Lohn- und Preisgefälle ein wesentlicher Grund für ihre Migration nach Hamburg war, kann dies für die frühere Phase der Sepharden nur in einem - allerdings sehr plausiblen - Analogieschluss vermutet werden. Wie Lois Dubin bei ihrer Entwicklung des Konzepts der Port Jews anmerkte, können solche Vergleiche mit anderen ethnisch-konfes-

82 José Merino/Martine Acerra/Jean Meyer, Europäische Kriegsmarinen im 17. und 18. Jahrhundert. Ein Überblick, in: Hermann Kellenbenz/Jürgen SchneIder (Hg.), Wirtschaftskräfte und Wirtschaftswege V., Stuttgart 1981, S. 267-282, hier: S. 269.

83 Ebd., S. 269.

84 Pierrick Pourchasse, Le Commerce du Nord. Les échanges commerciaux entre la France et l'Europe septentrionale au XVIII ${ }^{\mathrm{e}}$ siècle, Rennes 2006, S. 115-125, 195-215; ders., Probleme des französischen Nordeuropahandels im 18. Jahrhundert, in: Hamburger Wirtschafts-Chronik N.F. 7 (2008), S. 249-282. 
sionellen Minderheiten einiges zum Verständnis dieser besonderen jüdischen Gruppen beitragen. Vergleiche dieser Art sollten freilich zugleich zur empirischen Überprüfung solcher Schlüsse anregen ${ }^{85}$.

Dass das religiöse Motiv nur einer von mehreren Faktoren für die Zuwanderung von Juden und Hugenotten war, wird sehr stark untermauert von der Chronologie des Aufstiegs und Niedergangs der brasilianischen beziehungsweise der französischen Zuckerwirtschaft. Beide Entwicklungen decken sich recht gut mit derjenigen der sephardischen beziehungsweise der französischen Gemeinden in Hamburg. Zudem verlaufen der Niedergang der sephardischen Kolonie und der relative Abstieg der brasilianischen Zuckerproduktion parallel zum Aufstieg der französischen Antillen als Zuckerlieferanten und zur Niederlassung der Hugenotten an der Elbe. Faktisch ersetzten die Franzosen also die schon aus diesen externen Gründen immer schwächer werdenden Portugiesen in der Funktion, die sie für die Hamburger Wirtschaft hatten. Es ist deshalb wahrscheinlich, dass der Bedeutungsverlust der Sepharden auch ohne die schwere Abgabenerhöhung, die man 1697 auf Drängen von Pastoren und Zünften gegen sie verfügte, weiter fortgeschritten wäre.

Das Beispiel der überschaubaren Freien und Hansestadt Hamburg, bei dem kleine Gruppen und die Gründe für ihre Migration gut isoliert und einzeln betrachtet werden können, zeigt, dass die Zuwanderung von religiösen Minderheiten nicht immer und in erster Linie aus deren Verfolgung in der Heimat erklärt werden kann. Im besonderen Fall der hugenottischen Seekaufleute waren die Bedingungen am Zielort nicht viel besser als in der Heimat. Aufgrund ihrer spezifischen wirtschaftlichen Interessen nahmen sie die konfessionell-politischen Nachteile in Kauf, um ökonomische Standortvorteile nutzen zu können. Dabei soll die Unterdrückung in Frankreich und den iberischen Ländern keinesfalls verharmlost oder relativiert werden. Auch für weniger Betroffene wie die Seehändler bewirkte der Rechts- und Vertrauensbruch der Révocation einen solchen Verlust von Sicherheit, dass die Schwelle vor dem Schritt ins Ausland tiefer denn je sank. Die rein konfessionellen Auswanderungsgründe mischen sich jedoch immer und unvermeidlich mit ökonomischen Erwägungen, und die Härte der Verfolgung variiert meist nach dem sozialen Status und anderen Herkunftsmerkmalen der Verfolgten. Entsprechend wird das Mischungsverhältnis von konfessioneller und wirtschaftlicher Motivation bei den verschiedenen sozialen und regionalen Gruppen einer Minderheit stark variieren. Mikrountersuchungen können helfen, diese Gemengelagen und die komplexen Wanderungsbewegungen, die bei den Hugenotten selbst nach 1700 noch nicht ganz zur Ruhe kamen, besser zu verstehen.

85 Lois C. Dubin, The Port Jews of Habsburg Trieste. Absolutist Politics and Enlightenment Culture, Stanford 1999; siehe einleitende Passagen. 


\section{Susanne Lachenicht \\ Renaissance in der Diaspora?}

Hugenottische Migration und Identität(en) im »Refuge«

Identitäten sind, wie Dirk Hoerder formulierte, schwer zu definieren. Sie sind »contested ground «, und nur bestimmte Konstrukte von Identität ermöglichen Individuen und Gruppen Zugang zu den Ressourcen eines Staates oder einer Gesellschaft. Identitäten entstehen dann, wenn die Subjektivität des einzelnen Individuums mit Narrativen einer Kultur und ihrer Geschichte in Interaktion tritt. Dieser Prozess ist einem stetigen Wandel unterworfen, sowohl was die individuelle Genese von Identität anbelangt, als auch die Genese von Gruppenidentität, die sich wiederum aus Interaktionen innerhalb einer Gruppe und in Abgrenzung beziehungsweise durch Ausgrenzung von außerhalb ergibt. Identitäten sind immer polyphon und hybrid ${ }^{1}$.

Eine gewisse oberflächliche Stabilität als Projektionsfläche von und für eine Gruppe erhalten Identitäten durch so genannte gate-keepers, die in staatlichen, gesellschaftlichen, kulturellen und wirtschaftlichen Kontexten Gruppenidentität erzeugen, die wiederum von der Masse dieser Gruppe gelebt werden soll. Besonders wichtig für diese künstliche Konservierung von Identität sind Institutionen, die die Erinnerung an das Spezifische der Identität einer Gruppe bewahren: Familien, Schulen beziehungsweise Erziehungseinrichtungen generell, Medien und, wenn es sich um religiöse Gruppen handelt, Kirchen, Tempel, kurz Orte der Predigt und des Gebets. Hybridität beziehungsweise multiple, den jeweiligen politischen, sozialen, ökonomischen und kulturellen Kontexten angepasste Konstruktionen von Identität gehören damit zu den elementaren Grundlagen des Überlebens einer Diaspora. Dort, wo diese hybriden, multiplen Identitäten bei gleichzeitiger Wahrung der Kohäsion der Gruppe durch ihre Eliten, das heißt durch ihre gate-keepers, nicht mehr garantiert werden können, wo die Distanz der Mehrheit der Gruppe zu der Aufnahmegesellschaft aus wirtschaftlichen, sozialen, kulturellen oder politischen Gründen stark abnimmt, kommt es nicht mehr nur zu Akkulturation und Integration, sondern zur Assimilierung und folglich zur Auflösung der Diaspora ${ }^{2}$.

1 Dirk Hoerder, Transcultural States, Nations, and People, in: Ders. /Christiane Harzig/Adrian Shubert (Hg.), The Historical Practice of Diversity. Transcultural Interactions from the Early Modern Mediterranean to the Postcolonial World, New York 2003, S. 14.

2 Siehe Hoerder, Transcultural States, S. 14; Robin Cohen, Global Diasporas. An Introduction, Seattle 1997, S. 172. 
I.

Auch wenn in Frankreich der Prozess der Nationalstaatsbildung früher begann als in vielen anderen europäischen Ländern, waren Katholiken und Protestanten im Frankreich des 16. und 17. Jahrhunderts weniger Franzosen als Provençalen, Normannen, Bretonen oder Aquitanier. Zu den regionalen Bindungen kamen lokale, soziale, kulturelle und wirtschaftliche, die nur zum Teil miteinander kongruent waren. Die Verfolgung von Calvinisten in Frankreich beziehungsweise die Religionskriege ab den 1560er Jahren führten jedoch dazu, dass französische Protestanten, vor allem deren militärische und geistliche Eliten, eine eigene Gruppenidentität, eine eigene nation ${ }^{3}$, und den idealisierten homme protestant in Predigten, Druckschriften und Diplomatie zu beschwören begannen ${ }^{4}$.

Im theologischen Diskurs französisch-reformierter Pastoren findet sich in frühen Schriften ihre Selbstdefinition als »Fremde« im Königreich Frankreich. Dieser $\gg$ Fremde« stand abseits von all denen, die nicht den calvinistischen Glauben teilten. Ergänzt wurde diese Selbstdefinition durch den Begriff des »Auserwählten«, des »einzig wahren Christen«, der für seinen Glauben zum Märtyrer wurde 5 . Unter dem Eindruck der Religionskriege, der Revokation des Edikts von Nantes 1685 und der Massenflucht von Protestanten nach 1685 wurde der theologische Diskurs über die Identität des französischen Calvinisten durch einen politisch-gesellschaftlichen Diskurs erwei-

3 Im Sinne der englischen Semantik werden als nation im Folgenden ethnische und religiöse Gemeinschaften bezeichnet, die in der Phase vor der endgültigen Etablierung des Nationalstaates in der so genannten Moderne durch eine eigene Sprache, Kultur, nationalen Mythos und Religion verbunden waren, sich aber nicht zwangsläufig in einem Territorium beziehungsweise einem (National-)Staat konstituierten. Diese nations konnten sich auch in einer Diasporasituation befinden beziehungsweise sich als nations erst in einer solchen herausgebildet haben. Vgl. hierzu Susanne Lachenicht, Hugenotten in Europa und Nordamerika. Migration und Integration in der Frühen Neuzeit, Frankfurt am Main/New York 2010, Einleitung.

4 Myriam Yardeni setzt die Herausbildung nationalen Bewusstseins für Frankreich für das 16. Jahrhundert an; vor allem für die Phase der Religionskriege zwischen 1562 und 1598. Myriam YARDENI, Enquêtes sur l'Identité de la »Nation France«. De la Renaissance aux Lumières, Seyssel 2004, bes. S. 19, 22-42; dies., Religion et sentiment national en France aux XVI et XVII ${ }^{e}$ siècles, in: Alain TALLON (Hg.), Le sentiment national dans l'Europe méridionale aux $\mathrm{XVI}^{\mathrm{e}}$ et XVII ${ }^{\mathrm{e}}$ siècles (France, Espagne, Italie), Madrid 2007, S. 323-341. Siehe auch Eckart BiRnstiel, La naissance d'une »nation «. La réorganisation sociale dans le Refuge huguenot, in: Michelle BouIX (Hg.), Minorités et construction nationale, XVIII ${ }^{\mathrm{e}}-\mathrm{XX}^{\mathrm{e}}$ siècles, Pessac 2004, S. 23f.; Eckart Birnstiel, La France en quête de ses enfants perdus. Mythe et réalité du retour au »pays des ancêtres« des huguenots du Refuge, de la Réforme à la Révolution, in: Diasporas. Histoire et Sociétés 8 (2006), S. 22-44, hier: S. 39; Luc Racaut, Religious polemic and Huguenot identity, in: Raymond A. Mentzer/Andrew Spicer (Hg.), Society and Culture in the Huguenot World, Cambridge 2002, S. 29-43. Zum homme protestant vgl. Emile G. LÉONARD, Le Protestant français, Paris 1955; Janine Garrisson, L'homme protestant, Paris 1988.

5 Siehe hierzu vor allem Jean CRESPIN, Histoire des Martyrs persecutez et mis à mort pour la verité de l'Evangile, depuis le temps des Apostres jusques à l'an 1574, Genf 1582 sowie die 
tert $^{6}$ : Als sich Ludwig XIV. mit Beginn seiner persönlichen Herrschaft 1661 zunehmend weigerte, die Angehörigen der Religion prétendue réformée als treue und legitime Untertanen anzuerkennen, reagierten französische Calvinisten in Frankreich und in der Diaspora, indem sie den Patriotismus ihrer Glaubensbrüder herauszustellen begannen ${ }^{7}$. Pierre Jurieu, französischer Exulant in den Vereinigten Niederlanden, schrieb 1680: »Nous sommes Français autant que nous sommes chrétiens réformés « ${ }^{8}$. Der französisch-reformierte Pastor Elie Benoist (1640-1728), ein hugenottischer Immigrant in Delft, vermerkte in seiner Histoire de l'Édit de Nantes, dass das Edikt von 1598 Calvinisten in Frankreich die gleichen Rechte zugesichert habe wie französischen Katholiken. Auf der einen Seite definierten Benoist und Jurieu ihre Glaubensbrüder als Untertanen des französischen Königs, die bereit waren, »de verser tout leur sang pour l'intérest de sa grandeur [des Königs von Frankreich] et de son Estat «. Auf der anderen Seite machten führende französische Protestanten klar, dass die Prärogativen des französischen Königs begrenzt waren 9 . Im Refuge nahmen Benoist und Jurieu sich selbst und ihre Glaubengenossen nun nicht mehr als »Fremde« in Frankreich wahr, sondern als Gleiche unter Gleichen: »Ils [die französischen Calvinisten] ne sont pas étrangers, puisqu'ils sont nez dans le même air que les autres; sous la même autorité, sous les même loix $[. ..] \ll^{10}$. Folglich definierten sich französische Calvinisten durchaus als französische Patrioten, obwohl sie in den Religionskriegen zwischen 1562 und 1598 gegen die französische Krone gekämpft hatten. Aus

Ergänzungen in den Auflagen von 1597, 1608 und 1619; Nicolas DE GALLARs, Seconde apologie ou defense des vrais chrestiens, contre les calomnies impudentes des ennemis de l'Eglise catholique. Ou il est respondu aux diffames redoublez par un nommé Demochares docteur de la Sorbonne, Genf 1559. Zum Martyrium als konstitutivem Element protestantischer und damit auch französisch-reformierter Identität siehe u.a. Barbara B. DiefENDORF, The Huguenot Psalter and the Faith of French Protestants in the Sixteenth Century, in: Barbara B. Diefendorf /Carla Hesse (Hg.), Culture and Identity in Early Modern Europe (1500-1800). Essays in Honor of Natalie Zemon Davis, Ann Arbor 1993, S. 42; Brad S. Gregory, Salvation at Stake. Christian Martyrdom in Early Modern Europe, Harvard 1999, S. 76; David El Kenz, Les Bûchers du Roi. La Culture Protestante des Martyrs, 1523-1572, Paris 1995, S. 72; Peter Burschel, Sterben und Unsterblichkeit. Zur Kultur des Martyriums in der Frühen Neuzeit, München 2004; Christine VoGEL, Zwischen Gewalterfahrung und Heilserwartung. Das hugenottische Geschichtsbild in der Krise, in: Sabine Beneke/Hans Ottomeyer (Hg.), Zuwanderungsland Deutschland. Die Hugenotten, Wolfratshausen 2005, S. 156-158.

6 Myriam Yardeni, French Calvinist Political Thought, 1534-1715, in: Menna Prestwich (Hg.), International Calvinism, 1541-1715, Oxford 1985, S. 315-337, hier: S. 320-326; Myriam YARDENI, Repenser l'histoire. Aspects de l'historiographie huguenote des guerres de religion à la Révolution française, Paris 2000, S. 56f.

7 Hubert Bost, Ces Messieurs de la R.P.R. Histoires et écritures de huguenots, XVII ${ }^{\mathrm{e}}-\mathrm{XVIII}^{\mathrm{e}}$ siècles, Paris 2001, S. 281f.

8 Pierre Jurieu, La politique du clergé de France, Köln/Den Haag 1681, S. 125.

9 Henri Basnage de Beauval, Tolérance des religions, Rotterdam 1684, S. 41.

10 Elie Benoist, Histoire de l'Édit de Nantes, Bd. I, Rotterdam 1693-1695, S. 321; Bost, Ces Messieurs de la R.P.R., S. 281. 
theologischer Sicht waren sie die »Auserwählten « im eigenen Land, in politischer Perspektive die einzig wahren und treuen Untertanen Frankreichs ${ }^{11}$.

In den Ländern des Refuge bezeichneten sich französische Protestanten als »Franzosen « oder Réfugiés und wurden als solche auch von den Gesellschaften der Aufnahmestaaten identifiziert ${ }^{12}$. In englischen Quellen der zweiten Hälfte des 16. und des späten 17. Jahrhunderts werden die Réfugiés immer wieder als »French nation « bezeichnet, wobei der Begriff alle in England lebenden Réfugiés meint ${ }^{13}$. Doch während die Regierung Brandenburg-Preußens nach 1685 die Ansiedlung des französisch-reformierten Corps de nation in separaten Colonien ${ }^{14}$ mit eigenen Kirchen, eigener Rechtsprechung, eigenem Recht und eigener Administration gestaltete, waren diese Privilegien bereits im elisabethanischen England kaum denkbar. Zwar wurden auch den Fremdenkirchen weitreichende Privilegien zugestanden, doch die Etablierung de iure als separate nation mit eigenem Recht, selbständiger Verwaltung und Rechtssprechung war nominell nicht vorgesehen. Religiöser Konformismus der Réfugiés sollte in den 1630er Jahren unter Erzbischof William Laud und dann erneut ab den 1660er Jahren durch die Errichtung so genannter konformistischer französischer Kirchen erreicht werden. Allerdings scheiterten diese Ambitionen von Krone und anglikanischer Staatskirche, wie Robin Gwynn gezeigt hat ${ }^{15}$.

11 Yardeni, Enquêtes, S. 20f.

12 Élisabeth Labrousse, La révocation de l'Edit de Nantes: Une fois, une loi, un roi?, Paris 1990, S. $63 f$.

13 Vgl. beispielsweise Lambeth Palace Library, London, Miscellaneous Papers. ref. MS 941: 1603-1715, Nr. 87: Mémoire pour le Committé françois, 1699, consisting of a defence of the French Committee appointed to administer the royal bounty to distressed French ministers against charges and proposals, in: Memoires envoiés de Londres à M. par M. au sujet de l'etablissement d'un conseil pour veiller sur la conduite des Protestants français refugiés en Angleterre, 1699, S. 13f.

14 Als Colonie (im Unterschied zu »Kolonien«, das heißt Gebiete oder Länder unter der faktischen oder nominellen Souveränität eines kolonisierenden Landes oder Mutterlandes im Sinne der äußeren Kolonisierung) werden hier und im Folgenden Fremdengemeinden bezeichnet, die bürgerliche Sondergemeinden oder Privilegiengemeinschaften, im Idealfall - aus Sicht der Réfugiés - mit eigenem Recht, eigener Jurisdiktion, separatem Siedlungsraum, eigener Dorf- und/oder Stadtstruktur und eigenständiger kirchlicher und weltlicher Administration in den Aufnahmestaaten darstellten. Zur Etymologie des Begriffs vgl. die Übersicht bei Matthias Asche, Neusiedler im verheerten Land. Kriegsfolgenbewältigung, Migrationssteuerung und Konfessionspolitik im Zeichen des Landeswiederaufbaus. Die Mark Brandenburg nach den Kriegen des 17. Jahrhunderts, Münster 2006, S. 555f.

15 Robin D. Gwynn, Disorder and innovation. The reshaping of the French Churches of London after the Glorious Revolution, in: Ole Peter Grell/Jonathan I. IsRaEL/Nicholas Tyacke (Hg.), From Persecution to Toleration. The Glorious Revolution in England, Oxford 1991, S. 251-273; Robin D. Gwynn, Conformity, Non-conformity and Huguenot Settlement in England in the Later Seventeenth Century, in: Anne Dunan-Page (Hg.), The Religious Culture of the Huguenots, 1660-1750, Aldershot 2006, S. 23-41. 
Nicht nur in theologischer Hinsicht fühlten sich die Eliten der französischen Réfugiés in allen Aufnahmeländern noch in der zweiten, dritten und vierten Generation als Auserwählte, sondern auch hinsichtlich ihrer französischen Sprache und Kultur. ${ }^{16} \mathrm{Zu}$ den Topoi der Auserwähltheit und der kulturellen Überlegenheit der »Franzosen « im Refuge kamen Narrative, die die wirtschaftliche Innovations- und militärische Schlagkraft der Réfugiés betonten. Diese sollten französische Protestanten zu besonders wertvollen Untertanen der Aufnahmeländer machen, so argumentierten hugenottische Diplomaten an den Höfen der protestantischen Fürsten Europas ${ }^{17}$.

Grundlagen für diese Narrative wurden bereits im Vorfeld der Revokation des Edikts von Nantes 1685 geschaffen, wie Myriam Yardeni in Naissance et essor d'un mythe gezeigt hat ${ }^{18}$. Basierend auf der Erfahrung der Ausweisung der Sepharden aus Spanien 1492 (beziehungsweise aus Portugal 1580) und der Wahrnehmung des ökonomischen Niedergangs des Landes in dessen Folge warnten nicht nur Hugenotten, sondern auch Katholiken in Frankreich wie Hay du Chastelet bereits vor der Revokation des Edikts von Nantes vor den katastrophalen Folgen, die ein solcher Schritt für Frankreich haben könnte. In ihrer Selbstwahrnehmung und -darstellung avancierten die Hugenotten nicht nur in den Ländern des Refuge, sondern eben auch in Bezug auf ihr Heimatland zu dem Besten, was Frankreich zu bieten hatte, in ökonomischer, kultureller, militärischer und sozialer Hinsicht ${ }^{19}$. Unterstützt wurde die These vom Verlust, den Frankreich durch das Edikt von Fontainebleau und die Abwanderung französischer Protestanten nach 1685 erlitten habe, durch die sich nach 1685 häufenden Berichte von Vauban und den Intendanten Frankreichs über den ökonomischen Niedergang der Provinzen. Nur selten wurde hier allerdings der direkte Bezug zur Flucht der Protestanten hergestellt ${ }^{20}$.

Während sich im Refuge der Akzent in der Historiographie der Hugenotten vom Verlust Frankreichs hin zum Gewinn für die Aufnahmeländer verschob, manifestierte sich in Frankreich bei etlichen Vertretern der Aufklärung - nicht zuletzt bei Montesquieu und Voltaire - in den Folgen des Widerrufs des Edikts von Nantes der Zusammenhang von mangelnder religiöser Toleranz und ökonomischem Niedergang eines Landes. Andere Stimmen wie die Mirabeaus nahmen allerdings Warren Scovilles Argumente vorweg:

16 YARDENI, Enquêtes, S. 112-125.

17 Siehe Lachenicht, Hugenotten in Europa, Kap. 1.

18 Myriam Yardeni, Naissance et essor d'un mythe. La Révocation de l'Édit de Nantes et le déclin économique de la France, in: Bulletin de la Société de l'Histoire du Protestantisme Français 1 (1993), S. 79-97.

19 Siehe u.a. Leslie Page Moch, Moving Europeans. Migration in Western Europe since 1650, Bloomington 22003, S. 29; Pieter Emmer, Was Migration Beneficial?, in: Jan LuCassen/Leo Lucassen (Hg.), Migration, Migration History, History. Old Paradigms and New Perspectives, Bern u.a. 1997, S. 111-129.

20 Yardeni, Naissance et essort d'un mythe, S. 80-92. 
Frankreich habe den Rückgang seiner Macht und seines Einflusses nicht den Folgen des Edikts von Fontainebleau, sondern den Kriegen Ludwigs XIV. zu verdanken. Preußen, so Mirabeau in De la Monarchie prussienne sous Frédéric le Grand, hätte sich auch ohne die hugenottischen Zuwanderer aus Frankreich nach 1685 zu dem mächtigen Staat entwickelt, den es gegen Ende des 18. Jahrhunderts darstellte. Mirabeaus Thesen hatten jedoch weniger Wirkung auf die Wahrnehmung des Wertes und der Leistungen der Réfugiés als die Thesen Montesquieus und Voltaires. So wurde der Mythos der ökonomischen und kulturellen Leistungen der Réfugiés im Refuge - und vor 1685 in Frankreich - in die großen nationalen Narrative des 19. Jahrhunderts hineingetragen. Man findet ihn beispielsweise in Michelets Histoire de France $^{21}$. Die Rückständigkeit Frankreichs gegenüber England erklärte sich, so Michelet, aus den Folgen der Revokation, von denen sich Frankreich nie erholt habe. Dieser Mythos wurde zwar von Wirtschaftshistorikern wie Philippe Sagnac bereits zu Beginn des 20. Jahrhunderts, von Warren Scoville in den 1960er und Guy Chaussinand-Nogaret in den 1970er Jahren in Frage gestellt ${ }^{22}$, doch blieb er fest mit dem Bild der Hugenotten verwachsen, wie unter anderem der anhaltende Erfolg von Max Webers Die Protestantische Ethik und der Geist des Kapitalismus von 1904/1905 ${ }^{23}$ und seine Adaptierung im Kontext der Hugenottenforschung zeigt ${ }^{24}$. Von Wirtschaftshistorikern wird die Flucht von 150.000 bis 200.000 Hugenotten aus Frankreich (von insgesamt 750.000 französischen Protestanten) nach 1685 heute weniger als rein religiös motivierter Exodus verstanden, als vielmehr als Wirtschafts- und Religionsmigration. Diese These hat kürzlich Klaus Weber - im Kontext des Atlantikhandels - aus anderer Perspektive bestätigt. Hugenottische Kaufleute, Zuckerraffineure und Manufakturisten, aber auch Textilarbeiter und Weber verließen Frankreich, weil Arbeitskräfte in Zentralund Osteuropa für die Zuckerraffinerie billiger waren beziehungsweise dort Arbeitskräfte im Textilgewerbe gebraucht wurden, die zuhause in Frankreich aufgrund der Teuerung in Südwesteuropa keine Arbeit mehr fanden ${ }^{25}$.

Dass die so genannte Konfessionsmigration der Réfugiés sehr viel mehr als bislang angenommen von wirtschaftlichen Motiven bestimmt gewesen sein könnte, darauf weist auch, wie Pierre Chaunu und Emmanuel LeRoy Ladurie festgestellt haben, die Agonie des Protestantismus in Frankreich am

21 Vgl. Jules Michelet, Histoire de France, Bd. 3, Paris 1837.

22 Warren C. Scoville, The persecution of Huguenots and French economic development, 1680-1720, Berkeley 1960; Guy Chaussinand-Nogaret, Les Financiers de Languedoc au XVII ${ }^{\mathrm{e}}$ siècle, Paris 1970.

23 Vgl. Max Weber, Die protestantische Ethik und der Geist des Kapitalismus, München ${ }^{2} 2006$.

24 YARDENI, Naissance et essort d'un mythe, S. 80-92.

25 Klaus Weber, La migration huguenote dans le contexte de l'économie atlantique, in: Guido Braun/Susanne Lachenicht (Hg.), Les États allemands et les huguenots. Politique d'immigration et processus d'intégration, München 2007, S. 125-136. 
Vorabend der Revokation hin ${ }^{26}$ : Kurz vor der Revokation des Edikts von Nantes existierten nördlich der Loire nur noch Restbestände von reformierten Gemeinden, vor allem in Rouen, Metz und Sedan. Insgesamt lebten hier ca. siebzehn Prozent (134.900) der hugenottischen Bevölkerung Frankreichs, die zwischen 1660 und $1670 \mathrm{ca} .800 .000,1681 \mathrm{ca} .730 .000$ Mitglieder umfasste. Um 1610 hatte es ca. 950.000 Calvinisten in Frankreich gegeben ${ }^{27}$. Obwohl das Edikt von Fontainebleau das Ende des religiösen Pluralismus in Frankreich einläutete und als Katastrophe für den Protestantismus in Frankreich gedeutet wurde, haben nicht nur Historiker wie Emile Léonard und Philippe Joutard, sondern bereits Voltaire im Edikt von 1685 eine Art von neuem Impetus für den in Agonie befindlichen Protestantismus in Frankreich gesehen, ein Impetus, der dem französischen Protestantismus im Refuge und in Frankreich zu neuer Blüte verholfen habe ${ }^{28}$.

\section{II.}

Wie bereits erwähnt, war das Auserwähltsein französischer Calvinisten zunächst eine Theorie, die von Pastoren und militärischen Führern der Hugenotten in Frankreich beziehungsweise im Refuge propagiert wurde, vor allem von einer hugenottischen Oligarchie, wie sie sich in den Konsistorien der Kirchen des Refuge manifestierte ${ }^{29}$. Wie sehr es diesen gate-keepers gelang, die Narrative von der Auserwähltheit der französisch-reformierten $n a-$ tion zum Bestandteil der Identitäten ihrer Gemeinden zu machen, ist bislang nur unzureichend erforscht. Hier soll ein von Myriam Yardeni und mir beantragtes Forschungsprojekt mit dem Titel Diaspora Networks, Diaspora Identities - The Example of the Huguenots näheren Aufschluss geben. Im Refuge wurden diese Oligarchien zu den Bewahrern des orthodoxen calvinistischen Glaubens und zu den Verfechtern eines »Refuge spirituel, le vase clos d'une France protestante préservée intacte en pays étrangers $\ll^{30}$, nicht nur in Brandenburg. Dass es in den Kirchen des Refuge und unter calvinistischen

26 Pierre Chaunu, La décision royale? Un système de la révocation, in: Roger Zuber/Laurent Theis (Hg.), La révocation de l'Edit de Nantes et le protestantisme français en 1685, Paris 1986, S. 19; Emmanuel Le Roy Ladurie, Glorious Revolution, Shameful Revocation. Afterword, in: Bernard CоттRет, The Huguenots in England. Immigration and Settlement, c. 1550-1700, Cambridge 1991, S. 286.

27 Philip Benedict, The Huguenot population of France, 1600-1685. The demographic fate and customs of a religious minority, Philadelphia 1991, S. 9f., 76.

28 Emile G. LÉonARD, Histoire générale du protestantisme, Bd. II, Paris 1961, S. 346; Philippe Joutard, The Revocation of the Edict of Nantes. End or Renewal of French Protestantism?, in: Prestwich, International Calvinism, S. 339.

29 Ebd., S. 8.

30 Myriam Yardeni, Refuge et encadrement religieux, in: Dies. (Hg.), Idéologie et propagande en France, Paris 1987, S. 118. 
Theologen immer wieder zu Streit um die Reinheit beziehungsweise den wahren calvinistischen Glauben kam, sollte nicht unerwähnt bleiben. Gegenüber Staats- und Landeskirchen beziehungsweise den Regierungen der protestantischen Staaten Europas gerierten die gate-keepers der Réfugiés sich jedoch als eine eigene französisch-reformierte nation, auch im englischen, irischen und nordamerikanischen Refuge. Dass diese $»$ France protestante à l'étranger « ${ }^{31}$, um ein Zitat Etienne François' aufzugreifen, nicht den Vorstellungen von religiösem Konformismus und »Englishness« der Untertanen des englischen Staates entsprach und den Réfugiés zu Recht der Vorwurf des Separatismus gemacht wurde, zeigen interne und externe Debatten um Presbyterianismus und Eigenständigkeit der französischen nation im englischsprachigen Refuge $e^{32}$.

Doch kam es nun in den Ländern des Refuge zu einem Wiedererstarken des französischen Protestantismus, zur Herausbildung einer französischen protestantischen nation in der Diaspora? Oder handelt es sich hier um Konstrukte, die einerseits der Wahrung des in Frankreich verfolgten Glaubens, andererseits der Aushandlung von weitreichenden Privilegien für die nation der Réfugiés in den Aufnahmeländern dienen sollten, letztendlich aber am konfessionellen, sozialen und wirtschaftlichen Verhalten der Masse der Réfugiés scheiterten? Anders formuliert: Vermochten es die gate-keepers der Réfugiés, ihre eigenen Mitglieder in der Diaspora von ihren Narrativen der wirtschaftlichen und kulturellen Überlegenheit und der Auserwähltheit der Réfugiés langfristig zu überzeugen? Und inwieweit ist die Durchsetzung von Narrativen von Gruppenidentität und -kohärenz überhaupt für den Historiker messbar? Für England, Irland, die englischen Kolonien in Nordamerika und Brandenburg-Preußen sollen im Folgenden einige neuere Ergebnisse vorgestellt werden ${ }^{33}$ :

Wie viele andere Minoritäten auch heute bildeten die Réfugiés theoretisch eine überstaatlich agierende nation, die ihre ethnische, religiöse oder allgemein kulturelle - inklusive ihrer sprachlichen - Identität aufrecht zu erhalten gedachte. Dies zeigen vor allem Petitionen der Réfugiés in den 1680er Jahren an die protestantischen Fürsten Europas, die diese Topoi als Basis ihrer Forderungen nach weitreichenden Privilegien und ihrer Ansiedlung als separate nation zu nutzen versuchten ${ }^{34}$. Erfolgreich waren sie hier bekanntermaßen vor allem in Brandenburg-Preußen, weniger in England, Irland und den englischen Kolonien in Nordamerika, wo den Réfugiés ihre Ansiedlung in sepa-

31 Etienne François, La mémoire huguenote dans le pays du Refuge, in: Frédéric Hartweg/Stefi Jersch-Wenzel (Hg.), Die Hugenotten und das Refuge. Deutschland und Europa. Beiträge zu einer Tagung, Berlin 1990, S. 235f.

32 Siehe Lachenicht, Hugenotten in Europa, Kapitel 3.

33 Vgl. zu den Ergebnissen im Folgenden (Abschnitt II) ausführlich ebd.

34 Ebd., Kapitel 2. 
raten Colonien verweigert wurde. Die Konservierung der französisch-reformierten Identität, das heißt vor allem des durch die Verfolgung gefährdeten reformierten Bekenntnisses, war jedoch das eine, das wirtschaftliche Überleben von Individuen, Familien beziehungsweise des gesamten Corps de Refuge das andere. Abhängig unter anderem von persönlichen Präferenzen, unterschiedlichen Merkmalen von sozialen, lokalen Gruppen, wirtschaftlichen Zwängen, Ansiedlungsformen, gemeindlicher Autonomie oder Koexistenz mit anderen Gruppen und der Politik der Einwanderungsländer mussten in jedem Aufnahmeland sowohl von jedem Individuum als auch von den für die Réfugiés Sorge tragenden französisch-reformierten Gemeinden Modelle entwickelt und Entscheidungen getroffen werden, wie diese Desiderata zu erfüllen waren.

In allen Ländern des Refuge lässt sich für das späte 17. Jahrhundert zunächst Binnenintegration nachweisen ${ }^{35}$, das heißt die Verfestigung einer französisch-protestantischen nationalen Identität in der Selbst- und in der Fremdwahrnehmung, die durch ein clustering der Réfugiés und die Entstehung französisch-reformierter Kirchen begünstigt wurde. Der Prozess der Integration und Assimilierung einzelner Individuen in und an Wirtschaft, Kirchen, Kultur und Gesellschaft des Aufnahmelandes begann jedoch gleichzeitig mit der Verfestigung der nationalen Identität des Corps de Refuge, zunächst vor allem in wirtschaftlicher Hinsicht. In dem von Dichotomien geprägten Prozess von Akkulturation und Integration stellt diese Binnenintegration oder Amalgamierung von lokalen und regionalen Identitäten der Réfugiés ein Phänomen dar, das man auch bei französischen Katholiken in Kanada (Nouvelle France) und bei vielen anderen Migrantengruppen nachweisen kann. Dieser Prozess, der nicht zuletzt durch die Fremdwahrnehmung in den Ländern des Refuge mit initiiert und gefördert wurde, brachte in der Diaspora eine französische nation hervor, deren kreolisierter Charakter spätestens mit der Ankunft der Émigrés in London, Berlin, Boston und New York in Folge der Französischen Revolution deutlich zutage trat. Neben dieser französisch-reformierten Diasporaidentität der Réfugiés existierten jedoch zumindest in der ersten und zweiten Generation im Refuge regionale und lokale Identitäten fort, beziehungsweise die Gruppe war auch durch soziale und wirtschaftliche Diversität nicht homogen.

35 Thomas Klingebiel, Weserfranzosen. Studien zur Geschichte der Hugenottengemeinschaft in Hameln 1690-1757, Göttingen 1992, S. 10-12; ders., Grundzüge des Alltagslebens im Refuge. Neues Leben in alter Ordnung, in: Sabine Beneke/Hans OtтомeYer (Hg.), Zuwanderungsland Deutschland. Die Hugenotten, Wolfratshausen 2005, S. 114; Eckart Birnstiel, Asyl und Integration der Hugenotten in Brandenburg-Preußen, in: Guido Braun/Susanne Lachenicht (Hg.), Les États allemands et les huguenots. Politique d'immigration et processus d'intégration, München 2007, S. 139-154, hier: S. 140f. 
Trotz Xenophobie und Integrationsresistenzen auf beiden Seiten, der der Réfugiés und der der Aufnahmestaaten beziehungsweise -gesellschaften, kam es zu wechselseitigen Akkulturations-, dann auch Integrationstendenzen in allen hier untersuchten Ländern des Refuge. Dies war auch in BrandenburgPreußen bereits in der ersten Generation des Refuge der Fall, wie das Verhältnis von Kommunikantenzahlen und Mitgliedern der Colonie in Berlin zeigt ${ }^{36}$ - trotz der im Edikt von Potsdam fest geschriebenen Segregation der Réfugiés in separaten Colonien. Mit der Integration der Réfugiés in die Aufnahmegesellschaft ging die Desintegration ihrer französisch-reformierten Kirchengemeinden einher, in Brandenburg-Preußen auch die der Colonien. Französische Kirchen und Colonien wurden jedoch gleichzeitig auch zu einem Ort der Integration für in die Colonien einheiratende Deutsche. Allerdings war die umgekehrte Integration insgesamt geringer als die Integration der Réfugiés in die deutsche Aufnahmegesellschaft. In Irland, England und seinen Kolonien in Nordamerika entwickelten sich weniger die nonkonformistischen als die offiziell anglikanischen Kirchen zu Orten partieller Integration von Anglikanern oder niederländischen Reformierten, wie vor allem die erhöhte Mischehenrate (im Vergleich zu den französischen Nonkonformisten) in diesen Kirchen zeigt. Die in den nonkonformistischen französischen Kirchen verbleibenden Réfugiés zeichneten sich im Unterschied zu Berlin als bis in die dritte und vierte Generation endogam aus.

Prinzipiell kann nicht von einer grundsätzlich schnelleren Integration und Assimilierung des gesamten Corps de Refuge und damit von schnellerem Identitätsverlust der Réfugiés eines Aufnahmelandes im Vergleich zu anderen Aufnahmestaaten gesprochen werden. Sowohl in England, Irland und den englischen Kolonien in Nordamerika als auch in Brandenburg-Preußen kam es bereits im frühen 18. Jahrhundert zur Auflösung einzelner französisch-reformierter Kirchen, andere hielten sich, ausgestattet mit Konsistorien, französisch-reformierter Liturgie und Discipline, bis heute. Zeichen von zunehmender Desintegration des Corps de Refuge in einzelnen Gemeinden aller hier untersuchten Aufnahmeländer sind im späten 17. Jahrhundert beispielsweise für Kleve, Burg, Thorpe-le-Soken und einige der Kirchen in Spitalfields und Berwick Street (beide in London) nachweisbar. Einen kritischen Punkt erreichte die Desintegration einiger weiterer Kirchengemeinden der

36 François DAVID, Les colonies des réfugiés protestants français en Brandebourg-Prusse (16851809). Institutions, géographie et évolution de leur peuplement, in: BSHPF 1 (1994), S. 111142; ders., Le cas de la colonie française de Berlin, in: Eckart Birnstiel/Chrystel Bernat (Hg.), La Diaspora des Huguenots. Les réfugiés protestants de France et leur dispersion dans le monde $\left(\mathrm{XVI}^{\mathrm{e}}-\mathrm{XVIII}{ }^{\mathrm{e}}\right.$ siècles), Paris 2001, S. 75-97; ders., Les colonies françaises en Brandebourg-Prusse. Une étude statistique de leur population, in: Manuela BöHm/Jens HÄSELER/Robert Violet (Hg.), Hugenotten zwischen Migration und Integration. Neue Forschungen zum Refuge in Berlin und Brandenburg, Berlin 2005, S. 69-93. 
Réfugiés mit dem allmählichen Aussterben der ersten Immigrantengeneration, in den 1720er und 1730er Jahren, wie anhand der Londoner Savoykirche, der Kirche in West Street (Soho), New York, Portarlington oder Frankfurt / Oder deutlich wird. Existenzielle Desintegrationserscheinungen, das heißt ein massiver weiterer Mitgliederverlust in den Gemeinden, eine über dreißig, teilweise sogar über fünfzig Prozent liegende Mischehenrate, der Verlust der französischen Sprache und Identität ist bei der Mehrzahl der Réfugiés beziehungsweise ihrer Gemeinwesen in allen hier untersuchten Ländern des Refu$g e$ in den 1760er und 1770er Jahren feststellbar - also mit der dritten und vierten beziehungsweise dem sukzessiven Aussterben der zweiten Generation. Nun waren auch große Gemeinden betroffen wie die Berliner, Saint Jean in Spitalfields, die Kirche in der Threadneedle Street und weitgehend autonome hugenottische Gemeinwesen wie die in New Paltz und New Rochelle im Tal des Hudson. In diesem Zeitraum verstärkten sich konservativ-bewahrende Bemühungen der Pastoren und Konsistorien der verbleibenden französischreformierten Kirchen um die Wahrung der Gruppenkohärenz und -identität des gesamten Corps de Refuge. Dies lässt sich für das Schulwesen belegen, und hier vor allem für die so genannten Armenschulen, die die nächsten (die vierte und fünfte) Generationen erneut in die französisch-reformierten Kirchen integrieren sollten - bei gleichzeitiger Wahrung ihrer wirtschaftlichen Integration in die Aufnahmegesellschaft. Doch auch dort, wo sich die Masse des Corps de Refuge schneller in die Aufnahmegesellschaften zu integrieren begann, wie in New York oder einzelnen Colonien im Ruppiner Land, ist keine Assimilierung des gesamten Corps de Refuge nachweisbar, sondern bei der verbleibenden Gruppe ist oft eine extrem konservative Tendenz zu erkennen, die sich als besonders resistent gegenüber Konformismus und Integration erwies.

Der Ländervergleich wirft die Frage auf, inwiefern der Wandel oder auch der Verlust von Identitäten, Integrationsprozesse wie wirtschaftliche Integration, die Einheirat in die einheimische Bevölkerung, Konfessionswechsel und Sprachverlust durch Immigrationspolitik der Aufnahmestaaten gesteuert werden können oder aber unabhängig von der Einwanderungspolitik des jeweiligen Landes erfolgen beziehungsweise ob sie eher abhängig von Faktoren wie Größe, Infrastruktur und Autarkie der Colonie, Ansiedlung in der Stadt oder auf dem Land sowie allgemeinen, staatlich nicht steuerbaren globalen wirtschaftlichen Entwicklungen sind. Auf der Basis der bisher gewonnenen Ergebnisse lässt sich sagen, dass all diese Faktoren miteinander verknüpft auf Akkulturation, Integration und Wandel von Identitäten von Einheimischen und Réfugiés gewirkt haben und durch ihr komplexes $\mathrm{Zu}-$ sammenspiel weder von Seiten konservativer Pastoren der Diasporagruppe noch von Seiten der Regierungen der Aufnahmestaaten kontrollierbar waren. In England scheinen Integrations- und Konformitätsdruck vor allem zur 
schnellen Herausbildung hybrider Identitäten - auch hybrider konfessioneller Identitäten, wie sie für das England des späten 16. und dann auch wieder späten 17. Jahrhunderts nachweisbar sind ${ }^{37}$ - geführt zu haben. Inkonsequenter Konformitätsdruck, das heißt wenn dieser den Réfugiés nicht die rechtliche, religiöse und wirtschaftliche Gleichberechtigung zugestand, konnte auch zu Gegenreaktionen führen und die Bewahrung der kulturellen Identität zumindest im religiösen Bereich für einige Generationen zur wichtigsten Aufgabe der geistlichen Führer im Refuge machen. Dies zeigt besonders deutlich das Beispiel der New Yorker Église du Saint Esprit. Deren Konsistorium weigerte sich bis ins frühe 19. Jahrhundert, trotz schwindender Mitgliederzahlen aufgrund des Verlustes der französischen Sprache und aufgrund von Querelen innerhalb der französisch-reformierten Kirche, die französische Sprache und das reformierte Bekenntnis aufzugeben und sich - wenn auch nur nominell, wie dies viele französische Kirchen in England und seinen Kolonien getan hatten - unter das Dach der Anglikanischen Kirche zu begeben. Begründet wurde dies immer wieder - wie dieses Beispiel aus den 1760er Jahren zeigt - folgendermaßen:

[...] non que Nous ne Regardions l'Église anglicane comme une véritable Église de Jesus Christ notre Seigneur, mais par le Respect pour nos predecesseurs qui ont Etably \& fondé notre Église, que nous desirons de conserver \& Maintenir sur le meme pied qu'elle est établie, ce qui a été le sentiment unanime de tous les Membres du Comité $^{38}$.

Bei der Analyse von Integration, Assimilierung und Identitätswahrung beziehungsweise -verlust muss zwischen den Narrativen zur Identität der Réfugiés im Sinne der Identitätswahrung und den tatsächlichen Integrationsprozessen unterschieden werden. Während Fragen der Integration der Réfugiés in Brandenburg-Preußen in der preußischen Öffentlichkeit in den Printmedien offenbar erst mit der napoleonischen Zeit diskutiert wurden ${ }^{39}$, hatte der Prozess der faktischen Integration der Réfugiés und ihrer Nachfahren in wirtschaftlicher, gesellschaftlicher und konfessioneller, aber auch in nationaler Hinsicht schon mit der ersten Generation im späten 17. Jahrhundert eingesetzt. Zwar konnten die Institutionen der Französischen Colonie bis 1809 erhalten werden, die französischen Kirchen sogar über 1817 hinaus, da sie sich nicht

37 Siehe u.a. Raingard EssER, Niederländische Exulanten im England des 16. und 17. Jahrhunderts, Berlin 1996, S. 86-90; Patrick Collinson, England and International Calvinism 1558-1640, in: Prestwich, International Calvinism, S. 197-223; Andrew Pettegree, Foreign Protestant Communities in Sixteenth-Century London, Oxford 1986, S. $274 \mathrm{f}$.

38 New York Historical Society, Registre des Résolutions du Consistoire de l'Église Françoise de la Nouvelle York, 1723-1766, Eintrag vom 8. Januar 1764.

39 Myriam Yardeni, Le Refuge allemand et la France. Histoire d'une aliénation, in: Hartweg/Jersch-WenZel, Die Hugenotten und das Refuge, S. 187-203, hier: S. 189. 
der Kirchenunion Friedrich Wilhelms III. anschlossen. Sie waren jedoch zu einer Art von hohler Nussschale geworden, da immer mehr Réfugiés in sozialer, sprachlicher, wirtschaftlicher und religiöser Hinsicht diese separate Gemeinschaft bereits verlassen hatten ${ }^{40}$. Es ist nicht nur, wie Myriam Yardeni schreibt, »l'un des paradoxes du Refuge allemand que l'intégration politique et l'assimilation en constituent deux phénomènes distincts«, weil »les absolutismes allemands sont moins unificateurs, niveleurs et plus utilitaires que l'absolutisme français « ${ }^{41}$, ein weiteres Paradoxon besteht vielmehr auch im Festhalten an einer französisch-reformierten Identität und der Persistenz von identitären Narrativen, die für die Masse der Réfugiés beziehungsweise ihrer Nachfahren gegen Ende des 18. Jahrhunderts in allen vier Untersuchungsländern schon kaum mehr gegeben war.

III.

Im Fall der Réfugiés heißt erfolgreiche Immigration und Integration neben dem Stimulus und Impetus, den sie in die Aufnahmeländer trotz anfänglicher Armut und Hilfsbedürftigkeit mitbrachten, dass es einer Gruppe in der Diaspora, die sich selbst als Auserwählte und allen anderen Ethnien und Religionsgemeinschaften überlegen definierte, gelang, den Mythos ihrer Auserwählung, ihre von ihren gate-keepers konstruierten Identitäten den Bedürfnissen der Aufnahmeländer anzupassen und, mutatis mutandis, dabei Erwartungen und Klischees politisch, kulturell oder wirtschaftlich dominanter Gruppen im Aufnahmestaat zu bedienen. Während die Historiographie einiger deutscher Staaten bereits in der Mitte des 18. Jahrhunderts die Legende der separaten nation der Réfugiés und den Erhalt ihrer Identität in ihrer Separierung als positiv wertete, wurde in England ab dem frühen 19. Jahrhundert das ebenso wenig historisch korrekte Klischee der schnellen Assimilierung der Réfugiés - auf staatlicher und konfessioneller Ebene - kultiviert, da dies anscheinend den Interessen dieses Aufnahmelandes entsprach. Besonders in Brandenburg-Preußen und in einigen Bundesstaaten der USA wie South Carolina $^{42}$, amalgamierten sich die »Tugenden« der Réfugiés, deren Basis ihr reformierter Glaube bildete, erfolgreich mit den Narrativen der nationa-

40 So auch jüngst Manuela BöHм, Akkulturation und Sprachwechsel. Ein Vergleich der Sprachkontaktsituation in hugenottischen Stadt- und Landkolonien in Brandenburg und Berlin vom 17. bis 19. Jahrhundert, unveröffentlichte Dissertation, Universität Potsdam 2008, S. 51f.

41 Yardeni, Le Refuge allemand et la France, S. 188.

42 Bertrand Van Ruymbeke, Minority Survival. The Huguenot Paradigm in France and the Diaspora, in: Ders./Randy J. Sparks (Hg.), Memory and identity. The Huguenots in France and the Atlantic Diaspora, Columbia/SC 2003, S. 1-25; ders., Refuge or Diaspora? Historiographical reflections on the Huguenot dispersion in the Atlantic World, in: Susanne Lachenicht (Hg.), Religious Refugees in Europe, Asia and North America, $6^{\text {th }}-21^{\text {st }}$ century, Hamburg 2007, S. 155-169. 
len Tugenden des Amerikaners beziehungsweise, wie Etienne François und Rudolf von Thadden gezeigt haben, des Preußen, dann auch des Deutschen ${ }^{43}$. Probleme im Kontakt mit den Regierungen oder der Gesellschaft der Aufnahmestaaten, Loyalitätskonflikte, Wirtschaftskrisen und Ähnliches wurden sukzessive aus der Geschichtsschreibung getilgt. Dies geschah im Fall der Réfugiés weniger zum Zeitpunkt der Einwanderung selbst, als vielmehr zu dem Zeitpunkt, als massive Auflösungserscheinungen in der Diaspora neue Narrative für Gruppenidentität und ihren Stellenwert innerhalb der Aufnahmegesellschaften notwendig machten. Die Fähigkeit, die eigenen Legenden und selbst geschaffenen Mythen zu adaptieren und in die Narrative der Nationalhistoriographie der Aufnahmestaaten zu integrieren, prägt bis heute entscheidend die Wahrnehmung der Hugenotten, ihrer Immigration und Integration in die Länder des Refuge als Erfolgsmodell. Dies ist in allen Ländern des Refuge der Fall, trotz der unterschiedlichen Konzepte und Erwartungen, die in den Bereichen Integration und Nutzbringung an die Réfugiés gestellt wurden. Während also eine französisch-protestantische Identität, die überstaatliche nation der Réfugiés, vor allem ein Konstrukt der gate-keepers war, das sich bereits in der Konstruktionsphase selbst wiederum im Wandel und in Auflösung befand, waren die Narrative von hugenottischer Identität und Auserwähltheit weit resistenter als die Renaissance exklusiver französischprotestantischer Identität im Corps de refuge selbst ${ }^{44}$.

$\mathrm{Ob}$ diese persistenten Narrative, mit denen sich etliche Nachfahren der Réfugiés - und nicht nur diese - bis heute identifizieren, als erfolgreiche Identitätswahrung einer mittlerweile in weiten Teilen assimilierten und damit nicht mehr vorhandenen Diaspora gedeutet werden können, ob Erinnerungskultur, Hagiographie und Historiographie der Réfugiés die vollständige Assimilierung, das heißt die Auflösung dieser Diaspora, verhindert haben, da hugenottische Identität als Erinnerungskultur noch immer Bestandteil individueller, familiärer Identitäten oder der von calvinistischen Kirchengemeinden ist, bleibt dahin gestellt.

43 Siehe u.a. Etienne FrançoIs, Vom preußischen Patrioten zum besten Deutschen, in: Rudolf von Thadden/Michelle Magdelaine (Hg.), Die Hugenotten 1685-1985, München 1985, S. 198212; Etienne FrançoIs, Die Traditions- und Legendenbildung des deutschen Refuge, in: Heinz Duchiardt (Hg.), Der Exodus der Hugenotten. Die Aufhebung des Edikts von Nantes 1685 als europäisches Ereignis, Köln 1985, S. 177-193; Rudolf von THAdDEN, Vom Glaubensflüchtling zum preußischen Patrioten, in: Ders. / Magdelaine, Die Hugenotten, S. 186-197.

44 Susanne Lachenicht, Culture Clash and Hubris. The History and Historiography of the Huguenots in Germany and the Atlantic World, in: Gesa Mackenthun/Sünne JuterczenkA (Hg.), The fuzzy logic of encounter. New perspectives on cultural contact, Münster 2009, S. 75-96. 


\title{
Christian Windler \\ Katholische Mission und Diasporareligiosität
}

\author{
Christen europäischer Herkunft im Safavidenreich
}

In den Jahren 1762 und 1763 hatte das Heilige Offizium folgende dubia zu klären: »an liceat administrare baptismum filiis haereticorum «, »an id fieri possit in domo privata consulis Angli« und »an admitti possit patrinus haereticus una simul cum patrino Catholico $\ll^{1}$.

Für das Heilige Offizium und den Papst war die Sache klar: Man könne zwar dulden, dass die Protestanten »aus eigenem spontanem Willen $~(d i$ spontanea loro volontà) den Gottesdiensten und auch den Taufen der Katholiken beiwohnten; allerdings dürften die Katholiken die »Häretiker« nicht einladen, um nicht selbst zur communicatio in divinis beizutragen. Kinder »häretischer« Eltern sollten nicht getauft werden, wenn diesen die Erziehung anvertraut bleibe. Taufen von Kindern katholischer Eltern in Privathäusern seien nur zulässig, wenn die Kinder in Todesgefahr schwebten. »Häretikern « sei die Übernahme einer Patenschaft untersagt, da sie nicht dafür einstehen könnten, dass der Täufling im katholischen Glauben erzogen werde. Auf die doktrinäre Klärung folgte allerdings ein bemerkenswertes Zugeständnis: Wenn der Missionar die Beteiligung eines »Häretikers « nicht verhindern könne, müsse er wenigstens erklären, dass allein der Katholik das Amt des Paten übernehme und der »Häretiker« der Taufe bloß als Zeuge beiwohne. Im Taufregister sei dann ausschließlich der katholische Pate zu nennen ${ }^{2}$.

Im vorliegenden Fall beantwortete das Heilige Offizium eine Anfrage, welche die Propagandakongregation aufgrund eines Briefes des Präfekten der Mission in Tripolis im heutigen Libyen formuliert hatte, der die lokalen Taufpraktiken als positives Zeichen seines guten Verhältnisses zu den englischen Häretikern beschrieben hatte. Es war nicht das erste Mal, dass Missionare aus dem Osmanischen Reich oder aus Persien über konfessionelle Grenzüberschreitungen unter den Christen europäischer Herkunft berich-

1 ACDF, Sanctum Officium, Dubia circa Baptismum, Bd. 4: 1760-1766: 1762-1763, IX, fol. 380r-423v. - Der Verfasser dankt Nadine Amsler (Bern) für umfangreiche und sorgfältige Recherchen in Bibliotheken und Archiven in Frankreich und in der Schweiz.

2 Istruzione per il P. Filippo di Montevarchi Prefetto della Missione de' Riformati di Tripoli, o.D. [am 20.1.1763 durch Papst Clemens XIII. gebilligt; am 22.1.1763 der Propagandakongregation gesandt] (ACDF, Sanctum Officium, Dubia circa Baptismum, Bd. 4: 1760-1766: 1762-1763, IX, fol. 384r-385r). 
teten. Bei aller dogmatischen Klarheit in der Ablehnung von Praktiken, die communicatio in divinis implizierten, spricht aus den Stellungnahmen der consultores und der Kardinäle sowie aus dem päpstlichen Entscheid ein gewisses Verständnis für die besondere Situation, in welcher sich ein Missionar in der Frage der Taufe befinden konnte: Zwar hatte er Ketzer als Taufpaten abzulehnen, ihre Zulassung als Zeugen eröffnete indessen Handlungsspielräume im sozialen Umgang vor Ort. Offensichtlich war man sich in Rom bewusst, dass konfessionelle Grenzen weniger eindeutig gezogen wurden, wenn Katholiken und »Häretiker« als eine kleine christliche Minderheit in einem muslimischen Umfeld zusammenlebten.

Im Folgenden soll am Beispiel der europäischen Diaspora in Isfahan, der Residenzstadt der Safaviden, und in deren Vorstadt Neu-Djulfa im 17. und frühen 18. Jahrhundert nach den spezifischen Ausprägungen einer Diasporareligiosität von Christen europäischer Herkunft in einem muslimischen Umfeld gefragt werden. Dabei sei aber unterstrichen, dass sich die dortigen Praktiken nicht grundsätzlich von jenen unterscheiden, die etwa in den Hafenstädten des Maghreb beobachtet werden können ${ }^{3}$.

Als Quellen stehen in erster Linie die Korrespondenzen der Missionare mit ihren Ordensoberen und Propaganda Fide sowie die Akten der Propagandakongregation und des Heiligen Offiziums zur Verfügung. In den Vordergrund rücken damit quellenbedingt die Sichtweisen katholischer Geistlicher. Reiseberichte, die zum Teil auch von Protestanten verfasst wurden, liegen bei weitem nicht in der gleichen Dichte vor, ergänzen jedoch da und dort den Befund der kirchlichen Quellen.

Religiöse Grenzüberschreitungen in den muslimischen Ländern des Mittelmeerraums und des Nahen Osten haben in den letzten zwei Jahrzehnten in der Forschung vermehrt Aufmerksamkeit gefunden. Dies gilt etwa für das Phänomen der Konversion zum Islam ${ }^{4}$, aber auch für die Beziehungen zwischen den nichtmuslimischen religiösen Gemeinschaften im Osmanischen Reich. Während die ältere Forschung die Schärfe der Grenzziehungen betonte, haben neuere Arbeiten ein auf den ersten Blick überraschendes Maß an Durchlässigkeit religiöser Grenzen an den Tag gefördert, indem sie die vielfältigen Formen des Austausches zwischen den religiösen und ethnischen Gruppen beschrieben haben ${ }^{5}$. Die verschiedenen christlichen Gemeinschaf-

3 Christian WindeER, La diplomatie comme expérience de l'Autre. Consuls français au Maghreb (1700-1840), Genève 2002, S. 111-120.

4 Dazu die Beiträge in folgendem Sammelband: Mercedes García-Arenal (Hg.), Conversions islamiques. Identités religieuses en Islam méditerranéen/Islamic Conversions. Religious Identities in Mediterranean Islam, Paris 2001. Siehe auch Bartolomé Bennassar/Lucile Bennassar, Les chrétiens d'Allah. L'histoire extraordinaire des renégats, $\mathrm{XVI}^{\mathrm{e}}$ et $\mathrm{XVII}{ }^{\mathrm{e}}$ siècles, Paris 1989.

5 Siehe zum Beispiel François Georgeon/Paul Dumont (Hg.), Vivre dans l'Empire ottoman. Sociabilités et relations intercommunautaires (XVIII ${ }^{e}-\mathrm{XX}^{\mathrm{e}}$ siècles), Paris 1997; Marie-Car- 
ten teilten sich in vielen Fällen die gleichen sozialen Räume, was sowohl Konflikte um die Verteilung von Ressourcen und damit die Betonung der Gegensätzlichkeiten als auch enge Beziehungen in den verschiedensten Lebensbereichen zur Folge haben konnte. Im Osmanischen Reich relativierte die Vielfalt dieser Beziehungen die von den Herrschern gewollte Einbindung der nichtmuslimischen Untertanen in ihre jeweilige ta' ifa als Rahmen der Besteuerung und Jurisdiktion. Was dies für katholische Kirchlichkeit und Religiosität nach dem Konzil von Trient bedeutete, hat Bernard Heyberger in seinen Arbeiten über die syrischen Provinzen aufgezeigt ${ }^{6}$. Im Blickpunkt stehen bei Heyberger allerdings die Ostchristen und ihr Verhältnis zu den Missionaren und den römischen Unionsbestrebungen, während er die hier angesprochene Frage der Beziehungen lateinischer Christen verschiedener Konfession untereinander nicht thematisiert. Auch wenn letztere in ihrem Alltag vielfach in die Nähe der Ostchristen rückten und diese etwa mit Eheschließungen bekräftigten, unterschieden sie sich von diesen doch sehr stark aufgrund ihrer Lebenserfahrungen. Von einzelnen in vorosmanische Zeit zurückgehenden lateinischen Gemeinschaften im östlichen Mittelmeerraum (insbesondere der magnifica comunità di Pera in Konstantinopel ${ }^{7}$ oder Gemeinden im früher venezianischen Herrschaftsbereich) abgesehen, prägte ein hoher Grad an individueller geographischer Mobilität das Leben der meisten Mitglieder der europäischen Diasporen. Konsuln, Kaufleute, Agenten von Handelsgesellschaften oder spezialisierte Handwerker, insbesondere Uhrmacher, kamen in der Regel nicht mit der Absicht, sich dauerhaft an einem Ort niederzulassen, auch wenn in manchen Fällen schließlich genau dies eintrat. Die geographische Mobilität implizierte ein hohes Maß an individueller Lebensgestaltung. Ledige Männer waren in geringerem Maße der Disziplin ihres Verwandtschaftsverbandes unterworfen, was zum Beispiel Mischehen

men Smyrnelis, Une société hors de soi. Identités et relations sociales à Smyrne aux XVIII et XIX $^{\mathrm{e}}$ siècles, Leuven 2005; Lucette VALENSI, La Tour de Babel: groupes et relations ethniques au Moyen-Orient et en Afrique du Nord, in: AESC 41 (1986), S. 817-838; dies., Inter-communal Relations and Changes in Religion Affiliation in the Middle East (17th to 19th Centuries), in: CSSH 39 (1997), S. 251-269, und in leicht abgewandelter Form: Dies., Relations intercommunitaires et changements d'affiliation religieuse au Moyen-Orient (XVII $-\mathrm{XIX}^{\mathrm{e}}$ siècles), in: García-Arenal, Conversions islamiques, S. 227-244.

6 Bernard Heyberger, Les Chrétiens du Proche-Orient au temps de la Réforme catholique, Rom 1994; ders., Hindiyya (1720-1798), mystique et criminelle, Paris 2001. Zu den Unionsbemühungen gegenüber den Griechen siehe Ingo Herklotz, Die Academia Basiliana. Griechische Philologie, Kirchengeschichte und Unionsbemühungen im Rom der Barberini, Freiburg im Breisgau 2008.

7 Zu den lateinischen Christen in Konstantinopel im 17. Jahrhundert siehe Elisabetta BorromEO, Les catholiques à Constantinople: Galata et les églises de rite latin au XVII ${ }^{\mathrm{e}}$ siècle, in: Revue du monde musulman et de la Méditerranée 107-110 (2005), S. 227-243; Eric Dursteler, Education and identity in Constantinople's Latin Rite Community c. 1600, in: Renaissance Studies 18 (2004), S. 287-303. 
mit Töchtern ostchristlicher Familien begünstigte. Diesbezügliche Klagen wurden etwa in Genf mit Blick auf die nation genevoise in Konstantinopel formuliert ${ }^{8}$. Dabei unterschied sich die Lage in Konstantinopel aufgrund der Existenz reformierter Gemeindestrukturen mit eigenem Pfarrer grundsätzlich von der Situation in den übrigen europäischen Diasporen, wo meistens nur katholische Ordensgeistliche lebten und protestantische Gemeindestrukturen fehlten. Individuelle Formen protestantischer Religiosität entwickelten sich dort in Abwesenheit jener Multiplikatoren konfessioneller Kirchlichkeit, welche die Konfessionalisierungsforschung für Europa beschrieben hat.

Im Folgenden soll zuerst kurz auf die Bedingungen eingegangen werden, unter denen die europäische Diaspora in Isfahan seit dem frühen 17. Jahrhundert entstand und Mitte des 18. Jahrhunderts mit dem Niedergang dieser Stadt wieder verschwand. Am Beispiel eines Genfer Uhrmachers und Kaufmanns und dessen Sohnes sollen dann konfessionelle Grenzlagen illustriert werden, welche das Leben der Europäer in Persien prägten.

Der dritte Teil thematisiert die religiösen Praktiken der europäischen Diaspora. Es wird gezeigt, wie sich die katholischen Missionare in die überkonfessionelle Soziabilität vor Ort einfügten und mit ihren Vermittlungsleistungen in weltlichen und geistlichen Angelegenheiten in einem »dritten Raum« soziales Ansehen erlangten. Dabei suchten sie einen Ausgleich zwischen den Erwartungen ihres lokalen Umfeldes und den Anforderungen konfessioneller Regelobservanz, die seit den letzten Jahrzehnten des 17. Jahrhunderts zunehmend strikter wurden.

\section{Die europäische Diaspora in Isfahan und Neu-Djulfa}

Die europäische Präsenz in Isfahan war anfänglich mit der Niederlassung katholischer Orden verbunden ${ }^{9}$. Zu Beginn des 17. Jahrhunderts richteten portugiesische Augustiner als erste eine Mission in Isfahan ein. Ihr Superior ver-

8 Siehe z.B. Protokoll der Genfer Compagnie des pasteurs, 3.12.1652, ediert in: André ARChINARd/Théophile HeYer, Genève et Constantinople. 1592-1732, in: BSHPF 10 (1861), S. 233-258, hier: S. 235.

9 Siehe Wilhelm de VRIES, Die Propaganda und die Christen im Nahen asiatischen und afrikanischen Osten, in: Josef Metzler (Hg.), Sacrae Congregationis de Propaganda Fide Memoria Rerum, 1622-1972, Bd I / 1: 1622-1700, Freiburg im Breisgau 1973, S. 561-605; Josef MetzLER, Nicht erfüllte Hoffnungen in Persien, in: Ebd., S. 680-704; Ambrosius Eszer, Missionen im Halbrund der Länder zwischen Schwarzem Meer, Kaspisee und Persischem Golf: Krim, Kaukasien, Georgien und Persien, in: Ebd., Bd. II, S. 421-462; Robin E. WATERfIELd, Christians in Persia. Assyrians, Armenians, Roman Catholics and Protestants, London 1973, S. 62-75. Zu den Beziehungen der Missionare zum muslimischen Gelehrtenmilieu siehe Francis RichARD, Catholicisme et Islam chiite au »Grand Siècle«. Autour de quelques documents concernant les Missions catholiques en Perse au XVII ${ }^{\mathrm{e}}$ siècle, in: ED. Commentaria Urbaniana 33 (1980), S. 339-403. 
trat zugleich Philipp III. von Kastilien als König von Portugal am persischen Hof $^{10}$. 1607, also kurz nach den Augustinern, kamen die unbeschuhten Karmeliten nach Isfahan. Sie gehörten zur italienischen Ordensprovinz und wurden als Abgesandte des Papstes betrachtet ${ }^{11}$.

Mit den Niederlassungen der englischen und niederländischen Ostindiengesellschaften entstand in Isfahan zur Zeit von Schah Abbas I. auch eine kleine europäische Handelsdiaspora. Die englische East India Company war seit 1617 in Isfahan vertreten, wo ihr der Schah ein Gebäude in unmittelbarer Nähe des Basars zugesprochen hatte. Als Dank für die Unterstützung bei der Vertreibung der Portugiesen aus Hormuz erhielt die Handelsgesellschaft bedeutende Privilegien. Dazu gehörten neben Zollprivilegien in Bandar Abbas und der Handelsfreiheit im ganzen Reich die Anerkennung des Agenten der Gesellschaft in Isfahan als Gesandter des Königs von England, eine eigene Gerichtsbarkeit und freie Religionsausübung. Kurz nach den Engländern erhielt die Nederlandsche Oost-Indische Compagnie ähnliche Privilegien und konnte sich in Bandar Abbas und Isfahan niederlassen. Im Vergleich zu den Engländern und Niederländern waren die französischen Kaufleute im 17. Jahrhundert wenig erfolgreich, obwohl auch ihnen Privilegien des Schahs gewährt wurden ${ }^{12}$.

Ohne unmittelbare Bindung an die Handelsgesellschaften wirkten sodann verschiedene Handwerker europäischer Herkunft in Isfahan und Neu-Djulfa. Bereits zu Beginn des 17. Jahrhunderts bemerkte ein Karmelit, Schah Abbas I. empfange gerne talentierte Uhrmacher, Musiker, Maler und Baumeister an seinem Hof $^{13}$. Als John Fryer 1677 nach Neu-Djulfa kam, fand er dort Goldschmiede, Juweliere, Uhrmacher und Waffenschmiede europäischer Herkunft vor, die bei Hofe Arbeit gefunden hatten ${ }^{14}$.

Die Schwäche der französischen Handelspräsenz hatten Ludwig XIII. und Ludwig XIV. mit der Förderung von Niederlassungen französischer Kapuziner und Jesuiten kompensiert ${ }^{15}$. Jahrzehntelang galt der Guardian der 1628 gegründeten Kapuzinermission von Isfahan als Repräsentant des Königs von

$10 \mathrm{Zu}$ den Anfängen der Augustinermission siehe Carlos Alonso, Antonio de Gouvea, O.S.A., diplomático y visitador apostólico en Persia, Valladolid 2000.

$11 \mathrm{Zu}$ den Missionen der Karmeliten siehe Herbert Сніск, A Chronicle of the Carmelites in Persia and the Papal Mission of the XVIIth and XVIIIth Centuries, 2 Bde., London 1939.

12 Peter Jackson/Laurence Lockhart (Hg.), The Timurid and Safavid Periods, Cambridge 1986, S. 297f., 393f., 396-400, 404-407, 449-453, 459-466. Siehe Laurence LockHART, The Fall of the Safavi Dynasty and the Afghan Occupation of Persia, Cambridge 1958, S. 360-407, 426, 430-432, 469.

13 Waterfield, Christians in Persia, S. 66.

14 John Carswell, New Julfa. The Armenian Churches and other Buildings, Oxford 1968, S. 9.

15 Zur Mission der Kapuziner siehe Francis Richard (Hg.), Raphaël du Mans, missionnaire en Perse au XVIIe siècle, Bd. 1: Biographie. Correspondance, Bd. 2: Estats et Mémoire, Paris 1995 (Moyen Orient \& Océan Indien XVI'-XIX'e s. 9-1 und 2). 
Frankreich am Safavidenhof ${ }^{16}$. Um die Jahrhundertmitte ließen sich auch französische Jesuiten in Isfahan nieder. Seit 1661 wirkten sie in der armenischen Vorstadt Neu-Djulfa, wo sie eine Schule betrieben, deren Angebot sich an die armenischen Notabeln und die Europäer verschiedener Konfession richtete ${ }^{17}$.

Zuletzt gründete der Dominikaner Sebastian Knab, Erzbischof von Naxijevan, während eines Aufenthaltes in Isfahan in den Jahren 1684 bis 1686 eine Niederlassung seines Ordens in Neu-Djulfa, die mit der römischen Observanzkongregation von Santa Sabina und damit eng mit Propaganda Fide und der Kurie verbunden wurde ${ }^{18}$. Neben den genannten Orden waren im späten 17. und frühen 18. Jahrhundert einzelne französische Weltpriester der Missions étrangères in Persien tätig ${ }^{19}$. Die Konkurrenz unter den katholischen Herrschern führte dazu, dass es im frühen 18. Jahrhundert in Isfahan und Neu-Djulfa insgesamt sechs Ordensniederlassungen gab $^{20}$.

Die zahlreiche Präsenz katholischer Orden stand in einem eklatanten Missverhältnis zur Zahl der Christen europäischer Herkunft und zum geringen Erfolg der Mission bei den Armeniern. 1714 gab es in der armenischen Vorstadt Neu-Djulfa und deren Umgebung vier katholische Kirchen. Drei davon dienten den lateinischen Christen, deren Zahl sich damals dem apostolischen Vikar Barnaba Fedeli zufolge auf etwa hundert Personen belief: Neben den Jesuiten verfügten die Dominikaner und die unbeschuhten Karmeliten jeweils über eine Niederlassung. Die armenische Kaufmannsfamilie Sheriman übte das Patronat über die von ihr errichtete armenisch-katholische Pfarrei aus, der etwa neunzig Personen angehörten ${ }^{21}$. Wenn man bedenkt, dass in Neu-Djulfa schätzungsweise 30.000 bis 35.000 Armenier lebten ${ }^{22}$, war dies äußerst wenig. Die Missionen in Persien galten deshalb allgemein

16 Jackson/Lockhart, The Timurid and Safavid Periods, S. 396-398; Lockhart, The Fall of the Safavi Dynasty, S. 426-429.

17 Bruno Zimmel, Vorgeschichte und Gründung der Jesuitenmission in Isfahan (1642-1657), in: ZMR 53 (1969), S. 1-26.

18 Zur Tätigkeit der Dominikaner in Persien siehe v.a. Ambrosius Eszer, Sebastianus Knab O.P., Erzbischof von Naxijevan (1682-1690). Neue Forschungen zu seinem Leben, in: AFP 43 (1973), S. 215-286; ders., Barnaba Fedeli di Milano O.P. (1663-1731). Das Schicksal eines Missionars und Bischofs im Sturm der Zeiten, in: AFP 44 (1974), S. 179-262. Die Reformkongregation von Santa Sabina setzte sich die Verwirklichung strenger Regelobservanz zum Ziel und widmete sich insbesondere auch der Mission.

19 Dazu Guillaume de Vaumas, L'éveil missionnaire de la France d'Henri IV à la fondation du séminaire des Missions étrangères, Lyon 1959, S. 355-361; Anne Kroell, Nouvelles d'Ispahan, Paris 1979, S. 20-25.

20 Je eine Niederlassung der Augustiner und Kapuziner in Isfahan, zwei Niederlassungen der Karmeliten (je eine in Isfahan und Neu-Djulfa) sowie je eine Niederlassung der Jesuiten und Dominikaner in Neu-Djulfa.

21 »Congregazione generale« vom 27.8.1714 (APF, Acta, Bd. 84, fol. 745v-746r).

22 Lockhart, The Fall of the Safavi Dynasty, S. 74; Willem Floor, The Economy of Safavid Persia, Wiesbaden 2000, S. 16. 
als wenig erfolgreich, zumindest wenn man die Zahl der Konversionen als Maßstab ansetzte. Eine gewisse qualitative Bedeutung erlangte die Armeniermission dadurch, dass sich mit den Sheriman immerhin eine der führenden, wahrhaft global agierenden armenischen Kaufmannsfamilien zur Union mit Rom bekannte.

Gegenüber der Bekehrung Andersgläubiger traten machtpolitische Ziele in den Vordergrund, verbanden die katholischen Herrscher doch die Pflege einer religiös begründeten Legitimität durch die Bekehrung Andersgläubiger mit der Vertretung politischer Interessen am persischen Hof. Die kleine katholische Diaspora wurde damit auch zu einem Mikrokosmos der Konflikte, welche die nachtridentinische Kirche in Europa prägten.

Der Niedergang der europäischen Diaspora in Isfahan und Neu-Djulfa seit den 1720er Jahren war eine Folge des Sturzes der Safaviden. Nach der Absetzung von Schah Sultan Husain im Oktober 1722 waren die afghanischen Eroberer nicht in der Lage, ihre Autorität im früheren Herrschaftsbereich der Safaviden dauerhaft durchzusetzen. Erst in den 1760er Jahren setzte sich mit Karim Khan Zand ein Herrscher durch, der wieder ein für gedeihliche Handelsgeschäfte notwendiges Maß an Rechtssicherheit schuf. Shiraz trat nun allerdings an die Stelle Isfahans als Residenzstadt und übernahm auch dessen Rolle als wichtigstes Handelszentrum in Persien ${ }^{23}$. Die kriegerischen Verheerungen und der Bedeutungsverlust Isfahans drückten sich in dramatischen demographischen Verlusten aus: Auf der Grundlage zeitgenössischer niederländischer Schätzungen bezifferte Willem Floor die Einwohnerzahl 1710 auf 550.000, 1727 auf 240.000 und 1736 noch auf 50.000 Personen $^{24}$.

Dieser Bedeutungsverlust brachte auch die europäische Diaspora von Isfahan zum Verschwinden. 1739 wurde Jean Otter, der in französischem Auftrag reiste, in der von der Ostindiengesellschaft verlassenen englischen Faktorei untergebracht, nachdem er zuerst bei den Kapuzinern gelebt hatte ${ }^{25}$. Letztere gaben ihre Mission bald danach auf ${ }^{26}$. In den frühen 1750er Jahren wurde die Niederlassung der Augustiner ebenfalls geschlossen ${ }^{27}$. Nachdem die Jesuiten ihre Mission in Neu-Djulfa 1754 aufgegeben hatten ${ }^{28}$, überlebten nur noch

23 Dazu Jackson/Lockhart, The Timurid and Safavid Periods, S. 314-331; Peter Avery/Gavin Hambly / Charles Melville (Hg.), From Nadir Shah to the Islamic Republic, Cambridge 1991, S. 3-103. Über den Niedergang der Safavidendynastie und die afghanische Besetzung siehe LOCKHART, The Fall of the Safavi Dynasty.

24 Obwohl aufgrund der unsicheren Quellengrundlage Zweifel an den absoluten Zahlen angebracht sind, dürften sie den demographischen Niedergang der Stadt widerspiegeln. Siehe FLoor, The Economy of Safavid Persia, S. 3.

25 Journal des voyages du Sr [Jean] Otter, de Constantinople à Ispahan, d'Ispahan à Bassora, de Bassora à Constantinople, et de son retour en France, 1736-1743 (BN, Manuscrits, n.a. fol. 989, S. 46, 49).

26 Richard, Catholicisme et Islam chiite, S. 373.

27 Waterfield, Christians in Persia, S. 77.

281753 und 1754 schrieb es der Superior der Jesuiten, Pater Michel Raymond Desvignes, der gött- 
vereinzelte Karmeliten und Dominikaner unter schwierigen Bedingungen ${ }^{29}$. Das letzte datierbare Grab eines Europäers auf dem armenischen Friedhof von Neu-Djulfa ist jenes von Jacques Rousseau aus dem Jahre $1753^{30}$.

\section{II. »Iacobus Rousseau, Genevensis horologiorum faber«}

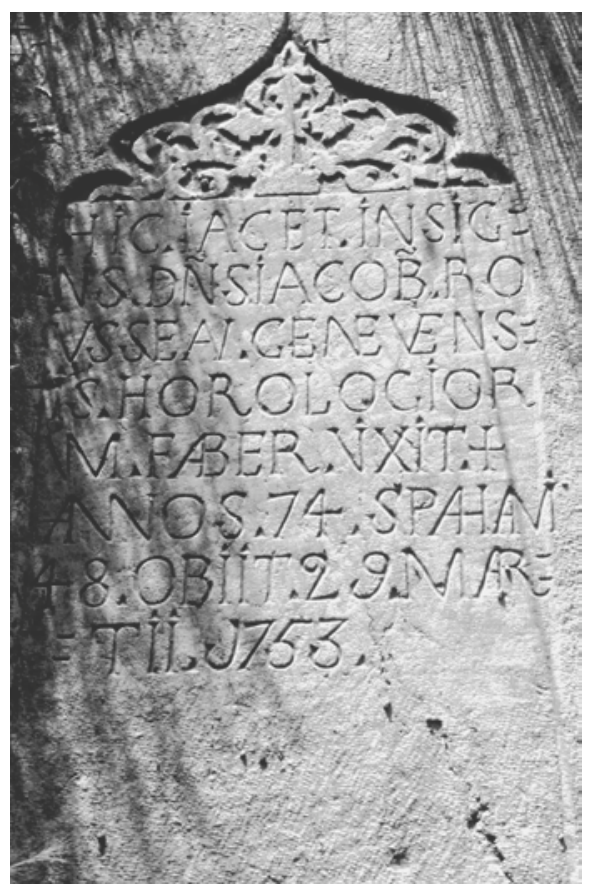

HIC IACET INSIGNIS D[OMI]N[V]S IACOB[VS] RO VSSEAV GENEVENSIS HOROLOGIOR VM FABER VIXIT ANNOS 74 SPAHANI 48 OBIIT 29 MARTII 1753

Hier ruht der ausgezeichnete Herr Jacques Rousseau, Uhrmacher aus Genf. Er lebte 74 Jahre, 48 davon in Isfahan. Er starb am 29. März 1753.

Abb. 1: Grabstein von Jacques Rousseau auf dem armenischen Friedhof von Neu-Djulfa (Aufnahme des Verfassers).

lichen Vorsehung zu, dass er nicht auch zu den Toten zählte. Die »Barbaren« verwüsteten alles - selbst die »vasa sacra« -, verlangten Tribute, welche die Möglichkeiten der Mission überstiegen, und hätten ihn »halblebendig « (»semivivum«) zurückgelassen. Siehe P. Michel Raymond Desvignes SJ an den Ordensgeneral, Neu-Djulfa, 13.2.1753 und 5.3.1754 (ARSI, Gallia, 106, fol. 109r-112v). Als Pater Desvignes 1754 die Mission schloss, fand er bei den Karmeliten Zuflucht. Er starb 1757 in Basra und wurde dort im Konvent der Karmeliten bestattet. Siehe [Index defunctorum], 1755-1816, Eintrag vom 25.9.1757 (Nr. 16) (AOCD 484/c).

29 Über die Karmeliten siehe Сніск, A Chronicle of the Carmelites in Persia, Bd. 1, S. 656-718; Waterfield, Christians in Persia, S. 77.

30 Thomas Wolsley Haig, Graves of Europeans in the Armenian Cemetery at Isfahan, in: Journal of the Royal Asiatic Society of Great Britain and Ireland 11 (1919), S. 321-352. 
Der Grabstein auf dem Friedhof der armenischen Vorstadt von Isfahan, NeuDjulfa, ist eines der leider eher seltenen Zeugnisse eines außergewöhnlichen Lebens. Jacques Rousseau verließ seine Geburtsstadt Genf im Jahr 1699, das heißt im Alter von zwanzig Jahren. Seine Gattin Marie Rousseau, geborene Blandin, blieb in Genf zurück ${ }^{31}$. Jacques Rousseaus Entschluss zu emigrieren war für junge Genfer Uhrmacher und Kaufleute nicht ungewöhnlich. Sein erstes Ziel, Konstantinopel, war bei diesen besonders beliebt, weil die Genfer hier aufnahmefähige Absatzmärkte für Uhren aus der heimischen Produktion fanden, deren Pflege und Reparatur dann den emigrierten Uhrmachern zu einem Auskommen verhalf. 1709 umfasste die Genfer Gemeinde von Konstantinopel, zu der damals auch einige französische Hugenotten sowie Protestanten aus dem Pays de Gex gehörten, etwa 50 Personen. 1725 war die Rede von 85 Personen, die im Stadtteil Pera eine Kirche errichtet hatten und sich nun um die Entsendung eines Genfer Pfarrers bemühten. 1737 zählte die reformierte Genfer Kirche von Pera immerhin 160 Personen - die meisten waren Genfer, dazu kamen einige Holländer, Schweizer und Ungarn ${ }^{32}$.

Im Gegensatz zu seinem Vetter Isaac Rousseau, der sich nach der Geburt seines ersten Sohnes im Jahre 1705 ebenfalls als Uhrmacher nach Konstantinopel begeben hatte und nach seiner Rückkehr nach Genf 1712 Vater eines zweiten Sohnes wurde, des späteren Philosophen Jean-Jacques, kehrte Jacques Rousseau nie wieder nach Genf zurück. 1706 reiste er stattdessen ins ferne Isfahan weiter, wohin sich nur wenige Genfer Kaufleute und Uhrmacher begaben. Vielleicht war es gerade dieses weitgehende Fehlen von Konkurrenten, welches es Rousseau erleichterte, als Uhrmacher, Juwelier und Kaufmann Wohlstand und Ansehen zu erwerben. Der polnische Jesuit Tadeusz Juda Krusinski, der von 1707 bis 1725 in Persien weilte und den Genfer gut gekannt haben muss, erwähnt Rousseau in einem Bericht über die Geschichte Persiens in dieser Zeit in dessen Funktion als angesehener chef der Uhrmacher von Schah Sultan Husain ${ }^{33}$.

1737 heiratete Jacques Rousseau in Neu-Djulfa in zweiter Ehe die Katholikin Reine de l'Étoile. Er verband sich so mit einer der wenigen Familien europäischer Herkunft, die sich schon seit der ersten Hälfte des 17. Jahrhunderts dauerhaft in Persien niedergelassen hatten. Die de l'Étoile, ursprüng-

31 Nach der Abreise von Jacques Rousseau wurde am 30. Januar 1700 auf Betreiben seiner Gattin ein Inventar des von ihm zurückgelassenen Mobiliars erstellt, dessen Wert sich auf nicht ganz 400 Gulden belief (Genève, Archives d'État, Jurisdictions civiles F d 9: Registre d'inventaire en cas de faillites, séparations de biens, interdictions, départs, deuxième série en portefeuilles, 1699-1700).

32 Antony BABEL, Histoire corporative de l'horlogerie, de l'orfèvrerie et des industries annexes, Genève 1916, S. 516-529; ders., L'horlogerie genevoise à Constantinople et dans le Levant du XVI ${ }^{\mathrm{e}}$ au XVIII ${ }^{\mathrm{e}}$ siècle, Genf 1926 (Auszug aus: »Étrennes Genevoises 1927«).

33 Jean-Antoine Du Cerceau, Histoire de la dernière Révolution de Perse, 2 Bde., Paris ${ }^{2} 1729$ (verfasst auf der Grundlage der Mémoires von Pater Tadeusz Juda Krusinski), Bd. 1, S. $128 f$. 
lich Hugenotten, waren aus der Gegend von Saint-Jean d'Angély zugewandert, einer der im Edikt von Nantes den Reformierten als Sicherheitsplätze zugesprochenen Städte südöstlich von La Rochelle. Ihre Mitglieder waren in Isfahan als Goldschmiede, Kaufleute und Agenten der Compagnie française des Indes tätig ${ }^{34}$. Ein Vorfahr von Reine de l'Étoile, Isaac Boutet de l'Étoile, hatte 1643 in eine armenische Familie eingeheiratet, die sich zur Union mit Rom bekannte; kurz vor seinem Tod 1667 konvertierte Isaac selbst zum Katholizismus. Die Jesuiten konnten dies damals als Erfolg einer Missionsstrategie verbuchen, welche mit dem Ziel der freundschaftlichen Nähe zu »Häretikern« und »Schismatikern« Abstriche bei der Einhaltung konfessionskirchlicher Regeln in Kauf nahm. Dazu gehörten Messfeiern in den Häusern von Protestanten, die in zweifacher Hinsicht gegen die Vorgaben der nachtridentinischen Kirche verstießen: Sie trugen das Sakrale in den weltlichen Raum von Privathäusern und leisteten der communicatio in divinis Vorschub. 1660 verzeichnete Pater Aimé Chézaud den Umstand, dass er an allen Sonn- und Feiertagen im Haus von Boutet de l'Étoile für dessen Familie und Nachbarschaft Messe lesen konnte, seinen Ordensoberen gegenüber als einen der wenigen greifbaren Erfolge der Mission in Isfahan ${ }^{35}$. Er hatte insofern nicht Unrecht, als die Nachkommen von Isaac tatsächlich eng mit den Jesuiten verbunden bleiben sollten und Berichten aus dem frühen 18. Jahrhundert zufolge damals die Kirche der Patres füllten ${ }^{36} .1662$ bezeichneten Chézaud und François Pallu, Bischof von Heliopolis und apostolischer Vikar in Isfahan, den späteren Konvertiten Isaac noch als Hugenotten. Chézaud sprach damals von ihm als »un de nos amis quoique calvinien $\ll^{37}$. Pallu nannte Boutet de l'Étoile den wichtigsten von sechs Franzosen in Neu-Djulfa. Er habe dort ein Vermögen gemacht. Seine Frau, seine Kinder und die ganze Familie lasse er im Katholizismus unterweisen: »Il y a 6 Français, dont le principal est $\mathrm{M}^{\mathrm{r}}$ de l'Étoile qui a fait ici sa fortune, fort honnête homme et très serviable, huguenot, quoiqu'il ait fait instruire dans notre Foi sa femme, ses enfants et toute sa famille $\ll^{38}$.

Nicht nur zu den Jesuiten, sondern auch zu den ebenfalls aus Frankreich stammenden Kapuzinern pflegte Isaac freundschaftliche Beziehungen. Als der Kapuziner Raphaël du Mans 1667 einen der Söhne des soeben verstorbenen Isaac Boutet de l'Étoile dem französischen Konsul in Aleppo empfahl,

34 Zwischen 1655 und 1745 wurden mehrere Mitglieder der Familie de l'Étoile auf dem armenischen Friedhof von Neu-Djulfa begraben. Siehe HAIG, Graves of Europeans, S. 340-342.

35 P. Aimé Chézaud SJ an P. Pierre Le Cabre, »assistant de France« in Rom, Isfahan, 21.10.1660 (ARSI, Gallia, 97 II, Dok. 108, fol. 315r).

36 Richard, Raphaël du Mans, Bd. 1, S. $203 \mathrm{f}$.

37 P. Aimé Chézaud SJ an P. Claude Boucher, »assistant de France« in Rom, Isfahan, 20.5.1662, Ergänzung vom 20.6.1662 (ARSI, Gallia, 97 II, Dok. 113, fol. 325r).

38 Zitiert nach Richard, Raphaël du Mans, Bd. 1, S. 54, Anm. 127. 
bezog er sich auf die über dreißigjährige »étroite amitié et correspondance« zwischen der Familie und den Patres. Der Verstorbene habe kaum etwas getan, ohne ihn zu konsultieren. Die beiden Söhne Louis und François habe er, Pater Raphaël, die Grundlagen des Glaubens sowie Lesen und Schreiben gelehrt ${ }^{39}$. Konnten die Jesuiten die Konversion von Isaac Boutet de l'Étoile als Erfolg ihrer auf soziale Nähe zu »Ketzern« und »Schismatikern« setzenden Missionsstrategie feiern, so fiel eine seiner Töchter, Angela, allerdings ebenso rasch wieder in die »Ketzerei« zurück, als sie den Sohn des Dolmetschers der East India Company heiratete, um dann in schwerer Krankheit den Karmelitenpater Angelus a Sancto Joseph um medizinische Hilfe anzugehen und eine Generalbeichte abzulegen ${ }^{40}$.

Die Heirat von Jacques Rousseau mit Reine de l'Étoile kann wohl als Zeichen dafür gesehen werden, dass die Bindung des Genfers an seine protestantische Heimatstadt lockerer wurde. Als Reine de l'Étoile ein Jahr nach der Trauung einen Sohn zur Welt brachte, wurde dieser bei den Jesuiten auf den Namen Jean-François-Xavier (und nicht bloß Jean-François wie der in Genf verbliebene Bruder von Jacques) getauft. Im Alter von neun Jahren sandte ihn Jacques Rousseau zu den Jesuiten in die Schule, wo er im Katholizismus unterwiesen wurde. Jacques Rousseau selbst soll dem Drängen der Patres, »der Religion seiner Väter abzuschwören«, widerstanden haben ${ }^{41}$.

Leider verfügen wir über keine Quellen, welche uns die persönliche religiöse Praxis Rousseaus näher bringen würden. Wir besitzen nur Hinweise auf äußere Formen des Zusammenlebens. Archivarisch ist der Genfer Uhrmacher und Kaufmann Rousseau in Isfahan vor allem als Kreditgeber der katholischen Missionare fassbar. 1718 lieh er dem Präfekten der Jesuiten, Pater Monier, 23 Toman, umgerechnet 1380 livres tournois ${ }^{42}$.

In den 1720er Jahren wurde Rousseau zum wichtigsten Kreditgeber des Dominikaners Barnaba Fedeli da Milano, der damals als katholischer Bischof von Isfahan amtierte. Die Kreditbeziehung lag im beiderseitigen Interesse: 1722 unterbrach die afghanische Invasion Persiens für mehrere Jahre die Verbindungen des Bischofs mit der Congregatio de Propaganda Fide in

39 Dazu P. Raphaël du Mans OFM Cap an François Baron, Konsul in Aleppo, Isfahan, 18.10.1667, ediert in: Ebd., Bd. 1, S. 207.

40 Angelus a Sancto Joseph OCD, Pharmacopoea persica ex idiomate persico in Latinum conversa. Opus missionariis, mercatoribus, caeterisque Regionum Orientalium Lustratoribus necessarium; nec non Europaeis Nationibus perutile. Accedunt in fine Specimen notarum in Pharmacopoeam Persicam; tum indices duo; alter Pharmaceuticus, compositiones in hoc opere contentas indigitans; alter pathologicus, remedia ad singulos morbos ostendens, Lutetiae Parisiorum [Paris] 1681, S. 22-24.

41 Notice historique sur J. F. Rousseau consul général de France à Bagdad, verfasst von AntoineIsaac Silvestre de Sacy, nicht datiert [zwischen 1808 und 1814] (MAE, Personnel, $1^{\text {ère }}$ série nominative. Volumes reliés, Bd. 61, fol. 188r-202v, hier: fol. 191r).

42 [P. Tadeusz Juda Krusinski, SJ], Informatio de missionibus persicis, ohne Datum [1727] (ARSI, Fondo Gesuitico, 720 II, Nr. 9). 
Rom, welche sich außerstande sah, die Subsidien der Missionare nach Persien zu senden. Jacques Rousseau, der als »reicher Kaufmann « beschrieben wurde, wollte seinerseits angesichts der vielfältigen Gefahren zumindest einen Teil seiner Ersparnisse nach Genf in Sicherheit bringen. Zugleich musste er einen Weg finden, um Lieferungen aus Genf zu bezahlen. Wechsel, die seinem Bruder Jean-François in Genf auszuzahlen waren, boten Jacques eine einigermaßen sichere Möglichkeit des Geldtransfers, die zudem mit einem Zinsgewinn verbunden war. Zwischen 1722, dem Jahr der Belagerung und Eroberung Isfahans durch die Afghanen, und 1731, dem Todesjahr von Barnaba Fedeli da Milano, gewährte Jacques Rousseau dem Bischof in mehreren Raten Kredite in Höhe von 1050 scuditi ${ }^{43}$.

Solche Gänge zu einem nichtkatholischen Kreditgeber waren zumindest der Kurie gegenüber erklärungsbedürftig: »Bei keinem anderen Kaufmann, auch wenn er katholisch sei«, finde er die »Feinheit«, die »Liebe« und den »großen Vorteil des Wechsels«, womit ihn Jacques Rousseau »begünstige«, rechtfertigte Bischof Fedeli 1728 gegenüber dem Präfekten der Propagandakongregation die wiederholte Kreditaufnahme bei einem Protestanten ${ }^{44}$.

Die Kredite eines Genfer Uhrmachers und Kaufmanns zugunsten eines katholischen Bischofs überraschten in Isfahan weniger als in Rom. In der Geschichte der katholischen Missionen im Safavidenreich hatten überkonfessionelle Kreditbeziehungen auch schon zuvor eine wichtige Rolle gespielt. So schoss der Hauptmann der niederländischen Ostindiengesellschaft, Nicolaas Jacobsz Overschie, Geld vor, als die Kapuziner, deren Mission in Isfahan 1628 von Frankreich aus gegründet wurde, ein eigenes Haus kauften. Zurückbezahlt wurden die Kredite von der französischen Krone ${ }^{45}$. Nicolaas Schorer, der Hauptmann des Kontors der niederländischen Ostindiengesellschaft in Isfahan, half in den 1720er Jahren den Not leidenden Jesuiten mit Almosen und lud sie sonntags an seinen Tisch ein, damit sie wenigstens einmal pro Woche reichlich essen konnten. Pater Krusinski zufolge mussten sich die Jesuiten in Isfahan sonst ausschließlich von Brot, Wasser und Hülsenfrüchten ernähren ${ }^{46}$.

43 P. Barnaba Fedeli an Vincenzo Kardinal Petra, Präfekt von »Propaganda Fide«, Neu-Djulfa, 6.10 .1728 (APF, SC. Mesopotamia, Persia, Caldei, Bd. 3, 554r); Gian Antonio Fedeli an Vincenzo Kardinal Petra, Präfekt von »Propaganda Fide«, Mailand, 23.4.1732; Jean-François Rousseau an Graf Fedeli, Genève, 25.8.1731 (APF, SC. Mesopotamia, Persia, Caldei, Bd. 4, fol. 550r/v, 551r/v).

44 P. Barnaba Fedeli di Milano OP an Vincenzo Kardinal Petra, Präfekt von »Propaganda Fide«, Neu-Djulfa, 6.10.1728: »Questo mercante mi hà favorito altre volte, come mi favorisce adesso con finezza, con amore, e con grande vantaggio del cambio ancora, ciò che non si ritrova in alcun'altro mercante, benche cattolico [...]«. (APF, SC. Mesopotamia, Persia, Caldei, Bd. 3, 554r).

45 Richard, Raphaël du Mans, Bd. 1, S. $23 f$. 
Als Jacques Rousseau 1753 starb, war er einer der wenigen Europäer, die noch in Isfahan und Neu-Djulfa verblieben waren. 1754 sah der nun sechzehnjährige, 1738 geborene Sohn von Jacques Rousseau und Reine de l'Étoile, Jean-François-Xavier, für sich in Isfahan keine Zukunft mehr und flüchtete deshalb nach Bandar Abbas. 1761 wurde Jean-François-Xavier Rousseau zum Agenten der Compagnie des Indes in Basra ernannt, der die Familie seiner Mutter seit den ersten Verhandlungen in Isfahan über die Eröffnung einer Faktorei in Bandar Abbas in den 1660er Jahren verbunden war ${ }^{47}$. Im gleichen Jahr heiratete er in der Kirche der dortigen Karmelitenmission eine Armenierin $^{48}$, die allerdings bereits zwei Jahre später starb. Dem Eintrag im Bestattungsregister der Karmelitenmission in Basra zufolge schien die Frau bei der Heirat die katholische Religion ihres Ehemannes angenommen zu haben. Deshalb wurde sie 1763 im Hof der Mission bestattet. Erst drei oder vier Tage nach ihrem Tod habe man bemerken können, dass sie »in den Prinzipien ihrer häretischen Religion« (in heretice sue Religionis principiis) gestorben sei. Dies hielt der Karmelit, der den Eintrag erstellte, zur Rechtfertigung der katholischen Bestattung fest ${ }^{49}$. So unwissend bezüglich der religiösen Zugehörigkeit der Frau dürfte der Pater allerdings nicht gewesen sein, hatte er doch selbst im Jahr zuvor bei der Taufe der ersten Tochter des Paares, Maria-Theresia-Regina, den Vater als »catholicus« und die Mutter als »armena « - nicht etwa als »armena catholica « - bezeichnet ${ }^{50} .1771$ heiratete Rousseau ein zweites Mal; nun waren laut dem Eheregister beide Ehegatten »latini ritus $\ll^{51}$. Einmal mehr erweist sich indessen die Kontextabhängigkeit solcher Zuschreibungen, stammte die Gattin, Anne-Marie Sahid, Tochter eines Dolmetschers der niederländischen Ostindischen Gesellschaft in Isfahan, doch aus einer syrisch-katholischen Familie ${ }^{52}$.

Obgleich die Karmeliten in Basra Rousseau selbst als Katholiken wahrnahmen, lebte auch er in konfessionellen und im weiteren Sinn kulturellen Grenzlagen. Im späten 18. Jahrhundert wurde Jean-François-Xavier Rousseau von seinen französischen und Genfer Verwandten und Bekannten gemeinhin als »Rousseau le Persan« oder »Rousseau de Perse« bezeichnet. Als er 1780 bei seinem einzigen Aufenthalt in Europa nach Paris reiste, befriedigte er mit seiner Kleidung und seinem Auftreten die »orientalistischen« Erwartungen seiner französischen Zeitgenossen. Auf der Grundlage der Er-

46 [P. Tadeusz Juda Krusinski SJ], Informatio de missionibus persicis, ohne Datum [1727] (ARSI, Fondo Gesuitico, 720 II, Nr. 9).

47 Anne Mézin, Les consuls de France au siècle des Lumières (1715-1792), Paris 1997, S. 528.

48 [Index matrimoniorum], 1755-1811, Eintrag vom 29.1.1761 (Nr. 15) (AOCD, 484/b).

49 [Index defunctorum], 1755-1816, Eintrag vom 27.2.1763 (Nr. 67) (AOCD, 484/c).

50 [Index baptizatorum], 1755-1843, Eintrag vom 28.4.1762 (Nr. 87) (AOCD, 484/a).

51 [Index matrimoniorum], 1755-1811, Eintrag vom 19.11.1771 (Nr. 44) (AOCD, 484/b).

52 Richard, Raphaël du Mans, Bd. 1, S. 28, $256 f$. 
innerungen seines Vaters beschrieb Stanislas de Girardin »Rousseau le Persan« folgendermaßen:

Il portait le costume persan qui consistait en un mouchoir roulé autour de la tête en forme de turban, une grande robe-de-chambre avec des culottes fort larges; des espèces de bottines de maroquin jaune et une ceinture autour du corps qui lui servait à mettre un poignard. Il avait des moustaches, le teint fort basané, comme presque tous les Orientaux, et, dans les yeux, une ressemblance frappante avec Jean-Jacques ${ }^{53}$.

Jean-François-Xavier pflegte ganz bewusst sein Bild als »Rousseau de Perse«, um auf diese Weise seine Fähigkeiten bei der Vermittlung von Beziehungen in einem fremden Umfeld herauszustreichen und auch seinen kommerziellen Projekten Glaubwürdigkeit zu verleihen. Nicht zufälligerweise unterzeichnete er die Briefe an Pierre-Michel Hennin, dessen Protektion entscheidend zu seiner Ernennung zum französischen Konsul in Basra (1781) beitrug, als $»$ Rousseau de Perse $\ll^{54}$.

Obwohl weder sein Vater noch er selbst zwischen 1699 und 1780 je nach Europa zurückgekehrt waren, blieben Beziehungen nach Genf erhalten. 1780 wurde Jean-François-Xavier als Verwandter des Philosophen empfangen. Man bemerkte die Ähnlichkeit ihrer Gesichtszüge und beehrte »Rousseau le Persan« mit Belegexemplaren der vier Bände der ersten Lieferung der Oeuvres Complètes seines illustren Verwandten ${ }^{55}$. Schon zuvor hatte Jean-FrançoisXavier verwandtschaftliche Beziehungen in Genf mobilisiert, um seine Geschäfte zu finanzieren oder Protektion zu finden. 1773 setzte sich Théodore Rousseau beim Résident des Königs von Frankreich in Genf, dem bereits genannten Pierre-Michel Hennin, für seinen Vetter zweiten Grades (cousin germain) ein, der damals in Basra lebte. Hennin sollte beim Marineministerium vorstellig werden, damit Jean-François-Xavier zum Nachfolger des verstorbenen Konsuls in Basra ernannt würde ${ }^{56}$. Zuvor hatte Jean-FrançoisXavier seinem Vetter Théodore immer wieder über sein Leben in Basra

53 Souvenirs de Stanislas de Girardin [1825], ediert in: Correspondance complète de Jean Jacques Rousseau, Edition R. A. Leigh, Bd. 40: Janvier 1775-juillet 1778, Oxford 1982, S. 369. Siehe ebd., Bd. 45: 1781-1788, Oxford 1986, S. 59.

54 »Rousseau de Perse« [Jean-François-Xavier Rousseau] an Pierre-Michel Hennin, Paris, 3.1., 23.3., 11.4., 9.7. und 25.12.1781, 14.6.1782, Bagdad, 20.5.1783 (Bibliothèque de l'Institut de France, Ms. 1275: Papiers et correspondance de Pierre-Michel Hennin, Bd. 56, fol. 200r-202r, 204r/v, 207r, 210r-211r, 214r-215v).

55 Correspondance complète de Jean Jacques Rousseau, Edition R. A. Leigh, Bd. 44: Septembre 1779-décembre 1780, Oxford 1985, S. 243; René-Louis, marquis de Girardin, à François d'Ivernois, [Ende Februar/Anf. März 1781], ediert in: Ebd., Bd. 45: 1781-1788, Oxford 1986, S. $6-8$.

56 Théodore Rousseau an Pierre-Michel Hennin, Genève, 26.11.1773 (Bibliothèque de l'Institut de France, Ms. 1275: Papiers et correspondance de Pierre-Michel Hennin, Bd. 56, fol. 194r-195r). 
und in Persien berichtet ${ }^{57}$. Jacques Rousseau und sein Sohn Jean-FrançoisXavier waren beide auf ihre Weise erfolgreiche Makler interkultureller Beziehungen. Die konfessionellen Grenzlagen, in welchen sie sich zeitlebens bewegten, waren charakteristisch für die europäischen Diasporen in Persien, im Osmanischen Reich und in den Regentschaften des Maghreb. Dies gilt sowohl für die Heirat des Calvinisten Jacques Rousseau mit einer katholischen Frau, die ihrerseits auf eine calvinistische und armenische Familiengeschichte zurückblickte, als auch für die beiden Ehen des bei den Jesuiten in Neu-Djulfa erzogenen Jean-François-Xavier, zuerst mit einer Armenierin und dann mit einer syrischen Katholikin.

\section{Gemeinchristliche Diasporareligiosität und konfessionelle Grenzziehungen}

In der persischen Diaspora teilte sich eine kleine Zahl europäischer Christen unterschiedlicher Konfession gemeinsame soziale Räume. Die Fremdheit der muslimischen Umgebung ließ Menschen zusammenrücken, die in Europa durch den Konfessionsunterschied voneinander getrennt gewesen wären. Schon bei der Anreise kamen die katholischen Missionare vielfach mit »Häretikern« in Kontakt. So begab sich der Karmelit Eliseus a Sancto Andrea 1625 auf einem niederländischen Schiff von Genua nach Iskenderun. Zwischen Aleppo und Isfahan teilte er dann die Gesellschaft zweier französischer Hugenotten ${ }^{58}$. John Fryer, Arzt der East India Company, reiste Anfang des Jahres 1678 in Begleitung eines Karmeliten von Isfahan nach Gombroon am Persischen Golf. Bei der Rückreise nach Isfahan im Frühjahr des gleichen Jahres unterbrach er die Reise in Shiraz, um als Arzt den Visitator der Karmeliten zu pflegen. Die Weiterreise nach Isfahan unternahm er in Begleitung eines reichen Kaufmanns, eines Dominikaners und eines Karmeliten $^{59}$.

In den Berichten der Missionare werden immer wieder die Hilfeleistungen ansässiger englischer oder niederländischer Kaufleute gegenüber muslimischen Obrigkeiten erwähnt. Aufschlussreich ist diesbezüglich etwa der Itinerario Orientale, den der Karmelitendonat Franciscus Maria a Sancto Siro nach seiner Rückkehr aus Persien 1706 in Wien verfasste. Der Verfas-

57 Auszüge aus Briefen von Jean-François-Xavier an Théodore Rousseau, Shiraz, 15.7.1768, Basra, 23.5.1770 und 10.6.1773 (Bibliothèque de l'Institut de France, Ms. 1275: Papiers et correspondance de Pierre-Michel Hennin, Bd. 56, fol. 195r-196v).

58 P. Eliseus a Sancto Andrea OCD an den Ordensgeneral in Rom, Isfahan, 27.5.1625 (AOCD 236/b/48).

59 John Fryer, A New Account of East India and Persia Being Nine Years Travels, 1672-1681, Edition William Crooke, Bd. 2, London 1912, S. 320, 344, 346. 
ser schildert, wie er und seine Reisegefährten auf dem Weg nach Persien in Erzurum die Protektion eines nichtkatholischen Engländers, $\mathbf{M}^{\mathrm{r}}$ Prescot, genossen, der dort Aufgaben als Konsul wahrnahm. Unmittelbar nach ihrer Ankunft in der Stadt habe er sie besucht und ihnen einen großen Hammel geschenkt. Der Engländer sei anderer Religion und dennoch der Protektor der durchreisenden Missionare gewesen, stellte der Donat fest. Prescot habe ihnen gegenüber den Türken geholfen, sie in seinem Haus aufgenommen und mit Geld für die Weiterreise unterstützt. Er habe alles getan, was der frömmste Katholik hätte tun können:

Era questo signore di differente religione della Cattolica Romana, contuttociò era il protettore de' Religiosi Missionarii, che passano per quella città. Li aiutava nelle vessazioni che li Turchi li fanno, li nascondeva in sua Casa, li sovveniva di denari, se gli mancavano per il viaggio, in somma faceva quello, che potesse fare il più pio cattolico $^{60}$.

Bei der Ankunft in Isfahan schuldete man sich innerhalb der kleinen europäischen Diaspora gegenseitige Höflichkeitsbezeugungen in Form von Besuchen und Gegenbesuchen, die seitens der Laien vielfach mit der Übergabe von Geschenken an die Geistlichen verbunden waren. In den Missionarsberichten leuchtet immer wieder das Bewusstsein auf, dass es sich um diasporaspezifische Formen überkonfessionellen Umgangs handelte. So schrieb der Jesuit Claude-Ignace Mercier 1672 dem assistant de France seines Ordens in Rom, in Europa sei er von den Häretikern noch bedroht worden, in Persien hingegen begegneten diese den Patres mit »toutes sortes de caresses«. Bei der Ankunft hätten sie ihm einen aus Europa importierten Käse geschenkt, und seither habe er oft kleine Geschenke aus dem Ertrag ihrer Jagd und ihres Fischfangs erhalten ${ }^{61}$. In einem 1730 gedruckten Reisebericht schrieb der Jesuit Jacques Villotte den »bontés«, mit denen ihn die Missionare aller Orden, die Franzosen im Dienste des Schahs und die englischen und niederländischen Kaufleute empfingen, und den »offices de charité« aller am persischen Hof anwesenden Europäer seine rasche Erholung von den Strapazen der Reise $\mathrm{zu}^{62}$. Umgekehrt erwähnt auch der Engländer William Hedges, der erste Gouverneur der East India Company in Bengalen (1681-1684), wie er 1685 am Tag nach seiner Ankunft in Isfahan von den Karmeliten und Domi-

60 Fr. Franciscus Maria a Sancto Siro OCD, Itinerario Orientale in cui si contengono varie notizie della Turchia, della Persia, di una gran parte delle Indie. Fatto, e composto da un Religioso Converso dell'Ordine de' Carmelitani Scalzi, che, come testimonio di veduta fedelmente l'addita, Mss., datiert S. 712: »Scritto in Vienna d'Austria l'anno 1706, e rescritto in Milano l'anno 1713« (Biblioteca Apostolica Vaticana, Borgiani Latini 317), S. 75.

61 P. Claude-Ignace Mercier SJ an P. Claude Boucher, »assistant de France $«$ in Rom, Isfahan, 28.2.1672 (ARSI, Gallia, 97 II, Dok. 127, fol. 350r).

62 Jacques Villotte SJ, Voyages d'un missionnaire de la Compagnie de Jésus en Turquie, en Perse, en Arménie, en Arabie, et en Barbarie, Paris 1730, S. 131. 
nikanern besucht worden sei; in den folgenden Tagen erwiderte Hedges die Besuche ${ }^{63}$.

Auf die Antrittsbesuche folgten Einladungen zu Banketten. Nachdem der Karmelit Leander a Sancta Caecilia 1737 die Besuche der in Isfahan anwesenden Missionare seines eigenen und der anderen Orden empfangen hatte, wurde er vom Vikar seines Ordens zum gerade in der Stadt anwesenden Gesandten des Zaren und zum niederländischen Faktor geführt, die ihn beide »con molta dimostrazione d'affetto« empfangen hätten. Für den Sonntag danach lud der russische Gesandte alle Missionare zu einem Gastmahl ein, bei dem er auf die Gesundheit des Papstes und des Bischofs von Isfahan, des Karmeliten Philippus Maria a Sancto Augustino, trank ${ }^{64}$.

Einladungen gingen nicht ausschließlich von den Laien aus. Wenn die Missionare aus Anlass eines Kirchenfestes zu einem convivium einluden, nahm der Austausch von Höflichkeiten einen religiösen Ton an, der von den Beteiligten durchaus vermerkt wurde, in der Diasporasituation jedoch kein Hindernis für einen »gutfreundschaftlichen« Umgang war. So schildert Adam Olearius in seiner Beschreibung der Persienreise der Gesandtschaft Friedrichs III. von Schleswig-Holstein-Gottorf, wie die Gesandten mit ihrem gesamten Gefolge, außerdem ein Russe, ein »armenischer Erzbischof mit etlichen Priestern « und die englischen Kaufleute von den »Catholischen Spanischen München, Herrn Patern Augustiner Ordens« 1637 zur Feier der Geburt Marias und einem Gastmahl eingeladen wurden und diese Einladung auch annahmen. »Unter den Unchristen« überbrücke die Gemeinsamkeit des »Christlichen Namens« die konfessionellen Unterschiede, welche die Gastgeber und ihre Gäste in Europa voneinander getrennt hätten:

Dann obwol diese Nationen an ihren Orten in der Christenheit der Religion halber einander nicht gerne leiden muegen, hielten sie doch allhier unter den Unchristen wegen des Christlichen Namens zusammen und pflogen zimlich gute Freundschafft unter einander.

Zu dieser »guten Freundschaft « gehörte, dass die Augustiner die lutherischen Gesandten und ihr Gefolge sogar zur Messe in ihre Kirche einluden - ein offensichtlicher Verstoß gegen das römische Verbot der communicatio in divinis. Olearius beschreibt, wie sie von den Patres »im ganzen Collegio« »freundlich « empfangen und »zuerst in die Kirche ihre Messe beyzuwohnen geführet« wurden. Nach dem Gottesdienst wurden die Gäste zu einer Mahlzeit mit »sehr wol zugerichteten« Speisen geladen. Anschließend habe

63 R. Frederick Barlow, The Diary of William Hedges during his Agency in Bengal, as well as on his voyage out and return overland (1681-1687), Bd. 1, London 1887, S. 210.

64 Leander a Sancta Caecilia OCD, Persia ovvero secondo viaggio di F. Leandro di Santa Cecilia Carmelitano Scalzo dell'Oriente. Scritto dal medesimo e dedicato a Sua Altezza Serenissima il Principe Carlo Arciduca d'Austria, Roma 1757, S. 182 f. 
man »die übrige Zeit des Tages mit gutem Gespräch und lustiger Music« im »schönen Lustgarten« des Klosters zu Ende gebracht. Am 1. Oktober 1637 luden die schleswig-holsteinischen Gesandten selbst zu einem »fürstlichen Bankett«: Gäste waren der Kalantar (Vorsteher) der armenischen Gemeinde mit seinen beiden Brüdern, die »fürnembsten der Englischen Compagnie«, »etliche Franzosen«, die »spanischen Augustiner« und »etliche italienische Carmeliten-Münche $\ll^{65}$.

In jeder Missionssituation stellte sich die Frage, wie weit auf die lokalen soziokulturellen Normen und Praktiken einzugehen war. Im Extremfall konnte es zu einer weitgehenden Integration in fremde soziale Systeme, das heißt zu einer Art soziokultureller Konversion der Missionare, kommen. Besonders bekannt ist diesbezüglich das Beispiel der Jesuiten in China, wo die Patres in der Verbindung mit einheimischen literati geachtete Positionen bei Hofe erlangten ${ }^{66}$. Folgt man dem Zeugnis der Briefe von Pietro della Valle an seinen Freund Mario Schipano in Neapel, wurde unter den Katholiken in Isfahan die Frage nach der Zulässigkeit sozialer Kontakte mit »Häretikern« durchaus gestellt. Im konkreten Fall ging es um den Engländer Edward Connok, der 1617 im Auftrag seines Königs und der East India Company am Hof von Schah Abbas I. Handelsprivilegien aushandelte, welche die Stellung der Portugiesen in Persien untergraben sollten. Man habe sich dafür entschieden, den Gesandten zu besuchen und mit ihm freundlich zu verkehren, weil die vor einem »ungläubigen « Herrscher offen zur Schau gestellte Zwietracht dem Ruf der Christen geschadet hätte. Neben den konfessionsübergreifenden $\mathrm{Zu}-$ sammenhalt als Christen in einem muslimischen Umfeld trat in diesem Fall die Unterscheidung von religiöser und säkularer Existenz. Nach Pietro della Valle wollte man dem Schah zeigen, dass man trotz des religiösen Dissenses im zivilen Umgang Einigkeit bewahrte: »E che era per ciò assai meglio, per ben comune, mostrare, al Rè di Persia, che se ben discordavamo nella vera Religione; nel resto tuttavia, e nelle cose civili, eravamo uniti e d'accordo«. Pietro della Valle verwies zur Rechtfertigung auf den Zusammenhalt von Katholiken und »Ketzern« im Osmanischen Reich, wo die englischen und

65 Adam Olearius, Vermehrte Newe Beschreibung der Muscowitischen und Persischen Reyse, so durch Gelegenheit einer Holsteinischen Gesandschaft an den Russischen Zaar und König in Persien geschehen, Schleswig 1656, S. 513f., 518.

66 Als Überblickswerk zur christlichen Chinamission siehe Nicolas Standaert (Hg.), Handbook of Christianity in China, Bd. 1: 635-1800, Leiden 2001. Zur Chinamission der Jesuiten siehe u.a. Liam Matthew Brockey, Journey to the East. The Jesuit Mission to China, 1579-1724, Cambridge (MA) 2007; Jean-Pierre Duteıl, Le mandat du Ciel. Le rôle des jésuites en Chine, Paris 1994; Daniel E. Mungello, Curious Land. Jesuit Accommodation and the Origins of Sinology, Stuttgart 1985. Zu wissenschaftlichen Vermittlungsleistungen der Patres siehe z.B. Catherine Jami/Hubert DelahaYe, L'Europe en Chine. Interactions scientifiques, religieuses et culturelles aux XVII et XVIII ${ }^{e}$ siècles, Paris 1993. 
niederländischen Gesandten den Jesuiten nicht als Feinde gegenüberträten, sondern sich als erste für sie einsetzten ${ }^{67}$.

In allen Orden stellte sich ein mehr oder weniger ausgeprägtes Spannungsverhältnis zwischen jenen ein, die auf buchstabengetreue Regelobservanz pochten, und jenen, die Abweichungen davon unter Berufung auf ihre Landeskenntnisse als unumgänglich rechtfertigten. So begründete der Jesuitenpater Jacques Tilhac 1700 seine Bitte an den Ordensgeneral, ihm die Erlaubnis seines Provinzials zur Rückkehr in seine Ordensprovinz zu verschaffen, damit, dass in Isfahan und Neu-Djulfa kaum missionarische Erfolge verzeichnet werden könnten und sich die ansässigen Katholiken den Geboten der römischen Kirche entzögen. Die Integration der Missionare in eine überkonfessionelle Soziabilität wertete Jacques Tilhac als Gegensatz zu ihrem kirchlichen Auftrag: Statt mit missionarischer und seelsorgerischer Arbeit verbrächten die Geistlichen einen guten Teil ihrer Zeit damit, andere Europäer zu besuchen. Selbst jene, die nicht so viel Zeit zu verlieren hätten, könnten sich dieser Verpflichtung nicht immer entziehen. Bei diesen Besuchen werde nach der Sitte des Landes viel gegessen und getrunken. Dazu kämen die Gastmähler der Missionare selbst aus Anlass der Ordens- und Kirchenfeste oder bei Gesandtschaften. Man sage, mit diesen Besuchen und Versammlungen werde die Nächstenliebe (la charité) unterhalten, doch die wahre Nächstenliebe eines Missionars, das heißt die Liebe Gottes (l'amour de Dieu) und die Sorge um das Seelenheil, pflege man kaum auf diese Weise. Eine lange Erfahrung zeige, dass die Besuche und Versammlungen bald »den ganzen inneren Geist eines Ordensgeistlichen« (tout l'esprit intérieur d'un religieux) ruinierten ${ }^{68}$.

In den Bettelorden wurde die Teilnahme an gesellschaftlichen Anlässen von Laien in besonderem Maße als Verstoß gegen das Armutsgebot wahrgenommen. So lässt die Korrespondenz der Visitatoren des Karmelitenordens deutliche Widersprüche zwischen den Erfordernissen eines weltabgewandten, kontemplativen und auf das Gebot der Armut festgelegten Lebens einerseits und den sozialen Gegebenheiten des Lebens in Isfahan und Neu-Djul$\mathrm{fa}$ - allgemein der durch die Mission vorgegebenen Notwendigkeit, soziale Kontakte zu pflegen - andererseits erkennen. Anlass, den Konvent zu verlassen, gebe es eigentlich selten; es genüge, einmal pro Woche nach Neu-Djulfa zu gehen, meinte beispielsweise 1677 ein Visitator. Völlig unangemessen sei es, wenn ein Karmelit außer Hauses mit Laien esse und trinke und an großen

67 Pietro della Valle an Mario Schipano, Isfahan, 18.12.1617, in: Pietro della Valle, Viaggi di Pietro della Valle il Pellegrino descritti da lui medesimo in Lettere familiari all'erudito suo Amico Mario Schipano. Parte seconda: La Persia, 2 Bde., Roma 1658, Bd. 1, S. 133-135 (Zitat: S. 134).

68 Denkschrift von P. Jacques Tilhac SJ. Beilage zu seinem Brief an P. Tirso González, Ordensgeneral, Isfahan, 27.12.1700 (ARSI, Gallia, 97 II, fol. 394r-395v). 
Banketten teilnehme. Einen Missstand sah er auch darin, dass die Karmeliten in Persien keine gemeinsame Hauswirtschaft hätten: Die Konventsoberen lebten in »großem Überfluss«. Viele suchten die Freundschaft von Laien, um sich besser zu versorgen; die Prioren behielten viele Geschenke einfach für sich, statt sie mit den übrigen Patres zu teilen. Infolgedessen reisten die einen als Ritter und die anderen als Bettler ${ }^{69}$. Durch solche Kritik ins Visier genommene Patres verwiesen einerseits unter Berufung auf ihre Landeskenntnisse und die geringe Erfahrung der aus Europa angereisten Visitatoren auf die sozialen Zwänge ihres Lebens in Persien, andererseits stellten sie die kritisierten Praktiken als insgesamt doch eher seltene Abweichungen von der strengen Einhaltung der Ordensregel dar ${ }^{70}$. Pater Angelus a Sancto Ioseph, Prior des Karmelitenkonvents von Isfahan, wehrte sich gegen den Vorwurf, »sich zum Freund der Laien « (se rendre ami des séculiers) zu machen, mit dem Hinweis, man müsse in Rom wissen, dass die Missionare seit mehreren Jahren in Persien nur noch geduldet würden, weil man sie mit den Handelsgesellschaften und deren Personal in Verbindung bringe ${ }^{71}$.

Aus der Perspektive der Missionare war die konfessionsübergreifende $\mathrm{Zu}-$ sammensetzung der Trauergemeinde - ein Hinweis auf die Sozialbeziehungen, welche der Verstorbene zu Lebzeiten gepflegt hatte - ein besonderes Zeichen für die Wertschätzung verstorbener Missionare ${ }^{72}$. Nach streng konfessionellen Kriterien hatte die Anwesenheit von Nichtkatholiken und ganz besonders jene nichtkatholischer Priester bei der Totenmesse als communicatio in divinis zu gelten. Als der Gründer und erste Superior der Jesuitenmission in Neu-Djulfa, Pater Aimé Chézaud, im September 1664 starb, sollen indessen dem Jesuitenpater Mercier zufolge neben den katholischen Ordensgeistlichen zahlreiche armenische Priester, drei oder vier armenische Vardapet $^{73}$ sowie ein Gesandter des Zaren mit seinem Gefolge der Totenmesse beigewohnt haben. An die Spitze des Trauerzuges zum christlichen Friedhof von Djulfa stellte sich nach dem Bericht von Pater Mercier eine Gruppe armenischer Priester, während die »häretischen Franzosen« zusammen mit den Engländern und Niederländern, zahlreichen armenischen Notabeln und

69 P. Joannes Baptista a Sancto Ioseph OCD an die »definitores generales« in Rom, Isfahan, 9.9.1677 (AOCD $236 / \mathrm{m} / 5$ ).

70 P. Angelus a Sancto Ioseph OCD an P. [Joannes Chrysostomus a Sancto Paulo, Ordensgeneral in Rom], Isfahan, 8.9.1675 (AOCD 236 / b / 19).

71 P. Angelus a Sancto Ioseph OCD an P. Joannes Chrysostomus a Sancto Paulo, »definitor « in Rom, Isfahan, 3.1.1673 (AOCD 236 / i / 23).

72 Auch aus dem syrischen Raum wird über Trauerzüge für Missionare berichtet, an denen Geistliche der verschiedenen Kirchen teilnahmen. Über das Begräbnis eines Karmeliten in Aleppo 1661 siehe Heyberger, Les Chrétiens du Proche-Orient, S. 61.

73 Im Brief ist die Rede von »évêques« (»Bischöfen«). Es handelte sich in Wirklichkeit wohl um so genannte Vardapet, d.h. besonders gebildete und angesehene Prediger mit Exkommunikationsgewalt. 
dem Gesandten des Zaren den Trauerzug hoch zu Pferde begleiteten ${ }^{74}$. Nach dem Tod des Kapuzinerpaters Valentin d'Angers im folgenden Jahr begleiteten neben den Karmeliten, Augustinern, Jesuiten und Kapuzinern auch »alle katholischen und häretischen Franken« (tous les Francs catholiques et hérétiques) den Trauerzug zum armenischen Friedhof von Neu-Djulfa ${ }^{75}$. Bei der Trauerfeier für den Kapuzinerpater Raphaël du Mans 1696 versammelten sich in der kleinen Kirche der Kapuziner neben den in Isfahan und Neu-Djulfa ansässigen katholischen Ordensgeistlichen auch der Kalantar der armenischen Gemeinde, zahlreiche armenische Notabeln sowie zwei Vertreter der englischen East India Company ${ }^{76}$. Einer der beiden ihn überlebenden Patres unterstrich in seinem Brief an den Guardian des Kapuzinerklosters in Le Mans, dass ihn »alle Europäer, Engländer, Holländer und andere Franken«, deren Handelsgesellschaften Raphaël du Mans »immer gute Dienste geleistet habe[n]«, ebenso wie die Armenier und Muslime geliebt hätten und nun vermissten $^{77}$.

74 Pater Claude-Ignace Mercier SJ an P. Nicolas de Sainte-Geneviève, Superior SJ in Konstantinopel, Neu-Djulfa, 25.1.1665: »En vérité, mon Révérend Père, on aurait dit que le père commun de tout Julfa était mort. [...] Les Révérends Pères Augustins, Capucins et Carmes m'aidèrent à réciter l'office des morts, [...] où assistèrent quantité de prêtres arméniens, et trois ou quatre de leurs évêques. [...] Nous étions déjà sortis de l'église, [...] quand trois ou quatre des principaux Arméniens vinrent me prier de trouver bon que le clergé assistât au convoi, avec leurs croix et leurs chapes, et d'arrêter un peu, pour leur donner le temps de nous joindre. Je ne leur dis pas que je refusais leur offre parce qu'ils étaient hérétiques, mais que je les remerciais, et qu'il n'était pas possible, étant déjà si tard, d'arrêter tant d'honnêtes gens. Par l'avis des autres religieux, nous voulions aller plus vite, mais la foule du peuple, qui remplissait les nefs, nous arrêtait, malgré que nous en fassions. [...] Nous ne pûmes donc pas empêcher qu'une troupe de prêtres, avec leur croix et leurs flambeaux, ne vînt nous couper chemin, et se mettre à la tête du convoi, chantant aussi bien que nous, tout le chemin, mais plus fortement, parce qu'ils étaient en plus grand nombre. Nos Français hérétiques, avec Messieurs les Anglais et Hollandais, y voulurent assister aussi à cheval, avec quantité des principaux Arméniens, ayant à leur tête l'ambassadeur de Moscovie. Ils ne fut pas jusqu'aux Turcs qui n'honorassent le Père. Plusieurs le vinrent visiter mort, et me témoigner le regret qu'ils en avaient comme aussi firent, le lendemain, les plus apparents de Julfa qui se trouvèrent dans notre maison. [...] Quand nous fûmes arrivés au lieu de la sépulture, un des plus grands de Julfa me pressa fort de lui accorder, disait-il, la grâce de lui permettre d'ensevelir le Père de leur nation, dans un beau sépulcre qu'il lui ferait dresser au milieu du grand bâtiment de brique qui semble un château, mais qu'il n'a fait bâtir que pour sa famille. Je ne voulus quitter le quartier des catholiques pour prendre celui-ci, et j'aimai mieux mettre le Père avec le P. de Rhodes et plusieurs autres religieux de divers ordres, comme il avait désiré, que d'accepter ce petit honneur devant le monde«. Ediert in: Antoine RabBath, Documents inédits pour server à l'histoire du christianisme en Orient, Paris 1905, S. 90f.

75 Relation de ce qui s'est passé dans les missions du Levant l'an 1665, écrite par F. Martial de Torigné, ediert in: Richard, Raphaël du Mans, Bd. 1, S. 162.

76 P. Séraphin d'Orléans OFM Cap an den Guardian des Kapuzinerklosters in Le Mans, 1.5.1696, und P. Jean-Baptiste de Montmoreau OFM Cap an John Gladman, Agent der »East India Company« in Bandar Abbas, Isfahan, 10.4.1696, in: Richard, Raphaël du Mans, Bd. 1, S. 8.

77 P. Séraphin d'Orléans OFM Cap an den Guardian des Kapuzinerklosters in Le Mans, 1.5.1696: »Il est mort [...] aimé et regretté de tous les Européens, Anglais, Hollandais, et au- 
Worin die »guten Dienste « eines Ordensgeistlichen gegenüber Laien verschiedener Konfession bestehen konnten, ist im Falle des Kapuziners Raphaël du Mans besonders gut dokumentiert. Als Dolmetscher und Übersetzer erwarb Pater Raphaël das besondere Vertrauen der drei Schahs, die während seines mehr als fünfzigjährigen Persienaufenthaltes von 1644 bis 1696 herrschten. Der Ausrichtung des Kapuziners auf die Kontakte mit der Hofgesellschaft und dem muslimischen Gelehrtenmilieu entsprachen seine hervorragenden Türkisch- und Persischkenntnisse. In seinem État de la Perse ${ }^{78}$ von 1660 trug der Kapuziner eine eindrückliche Fülle an Wissen über Glauben und Gebräuche der persischen Muslime zusammen. Der Reichtum der Bibliothek des Paters wurde von verschiedenen Reisenden gepriesen ${ }^{79}$. Landeskenntnisse und Beziehungen bei Hofe machten den Kapuziner zu einer bevorzugten Kontaktperson für Reisende unterschiedlicher Konfession. So pflegte der französische Hugenotte Jean-Baptiste Tavernier enge Beziehungen zu den Kapuzinern; bei seiner Abreise nach Indien hinterließ er 1665 den Patres zusammen mit einem niederländischen Kaufmann »ein gutes Almosen« als Dank für die Beziehungen, welche ihnen Pater Raphaël bei Hofe vermittelt hatte ${ }^{80}$. Seinen kleinen Neffen hatte Tavernier in Täbris in der Obhut des Kapuzinerpaters Gabriel de Chinon zurückgelassen, damit er ihm die türkische und persische Sprache beibringe ${ }^{81}$. Der eingangs zitierte Juwelenhändler Jean Chardin, ebenfalls ein französischer Hugenotte, genoss während seiner Aufenthalte in Persien in den Jahren 1666/67, 1669 und 16711677 mehrmals die Gastfreundschaft der Kapuziner. Als er während seines ersten Aufenthaltes im Kapuzinerhospiz wohnte, führte ihn Pater Raphäl bei gebildeten Muslimen ein, unter anderem bei einem Astronomen, der Astrolabien anfertigte. Der Kapuziner gewährte Chardin und wohl auch Tavernier Einsicht in sein Manuskript der Beschreibung Persiens. Nach dem letzten Aufenthalt Chardins in Isfahan pflegte der Pater den brieflichen Kontakt weiter. Chardin gab seinem Bericht über Persien, den er nach der Emigration im Gefolge der Aufhebung des Edikts von Nantes verfasste, zwar eine deutlich calvinistische Ausrichtung, wenn er die religiöse Duldsamkeit in Persien

tres Francs, auxquels il a toujours rendu de bons services pour leurs Compagnies établies en cette ville, et des Arméniens et Mahométans, qui en ont toujours dit des merveilles«. Zitiert in: Richard, Raphaël du Mans, Bd. 1, S. 7.

78 Siehe die Edition in: Ebd., Bd. 2, S. 1-199.

79 Siehe ebd., Bd. 1, S. 50-52.

80 Relation de ce qui s'est passé dans les missions du Levant l'an 1665, écrite par F. Martial de Thorigné, Isfahan 1665, ediert in: Ebd., hier: Bd. 1, S. 156. Über den Empfang Taverniers am persischen Hof und die Unterstützung des Paters siehe Jean-Baptiste TAVERNIER, Les six voyages de Jean-Baptiste Tavernier, [...] qu'il a faits en Turquie, en Perse, et aux Indes [...], Bd. 1, Paris 1676, S. 464-505.

81 Ebd., S. 471; Relation de ce qui s'est passé dans les missions du Levant l'an 1665, écrite par F. Martial de Thorigné, Isfahan 1665, ediert in: Richard, Raphaël du Mans, Bd. 1, S. 156. 
mit der Intoleranz im katholischen Frankreich verglich ${ }^{82}$. Der gleiche Chardin verfasste jedoch 1683 in Den Haag auch die approbation zum Druck des Gazophylacium linguae Persarum des Karmeliten Pater Angelus a Sancto Ioseph und lobte darin die Sprach- und Landeskenntnisse des ihm seit seinen Persienaufenthalten bekannten Karmeliten in hohen Tönen ${ }^{83}$.

Als der Engländer John Fryer, der als Arzt im Dienst der East India Company stand, 1677 für einige Wochen nach Isfahan kam, pries er wie Chardin die Qualität der Informationen, welche ihm Pater Raphaël du Mans vermittelte. Der Kapuziner sei nicht nur ein »heiliger Mann« mit einem beispielhaften Lebenswandel, sondern auch gelehrt und mit dem Land wohl vertraut. Im Gegensatz zu den meisten anderen Geistlichen forsche der Pater nicht nach den Grundlagen des Glaubens der Sterbenden, sondern empfehle diese mit ihrem eigenen Gewissen Gott ${ }^{84}$.

Der Niederländer Ludwig Fabritius, der in den 1680er Jahren zweimal als schwedischer Gesandter nach Isfahan kam, wurde von den Missionaren ebenfalls freundlich empfangen. Engeren Kontakt mit Raphaël du Mans knüpfte der Sekretär der schwedischen Gesandtschaft, Engelbert Kemper oder Kaempfer. Pater Raphaël, der von Kaempfer als »vir maximi candoris et eruditionis« bezeichnet wurde, pflegte den brieflichen Kontakt mit dem lutherischen Pastorensohn aus Lemgo in der Grafschaft Lippe noch mindestens zwei Jahre nach dessen Abreise im November 1685 weiter ${ }^{85}$. Pater Raphaël kam dem praktischen Informationsbedarf des Gesandtschaftssekretärs Kaempfer ebenso entgegen wie der curiositas des Universalgelehrten. Kaempfer erhielt auf diese Weise Informationen darüber, wie Anliegen der Gesandtschaft bei Hofe aufgenommen wurden, aber auch weitere Präzisierungen zu einer Kurzfassung der Beschreibung Persiens, die der Kapuziner 1684 auf der Grundlage seines État de la Perse eigens für ihn verfasst hatte. Für eine gewünschte Liste aller Schulen, Moscheen und Marktplätze Isfahans wandte sich Pater Raphaël seinerseits an einen schiitischen Geistlichen ${ }^{86}$.

82 Ebd., Bd. 1, S. 74-76, 98-101.

83 Souvenirs de la Perse safavide et autres lieux d'Orient (1664-1678) en version persane et européenne, traduits et annotés par Michel Bastiaensen, Bruxelles 1985, S. 17.

84 Fryer, A New Account of East India and Persia, S. 246f.: »And I must indeed confess some of them are not only holy men, but discreet and learned, the chief of whom is Father Raphael, a capuchin, who has lived exemplary among them many years, and is well acquainted with the country, from whom I must own I received the best and most authentic information. And this I speak knowingly of him, that he is no intruder on mens' principles, when about to depart this life, as most of them are, but recommends them to God with their own conscience«. Siehe Richard, Raphaël du Mans, Bd. 1, S. $106 f$.

85 Ebd., Bd. 1, S. 118-121.

86 Siehe dazu den Briefwechsel zwischen Kaempfer und dem Kapuzinerpater: Raphaël du Mans an Engelbert Kaempfer, [Isfahan], 22.9.1684, [Isfahan, wahrscheinlich Oktober 1684], [Isfahan], 13.10.[1684], [Isfahan], 8.10.1685, [Isfahan, nach März 1686], Isfahan, 6.6.1687, Isfahan, 
Mit seinen Vermittlungsleistungen trat Pater Raphaël in den Mittelpunkt einer Art »dritten Raumes«, in dem sein Ansehen weniger von der strengen Regelobservanz und der Beachtung der Direktiven der nachtridentinischen Konfessionskirche abhing als vielmehr von der Fähigkeit, immaterielle (und teilweise auch materielle) Ressourcen zu vermitteln. Deshalb mag es nicht überraschen, dass der bereits genannte Jesuitenpater Tilhac die von weltlichen Reisenden gelobten Beziehungen von Pater Raphaël du Mans mit Höflingen und Gelehrten als Beleg für das wenig regelkonforme Leben der Missionare in Isfahan und Neu-Djulfa anführte. Tilhac klagte, der Kapuziner habe mehr als fünfzig Jahre damit verbracht, mit einigen Herren des Hofes und Gelehrten Konversation zu pflegen. Auf die Vorwürfe der Propagandakongregation, er tue zu wenig für Gott und die Kirche, habe er entgegnet, es sei schon viel, dass er seinen Glauben noch nicht verloren habe ${ }^{87}$.

Pater Raphaël interessierte sich in der Tat wenig für die Armenier, die im Mittelpunkt der Missionstätigkeiten in Persien hätten stehen sollen. Obwohl er mehr als fünfzig Jahre in Persien tätig war, hielt er es nicht für notwendig, die armenische Sprache zu erlernen. Allerdings verstellen die Kriterien der Regelobservanz und der konfessionellen Norm den Blick auf die diasporaspezifischen seelsorgerischen Leistungen der Missionare. Wie dies die Aussagen von John Fryer über Pater Raphäls Verhalten bei der Sterbendenbegleitung bereits angedeutet haben, vermittelte dieser nicht nur Landeskenntnisse und Kontakte bei Hofe, sondern entsprach auch einer Nachfrage nach christlichen Ritualen, die wegen des Fehlens einer protestantischen kirchlichen Betreuung aus der strikten konfessionellen Festlegung herausgelöst wurden und deshalb von der Kurie vielfach als communicatio in divinis verurteilt wurden.

Auch in Isfahan und Neu-Djulfa stellten sich die Fragen der Taufe von Kindern nichtkatholischer Eltern und der Zulassung »häretischer« Taufpa-

10.7.1687; Engelbert Kaempfer an Raphaël du Mans, [vermutlich Isfahan, 1684], [Isfahan], 19.9.[1685], [Bandar Abbas, Herbst 1687], [Bandar Abbas], November 1687, [Bandar Abbas], 28.1.1688 (2 Briefe), Batavia, Oktober 1689, ediert in: Engelbert KAEMPFER, Briefe, 1683-1715, hg. v. Detlef Haberland, München 2001, S. 196f., 203-212, 218f., 230f., 245f., 250-252, 260-264, 286f., 299-302, 318-320. - Über Kaempfers Beschreibung Persiens siehe Stefan BraKENSIEK, Politische Urteilsbildung zwischen Empirie und Tradition. Der Persien-Bericht des Engelbert Kaempfer 1684/85, in: Sabine KLocke-Daffa/Jürgen Scheffler/Gisela Wilbertz (Hg.), Engelbert Kaempfer (1651-1716) und die kulturelle Begegnung zwischen Europa und Asien, Lemgo 2003, S. 93-124.

87 Denkschrift von P. Jacques Tilhac SJ. Beilage zu seinem Brief an P. Tirso González, Ordensgeneral, Isfahan, 27.12.1700: »Je me souviens à ce propos du fameux P. Raphaël Capucin, dont plus de cinquante années se sont passées ici à converser avec quelques seigneurs de la Cour, et quelques gens de lettres qui l'allaient voir. On lui écrivait de la Propaganda qu'on s'étonnait fort de ce qu'ayant autant de talents qu'il en avait, et étant aussi autorisé qu'il l'était dans ce pays, il faisait si peu pour la gloire de Dieu, et de son Église. Il leur répondit qu'il croyait y avoir fait beaucoup, puis qu'il n'y avait pas encore perdu la foi« (ARSI, Gallia, 97 II, fol. 395r). 
ten. 1658 hatte Propaganda Fide über ein Schreiben des Kapuziners Valentin d'Angers zu beraten, der die Nachteile schilderte, welche entstanden, wenn man die Protestanten nicht als Taufpaten zulasse: Die meisten von ihnen seien aufgrund ihrer Stellung im Dienst des Schahs oder ihrer Handelstätigkeiten mächtige Männer; wenn sie von der Ehre der Patenschaft ausgeschlossen würden, könnten sie der Mission viel Schaden zufügen. Gleiches galt für das Verbot von Mischehen; der Kapuziner berichtete diesbezüglich über den Fall eines Paares, das sich aufgrund des ablehnenden Bescheides des Bischofs von Babylon in der Kirche der Jakobiten trauen ließ; um sich für den Affront zu rächen, habe der protestantische Ehemann seiner Frau die Ausübung der katholischen Religion verboten, was er sonst nicht getan hätte. Wenn man die Mischehe zulasse, ließen die Protestanten ihre Gattinnen nach dem katholischen Ritus leben und die Kinder durch die Patres unterweisen ${ }^{88}$. Propaganda Fide und Heiliges Offizium waren dennoch in ihrer Ablehnung der Mischehe ebenso eindeutig wie in jener der Zulassung nichtkatholischer Taufpaten $^{89}$. In der Praxis bot allerdings die Unterscheidung zwischen der rechtlichen Gültigkeit einer Ehe einerseits und ihrer Unzulässigkeit andererseits beträchtliche Handlungsspielräume.

Propaganda Fide hatte sich 1658 nicht zum ersten Mal mit der Praxis zu befassen, »häretische« Patinnen und Paten zuzulassen. Eine einige Jahre früher ergangene Antwort der Kongregation fasste der Karmelit Cornelius a Sancto Cypriano mit den Worten zusammen, man sei erstaunt, dass die Missionare die Frage danach überhaupt gestellt hätten. Während sein Orden sich geweigert habe, hätten die Kapuziner und die Augustiner immer auch mit »häretischen« Paten und Patinnen getauft. Dies sei für die Karmeliten in ihrem Verhältnis zu Holländern, Engländern und Franzosen zur Ursache von Anfeindungen und Verdruss geworden. So hätten sie das Kind eines Niederländers nicht taufen wollen, obwohl ihnen dieser als Kryptokatholik bekannt gewesen sei, weil sie annahmen, er würde »Häretiker« als Taufpaten wählen. Der Niederländer reagierte heftig: Die Karmeliten seien in weltlichen Dingen rasch zur Stelle, »um Höflichkeit und Gnade entgegenzunehmen«, in geistlichen Angelegenheiten hingegen fürchteten sie »jede Art von Unbequemlichkeit«: »que in temporalibus nous étions bien prompts, et pour recevoir courtoisie et grâce, mais que in spiritualibus nous craignions toutes incommodités ${ }^{90}$. Die Vorgaben aus Rom standen in einem offensicht-

88 P. Valentin d'Angers OFM Cap an die Kardinäle von »Propaganda Fide«, Isfahan, 27.9.1657 (APF, SCOG, Bd. 238, fol. 56r/v).

89 »Congregazione generale« vom 6.8.1658 (APF, Acta, Bd. 27, fol. 217v-218r); P. Valentin d'Angers OFM Cap an den Präfekten von »Propaganda Fide«, Isfahan, 17.6.1660 (APF, SCOG, Bd. 238, fol. 64r).

90 P. Cornelius a Sancto Cypriano OCD an P. Isidorus a Sancto Ioseph, »definitor « in Rom, Isfahan, 10.1.1656 (AOCD 237 / a / 4). 
lichen Widerspruch zu den Beziehungen, welche die Missionare im Alltag mit Nichtkatholiken verbanden.

Da sich Protestanten in Isfahan und Neu-Djulfa in der Regel nicht an einen eigenen Pfarrer wenden konnten ${ }^{91}$, erwarteten sie von den katholischen Ordensgeistlichen, dass diese ihre Kinder tauften. Damit war keinerlei Absicht verbunden, sich zu bekehren oder die Kinder im katholischen Glauben zu erziehen. Um die konfessionelle Festlegung des Rituals abzuschwächen, zogen es die Eltern vor, die Taufen nicht in der Kirche, sondern im eigenen Haus stattfinden zu lassen. Gestützt auf die Moraltheologie Paul Laymanns wollten die Jesuiten in den 1720er Jahren dem Hauptmann des niederländischen Kontors, Nicolaas Schorer, und einem weiteren Niederländer einen solchen Gefallen tun, der auch als Erwiderung für die Überlebenshilfe verstanden werden konnte, die sie von den Niederländern damals erhielten. Bischof Barnaba Fedeli da Milano zeigte dafür kein Verständnis ${ }^{92}$. Ob er etwa hätte zulassen sollen, dass die Tochter eines »Häretikers « und dessen »türkischer Konkubine« im Elternhaus getauft würde, fragte der Dominikaner die Kardinäle der Propagandakongregation ${ }^{93}$. Wenn man dem Bischof Glauben schenkt, verweigerte er sich ganz allgemein dem Wunsch, Taufen in Privathäusern - auch in solchen von Katholiken - durchzuführen, außer wenn das Leben des Kindes in Gefahr sei. Viele Jahre vor seiner Ankunft habe ein Missionar, um den Niederländern einen Gefallen zu tun, ein Kind in deren Haus getauft ${ }^{94}$.

Ähnlich wie bei der Taufe stellte sich auch bei der Messe die Frage, ob diese in Privathäusern gefeiert werden dürfe. Messfeiern in Privathäusern waren ein zentrales Element jener zurückhaltenden Missionsstrategie, die die Jesuiten seit ihrer Niederlassung in Neu-Djulfa pflegten. Sie gewannen damit auch Zugang zu den Häusern von Protestanten, was je nach Standpunkt als Missionserfolg gefeiert oder als communicatio in divinis verurteilt wurde. Aus der Sicht eines Aimé Chézaud war es ein Erfolg, dass er an allen Sonnund Feiertagen im Haus des mit einer Katholikin verheirateten calvinistischen Kaufmanns Isaac Boutet de l'Étoile Messe lesen durfte. Messfeiern in Privathäusern der christlichen Vorstadt Neu-Djulfa wurden nach dem Vor-

91 Die Niederlassungen der englischen und der niederländischen Ostindiengesellschaft in Isfahan verfügten nur zeitweise über eigene Pfarrer. Siehe Lockhart, The Fall of the Safavi Dynasty, S. 78f. - So gehörte 1722 Reverend John Frost als Kaplan zum Personal der Faktorei der englischen »East India Company« in Isfahan. Er verließ Isfahan im April 1723 (ebd., S. 408, 415). In seiner Auflistung des Personals der niederländischen Faktorei im Jahre 1722 erwähnt Laurence Lockhart keinen Kaplan (ebd., S. 408).

92 Eszer, Barnaba Fedeli di Milano O.P, S. 247.

93 P. Barnaba Fedeli di Milano, O.P., an Giuseppe Kardinal Sacripanti, Präfekt von »Propaganda Fide«, Neu-Djulfa, 2.5.1726 (APF, SC. Mesopotamia, Persia, Caldei, Bd. 3, 552r).

94 P. Barnaba Fedeli di Milano OP an [Vincenzo Kardinal Petra], Präfekt von »Propaganda Fide«, Neu-Djulfa, 4.5.1727 (APF, SC. Mesopotamia, Persia, Caldei, Bd. 3, 543r/v). 
bild des Jesuiten auch von den Augustinern und dem Vikar des Bischofs von Babylon gefeiert ${ }^{95}$. Ebenso ist von den Karmeliten bekannt, dass sie in Privathäusern zelebrierten ${ }^{96}$. Dazu kam es insbesondere, wenn die Patres die Gastfreundschaft der englischen oder niederländischen Ostindiengesellschaften genossen. Obwohl diese Handelsgesellschaften protestantische Mächte vertraten, fanden sich unter deren Personal neben Protestanten auch katholische und orthodoxe Christen. Außerdem nahmen ihre Häuser teilweise Kaufleute unterschiedlichster Herkunft auf ${ }^{97} .1726$ zeigte Fedeli der Propagandakongregation einen Karmeliten an, der zusammen mit dem Agenten der englischen East India Company aus Bandar Abbas nach Isfahan gekommen war. Da er nicht zur Mission gehörte, wurde der Pater nicht im Haus seines Ordens aufgenommen. Stattdessen ließ er sich in der Faktorei der Engländer nieder. Unter dem Vorwand, dass sich im englischen Haus fünf oder sechs katholische französische Soldaten als Gefangene der East India Company aufhielten, nahm sich der Pater, so Bischof Fedeli, die Freiheit heraus, dort die Messe zu feiern. Gleiches habe er in der Faktorei der Niederländer und im Haus eines Muslims getan, in dem sich Christen aufhielten ${ }^{98}$.

Folgt man der Korrespondenz Fedelis mit Propaganda Fide, zögerten in den 1720er Jahren vor allem die Jesuiten nicht, der Nachfrage der ansässigen Protestanten nach christlichen Ritualen entgegenzukommen. Die Jesuitenmissionare von Neu-Djulfa und ihr Superior widersetzten sich denn auch ebenso wie die Karmeliten ${ }^{99}$ offen den Anordnungen von Bischof Barnaba Fedeli gegen das Feiern von Messen in Privathäusern. Bei den Auseinandersetzungen zwischen dem Bischof und den Patres ging es einerseits um die Praxis als solche, andererseits um das Recht des Bischofs, über deren $\mathrm{Zu}$ -

95 P. Aimé Chézaud SJ an P. »assistant de France« in Rom, Isfahan, 16.12.1661 (ARSI, Gallia, 97 II, Dok. 111, fol. 321r).

96 Copia della risposta fatta da Monsignore Barnaba vescovo d'Haspan alla reclamazione del P. Fr. Filippo Maria di San Agostino Carmelitano Scalzo sopra la censura fatta dal detto Monsignore al sudetto Padre circa il celebrar la messa fuori della chiesa (AOCD 236 / b / 7).

97 Im Haus der niederländischen Gesellschaft in Lar fand Jean de Thévenot neben protestantischen auch katholische und armenische Kaufleute vor. Siehe Jean DE ThÉvenot, Voyages de Mr. de Thévenot en Europe, Asie, Afrique, Bd. 4, Amsterdam ${ }^{3} 1727$, S. 461. Ebenso beschreibt della Valle, wie die Engländer in Isfahan einen gebürtigen Schotten als »gentiluomo della lor natione « anerkannten, obwohl dieser sich öffentlich zum Katholizismus bekannt habe. Die Engländer seien zwar meist keine Katholiken, hätten aber gewollt, dass der Neuankömmling bei ihnen wohne und in ihren Dienst eintrete. Siehe Pietro della Valle an Mario Schipano, Combrù, 29.11.1622, in: Della Valle, Viaggi di Pietro della Valle il Pellegrino, Bd. 2, S. 493-495.

98 P. Barnaba Fedeli di Milano OP an Giuseppe Kardinal Sacripanti, Präfekt von »Propaganda Fide«, Neu-Djulfa, 2.5.1726 (APF, SC. Mesopotamia, Persia, Caldei, Bd. 3, 550r). Siehe Cніск, A Chronicle of the Carmelites in Persia, Bd. 1, S. 588.

99 Dazu Copia della risposta fatta da Monsignore Barnaba vescovo d'Haspan alla reclamazione del P. Fr. Filippo Maria di San Agostino Carmelitano Scalzo sopra la censura fatta dal detto Monsignore al sudetto Padre circa il celebrar la messa fuori della chiesa (AOCD 236 / b / 7). 
lässigkeit zu befinden. 1724 begann Fedeli zufolge ein Jesuit regelmäßig im Haus der niederländischen syrisch-katholischen Dolmetscherfamilie Sahid ${ }^{100}$ Messe zu feiern. Er habe dies dem Pater zunächst zugestanden, weil dieser behauptete, die gebrechliche Mutter der Dolmetscher befinde sich ebenfalls im Haus. Dann habe er allerdings erfahren, dass dies nicht mehr zutreffe, das Haus sehr eng sei und die Messe in einem Raum gefeiert werde, der sonst benutzt wurde, um sich zu versammeln, zu essen, zu trinken, zu spielen und zu schlafen. Schließlich hörte Fedeli, dass auch der Hauptmann der Niederländer in zahlreicher Gesellschaft von Mitgliedern seines Hauses und »anderer schismatischer Armenier« den Feiern beiwohne. Außerdem hätten die Jesuiten auf Einladung der Dolmetscher auch an Werktagen die Messe gefeiert. Ein Brief des Bischofs hielt den Superior der Jesuiten, Pater Lagarde, nicht davon $a b$, weiter zu den niederländischen Dolmetschern zu gehen. So habe Lagarde nicht nur an Allerseelen, sondern auch am folgenden Tag in deren Haus Messe gefeiert, nachdem er nachts »fröhliche Konversation« mit fünfzehn oder sechzehn Laien, »Schismatikern« und »Häretikern« gepflegt habe, die zusammen gegessen, getrunken, gelacht und dann nach Landessitte alle durcheinander geschlafen hätten. Von Propaganda Fide wollte der Bischof wissen, ob er diesen »Ungehorsam« weiterhin dulden solle, der aus der Sicht der Ordensgeistlichen gar keiner war, weil sie beanspruchten, nicht von der Jurisdiktion des Bischofs abzuhängen. Sollte er zulassen, dass selbst die österliche Kommunion in den Häusern von Laien gespendet werde, und dies nicht nur Katholiken, sondern auch »Häretikern«? Entgegen diesem konfessionellen Diskurs wäre Bischof Fedeli bereit gewesen, die Messfeiern im Haus der niederländischen Dolmetscher und in Anwesenheit von Nichtkatholiken zu dulden, wenn die Familie Sahid wenigstens »einen kleinen Gebetsaal, oder eine kleine abgetrennte Kapelle« (un piccolo oratorio, o una piccola cappella propria, e segregata) eingerichtet hätte. Dies jedoch sei nicht geschehen $^{101}$.

Hintergründig ging es Fedeli bei seinem Rekurs nach Rom nicht bloß um die strikte Durchsetzung konfessioneller Regelobservanz. Mit den französischen Jesuiten war er auch in anderen Fragen zerstritten: Letztere akzeptierten seine Autorität als apostolischer Vikar und später Bischof gegenüber den Ordensgeistlichen nicht und sahen sich vielmehr dem französischen Konsul verpflichtet, der für seinen König die Protektion über die Missionen beanspruchte.

1001722 war Elias Sahid, den Laurence Lockhart fälschlicherweise als Juden bezeichnet, Dolmetscher der Niederländischen Ostindischen Gesellschaft. Siehe LocKHART, The Fall of the Safavi Dynasty, S. 408. Zur Familie Sahid siehe Richard, Raphaël du Mans, Bd. 1, S. $256 f$.

101 P. Barnaba Fedeli di Milano OP an Giuseppe Kardinal Sacripanti, Präfekt von »Propaganda Fide«, Neu-Djulfa, 2.5.1726 (APF, SC. Mesopotamia, Persia, Caldei, Bd. 3, 550r-552r). 
Ging es in diesem Fall um die Sakramentspendung und damit um соттиnicatio in divinis, so lassen andere Episoden erkennen, wie die Missionare mit nicht im engen Sinn kirchlichen Ritualen der Nachfrage nach dem Sakralen entsprachen. Wenn etwa die Engländer die Jesuiten baten, den Leichnam eines Hauptmannes bis zur Beerdigung in ihrem Haus aufzubahren, ging es ihnen nicht um das Sakrament der Totenmesse, sondern sie suchten einen in einem weiteren Sinn von der Sphäre des Weltlichen abgehobenen Ort. Die Beteuerung von Pater Jacques Villotte in seinem 1730 in Paris gedruckten Bericht, es habe sich um eine »rein weltliche« Angelegenheit gehandelt und es sei keineswegs davon die Rede gewesen, mit den Engländern gemeinsam zu beten oder eine religiöse Feier abzuhalten, ist vor dem Hintergrund der damals geführten Kontroversen über die Akkommodationspraktiken der Jesuitenmissionare zu sehen ${ }^{102}$.

Die Ausnahmesituation einer Diaspora, in welcher in der Regel nur katholische Geistliche die Nachfrage nach christlichen Ritualen befriedigen konnten, konditionierte die Umformung kirchlicher Praktiken. Katholische Missionare standen im konfessionellen Zeitalter in einem Spannungsfeld zwischen den universellen Ansprüchen der nachtridentinischen römischen Konfessionskirche und den Erfordernissen ihres lokalen Umfeldes, wo sie regelmäßige Kontakte mit »Ungläubigen«, »Schismatikern« und »Häretikern« pflegten, die sie nicht von vornherein vor den Kopf stoßen wollten. Die kirchliche Lehre und deren Auslegung durch das Heilige Offizium, die Congregatio de Propaganda Fide und die Ordensoberen kontrastierten mit den gesellschaftlichen Verhältnissen vor Ort. Die Schwierigkeiten, vor denen die Missionare standen, waren bereits in ihrem Auftrag angelegt. Mission beruhte zwar zunächst auf der festen Überzeugung von der eigenen Überlegenheit zumindest in Bezug auf den Besitz der religiösen Wahrheit, in der Praxis musste sie indessen mit vielfältigen Vermittlungsleistungen verbunden werden. Die Missionare hatten konfessionelle Normen weiterzugeben, mussten dazu aber auf die religiöse Kultur jener eingehen, deren Bekehrung oder »Versöhnung « mit Rom sie betreiben sollten.

Die Tätigkeit der Missionare vor Ort wurde in beträchtlichem Maße durch die lokalen Umstände bestimmt. Waren die Missionare grundsätzlich auf die Normen nachtridentinischer Kirchlichkeit festgelegt, so verhielten sie sich in der Praxis ähnlich wie vormoderne Herrschaftsbroker und stellten sich in den Mittelpunkt spezifischer »dritter Räume«. Dabei tendierten sie zwar

102 Villotte, Voyages d'un missionnaire, S. 418f. 
dazu, den Oberen in Rom Eindrücke getreuer Normerfüllung zu vermitteln. Wenn dennoch Kenntnisse der lokalen Praktiken nach Rom gelangten, so lag dies einerseits daran, dass die Missionare die soziale Annäherung an Andersgläubige vielfach selbst bereits als Erfolg wahrnahmen und in diesem Sinn ihren Oberen Bericht erstatteten. Andererseits suchte auch in Persien ein Teil der Missionare mit besonders strengen Positionen im Kontakt mit Rom eine Bestätigung gegenüber Konkurrenten vor Ort. Die Klagen von Bischof Fedeli gegen die Jesuiten in den 1720er Jahren bieten diesbezüglich gutes Anschauungsmaterial, fiel es Fedeli doch besonders schwer, seine Autorität als Bischof gegenüber den Jesuiten durchzusetzen. Damit resultierte die engere Auslegung und striktere Durchsetzung konfessioneller Normen nicht nur aus der Tätigkeit der Kurienkongregationen - des Heiligen Offiziums und von Propaganda Fide -, sondern auch aus den Interaktionen zwischen lokalen Akteuren und Rom.

Eine wichtige Frage, jene nach dem Wandel des Verhältnisses zwischen den Akteuren vor Ort und der Kurie, kann mit Bezug auf das Verhältnis der Missionare zu den Protestanten europäischer Herkunft wegen des beschränkten Quellenfundus vorerst bloß ansatzweise beantwortet werden. Weitere Aufschlüsse wird die systematische Auswertung der dubia bieten, welche das Heilige Offizium zu klären hatte ${ }^{103}$. Die Kontroversen zwischen Fedeli und den Jesuiten können als Hinweis darauf gedeutet werden, dass die Festlegung auf konfessionelle Normen strikter wurde. Aufschlussreich ist diesbezüglich der Blick auf das Verhältnis zu den Armeniern, für welches eine wesentlich dichtere Dokumentation vorliegt. Zeichen einer schärferen konfessionellen Abgrenzung zu den »Schismatikern«, wie sie Bernard Heyberger in seiner Studie über die katholischen Missionen in Syrien aufgezeigt hat ${ }^{104}$, sind in Persien ebenfalls seit dem späten 17. Jahrhundert deutlich zu erkennen. Eine solche Chronologie erinnert an die Kontroversen um Missionsstrategien in anderen Weltgegenden - etwa an die Auseinandersetzungen um die »chinesischen Riten«, die schon bei den Zeitgenossen wesentlich mehr Aufsehen erregten und entschieden besser erforscht sind ${ }^{105}$.

103 Im Rahmen eines breiter angelegten Projektes zu den Missionen im Safavidenreich arbeitet der Verfasser zur Zeit an der Auswertung dieser Dokumentation.

104 Heyberger, Les Chrétiens du Proche-Orient.

105 Zum Ritenstreit siehe George Minamiki, The Chinese Rites Controversy From Its Beginning To Modern Times, Chicago 1985; Daniel E. Mungello (Hg.), The Chinese Rites Controversy. Its History and Its Meaning, Nettetal 1994. Edition ausgewählter Quellen: René ÉTIEMBLE, Les Jésuites en Chine (1552-1733). La querelle des rites, Paris 1966. 


\author{
Felix Konrad
}

\title{
Soziale Mobilität europäischer Renegaten im frühneuzeitlichen Osmanischen Reich
}

\begin{abstract}
Einleitung
In der Frühen Neuzeit überschritten ungezählte west- und mitteleuropäische Christen die politische, gesellschaftliche und kulturelle Grenze, die sich quer durch das Mittelmeer und Südosteuropa zog, und wurden im dār al-islām, dem Machtbereich muslimischer Staaten, ansässig. Viele von ihnen gaben ihre angestammte Konfessionszugehörigkeit auf und traten zum Islam über. Das Interesse an diesen »Renegaten«, wie sie in den europäischen Quellen und auch in der Forschungsliteratur genannt werden, war im frühneuzeitlichen Europa entsprechend groß. Daher sind in unterschiedlichen Quellen umfangreiche Informationen über sie zu finden. Sie wurden in Reiseberichten und diplomatischen Dokumenten besprochen, und über jene, die in ihre katholische Heimat zurückkehrten, legte die Inquisition oft umfangreiche Akten an; selbst in Romanen und Theaterstücken wurde das Phänomen verarbeitet ${ }^{1}$.

Will man die Renegaten von der osmanischen Seite her betrachten, steht man jedoch vor einer nicht unproblematischen Quellenlage. Osmanisch-türkische Chroniken und Biographiensammlungen nennen zwar allenthalben europäische Renegaten, schenken aber ihrer Herkunft von außerhalb des Reiches weniger Aufmerksamkeit. Sie werden natürlich auch nicht als $\gg$ Renegaten« bezeichnet, sondern als »Franken« (Frenk oder Ifrenc) oder Menschen »fränkischer Herkunft«, also mit einem Ausdruck, der für lateinische Christen verwendet wurde ${ }^{2}$. Wenn in derartigen Quellen »Franken« auftauchen, die Muslime geworden sind, handelt es sich ausschließlich um solche, die in prominente Stellungen aufstiegen, und fast nur um Männer. Dabei in-
\end{abstract}

1 Siehe z.B. die Geschichte des Sklaven aus Algier in Miguel de Cervantes, Don Quijote, 1. Buch, München 2006, Kap. 39-41, in der bekannte Renegaten des späten 16. Jahrhunderts wie Kıllıç cAlī Paşa (»Uludsch-Alí«) und Venedikli Hasan Paşa (»Hassan-Agá«) eine Rolle spielen. Beide waren zeitweise osmanische Gouverneure von Algier (beğlerbeği) und Kommandanten der osmanischen Flotte ( kapudan paşa). Für Theaterstücke siehe Nabil MATAR, Introduction. England and Mediterranean Captivity, 1577-1704, in: Daniel J. Vitkus (Hg.), Piracy, Slavery, and Redemption. Barbary Captivity Narratives from Early Modern England, New York 2001, S. 1-52, hier: S. 4, 6, und Daniel J. Vitkus (Hg.), Three Turk Plays from Early Modern England: Selimus, A Christian Turned Turk, and The Renegado, New York 2000.

2 Siehe z.B. Meḥmed Efendi RĀşıD, Tārīhh-i Rāşid, 3 Bde., Istanbul 1153 [1740/41], Bd. I, fol. 176r, 260v, Bd. II, fol. 52r; siehe auch Anm. 41. 
teressierte die osmanischen Chronisten und Biographen vor allem die Bedeutung dieser Männer für das Osmanische Reich und ihre Stellung innerhalb der osmanischen Gesellschaft, ihr Wirken, ihr Prestige oder auch ihre sozialen Beziehungen ${ }^{3}$. Diese Männer werden in den osmanischen Quellen als sozial mobile Menschen fassbar, wobei sich ihr sozialer Aufstieg immer erst nach ihrem Übertritt zum Islam vollzog.

Thema dieses Beitrags sind solche West- und Mitteleuropäer, die nach ihrem Übertritt zum Islam im osmanischen Staatsapparat aufstiegen und Ämter in Verwaltung, Militär oder Sultanshaushalt bekleideten. Viele von ihnen bewegten sich im Zentrum der Macht, sei es als Wesire und Großwesire, als Kommandanten der Janitscharen und der Flotte oder als Leibärzte und Eunuchen im Sultanspalast. Anhand ausgewählter Biographien von zum Islam übergetretenen »Franken« soll den Zusammenhängen zwischen dem Wechsel der Religionszugehörigkeit und sozialer Mobilität von West- und Mitteleuropäern im frühneuzeitlichen Osmanischen Reich nachgegangen werden. Dabei wird nach den Gründen für ihre räumliche Mobilität und den Bedingungen und Umständen gefragt, unter denen sie den Islam annahmen. Insbesondere wird der Frage nachgegangen, wie der Übertritt zum Islam zu bewerten ist und welche Chancen sozialer Mobilität er eröffnen konnte.

Es wird im Folgenden der europäische Quellenbegriff »Renegaten « verwendet, obwohl ihm eine negative Konnotation unterliegt, da er die Sicht der Angehörigen jener Religionsgemeinschaft widerspiegelt, die Gläubige an eine andere Religion verliert. Der osmanische Begriff »Franke« allein wäre doppeldeutig, da sowohl ein lateinischer Christ, der zum Islam übergetreten ist, so bezeichnet werden kann, als auch einer, der nach wie vor zur katholischen oder zu einer protestantischen Kirche gehörte ${ }^{4}$.

\section{Gründe für die räumliche Mobilität}

Die Renegaten, um die es hier geht, gelangten unter verschiedenen Umständen nach Istanbul und in die Zentralprovinzen des Osmanischen Reiches. Diese Umstände sollen hier in einem breiteren Kontext besprochen werden.

Oft lagen die Gründe für ihre räumliche Mobilität in den lang andauernden kriegerischen Auseinandersetzungen an der Grenze: Während der Hegemonialkonflikte zwischen dem habsburgisch-spanischen beziehungsweise dem habsburgisch-österreichischen Reich und dem Osmanischen Reich

3 Osmanische Archivquellen konnten für diesen Aufsatz noch nicht herangezogen werden. Inwiefern sie Aufschluss über das Phänomen der Renegaten geben können, ist noch zu klären.

4 Die Entsprechung für »Renegat « im Arabischen und Osmanisch-Türkischen ist murtadd bzw. mürtedd. Dieser Begriff bezeichnet ausschließlich Menschen, die vom islamischen Glauben abfallen. 
im 16. und 17. Jahrhundert gelangten zahlreiche Europäer als Gefangene in die osmanischen Provinzen Nordafrikas, Vorderasiens und Südosteuropas ${ }^{5}$. In diesem Kontext sind die Aktivitäten muslimischer Korsaren im Mittelmeer, vor allem im westlichen, zu sehen. Maghrebinische Beutefahrer überfielen christliche Schiffe und Küstengebiete und führten zahllose Christen als Gefangene in die so genannten »Barbareskenstaaten« Tripolis, Tunis, Algier und Marokko. Im Falle der halbautonomen osmanischen Vasallenstaaten Algier, Tunis und Tripolis geschah dies oft in Abstimmung mit der osmanischen Seekriegsführung ${ }^{6}$. Meist aber betrieben die Barbareskenstaaten ihre Beuteökonomie auf eigene Rechnung, und auch dann, wenn sich das Osmanische Reich nicht im Kriegszustand befand. Sie waren als Lieferanten von Sklaven für das Reichszentrum von Bedeutung. Gouverneure und andere Amtsträger dieser autonomen Herrschaften machten dem Sultan und anderen hohen Würdenträgern in Istanbul oft Sklaven zum Geschenk, um ihre Loyalität zu demonstrieren ${ }^{7}$. Ähnlich, vielleicht in geringerer Zahl, gerieten Christen in Ostmitteleuropa während der so genannten »Türkenkriege« in Gefangenschaft und wurden in die Zentralprovinzen des Reiches um Istanbul überführt.

Viele der Gefangenen und Sklaven, die bei diesen Hegemonialkonflikten ins Osmanische Reich verschleppt wurden, kehrten nie zurück und traten zum Islam über. Die Zahl der Menschen, die auf diese Weise im 16. und 17. Jahrhundert über die Grenzen gebracht wurden, ist heute nicht mehr zu ermitteln; man kann aber wohl zu Recht annehmen, dass sie Hunderttausend bei weitem überstieg ${ }^{8}$. Im 18. Jahrhundert nahm der Zustrom von Gefange-

5 Für einen Überblick über europäische Gefangene im Osmanischen Reich siehe Suraiya FAROQHI, The Ottoman Empire and the World around it, London 2004, S. 119-136.

6 Siehe Andreas RiEger, Die Seeaktivitäten der muslimischen Beutefahrer als Bestandteil der staatlichen Flotte während der osmanischen Expansion im Mittelmeer im 15. und 16. Jahrhundert, Berlin 1994. Für einen Überblick über die Aktivitäten von (muslimischen und christlichen) Korsaren im Mittelmeer siehe Salvatore Bono, Corsari nel Mediterraneo. Cristiani e musulmani fra guerra, schiavitù e commercio, Mailand 1993.

7 Siehe z.B. Paul Ricaut, The History of the Present State of the Ottoman Empire. Containing the Maxims of the Turkish Polity, the most Material Points of the Mahometan Religion, their Sects and Heresies, their Convents and Religious Votaries. Their Military Discipline, with an Exact Computation of their Forces both by Sea and Land. Illustrated with divers Pieces of Sculpture representing the variety of Habits amongst the Turks, London ${ }^{5} 1682$, S. 46.

8 Vgl. Bartolomé Bennassar/Lucile Bennassar, Les Chrétiens d'Allah. L'histoire extraordinaire des renégats, XVIe et XVIIe siècles, Paris ${ }^{2} 2001$, S. 9. Bartolomé und Lucile Bennassar gehen davon aus, dass mehrere Zehn- oder gar Hunderttausend Europäer in Nordafrika und im Osmanischen Reich zum Islam übertraten, wobei hier die Gefangenen, die wieder zurückkehrten, nicht mitgerechnet sind. Eric Dursteler geht von mehreren Hunderttausend Renegaten im 16. Jahrhundert aus: Eric R. Dursteler, Venetians in Constantinople. Nation, Identity, and Coexistence in the Early Modern Mediterranean, Baltimore 2006, S. 112. Laut Pierre Dan gab es zu Beginn des 17. Jahrhunderts in Algier und Umgebung ca. 9000 Renegaten, in Tunesien 3 600-4 700: Pierre DAN, Histoire de Barbarie, et de ses corsaires, divisée en six livres. Où il est traitté de leur Gouvernement, de leurs Mœurs, de leurs Cruautez, de leurs Brigandages, 
nen ins Osmanische Reich ab. Dies lag einerseits daran, dass das Osmanische Reich gegenüber seinen Gegnern auf dem Kontinent in die Defensive geriet und kaum mehr auf feindlichen Territorien Gefangene machen konnte. Andererseits schränkte zur gleichen Zeit die Präsenz von Kriegsschiffen der westeuropäischen Seemächte den Handlungsspielraum der maghrebinischen Korsaren im Mittelmeer ein. Es scheint auch so, dass sich ihre Beuteökonomie im 18. Jahrhundert vom Sklavenhandel auf die Erpressung von Schutzgeldern und Lösegeldzahlungen für Geiseln verlagerte.

Weitere Gründe für die räumliche Mobilität von West- und Mitteleuropäern sind in den Lebensbedingungen in ihrer Heimat sowie in den Aufstiegsmöglichkeiten im Osmanischen Reich zu suchen, denn Emigration und Übertritt zum Islam waren nicht nur das Resultat von Verschleppung und Gefangenschaft, sondern hingen oft auch mit Armut, Machtlosigkeit und dem Streben nach einem besseren Leben zusammen'. So gab es neben den Europäern, die als Gefangene oder Geiseln ins Osmanische Reich gelangten, auch solche, die aus mehr oder weniger freien Stücken den Weg über die Grenze gingen und sich dort dauerhaft niederließen. Neuere Forschungen weisen darauf hin, dass im 16. und 17. Jahrhundert unterprivilegierte Europäer die Auswanderung in muslimische Länder und die darauf folgende Annahme des Islams oft als eine Chance sahen, ein neues Leben zu beginnen. Dies galt hauptsächlich für Bewohner der Mittelmeerküsten, aber bis in die Mitte des 17. Jahrhunderts, als die Auswanderung nach Nordamerika zu einer Alternative wurde, zum Beispiel auch für Briten. Insbesondere spezialisierte Handwerker wie Schiffsbauer, Zimmerleute, Seiler und Gewehrmacher, deren Tätigkeiten in den muslimischen Ländern gefragt waren, aber auch Seeleute und Soldaten erhofften sich gute Möglichkeiten für ein wirtschaftliches und soziales Fortkommen ${ }^{10}$.

Es waren aber nicht nur Angehörige der Unterschicht, die freiwillig den Weg über die Grenze nahmen. Manchmal traten auch Adelige in den Dienst des Sultans, da sie gerade in Militär und Diplomatie gute Kenntnisse anbieten und auf Aufstiegsmöglichkeiten hoffen konnten ${ }^{11}$. Im 18. Jahrhundert, aber

de leurs Sortileges, \& de plusieurs autres particularitez remarquables. Ensemble des grandes miseres \& des cruels tourmens qu'endurent les Chrestiens Captifs parmy ces Infideles, Paris 1637, S. 314. Fernand Braudel schätzt, dass zwischen 1598 und 1609 jährlich 138 bis 166 Schiffe im Mittelmeer gekapert wurden: Fernand Braudel, La Méditerranée et le monde méditerranéen à l'époque de Philippe II, Bd. II, Paris 1990, S. 643f., was einer Zahl von mehreren Tausend Gefangenen pro Jahr entsprechen dürfte. Vgl. auch MATAR, Introduction, S. 14-16.

9 Bennassar / Bennassar, Chrétiens d'Allah, S. 445-450; Matar, Introduction, S. 2; Dursteler, Venetians, S. 112-114.

10 Matar, Introduction, S. 2.

11 Vgl. Ralf C. MüLleR, Franken im Osten. Art, Umfang, Struktur und Dynamik der Migration aus dem lateinischen Westen in das Osmanische Reich des 15./16. Jahrhunderts auf der Grundlage von Reiseberichten, Leipzig 2005, S. 253f.; Dursteler, Venetians, S. 115. 
auch schon davor, fanden gut ausgebildete Europäer wie Ärzte, Ingenieure und Militärexperten, den Weg ins Osmanische Reich ${ }^{12}$. Die meisten dieser Adeligen und gut ausgebildeten Immigranten kamen aus den Küstenregionen des Mittelmeeres oder aus Gebieten, die direkt an das Osmanische Reich angrenzten, einige aber auch aus ferneren Gegenden. Wie die europäischen Gefangenen und Sklaven traten viele dieser frühneuzeitlichen »Arbeitsmigranten« zum Islam über und ähnlich wie diese nahmen einige von ihnen prestigeträchtige soziale, politische und militärische Stellungen ein.

Die Grenze zwischen dem Machtbereich der muslimischen Staaten und den abendländisch-christlichen Staaten bildete in der Frühen Neuzeit eine kulturelle, religiöse und soziale Schranke, die alles andere als undurchlässig war. Bewegungen von der einen Seite der Grenze auf die andere und zurück waren durchaus häufig. Auch der Wechsel der Religionszugehörigkeit - sogar der mehrmalige - war keine Seltenheit und verweist auf einen pragmatischen und flexiblen Umgang mit der Religion ${ }^{13}$. Die Attraktivität des Osmanischen Reiches und des Islams für Zuwanderer hing sicherlich auch mit dem (teils widersprüchlichen) Bild zusammen, das man sich in Europa von ihm machte: Einerseits galt das Osmanische Reich bis ins 17. Jahrhundert als »Schrecken Europas«. Ein Renegat galt also als ein Überläufer, als ein »Fahnenflüchtiger«, der nicht nur den Glauben seiner Vorfahren verleugnete, sondern auch zum Feind überlief. Auf der anderen Seite wurden das Osmanische Reich und damit auch die islamische Religion als erfolgreich und mächtig, reich und prosperierend angesehen. Das Osmanische Reich erschien als ein

$12 \mathrm{Zu}$ solchen Renegaten siehe z.B. Joseph von Hammer[-Purgstall], Geschichte des Osmanischen Reiches, grossentheils aus bisher unbenützten Handschriften und Archiven, 10 Bde, Pest 1827-1835 (Neudruck Graz 1963), Bd. VII, S. 122, 134f.

13 Allgemein zum Übertritt zum Islam im Osmanischen Reich siehe Claire NorTon, Conversion to Islam in the Ottoman Empire, in: Wiener Zeitschrift zur Geschichte der Neuzeit 7/2 (2007), S. 25-39; für den pragmatischen Umgang mit der Religionszugehörigkeit siehe ebd., S. 37. In der Frühneuzeit gab es nicht nur europäische Christen, die im dār al-islām ihre Religion wechselten, sondern auch Muslime, die in West- und Mitteleuropa zum Christentum übertraten. Ihre Zahl, die im Vergleich zu den christlichen Renegaten wesentlich geringer zu veranschlagen ist, erreichte um 1700 herum ihren Höhepunkt, als zahlreiche so genannte »Beutetürken«, die im Laufe des »Großen Türkenkrieges « (1683-1699) in Ungarn und auf dem Balkan in habsburgische Gefangenschaft gerieten, nach Mitteleuropa gebracht und dort zum Teil getauft wurden. Auch in Venedig kam es häufig vor, dass Muslime getauft wurden. Zu mitteleuropäischen »Türkentaufen« im späten 17. Jahrhundert siehe Karl TEPLY, Türkentaufen in Wien während des Großen Türkenkrieges 1683-1699. Wesen und Bedeutung der Türkentaufen, in: Jahrbuch des Vereins für die Geschichte des Stadt Wien 27 (1971), S. 57-87; zu Venedig siehe z.B. Georgios Plakotos, Christian and Muslim Converts from the Balkans in Early Modern Venice. Patterns of Social and Cultural Mobility and Identities, in: Raymond Detrez/Pieter Plas (Hg.), Developing Cultural Identity in the Balkans. Convergence vs. Divergence, Brüssel 2005, S. 125-145; E. Natalie Rothman, Becoming Venetian. Conversion and Transformation in the SeventeenthCentury Mediterranean, in: Mediterranean Historical Review 21 (2006), S. 39-75; Dursteler, Venetians, S. 116. Für muslimische Gefangene in Mitteleuropa und Italien vgl. FAROQHI, Ottoman Empire, S. 125f., 132f. 
Gemeinwesen, das ständig an Boden gewann und einem unternehmungslustigen Zuwanderer vielfältige Möglichkeiten bieten konnte ${ }^{14}$.

\section{Muster des Übertritts zum Islam}

Osmanische Chroniken und Biographiensammlungen machen kaum Aussagen über den Konversionsprozess von west- und mitteleuropäischen Renegaten. Anhand von knappen biographischen Hinweisen lassen sich dennoch Muster von Umständen und Situationen erkennen, unter denen »Franken« den Islam annahmen. Diese werden durch Aussagen europäischer Quellen wie Inquisitionsakten und Reise- und Gefangenenberichte bestätigt und ergänzt.

Grundsätzlich lassen sich zwei Muster unterscheiden: erstens der Übertritt zum Islam im Zustand der Unfreiheit; zweitens der freiwillige Übertritt zum Islam aus ökonomischen und sozialen oder auch politischen Gründen. In beiden Fällen hatte die Annahme des Islams verschiedene Implikationen und Konsequenzen. Diese waren sowohl religiöser, als auch sozialer, kultureller, rechtlicher und manchmal politischer Natur.

Das erste Muster - der Wechsel der Religionszugehörigkeit im Zustand der Unfreiheit - kann bei West- und Mitteleuropäern der Frühneuzeit als Regelfall des individuellen Übertritts zum Islam bezeichnet werden. Wie bereits erwähnt, wurde die Mehrzahl der Renegaten unfreiwillig oder unter Zwang in die muslimische Gesellschaft verpflanzt, vor allem als Kriegsgefangene oder Geiseln. Aber nicht nur die Grenzüberschreitung erfolgte im Zustand der Unfreiheit, sondern auch der Übertritt zum Islam. Dabei wurde zum Teil sozialer Druck oder sogar Zwang auf die Gefangenen ausgeübt ${ }^{15}$.

14 Vgl. Dursteler, Venetians, S. 114.

15 Stephan Gerlach berichtet zum Beispiel folgendermaßen über den Druck, der auf den in Gefangenschaft geratenen Italiener Scipione Cicala ausgeübt worden sei: »Da sie nach Gewonheit in des Kaysers Divan geführt/der Vater in die Siebenthürne/der Sohn aber/dieweil er munter herein getreten/zu den Verschnittenen gebracht worden/die dann ihm süß und sauer zugeredet/auch Maultaschen außgetheilet/bis er endlich ein Türck zu werden verwilliget/sonderlich weil sie ihm vorgeschwatzt/er könne dardurch sich und seinen Vater beym Leben erhalten«. Stephan Gerlach, Stephan Gerlachs deß Aeltern Tage-Buch. Der von zween Glorwürdigsten Römischen Käysern, Maximiliano und Rudolpho, Beyderseits den Andern dieses Nahmens Höchstseeligster Gedächtnüß, an die Ottomanische Pforte zu Constantinopel Abgefertigten, und durch den Wohlgebohrenen Hn. David Ungnad ... Mit würklicher Erhalt- und Verlängerung deß Friedens, zwischen dem Ottomannischen und Römischen Käyserthum ... Glücklichstvollbrachter Gesandschafft: Auß denen Gerlachischen ... Schrifften, Herfür gegeben durch Seinen Enckel M. Samuelem Gerlachium, Frankfurt am Main 1674, S. 245. Von diesem Renegaten wird später noch die Rede sein. Auch Renegaten, die in ihre Heimat zurückkehrten, berichteten oft, dass sie nur unter Zwang oder nur zum Schein zum Islam übergetreten seien. Für Beispiele siehe Bennassar/Bennassar, Chrétiens d'Allah, S. 49f., 381f. Für eine frühneuzeitliche Darstellung siehe DAN, Histoire de Barbarie, S. 305f. Dies kann auch eine Schutzbehauptung sein, 
Diese Renegaten nahmen den Islam also in einer Situation der ungewollten Entwurzelung und des Abgeschnitten-Seins von den vertrauten sozialen, kulturellen und familiären Verhältnissen an. Angesichts einer ungewissen Zukunft in osmanischer Gefangenschaft stellte der Übertritt zum Islam für viele Gefangene eine sinnvolle Option dar, da er ihnen einen größeren Bewegungsspielraum eröffnete und sich durch den Übertritt auch ihre Aussichten auf Freilassung oder Flucht erhöhen konnten ${ }^{16}$. Diese Aussicht auf Rückkehr in die Heimat und damit zur alten Religionsgemeinschaft, die in zahlreichen Fällen auch tatsächlich stattfand, zeichnete viele Renegaten als »Grenzgänger« aus. Oftmals war die Annahme des Islams also nur eine »bedingte «, da sie nur solange Gültigkeit hatte, wie sich der neue Muslim im dār al-islām aufhielt.

Viele Kriegsgefangene gelangten als Sklaven in den Besitz osmanischer Eliteangehöriger und wurden in deren Haushalte eingebunden. Der mit Abstand größte und wichtigste dieser Elitehaushalte war jener des Sultans, der bis ins frühe 17. Jahrhundert zahlreiche junge west- und mitteleuropäische Christen aufnahm. Dort traten sie nicht nur zum Islam über, sondern wurden auch als osmanische Eliteangehörige ( ${ }^{c}$ askerī) resozialisiert. Als neue Muslime wurden sie beschnitten und in den islamischen Glaubensgrundsätzen und kultischen Handlungen unterwiesen. Dabei wurde auch überprüft, ob sie den islamischen Glauben wirklich verinnerlicht hatten, nicht zuletzt, um sich ihrer Loyalität zum Sultan und zum Osmanischen Reich zu versichern ${ }^{17}$. Als zukünftige ${ }^{c}$ askeris erhielten sie eine mehrstufige Ausbildung, die den Unterricht in türkischer, arabischer und persischer Sprache, in Lesen und Schreiben sowie in anderen Fertigkeiten umfasste, zum Beispiel in einem Handwerk, in Kunst und vor allem in militärischen und administrativen Techniken. Nach der Ausbildung wurden sie in der Regel für Ämter und Posten im Sultanshaushalt selbst, insbesondere für den persönlichen Dienst am Herrscher, verwendet. Bei entsprechender Eignung oder Gunst des Sultans konnten sie von dort aus in verschiedenen Positionen innerhalb des Staatsapparats eingesetzt werden.

Bekanntheit erlangte zum Beispiel Ġażanfer Ağa (ca. 1550-1603), ein Venezianer, der als Knabe zusammen mit seinem Bruder in Gefangenschaft geraten und als Page (iç oğlanı) in den Haushalt von Prinz Selīm, dem spä-

vor allem dann, wenn sie diese Aussagen vor einem Inquisitionsgericht machten. Ausgenommen von diesem Druck waren wohl Geiseln, für die ein Lösegeld erwartet wurde, zumindest solange, wie die Aussicht auf ein solches bestand. Bei diesen gab es aber auch wenig Grund, sie zum Übertritt zum Islam zu veranlassen. Zu Lösegeldzahlungen für Gefangene siehe FAROQHI, Ottoman Empire, S. 124f., für den nordafrikanischen Kontext siehe MATAR, Introduction, S. 24-29.

16 Vgl. Bennassar/Bennassar, Chrétiens d'Allah, S. 147.

17 Ottaviano Bon, The Sultan's Seraglio. An Intimate Portrait of Life at the Ottoman Court. From the Seventeenth-Century Edition of John Withers, London 1996, S. 72. 
teren Sultan Selīm II. (reg. 1566-1574), gebracht worden war. Auf Betreiben Selīms hin wurde er kastriert und stieg unter seiner Herrschaft zum hāṣs oda başı (Vorsteher der Pagenkammer) und dann zum kapu ağası (oder bāb üs-sacādet ağast) auf, wurde also zum obersten weißen Eunuchen des Sultanshaushalts und Oberhofmeister des Palastes ${ }^{18}$. Dieses einflussreiche Amt hatte er auch noch unter Murād III. (reg. 1574-1595), als dessen Vertrauter er galt, und unter Mehmed III. (reg. 1595-1603) inne ${ }^{19}$. In dieser Funktion übte er großen politischen und sozialen Einfluss aus: Er kontrollierte nicht nur von Amtes wegen den Zugang zum Herrscher, sondern war auch zentraler Bestandteil eines weitgespannten Netzwerkes im Zentrum der osmanischen Elite, dem zahlreiche einflussreiche Persönlichkeiten wie Wesire und Prinzessinnen angehörten, unter ihnen mehrere italienische Renegaten ${ }^{20}$. Zentrum dieses Netzwerkes war Nūr Bānū Sulțān (ca. 1525-1583), Konkubine Sultan Selīms und Mutter Sultan Murāds III., die ebenfalls venezianischer Herkunft war ${ }^{21}$. Zudem pflegte Ġażanfer stets enge Beziehungen zu seiner Heimat und seiner Herkunftsfamilie, die er protegierte und förderte ${ }^{22}$. Trotz seiner zentralen Stellung in der Istanbuler Elite und am Hof verstand sich Ġażanfer Ağa immer noch als Venezianer. Auch von der Istanbuler Elite und dem venezianischen Gesandten wurde er sowohl als Venezianer als auch als Türke wahrgenommen ${ }^{23}$.

18 Für Pagen im Sultanspalast siehe H[amilton] A[lexander] R. GibB/Harold Bowen, Islamic Society and the West. A Study of the Impact of the Western Civilization on Moslem Culture in the Near East, Teil I: Islamic Society in the Eighteenth Century, 2 Bde., London 1950-1957, Bd. I, S. 77-82; für das Amt des kapu ağası und des hășș oda başı siehe ebd., S. 77-82, 331-333. Europäische Schilderungen der Pagen und der Pagenschule aus dem 17. Jahrhundert finden sich in Bon, Sultan's Seraglio, S. 67-78, und in Ricaut, Present State of the Ottoman Empire, S. 45-62. Zum kapu ağası siehe ebd., S. 65, und Bon, Sultan's Seraglio, S. 78, 80f.

19 Dursteler, Venetians, S. 119f.; Hammer, Geschichte, Bd. IV, S. 7. Hammer-Purgstall identifiziert Ġażanfer fälschlicherweise als Ungarn.

20 Dursteler, Venetians, S. 120f.

21 Zu Nūr Bānū siehe A[lexander] H. DE Groot, Art. Nūr Bānū Wālide Sulțān, in: Encyclopédie de l'islam. Nouvelle édition, Bd. VIII, Leiden 1995, S. 126f. Nūr Bānū wurde als uneheliche Tochter des Adeligen Nicolo Venier und der Violante Baffo in Paros geboren und trug ursprünglich den Namen Cecilia. In der Herrschaftszeit ihres Sohnes Murād III. war ihr Einfluss und der des Sultansharems so groß, dass die osmanischen Historiographen vom Beginn des »Sultanats der Frauen « (kadınlar salțanatı) sprachen.

22 Dursteler, Venetians, S. 121-123. Ġażanfer trat zudem in Istanbul als Mäzen für Kunst und Literatur auf und stiftete eine medrese (Schulkomplex) und eine Bibliothek. Siehe Faruk BıLıcI, Les bibliothèques vakıf-s à Istanbul au XVIe siècle, prémices de grandes bibliothèques publiques, in: Revue du Monde musulman et de la Méditerranée 87/88 (1999), S. 39-59, hier: S. 45, und Tülay Artan, Arts and Architecture, in: Suraiya N. Faroqhi (Hg.), The Cambridge History of Turkey, Bd. III: The Later Ottoman Empire. 1603-1839, Cambridge 2006, S. 408480, hier: S. 431.

23 Siehe Dursteler, Venetians, S. 121: 》Gazanfer Ağa continued to consider and describe himself as Venetian [...] [M]embers of the Ottoman ruling class also considered Gazanfer a Venetian [...] The bailo Gianfrancesco Morsini acknowledged the complexity of the kapıağası's identity: he described Gazanfer as a Venetian, but also >a true Turk « 
Ein weiterer bekannter italienischer Renegat und ein Mitglied von Ġażanfers Netzwerk war Çı̆̆ālazāde Yūsuf Sinān Paşa alias Scipione Cicala (15451605), der in jungen Jahren gemeinsam mit seinem Vater, einem genuesischen Adeligen und Korsaren in spanischen Diensten, von tripolitianischen Korsaren gefangen genommen worden war $^{24}$. Er wurde in den Palast des Sultans gebracht und trat zum Islam über, während sein Vater, für den man Lösegeld erwartete, im Gefängnis starb ${ }^{25}$. Wie Ġażanfer wurde er als Page im Palast ausgebildet, von wo aus seine Karriere über verschiedene Ämter im Herrscherhaushalt zum Kommando über die Janitscharen und über die Flotte sowie über mehrere Gouverneursposten bis zum Amt des Großwesirs führte. Çı̆gālazāde Sinān wurde zudem hintereinander mit zwei Prinzessinnen aus der Sultansfamilie vermählt ${ }^{26}$.

Gleich wie Ġażanfer hielt Çı̆̆ālazāde Sinān eine enge Beziehung zu seiner Herkunftsfamilie aufrecht. Während Ġażanfer seinen Neffen nach Istanbul rief, der ebenfalls den Islam annahm²7, ließ Çı̆gālazāde als Flottenchef (kapudan paşa) osmanische Galeeren nach seiner Geburtsstadt Messina auslaufen, um dort seine Mutter abzuholen ${ }^{28}$. Auch andere Verwandte rief er nach Istanbul, wie etwa seinen Bruder Carlo, den er protegierte und dem er Ämter im Osmanischen Reich zu verschaffen versuchte ${ }^{29}$. Çı̆ğālazāde Sinān war einer der wenigen Renegaten, die ihren alten Namen als Patronym behielten: Çı̆̆āazāāde heißt »Sohn Cigalas / Cicalas«.

Auch mehrere andere Renegaten derselben Zeit zeichnen sich dadurch aus, dass sie dem Sultanspalast nahestanden und in ihm (re-)sozialisiert wurden. Silıḥdār Halīl Ağa, der 1592 zum Kommandanten der Janitscharen ernannt wurde, war ebenfalls als Page in den Haushalt des Sultans eingegliedert worden $^{30}$. Ende 1593 hatte er das Amt eines Wesirs mit dem Titel paşa inne und heiratete Fāṭma Sulțān, eine Tochter Sultan Murāds III. ${ }^{31}$; auch dies ist eine Parallele zur Biographie Çı̆̆ālazāde Sināns. Während Çı̆̆ālazādes und Gażanfers italienische Herkunft feststeht, war Halīl laut europäischen Quel-

24 Für Kurzbiographien siehe V. J. PARrY, Art. Čighāla-zāde (Djighāla-zāde) Yūsuf Sinān Pasha, in: Encyclopédie de l'islam. Nouvelle édition, Bd. II, Leiden 1965, S. 34f., und Mehmed SüreYYā, Sicill-i ' Oșmān̄̄, Yahud Težkire-i Meşāhir-i ' Oșmānīye, Istanbul 1308-1315 [18901898], Bd. III, S. 111, für eine Biographie in einem historiographischen Werk des 17. Jahrhunderts siehe Kātib ÇELEBI, Tuḥfetü 'l-Kibār fī Efsāri 'l-Biḥār, Istanbul 1141 [1728/29], fol. 46.

25 Für einen europäischen Quellenbericht über Çı̆̆ālazādes Gefangennahme und seinen Übertritt zum Islam siehe Gerlach, Tage-Buch, S. $244 \mathrm{f}$.

26 Hammer, Geschichte, Bd. III, S. 423, und Bd. IV, S. 17, 102.

27 Ebd., Bd. IV, S. 301.

28 Hammer-Purgstall zitiert hierzu eine osmanische Quelle, die mir nicht zugänglich war (ebd.).

29 Ebd., Bd. IV, S. 230, 301. Vgl. auch Dursteler, Venetians, S. 128.

30 Selānikī Mușțafā EfEnd, Tārīh-i Selānikī, Istanbul 1281 [1864/65], S. 311.

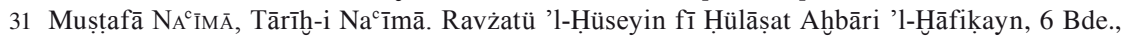
Istanbul 1280 [1863/64], Bd. I, S. 99f.; HAmmer, Geschichte, Bd. IV, S. 228, 230. 
len ein Italiener aus Ancona namens Paggi ${ }^{32}$, laut dem osmanischen Chronisten Selānikī Muștafā hingegen Grieche ${ }^{33}$. In der umfangreichen osmanischen Biographiensammlung von Meḥmed Süreyyā aus dem 19. Jahrhundert vermischt sich die Biographie von Sılı̣̣dār Halīl Ağa mit jenen zweier weiterer Osmanen mit dem Namen Halīl, die beide ebenfalls sllı̣̣dār (»Waffenträger«) waren, so dass diese drei Männer nicht mehr eindeutig zu identifizieren und auseinanderzuhalten $\operatorname{sind}^{34}$.

Sılı̣̣dār Halīl Ağa ist ein Beispiel für die Schwierigkeiten, auf die man bei der Rekonstruktion von Biographien europäischer Renegaten stößt. Diese Schwierigkeiten sind besonders groß, wenn man sich auf osmanische Quellen stützen will, da dort die Herkunftsangaben oft voneinander abweichen oder ungenau sind. Bei Renegaten wie Ġażanfer und Çı̆̆āazāde Yūsuf, die in europäischen Quellen gut dokumentiert sind, ist dies leichter. Bei der Herkunft von Semüz Aḥmed Paşa (1527?-1580) gibt es zum Beispiel ähnliche Unklarheiten wie bei S1lı̣dār Halīl. Semüz Aḥmed war in jungen Jahren als Sklave in den Herrscherhaushalt gekommen, wo er nach seiner Ausbildung das Amt des kapucı başı (»Obertürhüter«) einnahm; später wurde er Kommandant der Janitscharen und war schließlich im Jahr vor seinem Tod Großwesir. Als prominente Persönlichkeit heiratete er ebenfalls eine osmanische Prinzessin ${ }^{35}$. Semüz Ahmed Paşa stammte laut europäischen Quellen aus $\mathrm{Graz}^{36}$, in der osmanischen Biographiensammlung von Mehmed S Süreyyā hingegen wird er als Sohn eines Albaners bezeichnet ${ }^{37}$.

Dass Sılıḥdār Halīl und Semüz Aḥmed als Pagen im Sultanspalast ausgebildet wurden und aus diesem hervorgingen, ist ein klares Indiz dafür, dass sie als junge Sklaven in den Haushalt integriert worden sein müssen. Wenn

32 Hammer-Purgstall zitiert hier einen diplomatischen Bericht des kaiserlichen Gesandten Friedrich von Khrekwitz vom März 1592. Hammer, Geschichte, Bd. IV, S. 198.

33 SelĀnikī, Tārīh, S. 312: »... sein Name in griechischer Sprache war Vasilaki und ... er wurde Vasıl Ağa genannt«. (»Rum dilince adı Vāṣılākī olup ... Vāṣıl Ağa deyü mülaḳkab oldı«).

34 Laut Meḥmed Süreyyās Biographiensammlung, die (v.a. in Bezug auf Jahreszahlen) nicht immer zuverlässig ist, war der Sılıḥār Halīl Paşa, der 1002 Fāṭma Sulțān heiratete, ein Bosnier und wurde nicht im Jahr 1000 der hiğra (1592) zum Kommandanten der Janitscharen ernannt,

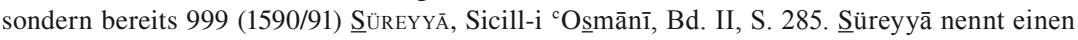
weiteren Silıḥdār Halīl Paşa (gest. 1601), der aus Kayseri (Zentralanatolien) stammte und im Jahr 1000 (1592) Kommandant der Janitscharen wurde (ebd.). Nach Hammer-Purgstall handelt es sich jedoch bei Halīl dem Bosnier, Halīl aus Kayseri und Halīl/Paggi um drei verschiedene Männer. Siehe Hammer, Geschichte, Bd. IV, S. 198, 228, 230, 439, 701.

35 Süreyyā, Sicill-i ' Oșmānī, Bd. I, S. 202; Hammer, Geschichte, Bd. IV, S. 26, 103f. Laut Hammer-Purgstall waren zudem zwei Töchter Semüz Aḥmeds mit Çı̆̆ālazāde Sinān verheiratet (ebd.); für die Hochzeit der einen Tochter (1575) siehe Gerlach, Tage-Buch, S. 265; für Semüz Ahmeds Großwesirsamt siehe SELĀNIKĪ, Tārīhn, S. 155.

36 Gerlach, Tage-Buch, S. 283; an derselben Stelle nennt Gerlach einen weiteren Renegaten, den Wesir Mạ̣mūd Paşa, einen Deutschen aus Laibach. Zu Semüz Aḥmed vgl. auch MüLler, Franken im Osten, S. 249f.

37 Sǘreyyā, Sicill-i ${ }^{\mathrm{c} O s} \underline{s} \bar{a} n \overline{1}, \mathrm{Bd}$. I, S. 202. 
sie beide aus christlichen Gebieten außerhalb des Reiches stammten, ist es naheliegend, dass sie als Kriegsgefangene dorthin gelangten und als Sklaven konvertierten. Solche Kriegsgefangene wurden noch bis ins mittlere 17. Jahrhundert in den Sultanshaushalt aufgenommen. So muss »Frenk« Mehmed Ağa wie Ġażanfer Ağa ein Eunuch gewesen sein, er hatte auch dieselben Ämter inne wie dieser, wenn auch nicht für so lange Zeit. Im Jahre 1658 musste er das Amt des hāạș oda başı abgeben, da er in Ungnade gefallen war, und mit dem niedrigeren Haushaltsposten des Schatzmeisters (hazinnedār başı ) Vorlieb nehmen. Bald darauf wurde er jedoch zum kapu ağası erhoben ${ }^{38}$. Gutierre Pantoja, ein spanischer Adeliger, geriet 1620 als Sechzehnjähriger in Gefangenschaft von tunesischen Beutefahrern. Obwohl er sich um Lösegeld bemühte, reichte ihn der Gouverneur von Tunis als Geschenk an den Sultan weiter. In dessen Palast wurde er zum Pagen und trat zum Islam über. Nach verschiedenen Posten im Sultanshaushalt machte er - ähnlich wie Çı̆̆ālazāde Sinān - Karriere in der Kriegsmarine. Als er 1669 in venezianische Gefangenschaft geriet, hatte er einen der höchsten Posten in der Flotte inne. Dank der Akten, die die Inquisition über ihn erstellte, ist sein Leben gut dokumentiert; sein muslimischer Name ließ sich bislang jedoch nicht eruieren ${ }^{39}$.

Das zweite Muster des individuellen Wechsels der Religionszugehörigkeitder freiwillige Übertritt zum Islam aus ökonomischen und sozialen oder auch politischen Gründen - war seltener als das erste. Oft handelte es sich dabei um Männer, die über spezialisierte Kenntnisse verfügten, die im Osmanischen Reich gefragt waren. Dies gilt in besonderem Maße für das 18. Jahrhundert und für solche Männer, die aus Ländern ohne direkte Grenzen mit dem Osmanischen Reich stammten.

So sind in den Chroniken des 18. Jahrhunderts europäische Renegaten in wichtigen Stellungen zu finden, welche sie einerseits aufgrund ihres Übertritts zum Islam, andererseits dank ihrer Kenntnisse und Fähigkeiten einnehmen konnten: Ein »Franke« namens Mehmed Ağa, ehemaliger Chef des Miniercorps (lağımcı başı), überwachte im Jahre 1700/01 die Instandsetzung von Befestigungsanlagen in Niš (Serbien), Belgrad und Temesvar (an der Grenze zu Ungarn $)^{40}$. Der Chronist Meḥmed Rāşid sagt nichts über die Umstände, unter denen Mehmed Ağa ins Osmanische Reich kam und den Islam annahm. Da sich der »Franke « aber offenbar mit Festungsbautechniken und dem Minierwesen gut auskannte, liegt es nahe, dass er als Erwachsener einwanderte und spezialisierte Kenntnisse mitbrachte, die er anbieten konnte.

Auch der Venezianer Nūḥ Efendi (gest. 1707) verfügte als Mediziner über besondere Kenntnisse, die ihm die Tür zu hohen Ämtern öffneten. In osma-

$38 \mathrm{NA}^{\mathrm{c}} \overline{\mathrm{I}} \mathrm{MA}, \mathrm{T}$ Tāīh, Bd. VI, S. 328f.

39 Zu Gutierre Pantoja siehe Bennassar/Bennassar, Chrétiens d'Allah, S. 145-169.

40 RĀşı, Tārīh, Bd. I, fol. 260v-261r. 
nischen Quellen wird Nūḥ jeweils als ein zum Islam konvertierter »Franke « bezeichnet ${ }^{41}$. Osmanische und italienische Quellen sind sich auch darüber einig, dass Nūh nach Istanbul auswanderte, weil er sich in Padua, wo er studiert hatte, in die Tochter eines osmanischen Kaufmanns namens Șafīye verliebte ${ }^{42}$. Nach seinem Übertritt zum Islam konnte er sie in Istanbul heiraten und fand den Weg in den Sultanspalast: Im Haushalt Sultan Mehmeds IV. (reg. 1648-1693) war er seit 1673/74 Chefchirurg (cerrāḥ başı); bei der Thronbesteigung Muștafās II. (reg. 1695-1703) wurde er zum Chefarzt des Sultans (hekīm başı/re ${ }^{\top} \overline{i s} \ddot{u}$ 'l-ațıbā) ernannt, ein Amt, das er auch noch unter Sultan Aḥmed III. (reg. 1703-1730) innehatte. Nūh Efendi wurden auch hohe Ränge in der zivilen Hierarchie verliehen: So erhielt er im Jahr 1693/94 den Rang mìrmìrān mit dem Titel paşa und im Jahr darauf wurde er zum Rumeli $k \grave{a} \dot{z} \imath^{c}$ asker (Heeresrichter von Rumelien) ernannt ${ }^{43}$. Nūḥ war offensichtlich gut in das muslimische Gelehrtenmilieu der osmanischen Hauptstadt integriert. Dafür spricht einerseits sein Amt als Heeresrichter, andererseits stiftete er eine Schule (medrese) und soll mystische Neigungen (»dervīş nihād idi«) gehabt haben ${ }^{44}$. Sein ältester Sohn Süleymān wurde ebenfalls Chefchirurg sowie Oberrichter (menlā), sein zweiter Sohn ${ }^{\mathrm{c} A l i ̄ ~ w u r d e ~ g a r ~ G r o ß w e-~}$

41 Laut dem Chronisten Meḥmed Rāşid gehörte er »der Herkunft nach zur Gruppe der Franken« (»aṣlında İfrenc țā̄ifesinden«) und wurde »durch die Ehre des Islams geehrt« (»şeref-i islām ile müşerref oldu«), ist also konvertiert; RĀșıD, Tārīh, Bd. II, fol. 56v. Der Biograph Şeyḩ̄i Meḥmed schreibt: »Der Herr Nūḥ ist fränkischer Herkunft. Er erlangte die göttliche Führung und das göttliche Geschenk und wanderte auf [irgend] einem Weg aus seinem Land aus und kam nach Konstantinopel, dem beschirmten Sitz des erhabenen Sultanats, und fand die Ehre des Islams«. (»El-mevlā Nūḥ ifrencī 'l-aṣıldır tevfīḳ-ı rabbān̄̄ ve hidāyet-i sübhāān̄ èrişüp bir țarīḳla diyārından hicret eyleyüp dāru 's-salțanatı 'l-calīye-i maḥmīye-yi Kosṭanținye'ye duhūl ve

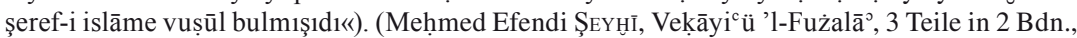

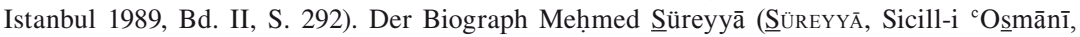
Bd. IV, S. 579) referiert sinngemäß Rāşid: »Nūḥ Efendi kam aus der Gruppe der Franken und fand zum rechten Glauben [...]« (»Nūḥ Efendi İfrenc țā̄ifesinden olup ihtidā eylemişdir [...]«). Nūḥs Todesjahr nach ebd., ŞEYhī, Veḳāyic ü 'l-Fużalā'o Bd. II, S. 293, und Hammer, Geschichte, Bd. VII, S. 134; abweichendes Todesjahr (1126/1714) ebd., S. 557.

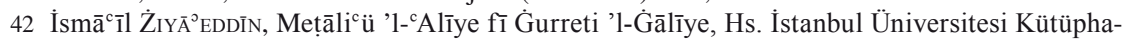
nesi, E. Mahmud Kamil Bey Koll. 3442, Istanbul 1173, fol. 5r-6r, zitiert nach Michael Robert Ніскок, Ottoman Military Administration in Eighteenth-Century Bosnia, Leiden 1997, S. XVII. Hammer-Purgstall fand dieselben Aussagen in venezianischen Akten im Haus-, Hofund Staatsarchiv, Wien (Bericht des venezianischen Gesandten Emmo vom 25. Mai 1732); Hammer, Geschichte, Bd. VII, S. 409, Anm. a.

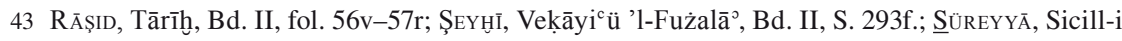
${ }^{c}$ Ossmānī, Bd. IV, S. 579.

44 Ebd. Laut Hammer-Purgstall übersetzte Nūḥ Efendi die Religionsgeschichte (Kitāb al-milal wa-'n-nihal) von Tāğ ad-Dīn Abū 'l-Fatḥ Muḥammad ibn 'Abd al-Karīm aš-Šahrastānī (1086?1153); Hammer, Geschichte, Bd. VII, S. 134, 173. Tatsächlich wurde das Werk aber von seinem Namensvetter Nūḥ ibn Mușțafā (gest. 1659), einem Theologen aus Anatolien, der in Ägypten lebte, ins Türkische übersetzt. Siehe F[ranz] Babinger, Art. Nūḥ b. Mușțafā, in: Encyclopédie de l'islam. Nouvelle édition, Bd. VIII, Leiden 1995, S. 112 f. 
$\operatorname{sir}^{45}$. Nūh Efendi scheint seine Karriere ausschließlich im Sultanshaushalt gemacht zu haben, wurde aber nicht - wie die Renegaten im 16. und frühen 17. Jahrhundert - als Page im Sultanshaushalt sozialisiert, sondern fand als erwachsener »Experte« Zugang zum Palast.

Sicher spielten bei Nūḥs Karriere die Sultane als Patrone eine entscheidende Rolle. Ab der zweiten Hälfte des 17. Jahrhunderts begannen jedoch auch vermehrt administrative und militärische Amtsträger Europäern Patronage anzubieten. Dies hing vor allem damit zusammen, dass sich im 17. Jahrhundert Haushalte von hochrangigen Eliteangehörigen wie Wesiren und Provinzgouverneuren als Patronagezentren herauskristallisierten, die große Gefolgschaften an sich banden und so das Patronagemonopol des Sultanshaushaltes beschnitten $^{46}$.

Ein Beispiel für einen Renegaten, dessen Karriere von der Förderung einflussreicher Männer der militärisch-administrativen Elite abhing, ist der Franzose Gerçek Dāvud Ağa. Der Chronist Çelebizāde İsmā̄ $\overline{1} l{ }^{~} \bar{A}$ șı tet, dass Dāvud mit zehn Angehörigen über die Niederlande nach Galata gekommen war, da er eine »Neigung und Liebe zum Islam « (dīn-i isläme meyil ü muhabbet) gehabt habe ${ }^{47}$. Er suggeriert also, dass sich der Franzose durch die islamische Religion angezogen fühlte. Dabei wird in dem Text nicht ganz klar, wann und wo Dāvud diese »Neigung und Liebe zum Islam« entwickelt haben soll; dem Anschein nach vor der Auswanderung nach Istanbul, was aber unwahrscheinlich ist. Die Formulierung, dass Dāvud eine »Neigung und Liebe zum Islam « entwickelt habe, könnte auch nur ein Topos sein, mit dem der Chronist auf den Übertritt hinweist, ohne dass er in der Lage wäre, genauere Aussagen darüber zu machen.

Gerçek Dāvud Ağas Übertritt zum Islam muss jedoch im spezifischen sozialen Kontext eines Patron-Klient-Verhältnisses betrachtet werden. Er trat zunächst in den Dienst der osmanischen Flotte, wo er sich während Auseinandersetzungen mit Venedig um die Kontrolle Kretas und der Peloponnes als Kanonier auszeichnete ${ }^{48}$. Dies trug ihm die Gunst und damit die Patronage des Wesirs İbrāhīm Paşa, Flottenkommandant (kapudan paşa) und Gouver-

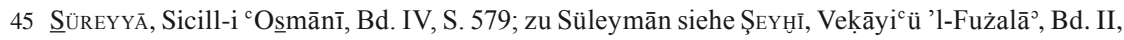
S. $596 f$.

46 Carter Vaughn Findley, Political Culture and the Great Households, in: Suraiya N. FAROQHI (Hg.), The Cambridge History of Turkey, Bd. III: The Later Ottoman Empire. 1603-1839, Cambridge 2006, S. 65-80, bes. S. 66f. und 74-79.

47 »Gerçek Dāvud Ağa [...], war von französischer Herkunft. Nachdem er in die Niederlande gereist und dort einige Tage geblieben war, kam er mit seinen Angehörigen im Jahr achtundzwanzig [1128 h. = 1716] und liess sich in Galata nieder, da er eine Neigung und Liebe zum Islam hatte [...] (»Gerçek Dāvud Ağa [...] fī 'l-asıl Fransalı iken Felemenk diyārına riḥlet ve bir az eyyām anda iḳāmet ètikden soñra dīn-i islāme meyil ü muhabbet ve on nefer-i ehil ve cayāl ile yirmi sekiz tārīhinde gelüp Ġalața'da iḳāmet èdüp [...]«). İsmāc ${ }^{c} 1{ }^{c} \bar{A} s ̦ ı m$ Efendi ÇELEBIZĀDE, Tārīh-i Çelebizāde, Istanbul 1153 [1740/41], fol. 64r.

48 ÇelebizĀDe, Tārīh, fol. 64r; vgl. SüüreyYā, Sicill-i ' Oṣmānī, Bd. II, S. 326. 
neur von Kreta, ein ${ }^{49}$. Dāvuds Übertritt zum Islam fand laut Çelebizāde erst nach der Rückkehr von der Marineexpedition statt, also sehr wahrscheinlich unter dem Patronageverhältnis zu İbrāhīm Paşa. Gleichzeitig mit Dāvud »erlangten« auch seine Angehörigen »die Ehre des Islams«, wie es in der Chronik heißt, und er nahm den Namen Gerçek Dāvud (»David der Treue«) an ${ }^{50}$. Später schlug Dāvud dem Großwesir Nevşehirli Dāmād İbrāhīm Paşa (im Amt 1718-1730) die Einrichtung einer Feuerwehr nach europäischem Vorbild vor, die das Löschwasser statt mit Kesseln mittels Pumpen und Schläuchen zum Brandherd bringen konnte. 1719/20 wurde Dāvud zum Kommandanten dieses neuen Istanbuler Feuerwehrcorps ernannt (țlumbacı ăgası) und mit einem ansehnlichen Sold von 120 akça pro Tag ausgestattet, der später erhöht wurde ${ }^{51}$.

Gerçek Dāvud verfügte also über spezialisierte Fertigkeiten und Kenntnisse, einerseits als Marinesoldat und Kanonier, andererseits in der Brandbekämpfung, die er im Osmanischen Reich anbieten konnte. Dies ermöglichte ihm den Eintritt in ein Patronageverhältnis zu einem hohen Amtsträger, in diesem Fall zum Wesir İbrāhīm Paşa, mit dem er während seiner Dienstzeit bei der Flotte direkten Kontakt hergestellt haben muss. Patronage und spezialisierte Kenntnisse eröffneten ihm schließlich die lukrative Stellung als Feuerwehrkommandant in der Hauptstadt, die er aber erst einnehmen konnte, nachdem er zum Islam übergetreten war.

Dass der Übertritt zum Islam in Zusammenhang mit Patronage-Verhältnissen stehen konnte, lässt sich nicht nur bei Gerçek Dāvud nachweisen, sondern auch beim wohl bekanntesten Renegaten des 18. Jahrhunderts, bei Aḥmed Paşa alias Claude-Alexandre de Bonneval (1675-1747). Bonneval, ein französischer Adeliger und Militär, der bei verschiedenen europäischen Mächten in Dienst gestanden hatte, kam 1729 aufgrund eines Zerwürfnisses mit seinem ehemaligen Dienstherrn, dem habsburgischen Feldherrn Eu-

49 »Er genoss Zuwendung und Gunst von Seiten des oben erwähnten Wesirs«. (»Vezīr-i müşārün ileyhi țarafından maz̧har-i iltifāt ü iḥsān olup ...«). ÇELEBizāde, Tārīh, fol. 64r. İbrāhīm Paşa lässt sich nicht zweifelsfrei identifizieren. Laut der Liste der Flottenkommandanten (kapudan paşa) in Hammer, Geschichte, Bd. VII, S. 624, gab es zwei Flottenkommandanten mit dem Namen İbrāhīm: Kāhyā İbrāhīm Paşa, der 1709 bis 1711 und 1717 bis 1718 im Amt war, und Hoca İbrāhīm, der den Posten von Januar bis April 1713 bekleidete; Letzterer hatte den Rang eines Wesirs inne und wurde 1713, nachdem er drei Wochen lang Großwesir gewesen war, wegen einer Verschwörung hingerichtet; ebd., S. 165f., 623. Es ist also möglich, dass Dāvud bereits vor seiner Niederlassung in Galata im Dienst der Flotte gestanden hatte.

50 »Nach der Rückkehr erlangte er zusammen mit seinem Sohn und seinen Angehörigen die Ehre des Islams und wurde unter dem Namen Gerçek Dāvud bekannt und berühmt«. (»'Avdetden șoñra oğlu ve ${ }^{c}$ ayāli ile şerefyāb-1 islām ve Gerçek Dāvud ismile ma ${ }^{c}$ rūf ve benām olmışıdı«). ÇELEBIZĀDE, Tārīhn, fol. 64r.

51 Ebd. Die 120 akça täglich waren dreimal soviel wie ein Kommandant einer Festungsartillerietruppe in Bosnien bezog, dem jedoch 90 Männer unterstanden (siehe Нıскок, Ottoman Military Administration, S. 61), während Gerçek Dāvud als țulumbacı ağası nur 53 Männer befehligte. 
gen von Savoyen-Carignan (1663-1736), ins Osmanische Reich, wo er dem Sultan Ahmed III. seine Dienste anbot ${ }^{52}$. Er trat zum Islam über, nachdem er unter den Schutz des Gouverneurs von Bosnien, Ġāzī Aḥmed Paşa, und des dortigen Janitscharencorps getreten war. Durch die Annahme des Islams und dank der Protektion Ġāzī Aḥmeds kam er einer drohenden Ausweisung zuvor $^{53}$. Bonneval, der - vielleicht als Zeichen der Verbundenheit mit seinem Protektor Ġāzī Aḥmed Paşa - den Namen Aḥmed angenommen hatte,

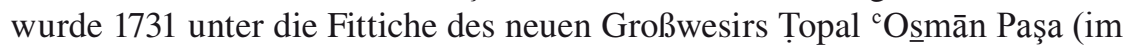
Amt 1731-1732) genommen. Dieser rief ihn nach Istanbul und beauftragte ihn mit der Schaffung eines neuen Granatwerfercorps für die Armee ${ }^{54}$.

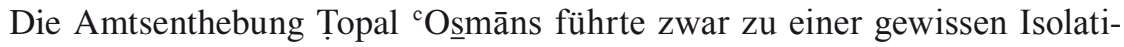
on Aḥmeds / Bonnevals, er fand aber mit der Zeit Zugang zum neuen Großwesir Hekīmoğlu ${ }^{\mathrm{c} A l i ̄ ~ P a s ̧ a ~(i m ~ A m t ~ 1732-1735, ~ 1742-1743 ~ u n d ~ 1755) . ~ U n-~}$ ter Hekīmoğlu ${ }^{\mathrm{c}} \mathrm{Al} \overline{1}$ erlange er Bedeutung und Einfluss als außenpolitischer und militärischer Berater der Regierung. Hekīmoğlu ' $\mathrm{Al}$ ī Paşas Protektion, der notabene ein Sohn Nūḥ Efendis, des ehemaligen Leibarztes Aḥmeds III., war, verdankte er auch die Ernennung zum Chef des Granatwerfercorps (kumbaracı/humbaracı başı) und damit die Beförderung zum paşa ${ }^{55}$. Später fiel der französische Renegat bei einem anderen Großwesir, Yeğen Mehmed Paşa (im Amt 1737-1739), in Ungnade und wurde nach Kastamonu (Nordanatolien) verbannt; er konnte jedoch auf die Protektion von el-Hāacc Beşīr Ağa (gest. 1746), dem Obereunuchen des Sultansharems (kılar ağası), bauen ${ }^{56}$.

Hier ist kein Platz, um alle Amtsversetzungen, Gunstbezeugungen und Gunstentzüge zu besprechen, die Aḥmed Paşa alias Bonneval erlebte, oder auf die diplomatischen Aktivitäten einzugehen, die er in Istanbul betrieb ${ }^{57}$. Wichtig ist aber, dass Bonneval in den hohen Stellungen, die er als Ahmed Paşa bekleidete, selbst als Patron auftreten konnte und auch eine Anzahl europäischer Renegaten protegierte. Schon bei seiner Reise nach Istanbul Anfang 1732 wurde er von »einem 20-köpfigen Gefolge von Renegaten, die sich

52 Für eine Kurzbiographie Bonnevals siehe H[arold] Bowen, Art. Aḥmad Pasha Bonneval, in: Encyclopédie de l'islam. Nouvelle édition, Bd. I, Leiden 1960, S. 292.

53 Charles de Ligne, Mémoire sur le comte de Bonneval, in: Ders., Euvres choisies, littéraires, historiques et militaires, Bd. I, Genf 1809, S. 258-408, hier: S. 394-404; siehe auch Albert Vandal, Le pacha Bonneval, Paris 1885, S. 35f., und Heinrich Benedikt, Der Pascha-Graf Alexander von Bonneval. 1675-1747, Graz 1959, S. 86-90.

54 De Ligne, Mémoire, S. 404f.; Vandal, Bonneval, S. 38f.; Hammer, Geschichte, Bd. VII, S. 414; BENEDIKT, Bonneval, S. 93-95.

55 Vandal, Bonneval, S. 40-45; Hammer, Geschichte, Bd. VII, S. 436; Benedikt, Bonneval, S. 114-117.

56 Hammer, Geschichte, Bd. VIII, S. 2. Für el-Hāec Beşīr Ağa siehe Henning Sievert, Zwischen arabischer Provinz und Hoher Pforte. Beziehungen, Bildung und Politik des osmanischen Bürokraten Rāg̀ıb Meḥmed Paşa (st. 1763), Würzburg 2008, S. 521; für Hekīmoğlu 'Alī Paşa und Yeğen Meḥmed Paşa siehe ebd., S. 526f. bzw. S. 543.

57 Ausführlich dazu Benedikt, Bonneval. 
ihm angeschlossen hatten «, begleitet ${ }^{58}$. Im Jahre 1733 boten ihm drei Europäer in einem Brief an, in den Dienst des Sultans zu treten und Muslime zu werden; Bonneval ordnete sie später als Offiziere in sein Granatwerfercorps $e^{2 i n}{ }^{59}$. Des Weiteren beschäftigte Bonneval als Aḥmed Paşa »un abbé renégat « als Sekretär ${ }^{60}$ und hatte in dem Mailänder Renegaten Süleymān einen Adoptivsohn, der früher sein Kammerdiener gewesen war und im Osmanischen Reich mit seiner Ehefrau aus Rochefort im Haushalt seines Adoptivvaters lebte. Dieser Süleymān folgte ihm nach seinem Tode als Befehlshaber des Granatwerfercorps nach ${ }^{61}$.

\section{Soziale Konversion}

Wenn man die oben angesprochenen Biographien europäischer Renegaten vor Augen hat, stellt sich die Frage nach der sozialen Relevanz ihres Beitritts zur muslimischen Religionsgemeinschaft. Um diese Frage zu beantworten, kann das Konzept der »sozialen Konversion« herangezogen werden. In Anlehnung an Richard Bulliet versteht man eine soziale Konversion als den Übertritt von der einen religiös definierten sozialen Gemeinschaft zu einer anderen. Eine soziale Konversion impliziert, dass sich ein Individuum nach der formellen Konversion zum Islam, das heißt nach dem öffentlichen Aussprechen des islamischen Glaubensbekenntnisses ( $\check{s} a h \bar{a} d a$ ), als Angehöriger der muslimischen Religionsgemeinschaft verstand und begann, sich als Muslim neu zu definieren ${ }^{62}$. Bei der Diskussion der sozialen Konsequenzen des Übertritts zum Islam geht Bulliet von dem Axiom aus, dass ein Individuum nur dann konvertierte, wenn die Konversion seinen sozialen Status nicht beeinträchtigte ${ }^{63}$ : Die Konversion zum Islam war demnach vor allem dann eine Option, wenn sie zur Verbesserung der gesellschaftlichen Stellung des Konvertiten beitrug. Wenn man also den Übertritt zum Islam als eine soziale Konversion begreift, muss man das Augenmerk auf seine sozialen Ursachen und Auswirkungen legen.

58 Ebd., S. 93.

59 Hammer, Geschichte, Bd. VII, S. 449. In ihrem Brief an Bonneval vom 26. Dez. 1733 stellten sie sich als »trois François, l'Abbé de Maccarthy d'Aglis, le C. de Ramzay et le Marquis de Mornay Monchevreuil« vor: »Nous venons de quitter la France dans le dessein d'offrir nos services à S.H. [d.h. dem Sultan] et de nous faire Musulmans«. Laut Charles de Ligne handelte es sich um den Franzosen »Mormai«, den Schotten »Ramsay« und den Iren »Macarty«, die sich bald wieder absetzten, nachdem ihnen die Türkei verleidet war. Vgl. DE Ligne, Mémoire, S. 301f.

60 VANDAL, Bonneval, S. 58.

61 De Ligne, Mémoire, S. 312; Hammer, Geschichte, Bd. VIII, S. 87, 203.

62 Richard W. Bulliet, Conversion to Islam in the Medieval Period. An Essay in Quantitative History, Cambridge Mass. 1979, S. 33f.

63 Ebd., S. 41. 
Im frühneuzeitlichen Osmanischen Reich war die Zugehörigkeit zur muslimischen Religionsgemeinschaft ein wichtiger Faktor für die soziale Identität eines Individuums, von dem auch seine sozialen Aufstiegsmöglichkeiten abhingen. So konnte die Annahme des Islams für einen räumlich mobilen Menschen, der - unter welchen Umständen auch immer - im Osmanischen Reich ankam, ein Mittel sein, um soziale und kulturelle Schranken zu überwinden. Der Übertritt eröffnete ihm sowohl Chancen auf Integration als auch zum sozialen Aufstieg, da es ihm so möglich wurde, von einer sozialen Gruppe in eine andere zu wechseln.

Die frühneuzeitliche osmanische Gesellschaft bestand aus klar definierten und voneinander abgegrenzten sozialen Gruppen mit unterschiedlicher rechtlicher Stellung: Der Mehrheit der Steuern zahlenden Untertanen - den $r e^{c} \bar{a} y \bar{a}(»$ Herde $\ll)$ - stand die rechtlich und steuerlich privilegierte Schicht der ${ }^{c}$ askerī (»Militär«) gegenüber, deren Mitglieder die Herrschaft ausübten oder mit der Herrschaft verbunden waren. Diese ${ }^{c}$ askeri-Schicht war hierarchisch strukturiert und ihrerseits in drei Gruppen mit unterschiedlichen Funktionen und sozialen Rollen gegliedert; nämlich in das Militär im eigentlichen Sinne (seyflye), in die Angehörigen des staatlichen Verwaltungsapparates (kalemīye) und in die religiös-juristische Elite aus Religions- und Rechtsgelehrten ( ${ }^{c} i l m \bar{i} y e$ ). Ebenso wichtig wie die Gegenüberstellung von ${ }^{c}$ asker $\bar{\imath}$ und $r e^{c} \bar{a} y \bar{a}$ war die Unterscheidung zwischen Freien und Unfreien (Sklaven), sowie die Unterscheidung nach Religionsgruppen (millet). Unfreie hatten selbstredend weniger Rechte als Freie, und Muslime standen gesellschaftlich über den rechtlich und steuerlich unterprivilegierten Christen und Juden (zimmīs). Frauen schließlich standen, gleich ob sie Musliminnen waren oder nicht, in der Gesellschaftshierarchie unter den Männern. Die Stellung eines jeden Individuums hing also von mehreren juristisch relevanten Unterscheidungsmerkmalen ab, nämlich davon, ob eine Person männlich oder weiblich war, Muslim oder Nichtmuslim, frei oder unfrei und ob sie zur herrschenden Schicht der ${ }^{c} a s k e r \bar{\imath}$, oder zur Mehrheit der Untertanen, den $r e^{c} \bar{a} y \bar{a}$, gehörte. Die ethnische Zugehörigkeit spielte neben diesen vier hauptsächlichen Unterscheidungsmerkmalen nur eine untergeordnete Rolle ${ }^{64}$.

Obwohl diese Unterscheidungsmerkmale eine festgefügte gesellschaftliche Hierarchie und stabil erscheinende Gruppenzugehörigkeiten definierten, waren die gesellschaftlichen Schranken, die die einzelnen Gruppen voneinander trennten, keineswegs undurchlässig. Vielmehr bot die osmanische Gesellschaft Möglichkeiten, von der einen Gruppe in die andere zu wech-

64 Einen guten Überblick über diese sozialen Unterscheidungsmerkmale findet sich in Marc BAER, Islamic Conversion Narratives of Women. Social Change and Gendered Religious Hierarchy in Early Modern Ottoman Istanbul, in: Gender \& History 16 (2004), S. 425-458, hier: S. 431-433. 
seln, wenn man das Geschlecht - die wahrscheinlich wichtigste soziale Determinante - außer Acht lässt ${ }^{65}$.

So war etwa der soziale Status von Sklaven wandelbar: Sklaverei war üblicherweise kein permanenter Zustand, da Sklaven oft durch Freilassung die Rechte von frei geborenen Menschen erlangen konnten. Sklaven kamen in der Regel von außerhalb des Reiches, sie waren Kriegsgefangene oder »Kriegsbeute «, da frei geborene Muslime wie auch andersgläubige Untertanen des Osmanischen Reiches von Rechts wegen nicht versklavt werden durften. Eine Ausnahme stellten jene Eliteangehörige dar, die über die devşirme (»Knabenlese«) rekrutiert wurden, durch die über lange Zeit hinweg die Reihen der Janitscharen und die Stellungen im Sultanspalast gefüllt wurden. Diese Männer waren dem Staat im Knabenalter von den christlichen Untertanen als eine Art »Steuer« übergeben worden. Im Laufe ihrer Ausbildung und Resozialisation traten sie zum Islam über und wurden dann als Erwachsene in militärische und administrative Funktionen eingesetzt. Sie galten als kapu kulları (»Sklaven der Pforte«, d.h. des Sultans) und behielten den rechtlichen Status als Sklaven auch dann bei, wenn sie als ${ }^{c}$ askerīs Herrschaftsfunktionen ausübten ${ }^{66}$.

Jugendliche Kriegsgefangene, die als Sklaven in den Sultanshaushalt kamen, wurden dort in derselben Art als Osmanen resozialisiert wie jene unter den kapu kulları, die über die Knabenlese rekrutiert wurden. Zwischen Kriegsgefangenen und devşirme-Rekruten wurde nicht unterschieden und auch ihre Karrieremuster sind die gleichen. Unter den Kriegsgefangenen wurden gerade junge Adelige wie Scipione Cicala und Gutierre Pantoja als geeignet angesehen, um im Sultanshaushalt integriert zu werden und dort die übliche Ausbildung als Pagen zu durchlaufen. Denn vornehme Herkunft galt - wie auch ein gefälliges Aussehen - als gute Voraussetzung, um nach erfolgter Resozialisierung und Ausbildung als Herrschaftsträger zu fungie$\mathrm{ren}^{67}$. Die rechtliche Stellung als kapu kulları und die daraus resultierende Zugehörigkeit zum Sultanshaushalt bestimmten den sozialen Status und damit die soziale Identität dieser Männer. Bei Çı̆̆āazazāde Sinān Paşa wurde diese persönliche Bindung an den Sultanshaushalt durch Ehen mit Sultanstöchtern gestärkt ${ }^{68}$, wobei der Status eines Schwiegersohns des Sultans

65 Vgl. dazu und für das Folgende BAER, Conversion Narratives, S. 433-435.

$66 \mathrm{Zu}$ den kapu kulları und anderen Aspekten der Sklaverei im Osmanischen Reich siehe Daniel Goffman, The Ottoman Empire and Early Modern Europe, Cambridge 2002, S. 64-69.

67 Siehe Bon, Sultan's Seraglio, S. 67f.

68 Dies gilt auch für die Einbindung in andere osmanische Elitehaushalte. Jocelyne Dakhlia hat darauf hingewiesen, dass die Konversion von Renegaten in Nordafrika nicht nur Auswirkungen auf ihre religiöse Identität hatte, sondern auch auf die soziale, da ihr Resozialisierungsprozess in den Elitehaushalten auch eine Neudefinition der familiären oder abstammungsmäßigen Identität implizieren konnte. Ausschlaggebend war hierbei die Einbindung in eine neue »Familie« durch eine Art Adoption (bei Minderjährigen) oder durch eine Ehe (bei Mündigen). Siehe 
$(d \bar{a} m \bar{a} d)$ als großes Privileg und als Auszeichnung galt ${ }^{69}$. Die ${ }^{c}$ askerī-Schicht setzte sich nicht nur aus devşirme-Rekruten und Kriegsgefangenen zusammen. Vielmehr hatten auch erwachsene Angehörige der $r e^{c} \bar{a} y \bar{a}$ die Möglichkeit, in die herrschende Schicht der ${ }^{c}$ askerīs einzutreten, wenn sie für den Dienst des Sultans beziehungsweise des Staates rekrutiert wurden. Dies wurde spätestens ab dem 17. Jahrhundert einfacher, als die Schranken zwischen den beiden Gruppen nach und nach niedriger wurden ${ }^{70}$. Diese Entwicklung ging mit dem Ende der Rekrutierungsmethode der devşirme einher, die ab Mitte des 17. Jahrhunderts mehr und mehr außer Gebrauch kam und schließlich ganz aufgegeben wurde. In derselben Zeit ist ein Erstarken der Haushalte von hochstehenden Angehörigen der ${ }^{c}$ askerī-Schicht zu beobachten. Dadurch wurde eine indirekte Rekrutierung in den Staatsdienst häufiger, indem $r e^{c} \bar{a} y \bar{a}$-Angehörige durch Patronage- und Gefolgschaftsverhältnisse (intisāb) an Elitemitglieder gebunden und durch ihre Patrone in Stellen des Staatsapparats eingesetzt wurden ${ }^{71}$.

Wie Reichsuntertanen konnten auch Zuwanderer von außen in Patronageund Gefolgschaftsverhältnisse von Eliteangehörigen aufgenommen werden. Ihre Zugehörigkeit zu einem Elitehaushalt konnte so zu einem Faktor für ihre Integration und soziale Mobilität werden. Auch die Annahme des Islams muss im Zusammenhang mit der Einbindung in osmanische Elitehaushalte und deren Patronagenetzwerke gesehen werden ${ }^{72}$. Darauf deutet etwa

Jocelyne DAKHLIA, «Turcs de profession»? Réinscriptions lignagères et redéfinitions sexuelles des convertis dans les cours maghrébines (XVI $-\mathrm{XIX}^{\mathrm{e}}$ siècles), in: Mercedes García-ArenaL (Hg.), Conversions islamiques. Identités religieuses en islam méditerranéen/Islamic Conversions. Religious Identities in Mediterranean Islam, Paris 2001, S. 151-171.

69 Dieser Status war ein wichtiges Distinktionsmerkmal, was sich daran zeigt, dass Schwiegersöhne des Sultans oft den Namenszusatz dāmād trugen (z.B. Nevşehirli Dāmād İbrāhīm Paşa).

70 Zahlreiche muslimische Untertanen, insbesondere städtische Handwerker, nutzten ab dieser Zeit die Möglichkeit, sich in den Soldlisten der Militärcorps, vor allem der Janitscharen, eintragen zu lassen. Sie wurden so zu ${ }^{c}$ askerīs, auch wenn sie nie Militärdienst leisteten, und konnten damit Steuern umgehen und von der Protektion durch Janitscharenoffiziere profitieren. Auch Janitscharen, die auf dem regulären Weg in die Corps gekommen waren, engagierten sich in dieser Zeit zunehmend als Handwerker und Kaufleute in städtischen Gewerben, um ihren Sold aufzubessern. Im späten 18. Jahrhundert hatte die Unterscheidung zwischen $r e^{c} \bar{a} y \bar{a}$ und 'askerī, wie auch die Aufgliederung der Letzteren in seyfīye, kalemīye und 'ilmīye eher idealtypische Bedeutung, vor allem für die politische Theorie. Siehe SIEvERT, Rāġıb Mehmed, S. 30.

71 Auch Patronagebeziehungen zu Eliteangehörigen (Wesire, Gouverneure, Offiziere usw.) gingen oft mit der formellen Einbindung in deren Haushalt einher. Dort pflegte man Gefolgschafts- oder Patronageverhältnisse im Vokabular der Freundschaft oder der Verwandtschaft auszudrücken: Man findet in diesem Zusammenhang Ausdrücke wie tacalluḳāt oder aḳrabā (»Verwandte «) und $t a \bar{a} b i^{c}$ (»Anhänger $\ll$ ). Siehe DAkHLiA, Turcs de profession; für die osmanischen Elitehaushalte siehe auch Sievert, Rāg̀ı Meḥmed, S. 30-35.

72 Für den Zusammenhang von Patronage und Konversion siehe auch Tijana Krstić, Illuminated by the Light of Islam and the Glory of the Ottoman Sultanate: Self-Narratives of Conversion to Islam in the Age of Confessionalization, in: CSSH 51/1 (2009), S. 35-63, hier: S. 43. 
Gerçek Dāvuds Übertritt zum Islam hin, der erst dann erfolgte, als er in der Gunst eines hohen Amtsträgers stand. Hinweise auf den Zusammenhang von Patronagebeziehungen und dem Wechsel der Religionszugehörigkeit lassen sich auch bei Ahmed Bonneval finden. Nahmen Renegaten wie Letzterer hohe Stellungen ein, konnten sie gleich wie osmanische Eliteangehörige als Patrone agieren.

Die Aussicht auf Stellungen in Staat und Militär oder auch die Suche nach steuerlichen und rechtlichen Privilegien, die ${ }^{c}$ askerī-Angehörigen zustanden, kann bei vielen Reichsuntertanen als Beweggrund für den Übertritt zum Islam betrachtet werden. So begannen in der Zeit, als die devşirme-Praxis aufgegeben wurde, nichtmuslimische Reichsuntertanen die Annahme des Islams zu nutzen, um sich so Zutritt zu militärischen oder paramilitärischen Verbänden zu verschaffen, war doch die Zugehörigkeit zur muslimischen Religionsgemeinschaft eine Voraussetzung für den Dienst in den osmanischen Militärcorps ${ }^{73}$. Aber auch ohne einen nachfolgenden Eintritt in die ${ }^{c}$ askerīSchicht konnte ein Nichtmuslim durch die Annahme des Islams die relativen Privilegien erlangen, die osmanische Muslime in rechtlicher, steuerlicher und sozialer Hinsicht gegenüber den zimmīs genossen. Jedoch nicht nur christliche und jüdische Reichsuntertanen konnten ihren sozialen Status durch die Annahme des Islams gewinnbringend verändern ${ }^{74}$, sondern auch Zuwanderer von außerhalb des Reiches oder Nichtmuslime, die zwangsweise ins Osmanische Reich verpflanzt worden waren.

Es waren die gesellschaftliche Flexibilität und die Durchlässigkeit der sozialen Grenzen, die es Zuwanderern von außen erlaubten, sich in die osmanische Gesellschaft zu integrieren und in ihr aufzusteigen. Europäer, die als Jugendliche in den Haushalt des Sultans eingebunden wurden, durchliefen im Sultanspalast einen sozialen und kulturellen Transformationsprozess, der sie zu Angehörigen der osmanischen ${ }^{c}$ askerī-Elite machte. Wie devşirmeRekruten konnten sie in die höchsten Staatsämter aufsteigen. Europäer, die als Erwachsene aufgrund spezialisierter Kenntnisse die Protektion von osmanischen Amtsträgern erlangten, konnten nach dem Übertritt zum Islam ebenfalls in die Reihen der ${ }^{c}$ askerīs eintreten. Ihre Aufstiegsmöglichkeiten waren jedoch begrenzt. Gerçek Dāvud ist als Feuerwehrkommandant in Istanbul allenfalls in der Mitte der militärischen und administrativen Hierarchie anzusiedeln. Bonneval wurde zwar paşa, konnte sich aber keine dauerhafte Position sichern, da er wahrscheinlich nicht zuletzt aufgrund seiner

73 Siehe Anton Minkov, Conversion to Islam in the Balkans. Kisve Bahası Petitions and Ottoman Social Life, 1670-1730, Leiden 2004, S. 109.

74 Für soziale Auswirkungen der Konversion bei osmanischen Reichsuntertanen vgl. MinKov, Conversion to Islam, und Marc David BAER, Honored by the Glory of Islam. Conversion and Conquest in Ottoman Europe, New York 2008, S. 14f. 
mangelnden sprachlichen und kulturellen Kenntnisse ein Außenseiter blieb. Er blieb stark von der Gunst höhergestellter Amtsträger abhängig.

\section{Schlussbetrachtungen}

In den Biographien der europäischen Renegaten, die hier besprochen wurden, zeigt sich, dass ihr Übertritt zum Islam in zwei unterschiedlichen Situationen erfolgte: Auf der einen Seite gab es Sklaven und Gefangene, die im Zustand der Unfreiheit den Islam annahmen; auf der anderen Seite nahmen Migranten, die aus mehr oder weniger freien Stücken ins Osmanische Reich kamen, den Islam freiwillig an. In beiden Fällen hatte der Übertritt zur muslimischen Religionsgemeinschaft soziale Auswirkungen und Folgen; diese konnten aber je nach Situation, in der ein Übertritt erfolgte, anders aussehen, da die Stellung als Sklave beziehungsweise als Freier unterschiedliche Voraussetzungen und Möglichkeiten für Integration und sozialen Aufstieg bot.

Gefangene und Sklaven nahmen den Islam im Verlauf ihrer Resozialisierung in einem Elitehaushalt an. Besondere Bedeutung kam dabei dem Sultanshaushalt zu, in den mindestens bis in die Mitte des 17. Jahrhunderts west- und mitteleuropäische Kriegsgefangene als Sklaven integriert wurden. Dies hing mit der Expansion des Reiches zusammen, die einen steten Bedarf an Verwaltungsfunktionären und Militärs generierte. Bei Männern wie Ġażanfer Ağa und »Frenk» Meḥmed Ağa, Çı̆̆ālazāde Yūsuf Sinān Paşa und Gutierre Pantoja waren soziale Integration und Aufstieg daher eng mit den spezifisch osmanischen Methoden der Elitebildung verknüpft. Sie alle gelangten als Jugendliche in den Haushalt eines Sultans und hatten als junge Sklaven wohl keine Wahl, ihrer angestammten Religion treu zu bleiben. Die Resozialisierung und Ausbildung, die sie als Pagen erfuhren, befähigten sie, als Erwachsene hohe Ämter im Sultanshaushalt, im Militär und in der Zentralverwaltung bis hin zum Großwesir zu bekleiden. Çı̆̆ālazāde Yūsuf Sinān und Gutierre Pantoja waren zudem auch adeliger Abkunft. Ihre soziale Herkunft machte sie für eine Integration in den Haushalt des Sultans besonders attraktiv oder wurde als gute Voraussetzung dafür gesehen, ihnen später einmal hohe Funktionen zu übertragen.

West- und Mitteleuropäer wie Gerçek Dāvud Ağa und Aḥmed Paşa Bonneval, die als Erwachsene mehr oder weniger freiwillig ins Osmanische Reich kamen, traten im Zuge ihrer Integration in die osmanische Gesellschaft zum Islam über. Sie brachten beide spezialisierte Kenntnisse und Fähigkeiten mit, die sie anbieten konnten, ein Kapital, das sie durch ihren Übertritt zum Islam ergänzten. Als Muslime hatten sie die Möglichkeit, in die ${ }^{c}$ askerī-Schicht einzutreten und Stellungen in Staatsapparat und Militär einzunehmen. Ihr Übertritt zum Islam und ihre Einsetzung in staatliche Ämter standen aber 
auch in Zusammenhang mit Patronageverhältnissen zu Angehörigen der osmanischen Elite und deren Haushalten. Beide agierten im Kontext der erstarkenden osmanischen Elitehaushalte des 18. Jahrhunderts und waren in Bezug auf ihre Ämter und ihre soziale Stellung auf die Protektion und Förderung durch Wesire angewiesen. Als erwachsene Zuwanderer hatten sie jedoch nicht dieselben Karrieremöglichkeiten wie jene West- und Mitteleuropäer, die in jungen Jahren im Herrscherhaushalt resozialisiert und ausgebildet wurden.

Der Übertritt zum Islam, den die in diesem Beitrag besprochenen Renegaten vollzogen, ist als eine soziale Konversion zu sehen. Als solche war er ein zentrales Element in einem Adaptionsprozess an ein neues soziales und kulturelles Umfeld. Er hatte sowohl soziale Ursachen als auch soziale Auswirkungen, da er eine Veränderung der rechtlichen und sozialen Stellung des Renegaten mit sich brachte. In diesem Sinne war der Übertritt zum Islam Bestandteil oder Ausgangspunkt eines Transformationsprozesses, der auf eine Neudefinition des Renegaten in sozialer, religiöser und kultureller Hinsicht hinauslaufen konnte. Die Annahme des Islams war zwar ein notwendiger Bestandteil der Resozialisierung im Sultanspalast und eine Voraussetzung für den Eintritt in den Staatsdienst, aber sie war sicher nicht allein ausschlaggebend für einen sozialen Aufstieg und eine Karriere im Staatsapparat. Vielmehr spielten hierbei stets auch andere Faktoren eine Rolle: Die richtigen Kontakte und ein einflussreicher Patron waren maßgeblich für ein Fortkommen. Beziehungen zu anderen Renegaten, Netzwerke innerhalb der Elite sowie Ehen beeinflussten die Stellung eines Renegaten. Bei erwachsenen $\mathrm{Zu}-$ wanderern konnten spezialisierte Kenntnisse in Militärwesen, Politik und Diplomatie, Medizin und anderen Bereichen Karrierewege öffnen. Zudem konnten sie Beziehungen, die sie mit ihrer Herkunftsregion unterhielten, als soziales Kapital nutzbar machen. 


\title{
Manuel F. Fernández Chaves and Rafael M. Pérez García
}

\section{Mobility under suspicion}

\author{
The Moriscos in early modern Spain*
}

\section{The Moriscos in Spain, 1502-1568}

Those Muslims who lived on the Iberian Peninsula and were obliged to convert to Catholicism or to leave the kingdom of Castile after 1502 and the kingdom of Aragon after 1526 are known as Moriscos or cristianos nuevos de moros $^{1}$. Castile and Aragon were both governed by the same dynasty (first Trastámara, then Habsburg), and the conversion of the Muslims in both areas was linked to violent uprisings and coercion by civil and ecclesiastic authorities combined with considerable pressure to uproot Islam from the territories pertaining to the Catholic monarch. The newly converted became secondclass citizens, enduring greater fiscal burdens and continually suspected of lacking fidelity to the monarchy's official religious creed, and sought refuge in seigniorial jurisdictions to mitigate the enforcement of civil and religious dictates seeking their control and vigilance. The Muslims who lived in Castile, the »Mudejars« (mudéjares), were also subjected to these measures, although longer periods of cohabitation with Old Christians (cristianos viejos) made them appear less suspicious to the authorities. Nevertheless, the immense majority of the Moriscos were considered potential rebels and social suspects, largely due to the forced nature of their conversions and, for many, their manifest preservation of the Islamic faith.

After the rebellions and conversions of 1499-1501, the Moriscos of the kingdom of Granada remained in a state of relative peace, due to the fact that the measures for their acculturation proclaimed under the Catholic Monarchs, their daughter Queen Juana, and their grandson, the Emperor Charles V, and synthesized in specific ordinances dictated in the Royal Chapel of Granada in 1526, remained largely ineffective due to delays in their enforcement that the Moriscos »purchased« in exchange for important sums ${ }^{2}$. The monarchs' temporary leniency did not fully prevent pressure from Inquisitorial tribu-

* This article has been researched, written and translated within the project of excellence, »En los orígenes de la Andalucía multicultural. Integración y rechazo de los moriscos (Reinos de Córdoba y Sevilla, siglos XVI y XVII)«, (P07-HUM-2681), financed by the Consejería de Innovación, Ciencia y Empresa of the Junta de Andalucía.

1 Literally »new Christians from Moors «.

2 The matter of this forty-year »truce «, largely mythified in the historiography itself, has been 
nals nor exactions of secular justice ${ }^{3}$. During the reign of Philip II, a policy of assimilation through the negation of the minority's specific cultural traits (dress, traditional marriage customs, baptism and death, baths, songs and music, etc.), alongside the harshening of its treatment as a conquered population (special taxes - the farda exacted in the kingdom of Granada to finance the defense of the coasts) and constant vigilance over its observance of Catholic rites, with penalties imposed for noncompliance, in addition to its possible role - considered a fifth column in the heart of the Empire ${ }^{4}$ - in supporting a potential Turkish landing, only exacerbated the situation. Philip II abolished the temporary policy of »looking the other way « by emitting a decree in 1567 that established a period of one year for eliminating all cultural traits of the Moriscos without a trace. After various attempts at negotiations, an uprising of the Moriscos of the kingdom of Granada on Christmas of 1568 unleashed a bloody war, the most sought-after by-product of which was human booty, made possible by royal authorization to enslave defeated rebels. This war and its immediate aftermath entailed a very important loss of population in the kingdom of Granada, as Philip II attempted to break the Moriscos' networks of solidarity and ties to Islam by deporting large contingents of them. Thus began the second period of the Moriscos in Castile. The Valencian Moriscos, much more tied to the land and more dependent on their lords, did not stage a similar rebellion, although their greater success in preserving the Islamic faith made the king and his ministers continually suspicious of them ${ }^{5}$. The problem of the Moriscos and their integration became more complex during the following period and until their definitive expulsion in 1609-1614.

\section{Forced Conversions or the Search for Salvation}

From the time of their conversion, Moriscos were considered potential apostates, continually suspected of heresy. Hence, their freedom of movement was questioned from the moment that it might lead to contact with North

reviewed and updated in Rafael Benítez Sánchez Blanco, Heroicas decisiones. La Monarquía Católica y los moriscos valencianos, Valencia 2001.

3 Regarding the differential taxation of Mudejars and then Moriscos, see Ángel GaLÁn SÁncheZ, »Herejes consentidos«. La justificación de una fiscalidad diferencial en el Reino de Granada, in: Historia, Instituciones, Documentos 33 (2006), pp. 173-209.

4 On the extent of understandings with the Turk, see Andrew C. Hess, The Moriscos: An Ottoman fifth column in Sixteenth-Century Spain, in: AHR 74/1 (1968), pp. 1-25. Also, Joan ReGLÀ, La cuestión morisca y la coyuntura internacional en tiempos de Felipe II, in: Estudios de Historia Moderna 3 (1953), pp. 219-234.

5 This process in its entirety was explained in Antonio Domínguez Ortiz/Bernard Vincent, Historia de los moriscos, Madrid ${ }^{52003, ~ p p . ~ 17-33 . ~ F o r ~ a n ~ u p d a t e ~ r e g a r d i n g ~ t h e ~ k i n g d o m ~ o f ~}$ Granada, see Manuel Barrios Aguilera (ed.), Historia del Reino de Granada, vol. II, Granada 2001. 
African Islam. With this in mind, Queen Juana dictated in 1515 a provision that prohibited the »newly converted « of the kingdom of Granada as well as other kingdoms pertaining to the crown of Castile from selling their property. In this way, the crown attempted to prevent Moriscos from gathering resources in order to travel to North Africa and renege the Catholic faith, disdaining the benefits of their conversion to Christianity ${ }^{6}$. Similarly, another decree of the same date prohibited Castilian Moriscos from going to the kingdom of Granada to do business, due to the supposed threat to the integrity of their new faith ${ }^{7}$. In a state of tension with North African Islam, commerce with the market towns on the littoral façade of that continent was also prohibited, especially the passing of arms, gunpowder, ammunition, or worked metals $^{8}$. These decrees were issued after the conversions of 1502, when an emigration barely controlled by the authorities began in the kingdom of Granada as well as on the other side of the straits of Gibraltar ${ }^{9}$, dramatically reducing the population of many coastal regions and the income of the crown. Many Moriscos followed the fatwa of al-Wansarisi, which encouraged emigration to an Islamic land if one could not practice the true faith, producing an important number of flights allende (»beyond the other side «) during three well-defined periods in the sixteenth century: 1500-1512, 1526-1535, 1560-1575. Other instances of fleeing from the actions of the Inquisition are also documented in that institution's records ${ }^{10}$.

Similar regulations were dictated in the kingdom of Valencia after the massive (and forced) conversions of 1521-1526. In the kingdom of Valencia, the Moriscos had been granted a period of time to adapt to the new faith and the restrictions were few after 1526. Nevertheless, prohibitions on mobility were enacted much earlier than those regarding religious matters. In 1530, for example, Charles V promulgated an edict that denounced the connivance between the newly converted and those Moors and Turks who devastated the coast of the exposed kingdom of Valencia, on the one hand, and the subsequent need to consistently limit their movements, on the other. From that time on, Moriscos who changed residence or lord without the requisite royal

6 Archivo General de Simancas (hereafter AGS): Cámara de Castilla (hereafter CC), Diversos (hereafter D), leg. 8, doc. 121, Arévalo, 15-II-1515. Cited in Serafín de TAPIA SÁnChez, La comunidad morisca de Avila, Salamanca 1991, p. 327, note 66 (the autor indicates a different location).

7 AGS: CC, D, leg. 8, doc. 120. Serafín de Tapia discusses this decree in his book.

8 AGS: CC, D, leg. 9, doc. 6.

9 Ángel Galán Sánchez/Rafael Peinado Santaella, Hacienda regia y población en el Reino de Granada. La geografía morisca a comienzos del siglo XVI, Granada 1997, pp. 80-117.

10 Jean-Pierre Dedieu/Bernard Vincent, Face a l'Inquisition. Jugements et attitudes des morisques à l'egard du tribunal, in: Louis CARDAILlAC (ed.), Les morisques et l'Inquisition, Paris 1990, pp. 83-84. The phases and movements of migrations to North Africa are treated in Domínguez Ortiz/Vincent, Historia de los moriscos, pp. 86-87. 
permission would be punished. Moriscos were not permitted in certain coastal areas, nor on roads near the sea that connected Alicante and Barcelona through Valencia, nor could they counsel Moors or Turks. Lords who protected such activities would also be punished ${ }^{11}$. These provisions were reiterated and expanded in 1541, claiming that changing residence served as an excuse to approach the coast and depart for Barbary in order to renege the Catholic faith. For this reason, the Pragmatic of 1541 repeated the provisions issued in previous years and considered receiving Moriscos from other kingdoms, such as Aragon, Catalonia or Granada, dangerous. Thus, anyone who moved would be »at the mercy of the royal Majesty and even upon pain of death or the loss of silver, coins, jewels and whatever movable goods could in fact be lost $\ll^{12}$. Moriscos could only move with royal authorization and, of course, lords of vassals could only accept new residents who carried this license. Upon penalty of death, Moriscos from other kingdoms had to leave Valencia if they had resided there fewer than five years ${ }^{13}$. As would be expected, receiving Turks or renegades who disembarked on the coast of Valencia, like Moriscos from other parts of the Iberian Peninsula, was strictly prohibited.

This decree was reissued with minor variations in $1545^{14}$. In any case, the presence of Aragonese Moriscos dedicated to the carrying trade and poor Castilian Moriscos remained constant. Alongside these groups, the continual arrival of enslaved Berbers helped maintain the vigor of Islam in the kingdom of Valencia. Many of the same Valencian Moriscos spent part of the year as muleteers, for, according to their lords, the excessive fiscal burden they bore forced them to seek to supplement their predominately agriculturallybased economy. They protagonized a frequent middle-distance commerce of considerable economic importance, whose requisite mobility was not subject to the lords' excessive vigilance ${ }^{15}$.

The Moriscos, who logically appreciated freedom of movement, rarely obtained it. Such freedom was one of the requests that the Moriscos of Cinco Villas del Campo de Calatrava made of the Catholic Monarchs in their voluntary conversion of 1502, when the Catholic Monarchs granted special guarantees for travelers alongside tax exemptions: »and that we order that you may go and travel and be in any cities, towns or places of our kingdoms

11 Valencia, 11-I-1530. See Manuel Danvila y Collado, La expulsión de los moriscos españoles. Ed., introd. y not. Kafael Benítez, Valencia 2007, pp. 253-255.

$12 \gg .$. a merce de la real Magestad fins a pena de mort inclusive e la roba, or, argent, diners, joyes, e bens mobles de aquelles ipso facto sien perduts «.

13 Pascual Boronat y Barrachina, Los moriscos españoles y su expulsión, two volumes, Granada 1992 [Facs. of the 1891 ed.]. Royal decree restricting the freedom of the Valencian Moriscos, 28-VII-1541, vol. I, pp. 469-473.

14 Boronat y Barrachina, Los moriscos españoles, vol. I, pp. 499-504.

15 Tulio Halperin Donghi, Un conflicto nacional. Moriscos y cristianos viejos en Valencia, Valencia 2008, pp. 69-71, 76-77. 
and lordships now and always, with no impediment placed upon you $[\ldots] \ll^{16}$ Cases like this one, nevertheless, were few and remained confined to certain populations of the kingdom of Granada that surrendered without a fight or to certain members of the collaborating elite $^{17}$. In the second case, the experiences of the Granada Venegas and the Muley Fez families, among others, are paradigmatic ${ }^{18}$.

Thus it seems clear that the principal risk that the monarchs sought to avoid was the loss of population, which would have implied the failure of the policies of Christian conquest as the axis of the expansionist discourse and effort systematically applied from the end of the fifteenth century. For this reason, the offense of fleeing to Barbary was one of those most punished by the Inquisition, as Michel Boeglin demonstrates for the tribunal of Seville and its kingdom ${ }^{19}$. Nevertheless, much more serious than in the Straits of Gibraltar was the problem in Valencia, above all in the south, where the same lords who permitted Islamic forms of life attempted to halt the immigration of Moriscos from the north of Africa, which the development of the state's mechanisms of costal vigilance would not reduce until the second half of the century. By this time the tolerance by certain lords of this traffic (letting others' vassals pass through for a charge) was giving way to direct relations

16 »y que mandasemos que agora y en qualquier tiempo pudiesedes yr e andar y estar en qualesquier ciudades villas e lugares de nuestros rreynos e señorios sin que vos fuese puesto ympendimiento alguno ...« The decree of the Catholic Monarchs appears in the genealogical information of a Morisco originally from Almagro in AGS, CC, leg. 2205, Información de Andrés Pastor, 1585.

17 This privilege was published by Luis Vázquez Fernández, Privilegio de no expulsión de los moriscos antiguos de las Cinco Villas del Campo de Calatrava (Ciudad Real). Documento para la Hisotria demográfica de Almagro, Bolaños, Vilarrubia, Daimiel y Aldea del Rey, in: I congreso de Historia de Castilla-La Mancha, vol. VII, Toledo 1988, pp. 289-299. See also the extensive analysis of Trevor J. DAdson, Los moriscos de Villarrubia de los Ojos (siglos XVXVIII). Historia de una minoría asimilada, expulsada y reintegrada, Madrid/Frankfurt am Main 2007.

18 Regarding the different capitulations for the surrender of different populations of the kingdom of Granada to the Catholic Monarchs, as a basis for the future internal legal differentiation of the Granadine Moriscos, see Miguel Ángel Ladero Quesada, Los mudéjares de Castilla en tiempos de Isabel I, Valladolid 1969. On social elites, see Enrique SoRIA Mesa, De la conquista a la asimilación. La integración de la aristocracia nazarí en la oligarquía granadina. Siglos XVXVII, in: Áreas 14 (1992), pp. 51-64; id., Una versión genealógica del ansia integradora de la élite morisca. El »Origen de la Casa de Granada«, in: Sharq al-Andalus 12 (1995), pp. 213-221, and id., Don Alonso de Granada Venegas y la rebelión de los moriscos. Correspondencia y mercedes de don Juan de Austria, in: Chronica Nova 21 (1993/1994), pp. 547-560. See also Juan Antonio García Luján, De arte y milicia. El linaje Granada Venegas, marqueses de Campo Téjar, in: Legajos 3 (2000), pp. 11-16, and María Jesús RuBiera MATA, La familia morisca de los Muley-Fez, príncipes meriníes e infantes de Granada, in: Sharq al-Andalus 13 (1996), pp. 159-167, as well as Bernard Vincent, Histoire d’une déchéance. La famille des Fez Muley à Grenade au XVIème siècle, in: Cahiers du C.R.I.A.R. 21 (2002), pp. 69-79.

19 Michel Boeglin, L'Inquisition espagnole au lendemain du Concile de Trente. Le tribunal du Saint-Office de Séville. 1560-1700, Montpellier 2003, pp. 235, 249-258. 
between the Valencian Moriscos and the inhabitants of Algiers and other localities, relations which took them to the other side of the ocean, although this clandestine emigration diminished in intensity ${ }^{20}$. We might classify this mobility as »religious «, for the aim of flight was to live and die under a law considered adequate for salvation. One of the most notorious cases was that of D. Sancho de Cardona, admiral of Aragón. This noble guaranteed his vassals safe passage to the coast, providing them, in exchange for small sums, with »guiatges« or passports to places in his lordship near the shore, where they could embark for the North of Africa. Because of this, he was denounced by various Old Christians and ecclesiastics in the region ${ }^{21}$. In the area, there existed a previously demolished mosque that had been rebuilt with the lord's permission, making it a center of pilgrimage for the Moriscos of Valencia, Aragon, Catalonia and Granada, a less drastic option for those who did not wish to emigrate to the neighboring continent: »many times there gathered more than six hundred persons, many of whom went there barefooted as if on a pilgrimage $\ll^{22}$. This fragment shows eloquently how the Moriscos managed to elude many of the restrictions upon their movements and to continue maintaining on the Peninsula the umma supposedly destroyed.

Hence, from early on, migration within the peninsula as well as the movement of cristianos nuevos de moros to the lands of Islam were considered subversive, although there were always exceptions. The motivations were of a religious, and undoubtedly also of an economic nature, given the demographic loss that the uncontrolled development of this problem entailed. The unwelcome loss of craftsmen and farmers was combined with the even greater problem of the return of many of them as corsairs, experts well acquainted with the peninsular hinterland and its weaknesses ${ }^{23}$. This situation, however, would change after the 1568 uprising in the kingdom of Granada and the succeeding war.

20 Halperin Donghi, Un conflicto nacional, pp. 106-116.

21 Boronat y Barrachina, Los moriscos españoles, vol. I, pp. 444-445, analyzed by Danvila y Collado, La expulsión de los moriscos, pp. 109-110. One of the accusations against the Andalusian preacher in Valencia, fray Bartolomé de los Ángeles, was that he had sold passports in order to subsist. HaLPerin Donghi, Un conflicto nacional, p. 127.

22 »muchas veces se juntaban a ello mas de seicientas personas muchas de las cuales iban alli descalzas como si fuessen en romeria«. The accusation of the Inquisitors of Valencia against don Sancho de Cardona is found in Boronat y Barrachina, Los moriscos españoles, vol. I, p. 451.

23 This migratory movement also attracted old Christians who went, willingly or kidnapped, to North Africa and returned as terrifying corsairs. Bartolomé Bennassar/Lucille Bennassar, Los cristianos de Alá. La fascinante aventura de los renegados, Madrid 1989. 


\section{The Moriscos after 1570}

Whereas flights and evangelization problems succeeded one another in the kingdom of Valencia, the situation in the kingdom of Granada reached a certain stability between 1530 and 1550 . Nevertheless, this stability would crumble as the reign of the emperor reached its end and his son, Philip, began assuming control of the government. His line of action, clearly favoring the resolutions of the Council of Trent, would soon impact the Moriscos.

The dispositions of the synod of Guadix of 1554 and of the Provincial Council of Granada of 1565, Inquisitorial action, and the decree issued in 1567 to eliminate all cultural traits pertaining to the Morisco minority led to the uprising against Philip II during Christmas of 1568, thus igniting a cruel war that would extend until the end of $1570^{24}$. The conflict and the subsequent decision of Philip II to expel the majority of the Moriscos of Granada, rebels or not, to Castile, ruined the economy of the kingdom of Granada and transformed the »nation « of the Moriscos of Granada permanently, causing deep political and social repercussions.

This »domestic « war generated an important historiographical current and commentary upon it, which filled various books of history written in the second half of the sixteenth century ${ }^{25}$. Some authors believed that the stiff resistance and living memory of independence derived from the continued presence of the Moriscos of Granada on the land of the old Nasrid kingdom. Such was the case in the work written in 1597, Excelencias de la Monarchia $y$ Reyno de España by the judge of the Chancellery of Granada, Gregorio López Madera. This work held that the great achievement of Spain consisted in »recovering itself « from the yoke imposed by the Muslims, and to those who doubted the glory of that »recovery « because of the difficulties of the War of Granada, Madera addressed the observation:

as if these were not also Spaniards with the advantage of the situation and knowledge of their land, which they defended with their freedoms, sons and wives, and with the great assistance that had always reached them from Africa, making them a difficult conquest ${ }^{26}$.

24 Antonio Gallego Burín/Alfonso Gámir Sandoval, Los moriscos del Reino de Granada según el Sínodo de Guadix de 1554, Granada 1996. See also, Flora García Ivars, La represión del tribunal inquisitorial de Granada, Madrid 1991. About the War, Valeriano SÁnchez Ramos, La Guerra de las Alpujarras (1568-1570), in: Barrios Aguilera (ed.), Historia del Reino, pp. 508-542.

25 The most important books on the war of the Alpujarras were Diego Hurtado De Mendoza, Guerra de Granada, Madrid 1970; Ginés Pérez De Hita, La Guerra de los Moriscos (Segunda parte de las guerras civiles de Granada). Facsimile edition, preliminary study and indexes by Joaquín Gil Sanjuán, Granada 1998; and the essential and very modern work of Luis DEL MÁrmOL Carvajal, Historia del rebelión y castigo de los moriscos, Málaga 1991. 
Thus Madera explained the survival and the tenacity of the Moriscos, while putting them on the same level with other Spaniards. Madera knew the Moriscos well after serving as a judge in the Court of Seville and the Chancellery of Granada and was a defender of the frustrated attempt at Morisco acculturation through the 'lead books' of the Sacromonte of Granada ${ }^{27}$. Morisco tenacity also stemmed from their control of the land and its proximity to Africa, which would have assured the efficacy of the expulsion a priori.

The war gave the king the necessary justification to undertake a series of operations designed to cleanse the body of the kingdom of Granada of undesirable elements that infected the society's good health. The fragmentation of Morisco society would have two aspects: (1) as a result of the initiative of individual soldiers and the market for labor, many Moriscos (an estimated 25 to 30,000) would be enslaved, taken far from their lands of origin; (2) in a parallel fashion, the monarchy's bureaucrats and military apparatus would oversee the deportation of the Morisco population (some 80,000 individuals) from the kingdom of Granada, and not only those who rose up in arms, but rather many »peaceful Moriscos « who even so were »extirpated « from the kingdom. Philip II's plan foresaw the maximum division of these contingents, leaving only certain families in each assigned nucleus of population, generally distant from the old frontier with the kingdom of Granada ${ }^{28}$. The hope thereby was that Castile could »absorb « these socially pathological elements, whose aggressiveness would be reduced by the meager numbers received in different populations and the detachment from their land of origin. Such tactics produced an initial phenomenon of large-scale, uncontrolled mobility. Thus, the progressive emptying of the kingdom of Granada did not culminate in the dispersion of the Moriscos, since many of them would end up reassembling in large cities and towns near the kingdom of Granada ${ }^{29}$.

26 »como si éstos no fueran también españoles aventajados en sitio y conoscimiento de su tierra, y que la defendían con su libertad, hijos y mugeres, y con grandes ayudas que siempre de Africa les venían para ser dificultosísimamente conquistados«. Gregorio LóPEz MADERA, Excelencias de la Monarchia y Reyno de España, by Diego Fernández de Córdoba, printer/Valladolid 1597, Madrid 1999, p. 118.

27 Regarding this interesting personage, see Enrique García BALlesteros/José Antonio MartíNEZ ToRres, Gregorio López Madera (1562-1649). Un jurista al servicio de la corona, in: Torre de los Lujanes 37 (1998), pp. 163-178. On the passionate attempt at cultural and religious syncretism that the invention of the lead tablets entailed, see Manuel BARrios AguiLera/Mercedes García-Arenal (eds.), Los plomos del sacromonte. Invención y tesoro, Valencia 2006.

28 The deportation operations were studied in the already-classic work by Bernard VINCENT, La expulsión de los moriscos del Reino de Granada y su reparto en Castilla in the same author's book, Andalucía en la Edad Moderna. Economía y sociedad, Granada 1985, pp. 215-266.

29 Henri LAPEyre, Geografía de la España Morisca, Valencia 1986, pp. 150-158. The author studied the process of the distribution of the Moriscos from Granada in its national dimensions. Alongside this movement, spontaneous migrations fleeing the war took place, as studied in the case of Murcia, the kingdom that received diverse contingents in the 1580's as well as during the war of 1568-1570. See Juan Bautista Vilar, L'Inquisition de Murcie, in: Louis Cardail- 
The deportation measures that followed the rebellion of the Moriscos of the kingdom of Granada and the subsequent war between Christmas 1568 and the early months of 1571 represented in the eyes of some contemporaries an act of mercy on the part of Philip II,

who was served to order them removed from the brush and the mountains where they lived and to give them for their residence the flat and abundant land of Andalusia and the kingdom of Toledo, where, continuing their inequities, they have killed many Christians grievously, attacking and robbing them on the roads, and in Seville a great number of the said Moriscos assembled and taught the sect of Muhammad among themselves, as appears in the registers of the Inquisition of Seville ${ }^{30}$.

This opinion, articulated in the 1580s, reveals not only an appraisal of the Moriscos as dangerous elements, but also a criticism of their departure from the kingdom of Granada, which had led to more disorder than control.

With the arrival of the Moriscos in places where their presence had traditionally been little felt or where coexistence with the Mudejars had generated no particular concern, the town council had to confront an important challenge that included the need to locate these Moriscos spatially and offer them a niche in the productive fabric from which they could be reinserted into the social body. With the arrival of the first groups in the places that received them, like Seville, clear orders were issued that they could not change residence without royal license, for the aim was to install them where they could participate in the labor market ${ }^{31}$. To this end, on 6 October 1572, Philip II issued a pragmatic that established the procedure that should be followed in order to control the Moriscos ${ }^{32}$. The principal objective consisted of as-

LAC (ed.), Les morisques et l'Inquisition, Paris 1990, pp. 241-257, especially pp. 242, 246-247. The phenomenon has also been studied in other areas such as the kingdom of Cordoba: Juan Aranda Doncel, Los moriscos en tierras de Córdoba, Córdoba 1984. Regarding the kingdom of Seville, see Manuel F. Fernández Chaves/Rafael M. Pérez García, En los márgenes de la ciudad de Dios. Moriscos en Sevilla, Valencia 2009.

$30 \gg .$. fue servido mandarlos sacar de las breñas y montañas donde vivian y darles para su habitacion la tierra llana y abundante de la Andalucia y reyno de Toledo donde continuando la iniquidad an muerto gran numero de cristianos alevosamente, saltando y robando los caminos, y en Sevilla se juncto gran numero de los dichos moriscos y entre ellos se enseñava la secta de mahoma como paresce por los registros de las inquisiciones de Sevilla«. Opinion of the bishop of Segorbe on the state of the Moriscos of the kingdom of Valencia, cited in BoronAt y BARRACHINA, Los moriscos españoles, vol. I, p. 624.

31 AGS: CC, leg. 2159, fol. 80r. King Philip II to the count of Priego, chief magistrate of Seville. Madrid, 11-XII-1570.

32 Pragmatica y declaracion sobre los Moriscos del Reyno de Granada, Establishment of Alonso Gómez, printer/Madrid 1572. Biblioteca Nacional de Madrid (hereafter BN), Varios Especiales, 36/8. The following quotations are from this document. It was reedited in 1573, this edition can be found in the Real Academia de la Historia, 4/640, \#51. Notice of this work was published in Faustino GiL Ayuso (ed.), Noticia bibliográfica de textos y disposiciones legales de 
similating the Moriscos by undertaking a new campaign to evangelize them, which drew upon the participation of all of the ministers of the Church, and dissolving small groups of Moriscos in the heart of the Old Christian society $^{33}$. This declared objective of assimilation required the systematic registration of the Moriscos located in each locality, counting on cooperation by secular authorities,

registering the names of all of them, and from where they came and originated, according to their declarations, noting likewise their ages and signs regarding their stature and appearance, their occupations or trades, and the parish where they reside, which should and must be registered by a judge and one or two town councilors before the council's notary ${ }^{34}$.

In the same way, it was considered essential to rally the cooperation of ecclesiastical infrastructure, the base and primary pillar of which were the parish priests, who closely watched the development of these censuses. In order to evaluate the progress of the evangelizing campaign and to control this uprooted and suspicious population more effectively, its mobility was drastically limited:

Because if the said Moriscos had the freedom to move and leave the places and areas where they are distributed, it would not be possible to keep records as necessary, and some might attempt, as they have, to travel to other foreign kingdoms or to return to the said kingdom of Granada or its mountains, we order, prohibit and uphold that no or none of the said Moriscos of the said kingdom of Granada of any estate, quality, sex or age, can, for any reason move, leave or absent themselves from the places and parts where they are distributed to spend the night elsewhere without express and particular license of the justice of the place and part where they reside, which said license should be given in writing signed by the said justice and by the council's notary, indicating the name and signs and period and motive of the leave granted, and the destination, so that there may be no fraud, nor may some use the licenses given to others ${ }^{35}$.

los reinos de Castilla impresos en los siglos XVI y XVII, Madrid 1935. The following citations are taken from the facsimile edition of this key piece in Francisco IzQuierdo, La expulsión de los moriscos del Reino de Granada (pragmáticas, provisiones y órdenes reales), facsimile edition with an introduction by the author, Madrid 1983.

33 Fernández Chaves/Pérez García, En los márgenes, pp. 83-213.

$34 \gg .$. poniendose en el registro los nombres de todos, y de donde fueron traydos y son naturales, según que ellos lo declaran, poniendo ansi mismo la edad y señas de estatura y rostro, y el officio y tracto que tuuiere, y la casa parrochia donde viviere, el qual registro se aya de hazer y haga por la justicia y vno o dos Regidores ante el escriuano del concejo«. Pragmatica y declaracion.

35 »Y porque si los dichos Moriscos tuuiessen libre facultad de mudarse y salir de los lugares y partes donde estan repartidos, no se podria tener la cuenta que conuiene, y algunos podrian intentar como lo han hecho, de passarse allende a otros reynos estraños, o tornarse al dicho 
It was nevertheless declared convenient for those who had businesses to be permitted to travel from one place to another, with the exception of the kingdom of Granada. If the change of location were not temporary, it was thought that »for the moment we must keep tight control $\aleph^{36}$, so that any move required submitting the license conceded by the authorities to the approval of the Royal Council, and in the case of changes of residence within a single city the priests of each parish had to be notified. The contravention of these norms would incur the death penalty for those who were found in the kingdom of Granada or within ten leagues of it and the abduction of any children with the purpose of having them raised in the homes of Old Christians, while the penalties of lashes and the galleys were reserved for those who showed up in other kingdoms. Such Moriscos would be treated as fugitives, and those who harbored them would likewise be punished ${ }^{37}$. During the same year of 1572, a continual flight of slaves and free Moriscos toward their former homeland was detected in many places near the kingdom of Granada, like Cordoba ${ }^{38}$.

Cooperation between the secular councils and the Church nevertheless cooled down within a decade after the war. Hence, in 1580 the parish councilors of Seville denounced faulty vigilance over the Moriscos, who had concentrated themselves in different neighborhoods far from the center and lived together in communal dwellings. Troubled by this situation, the parish councilors demanded that the city council fully comply with the pragmatic of 1572, requesting cooperation on the part of the ecclesiastical authorities: »They ask of the lord Archbishop that in those areas their priests issue memorials about the houses where they live so that they cannot conceal themselves $[\ldots] \ll \ll^{39}$ particularly emphasizing the control of arms and compliance with royal pragmatics. They also suggested periodic controls:

reyno de Granada, o a las sierras de el. Mandamos, prohibimos y defendemos, que ninguno ni algunos de los dichos Moriscos del dicho Reyno de Granada de qualquier estado, calidad, sexo y edad que sean, no puedan por ninguna causa ni razon mudarse, salir, ni ausentarse de los lugares y partes donde estan repartidos para hazer noche fuera sin expressa y particular licencia de la justicia del lugar y parte donde residiere, la qual dicha licencia se de por escripto firmada de la dicha justicia, y de escriuano de concejo, poniendo en ella el nombre y señas, y el tiempo porque se le da, y a donde va, para que no pueda hauer fraude, ni vsar vnos de las licencias que se dieron a otros«. Pragmatica y declaracion.

$36 » \ldots$ por agora conuiene tenerse mucho la mano«.

37 This pragmatic was analyzed in María José García Gómez, Control de la Iglesia a un proyecto político de Felipe II. La integración de los moriscos granadinos deportados a Castilla (15701610), in: Iglesia y religiosidad en España. Historia y archivos. Actas de las V jornadas de Castilla La Mancha sobre investigación en archivos, vol. I, Guadalajara 2002, pp. 1421-1453, here p. 1437.

38 Florencio JANER, Condición social de los moriscos en España, Sevilla 2006 [1 ${ }^{\text {st }}$ ed. Madrid 1857], pp. 315-317.

39 »Pidan al señor arçobispo que en las collaçiones los curas dellas den memoriales de las casas adonde los ay para que no se puedan encubrir ...« 
We ask and beg Your Lordship to give orders to remedy this [situation] by undertaking monthly visits by areas, visiting the houses and corrals they inhabit, seeing the arms they have and prohibiting them, and declaring how many might live together in a house or corral [...] Ordering them being punished for speaking Arabic ${ }^{40}$.

The parish councilors feared a lack of control over the Moriscos, for, although their movements had been limited, they had not been settled in small groups, but rather had concentrated themselves in large numbers in the cheapest and poorest neighborhoods. This special arrangement also bared its risks, since in grouping themselves against the orders of Philip II's pragmatic, the Moriscos regenerated ties of social solidarity sundered by war and slavery. The parish councilors requested records regarding the Morisco population and registers that parish priests could have formulated in agreement with the dispositions of 1572 .

This criticism of the lack of control over the Morisco population revealed the prompt abandonment of the duties assigned to the municipal powers. The authorities were more attentive to the vigilance of suspicious movements among the Moriscos, and investigated individual denunciations of such activity. These investigations undertaken by municipal agents and nourished by the web of Inquisitorial information led to the foiling of an attempted rebellion in Seville in 1580, which confirmed suspicions about this group ${ }^{41}$. It became clear that the system of registration handled by the officials of royal justice left much to be desired. In 1581 a royal provision was sent to all of the kingdom's cities and towns demanding control over the movements of the Moriscos, who were departing in mass from the places assigned to them:

because, on the pretext of the licenses and passports given to them, they leave and go wherever they want, and the worst of it is that this liberty and little accounting for them and for requesting their licenses and passports, which some of them give to others,

40 »Pedimos y Suplicamos a Vuestra Señoría mande dar horden en que esto se rremedie haziendo bisitas cada mes por las collaçiones visitando las casas e corrales de sus moradas viendo las armas que tienen y proybiendoles que no las tengan declarando el numero de la cantidad que pudieren bibir juntos en una casa o en el corral ... Manden executar en ellos la pena porque ablan en algaravia ...« Archivo Municipal de Sevilla (hereafter AMS), Diversos, 104/1580.

41 Regarding the uprising, see Celestino López Martínez, Mudéjares y moriscos sevillanos, Sevilla 1994. Antonio Luis CoRTÉs PEÑA, Una consecuencia del exilio. Los moriscos granadinos en Sevilla, in: Ernest Belenguer CeBrià (ed.), Felipe II y el Mediterráneo, vol. II, Madrid 1999, pp. 537-553. See also Bernard Vincent, Les rumeurs de Séville, in: Bartolomé Bennassar (ed.), Vivir el Siglo de Oro. Poder, cultura e historia en la época moderna. Estudios en homenaje al profesor Ángel Rodríguez Sánchez, Salamanca 2003, pp. 165-177. A recently published work updates the state of the question: Michel Boeglin, Entre la resistencia a la política de asimilación y la fabulación. El »levantamiento« de los moriscos andaluces de 1580, in: Historia, Instituciones, Documentos 34 (2007), pp. 29-55. Regarding all of these works, see FERNÁNDEZ Chaves / Pérez García, En los márgenes, pp. 271-361. 
changing the names and using other forms of deception and stealth, gives them the opportunity to commit $[\ldots]$ many murders, thefts, and muggings $[\ldots]^{42}$.

In regard of this situation, in 1576 the Royal Council hardened the conditions to obtain a license: all licenses should be approved by the Council's members. But in 1582 they recognised the limited effects of this measure ${ }^{43}$. A document drafted for consultation with the king by the Junta de Población, a committee charged with managing the movements of the deported Moriscos and the new settlements made in the kingdom of Granada in 1582, indicated the existing disorder with passports, as many Moriscos took advantage of corrupt notaries and officials in order to return to the kingdom of Granada or to change their place of residence. In this way, they mocked the controls and invalidated the censuses and registers undertaken by the Church and civil authorities ${ }^{44}$. Beginning in 1583, in the face of the chief magistrates' progressive inefficiency in the registration and control of the Moriscos, the archbishops and their well-established networks of parochial control would assume responsibility over the settled Morisco population at the request of Philip II. Nevertheless, matters regarding mobility remained in the hands of the population committee ${ }^{45}$. This appeal to a superior government agency was due to the little attention that judges and chief magistrates paid to the Moriscos's mobility and the granting of licenses for movement without much control. That same year, Philip II ordered the local authorities to end the concession of licenses for travel following the orders to remove Moriscos from the kingdom of Granada, Alcalá la Real and Antequera, recognizing the careless application of the pragmatic of 1572 and

by the facility and excess with which the said licenses had been given, many of the said Moriscos had moved from where they were distributed and wandered from place to place, leading to many murders, robberies and muggings and other offenses that some of the said Moriscos had committed and other disruptions ${ }^{46}$.

$42 \gg$... porque con la ocasión que toman de las licencias y pasaportes que se les dan se ausentan y van a donde quieren, y lo que peor es que desta libertad y poca quenta que con ellos se ha tenido y de pedir las licencias y pasaportes que se les dan unos para otros mudándose los nombres y usando de otros engaños y cautelas con venir a tener ocasión de hacer ... muchas muertes, robos y salteamientos ...« JANER, Condición social, pp. 311-313. Royal Provision given in Malaga, 12-IX-1581.

43 Aurelio García López, Conflictividad y conciencia. La aplicación de justicia y la minoría morisca en el reino de Castilla, in: Antonio Mestre Sanchís/Enrique Giménez López (eds.), Disidencias y exilios en la España Moderna, vol. II, Alicante 1996, pp. 455-468, here p. 462.

44 Boronat y Barrachina, Los moriscos españoles, vol. I, pp. 592-593.

45 García Gómez, Control de la Iglesia, pp. 1435-1436.

$46 \gg$... por la facilidad y exceso con que habían dado las dichas licencias, muchos de los dichos moriscos se habían mudado de donde fueron repartidos y andaban vagando de unas partes a otras, de cuya causa habían sucedido muchas muertes, robos y salteamientos y otros delitos 
Even so, the authorities were always alert regarding unregistered Moriscos, as occurred in 1585 in Seville when the lieutenant governor of the city indicated that

proceeding by the street of Santa Marina, that Ambrosio Pablo de Aguilar was a Morisco from the kingdom of Granada, originally from Cáxar de la Bega, and that he was in this city without the [requisite] orders, against the law and pragmatic of his Majesty, without being registered or having orders to be here, and the said Morisco, now living on the street of Santa Maria, when he saw the lord lieutenant, went fleeing and fled and [the lieutenant] sent after the said Ambrosio Pablo and arrested him and sent him to jail $[\ldots]^{47}$.

As Serafín de Tapia pointed out, the Moriscos undertook »constant mobility«. Hence the priest and historian of the city, Alonso Morgado, entrusted with the census of the central areas of Seville, reflected on the small number of Moriscos present in that area due to the expensiveness of accommodations and because

The Moriscos have the freedom to move at will, from one parish to another, and as it occurs that the parochial priests do not summon them or register them other than during lent, they cannot account for them as well as his Most Illustrious [Archbishop] has instructed, especially in giving them mass and Christian doctrine and teaching it to them, being obliged to seek them and come to them again every few weeks, reforming the registers ${ }^{48}$.

que algunos de los dichos moriscos habían cometido y se habían seguido otros inconvenientes«. AGS, CC, leg. 2186, 30-III-1583. We thank professor Enrique Soria Mesa for the reference to this document.

$47 \gg$... yendo por la calle de santa marina que Ambrosio Pablo de Aguilar hera morisco de los del rreino de granada y que hera natural de Cáxar de la Bega y que estaua en esta ciudad sin la horden contra la ley e prematica de su magestad sin estar alistado ni tener horden para estar en ella y el susodicho uiniendo agora por la calle de santa marina como uido al señor teniente se fue huyendo e se huyo e ynbio tras del dicho ambrossio Pablo y lo prendio e ynbio a la carçel ...« AGS, CC, leg. 2209. Trial of Ambrosio Pablo de Aguilar, Seville, 1585, undated. Precisely in that year the crown toughened up the measures to forbid the use of arms by the Moriscos. See, María José García Gómez, La provisión real de 3 de septiembre de 1585. Los procesos sobre la condición social de los moriscos de la corona de Castilla, in: La administracion de justicia en la historia de España, Guadalajara 1999, pp. 169-190.

48 »Tienen libertad los moriscos de mudarse a su aluedrio, de unas a otras collaciones, y como quiera que los curas Parroquiales no los requieren ni empadronan sino por las quaresmas no pueden dar dellos, aquella buena quenta que los curas particulares que su Ilustrisima les tiene señalados para en el particular de dezirles missa y la doctrina cristiana y enseñarsela siendo obligados a buscarlos y recorrerles de nuevo por semanas reformando los padrones «. AGS, CC, leg. 2169. Register of Moriscos in Seville in 1589. The most complete study of Morisco demography in Seville is Fernández Chaves/Pérez García, En los márgenes, pp. 59-213. Another substantial case has been analyzed recently in Francisco J. Moreno Díaz Del Campo, Los moriscos de La Mancha, Madrid 2009. 
No one could halt a »spontaneous mobility« born of the needs of an uprooted population to seek opportunities for social improvement and to recover a lost, but necessary, cultural cohesion. Within a few years, the concentration of Moriscos in population nuclei of a certain extension or which offered opportunities for economic development, particularly in Baetic Andalusia, clearly demonstrated the relative failure of the policy of deportations and disper$\operatorname{sion}^{49}$. The city of Seville constituted a clear example: over 7500 Moriscos were registered during the year of the expulsion (1610), not including those who eluded the records. At the beginning of the seventeenth century places like Almagro experienced a clandestine and selective immigration of powerful Moriscos who made important investments in expanding the town's oilpressing industry. Other fellow Moriscos had either lost their residence permits (cédulas de vecindad) or changed their place of residence and therefore faced legal proceeding $\mathrm{s}^{50}$. In general it seems that,

in the Campo de Calatrava, as in the rest of Castile, it happened that many of those registered had returned to their places of origin or meandered about the province (being generalized the exodus from the country to the cities), eluding the rigid system of valid passports and carrying arms on whatever pretext $t^{51}$.

Alongside this mobility of individuals and groups who sought to reconstruct a disunited society, this minority's commercial and economic needs produced further mobility, undertaken mainly by traders and muleteers. Although many people condemned mobility derived from commerce and transportation-related activities, they had no other choice than to accept them. In fact, the very pragmatic of 1572 that limited movements also indicated:

Because our intention is not to hinder the said Moriscos in their trade and commerce and form of life, but rather than they be helped and favored in this matter, we order that the said license should be given, for a limited time, to the persons who request it, being trustworthy, and free of the suspicion that they will leave or go away, or, in the case that we are not so certain in this matter, taking the convenient securities from them ${ }^{52}$.

49 For the case of Cordoba, see Aranda Doncel, Los moriscos and for Seville, Fernández Chaves / PÉrez García, En los márgenes, pp. 59-140.

50 Miguel Fernando Gómez Vozmediano, Mudéjares y moriscos en el Campo de Calatrava. Reductos de convivencia, tiempos de intolerancia (siglos XV-XVII), Ciudad Real 2000, pp. 126-128.

51 »En el Campo de Calatrava, como en el resto de Castilla, se da la circunstancia de que muchos de los alistados habían retornado a su lugar de origen o pululaban por la comarca (siendo generalizado el éxodo del campo a las ciudades), soslayando el rígido sistema de pasaportes vigentes y portando armas con cualquier pretexto«. Gómez Vozmediano, Mudéjares y moriscos, p. 132.

52 »Y porque nuestra intencion no es que los dichos Moriscos sean embaraçados en el trato y 
The pragmatic only further complicated the situation for many Moriscos who earned a living by transporting goods. Certainly, in the immediate aftermath of the war, the movements of Moriscos were very restricted, leading some, like Miguel Fernández de Granada, deported to Osuna, to complain that

his trade was as an ordinary muleteer who came to our court and the city of Toledo and other parts with his wares, with the things that had been ordered from him, in the said city of Granada as in the town of Osuna, Seville and Cordoba and other parts, and generally traveled all of Spain $[\ldots]$ and $[\ldots]$ wherever he reached, they used to impede his travels, even if he showed a passport, and seize his merchandise [...] which caused him much damage and offense ${ }^{53}$.

This Morisco also complained about not even being permitted to carry a knife with a rounded point. His arm was seized, although the royal and municipal judges upheld his right to travel without impediments ${ }^{54}$.

Although the last word remained with the judges, they often preferred to avoid taking risks, as in Almagro, when from 1583, anyone who requested a license had to deposit funds, and the governor of the Campo de Calatrava proved reluctant to permit the most wealthy traders to depart ${ }^{55}$. In Seville, the Inquisition even proclaimed $»$ that no Morisco can be a boatman, because they began trading fruit that they brought to the river, then journeyed to Sanlúcar and the fishing coves for tuna, and to Huelva for oysters, and from there to Barbary $\ll^{56}$. As Domínguez Ortiz and Vincent observed:

Good popular sense had also perceived the Moriscos' great mobility [...] familiar images of the Morisco included those of muleteer and ambulant fritter-seller [...] with the suspicion that, alongside their ostensible activities, they secretly undertook others.

comercio y modo de viuir que pueden tener antes en esto sean ayudados y fauorescidos, mandamos que la dicha licencia se aya de dar y de por tiempo limitado a las personas que la pidieren, siendo seguras, y sin sospecha de que no se ausentaran ni yran, o en caso que desto no huuiesse tanta satisfacion, tomando dellos la seguridad que conuenga«. Pragmática y declaración.

53 »... su oficio era arriero ordinario que venia a esta nuestra corte y a la ciudad de Toledo y a otras partes con su requa, con cosas que se le encargaba, así en la dicha ciudad de Granada como en la dicha villa de Osuna, Sevilla e Cordoba e otras partes y generalmente andaba por toda España ... y ... donde llegaba le solian poner impedimento a su viaje e aunque les mostraba pasaporte ... le tomaban sus recuas ... en lo qual rescibia mucho daño e agrabio ...«

54 JANER, Condición social, pp. 305, 309-311. Petition to the city Council of Cordoba of 13-VI-1576, and Royal Provision prohibiting this Morisco from bearing an arm, Madrid, 12-IX-1581.

55 Gómez Vozmediano, Mudéjares y moriscos, pp. 119-121.

56 »... que ningun morisco pudiera ser barquero porque empezaban por comerciar con frutas que traían por el río, luego se alargaban a Sanlúcar y las almadrabas por atún y a Huelva por ostiones y de allí hasta Berbería «. Antonio Domínguez Ortiz, La Sevilla del siglo XVII, Sevilla 1984, p. 188. 
They could transmit news or signals or be agents of proselytism, and it could not be denied that the continuous displacements among the regions that they inhabited maintained cohension among Moriscos [...] But this mobility, which the Christians decried, was largely their own responsibility, at least after $1570^{57}$.

Hence, in Valencia, but especially in Castile, the Moriscos specialized in the long-distance muleteer trade, where they faced less competition from Old Christians. The Moriscos of Avila, for example, specialized in this trade, but there were also non-Morisco groups like the Maragatos of Leon engaged in this trade ${ }^{58}$. This commercial activity, along with the existence of inns run by Moriscos, served to maintain effective communications among the diverse Morisco communities, and contributed partly to rebellion attempts and conversations with foreign powers. In the case of the muleteers of Avila, ties to Seville (followed by Granada) were a priority after 1558, for Seville became the place where the most numerous Morisco community on the Peninsula would form after $1570^{59}$. Regarding the Moriscos of Hornachos, the majority population in that locality, the royal chronicler, Salazar de Mendoza, observed that

Many of them were muleteers, and by this road knew everything that happened in Spain and even abroad, because they corresponded with Turks and Moors. When they came to Toledo, the Moriscos of Granada forged a tight alliance and friendship with them. They communicated by a route that they called Moruna, which passed through depopulated areas the 40 leagues from Toledo to Hornachos ${ }^{60}$.

57 »El buen sentido popular había también percibido la gran movilidad de los moriscos ... entre las imágenes familiares del morisco figuran las del arriero o el vendedor ambulante de buñuelos, ... se sospechaba que, al margen de sus actividades confesadas, desempeñaban otras clandestinas. Podrían transmitir noticias y consignas o ser agentes de proselitismo; y no puede negarse que la cohesión entre los moriscos se mantuvo gracias a continuos desplazamientos entre las regiones que habitaban ... Pero esta movilidad, de la que se quejaban los cristianos, era en gran parte responsabilidad de estos mismos, por lo menos a partir de 1570«. Domínguez OrTiz/VincENT, Historia de los moriscos, p. 88.

58 Laureano M. Rubio Pérez, Arrieros maragatos. Poder, negocio, linaje y familia. Siglos XVIXIX, Madrid 1995.

59 TAPIA SÁnchez, La comunidad morisca, pp. 324-325; id., Las redes comerciales de los moriscos de Castilla la Vieja. Un vehículo para sus »complicidades«, in: Studia Historica. Historia Moderna XI (1993), pp. 231-243.

60 »Eran muchos arrieros, y sabían por ese camino todo lo que pasaba en España y aún fuera, porque tenían correspondencia con turcos y moros. Cuando vinieron a Toledo, los moriscos de Granada trabaron con ellos liga y amistad muy estrecha. Comunicábanse por una senda que llamaron - Moruna -, que iba por despoblados las 40 leguas que hay de Toledo a Hornachos «. Pedro Salazar de Mendoza, Origen de las dignidades seglares de Castilla y León, Madrid 1618. Cited in Alberto González Rodríguez, Hornachos, enclave morisco, Mérida 1990, p. 77. 
As we have seen, the plan to remove and disperse the Morisco social body to the greatest degree possible was not carried out to perfection. Due either to the ineffectiveness or the party interests of local authorities, as well as the relative negligence on the part of the central powers which were forced to attend to urgent matters of international politics, important groups of Moriscos emerged. This development, however, was also due to economic criteria, since they were attracted by opportunities of economic improvement in the localities in which they settled. This phenomenon was instrumentalized by the monarchy, for

Upon realizing that the ideal distribution plans were not applicable, the royal councils adopted a policy of controlled mobility that favored the most enterprising and led to the constitution of urban communities that it attempted to structure. The recognition of representatives of these communities, undoubtedly important for those affected, did not lack advantages for the monarchy ${ }^{61}$.

In addition to everything discussed up to this point, from the end of the 1570s, a group of powerful and noble Moriscos unsuccessfully attempted to offer monetary services to the crown in exchange for allowing a select group of several thousand families to return to the kingdom of Granada. What the crown did end up doing, was to impose the payment of this new tax upon all Moriscos, which replaced the payment of the farda in the kingdom of Granada. It also forced many Moriscos to perform services as sappers in the army, thus belying the myth of their non-participation in war $^{62}$. This measure implied an acceptance of mobility in institutional circles that reflected the degree to which royal authorities considered the employment of Moriscos as a source of wealth. Many of the solutions proposed during these years ranged from enslaving the Moriscos and reducing deported free Moriscos to dependence upon citizens as part of their domestic service, a primary productive sector of the urban economy. In this way, the authorities attempted to settle the Moriscos in isolation from each other and under the supervision of Old

61 »A1 darse cuenta de que los planes ideales de reparto no eran aplicables, los consejos reales adoptaron una política de movilidad bajo control que favorecía a los más emprendedores y que condujo a la constitución de comunidades urbanas a las que se trató de estructurar. El reconocimiento de representantes de esas comunidades, importante sin duda para los interesados, no dejaba de ser ventajoso para la monarquía«. Bernard Vincent, Los moriscos granadinos y la monarquía, in: Juan I. Fortea/Juan E. Gelabert (eds.), Ciudades en conflicto (siglos XVIXVIII), Valladolid 2008, pp. 163-179, here p. 178.

62 VincEnt, Los moriscos granadinos, pp. 163-179. On the new taxes that the Moriscos had to pay after the deportations, see Juan J. Bravo CARo, Un impuesto de desterrados. El servicio de los naturales del Reino de Granada, in: Estudios modernistas sobre el Reino de Granada. Homenaje al Dr. Joaquín Gil Sanjuán, Málaga 2003, pp. 45-82. 
Christian families, although this only took place on a small scale at the beginning of the deportations.

Slaves, who were the objects of involuntary displacement, sometimes disseminated an Islam that was practiced as a sign of identity. In some cases, Moriscos spread Islam on an elementary level in places where they could reunite, as on the Balearic islands or the kingdoms of Sicily and Naples ${ }^{63}$. Moreover, different authors have documented the passage of Moriscos to colonial America, although this never became a mass movement. Some Moriscos traveled as slaves, outwitting dispositions that prohibited the passage of Protestants, Jews, and Moors or their descendents. Others managed to otherwise elude official controls, like three Moriscos of Avila mentioned by Tapia, or a wealthy Morisca who dictated her testament in Quito in $1594^{64}$. In almost every case, these individuals belonged to the elites of the community and possessed the money and good reputation necessary to undertake the voyage ${ }^{65}$. Port cities like Seville had to maximize the vigilance, and the town councilors agreed along with the House of Trade to proclaim in 1578 that no captain should accept any Morisco as a cabin boy or sailor, for it was known that

many masters of Triana receive Moriscos on their ships as cabin boys and sailors to take them to the Indies and other parts, although it would be quite harmful if they knew how to navigate to the Indies or to other parts, so that it convenes the city to provide that no Morisco nor son of a Morisco from the kingdom of Granada can go anywhere in a boat or caravel or nave $[\ldots]^{66}$.

Louis Cardaillac indicated the existence of legislation that prohibited the passage of Moriscos, free or enslaved, to the Americas, in an attempt to prevent the diffusion of pernicious ideas among native Americans. In 1540 the Emperor decided to prohibit Morisco or Berber migration toward the American continent ${ }^{67}$. The actual physical presence of Moriscos in colonial territories

63 Louis Cardaillac et al., Les tribunaux des Îles et d'Outre-Mer, in: Id. (ed.), Les morisques, pp. 316-323.

64 Cited in Kris Lane, Captivity and redemption. Aspects of slave life in early colonial Quito and Popayán, in: Americas 57/2 (2000), pp. 225-246, here pp. 225-226.

65 TAPIA SÁnchez, La comunidad morisca, pp. 328-330.

$66 \gg .$. muchos maestres de triana que rreçiben en sus naos para llevar a las yndias por grumetes y marineros y a otras partes moriscos de que resultaria mucho daño si supiesen la nauegaçion de las yndias o de otras partes que converna que la çiudad proyea que ningun morisco ni hijo de morisco del rreyno de granada pueda yr a ninguna parte en barco ni carauela ni nauio ...« AMS: Actas Capitulares, book H-1551, meeting of 17-XI-1578, fol. 108v-109v.

67 Louis Cardaillac, Le problème morisque en Amerique, in: Mélanges de la Casa de Velázquez 12 (1976), pp. 283-303. On the convergences and divergences of missionary considerations regarding the propagation of the Christian faith among Indians and Moriscos, see Youssef El Alaoui, Jésuites, Morisques et Indiens. Étude comparative des méthodes d'évangélisation 
was always rare, more present in the collective imagination than in the constant, but numerically insignificant, passage of this minority to other coasts ${ }^{68}$, although in certain cases the presence of female »white slaves « of Berber or Morisco origin was influential in the first decades of Peruvian colonies, which lacked women of Peninsular origins ${ }^{69}$.

\section{Political Discourses regarding Mobility}

The need to control a »massive minority « led to considerations of the convenience of registering Moriscos, settling them in urban spaces and subjecting them to the distinction of paying special taxes. These measures attempted to curtail their threat by reducing their income and limiting, at the same time, their ability to move, in light of permanent suspicions of their role as subversive agents.

The image of the dangerous Morisco, highway robber and expert bandit, although it stemmed from an unquestionable reality, essentially served the purpose of continuing the discriminatory practice of prohibiting the Moriscos from bearing arms. Certain Moriscos managed to evade this norm, already established in the kingdom of Granada and reiterated in the pragmatic of 1572, thanks to the interests of the authorities, bribes, or even the recognition of special privileges for the conversion of their ancestors before the fall of Granada in 1492. Recognition as Old Christians through this channel granted them freedom of movement, and this was translated into attempts to return, or at least get closer, to the kingdom of Granada, as foreseen in a royal provision dictated in 1585 to avoid the proliferation of such recognitions ${ }^{70}$. The Moriscos' economic role and the magistrates' neglect led many Moriscos to undertake a double movement: return to Granada and concentration in

de la Compagnie de Jésus d'après les traités de José de Acosta (1588) et d'Ignacio de la Casas (1605-1607), Paris 2006.

68 On the existence of a symbolic construction that projected the idea of suspicion and betrayal hanging over the Moriscos upon the native Americans, Japanese converts and other ethnicities, and the need to combat Islam and its cultural legacy beyond the Peninsula, see Ramón MúJicA Pinilla, Apuntes sobre moros y turcos en el imaginario andino virreinal, in: Anuario de Historia de la Iglesia XVI (2007), pp. 169-179. See also, Ana Díaz Serrano, La figure de l'ennemi musulman dans les Indes Occidentales et Orientales aux 16e et 17e siècles, in: Siècles 26 (2008), pp. 67-80 and Max Harris, Aztecs, moors and christians. Festivals of Reconquest in Mexico and Spain, Austin 2000.

69 Jaime CÁCEREs EnRíQuez, La mujer morisca o esclava blanca en el Perú del siglo XVI, in: Sharq-alAndalus 12 (1995), pp. 565-574.

70 Provision Real de Su Magestad, sobre la orden que se ha de tener en los negocios tocantes a los Moriscos del Reyno de Granada, que pretendieren ser Chistianos viejos. Guillermo Droy, printer/Madrid 1585. BN: R/7673. Also recently republished by Izquierdo, La expulsión de los moriscos. 
the more populous places, preferably where old Mudejars (i.e., Muslims who were allowed to remain under Christian rule) or old Islamic communities existed. This permissiveness often coincided with the connivance of local authorities, who thereby foresaw increases in the population and the incomes of the cities they governed. Such interests led to the petition to the Cortes in 1551 to suspend the prohibition on Morisco travel to Granada, as it made little sense since 1502, which undoubtedly responded to the interest of the delegates in the Cortes to ease exchanges ${ }^{71}$. In the same sense, the city of Guadalajara declared in 1584, upon requesting passports for its muleteer householders:

in the said city many new Christians were registered who had been brought from the kingdom of Granada, whose principal trade and living is traveling with animals to bring provisions and supplies to the said city, which provide it with necessary things at moderate prices, as they go buy goods at fairs and markets [...] and this practice benefited our transport taxes $[\ldots]^{72}$,

so that the end of this activity would lead to scarcity and fiscal disaster ${ }^{73}$. Undoubtedly, in the subsistence crisis at the end of the century that marked the second part of the reign of Philip II, a lack of basic foodstuffs in many localities made the role of transporters of food and merchandise very important. In spite of the restrictions on their mobility, the Moriscos »with or without licenses [...] acquired such predominance in the Castilian muleteering business that their absence was felt at the time of the general expulsion $\ll^{74}$.

There exists a discourse produced by the urban oligarchies that considered the Moriscos productive agents. The same oligarchies nevertheless constructed another, pejorative, discourse against the Moriscos, which in the end would prevail over the positive valuation of their role in the urban economy.

Regarding the Moriscos, a common stereotype was recorded in the literature of the day as well as in diverse political texts. This construction highlighted a series of characteristics that reduced the Morisco to a welldefined type independent of social status, origin, degree of integration or

71 TAPIA SÁNCheZ, La comunidad morisca, pp. 327-328.

72 »en la dicha ciudad estaban alistados mucha cantidad de cristianos nuebos que se abian traido del Reino de Granada, los quales su prinçipal trato y grangería es traginar con bestias para traer probision y bastimentos a la dicha çiudad, con lo que venya a estar probeida de lo neçesario a preçios moderados por yr a comprar mantenymientos a ferias y mercados ... y dello resultava grande aprovechamyento a nuestras alcavalas ...«

73 Moisés García De La Torre, Diversos aspectos de un grupo social marginado. Los arrieros en la España de los Austrias, in: Revista internacional de Sociología 41 (1983), pp. 639-662, here p. 649.

74 »con licencia o sin ella ... adquirieron tal predominio en la arriería castellana que se echó de menos su falta al llegar la expulsión general«. Domínguez Ortiz/Vincent, Historia de los moriscos, pp. 120-121. 
religious behavior ${ }^{75}$. These included »social avarice«, accusing the Moriscos of unhindered reproduction in light of their lack of integration in the celibate clergy or participation in the war, as well as excessive frugality, retaining large quantities of coin and thereby undermining the Peninsular kingdoms' demography and economy. If the rate of reproduction of the Moriscos appears, in fact, to be equal to or somewhat higher than that of Old Christians, as can be deduced in La Mancha or Seville ${ }^{76}$, this did not necessarily mean that they would outnumber the Old Christian population.

The fundamental accusation in economic matters was that the Moriscos were controlling the market of vital goods which was crucial for the functioning of the city, hitherto a monopoly of the governing oligarchy and a fundamental prerequisite for maintaining social peace within the city walls. Small-scale vendors who sold foodstuffs in their stores would be criticized alongside their Morisco suppliers dedicated to transportation. This stereotype appeared confirmed, and formed an essential part of most of the political discourses uttered over this minority ${ }^{77}$. Hence, in 1608, state councilor Juan Idiáquez, comendador mayor of Leon, indicated that the problem of the Morisco presence was intimately linked to state security, due to their unrestrained reproduction: »since they are free of accidental deaths, for not going to war nor leaving their homes, and live longer for their abstinence in eating and drinking, they multiply in a way that they will outnumber Old Christians in the long term $\ll^{78}$.

Miguel de Cervantes recorded the same belief in his short novel The Colloquy of Dogs:

Among them [the Moriscos] there is no chastity, nor do they enter into religion; all of them get married, all of them multiply, for living with sobriety improves reproduction. They are not consumed by war nor by excessive work [...] Of the twelve sons of Jacob that I have heard entered Egypt, when Moses led them out from slavery, there

75 This symbolic construction is analyzed in José María Perceval, Todos son uno. Arquetipos, xenofobia y racismo. La imagen del morisco en la monarquía española durante los siglos XVI y XVII, Almería 1997.

76 At least for Almagro as writes Gómez Vozmediano, Mudéjares y moriscos, p. 138. See also, Fernández Chaves/Pérez García, En los márgenes, pp. 83-140; id., San Bernardo morisco. Familia, ocupación del espacio urbano y movilidad de una minoría en la Sevilla de Felipe II, in: XI Simposio Internacional de Mudejarismo, Ternel 2009, pp. 825-836.

77 One of the first authors who pointed out the continuous appearance of this reasoning in the political discourses was LAPEYRE, Geografía, pp. 158-162.

78 »... como esta libre de muertes accidentales por no yr a la guerra ni salir de sus casas, y vive mas por su abstinencia en el comer y bever, multiplicando de manera que a largo andar seran mas que los christianos viejos ...« Boronat y Barrachina, Los moriscos españoles, vol. I, p. 464. Copied from the original document in AGS, E, leg. 212. 
went seven hundred thousand men, without counting children or women, from which one can infer the reproductive potential of these men, who are undoubtedly greater in numbers ${ }^{79}$.

In these cases, as we have seen, mobility entailed the circulation of potentially subversive ideas and information, although this was not all. It also represented a form of overcoming economic dependence by elaborating a nonagrarian way of life, clearly urban and not dependent on a settlement in a concrete space. The idea that certain virtually pathological agents circulated throughout the social territory of the kingdom implied a constant fear of exposure to contagion. For this reason, these discourses accentuated the possibilities of the Moriscos' economic progress and success, which in reality never surpassed a modest level and whose capital almost never entered fully into the big business of supplying the cities, which powerful local oligarchs controlled $^{80}$.

In 1588, a year in which the failure of the Armada led to new orientations in international and domestic politics, the anti-Morisco discourses continued being reinforced. Hence, the licentiate D. Alonso Gutiérrez thought that in Seville the problem of Morisco reproduction and monopolization of the market of provisions for the city could only be remedied by dividing the population in various »lineages « of 200 members, each controlled by an Old Christian (el cavo, »the corporal «) who would oversee their customs and authorize their marriages, as well as collecting an annual tax of one thousand ducats of gold from each of them. Of course, mobility would be completely prohibited unless authorized by the Old Christian cavo:

Item, that no Morisco may leave the city or town where he lives without the license of his corporal, which will be granted for a limited number of days, and on the condition that the said Morisco returns with testimony about where he went and the time he was there [...] and without this license he cannot leave the city walls upon penalty of losing his freedom, and since the Moriscos often care to adorn their faces, arms and hands, the Morisco should be marked with a letter or sign on the face, where it cannot be covered, so that he will be known as a Morisco ${ }^{81}$.

79 »Entre ellos no hay castidad, ni entran en religión ellos ni ellas; todos se casan, todos se multiplican, porque el vivir sobriamente aumenta la causa de la generación. No los consume la guerra, ni ejercicio que demasiadamente los trabaje ... De los doce hijos de Jacob que he oído decir que entraron en Egipto, cuando los sacó Moisés de aquel cautiverio, salieron seiscientos mil varones, sin niños ni mujeres, de aquí se podrá inferir lo que multiplicarán las de estos, que sin comparación, son en mayor número«. Miguel De Cervantes SaAvedra, Coloquio de los perros, in: id., Novelas ejemplares, Barcelona 1967, p. 175.

80 All this is treated in Fernández Chaves/Pérez García, En los márgenes.

81 »Item, que ningun morisco pueda salir de la ciudad o pueblo donde viviere sin licencia de su cavo, la qual le dara limitada por dias, y que traiga el tal morisco a la buelta testimonio de el 
The entire scheme was canonized with the necessary additions in the Cortes of Castile of 1593 by the procurator of Seville Rodrigo Sánchez Doria, who denounced the Moriscos:

for being as they are ensconced in the Republics in all trades and exchanges, especially in that of provisioning, which is the crucible where the money is forged, because they gather and hide [the provisions] at the time of the harvests, requiring that they would be purchased from them, and leaving years barren in this way. In order to operate better, they have become storekeepers, suppliers, bakers, butchers, tavern-keepers and water carriers, by which they likewise gather and hide all of the money, and not one of them buys nor has property, and thus they are rich and powerful and have addressed the ecclesiastic and secular justices, who favor them with such strength, that they hereby live so licentiously, that their little Christianity is clearly perceived $[\ldots]^{82}$.

The solution that Doria proposed and other delegates to the Cortes and political authors followed, entailed the new division and settlement of the Moriscos in rural areas as agricultural producers in a Castile whose internal income had begun to decline. By annulling the Moriscos' mobility and controlling them better, they would no longer be dangerous and could be used to solve the kingdom's economic crisis ${ }^{83}$. In this way, the monarchy's religious concerns, revealed in the legislation proclaimed between 1502 and 1572 , gave way to the economic preoccupations of the cities, which viewed

lugar donde fue [y] del tiempo que alli estubo ... y sin esta licencia no pueda salir de los muros afuera so pena de perder la libertad; y pues de zelo se suelen labrar los rostros, braços y manos, se señalen de una letra o señal en el rostro donde no se pueda encubrir para que sea conoscido por morisco«. Informe de D. Alonso Gutiérrez acerca de la cuestión morisca; su fecha en Sevilla a 6 de septiembre de 1588. Published in Boronat y Barrachina, Los moriscos españoles, vol. I, pp. 634-638.

82 »por estar como estan apoderados en las republicas en todos los tratos y contrataciones, mayormente en los mantenimientos, que es el crisol donde se funde la moneda, porque los recogen y esconden al tiempo de las cosechas, necesitando a que se compren de su mano, y estirilizando los años con esta orden, que para mexor usar della, se han hecho tenderos, despenseros, panaderos, carniceros, taberneros y aguadores, con lo qual recogen y esconden asimesmo todo el dinero, y ninguno de dellos conpra ni tiene bienes raizes, y con esto están ricos y poderosos y se han allegado a las justizias eclesiasticas y seglares, los quales los favorezen con tanta fuerza, que mediante esto viven tan licenciosos, que se entiende claramente su poca cristiandad .... Actas de las Cortes de Castilla: 16-XI-1593, p. 94. Published by Danvila y Collado, La expulsión de los moriscos, pp. 310-312. This suspicious image of the laborious Morisco who ownes stores and participates in the extensive networks of trading organized throughout the country appears in a sixteenth-century Inquisitorial report in Avila, which asserted, regarding the Moriscos: »One thing that we can say about them that leads to great suspicions that is understood in this town and in other parts is that they have large sums of money and buy no houses, lands, or vineyards, and only deal in merchandise. And, in this way, all of Castile eats from their hands, which is greatly troubling «. TAPIA SÁnchez, La comunidad morisca, p. 268.

83 These arguments are developed in Fernández Chaves/Pérez García, En los márgenes, pp. 271-449. 
the minority through the prism of its productivity and its more convenient insertion in the economic sectors that interested it. Serafín de Tapia has already indicated how the Cortes of the 1580s and 1590s and those inaugurated in 1601 were marked by requests to redistribute and settle the Moriscos on the land as farmers, requiring them to completely abandon the muleteer trade. In this way, sufficient hands would be devoted to agricultural production and prices would lower, in addition to increasing the profits of landowners with this undemanding labor force ${ }^{84}$. This new consideration reappeared in a compendium of deliberations that the State Council undertook in 1608, where a councilor asserted:

It is also considered that it would be good to spread the Moriscos of the kingdoms of Castile more, distributing them throughout small localities as much-needed farmers, with the idea that the Old Christians would always remain very superior and that this be done not at once but bit-by-bit, for in light of the great need for someone to cultivate the land, it is not right for men who know the culture to live by the gifts of their gardens, and although they claim that they do not do it [farm] well, this is because they do not want to do what is useful for everyone, but rather what profits them alone. In order to oblige them to farm, it would be good to prohibit them from ambulant trade, and thus there will be many farmers and peons, and no one will think that this is done out of fear of them, but rather to supply the need that exists in the countryside; with this [measure] they will cultivate the fields, the Morisco children will be raised better among Old Christians, and the priests will be able to attend comfortably to instructing the Moriscos [and] to removing the feared thoughts of their uprising. In addition [...] it is charged not to place them close to the sea where they might correspond with Barbary $^{85}$.

Doria's discourse attempted to restore the spirit that had encouraged the deportations while avoiding the settlement of Moriscos in the cities, and in

84 TAPIA SÁnchez, La comunidad morisca, p. 328

85 »También se considera que los moriscos destos Reynos de Castilla seria bien derramarlos mas repartiendose por los lugares pequeños a titulo de la labrança de que tanta falta ay, con consideracion de que los christianos viejos quedasen siempre muy superiores y que esto no se hiziese de golpe sino poco a poco, pues haviendo tanta falta de quien cultive la tierra no es bien que hombres que saben la cultura se esten al regalo de sus huertas y aunque dizen que no lo hazen bien es porque no quieren tratar de lo que es util a todos sino de aquello que a ellos solo les es de provecho para obligarles a la labrança seria bien prohivirles el traginar, que con esto abra muchos labradores y peones, y no se podra juzgar que esto se haze por recelo que se tenga dellos sino por suplir la falta que ay de parte del campo; con esto se cultivaran los campos, los niños moriscos se criaran mejor entre los christianos viejos, los curas podran attender comodamente a la instruccion de los moriscos [y] quitarles a el pensamiento de que se teme que se levanten. Demas desto ... [se] comisione que no se pongan en lugares cerca de la mar porque no puedan tener correspondencia con Berbería «. Published in Boronat y BARRACHINA, Los moriscos españoles, vol. II, pp. 459-460. Tomado de AGS, E, leg. 220. 
itself evinced the clear failure of the expulsions after 1569. Doria made this clear before Philip II in an assembly of the Cortes that would be the most difficult of his government, while proposing a reconsideration of the Morisco problem based on the interests of urban oligarchies.

Others had already dissented along the same lines years before. Eighteen years after the first deportations, it appeared clear that the policy of assimilation by inserting small communities of Moriscos into the heart of Christian society had failed, as the Councilor of State and Bishop of Segorbe D. Martín de Salvatierra thought in 1587:

Nor is it a sufficient or convenient remedy to reduce the said Moors by distributing them among the places of Old Christians, because [...] the great population and influx of people in the said cities and towns is the reason why they have been living and still live keeping the sect of Muhammad with greater liberty than if they lived in individual hamlets [...] This is confirmed by the experience in Spain with the Moors who were taken out of the kingdom of Granada, who after so many years living in places in Castile, where they were distributed, and having heard there in a very personal and Christian way and continually understood the teachings of Christian doctrine [...] now appear clearly to be as Moorish as they were in the said kingdom [of Granada], whether they live in their own houses or in the service of Old Christians $[\ldots]^{86}$.

This idea was amplified by the patriarch of Valencia, Juan de Ribera, following the demise of Philip II. Ribera supported the expulsion of the Castilian Moriscos, but not of the Valencians and Aragonese, for the first were $\gg$ unharnessed « (sueltos) and therefore more dangerous than those of Valencia, submitted to seigniorial jurisdiction. In this way, Ribera attempted to avoid the eventual socio-economic consequences of an expulsion from Valencia ${ }^{87}$. Along the same lines, in 1608 the duke of Lerma and powerful favorite of the King affirmed that the removal of the Moriscos from the Alpujarra mountains had been a »serious error ( gran yerro) because they could have been

86 »Tampoco es bastante remedio ni conveniente para la reduccion de los dichos moros, repatirlos por lugares de cristianos viejos, pues ... la mucha poblacion y concurso de gente de las dichas ciudades y villas es causa de que ellos ayan vivido y vivan guardando la secta de mahoma con mayor libertad que si vivieran en aldeas particulares ... esto se confirma ... con las esperiencias que se tienen en España de los moros que sacaron del reyno de Granada que con haver tantos años que viven en los lugares de Castilla, donde fueron repartidos, y en ellos muy particular y cristianamente an oydo y entendido continuamente el enseñamiento de la doctrina cristiana ... agora es cosa clara que son tan moros como lo eran en el dicho reyno asi los que viven en sus casas particulares como los que viven en servicio de cristianos viejos ...« Opinion of the bishop of Segorve, cited in Boronat y Barrachina, Los moriscos españoles, vol. I, p. 630.

87 Regarding these memorials, see Francisco Márquez Villanueva, El problema morisco. Desde otras laderas, Madrid 1991. 
controlled in a fortress, rather than enjoying the freedom of movement and ability to hide that they had in Castile ${ }^{88}$.

In this way, the mobility of the Moriscos constituted a veritable source of suspicions regarding their dangerousness and socio-religious orthodoxy. The interests of many oligarchies led to proposals for distancing Moriscos from the cities, but in many cases these proposals may have served more to express opposition in Cortes to the imposition of a deportation rather than to report real harm to these groups' urban economic interests. At the time of the expulsion, many cities and groups changed their rhetoric of lamentations and suggestions on behalf of the Moriscos' agrarian ostracism into a defense of the minority's assimilation as well as its economic value. Such was the case of Seville and of other cities, which fought with greater or lesser intensity to halt or at least avoid as much as possible the measures of the general expulsion, effective in the kingdom of Valencia in 1609 and after 1610 in Andalusia, Murcia and the other peninsular kingdoms (except Portugal) of the Hispanic Monarchy.

\section{The last forced Migration: The Expulsion of 1610}

The political debate that took place within the Council of State in the years leading up to the expulsion entailed an important exchange of ideas that led to the decision to expel the Moriscos from the Peninsula. To ensure the broadest possible effect, the attempt was made to keep the measure secret. Nevertheless, many Moriscos, unsettled by the perceptible political turn, decided to emigrate on their own. One of the first symptoms of this change was the action of the royal magistrate Gregorio López Madera, commissioned to punish the Moriscos of the town of Hornachos, who had no doubts about detaining and condemning many of them, finding secret arsenals and abundant evidence of their practice of Islam ${ }^{89}$. The ensuing attempts at emigration were repressed where they were detected, fundamentally for two

88 Published in Boronat y Barrachina, Los moriscos españoles, vol. II, p. 469.

89 Moriscos who attempted to cross the Aragonese Pyrenees with their families were detained as early as 1608. BoronAt y BARRACHINA, Los moriscos españoles, vol. II, pp. 490-493. Upon returning from Rome where he had attempted to convince the Pope to support the expulsion of the Moriscos in 1609, the Dominican friar Jaime Bleda encountered many Moriscos in the French town of Agde, who told him »that they were from Seville, with all the love of their homeland, and the affection that they left there, many of them would return and try, if the just indignation of the Catholic King would have been mitigated. Those that I found in that city mourned the treats that they had enjoyed in the large and rich city of Seville«. Jaime BLEDA, Corónica de los moros de España (Introductory study by Bernard Vincent and Rafael Benítez Sánchez-Blanco), Valencia 2001, p. 1042. For an essential study of the process of decisionmaking and the working mechanisms of the Council of State regarding this matter, see BENítez Sánchez Blanco, Heroicas decisiones. 
reasons: if flight became generalized, the measures for the expulsion would be worth little, and if the were given too much time, the Moriscos would depart with their goods and estates converted into gold and silver, which they would remove from the country.

The moment of the expulsion that began in 1609 had a historically much more distant parallel in the expulsion of the Sephardic Jews. Many of the Hebrew families that had lived in Fez since 1492 and in the kingdom of Morocco for all of the sixteenth century had decided to re-emigrate to the northern Mediterranean at the beginning of the seventeenth century, either to Italian cities where they could freely practice Judaism, or to convert to Christianity and return to the land of their ancestors on the Iberian Peninsula. The deterioration of public order and growing insecurity as well as a long subsistence crisis in the area inspired many to retrace the steps of their forefathers ${ }^{90}$. The Moriscos who decided to depart for the North of Africa did not wait so long to return, and clandestine reentries were denounced from the very first moment by the count of Salazar. Lapeyre calculated the number of returning Moriscos as some thirty thousand, although it appears certain that the numbers derived from royal documentation conceal a more numerous and diffuse reality. The phenomenon was important, judging from the continual edicts issued in order to prevent the return of those exiled in 1611 and $1613^{91}$. Alongside the illegal returnees, others openly opted to return as corsairs, this being a short-term phenomenon (of some 25 years) with profound economic repercussions and a considerable media coverage ${ }^{92}$.

What is most interesting both with regards to those Moriscos who remained half-hidden in the thickets of bureaucracy as well as to those who were able to return, is the progressive change of attitude which we can observe in the authorities after 1615, which passed to a contained laissez faire that not even

90 Many examples appear in Mercedes García-Arenal/Gerard Wiegers, A man of Three Worlds. Samuel Pallache, a Moroccan Jew in Catholic and Protestant Europe, Baltimore 2003.

91 A selection of these can be found in JANER, Condición social, pp. 440-455. See also Ignacio Bauer y Landauer, Papeles de mi archivo. Relaciones y manuscritos (moriscos), Madrid 1921. They are analyzed for the case of Andalusia by Fernández Chaves/PÉrez García, En los márgenes, pp. 363-449.

92 Regarding the Berber corsair and the extent of its Morisco reinforcements, see Már Jónsson, The expulsion of the last Muslims from Spain in 1609-1614. The destruction of an Islamic periphery, in: Journal of global History $2 / 2$ (2007). On the Moriscos as protagonists and antagonists on the Mediterranean frontier, see Augustin REDondo, La doble visión en España de los moriscos expulsados, a través de unas cuantas relaciones de sucesos de los años 1609-1614, in: Pierre Civil et. al. (eds.), España y el mundo Mediterráneo a través de las relaciones de sucesos (1500-1750), Salamanca 2008, pp. 271-286. In the same volumen see Didier RAult, La lucha naval con turcos y berberiscos en el Mediterráneo según las relaciones de sucesos (siglo XVII), pp. 237-252. See also Manuel F. Fernández Chaves, Entre quality papers y prensa amarilla. Turcos, moriscos y renegados, in: Carmen Espejo Cala et. al. (eds.), Relaciones de sucesos en la BUS, antes de que existiera la prensa, Sevilla 2008. 
the late publication of the last work of the apologist Jaime Bleda could alter ${ }^{93}$. This situation was largely due to the lack of interest in a phenomenon that offered the monarchy little prestige, and that required time-consuming operations of vigilance and control, left in the hands of local authorities much more interested in preserving a population useful to their interests.

What we have presented up to this point enables us to conclude that the Moriscos were the protagonists of a constant mobility, the principal motivations of which were emigration to Islamic lands and, in a second phase, the search for economic supplements and ways to maintain group cohesion through the muleteer trade and commerce. The deportation measures undertaken by Philip II and his administration accentuated these tendencies, producing a situation that legal prohibitions could not halt. The great expulsion of 1609-1614 further muddied the waters, creating a movement of return that ended up being tolerated after the first years. After that moment, the Moriscos officially ceased to exist, and the new problem became the Islam still practiced on the borders of a theoretically purified and homogenous society. The Islam was that of the Berbers, who reached the Peninsula as slaves or involuntary migrants fleeing famines and wars that occurred in North Africa. Reports and memorials were written about them, and there were even fervent efforts to indoctrinate them ${ }^{94}$, but their massive presence was limited to the coasts and capitals of a certain size where there were slaves. They were never considered a very serious threat, nor did they stage important movements. Following the expulsion of the Moriscos, the authorities' concerns with mobile populations centered on the gypsies, making the preoccupations and measures discussed here a matter of history.

93 BLEDA, Corónica.

94 Manuel F. Fernández Chaves/José Jaime García Bernal, Las relaciones de conversión y bautismo de infieles en las relaciones de sucesos sevillanas del Barroco, in: Patrick BÉGRAND (ed.), Representaciones de la alteridad, ideológica, religiosa, humana y epacial en las relaciones de sucesos publicadas en España, Italia y Francia en los siglos XVI-XVIII, Besançon 2009, pp. 335-375. 


\section{Margit Kern}

\section{Übersetzungsprozesse in der religiösen Kunst der Frühen Neuzeit: Die Mission in Neuspanien}

Übersetzungsprozesse finden nicht im luftleeren Raum statt, als freies Spiel der freien Kräfte, sondern sind ganz deutlich von hegemonialen Beziehungen geprägt und überformt ${ }^{1}$. Auch die spätere Beurteilung und Lektüre von künstlerischen Übersetzungsprozessen spiegelt häufig machtpolitische Auseinandersetzungen wider. Das lässt sich sehr gut in der kunsthistorischen Forschung der 20er und 30er Jahre in Mexiko beobachten: In die Zeit, in der die Anfänge einer wissenschaftlichen Beschäftigung mit der Kunst der Kolonialzeit liegen, fällt zugleich der Cristero-Aufstand (1926-1929), der sich gegen den Antiklerikalismus der mexikanischen Revolution richtete und versuchte, das angespannte Verhältnis zwischen Kirche und Staat zu verändern ${ }^{2}$. Die Kirche hatte nach der Revolution zahlreiche Einschränkungen erfahren und war gezwungen, ihre Aktivitäten im öffentlichen Raum weitgehend einzustellen. Diese Situation löste in einigen Bundesstaaten im Zentrum und im Westen Mexikos einen bewaffneten Aufstand aus.

Im Rahmen dieses Konflikts - und auch in der anschließenden wissenschaftlichen Aufarbeitung - spielte eine Frage eine zentrale Rolle: Gibt es eine eigenständige nationale Ausprägung des Christentums in Mexiko? Diese Frage war deshalb so umstritten, weil eine Bejahung die harte Gangart der Anhänger der Revolution gegenüber Rom legitimieren und als Rechtfertigung der kirchenpolitischen Weichenstellungen dienen konnte. Die subversive Vorstellung von den so genannten »Idolen hinter den Altären« (Idols behind altars $)^{3}$ hob die emanzipatorische und selbstdefinierende Kraft der Indigenen besonders hervor und sprach der Kirche Mexikos einen »Sonderweg« zu, der sie von der römischen Kirche trennte. Ohne das Wissen der Missionare seien die ursprünglichen Kulte weiterpraktiziert worden, die

1 Doris Bachmann-Medick, Einleitung, in: Dies. (Hg.), Übersetzung als Repräsentation fremder Kulturen, Berlin 1997, S. 1-18.

2 Vgl. im Folgenden Ramón JRADE, Inquiries into the Cristero Insurrection against the Mexican Revolution, in: Latin American Research Review 20 (1985), S. 53-69; Jennie Purnell, Popular Movements and State Formation in Revolutionary Mexico. The »Agraristas« and »Cristeros« of Michoacán, Durham/London 1999.

3 So der Titel des zeitgleich erschienenen Buches: Anita Brenner, Idols Behind Altars, New York 1929. 
Vermischung christlicher und prähispanischer Bildmotive, die von einheimischen Künstlern ausgeführt wurde, habe auf die Kontinuität alter Glaubensvorstellungen abgezielt. Diese bis heute andauernde Forschungsdiskussion zeigt, dass man der eurozentrischen Perspektive, der Vorstellung, die katholische Kirche in Mexiko sei ganz und gar europäisch geprägt, zunächst eine andere Form von Essentialisierung entgegensetzte, indem man die Kontinuität einer ursprünglichen »Reinheit« und Authentizität propagierte. Dem Eurozentrismus wurde ein amerikanisches Äquivalent, die kulturelle Partikularität des indigenismo, gegenübergestellt. In der Forschung der 20er und 30er Jahre dienten kolonialzeitliche Ikonographien daher als Argumente in den religionspolitischen Konflikten der Gegenwart. Welche Bedeutung die Durchdringung zweier Repräsentationssysteme im 16. Jahrhundert in Mexiko hatte, geriet unter dieser Indienstnahme aus dem Blick. Die in der Zeit der indigenista-Bewegung und des mexikanischen »Kirchenkampfes«, des Cristero-Aufstands, geschaffenen kunsthistorischen Modelle, die schlichten Schablonen von Unterwerfung einerseits und Subversion andererseits, zeichnen das Kräfteverhältnis in den Ikonographien der Frühen Neuzeit im Vizekönigreich Neuspanien daher nur unzureichend nach. Sie vereinfachen das Bild, denn sie konfrontieren zwei essentialisierte visuelle Systeme in einer eindeutig festgeschriebenen, an ethnischen Kategorien orientierten hegemonialen Hierarchie miteinander und schreiben, der politischen Ausrichtung des jeweiligen Autors entsprechend, einer von ihnen die Oberhand, das heißt die kulturelle Definitionsmacht, zu.

Die nun folgende Analyse soll dagegen belegen, dass die kulturelle Verortung der Zeichenformationen erst in der Rezeption, im performativen Akt der Sinnstiftung, zu einem Abschluss kommt und dieser Akt durchaus unterschiedliche Ergebnisse generieren kann. Die Frage, die in der Forschung zur Geschichte der lateinamerikanischen Kunst der Frühen Neuzeit im Zentrum stand und zugleich so heftig umstritten war - welcher Kultur die jeweiligen Ikonographien zuzurechnen sind und ob die prähispanischen Elemente inhaltsleere Dekorationen oder Zeichen des indigenen Widerstands, einer Kontinuität indigener Kultur, sind - basiert letztlich auf einem Containermodell von Kultur im Herderschen Sinn und verkennt die prozesshafte Dimension der Bildgenerierung, die Birgit Mersmann im Anschluss an Tom Holert so treffend mit dem Begriff des Imagineering umschreibt ${ }^{4}$. Mersmanns Plädoyer für einen transkulturellen Iconic turn in der Kunstgeschichte lässt sich vor allem für die kolonialen Bildkulturen Neuspaniens fruchtbar machen, um die aus historischen Umständen heraus ideologisch besetzte Frage nach

Birgit Mersmann, Bildkulturwissenschaft als Kulturbildwissenschaft? Von der Notwendigkeit eines inter- und transkulturellen Iconic Turn, in: Zeitschrift für Ästhetik und allgemeine Kunstwissenschaft 49 (2004), S. 91-109, hier: S. 91. 
der Bildgenese zu entschärfen und stattdessen die Frage nach dem Übersetzungsmodell oder der Synthetisierungsstrategie ins Zentrum zu stellen. Die vorliegende Analyse von Übersetzungsmodellen befasst sich mit der Frage, welche Interessen in der transkulturellen Imagination des Religiösen in den Kolonien eine Rolle spielen und welche Form von Partizipation für einzelne Protagonisten realisierbar war.

Homi Bhabha hat den Ausweg aus einer dichotomisierenden Perspektive gewiesen, indem er die performative Struktur und die innere Dynamik in der Rezeption und der Aneignung von hybriden Formen in den Mittelpunkt stellte und sie nicht primär durch ihre Genese definiert wissen wollte:

Die Bedingungen kultureller Bindung, gleichgültig, ob diese nun antagonistisch oder integrativ sind, ergeben sich performativ. Die Repräsentation von Differenz darf nicht vorschnell als Widerspiegelung vor-gegebener ethnischer oder kultureller Merkmale gelesen werden, die in der Tradition festgeschrieben sind. Die gesellschaftliche Artikulation von Differenz ist aus der Minderheitenperspektive ein komplexes, fortlaufendes Verhandeln, welches versucht, kulturelle Hybriditäten zu autorisieren, die in Augenblicken historischen Wandels aufkommen ${ }^{5}$.

Auch Carolyn Dean und Dana Leibsohn plädieren für einen solchen Hybriditätsbegriff, der nicht primär an der Genese der kulturellen Codes orientiert ist, sondern an deren Gebrauch: »[...] hybridity does not inhere in objects or practices. The perception of hybridity is generated from the contexts in which things circulate, and the settings in which mixed acts are performed or practiced $\ll^{6}$.

Konsequenzen hat das vor allem für die kunsthistorische Forschung mit ihrer traditionellen Konzentration auf den Ursprung der Motive, etwa im Rahmen einer Geschichte ikonographischer Typen oder einer Stilgeschichte.

Implizit nimmt man an, mit der Genese des Motivs auch zugleich dessen Bedeutung ermitteln zu können. Dieses Vorgehen legt ein essentialisiertes Modell von visuellen Systemen zugrunde, das eine Transferierbarkeit, eine Übersetzbarkeit von kulturellen Zeichen, letztlich ausschließt. In der Praxis zeigt sich jedoch: Der »Text« oder die Zeichenfiguration bestimmen nicht allein darüber, welche mentalen Bilder der Rezipient ihnen zuordnet.

5 Homi K. BhabHa, Die Verortung der Kultur, Tübingen 2000, S. 3.

6 Carolyn Dean/Dana Leibsohn, Hybridity and Its Discontents: Considering Visual Culture in Colonial Spanish America, in: Colonial Latin American Review 12 (2003), S. 5-35, hier: S. 26. Auch Serge Gruzinski hat hervorgehoben, dass die Verortung der kolonialzeitlichen Ikonographien letztlich vom Betrachter abhängt. Serge Gruzinski, La pensée métisse, Paris 1999, S. 194-196. An anderer Stelle sprach er sich allerdings für das Widerstandsmodell der »hidden idols« aus: Serge Gruzinski, Images at war. Mexico from Columbus to Blade Runner (14922019), Durham/London 2001. 
Plakativ gesagt: In welcher Sprache das Wort »Brot« ausgesprochen wird, kann nicht definitiv sicherstellen, dass der Zuhörer ein deutsches, französisches oder italienisches Backprodukt vor seinem inneren Auge hat. Die Verortung der Zeichen in einem bestimmten kulturellen Kontext modifiziert und verändert sie. Repräsentations- und Rezeptionsstrategien können konvergieren und sich ergänzen, sie können allerdings auch zu Widersprüchen führen. Daher vermag gerade die Doppelcodierung als Phänomen einer missionarischen Übersetzungsstrategie zu illustrieren, weshalb aus der Genese hybrider Formen nicht auf den Hybridisierungshorizont der anschließenden Lektüren zurückgeschlossen werden kann. Der Ursprung des Motivs kann nicht festlegen, in welche Richtung der Übersetzungsprozess führt und wie er zum Abschluss gebracht wird. Diese performative Dimension der Rezeption von religiösen Kunstwerken in der Kolonialzeit in Neuspanien wurde immer wieder vernachlässigt. Die umstrittene Frage, welche Lesart hybrider Ikonographien die richtige ist, erscheint aus dieser Perspektive obsolet. Negiert man die performative Dimension und versucht Dichotomien etwa in kunsthistorischen Kategorien von Motiv- oder Stilgeschichte festzuschreiben, so essentialisiert man rückwirkend visuelle Kulturen, die im Zeitpunkt ihrer Entstehung flexibler und dehnbarer waren als heute, wo prähispanische und europäische Kunstgeschichte von verschiedenen universitären Disziplinen vertreten werden. Ob es sich um eine Nahuatlisierung des Christentums ${ }^{7}$ oder um eine Christianisierung der Religion der Mexica handelt, ist nicht nur eine Frage der Formen oder des Zeichenrepertoires, sondern vor allem auch eine der Perspektive, der Aneignung der Formen und Zeichen. Differenzen und Parallelen werden durch Zuschreibungen erst autorisiert und erzeugt, sie erhalten in performativen Prozessen Gewicht.

Aus diesem Grund ist auch die Systematisierung von kulturellen $\gg \mathrm{Mi}^{-}$ schungsverhältnissen « in Kunstwerken mit Begriffen wie »juxtaposition, convergence, and syncretism « - die letztlich auf $\mathrm{Kubler}^{8}$ zurückgehen und die in jüngerer Zeit von Jeanette Favrot Peterson und Gauvin Alexander Bailey wieder aufgegriffen wurden ${ }^{9}-$ nicht wirklich durchführbar, weil sie für

7 Vgl. Charles E. Dibble, The Nahuatlization of Christianity, in: Munro S. Edmonson (Hg.), Sixteenth-Century Mexico. The Work of Sahagún, Albuquerque 1974, S. 225-233. Der Titel des Aufsatzes wurde zu einem Schlagwort in der Forschung. Dibble macht die interessante Beobachtung, dass der Metaphernreichtum sowie die Vorliebe für Dopplungen und Wiederholungen, wie sie im Nahuatl üblich sind, in den christlichen Texten beibehalten und auf christliche Themen angewandt wurden.

8 George Kubler, On the Colonial Extinction of the Motifs of Pre-Columbian Art, in: Thomas F. ReEse (Hg.), Studies in Ancient American and European Art. The Collected Essays of George Kubler, New Haven/London 1985, S. 66-74, hier: S. 68-71. Erstmals erschienen in: Samuel Kirkland Lothrop u.a. (Hg.), Essays in Pre-Columbian Art and Archaeology, Cambridge 1961, S. 14-34, 450-452, 485f.

9 Bailey und Peterson greifen diese Kategorien auf und modifizieren sie. Bailey sieht den Anteil des Betrachters zwar als Problem, jedoch ohne die Systematik grundsätzlich in Frage zu stel- 
jedes Kunstwerk festgeschriebene Rezeptionssituationen voraussetzen. Im ersten Fall würden Kubler zufolge Zeichen aus beiden Kulturen nebeneinandergestellt, ohne ihre ursprüngliche Bedeutung zu verändern. Im zweiten Fall erfährt dasselbe Zeichen in beiden Kulturen eine ähnliche Interpretation. Synkretismus meint laut Bailey die Vermischung von Symbolen und Vorstellungen aus zwei verschiedenen Kulturen, so dass sie am Ende nicht mehr differenzierbar sind ${ }^{10}$. Über den Grad der Aneignung beziehungsweise die Art der Verbindung der verschiedenen Repräsentationssysteme entscheidet jedoch vor allem der Betrachter. Der Übergang von einer objektorientierten Analyse zu einer prozessorientierten ist für die Kunstgeschichte der Kolonialzeit vor allem deshalb so wichtig, weil mit der Übersetzung des Zeichens noch nicht die Übersetzung des Bezeichneten gesichert ist. Daher ist nicht das Kunstwerk allein zu diskutieren, sondern auch mögliche Aneignungsund Rezeptionsprozesse. Dies bedeutet vor allem, dass es nicht mehr eine richtige Lektüre gibt - auf die man sich in der Forschung ja auch nicht einigen konnte - sondern mehrere Lektüren.

Aus diesen Perspektiven heraus lässt sich das Paradox besser verstehen, das Homi Bhabha mit seinem third space, dem dritten Raum der Hybridisierung, entworfen hat: »Dieser zwischenräumliche Übergang zwischen festen Identifikationen eröffnet die Möglichkeit einer kulturellen Hybridität, in der es einen Platz für Differenz ohne eine übernommene oder verordnete Hierarchie gibt $\ll^{11}$. Anhand eines Beispiels soll im Folgenden die Entstehung transkultureller Imaginationen und die Genese kolonialer Bildkulturen nachgezeichnet und gezeigt werden, dass koloniale Bildkulturen nicht mehr in einzelne essentialisierte Teilsysteme zerlegbar sind, weil die Mischung und Verflechtung etwas Neues entstehen lässt, das mehr ist als die Summe seiner Teile. Es zeigt sich, dass die von einer Gruppe tradierten Bildtypen von anderen Teilnehmern der Kolonialgesellschaft aufgegriffen und entsprechend ihrer Repräsentationserfahrung und ihrer Perspektive auf die koloniale Wirklichkeit gelesen und weiterverarbeitet werden.

len. Gauvin Alexander Bailey, Art on the Jesuit Missions in Asia and Latin America, 15421773, hier: S. 28f., Toronto u.a. 1999; Jeanette Favrot Peterson, The Paradise Garden Murals of Malinalco. Utopia and Empire in Sixteenth-Century Mexico, Austin 1993, hier: S. 7-9.

10 Zur Kritik am Begriff des Synkretismus in der neueren Forschung vgl. Fritz Graf, Art. Syncretism [further considerations], in: The Encyclopedia of Religion 13 (22005), S. 8934-8938. Synkretismus impliziert Assoziationen von Verfall und Schwäche, das heißt, dem Begriff liegt die normative Annahme zugrunde, es gebe reine Religionen als autonome Gebilde und Reinheit sei ihr ursprünglicher Zustand. Reinheit und Ursprung werden jedoch bei näherer Betrachtung meist durch hierarchisch höher gestellte und mächtigere Akteure definiert, die eine nationale gegen fremde Religionen, eine orthodoxe Lehre gegen Häresien, eine korrekte Religion gegen indigene Missverständnisse abgrenzen. Der Diskurs ist somit unweigerlich politisch.

11 Bhabha, Die Verortung der Kultur, S. 5. 
Auf dem Steinkreuz in Cuautitlán (México) (Abb. 1), das sich ehemals im atrio des 1532 gegründeten Franziskanerklosters ${ }^{12}$ befand, ist ein tief hinterschnittenes Relief mit den Arma Christi zu sehen ${ }^{13}$. Es fällt auf, dass die »Waffen« nicht willkürlich auf den Balken verteilt wurden. Durch die symmetrische Anordnung der einzelnen Zeichen strebte man in Cuautitlán offenkundig eine ausgewogene Komposition an. Zu diesem Eindruck trägt vor allem die mittige Anbringung der Leiter direkt unter dem Dornenkranz im Zentrum des Kreuzes bei. Die drei Akanthusblätter an der Spitze und an den Armenden, die Pedro Rojas ${ }^{14}$ und Jaime Lara ${ }^{15}$ überzeugend als zu Federn umgeformten Akanthus identifiziert haben, wurden ebenso gleich gestaltet wie die beiden blutenden Wunden auf den Kreuzarmen. Die dekorative Anbringung der Silberlinge als horizontale Zierbordüre über dem Dornenkranz gleicht die Neigung der INRI-Tafel darüber optisch aus. Diesem deutlich erkennbaren Sinn für Symmetrie folgt auch die Gestaltung der beiden Köpfe auf den Kreuzarmen. Zwei Männer sind hier dargestellt, die in Dreiviertelansicht einander zugewandt erscheinen. Links ein bärtiger Mann mit knochigem Gesicht und langem, leicht gewelltem Haar, rechts ein älterer, bartloser Mann mit rundem Schädel. Der dichte, kurz geschnittene Haarkranz auf dem Hinterkopf legt bei Letzterem nicht nur deutlich das linke Ohr, sondern auch eine hohe, in Falten gelegte Stirn frei. Unter den beiden Männerköpfen sind zwei Arme zu erkennen, die durch ihre Gestik und ihren Anbringungsort eine Lektüre zusammen mit den Köpfen darüber nahelegen, obwohl ein plastisches Körperkontinuum nicht besteht. Die linke Hand hält einen Beutel, und auch die Bluse des Oberarms ist so geschnürt, dass sie an eine Geldbörse erinnert. Auf der rechten Seite erkennt man eine Hand mit ausgestreckten Fingern.

Die paarweise Anbringung der Figuren forderte die Forschung früh zu Hypothesen heraus, bei denen vor allem die gegensätzliche Haartracht der Protagonisten eine Rolle spielte. Man dachte an zeitgenössische Persönlichkeiten, die an diesem Kreuz porträtiert sein könnten. Während die vollbärtige, knochige Physiognomie als Hernán Cortés oder als der encomendero ${ }^{16}$ Alon-

12 George Kubler, Mexican Architecture of the Sixteenth Century, 2 Bde., New Haven 1948, Bd. 2, S. 457. Laut Kubler ist in den Quellen für Cuautitlán eine Bauphase zwischen 1530 und 1540 nachweisbar (vgl. ebd., Bd. 1, S. 62).

13 Santiago Sebastián u.a., Iconografía del arte del siglo XVI en México, Mexiko-Stadt 1995, S. 48. Allgemein zu den Steinkreuzen in Mexiko vgl. auch Mildred Monteverde, SixteenthCentury Mexican >Atrio< Crosses, Ph.D. Diss. University of California, Los Angeles 1972; Jaime LARA, El espejo en la cruz. Una reflexión medieval sobre las cruces atriales mexicanas, in: Anales del Instituto de Investigaciones Estéticas 18 (1996), Nr. 69, S. 5-40.

14 Pedro RoJAs, Historia general del arte mexicano. Época colonial, Mexiko-Stadt u.a. 1963, S. 19.

15 Jaime Lara, City, Temple, Stage. Eschatological Architecture and Liturgical Theatrics in New Spain, Notre Dame 2004, S. $156 f$.

16 Als »encomendero« bezeichnete man einen spanischen Konquistador, dem ein sehr großes 
so de Ávila beziehungsweise dessen Vater Gil González de Ávila identifiziert wurde, erkannte man an der rechten Figur eine Tonsur ${ }^{17}$. Das Mönchsporträt schien sich auf einen der Gründer des Klosters zu beziehen, Francisco Bustamante wurde hier ebenso in Erwägung gezogen wie Pedro de Gante. Folgt man den Interpretationen, standen sich hier zwei Vertreter der spanischen Kolonialmacht gegenüber, ein weltlicher Anführer und ein Kirchenmann.

Diesen Spekulationen, auf die sich sogar Manuel Toussaint bezogen hat ${ }^{18}$, widersprachen Santiago Sebastián, Mariano Monterrosa und José Antonio Terán 1995 ganz entschieden. Ihr Argument lautete: Weder der encomendero noch der Mönch stehe in irgendeiner Beziehung zum Passionsgeschehen ${ }^{19}$. Die linke Figur sei aufgrund ihrer Geldbörse eindeutig als Judas zu lesen, während die rechte Figur einen der Schergen darstelle, die Christus verspotteten. Zieht man zum Vergleich Beispiele aus der europäischen Druckgraphik heran, etwa einen um 1480 entstandenen Holzschnitt der Gregorsmesse mit den Arma Christi (Abb. 2 und Abb. 3), so ist dem zuzustimmen. Ja, Judas scheint sogar mit zwei Börsen versehen, da ihm in Cuautitlán zwar eine Schnur um den Hals hängt, der in der Druckgraphik traditionell daran hängende Beutel im Relief dann aber zum gerafften Ärmel umgedeutet wurde. Dennoch fällt auf, dass diese beiden Figuren in der europäischen Bildtradition niemals so explizit aufeinander bezogen wurden. Meist finden sich unter den Arma Christi noch zahlreiche andere Köpfe, neben Pilatus, Herodes und Kaiphas erscheinen Petrus und die Magd, so etwa in einem um 1460 in den Niederlanden entstandenen Holzschnitt wiederum mit der Gregorsmesse (Abb. 4). Wenn tatsächlich nur diese beiden Protagonisten des Passionsgeschehens ausgewählt wurden, wie es in einem 1517 in Augsburg entstandenen Tafelbild der Fall ist, dann stehen sie sich in der Bildkomposition nie so gegenüber, dass man sie paarweise aufeinander bezogen lesen könnte ${ }^{20}$.

Anders dagegen in Neuspanien: Hier finden sich zahlreiche Beispiele, die ähnlich strukturiert sind wie die Ikonographie des Steinkreuzes von Cuautitlán - und auch die Interpretationen, die zum Teil auf mündlicher Überlieferung zu beruhen scheinen, ähneln sich. So hat Pedro Rojas etwa die beiden Köpfe auf den Balken des Kreuzes in Tizayuca (Hidalgo) als Porträt eines spanischen encomenderos und eines indigenen Kaziken gelesen ${ }^{21}$.

Landgut übertragen wurde und dem die indigene Bevölkerung in diesem Gebiet tributpflichtig war.

17 Rojas, Historia general del arte mexicano. Época colonial, S. 19; SEBASTIÁn, Iconografía del arte del siglo XVI en México, S. 48.

18 Manuel Toussaint, Colonial Art in Mexico, Austin/London 1967, S. 57.

19 Sebastián u.a., Iconografía del arte del siglo XVI en México, S. $48 f$.

20 Augsburg, Schmerzensmann mit Arma Christi, Tür eines Sakramentshauses, Tafelmalerei, 1517, Augsburg, Maximilianmuseum Arch. Nr. 82396 (Gertrud Schiller, Ikonographie der christlichen Kunst, Bd. 2: Die Passion Jesu Christi, Gütersloh 1968, S. 621, Abb. 717).

21 RoJAs, Historia general del arte mexicano. Época colonial, S. 19. 
Ähnlich wurde mir von dem Stadtchronisten Ernesto Gómez Aco die Ikonographie einer Wandmalerei im Franziskanerkloster von Otumba (Méxi-

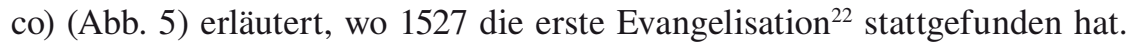
Auch bei diesem Beispiel fällt die strenge Symmetrie der Komposition auf. Drei Kreuze mit deutlich erkennbarer Holzmaserung stehen auf pyramidalen Steinsockeln mit einer mittigen Höhlung. Das Kreuz Christi wird durch seine Form und Größe, seine mittige Position und die Darstellung der drei Nägel in den Holzbalken besonders hervorgehoben. Die langen Diagonalen der Lanze und des Stabes mit dem Schwamm flankieren es ebenso wie der rhythmisierte Wechsel von Bäumen und Kreuzen. Auch die beiden Geißeln sind symmetrisch neben den Kreuzstamm gesetzt, darüber hinaus sind die Arma Hammer, Silberlinge, Zange und Würfel zu sehen. Die Köpfe über den beiden seitlichen Kreuzen zeichnen sich ähnlich wie in Cuautitlán durch ihre Gegensätzlichkeit aus. Während der linke einen Vollbart hat (Abb. 6) und offenes gewelltes Haar, ist der rechte (Abb. 8) bartlos und trägt die Haare im Nacken gebunden. Der Beutel des einen und die Klümpchen vor dem Mund des anderen erlauben eine Identifizierung im Sinn der christlichen Bildtradition als Judas und als Scherge, der Christus bei der Verspottung bespuckt.

Die Darstellung des Speichels unterscheidet sich jedoch bei näherer Betrachtung deutlich von den europäischen Vorbildern, bei denen die Spucke entweder in kleinen Klümpchen dargestellt wird, wie auf dem um 1460 datierten niederländischen Holzschnitt (Abb. 7), oder in langen Schlieren direkt vom Mund ausgeht, wie auf dem eingangs bereits erwähnten um 1480 in Brünn entstandenen Holzschnitt der Gregorsmesse (Abb. 3). Aus dem Mund des Mannes in Otumba kommen jedoch zwei aufeinanderfolgende, genau gleich große, gerundete Formen. Darüber hinaus ist sein Mund leicht geöffnet, während Spuckende meist mit geschlossenem Mund dargestellt werden. Die schneckenförmige Kontur und die Stellung zum Mund erinnern an Sprechglyphen (Abb. 9), wie sie in den Codices erscheinen, etwa in dem um 1541 entstandenen Codex Mendoza. Der in Folio fünf verso dargestellte König Itzcoatl (Abb. 10) ähnelt der Figur in Otumba auch noch in anderer Hinsicht. Auch bei Itzcoatl liegt der Hauptakzent auf dem Kopf, der Körper tritt unter dem Umhang kaum in Erscheinung, während die Herrschaftsattribute, die Itzcoatl umgeben, und die Namensglyphe über ihm vorrangig wahrgenommen werden.

Diese Repräsentationsform des Sprechakts lässt sich auch noch 1579 in der Rhetorica Christiana von Valadés beobachten. Der Autor des 1579 in Perugia erschienenen Missionstraktats, Diego Valadés - als Sohn eines Spaniers und einer Frau aus Tlaxcala 1533 vermutlich in Neuspanien geboren - gilt als

22 Kubler, Mexican Architecture of the Sixteenth Century, Bd. 2, S. 468. Baudaten sind hier nicht überliefert. 
berühmtester Schüler von Fray Pedro de Gante in dem Franziskanerkloster San Francisco de México. Mitte des 16. Jahrhunderts trat Valadés selbst dem Orden bei und dokumentierte in der Rhetorica Christiana die Missionsmethoden der Franziskaner. In einer Illustration dieses Traktats (Abb. 11), welche die hierarchische Struktur des Staatswesens im Bild des Baumes vom Kaiser über den König bis zum pater familias durchdekliniert, erkennt man nun gleichfalls einen Regen von Glyphen, der sich vom Richter auf den Delinquenten sowie vom pater familias auf die Schutzbefohlenen ergießt und so die Rede des sozial höher Gestellten anzeigt.

Bei diesem Vergleich wird deutlich, dass die bartlose Erscheinung und der als Sprechglyphen gelesene Speichel dazu geführt haben, dass man in der rechten Figur in Otumba einen indigenen Anführer, einen Kaziken, erkannte, während im Gegensatz dazu der Geldbeutel und der Vollbart sein Pendant als Spanier (Abb. 5) charakterisierten. Der Beutel wurde auf die Tributpflichtigkeit der indigenen Bevölkerung gegenüber dem spanischen encomendero bezogen. Es standen sich also zwei Vertreter der kolonialen Elite gegenüber. Welchen Sinn haben diese »Herrscherbildnisse« aber im Zusammenhang mit der christlichen Ikonographie, die sich allein auf den Opfertod Christi bezieht? Auch diese Verbindung lässt sich mühelos ziehen: In der prähispanischen Gesellschaft wurden die Opferkulte von einer herrschenden Elite verwaltet, der man tributpflichtig war. Die koloniale Dimension kommt demnach vor allem in der Verteilung dieser zentralen Aufgaben auf zwei Funktionsträger zum Ausdruck. Es handelt sich hier nicht um vermeintlich prähispanische Kontinuitäten, die eine falsche Lektüre europäischer Prototypen produzieren, sondern es ist eine eigene Bildform entstanden, die sich auf koloniale Sozialstrukturen bezieht, die vor der Conquista so nicht bestanden. Der Versuch, die Bildformen entsprechend ihrer Genese nach ethnischen Kategorien zu differenzieren, muss hier scheitern. Es handelt sich um koloniale Imaginationen, die weder europäisch noch prähispanisch sind.

Das zeigt auch die Weiterentwicklung dieses Bildtypus in Tepeapulco (Hidalgo). Zwei Köpfe auf dem Steinkreuz (Abb. 12), das heute vor der Fassade des 1528/29 gegründeten Franziskanerklosters ${ }^{23}$ aufgestellt ist, wurden ebenfalls als encomendero und als Kazike interpretiert. Es liegt nahe, hier von einer lokalen mündlichen Tradition auszugehen. So wird diese Interpretation auch im Reiseführer ${ }^{24}$ vorgeschlagen, einer Textsorte, in die mündlich tradierte Lektüren unmittelbarer und leichter Eingang finden als in die wissenschaftliche Literatur.

23 Kubler, Mexican Architecture of the Sixteenth Century, Bd. 2, S. 475 und ebd., Bd. 1, S. 62 verzeichnet hier zwei Phasen von Bautätigkeit: 1530/40 und 1550/60.

24 Wolfgang Rössig u.a., Knaurs Kulturführer in Farbe, München 1993, S. 257. 
Zunächst lassen sich die wesentlichen Charakteristika der neuspanischen Steinkreuze mit Arma-Christi-Ikonographie auch bei diesem Beispiel feststellen. Im Zentrum befindet sich die Dornenkrone, umgeben von den drei Wundmalen und der INRI-Tafel darüber. Der Eucharistiekelch, der das strömende Blut Christi auffängt, fehlt ebenso wenig wie der von zwei Knochen gerahmte Totenschädel am Fuß des Kreuzes. Auf der Vorderseite erscheint zudem der bärtige Kopf eines Schergen, der seine Zunge herausstreckt, um Christus zu verspotten - ein in der europäischen Ikonographie geläufiges Motiv. An den beiden mit weiteren Werkzeugen versehenen Schmalseiten des Kreuzstammes, rechts und links, stehen sich auf einer Ebene die beiden bereits bekannten Kopftypen gegenüber. Links gewährleistet angesichts der etwas undeutlichen Gesichtszüge vor allem der monumentale Geldbeutel die Identifizierung: Es handelt sich um Judas oder - in einer anderen Lesart den encomendero. Die Physiognomie des Kopfes auf der rechten Seite (Abb. 13) unterscheidet sich ganz wesentlich von den bisher analysierten Beispielen. Über hohen, voluminösen Wangen sitzen schmale Augen mit auffallend geraden Brauen, die Stirn ist von einem dichten glatten Pony bedeckt, vor den dicken Lippen steht eine Wolkenform, die als Speichel oder als Sprechglyphe interpretiert werden kann. Der Gesichtstypus weist hier eindeutig indigene Züge auf, wie ein Vergleich mit einigen Illustrationen des Codex Florentinus (Abb. 14) nahe legt, in dem Indigene ebenfalls meist durch einen kurzen glatten Pony gekennzeichnet werden.

Die Interpretation des spuckenden Schergen als Kaziken und als Pendant zum spanischen encomendero mit Geldbeutel hat hier zu einer Weiterentwicklung und Veränderung der Bildtradition geführt. Der Kazike mit Sprechglyphe ist nun auch als indigener Anführer erkennbar. Die neue, koloniale Lektüre wurde den Arma-Christi-Symbolen sichtbar eingeschrieben.

Dieser am Beispiel der Passionsikonographie aufgezeigte künstlerische Übersetzungsprozess lässt sich auch in anderen Bereichen kolonialer Bildkulturen beobachten. Vor allem Historiker und Anthropologen haben bisher Modelle für diesen Prozess entwickelt. James Lockhart charakterisiert die Struktur der »cultural interaction between Europeans and indigenous people in the central regions of Spanish America « mit dem Begriff der »Double Mistaken Identity«, der in der Folge auch von Kunsthistorikern ${ }^{25}$ übernommen wurde:

To give it a name, one might call it the process of Double Mistaken Identity, in which each side of the cultural exchange presumes that a given form or concept is operating

25 Jeanette Favrot Peterson, The Paradise Garden Murals of Malinalco. Utopia and Empire in Sixteenth-Century Mexico, Austin 1993, S. 8 und 104f.; Gauvin Alexander BAILeY, Art on the Jesuit Missions in Asia and Latin America, 1542-1773, Toronto u.a. 1999, S. 22. 
in the way familiar within its own tradition and is unaware of or unimpressed by the other side's interpretation. [...] Neither side would be entirely wrong ${ }^{26}$.

Die Feststellung, dass von den Spaniern vor allem kulturelle Elemente erfolgreich implementiert werden konnten, die früheren, prähispanischen Traditionen entsprachen, ist dabei ebenso wichtig wie die Erkenntnis, dass die Annäherung an die andere kulturelle Codierung zugleich immer auch eine Veränderung des ursprünglichen Konzepts mit sich bringt. Gleichwohl steht der Nachsatz, dass sich keiner der beteiligten Protagonisten in seiner spezifischen Lektüre vollständig irrte, im Widerspruch zur Charakterisierung als »wechselseitiges kulturelles Missverständnis«. Als Normverstöße lassen sich diese neuen Ikonographien in der Kunst der Kolonialzeit nur dann bezeichnen, wenn man ethnisch homogene, statische, geschlossene visuelle Systeme als Ursprung und Maßstab für die kolonialen Hybridisierungen annimmt.

Ähnlich hat auch Louise M. Burkhart aus ihrer Analyse der Katechismen und anderer Missionsschriften der Mönche zusammenfassend geschlossen, dass diesen neuen, im Rahmen des Übersetzungsprozesses entstandenen Synthesen aus zwei verschiedenen religiösen Systemen, dem in Dichotomien organisierten Christentum mit seinem Dualismus zwischen Leib und Seele und dem monistisch strukturierten Kosmos der Nahua, ein Mangel anhaftet: Sie können systematisch in sich nicht schlüssig sein; das neu entstandene religiöse System ist inkonsistent.

A religion combining equal parts of Christianity and Nahua belief could not function as a cultural system: there is no neutral middle ground between a sacrifice-oriented monism and a soteriologically-oriented matter/spirit dualism. [...] From this confused standpoint, the premises of Christianity were not understood and therefore only superficial aspects of Christian rites could be incorporated into one's own religion [...] The result was >syncretic $<$ in the sense that it combined elements of both cultures, but not in the sense of a simple sum of parts, nor of attaining a true synthesis. The frontier was a liminal zone full of contradictions and inconsistencies ${ }^{27}$.

Die Autorin nimmt hier die Perspektive jener Dogmatiker ein, die über Jahrhunderte an einer widerspruchsfreien Theologie feilten und für die systematische Geschlossenheit ein wesentliches Merkmal einer Religion darstellte. Gerade die christliche Kirchengeschichte dokumentiert jedoch bei näherer Betrachtung vor allem die fortwährende Auseinandersetzung und das Rin-

26 James Lockhart, Some Nahua Concepts in Postconquest Guise, in: History of European Ideas 6 (1985), S. 465-482, hier: S. 477.

27 Louise M. Burkhart, The Slippery Earth. Nahua-Christian Moral Dialogue in Sixteenth-Century Mexico, Tucson 1989, S. 188. 
gen um diese eine widerspruchsfreie Lehre. Wenn selbst in der streng hierarchisch organisierten katholischen Religion in Europa neue theologische Ansichten immer wieder geprüft und integriert oder verworfen wurden, die systematische Geschlossenheit mithin in einem performativen Prozess aus beständigen Korrekturen und Modifikationen immer wieder neu gewonnen werden musste, um wie viel wandlungsfähiger muss man sich die religiösen Strukturen der Mexica vorstellen, denen die Reinheit der Lehre nicht als zentrales Ziel vor Augen stand. Von der Ebene der Eliten abgesehen muss man sich darüber hinaus in jeder Religion fragen, wie konsistent die Glaubenstheorie noch sein konnte, wenn sie eine konkrete Übertragung in die Glaubenspraxis und die Frömmigkeitsübung des Alltags erfahren hatte. Vor diesem Hintergrund muss die Vorstellung, die neu entstandenen Systeme entbehrten der systematischen Geschlossenheit, welche den reinen Urformen durchaus zukomme, generell in Frage gestellt werden.

Transkulturelle Imaginationen, wie sie in der Passionsikonographie von Cuautitlán, Tizayuca, Otumba und Tepeapulco ablesbar werden, sollte man nicht als Korrumpierung der ursprünglichen Ordnung und Logik ansehen, sondern ihr kreatives Potenzial ins Zentrum der Analyse stellen. In diesen paradigmatischen Konstellationen kann zum einen die Modifizierbarkeit und Unabgeschlossenheit von visuellen Systemen untersucht werden, und zum anderen können gerade koloniale Imaginationen als Modellfall für die Generierung neuer Bildsemantiken ${ }^{28}$ gelten.

Die Deutung dieser neuen Bildschöpfungen als visuelle Irrtümer stützt sich implizit auf die Grundannahme, dass neue Bilder zwangsläufig auf der Grundlage neuer Texte entstehen. Aber auch Bilder können neue Imaginationen anstoßen - und sich unter diesen Voraussetzungen durchaus vom ursprünglichen Text lösen, so wie Kazike und encomendero im biblischen Passionsbericht fehlen. Wenn Leopold Kretzenbacher das »Sekundär-Ausdeuten« von Bildern mit dem schönen Begriff der »Ikonotropie « bezeichnet ${ }^{29}$, so charakterisiert dieser Terminus sehr genau ein grundlegendes Phänomen von Bilderangst, nicht nur im Bereich der religiösen Kunst. Nur ihre Referenz zu textlichen Ordnungsprinzipien kann demnach bildliche Imaginationen vor dem semantischen Chaos bewahren. Der Angst vor dem Bedeutungsüberschuss und der Verselbstständigung von Bildern auf der einen Seite entspricht auf der anderen ein Vertrauen in die Eindeutigkeit der Texte; eine Überzeugung, die zwar kulturell, aber nicht logisch begründet erscheint.

28 Eine ähnliche Modellsituation innerhalb der europäischen Kunstgeschichte habe ich im Rahmen meiner Dissertation über die Neusemantisierung der Tugendikonographie in der Reformationszeit analysiert. Vgl. Margit Kern, Tugend versus Gnade. Protestantische Bildprogramme in Nürnberg, Pirna, Regensburg und Ulm, Berlin 2002.

29 Leopold KretzenBacher, Nachtridentinisch untergegangene Bildthemen und Sonderkulte der »Volksfrömmigkeit« in den Südost-Alpenländern, München 1994, S. 34-73, hier: S. 52. 
Der Blick auf die Kunstgeschichte lehrt jedoch: Alle Bildlichkeit ist ikonotropisch und nur weil es so ist, kann sie weiterbestehen und sich verändern. Dass die Entstehung neuer Bildtypen in Europa an vielen Stellen durchaus ähnlich verlaufen ist wie in dem eben analysierten Beispiel aus Neuspanien, lässt sich an einer vergleichbaren Ikonographie demonstrieren. In den zwischen der Mitte des 14. und der Mitte des 16. Jahrhunderts verbreiteten Darstellungen des so genannten »Feiertagschristus« (Abb. 15) befindet sich Jesus, zumeist als Schmerzensmann, inmitten zahlreicher Werkzeuge. Die Geräte richten sich auf den Leib des Erlösers, verletzen ihn gelegentlich sogar. Auf diese Weise soll der Verstoß gegen das Arbeitsverbot an Feiertagen visualisiert werden, der Christus, wie zugehörige Inschriften in einigen Beispielen erläutern, verletzt und kränkt.

Die Frage nach der Genese dieses Bildtypus beantwortete schon Rudolf Berliner $^{30}$ mit einem Hinweis auf die Darstellung Christi inmitten seiner Arma. Diese in der Forschung kontrovers diskutierte These ${ }^{31}$ bestätigte Athene Reiss vor kurzem in einer umfangreichen Untersuchung. Sie stellte fest, dass sich die Bildkomposition nicht aus einer vorhergehenden Texttradition ableiten lässt ${ }^{32}$. Da jedoch Christus häufig nicht nur von den verschiedensten Arbeitsgeräten, sondern auch von Zeichen umgeben ist, die eindeutig den Arma Christi zuzurechnen sind, spricht einiges dafür, die Werkzeuge des »Feiertagschristus« für eine Weiterentwicklung der Marterwerkzeuge aus der Arma-Ikonographie zu halten ${ }^{33}$. So tauchen etwa in einer 1460/70 datierten Wandmalerei in Crngrob (Slowenien) neben der Hacke, der Garnhaspel und dem Webstuhl Symbole der Passion des Erlösers auf, wie die Geißelsäule, die Köpfe von Petrus, Annas, Kaiphas, Herodes und Judas sowie Pilatus, der seine Hände wäscht ${ }^{34}$. In Zanigrad bei Črni Kal (Slowenien) sind neben den Handwerksgeräten die Schergen unter dem Kreuz und der Becher mit den drei Würfeln zu sehen. An diesen Beispielen wird deutlich: Die Werkzeuge der Passion, wie Hammer, Zange, Nägel etc., ließen sich nicht nur auf die biblische Erzählung, sondern auch auf vertraute alltägliche Arbeitsprozesse beziehen, so dass die Transformation der Bildaussage und die Ergänzung der bereits bestehenden Attribute in diesem Sinn nahe lag. Auch bei dieser Neusemantisierung handelt es sich nicht um einen Irrtum, der ur-

30 Rudolf Berliner, Arma Christi, in: MJBK 6 (1955), S. 35-152, hier: S. 112-116.

31 Wildhaber argumentiert mit den Textbestandteilen der Bilder. Da die Inschriften nicht auf die Passionsikonographie verweisen, lehnt er eine Genese aus dieser Bildtradition ab. Die Möglichkeit, dass die Texte nicht über eine vorhergehende Tradition verfügen, sondern unmittelbar für den Bildtypus verfasst wurden, zieht er nicht in Betracht. Robert WiLdHABER, Art. Feiertagschristus, in: RDK 7 (1981), Sp. 1002-1010, hier: Sp. 1008.

32 Athene ReIss, The Sunday Christ. Sabbatarianism in English medieval wall painting, Oxford 2000, bes. S. 2, 23-27 und 58.

33 Ebd., S. 26.

34 Vgl. im Folgenden Kretzenbacher, Nachtridentinisch untergegangene Bildthemen, S. 52f. 
sprüngliche Sinnzusammenhänge verkehrt, sondern um eine Weiterentwicklung, die bildimmanent neuen Sinn stiftet und auf veränderte außerbildliche Phänomene beziehbar macht.

Ähnlich liegt bei den Arma Christi mit Kazike und spanischem encomendero nicht eine Verwechslung europäischer Ikonographie vor, sondern die Entwicklung eines neuen Bildtypus aus verschiedenen Elementen, die in der kolonialen Gesellschaft Neuspaniens präsent und relevant waren - und die wiederum auf unterschiedliche Art und Weise rezipierbar sind. Es gibt nicht nur eine einzige Interpretation; der Kazike kann auch immer noch als spuckender Scherge des Passionsgeschehens gedeutet werden. Neben diesen beiden Rezeptionsformen sind allerdings noch viele verschiedene Zwischenstufen erkennbar, in denen die ikonographischen Grundelemente jeweils auf andere Traditionen beziehbar sind ${ }^{35}$. Die Beobachtung, dass die beiden Köpfe so pointiert gegenübergestellt wurden und eine individuelle Charakterisierung erfahren haben, führte zur Identifikation als Stifterfiguren ${ }^{36}$ oder als historische Persönlichkeiten, die mit der Christianisierung des Ortes verbunden waren. Sebastián, Monterrosa und Terán versuchten, die unübersehbaren Modifikationen auf andere Art und Weise mit der europäischen Passionsikonographie, der sie als Interpretationsrahmen den Vorrang gaben, in Einklang zu bringen ${ }^{37}$ : Die Tatsache, dass die Zeichen für Speichel zu Sprechglyphen mutierten, lasen sie als Darstellung der Schimpfworte und Beleidigungen, die der Gottessohn erdulden musste. Auch diese Lesart lässt sich widerspruchsfrei an die Ikonographie des Kreuzes von Tizayuca herantragen.

Die Varianz der Lektüren vermisst den Raum der Hybridität und zeigt, dass der third space, von dem Bhabha ${ }^{38}$ spricht, visuelle Kulturen gerade nicht fälschlich homogenisiert und abgeschlossen definiert ${ }^{39}$, sondern, im

35 Jan Bobbe, Andreas Heiser und Anselm Schubert danke ich für den Hinweis, dass die beiden Köpfe als Verweis auf die zwei Schächer gelesen werden könnten. Auch dabei würde es sich um eine Neuinterpretation handeln, da in der europäischen Bildtradition nur die Köpfe von Schergen, von Petrus mit der Magd oder von Malchus, Herodes, Kaiphas, Pilatus und Judas unter den Arma Christi dargestellt wurden (vgl. Abb. 4). Vgl. hierzu die Übersicht bei Karsten Kelberg, Die Darstellung der Gregorsmesse in Deutschland, Diss. Münster 1983, S. 75f.

36 Rojas, Historia general del arte mexicano. Época colonial, S. 19.

37 Sebastián u.a., Iconografía del arte del siglo XVI en México, S. $48 f$.

38 Vgl. Bhabha, Die Verortung der Kultur, S. 5.

39 Dean und Leibsohn setzen sich kritisch mit diesem Hybriditätsbegriff auseinander, indem sie monieren, dass jede Theorie des Dazwischen Definitionen und damit Grenzen vorhergehender Entitäten voraussetze, so dass gerade »Hybridität« als Sekundärform eine Essentialisierung der implizit vorausgesetzten kulturellen Quellen fördere: »The descriptive term >hybrid< therefore performs a double move: it homogenizes things European and sets them in opposition to similarly homogenized non-European conventions. [...] Hybridity thus describes exceptions within a system that is at once exclusivistic and dependant upon the recognition of difference «. »Moreover all of these terms throw into relief questions of purity and authenticity. That is, they all accent discrete cultural origins [...]«. Dean/Leibsohn, Hybridity and Its Discontents, S. 6 und 8. 
Gegenteil, den Fokus auf die Unschärfen der Ränder richten hilft und die prozessuale Dimension der Bildgenerierung besonders bewusst macht. Erst die Rezeption bringt die Verortung der Ikonographien zum Abschluss, und aus einer spezifischen Form der Rezeption können sich in einem zweiten Schritt neue Repräsentationsformen entwickeln.

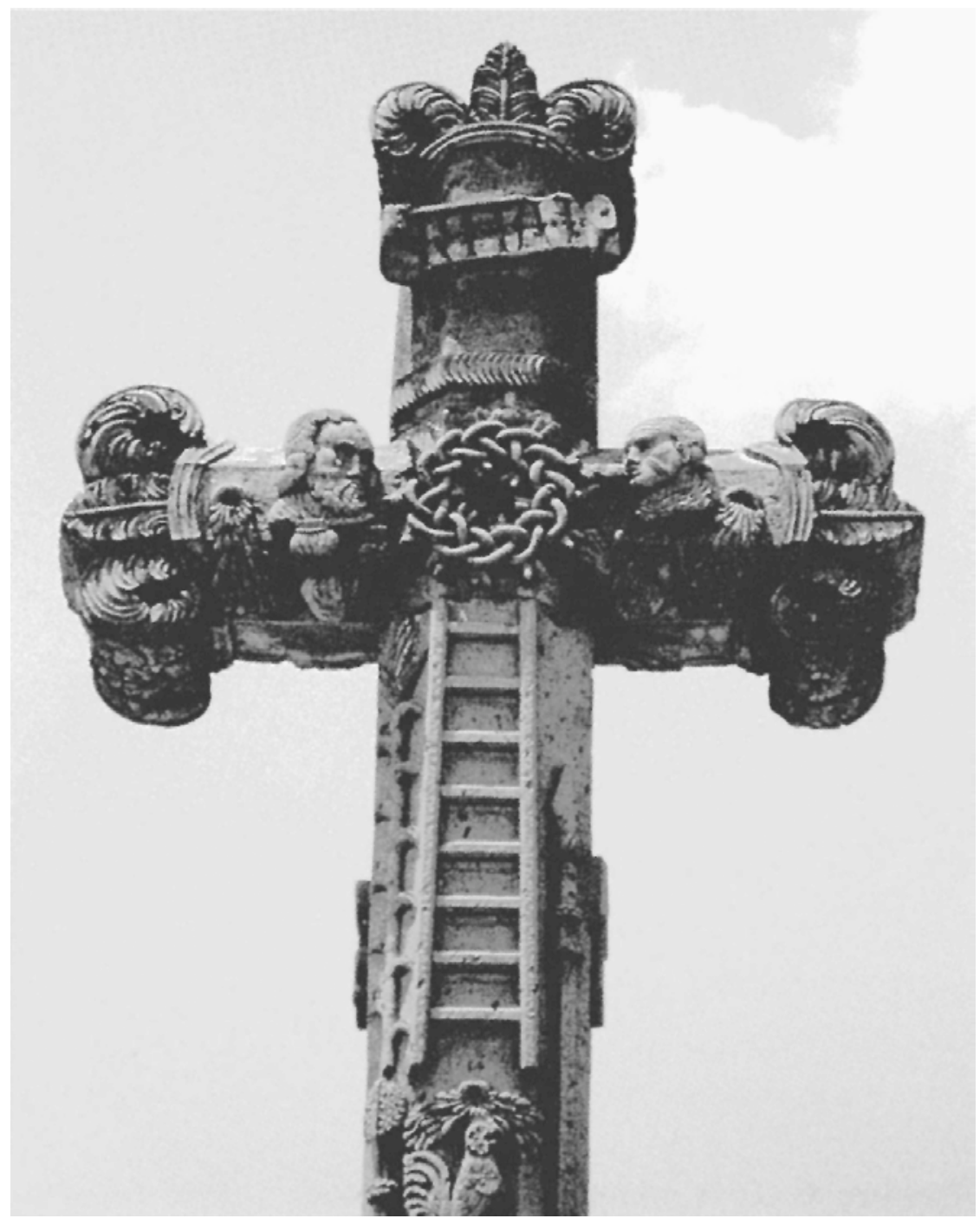

Abb. 1: Steinkreuz in Cuautitlán (México), Mexiko. 


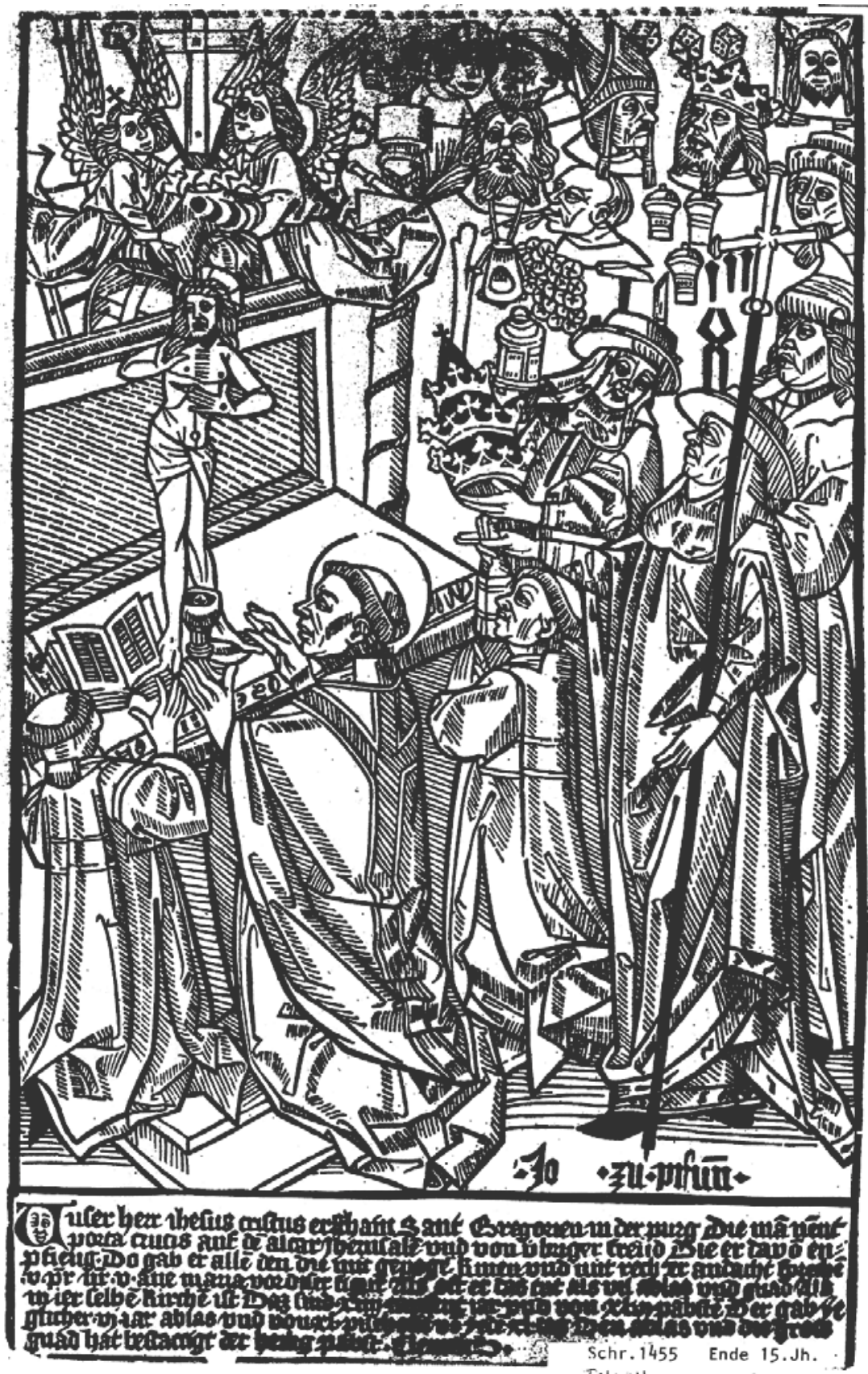

Abb. 2: Gregorsmesse, Holzschnitt, 393 x 250 mm, um 1480, Brünn, Franzens-Museum. 


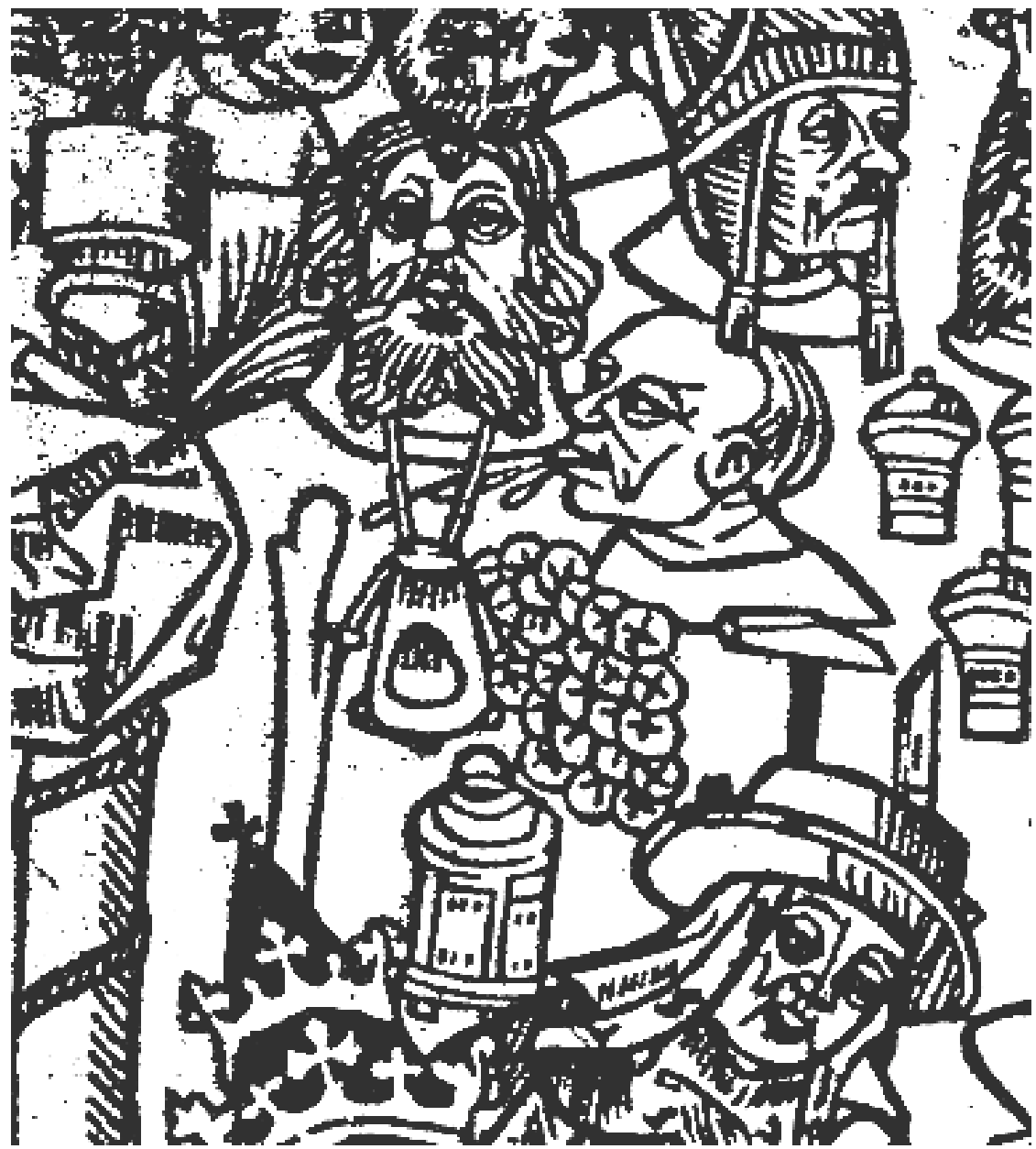

Abb. 3: Gregorsmesse (Detail aus Abb. 2), Judas mit der Geldbörse um den Hals und ein Spuckender. 


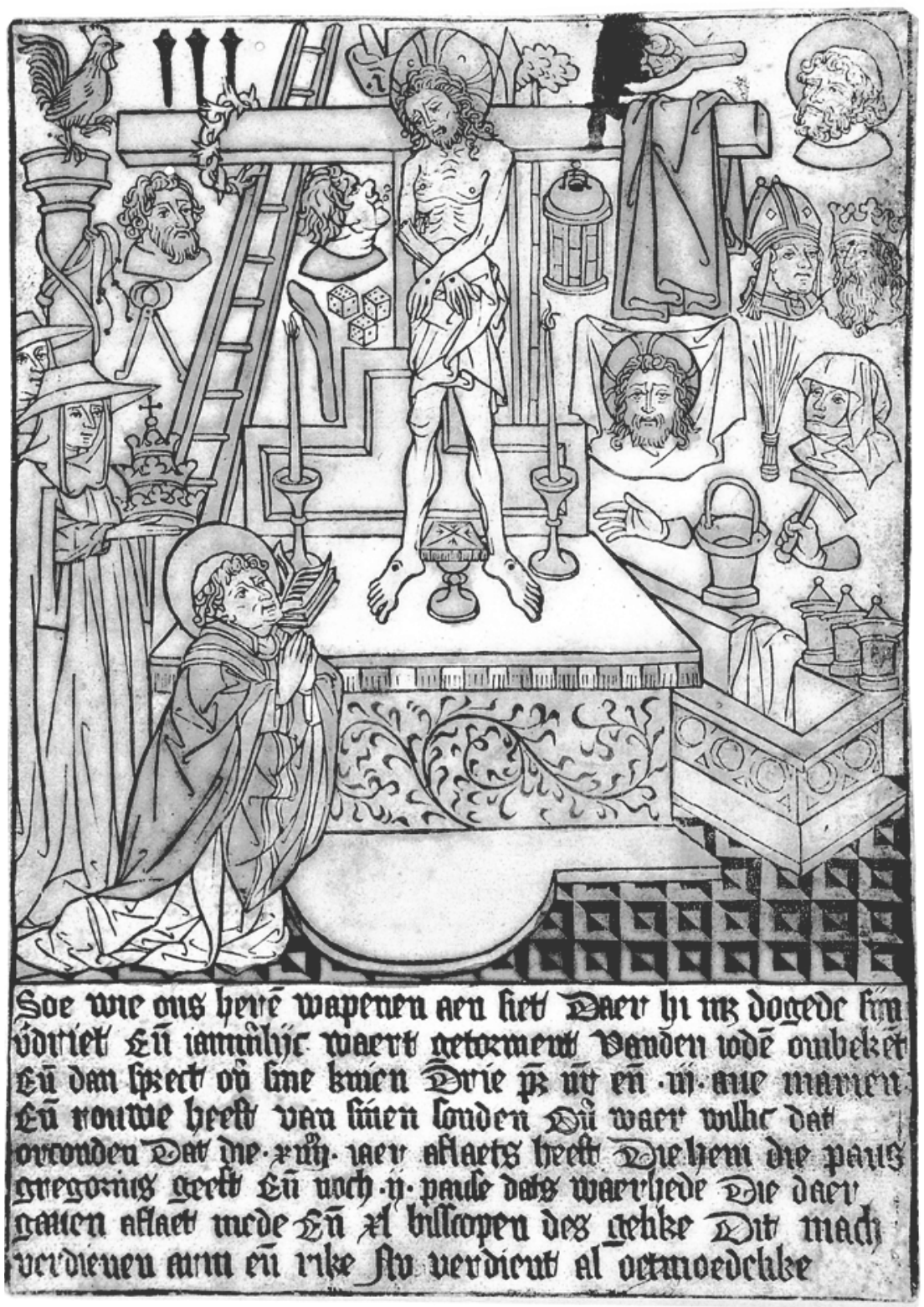

Abb. 4: Niederländisch, Gregorsmesse, Holzschnitt, 253 x 180 mm, um 1460, Nürnberg, Germanisches Nationalmuseum. 


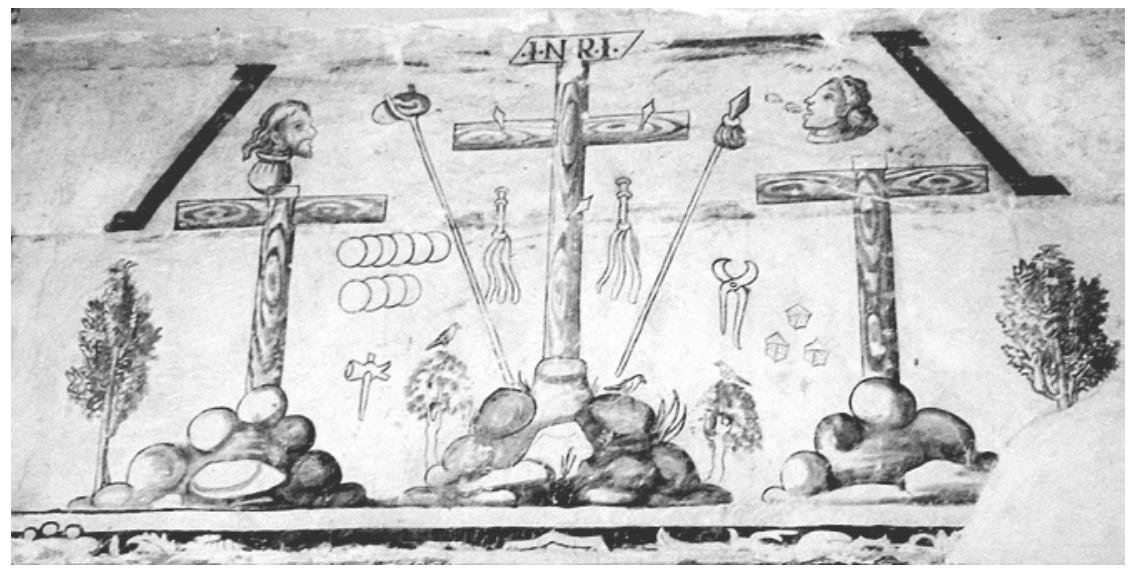

Abb. 5: Wandmalerei, ehem. Franziskanerkonvent, Otumba (Hidalgo), Mexiko.

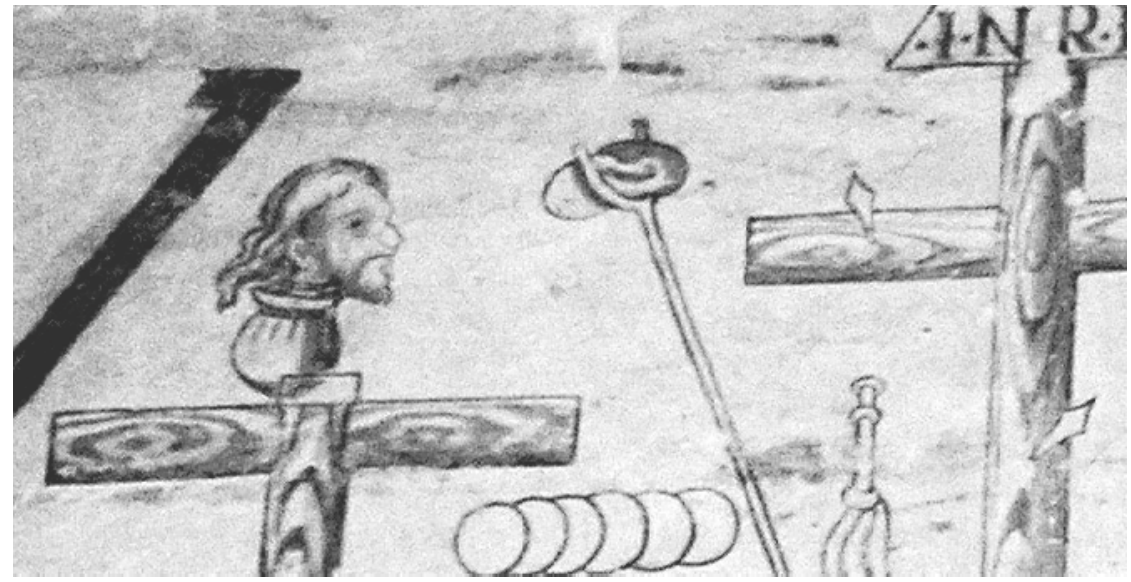

Abb. 6: Wandmalerei

(Detail aus Abb. 5). 


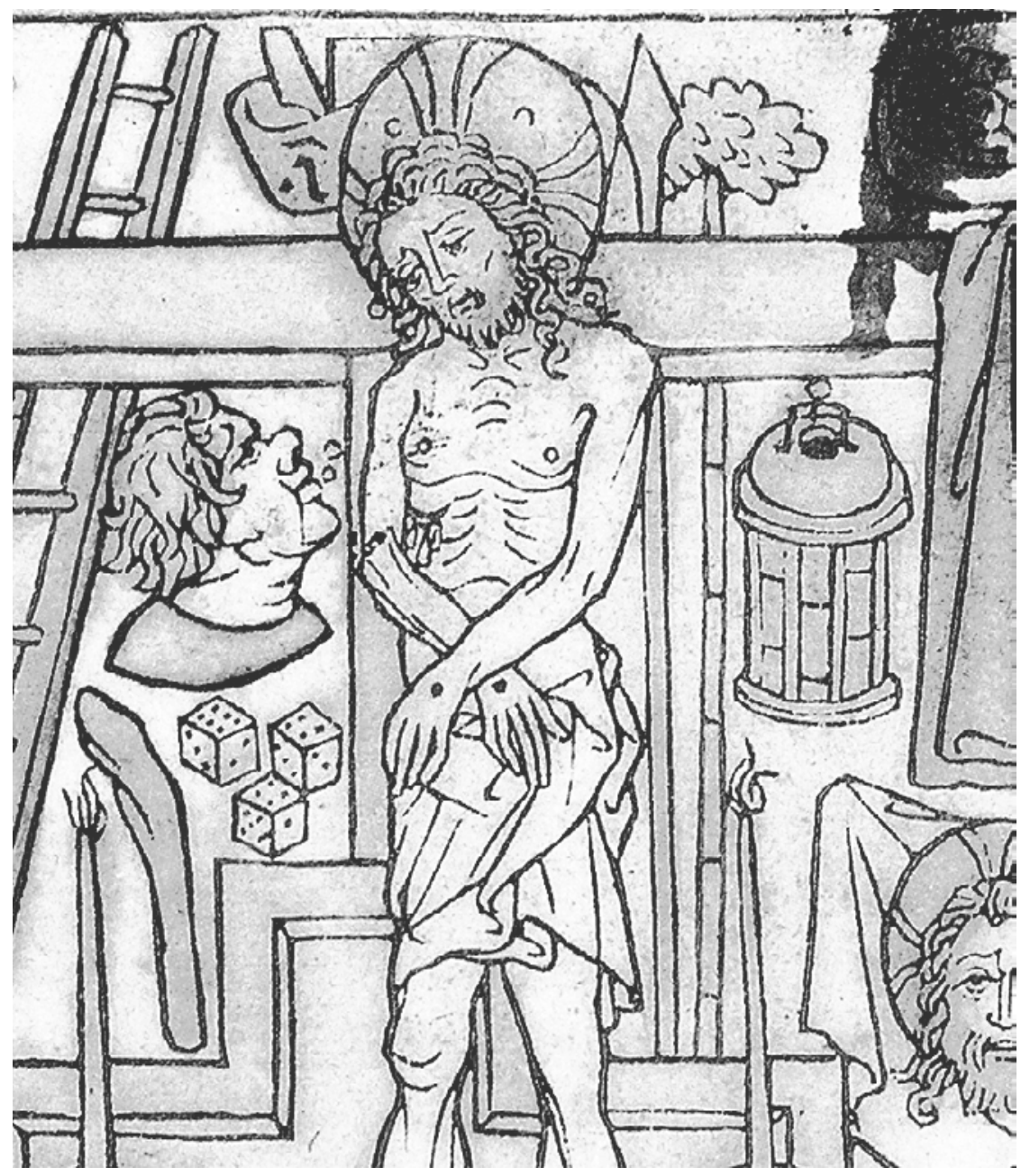




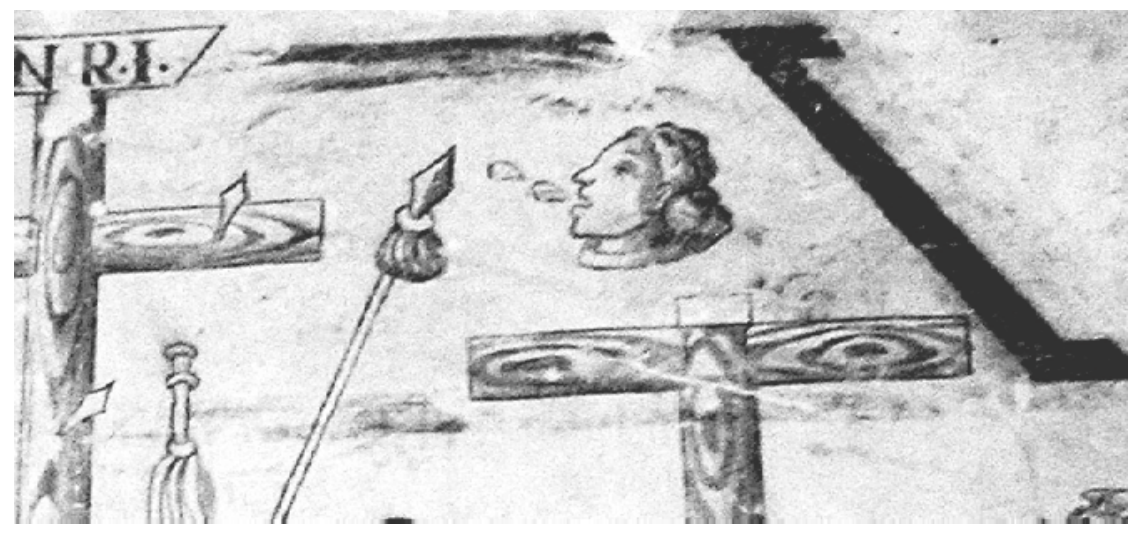

Abb. 8: Wandmalerei (Detail aus Abb. 5).

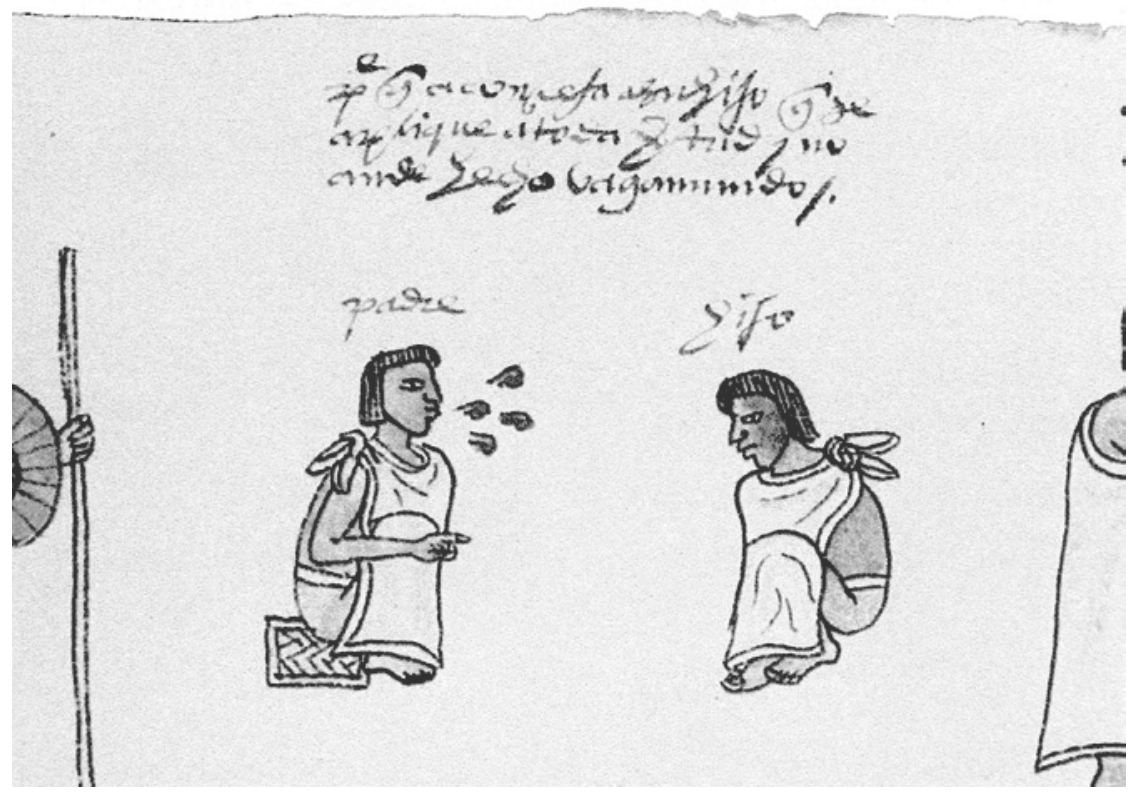

Abb. 9: Ein Gutsverwalter gibt einem jungen Burschen gute Ratschläge, Codex Mendoza, Papier, 20,6 x 30,6 cm, um 1541, Bodleian Library, Oxford, fol. 70r (Detail). 


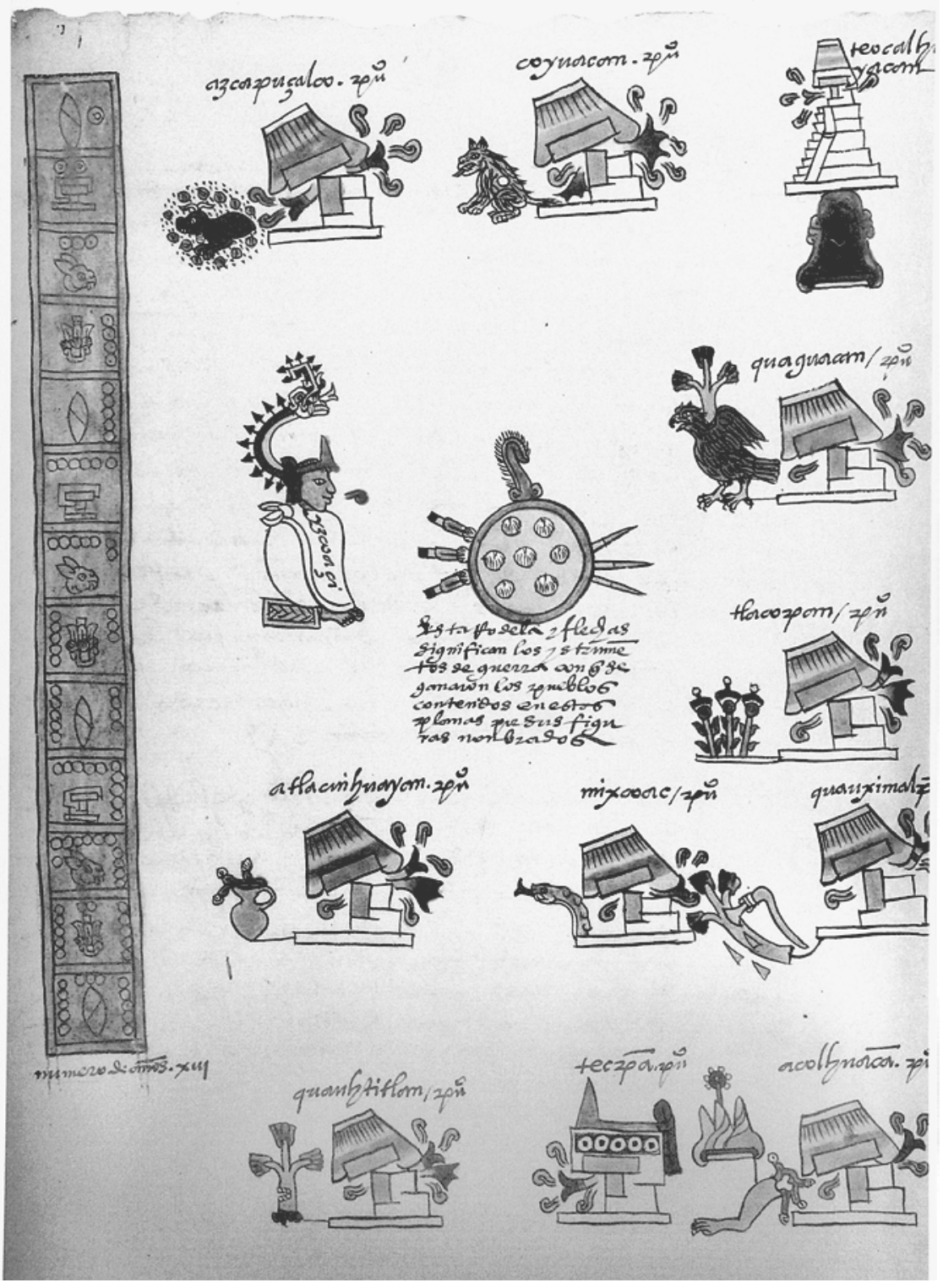

Abb. 10: Der Herrscher Itzcoatl und seine Eroberungen, Codex Mendoza, Papier, 20,6 x 30,6 cm, um 1541, Bodleian Library, Oxford, fol. 5v. 


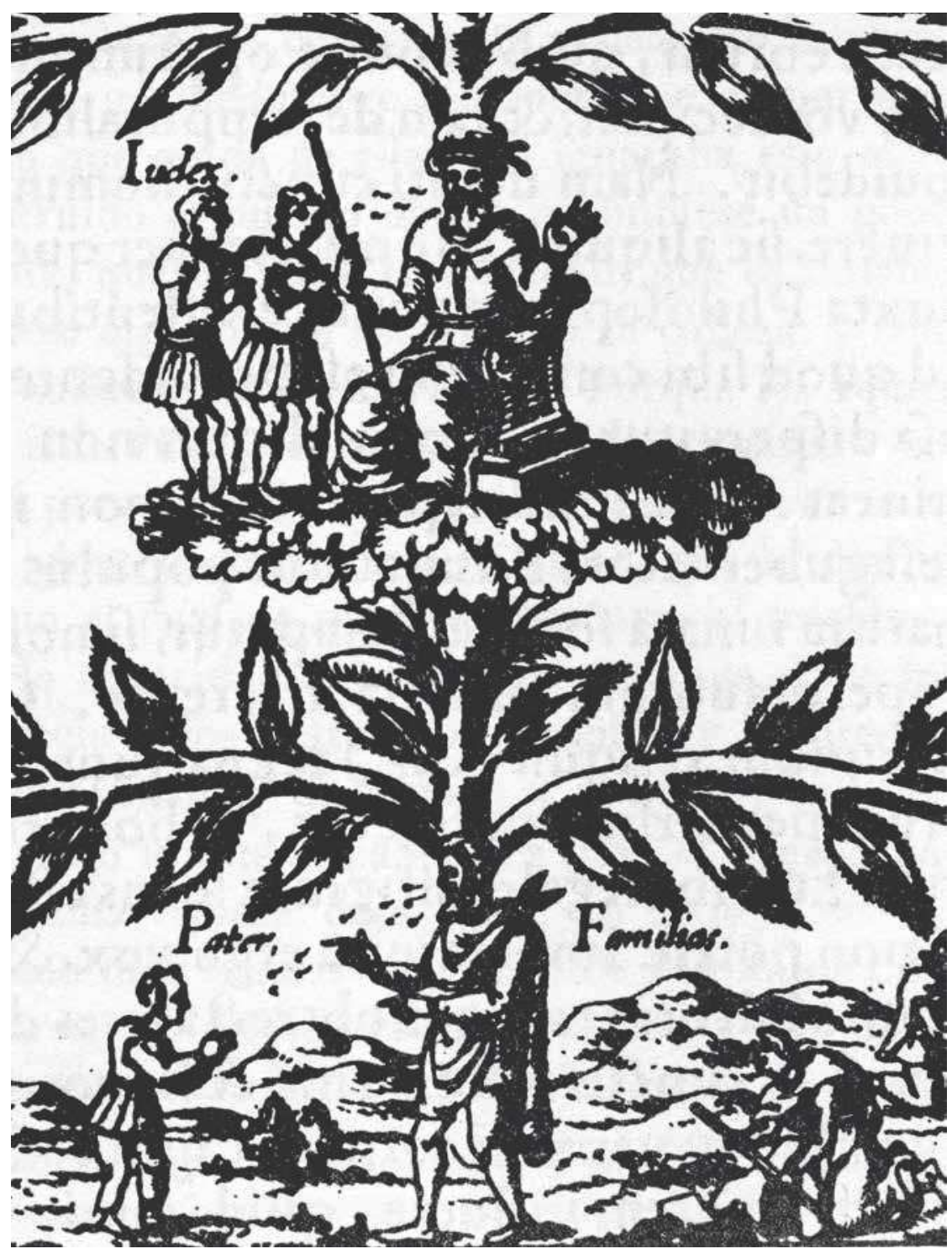

Abb. 11: Die weltliche Hierarchie, Illustration, Detail aus: Diego Valadés,

Rhetorica Christiana, Perugia 1579, Illustrationen o. S. (nach S. 180). 


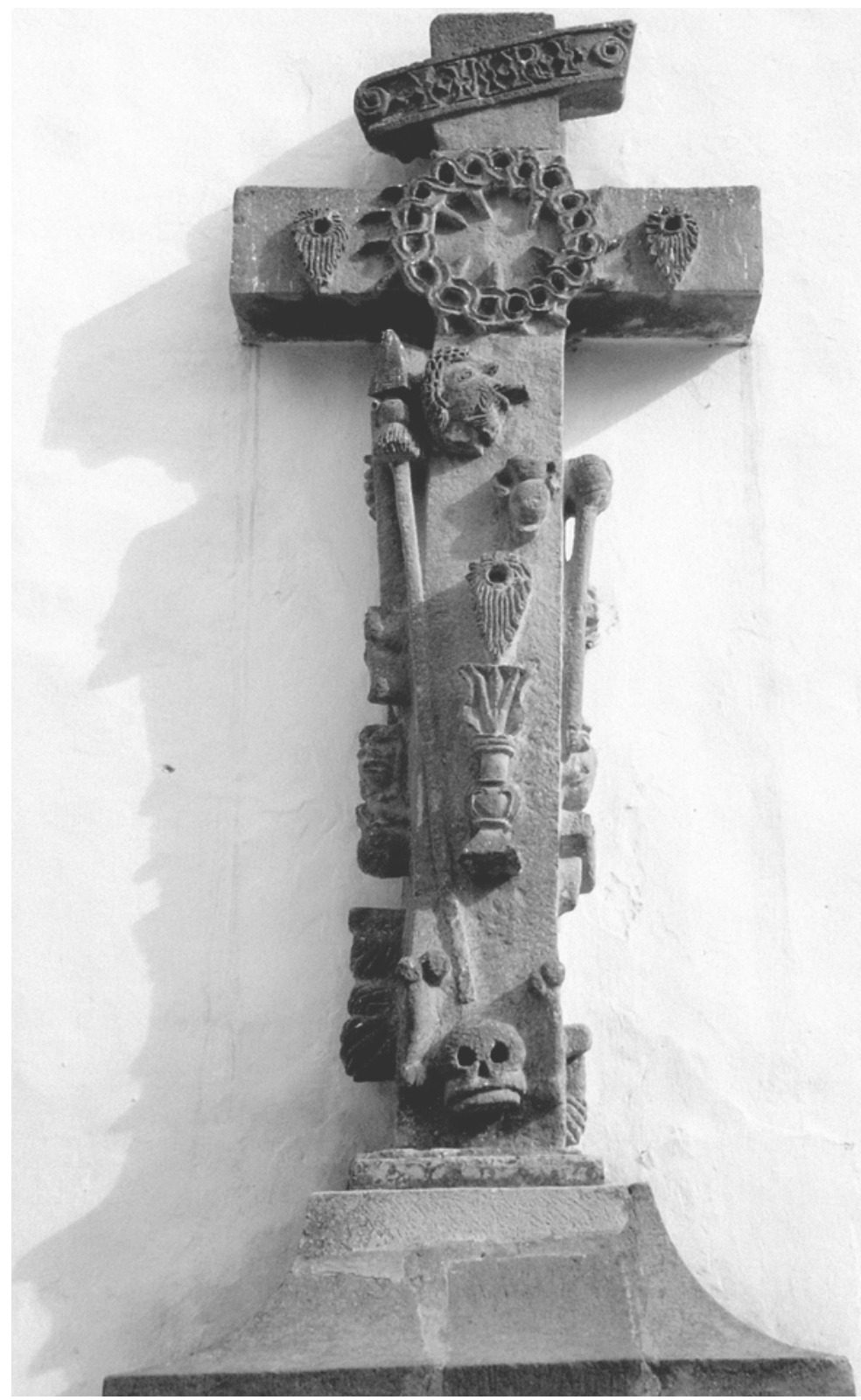

Abb. 12: Steinkreuz, Franziskanerkloster, Tepeapulco

(Hidalgo), Mexiko. 


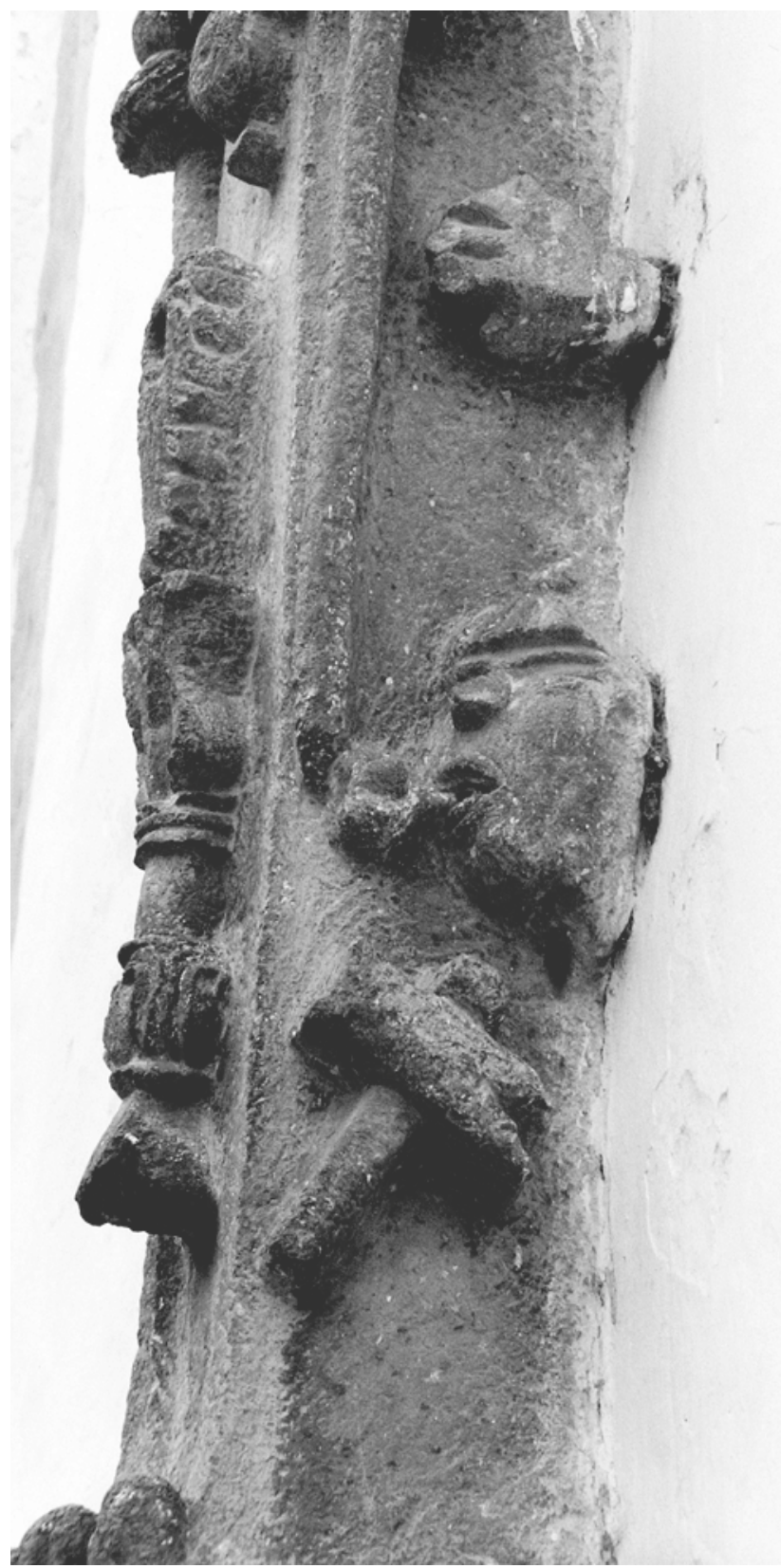

Abb. 13: Steinkreuz, Seitenansicht, Kazike. 


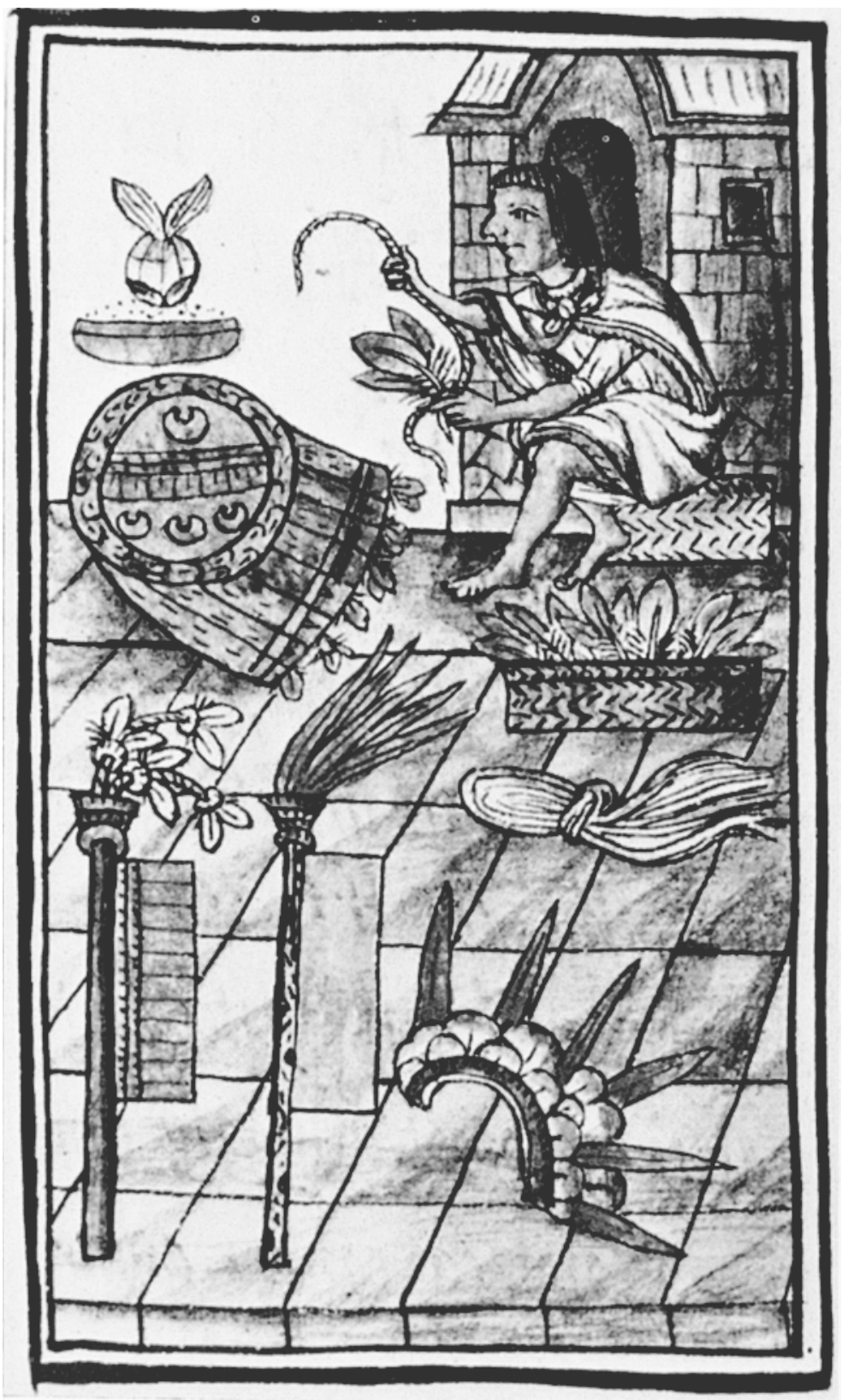

Abb. 14: Codex Florentinus, 1559-1570, Florenz, Biblioteca Medicea Laurenziana (Ms 218-22), Bd. 2, fol. 373v. 

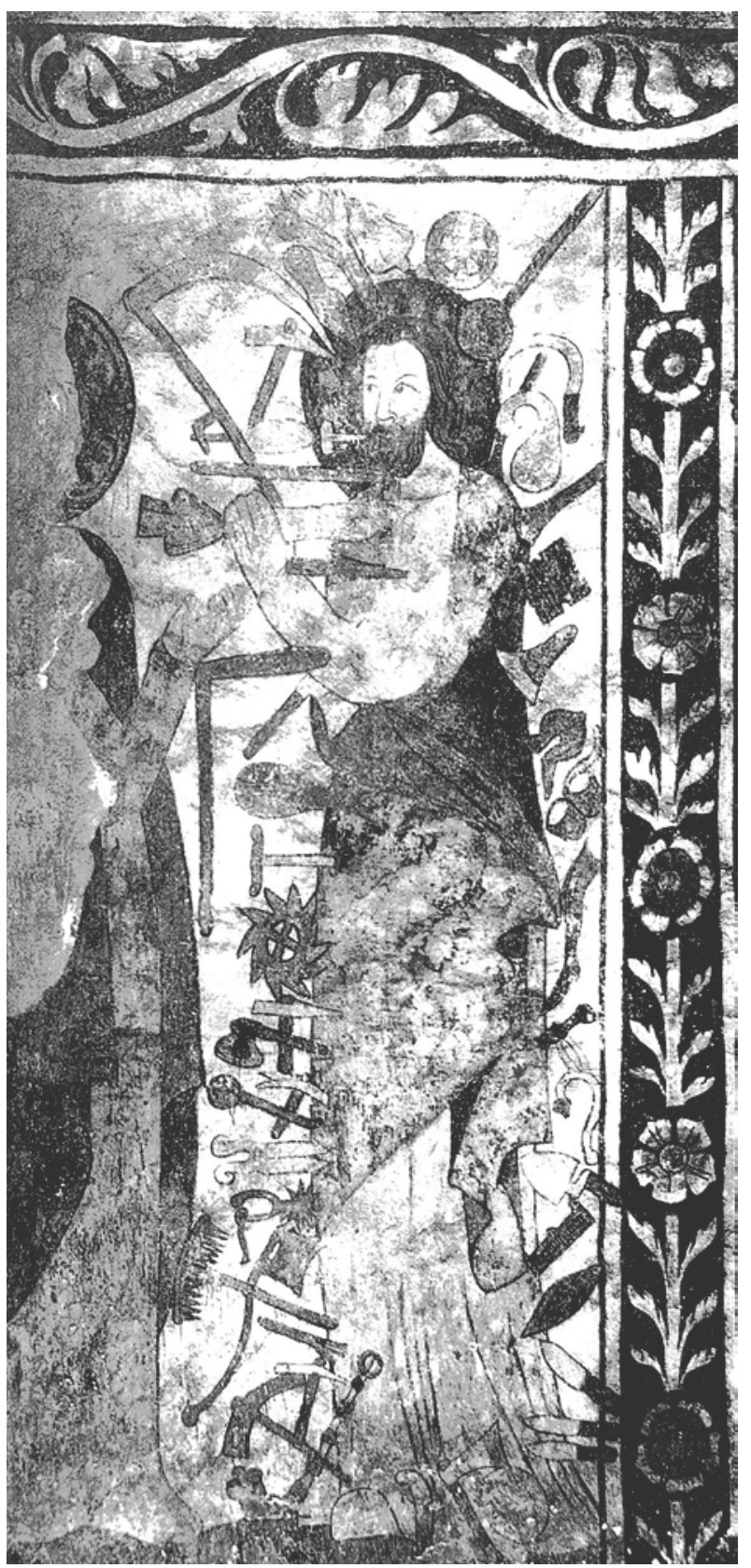

Abb. 15: Feiertagschristus, Wandmalerei, Ormalingen, Schweiz, um 1400. 


\section{Thomas Weller}

\section{Vom Kaufmann zum protestantischen Märtyrer: Johann Avontroot (1559-1633)}

Am 22. Mai 1633 wurde in Toledo ein über siebzigjähriger Mann wegen Ketzerei auf dem Scheiterhaufen verbrannt. Das Schicksal dieses Mannes ist so bemerkenswert, dass er schon bald nach seinem Tod in den Rang eines protestantischen Märtyrers aufstieg. Eine niederländische Übersetzung des Urteils, dessen Original leider verloren gegangen ist, erschien noch im 17. Jahrhundert in Amsterdam im Druck ${ }^{1}$. Und auch eine 1682 in Bremen gedruckte deutsche Übersetzung und Fortführung von Jean Crespins Histoire des martyrs enthält eine Lebensbeschreibung jenes Johann Avontroot ${ }^{2}$, der wohl aus der Nähe von Kleve stammte und schon in jungen Jahren, vermutlich über die Niederlande, auf die Kanarischen Inseln gelangte, wo er 1589 erstmals ins Visier der Inquisition geriet. Nach langjähriger Tätigkeit als Plantagenbesitzer und Fernhandelskaufmann auf den Kanaren und in Peru verbrachte Avontroot sein letztes Lebensdrittel in den Niederlanden. Dort trat er als Verfasser religiöser Pamphlete hervor, die er in Spanien und Südamerika zu verbreiten suchte. Schließlich machte er sich im Jahre 1632 trotz seines hohen Alters persönlich auf den Weg nach Madrid, um den spanischen König zum reformierten Glauben zu bekehren - ein Unterfangen, dessen Ausgang in gewisser Weise vorhersehbar war ${ }^{3}$.

1 Copye Van't Proces ende Sententie teghens Joan Avontroot Die gekomen is in Spangien in't Hof van Madril, om te spreken met den Koningh van liberteyt van Conscientie, maer vande Inquisiti gevangen en na Toledo ghebracht Ende na seven Maenden ghevangenis levendigh verbrant op den 22. Mey 1632 [sic!] Ende nu van en Liefhebber der waerheyt overgeset in onse tale, Amsterdam o.J.

2 [Jean CResPin] Paul Crocius, Das große Martyr-Buch \& Kirchen-Historien, worinnen herzliche und in Gottes Wort gegründete Glaubens-Bekänntnissen, Gespräch \& Disputationen wider die Ketzer \& Feinde der Göttlichen Warheit sampt andern denckwürdigen Reden \& Thaten vieler heiligen Märtyrer beschrieben werden, welche nach den Zeiten der Aposteln biß auff das Jahr 1572 hin \& wieder in Teutschland, Franckreich [...] um der evangelischen Wahrheit willen [...] verfolget, gemartert [...] hingerichtet worden [...] Anitz biß auff das Jahr 1656 continuirt \& mit der [...] Verfolg- \& Nieder-Metzelung der sogenannten Waldenser [...] in Piemont vermehrt, Bremen 1682, S. 1571f.

3 Zu Avontroots Biographie vgl. [Pierre] C[onstantin] vAN DER ELST, Une dernière victime belge du Saint-Office 1632: J.-B. Avontroot, in: Revue trimestrielle 23 (1859), S. 160-195; Marcelino Menéndez Pelayo, Historia de los Heterodoxos españoles, tomo II, Madrid 52000, S. 130f.; Agustín Millares Carlo, Algunas noticias y documentos referentes a Juan Bartolomé Avontroot, in: El Museo Canario 3 (1935), S. 1-26; Alejandro Cioranescu, Un visionario en la 
Für die hier zu behandelnden Fragen ist Avontroots Vita freilich weniger deshalb von Interesse, weil sie so kurios ist, sondern weil sie zugleich Elemente aufweist, die als durchaus typisch für eine Personengruppe gelten können, die wohl zu den mobilsten im frühneuzeitlichen Europa gehörte. Angehende Fernhandelskaufleute reisten meist schon in jungen Jahren in fremde Länder, um dort das Geschäft zu erlernen und Kenntnisse in fremden Sprachen zu erwerben. Auch später unternahmen sie im Rahmen ihrer Tätigkeit häufig weite Reisen, manche ließen sich sogar dauerhaft in der Fremde nieder. Dies konnte für die kulturelle, besonders auch für die religiös-konfessionelle Identität der Betreffenden nicht ohne Folgen bleiben ${ }^{4}$.

Die Ausübung der eigenen Religion war in anderen Ländern oft nur unter erheblichen Einschränkungen oder im Geheimen möglich. Mit der konfessionellen Spaltung der lateinischen Christenheit und der nachfolgenden Konfessionalisierung in den Territorien sollten sich die Bedingungen auch innerhalb Europas erheblich verschärfen. Gerade im Herrschaftsbereich der spanischen Monarchie, die sich in besonderer Weise als Vorkämpferin des tridentinischen Katholizismus verstand, ging ein erheblicher Anpassungsdruck von den kirchlichen und weltlichen Obrigkeiten, häufig aber auch vom sozialen Umfeld der fremden Kaufleute aus. Bis weit ins 17. Jahrhundert waren letztere, soweit sie nicht katholisch waren, für die Dauer ihres Aufenthaltes in den Territorien der spanischen Krone genötigt, sich zumindest äuBerlich den katholischen Riten anzupassen, um sich nicht dem Verdacht der Häresie und der Verfolgung durch die Inquisition auszusetzen.

Wie sich diese Praxis auf den Prozess der religiös-konfessionellen Identitätsbildung auswirkte, soll im Folgenden am Beispiel Johann Avontroots näher untersucht werden, dem sein späteres Schicksal als protestantischer Märtyrer keineswegs vorherbestimmt war. Wie viele seiner Glaubensgenossen schien auch Avontroot sich vielmehr lange Zeit recht pragmatisch mit den Umständen in Spanien zu arrangieren und sich mehr um seine kaufmännischen Interessen als um sein Seelenheil zu sorgen.

hoguera. La vida y las obras de Juan Bartolomé Avontroot, in: Anuario de Estudios Atlánticos 20 (1974), S. 542-609; Werner Thomas, El hombre que intentó convertir al rey de España: Hans Avontroot (1559-1633), in: Jan Lechner (Hg.), Contactos entre los Países Bajos y el mundo Ibérico (Foro Hispánico), Amsterdam/Atlanta 1992, S. 45-66.

4 Vgl. Albrecht Burkardt (Hg.), Commerce, voyage et expérience religieuse. XVIe-XVIIIe siècles, Rennes 2007; allg. Philipp D. Curtin, Cross-Cultural Trade in World History, Cambridge 1984; Frédéric MAuro, Merchant Communities, 1350-1750, in: James D. TraCy (Hg.), The rise of merchant empires. Long-Distance Trade in the Early Modern World, 1350-1750, Cambridge 1995, S. 255-286; Anthony Molno/Diogo Ramada Curto, Les réseaux marchands à l'époque moderne, in: Annales 58 (2003), S. 569-579; Margrit Schulte BeErbühl/Jörg Vögele (Hg.), Spinning the commercial web. International trade, merchants, and commercial cities, c. 1640-1939, Frankfurt am Main 2004. 
Ausgehend von Avontroots erstem Inquisitionsprozess im Jahre 1589 (I.) soll zunächst ein allgemeiner Blick auf die Lebensbedingungen und die Religiosität protestantischer Kaufleute im Spanien des 16. und 17. Jahrhunderts und die besondere Situation auf den Kanaren geworfen werden (II.). Im Anschluss daran wird von Avontroots weiterem Lebensweg und seiner späten Berufung zum Autor religiöser Schriften und zum Missionar zu sprechen sein (III.). Abschließend sollen die am konkreten Fallbeispiel gemachten Beobachtungen noch einmal zusammengefasst und in den Kontext der leitenden Fragestellung nach dem Zusammenhang von Mobilität und religiös-konfessioneller Identitätsbildung gerückt werden, wobei auch nach den möglichen Gründen für Avontroots >paulinische Wende< zu fragen ist (IV.).

I.

Dass der vom Niederrhein stammende Kaufmann Johann Avontroot einmal als Ketzer auf dem Scheiterhaufen verbrannt werden würde, stand in den ersten Jahrzehnten seines Lebens kaum ernsthaft zu befürchten, wenngleich er sich bereits im Alter von 35 Jahren erstmals gegen den Vorwurf der Häresie zu verteidigen hatte. Erst seit dieser Zeit sind wir auch über seinen Lebensweg genauer informiert, über Avontroots Kindheit und Jugend hingegen wissen wir fast nichts; nicht einmal sein Geburtsjahr und -ort lassen sich mit letzter Gewissheit bestimmen.

Höchstwahrscheinlich erblickte Johann Avontroot im Jahre $1559^{5}$ in der kleinen Ortschaft Haldern, heute zu Rees in der Nähe von Kleve gehörig, das Licht der Welt. In den Inquisitionsakten heißt es, Avontroot stamme aus »Altran en Alemania la Baja«, teilweise wird der Name des Orts auch mit $»$ Halteren« oder »Haltren« wiedergegeben. Die ältere Forschung hat diese Herkunftsangaben zunächst mit der flandrischen Gemeinde Aalter, auf halbem Weg zwischen Gent und Brügge gelegen, identifiziert ${ }^{6}$. Dies erscheint

5 Bei seiner ersten Vernehmung durch die Inquisition, kurz nach dem 14. Februar 1590, gab Avontroot selbst sein Alter mit 30 Jahren an (Archivo Histórico Nacional [AHN], Sección de Inquisición [Inq.], legajo [leg.] 1829-1L, no 10). Am 17. April 1595 war er nach eigenen Angaben 36 und am 12. Mai 159738 Jahre alt (AHN, Inq., leg. 1831-4, fol. 305v, 873r). Demnach wäre Avontroot zwischen Mitte Februar und dem 17. April 1559 geboren. Bei seiner Vernehmung durch das Tribunal von Toledo, im November 1632 allerdings behauptete Avontroot, er habe bereits das 77. Lebensjahr vollendet, womit nicht 1559, sondern 1555 als sein Geburtsjahr anzusetzen wäre (AHN, Inq., leg. 146-4, fol. 57r). Stellt man Avontroots fortgeschrittenes Alter und die besonderen Umstände bei seiner letzten Vernehmung in Rechnung, erscheint es aber durchaus denkbar, dass diese letzte Angabe unzutreffend war, vgl. ThомAs, El hombre, S. 60, Anm. 6.

6 So noch van der Elst, Une dernière victime; Menéndez Pelayo, Historia de los heterodoxos; Millares Carlo, Algunas noticias; Art. Avontroot, Johannes Bartholomaeus, in: Nieuw Nederlandsch Biografisch Woordenboek, Teil 1, Leiden 1911, S. 201. 
jedoch wenig plausibel, denn Avontroot selbst bezeichnete sich im Rahmen seiner Vernehmungen ausdrücklich als »alemán y flamenco«, gebürtig in »Alemania la Baja« und derzeit Bürger von Utrecht »en los Países Bajos de Flandes «? . Diese Unterscheidung wäre überflüssig gewesen, wenn auch sein Geburtsort in den Niederlanden gelegen hätte. Mehrere vom Tribunal von Toledo vernommene Zeugen sagten überdies aus, Avontroot stamme aus Kleve ${ }^{8}$. Der 1615 auf den Kanarischen Inseln als Zeuge vernommene Hans Bullens, ein Freund Avontroots, behauptete, letzterer sei »natural de la ciudad de Halteren en Alemania, cabe Colonia «9. Der Hinweis auf Köln stellte aber wohl eher eine grobe Richtungsangabe für die mit der niederdeutschen Topographie kaum vertrauten spanischen Inquisitoren dar und spricht daher nicht gegen Haldern bei Kleve als Geburtsort Avontroots.

Dass Avontroot aus Haltern in Westfalen stammte, wie andere Autoren vermuten ${ }^{10}$, erscheint unter diesem Gesichtspunkt zwar ebenso plausibel, muss aber aus anderen Gründen als unwahrscheinlich gelten. Denn erstens lässt sich der Name Avontroot in den Halterner Quellen des 16. Jahrhundert nicht nachweisen ${ }^{11}$, und zweitens gehörte das im Fürstbistum Münster gelegene Haltern zu jenen Orten Westfalens, in denen es nicht einmal ein reformatorisches Zwischenspiel gegeben hat ${ }^{12}$. Wie sich gleich zeigen wird, ist aber mit hoher Wahrscheinlichkeit davon auszugehen, dass Avontroot im reformierten Glauben erzogen wurde, was eher für Haldern bei Kleve als für Haltern in Westfalen als Herkunftsort spräche ${ }^{13}$.

Avontroot muss seine Heimat aber schon in sehr jungen Jahren verlassen haben und, wohl über die Niederlande, auf die Kanarischen Inseln gelangt sein, wo er 1584 erstmals als Bürge für einen Kaufmann aus Aachen

7 AHN, Inq., leg. 146-4, fol. 57r; vgl. Thomas, El hombre, S. 46.

8 AHN, Inq., leg. 146-4, fol. 62r, 78r; vgl. ebd.

9 Zit. nach Cioranescu, Un visionario, S. 546.

10 Ebd., S. 6; Claus Veltmann, Die Hanse, Westeuropa und die Ausbreitung der Reformation. Eine Skizze über die Rolle von Hansekaufleuten im europäischen Konfessionalisierungsprozess, in: HGB 123 (2005), S. 61-83, hier: S. 81.

11 Veltmann, Die Hanse, S. 81, Anm. 74.

121532 sprach sich Haltern gemeinsam mit den übrigen Städten des westlichen Münsterlandes gegen die Einführung der Reformation aus und blieb auch in der Folgezeit beim alten Glauben, vgl. Alois SCHRÖER, Die Reformation in Westfalen. Der Glaubenskampf einer Landschaft, Bd. 2, Münster 1983, S. 139, 514.

13 Im Rahmen ihrer irenischen Kirchenpolitik ließen die Herzöge von Jülich-Kleve-Berg die Gründung lutherischer und auch reformierter Gemeinden in Teilen ihrer Territorien zu, vgl. Heribert Smolinsky, Jülich-Kleve-Berg, in: Anton Schindling (Hg.), Die Territorien des Reichs im Zeitalter der Reformation und Konfessionalisierung: Land und Konfession 1500-1650, Bd. 3: Der Nordwesten, Münster 1991, S. 86-106. In Haldern bildete sich aus der Patronatsgemeinde der Freiherren von Wittenhorst, die schon im 16. Jahrhundert zum reformierten Glauben übertraten, eine evangelische Gemeinde, vgl. Renate NAGLER, Die Evangelische Kirche Haldern. Bedeutung als Baudenkmal und Mittelpunkt der Gemeinde, in: Haldern einst und jetzt 76 (1995), S. 75-88, hier: S. 78. 
aktenkundig wurde ${ }^{14}$. Spätestens seit 1586 war er auf La Palma, der nordwestlichsten Insel des Archipels, als Verwalter (»factor«) der hacienda von Argual y Tazacorte, einer der größten und ertragreichsten Zuckerrohrplantagen, tätig ${ }^{15}$.

Um das Eigentum an dieser finca stritten sich zu diesem Zeitpunkt zwei Familien: 1513 war die Plantage von den Welsern in den Besitz der ursprünglich aus Köln stammenden und in Antwerpen ansässigen Kaufmannsfamilie Groenenberg (Monteverde) übergegangen ${ }^{16}$. Melchor de Monteverde, der Sohn von Jakob Groenenberg, verkaufte die finca dann im Jahre 1562 an den ebenfalls in Antwerpen residierenden Kaufmann Paul van Dale, mit dessen Tochter María er sich zuvor vermählt hatte. Über die Rechtsgültigkeit der zwischen Melchor de Monteverde und Paul van Dale getroffenen Kaufvereinbarung entbrannte jedoch bald ein Streit zwischen beiden Familien, der auch nach dem Tod Melchors de Monteverde nicht zum Erliegen $\mathrm{kam}^{17}$. Die Witwe des Verstorbenen, María van Dale, stand nun mit dem umstrittenen Erbe und vier minderjährigen Kindern alleine da. Angesichts dieser Lage verwundert es nicht, dass sie daran interessiert war, so bald wie möglich wieder eine Ehe einzugehen. Auch dass ihre Wahl dabei auf den bisherigen Verwalter der finca fiel, den um einige Jahre jüngeren Johann Avontroot, stellte durchaus nichts Ungewöhnliches dar, sondern entsprach einer bei Kaufmannswitwen durchaus üblichen Heiratsstrategie.

Beim Rest ihrer Familie stieß ihre Entscheidung jedoch auf wenig Gegenliebe, mehr noch: um den unerwünschten Eindringling so rasch wie möglich wieder los zu werden, war den um ihren eigenen Anteil am Familienbesitz besorgten Kindern aus erster Ehe offenbar jedes Mittel recht. Am 23. September 1589, nur vier Monate nach der Eheschließung María van Dales mit Johann Avontroot, denunzierte Andrés Salgado de Faria, der Gatte von María van Dales ältester Tochter Ana de Monteverde, den neuen Ehemann seiner Schwiegermutter bei der Inquisition.

14 Santa Cruz de Tenerife, Archivo Histórico Provincial, tomo 406, fol. 269; vgl. Cioranescu, Un visionario, S. 549.

15 Ebd., S. 550.

16 Vgl. Carl Mollwo, Kölner Kaufleute im 16. Jahrhundert auf den Kanarischen Inseln, in: MSAK 28 (1899), S. 134-140; Fernand Donnet, Histoire de l'etablissement des anversois aux Canaries au XVIe siècle, Antwerpen 1895, S. 27; José Peraza de Ayala, Historia de las casas de Machado y Monteverde, Madrid 1930; Klaus Weber, Deutschland, der atlantische Sklavenhandel und die Plantagenwirtschaft der Neuen Welt, 15. bis 19. Jahrhundert, in: Journal of Modern European History 7 (2009), S. 39-69, hier: S. 43; Alberto VIEIRA, Sugar Islands. The Sugar Economy of Madeira and the Canaries, 1450-1650, in: Stuart. B. Schwartz (Hg.), Tropical Babylons. Sugar and the Making of the Atlantic World, 1450-1680, Chapel Hill/London 2004, S. 42-84, hier: S. 47, 69; Eddie Stols, The Expansion of the Sugar Market in Western Europe, in: ebd., S. 237-288, hier: S. 261.

17 Vgl. zu den Einzelheiten Cioranescu, Un visionario, S. 551-553; Millares Carlo, Algunas noticias, S. 22. 
Von seiner Frau Ana habe er erfahren - so ließ Salgado die Inquisitoren wissen -, dass Johann Avontroot sich nicht an die Fastengebote der katholischen Kirche halte. Einmal an einem Freitag, als die Familie unterwegs gemeinsam zu Mittag gegessen habe, habe Avontroot von den ihm vorgesetzten Fisch nichts angerührt, sondern heimlich von einem eigens mitgebrachten Hähnchen gegessen, das er unter seinem Mantel verborgen hielt. Als die anderen am Tisch sich darüber lustig machten, habe er sie gefragt, warum sie lachten, denn nicht das, was zum Mund hineingehe, schade der Seele, sondern das, was herauskomme ${ }^{18}$. Ein anderes Mal habe ihn die zweite Tochter von María van Dale dabei erwischt, wie er am Karfreitag heimlich von einer Kalbszunge gegessen habe. Leicht fänden sich noch weitere Zeugen, die bestätigen könnten, dass Avontroot auch in der Fastenzeit regelmäßig Fleisch esse, wobei er eine angebliche Krankheit vorschütze, um unbehelligt das Fastengebot brechen zu können.

Überdies sei unter den Plantagenarbeitern allgemein bekannt, dass Avontroot nur an Sonn- und Feiertagen die Messe höre, und dies auch nur, um der Pflicht genüge zu tun (»sólo por cumplir«), nie aber unter der Woche, obwohl es doch auf der hacienda eine eigene Kapelle gebe ${ }^{19}$. Wenn man das Heilige Sakrament zu einem Kranken trage, verstecke sich Avontroot stets in seinem Haus und sei noch nie mitgegangen. Als er einmal an der Reihe gewesen sei, bei einer Prozession das Kreuz zu tragen, habe er an seiner Stelle einen Sklaven geschickt. Gegenüber seinen Töchtern habe er geäußert, dass man bei der Beichte nicht alle Sünden gestehen müsse. Er selbst gehe nur ein einziges Mal im Jahr zur Beichte, um seine Pflicht zu erfüllen. Verschiedentlich habe er sich auch öffentlich gegen die Verehrung der Heiligen ausgesprochen und die Auffassung vertreten, dass der Papst nur ein Mensch sei und genau wie er in die Hölle kommen könne.

Wenn Avontroot die fraglichen Äußerungen tatsächlich so getätigt hatte, musste er sich über die damit verbundenen Gefahren eigentlich im Klaren gewesen sein. Angeblich hatte Avontroots spätere Frau ihn schon vor ihrer Eheschließung sogar ausdrücklich ermahnt, in Gegenwart der Spanier seine Zunge zu hüten, da man ihn sonst anzeigen werde. Avontroot aber hatte ihr damals zur Antwort gegeben, er wisse sehr wohl, was er sage, und wenn er sich wegen seiner Worte eines Tages vor dem Bischof oder dem Inquisitor rechtfertigen müsse, dann werde er auch diesen Rede und Antwort stehen,

18 „De qué os reys?, no lo que entra por la boca daña«, Las Palmas de Gran Canaria, Museo Canario, Inquisición XIII, fol. 93-95, zit. nach Cioranescu, Un visionario, S. 557. Melchor de Monteverde, Avontroots Stiefsohn, bestätigte den Vorfall später und gab die Worte des Beschuldigten folgendermaßen wieder: »[...] no era lo que dañava el alma lo que entraba por la boca, sino lo que salía«, AHN, Inq., leg. 1829-1L, no 10, zit. nach CioranESCU, Un visionario, S. 562, vgl. Thомas, El hombre, S. 49.

19 Zit. nach Cioranescu, Un visionario, S. 558. 
denn auch er sei gebildet und des Lateinischen mächtig (»se precía de hombre latino y letrado $\ll)^{20}$.

Die Gelegenheit, seine Fähigkeiten unter Beweis zu stellen, sollte sich eher ergeben als Avontroot vermutlich lieb war. Am 28. November 1589, genau zwei Monate nach der Denunziation durch Andrés Salgado, ordnete die Inquisition Avontroots Verhaftung an, und am 14. Februar 1590 wurde er in das geheime Inquisitionsgefängnis von Las Palmas gebracht ${ }^{21}$.

Unterdessen hatte das auf Gran Canaria ansässige Tribunal einen Kommissar nach La Palma geschickt, um die vom Denunzianten benannten Zeugen zu vernehmen. Letztere bestätigten ausnahmslos die gegen Avontroot erhobenen Anschuldigungen. Lediglich seine Frau María bestritt alle Vorwürfe. Der örtliche Pfarrer hingegen wusste noch hinzuzufügen, dass Avontroot bei ihm nur ein einziges Mal gebeichtet und aus seinen Händen das Sakrament empfangen habe. Und Sebastián de Paz, ein familiar der Inquisition, berichtete, wie er den Beschuldigten einmal während der Messe beobachtet habe: Bei der Elevation der Hostie habe Letzterer die Lippen nicht bewegt und seinen Blick die ganze Zeit über nicht einmal gehoben, so dass er vielleicht die Füße des Priesters, kaum aber das Heilige Sakrament habe sehen können ${ }^{22}$.

Als Avontroot dann selbst in der Sache gehört wurde, stellten die Inquisitoren im Rahmen der zu Beginn des Verfahrens üblichen Befragung des Angeklagten zunächst einmal fest, dass er sich nicht bekreuzigen ${ }^{23}$ und die zehn Gebote nur in lateinischer Sprache nach Exodus 20 aufsagen konnte ${ }^{24}$. Beim

20 Zit. nach ebd.

21 Millares Carlo, Algunas noticias, S. $22 \mathrm{f}$.

22 Museo Canario, Las Palmas, Inquisición VIII, 2 vol. 67-80, zit. nach Cioranescu, Un visionario, S. 563. Was der Denunziant selbst in diesem Augenblick sah, schien offenbar niemand zu interessieren. Wie genau mutmaßliche Häretiker von den Spitzeln der Inquisition beobachtet wurden, belegt aber auch eine ähnliche Aussage aus dem kastilischen Cuenca. Über einen dort ansässigen französischen Silberschmied, den man ebenfalls des Protestantismus verdächtigte, sagte ein Zeuge aus, wenn die fragliche Person an religiösen Handlungen teilnehme, verdecke er sein Gesicht so weit es ihm möglich sei, spreche die Worte nur zwischen den Zähnen aus und blicke dabei die Person nicht an, mit der er spreche (»se encubre lo más que puede e lo que habla es entredientes, mijrando como de través y no a la persona con qjen habla «), Archivo Diocesano de Cuenca [ACD], Inq., leg. 232-2498: testificación de Esteban Jamete, Cuenca 16 de feberero de 1564, zit. nach Werner Thомаs, Los protestantes y la Inquisición en España en tiempos de Reforma y Contrareforma, Leuven 2001, S. 389.

23 Während Luther das Kreuzeszeichen an bestimmten Stellen in der Liturgie erhielt und auch den Gläubigen in seinem kleinen Katechismus noch empfahl, sich vor dem Morgens- und Abendgebet zu bekreuzigen, lehnten die reformierten Kirchen das Kreuzeszeichen grundsätzlich ab, vgl. Andreas HeInz, Art. Kreuzeszeichen/Bekreuzigung, in: RGG 4 ( $\left.{ }^{4} 2001\right)$, Sp. 1757; Karl-Heinz zur MüHLEn, Art. Kreuz V., in: TRE 19 (1990), S. 762-765, hier: S. 764.

24 Der in den reformierten Kirchen übliche Dekalog unterscheidet sich hinsichtlich der Zahl und Anordnung der Gebote noch heute von den im Luthertum und in der katholischen Kirche üblichen Dekalogversionen und orientiert sich im Hinblick auf das 9. und 10. Gebot an Ex 20,2-17, während die Katholische Kirche und auch Luther hier der deuteronomischen 
Ave Maria ließ er den zweiten Teil weg, der die Bitte um Fürsprache enthält ${ }^{25}$. Als man ihn darauf hinwies, dass er die Gebete in der Art und Weise der Protestanten (»luteranos«) spreche, führte er zu seiner Entschuldigung an, dass er dies als Kind so in seiner Heimat gelernt habe ${ }^{26}$.

Im weiteren Verlauf des Prozesses stritt Avontroot alle weiteren gegen ihn erhobenen Vorwürfe ab und räumte lediglich ein, während der Fastenzeit Fleisch gegessen zu haben, allerdings auf ärztlichen Rat und mit Einwilligung der Kirche. Tatsächlich konnte Avontroot eine schriftliche Genehmigung des Vikars vorlegen, die ihm den Fleischverzehr an Fastentagen aus gesundheitlichen Gründen gestattete. Derselbe Vikar hatte ihm ebenfalls schriftlich die Erlaubnis erteilt, in der familieneigenen Kapelle die Messe zu hören, zu beichten und die Eucharistie zu empfangen. Dies sei auch der Grund, weshalb ihn der örtliche Pfarrer nie in der Dorfkirche gesehen habe. Vor allem aber wies Avontroot mit Nachdruck darauf hin, dass er alle Anschuldigungen, die gegen ihn vorgebracht worden waren, einzig und allein dem Hass und dem Neid seiner Verwandten zu verdanken habe ${ }^{27}$.

$\mathrm{Ob}$ die von Avontroot zu seiner Verteidigung vorgebrachten Argumente tatsächlich verfingen, wissen wir nicht. Im Bericht an den zentralen Inquisitionsrat in Madrid (Consejo de la Suprema y General Inquisición, kurz: Suprema) heißt es, Avontroot habe sich gut verteidigt (»dió muy buenas defensas « ${ }^{28}$. Wahrscheinlicher ist jedoch, dass die Inquisitoren in diesem Fall aus ganz anderen Gründen Gnade vor Recht ergehen ließen. Darauf ist

Version (Dtn 5,6-21) folgen, vgl. dazu ausführlich Bo ReIcke, Die zehn Worte in Geschichte und Gegenwart. Zählung und Bedeutung der Gebote in den verschiedenen Konfessionen, Tübingen 1973 .

25 Der noch heute gebräuchliche Text lautet: »Heilige Maria, Mutter Gottes, bitte für uns Sünder, jetzt und in der Stunde unseres Todes«. Im Gegensatz zum ersten Teil des Gebets, der auf die Marienanreden des Erzengels Gabriel (Lk 1,28) und Elisabeths (Lk 1,42) zurückgeht, ist der zweite Teil nicht biblisch, sondern stammt vermutlich aus dem 13. Jahrhundert. Seit dem 14. und 15. Jahrhundert fand er zunehmende Verbreitung, wurde aber erst mit dem römischen Katechismus von 1566 und dem Brevier von Pius V. (1568) offiziell als unverzichtbarer Bestandteil des Gebets in der Katholischen Kirche festgeschrieben. Die Reformatoren lehnten den Zusatz ab, da hier nicht mehr die Lobpreisung Marias als Gottesmutter im Vordergrund steht, sondern ihre Rolle als Fürsprecherin betont wird. Calvin sprach sich schließlich wegen der Gefahr des Missbrauchs gegen das Gebet in seiner Gesamtheit aus, und auch in Zürich verschwand das Ave Maria 1563 gänzlich aus der Gottesdienstordnung. Vgl. William Flynn, Art. Ave Maria, in: RGG 1 ( $\left.{ }^{4} 1998\right)$, Sp. 1021; German RoviRA, Der Gruß des Engels an Maria, in: Mariologisches, Dezember 2005, S. 1-4; Hans DüFeL, Luthers Stellung zur Marienverehrung, Göttingen 1968, S. 147-155; Reintraut Schimmelpfennig, Die Geschichte der Marienverehrung im deutschen Protestantismus, Paderborn 1952, S. 27; Walter TAPpolet, Das Marienlob der Reformatoren. Martin Luther - Johannes Calvin - Huldrych Zwingli - Heinrich Bullinger, Tübingen 1962, S. 124-126, 207.

26 AHN, Inq., leg. 1829-1L, no 10; vgl. Thomas, El hombre, S. 60, Anm. 12; Cioranescu, Un visionario, S. 563.

27 AHN, Inq., leg. 1829-1L, no 10; vgl. ThомAs, El hombre, S. 51.

28 Ebd. 
noch zurückzukommen. Der Beschuldigte kam jedenfalls mit einer Ermahnung und einer Geldstrafe von zweihundert Dukaten davon. Die Summe entsprach etwa einem Zehntel der jährlichen Einnahmen der hacienda und machte ihn und seine Frau sicher nicht $\operatorname{arm}^{29}$. Die Gegenstände, die Avontroot laut einem Inventar bei seiner Verhaftung mit sich führte und die ihm auch während der Haftzeit nicht abgenommen wurden, lassen im Übrigen darauf schließen, dass schon seine Zeit im Inquisitionsgefängnis nicht allzu entbehrungsreich war ${ }^{30}$. Im Mai 1590 gestattet man Avontroot gegen Zahlung einer Kaution sogar, das Gefängnis aus gesundheitlichen Gründen gegen ein privates Quartier einzutauschen. Erst drei Monate später kehrte er wieder in das Inquisitionsgefängnis zurück, jedoch nur für wenige Tage, bis er gegen eine erneute Kautionszahlung schließlich die Erlaubnis erhielt, sich auf der gesamten Insel frei zu bewegen ${ }^{31}$. Am 24. Oktober 1590, keine neun Monate nach seiner Verhaftung, wurde Avontroot wieder auf freien Fuß gesetzt.

Trotz des auf den ersten Blick überraschenden Ausgangs ist Avontroots Prozess in mehrfacher Hinsicht typisch für eine Vielzahl anderer Verfahren. Der Hintergrund für die Denunziation war ganz eindeutig in dem schwelenden Erbschafts- und Familienstreit zu sehen. Sämtliche gegen Avontroot erhobenen Vorwürfe bezogen sich auf den Vollzug oder eben Nicht-Vollzug bestimmter äußerer Handlungen und Riten, die gleichsam als sichtbare Unterscheidungsmerkmale zwischen den Konfessionen fungierten, beziehungsweise auf kritische Äußerungen zu bestimmten Glaubensinhalten der katholischen Kirche. Ob die Denunzianten deren theologische Begründung kannten, darf mit gutem Grund bezweifelt werden; sie wussten aber ganz genau, worauf sie zu achten hatten beziehungsweise was die Inquisitoren besonders interessierte. Im Rahmen der einmal im Jahr öffentlich verlesenen edictos de $f e$ schärften die Inquisitoren der Bevölkerung jene »handful of easily identifiable ingredients $\aleph^{32}$ ein, an denen Protestanten zu erkennen waren ${ }^{33}$. Die Anzeige und die Aussagen der im Verlauf des Prozesses vernommenen Zeu-

29 Cioranescu, Un visionario, S. 564.

30 Die Liste umfasst neben zwei Kisten mit Quittenbrot sowie Tischdecken und Servietten, eine nicht nur für einen Häftling umfangreiche und teure Garderobe. Sogar auf eine Kleiderbürste wollte Avontroot im Gefängnis nicht verzichten, vgl. Millares Carlo, Algunas noticias, S. 22f.; Cioranescu, Un visionario, S. 561; vgl. Thomas, El hombre, S. 50.

31 AHN, Inq., leg. 1831-4, fol. 1123-1124, zit. nach ebd.

32 William Monter, Frontiers of Heresy. The Spanish Inquisition from the Basque Lands to Sicily, Cambridge 1990, S. 240.

33 Dazu gehörten die Ablehnung oder Leugnung der Beichte, der Realpräsenz Christi in der geweihten Hostie, der Bilder- und Heiligenverehrung, des Fegefeuers sowie der guten Werke und der Gebete als Heilsmittel, die Verteidigung der Rechtfertigung allein durch den Glauben, die Ablehnung der Autorität des Papstes, des Zölibats, der Klöster und Stifte, der Fastenzeit sowie der Fastengebote an Feiertagen und Vigilien, die Hebung des Ehestands über den Priesterstand und schließlich die Verteidigung der Lehre vom Priestertum aller Gläubigen, vgl. Thomas, Los Protestantes, S. 345; Monter, Frontiers of Heresy, S. 100. 
gen lassen auf eine gewisse Vertrautheit mit diesen von der Inquisition öffentlich verlesenen Kriterienkatalogen schließen.

Dass wohl nicht alle gegen Avontroot erhobenen Anschuldigungen den Tatsachen entsprachen, dürfte folglich auch den Inquisitoren klar gewesen sein. Und es sind durchaus Fälle bekannt, in denen das Verfahren wieder eingestellt wurde, weil die Denunziation aus reiner Böswilligkeit erfolgt war und offensichtlich jeder Grundlage entbehrte ${ }^{34}$. Doch im Falle Avontroots hätte es durchaus begründeten Anlass zu Zweifeln an der Rechtgläubigkeit des Angeklagten gegeben. Insbesondere sein auffälliges Verhalten bei seiner ersten Vernehmung musste den Verdacht der Inquisitoren erregen. Die Tatsache, dass er sich nicht bekreuzigen konnte (oder wollte), den zweiten Teil des Ave Marias wegließ und die zehn Gebote nach der Zählung der Reformierten aufsagte, legt die Vermutung nahe, dass Avontroot, wenn zu diesem Zeitpunkt auch kein bekennender Protestant, so doch im reformierten Glauben aufgewachsen und mit den Riten der katholischen Kirche gar nicht oder nur sehr oberflächlich vertraut war ${ }^{35}$. Trotzdem sahen die Inquisitoren von weiteren Nachforschungen ab und verzichteten auf eine Befragung des Angeklagten unter der Folter, wie es sonst in solchen Fällen üblich war.

II.

Sucht man nach den Gründen für die auf den ersten Blick überraschende Milde der Inquisition im Falle Avontroots, so erweist sich zunächst ein Blick auf den historischen Kontext als hilfreich, in den sich sein Prozess einschreibt.

Während die spanische Inquisition gerade in ihren Anfangsjahren mit auBerordentlicher Härte gegen die so genannten judaizantes (zwangskonvertierte Juden, die im Verborgenen weiterhin die jüdische Religion ausübten) und später auch gegen die ebenfalls unter Zwang zum Christentum übergetretenen Muslime (moriscos) vorging, erschien der Protestantismus den Inquisitoren lange Zeit als minder schwere Bedrohung ${ }^{36}$. Dies sollte sich jedoch

34 So zum Beispiel als im Jahre 1637 in Tarragona der aus Frankreich stammende Nadelmacher Felipe Leonart von seiner Frau, seinem Sohn und dem Schwiegersohn als Lutheraner angezeigt wurde, vgl. Henry Kamen, The Spanish Inquisition, New Haven/London 1997, S. 181.

35 Diese Vermutung deckt sich auch mit Avontroots späteren Aussagen vor dem Tribunal von Toledo, wonach schon seine Eltern und Großeltern Protestanten gewesen seien, vgl. AHN, Inq. leg. 146-4, fol. 57r; vgl. Thomas, El hombre, S. 46. Auch in der gedruckten Übersetzung des Urteil heißt es Avontroot habe sein ganzes Leben lang "geleeft [...] in de Sect van Calvinus«, Copye van't Proces, S. 3.

36 Vgl. William Monter, Zwangskonfessionalisierung? Die spanische Inquisition gegen Lutheraner und Morisken, in: Wolfgang Reinhard/Heinz Schilling (Hg.), Die katholische Konfessionalisierung, Münster 1995, S. 135-144; Werner ThомAs, La represión del protestantismo en España. 1517-1648, Leuven 2001; zu den Morisken vgl. auch den Beitrag von Manuel F. Fernández Chaves und Rafael M. Pérez García in diesem Band. 
schlagartig ändern, als in den Jahren 1557 und 1558 zwei protestantische Konventikel in Sevilla und Valladolid aufgedeckt wurden. Bei den Verurteilten handelte es sich mit nur einer Ausnahme um gebürtige Spanier, in beiden Fällen bestand aber ein unmittelbarer Zusammenhang mit dem Eindringen protestantischen Schrifttums in den Herrschaftsbereich der spanischen Krone ${ }^{37}$.

Die Ereignisse der Jahre 1557/58 lösten eine regelrechte Hysterie aus und versetzten die Inquisition und die weltlichen Obrigkeiten in der Folgezeit in ständige Alarmbereitschaft. Zwischen 1558 und 1603 erließ die Krone nicht weniger als 35 Verordnungen, die die lokalen Obrigkeiten zu erhöhter Wachsamkeit gegenüber Reisenden und Zuwanderern aus protestantischen Territorien ermahnten ${ }^{38}$. Während dabei im Norden der Iberischen Halbinsel vor allem die saisonale Arbeitsmigration aus Frankreich eine Rolle spielte, waren es in den großen Hafenstädten und auf den Inseln vornehmlich Kaufleute und Seeleute, die nun vermehrt ins Visier der Inquisition gerieten ${ }^{39}$. Seit 1558 wurden Schiffe aus protestantischen Territorien in den spanischen Häfen systematisch auf indizierte Schriften untersucht und die Besatzungen und Passagiere nach ihrem Bekenntnis und ihren religiösen Praktiken befragt ${ }^{40}$. Noch bis zum Ende des 16. Jahrhunderts ahndeten die Inquisitoren dabei mit größter Selbstverständlichkeit auch Vergehen, die vor der Ankunft des Schiffes außerhalb des Herrschaftsbereichs der spanischen Monarchie begangen

37 Vgl. Thomas, La represión, S. 211-235; Ernst SchäFer, Beiträge zur Geschichte des spanischen Protestantismus und der Inquisition im sechzehnten Jahrhundert. Nach den Originalakten in Madrid und Simancas, 3 Bde., Gütersloh 1902; Klaus WAGNER, Luteranos y otros disidentes en la España del Emperador, in: Christoph Strosetzki (Hg.), Aspectos históricos y culturales bajo Carlos V, Frankfurt am Main 2000, S. 97-105; Michel BoEglin, Evangelismo y sensibilidad religiosa en la Sevilla del quinientos. Consideraciones acerca de la represión de los luteranos sevillanos, in: Studia Historica. Historia Moderna 27 (2005), S. 163-189.

38 Vgl.VirgilioPintoCRESPo,InquisiciónycontrolideológicoenlaEspañadelsigloXVI,Madrid1983, S. 97-124; Carlos GómeZ-Centurión Jiménez, Pragmatismo económico y tolerancia religiosa. Los acuerdos Cobham-Alba de 1576, in: Cuadernos de Historia Moderna 8 (1987), S. 57-81, hier: S. 62; Thомаs, La represión, S. 229-231.

39 Vgl. Thomas, Los Protestantes, S. 175-195, 469-471; Monter, Frontiers of Heresy, S. 231-252.

40 Vgl. Juan Carlos Galende Díaz/Bárbara Santiago Medina, Las visitas de navíos durante los siglos XVI y XVII. Historia y documentación de una práctica inquisitorial, in: Documenta \& Instrumenta 5 (2007), S. 51-76; Jaime Contreras, El Santo Oficio de la Inquisición en Galicia 1560-1700. Poder, sociedad y cultura, Madrid 1982, S. 151-157; Elisa Torres SANTANA, Visitas de navíos extranjeros en Canarias durante el siglo XVII, in: Francisco Morales Padrón (Hg.), V Coloquio de Historia Canario-Americana, Bd. 4, Las Palmas 1985, S. 427-454; Jesús GonZÁlez Chávez de Menéndez, Las visitas de navíos en el tribunal de la Inquisición de Canarias. Siglo XVIII, in: Francisco Morales PAdrón (Hg.), VII Coloquio de Historia Canario-Americana (1986), Las Palmas 1990, S. 713-732; Francisco FAJARdo Spínola, La vigilancia del mar. La inquisición canaria y las visitas de navíos, in: Anuario de Estudios Atlánticos 49 (2003), S. 87-124; Alexis Brito GonZÁlez, Visitas de navío en el Tribunal de la Inquisición de Canarias en el siglo XVI, in: Vegueta 3 (1997/98), S. 89-100; ders., Visitas de navío en el tribunal inquisitorial canario. Conflictos jurisdiccionales y percepción de derechos, in: Francisco FajARdo Spínola/Luis Alberto Anaya Hernández (Hg.), El Tribunal del Santo Oficio de la Inquisición de Canarias, V centenario de su creación, Las Palmas de Gran Canaria 2006, S. 165-181. 
worden waren, so etwa, wenn Zeugen aussagten, dass während der Überfahrt protestantische Gottesdienste an Bord abgehalten worden waren ${ }^{41}$.

Auch die Einrichtung eines eigenständigen Inquisitionstribunals auf den Kanarischen Inseln im Jahre 1568 stand in unmittelbarem Zusammenhang mit diesen Maßnahmen. Zuvor gab es auf den Kanaren, einem der wichtigsten Warenumschlagplätze für den Handel mit Nordwest- und Mitteleuropa, lediglich Kommissare der Inquisition, die dem Tribunal von Sevilla unterstellt waren. Schon 1555 forderte der Inquisitor Luis de Padilla eine stärkere Präsenz des Santo Oficio auf den Inseln wegen des großen Zulaufs von Fremden (»concurso de gente estrangera $\ll)^{42}$. Im Jahre 1562 rechtfertigte dann auch die Suprema die angestrebte Einrichtung eines eigenständigen Tribunals mit dem großen Zustrom von Kaufleuten aus aller Herren Ländern und verwies in diesem Zusammenhang auch ausdrücklich auf die bewegten und gefährlichen Zeiten (»por el comercio común que de todas las naciones ocurren a esas yslas, segund andan los tiempos trabajosos y peligrosos « $)^{43}$.

Die gewachsene Furcht vor der protestantischen Bedrohung nach 1558/59 schlug sich auch in der Verfolgungspraxis der Inquisition nieder: Von den insgesamt 190 Verfahren, die die Inquisition auf den Kanarischen Inseln zwischen 1521 und 1806 gegen Protestanten anstrengte, fallen 172, also fast $90 \%$, in den Zeitraum zwischen 1560 und $1615^{44}$, eine Verteilung, die sich weitgehend mit der auf der Iberischen Halbinsel deckt ${ }^{45}$. Bei den Beschuldigten handelte es sich durchweg um Ausländer, fast alle waren See- oder Kaufleute $^{46}$. In immerhin drei Fällen wurden die Angeklagten zum Tod auf dem Scheiterhaufen verurteilt. Nur zwei Jahre bevor die Inquisition ihre Ermitt-

41 Aus diesem Grund verurteilte das Tribunal in Sevilla im Jahre 1562 den Kapitän und ersten Offizier des niederländischen Schiffes »El Ángel«als »dogmatizadores«. 1577 und 1592 ereilte das gleiche Schicksal den englischen Schiffsoffizier Rogal Anquin und den schottischen Kapitän Juan Morray. Während im Falle Anquins aus Furcht vor diplomatischen Verwicklungen mit England das Todesurteil durch den Inquisitionsrat in Madrid in eine Galeerenstrafe umgewandelt wurde, wurde Morray auf dem Scheiterhaufen verbrannt, vgl. Thomas, Protestantes, S. 360.

42 AHN, Inq., lib. 575, fol. 1., zit. nach Francisco Fajardo Spínola, El tribunal del Atlántico. Los europeos protestantes y la inquisición de Canarias, in: Antonio de BéthenCourt Massieu (Hg.), Coloquio Internacional Canarias y el Atlántico 1580-1648, Las Palmas 2001, S. 561-586, hier: S. $561 f$.

43 AHN Inq., Libro 4o de Castilla, lib. 575., fol. 124, zit. nach ebd.; vgl. auch Fransisco FAJARdo SpínOlA, Las víctimas de la Inquisición en las Islas Canarias, La Laguna 2005, S. 116f.; Francisco Fajardo Spínola, La Inquisición de las Islas Canarias bajo Felipe II. Corso contrabando y herejía, in: José L. Pereira Iglesias (Hg.), V Reunión Científica Asociación Española de Historia Moderna 1, Cádiz 1999, S. 447-453.

44 Fajardo Spínola, El tribunal, S. 566f.; ders., Las víctimas, S. 120. Insgesamt spielte das Delikt jedoch eine nachgeordnete Rolle. Der Anteil der Prozesse gegen Protestanten macht gerade einmal 8,5\% der gesamten Verfahren (2319) im Zeitraum zwischen 1505 und 1820 aus, vgl. FAJARdo Spínola, Las víctimas, S. 49.

45 Vgl. die Schaubilder bei Thomas, La represión, S. 257, 272, 280.

46 Fajardo Spínola, Las víctimas, S. 121. 
lungen gegen Johann Avontroot aufnahm, war der Engländer George Gaspar als »luterano« verbrannt worden, zwei weitere Todesurteile wurden in den Jahren 1614 und 1615 gegen die Niederländer Gaspar Nicolás Clayesen und Tobias Lorenzo vollstreckt ${ }^{47}$. Angesichts von nur 10 Todesurteilen, die der Santo Oficio insgesamt auf den Kanaren aussprach ${ }^{48}$, zeugt wohl auch dieser Umstand von der Absicht, einem möglichen Vordringen des Protestantismus auf den Inseln mit allen Mitteln Einhalt zu gebieten.

Auf der anderen Seite zeichneten sich aber bereits seit den 1570er Jahren durchaus auch gegenläufige Tendenzen ab. Den politischen Entscheidungsträgern in Madrid war nicht entgangen, dass vom Handel mit den protestantischen Seemächten Wohl und Wehe des spanischen Imperiums abhingen ${ }^{49}$. Als die Handelsbeziehungen zwischen Spanien und England wegen der politischen Spannungen in der Zeit zwischen 1569 und 1573 vollständig zum Erliegen kamen, hätten die wirtschaftlichen Folgen kaum schlimmer sein können ${ }^{50}$. Auch die gegen die aufständischen Provinzen der nördlichen Niederlande gerichtete Embargopolitik schädigte nicht zuletzt die eigene Wirtschaft $^{51}$. Im Jahr 1575 musste sogar der Großinquisitor, Kardinal Quiroga, einräumen, dass friedliche Beziehungen zu den protestantischen Mächten von vitalem Interesse für die spanische Monarchie seien und ein Handelsverbot für englische Kaufleute den Reichen der spanischen Krone großen Schaden bringe ${ }^{52}$. Als die englische Regierung aufgrund der zahlreichen Beschwerden englischer Kaufleute 1575 mit einem neuerlichen Abbruch der Handelsbeziehungen drohte, wurde schließlich ein Abkommen zwischen beiden Mächten geschlossen, dass den Untertanen der englischen Königin künftig einen gewissen Schutz vor der Verfolgung durch die Inquisition in

47 Ebd., S. 133f.; Fajardo Spínola, El tribunal, S. 581-583.

48 Die anderen sieben wurden 1526 gegen »judaizantes« verhängt, vgl. FAJARdo Spínola, Las víctimas, S. 73.

49 Vgl. Gómez-Centurión Jiménez, Pragmatismo económico, S. 57-81; Pauline Croft, Trading With the Enemy, in: HistJ 32 (1989), S. 281-302; Bartolomé Yun Casalilla, Marte contra Minerva. El precio del imperio español, c. 1450-1600, Barcelona 2004, bes. S. 518-530; Ángel Alloza Aparicio, Europa en el mercado español. Mercaderes, represalias y contrabando en el siglo XVII, Salamanca 2006; Andrea WeIndL, Wer kleidet die Welt? Globale Märkte und merkantile Kräfte in der europäischen Politik der Frühen Neuzeit, Mainz 2007.

50 Dies betraf beide Seiten. So brach etwa im Jahre 1570 ein bedeutender Teil der englischen Textilproduktion zusammen, da die Einfuhr des für die Reinigung der Schafwolle dringend benötigten Olivenöls praktisch zum Erliegen gekommen war. Die Folge waren Weberaufstände, vgl. Gómez-Centurión Jiménez, Pragmatismo económico, S. 73; vgl. auch Henri Lapeyre, El comercio exterior de Castilla a tracvés de las aduanas de Felipe II, Valladolid 1981.

51 Vgl. Manuel Herrero Sánchez, La política de embargos y el contrabando de productos de lujo en Madrid (1635-1673). Sociedad cortesana y dependencia de los mercados internacionales, in: Hisp. 59 (1999), S. 171-191; Miguel Ángel Echevarría BaCigalupe, Guerra económica en Flandes (siglos XVI-XVII), in: Studia Histórica 27 (2005), S. 105-124.

52 Archivo General de Simancas [AGS], Estado, leg. 829, fol. 72, zit. nach GómeZ-Centurión JiMÉnEZ, Pragmatismo económico, S. 65. 
spanischen Häfen bieten sollte ${ }^{53}$. Das so genannte Alba-Cobham-Abkommen wurde in einer geheimen Zusatzvereinbarung zum englisch-spanischen Friedensvertrag von 1604 erneut bestätigt ${ }^{54} .1609$ gewährte die spanische Krone den Niederländern im Rahmen des zwölfjährigen Waffenstillstands die gleichen Privilegien wie den Engländern, und 1648 wurden diese Privilegien im spanisch-niederländischen Frieden von Münster bestätigt und in einer $\mathrm{Zu}$ satzbestimmung auch auf die Hansekaufleute ausgedehnt ${ }^{55}$.

Mit der Gewährung von Gewissensfreiheit oder religiöser Toleranz hatte das alles freilich recht wenig zu tun ${ }^{56}$. Es handelte sich hier lediglich um eine aus ökonomischen Nützlichkeitserwägungen gewährte Duldung auswärtiger Protestanten unter strengen Auflagen - nicht mehr und nicht weniger. Trotz der Vereinbarungen kam es auch weiterhin verschiedentlich zu Übergriffen gegen Protestanten, zumeist dann, wenn letztere gegen die Auflagen der Verträge verstießen oder Uneinigkeit über deren Geltungsbereich bestand. Auf lange Sicht aber verschafften die genannten Vereinbarungen den protestantischen Kaufleuten auf spanischem Boden mehr Handlungsfreiheit und einen gewissen Schutz vor Verfolgung. Für bestimmte Orte innerhalb Spaniens, namentlich die großen Handelsumschlagplätze, kann man bereits seit dem Beginn des 17. Jahrhundert von einer überwiegend friedlichen Koexistenz beider Konfessionen sprechen - mit der nicht unmaßgeblichen Einschränkung freilich, dass die Anhänger der einen, ihren Glauben nicht offen praktizieren durften.

Die meisten der in Spanien ansässigen protestantischen Kaufleute waren deshalb auch nach 1609 tunlichst darauf bedacht, kein Aufsehen zu erregen, und praktizierten ihren Glauben allenfalls im Geheimen. Als der kanarische Inquisitor Messía Lobo im Jahre 1619 eine Visitationsreise zu den drei west-

53 Das Abkommen sah vor, dass englische Protestanten von der Inquisition nicht mehr für Vergehen belangt werden konnten, die sie außerhalb des Herrschaftsbereichs der spanischen Krone begangen hatten. Während ihres Aufenthalts in Spanien waren sie nicht länger verpflichtet die Messe zu besuchen, durften aber außerhalb der Messfeiern Gotteshäuser betreten. Dabei und bei allen andern Anlässen hatten sie den religiösen Symbolen der katholischen Kirche, insbesondere der geweihten Hostie, den gebührenden Respekt zu zollen. Die von der Inquisition üblicherweise verhängte Beschlagnahmung von Gütern sollte sich künftig nur noch auf den Privatbesitz eines Verdächtigen erstrecken, keinesfalls aber auf die mitgeführten Handelsgüter, vgl. Gómez-Centurión Jiménez, Pragmatismo económico, S. 66f.; Pauline Croft, Englishmen and the Spanish Inquisition 1558-1625, in: EHR 87 (1972), S. 249-268, hier: S. 244f.; WeINDL, Wer kleidet die Welt, S. 79; Tномаs, La represión, S. $275 f$.

54 Vgl. Croft, Englishmen, S. 257; Weind, Wer kleidet die Welt, S. 93; Thomas, La represión, S. 306-308; ausführlich Albert J. Loomie, Toleration and Diplomacy. The Religious Issue in Anglo-Spanish Relations, 1603-1605, Philadelphia 1963.

55 Vgl. Thomas, La represión, S. 341, 357f.; Rainer Postel, Zur »erhaltung dern commercien und darüber habende privilegia«. Hansische Politik auf dem Westfälischen Friedenskongreß, in: Heinz Duchinardt (Hg.), Der Westfälische Friede, München 1998, S. 523-540, hier: S. 539.

56 Antonio Domínguez Ortiz, El primer esbozo de tolerancia religiosa en la España de los Austrias, in: Cuadernos de Historia Moderna y Contemporanea 2 (1981), S. 13-20. 
lichsten Inseln des Archipels (La Palma, La Gomera und El Hierro) unternahm, berichtete er, dass dort zwar sehr viele Fremde lebten, die aber alle sehr vorsichtig und zurückhaltend seien (»andan con recato«) und sich ihren Geschäften widmeten, ohne sich in religiöse Dinge einzumischen (»acuden a su comercio sin meterse en cosas de religión «) $)^{57}$.

Hier liegt vielleicht auch der Schlüssel für das auf den ersten Blick überraschende Vorgehen der Inquisition im Fall Avontroot. Die Zeugenaussagen legen die Vermutung nahe, dass der Beschuldigte es in Worten und Taten verschiedentlich an der nötigen Vorsicht hatte mangeln lassen, wodurch sich sein katholisches Umfeld möglicherweise provoziert fühlte. Dies betraf offenbar besonders das Übertreten der Fastengebote, obgleich einer der Zeugen sogar ausdrücklich darauf hinwies, dass es noch viele andere gebe, die sich wie Avontroot wegen einer vorgeschützten Krankheit einen kirchlichen Dispens erteilen ließen. Dass aber gerade für Fremde hier besondere Vorsicht geboten war, zeigt auch das Beispiel eines auf den kanarischen Inseln ansässigen Deutschen namens Hieronymus Lievent, der im Jahre 1654 die Mitglieder einer schwedischen Expedition in seinem Haus beherbergte. Lievent, ursprünglich Lutheraner, war 1637 zum Katholizismus übergetreten, als er eine Ehe mit einer Einheimischen einging. Obwohl der Besuch der Schweden in die Fastenzeit fiel, gab es im Hause Lievents Fleisch zu essen, das der Gastgeber aber eiligst verschwinden ließ, als eine Gruppe von Ordensgeistlichen unangekündigt das Haus betrat ${ }^{58}$. Das gegen Johann Avontroot verhängte Urteil war also offenbar vornehmlich als Warnung gedacht, in Zukunft mehr Zurückhaltung an den Tag zu legen. Ob Avontroot nun tatsächlich Protestant war oder nicht, schien die Inquisitoren gar nicht so sehr zu interessieren.

In diesem Zusammenhang gilt es freilich, noch einen weiteren Faktor zu berücksichtigen: Weite Teile der einheimischen Bevölkerung profitierten nicht unerheblich von der Anwesenheit der Fremden und standen dem Vorgehen der Inquisition deshalb nicht immer wohlwollend gegenüber. Die wirtschaftlichen Interessen der ortsansässigen Eliten waren mit denen der auswärtigen Kaufleute eng verflochten, was sich bei mehr als einer Gelegenheit auf den Ausgang der von der Inquisition angestrengten Verfahren auswirkte ${ }^{59}$.

57 AHN, Inq. 2367-2, carta T/C, 28-IX-1619, zit. nach Francisco Fajardo Spinola, Los europeos protestantes y la Inquisición de Canarias, in: Antonio de Béthencourt Massieu (Hg.), Coloquio internacional Canarias y el Atlántico 1580-1648. IV. Centenario del ataque de van der Does a las Palmas de Gran Canaria (1999), Las Palmas de Gran Canaria 2001, S. 561-586, hier: S. 584.

58 Peter Lindeström, Geographia Americae with an Account of the Delaware Indians. Based on Surveys and Notes Made in 1654-1656. Translated from the Original Manuscript [...] by Amandus Johnson, Philadelphia 1925, S. 47f.; vgl. Fransisco Fajardo Spínola, Las conversiones de protestantes en Canarias, siglos XVII y XVIII, Las Palmas de Gran Canaria 1996, S. 95.

59 Vgl. Luis Alberto Anaya Hernández/Francisco Fajardo Spínola, Oposición a la Inquisición, 
Johann Avontroot war keineswegs der erste Fremde auf La Palma, der sich vom Verdacht des Protestantismus zu reinigen hatte. Schon der bereits erwähnte Jakob Groenenberg, der Vater von María van Dales erstem Mann Melchor de Monteverde, war im Jahre 1524/25 anlässlich einer Visitation als Ketzer denunziert worden, weil er sich gegenüber einem Geistlichen wohlwollend über Luther geäußert hatte. Doch erst zwei Jahre später erfolgte seine Festnahme. Nach einem lang wierigen Prozess verurteilte man ihn schließlich dazu, seinen Irrtümern abzuschwören und den zehnten Teil seiner Güter als Strafe zu bezahlen. Nach der Zahlung dieser Summe - wobei Groenenberg mit den Inquisitoren noch darüber verhandelte, ob auch sein Besitz in den Niederlanden mit einzurechnen sei - war der Fall erledigt und Groenenberg wurde in der Folgezeit nie wieder von der Inquisition behelligt ${ }^{60}$. Während in vielen anderen Fällen die eigentliche Strafe weniger in den auferlegten Bußen, als vielmehr in der sozialen Ächtung bestand, die eine Verurteilung durch die Inquisition nach sich zog, blieb in diesem Fall auch die Ehre des Verurteilten und seiner Angehörigen augenscheinlich völlig unbeschädigt; die Monteverdes gehörten weiterhin zu den angesehensten Familien der Insel.

Die sozialen Netzwerke, in die die fremden Kaufleute eingebunden waren, erwiesen sich in der Praxis also oftmals als der wirksamste Schutz vor Verfolgung durch die Inquisition, zumal auch die Mitglieder des »Santo Oficio « selbst nicht selten in die bestehenden Klientel- und Patronage-Beziehungen integriert waren ${ }^{61}$. Letzteres dürfte auch im Falle Avontroots ein weiterer wesentlicher Grund für den auf den ersten Blick überraschenden Ausgang des Prozesses gewesen sein.

Schon 1587 hatte Johann Avontroot einen Alonso Redondo in seine Dienste genommen, der sich um die vor der Audiencia Real in Las Palmas anhängigen Rechtsangelegenheiten der hacienda kümmern sollte. Letzterer übte zugleich das Amt eines nuncio des Santo Oficio aus ${ }^{62}$. Im Herbst 1588 kündigte Redondo Avontroot eine geplante Visitationsreise des Inquisitors Madaleno nach La Palma an, für die es aber noch an den nötigen Mitteln mangele. Redondo schlug Avontroot daher vor, Madaleno die Reise zu finanzieren und ihm während seines Aufenthalts auf der Insel auf dem Anwesen in Tazacorte zu beherbergen. Avontroot konnte sich diesem Ansinnen schwerlich ver-

conflictos y abusos de poder a fines del siglo XVI. Las visitas de inspección a la Inquisición canaria, in: MCan 47 (1985), S. 217-235.

60 Vgl. zum Prozess gegen Jakob Groenenberg FaJardo Sí́nola, Las víctimas, S. 113-115, $251 \mathrm{f}$.

61 Vgl. Jean Pierre Dedieu, De la inquisición y su inserción social. Nuevas directrices en la historiografía inquisitorial, in: Francisco Fajardo Spínola/Luis Alberto Anaya Hernández (Hg.), El Tribunal del Santo Oficio de la Inquisición de Canarias, V centenario de su creación, Las Palmas de Gran Canaria 2006, S. 59-82.

62 Der nuncio erledigte im Wesentlichen Kurierdienste für das Tribunal, vgl. Joaquín Pérez 
weigern und ließ deshalb umgehend eine entsprechende Summe an Redondo anweisen. Auf Nachfrage bei dem Sekretär des Tribunals stellte sich dann aber heraus, dass Redondo das Projekt einer Visitationsreise nach La Palma erfunden und das von Avontroot gezahlte Geld unterschlagen hatte. Noch 1595 beschwerte sich Avontroot darüber, dass Redondo ihm den Betrag nicht zurückerstattet habe ${ }^{63}$.

Dass Avontroot im Verlauf seines Prozesses bemüht war, gegen entsprechende finanzielle Gegenleistungen eine Erleichterung seiner Haftbedingungen zu erwirken, entsprach einer generell üblichen Praxis, wenngleich die Vergünstigungen, die man Avontroot gewährte, wohl das normale Maß überschritten $^{64}$. Eine gänzlich andere Qualität aber hatte wohl die von Avontroot noch während seiner Haftzeit veranlasste Anweisung einer größeren Summe an den Ankläger (fiscal) des Tribunals, Joseph de Armas. Letzterer hatte den Betrag in Form eines auf Sevilla ausgestellten Wechsels erhalten, ein Vorgang, der erst im Rahmen einer 1597 von der Suprema in Madrid veranlassten Visitation ans Licht kam ${ }^{65}$. Welchem Zweck diese Zahlung offenbar diente, geht aus der Aussage des Sekretärs des Tribunals, Francisco Ybáñez, hervor. Ybáñez behauptete, de Armas habe ihm kurz vor der entscheidenden Sitzung des Tribunals noch versichert, er werde umgehend Einspruch bei der Suprema einlegen, wenn man sich dagegen aussprechen sollte, Avontroot unter der Folter zu befragen. Der Angeklagte sei von zahlreichen Zeugen schwer belastet worden und als Ausländer per se verdächtig (»porque estaba bien testificado y sospechoso por ser extranjero $\ll$ ). Als sich die Inquisitoren dann aber tatsächlich mehrheitlich gegen eine neuerliche Befragung des Angeklagten unter der Folter aussprachen, sei der »fiscal «plötzlich »weicher als ein Handschuh gewesen« (»estuvo más blando que un guante«) und habe auf den angekündigten Einspruch verzichtet ${ }^{66}$.

Dass Avontroot auch in der Folgezeit von der Inquisition nichts mehr zu befürchten hatte, sollte sich schon bald darauf herausstellen. 1593 wurde der Niederländer Gaspar Nicolás Clayesen vom Tribunal in Las Palmas des Protestantismus und des Schmuggels niederländischer Waren überführt ${ }^{67}$.

de Villanueva/Bartolomé Escandell Bonet (Hg.), Historia de la Inquisición en España y América, Bd. 1, Madrid 1984, S. 419f.

63 Vgl. Thomas, El hombre, S. 47f.

64 Vgl. oben bei Anm. 30.

65 AGS, Canarias, Expedientes de Visitas, leg. 250, lib. III, cuad. 3, zit. nach Henry Charles LEA, Inquisition of the Spanish Dependecies, London 1908, S. $150 \mathrm{f}$.

66 AHN, Inq., leg. 1831-4, fol. 244v, 250, zit. nach Thomas, El Hombre, S. 51.

67 Dabei handelte es sich um denselben Gaspar Nicolás Clayesen, der im Jahre 1614 zum Tode auf dem Scheiterhaufen verurteilt werden sollte. Clayesen war nach seinem ersten Prozess im Jahre 1593 auf Lebenszeit von den Inseln verbannt worden und hatte geglaubt, unter dem Schutz des spanisch-niederländischen Waffenstillstands von 1609 wieder unbehelligt Handel mit den Kanaren treiben zu können, vgl. oben Anm. 47. 
Clayesen berichtete den Inquisitoren von einem niederländischen Schmugglernetz und sagte in diesem Zusammenhang aus, dass all jene Kaufleute, die behaupteten mit ihren Schiffen aus Emden oder Hamburg zu kommen, in Wirklichkeit niederländische Calvinisten seien und illegal Waren aus Holland und Seeland einführten. Clayesen nannte in diesem Zusammenhang ausdrücklich auch den Namen Johann Avontroot, dem er verschiedentlich in Middelburg und Vlissingen begegnet sei ${ }^{68}$. Am 7. Januar 1593 informierte der für La Palma zuständige comisario der Inquisition dann das Tribunal auf Gran Canaria, dass Avontroot soeben mit einem mit Handelswaren beladenen Schiff gelandet war und auf Nachfrage angab, aus Hamburg zu kom$m^{6}{ }^{69}$. Doch wieder verzichtete die Inquisition trotz erheblicher Verdachtsmomente auf weitere Nachforschungen. Bald darauf ging man sogar noch einen Schritt weiter und hegte nun nicht einmal mehr Bedenken, Avontroot selbst um Dienstleistungen für die Inquisition zu bitten. 1595 trat er im Namen der Inquisition als Treuhänder (»depositario«) für die beschlagnahmten Güter eines niederländischen Kaufmanns namens Andrés Manrique auf ${ }^{70}$, und am 17. Mai 1596 bat die Inquisition Avontroot, künftig als Dolmetscher bei der Visitation deutscher und holländischer Schiffe behilflich zu sein ${ }^{71}$. Im Jahre 1606, vielleicht auch schon früher, wurde Avontroot überdies der Rang eines Hauptmanns der Miliz (»capitán de milicia«) von La Palma verliehen, was einer Aufnahme in den lokalen Adelsstand gleichkam ${ }^{72}$. Genau wie sechs Jahrzehnte zuvor bei Jacob Groenenberg hatte die Verurteilung durch die Inquisition dem sozialen Ansehen Johann Avontroots also keinerlei Abbruch getan.

III.

Auch wenn Avontroot bestimmten Frömmigkeitspraktiken und Glaubensinhalten der katholischen Kirche offenbar ablehnend gegenüberstand, schienen religiöse Fragen für ihn bis zu diesem Zeitpunkt keine übergeordnete Rolle zu spielen. Vielleicht hatte er auch aus dem Prozess seine Lehren gezogen und unterließ in der Folgezeit, dem Beispiel seiner Glaubensgenossen folgend, alles, was den Anstoß seines katholischen Umfelds hätte erregen kön-

68 AHN, Inq., leg. 1829-1N, no 35, zit. nach Thомаs, El hombre, S. 52.

69 AHN, Inq., leg. 2365-5: Cueva al Consejo, Las Palmas 20-II-1593, zit. nach ThомAs, El hombre, S. 52; Las Palmas, Museo Canario, Inquisición CV, 7, zit. nach Cioranescu, Un visionario, S. 564.

70 Thomas, El hombre, S. 52.

71 Las Palmas, Museo Canario, Inquisición LXXXVII, 12, zit. nach Cioranescu, Un visionario, S. 565.

72 Cioranescu, Un visionario, S. 565. 
nen. Rein gar nichts schien zu diesem Zeitpunkt jedenfalls darauf hinzudeuten, dass Avontroot nur wenige Jahre später als Verfasser religiöser Bekehrungsschriften hervortreten würde.

Umso mehr machte er indes durch seine geschäftlichen Aktivitäten von sich Reden, die immer breitere Kreise zogen und ihm bald auch Kontakt zu einflussreichen Personen bei Hof verschaffen sollten. Nachdem Avontroot schon zu Beginn der 1590er Jahre erfolgreich Handel mit den Niederlanden und mit Hamburg getrieben hatte, gelang ihm wenige Jahre später das, wovon alle in Spanien ansässigen fremden Kaufleute zu dieser Zeit träumten. Wohl Anfang des Jahres 1597 überquerte er im Gefolge des Conde de La Gomera, Antonio Peraza de Ayala y Castilla Rojas (1568-1626), der zum Gouverneur von Chuquito in Peru ernannt worden war, den Atlantik, um Geschäftsbeziehungen mit den Kolonien zu knüpfen ${ }^{73}$. Der direkte Handel mit den überseeischen Besitzungen der spanischen Krone war Nichtspaniern eigentlich strikt verboten. Für die Überfahrt brauchte es eigens eine Genehmigung der dem Indienrat unterstellten Casa de Contratación, die auch versagt werden konnte, wenn Zweifel an der Rechtgläubigkeit der Reisenden bestan$\operatorname{den}^{74}$. Avontroot besaß zwar den Status eines »vecino« von La Palma, hat sich aber ganz offensichtlich zeitlebens nie um einen Naturalisierungsbrief (»carta de naturaleza«) bemüht, der ihn zu einem Untertan des spanischen Königs mit allen Rechten und Pflichten gemacht hätte ${ }^{75}$. Dass ihm dennoch die Überfahrt gestattet wurde, dürfte wohl damit zusammenhängen, dass er im Gefolge des Conde de La Gomera und künftigen Gouverneurs von Chuquito reiste. Nach eigenen Angaben hielt sich Avontroot vier Jahre in Peru auf $^{76}$, wo er sein ohnehin schon beträchtliches Vermögen offenbar noch einmal erheblich vergrößerte ${ }^{77}$.

Dieser Erfolg ermutigte ihn bald zu noch kühneren Projekten. Im Jahr 1605 wandte sich Avontroot an den Indienrat mit dem Angebot, 6 Kanonen und 1500 Kugeln Munition für die Hafenbefestigungen von Arica und Callao an der südamerikanischen Pazifikküste zur Verfügung zu stellen, wenn man ihm im Gegenzug die Genehmigung erteile, jährlich einmal ein Schiff durch

73 Das Datum der Abreise lässt sich nicht genau bestimmen, vgl. dazu CiorANESCu, Un visionario, S. 566f.; Thомаs, El hombre, S. 52f.

74 Vgl. Bernhard Siegert, Passagiere und Papiere. Schreibakte auf der Schwelle zwischen Spanien und Amerika, München 2006.

75 Vgl. Tamar Herzog, Defining Nations. Immigrants and Citizens in Early Modern Spain and Spanish America, New Haven/London 2003; Francisco Domínguez Compañy, La condición jurídica del extranjero en América según las leyes de Indias, in: RHA 39 (1955), S. 107-117; Antonio Domínguez OrTiz, La concesión de naturalezas para comerciar con Indias durante el siglo XVII, in: Revista de Indias 19 (1959), S. 227-239.

76 Das geht aus seinem Bericht über die Beschaffenheit des Landes und die spanischen Befestigungsanlagen hervor, den Avontroot 1623 für den niederländischen Kapitän Jacques l'Hermite verfasste, vgl. unten bei Anm. 98; Thomas, El hombre (wie Anm. 3), S. 53.

77 Millares Carlo, Algunas noticias, S. 25. 
die Magellanstraße nach Peru zu schicken. In einer zweiten Eingabe bat er um die Genehmigung, zwei Schiffe jährlich von den Kanaren nach Kuba auszurüsten sowie eine autorisierte Faktorei in Hamburg zu gründen, die die Be- und Entladung dieser Schiffe übernehmen sollte. Beide Projekte wurden jedoch am 9. Februar 1605 vom Indienrat abgelehnt ${ }^{78}$.

Wohl zur gleichen Zeit wandte sich Avontroot auch an den Duque de Lerma, den mächtigen Günstlingsminister Philipps III., den er in mehreren Schreiben aufforderte, die umstrittenen Münzverschlechterungen, die in den Jahren 1602 und 1603 zur Sanierung der Staatsfinanzen angeordnet worden waren, wieder zurückzunehmen. Um die Staatseinnahmen zu verbessern, regte Avontroot stattdessen an, die im Besitz der Kirche befindlichen Güter zu säkularisieren. Es gelang ihm schließlich sogar, eine persönliche Audienz beim Duque de Lerma zu erwirken, um ihm seinen Standpunkt zu erläutern ${ }^{79}$. So ungeheuerlich dieser Vorschlag aus heutiger Sicht auch erscheinen mag bis zu seiner Realisierung unter dem liberalen Minister Mendizábal sollten noch mehr als zweihundert Jahre vergehen -, Avontroot war keineswegs der einzige, der der spanischen Krone solche und noch viel aberwitzigere Vorschläge unterbreitete. Wie die meisten Verfasser solcher Denkschriften (arbitrios) war Avontroot dabei wohl nicht zuletzt auf seine eigenen wirtschaftlichen Interessen bedacht und spekulierte auf entsprechende Gegenleistungen der Krone ${ }^{80}$. Weder Lerma noch sonst irgendjemand aber sah in seinem Vorschlag einen ernst zu nehmenden Angriff auf die Kirche. Avontroot erhielt lediglich zur Antwort, der spanische König verfüge nicht über die nötigen Machtmittel, um einen solchen Schritt in die Tat umzusetzen.

Einige Jahre später wurde Avontroot erneut bei Hof vorstellig. Im April 1609 war der zwölfjährige Waffenstillstand zwischen der Spanischen Krone und den aufständischen Provinzen der Niederlande geschlossen worden. Aus diesem Anlass überreichte Avontroot, der sich zu diesem Zeitpunkt gerade in Madrid aufhielt, dem Duque de Lerma erneut eine Denkschrift, in der er Philipp III. aufforderte, die verborgenen Sünden (»pecados ocultos«) in seinen Reichen auszurotten, die für die Kriege verantwortlich seien, die Spanien mit

78 Archivo General de Indias [AGI], Sevilla, Indiferente general 748; Cioranescu, Un visionario, S. 568.

79 AHN, Inq., leg. 146-4, fol. 63v; Copye Van’t Process, S. 5f.; Thomas, El hombre, S. 55; CioraNESCu, Un visionario, S. 568f.

80 Vgl. Elena María García Guerra, Alteraciones monetarias. Arbitrismo y comercio en el siglo XVII, in: Luis Miguel Enciso Recio (Hg.), La burguesia española en la Edad Moderna. Actas del Congreso Internacional celebrado en Madrid y Soria los dias 16 a 18 de diciembre de 1991, 3 Bde., Valladolid 1996, hier: Bd. 2, S. 633-648; Alfredo Alvar Ezquerra, Sobre las guerras de Flandes y el arbitrismo. Una reivindicación, in: Diálogos hispánicos de Amsterdam 16 (1995), S. 57-80; Miguel Angel EchevarRía BaCigalupe, Arbitrismo y política económica, siglos XVI y XVII, in: Luis Antonio Ribot García/Luigi De Rosa/Carlos Belloso MarTín (Hg.), Pensamiento y política económica en la época moderna, Madrid 2000, S. 15-30. 
seinen Feinden führe. Aus dem Kontext wird deutlich, dass sich diese Formulierung auf die katholische Kirche und ihre Doktrin bezog, doch wieder maßen weder Lerma noch der König der Eingabe größere Bedeutung bei.

Avontroot aber wartete die Antwort gar nicht ab, sondern verließ kurz darauf Madrid, um auf die Kanaren zu reisen, wo seine Frau schwer erkrankt war. Am 17. November 1609 erlag sie ihrem Leiden. Wohl um sich den finanziellen Forderungen seiner Verwandtschaft zu entziehen, hatte Avontroot schon zuvor alle beweglichen Vermögenswerte nach Sevilla und in die Niederlande transferiert und seine Frau gedrängt, den ihm zustehenden Erbteil seinem Neffen Johann Coot zu überschreiben, der seit seinem 14. Lebenjahr an Avontroots Seite war und den er wie einen Sohn behandelte ${ }^{81}$. Zwei Monate nach dem Ableben seiner Frau verließ Avontroot dann für immer die Kanaren und reiste in Begleitung seines Neffen wieder nach Madrid, wo er sich ein weiteres Mal mit dem Herzog von Lerma traf und ihn von seinen Plänen unterrichtete, sich dauerhaft in den Niederlanden niederzulassen.

Bei dieser Gelegenheit überreichte er dem Herzog eine weitere Denkschrift an den König, in der er - nun erstmals mit deutlichen Worten - die katholische Kirche und den Papst angriff und Philipp III. aufforderte, sich zum Calvinismus zu bekehren. Als der Herzog sich weigerte, den Brief weiterzuleiten, bat Avontroot selbst um eine Audienz, wurde aber lediglich zum königlichen Sekretär Andrés de Prada vorgelassen. Als er Prada zu erklären versuchte, dass der Papst der Antichrist sei, riet ihm der Sekretär des Königs, Spanien so schnell wie möglich zu verlassen ${ }^{82}$. Am 12. Oktober 1610 sandte er Prada aus London eine weitere gegen das »imperio del anticristiano de Roma« gerichtete Schrift, ohne jedoch eine Antwort zu erhalten ${ }^{83}$. Im darauffolgenden Jahr verstarb Prada. Avontroot, der inzwischen über Antwerpen nach Amsterdam weitergereist war, wo er sich dauerhaft niederzulassen gedachte, schrieb im April 1611 einen weiteren Brief, den er direkt an den König adressierte. Da er auch auf dieses Schreiben keine Antwort erhielt, schickte er im Herbst desselben Jahres seinen Neffen Johann Coot persönlich nach Madrid, um erneut mit Lerma zu sprechen. Als Coot nach Amsterdam zurückkehrte, ohne das Geringste erreicht zu haben, reifte in Avontroot offenbar der Entschluss, seine Briefe einer größeren Öffentlichkeit zugänglich zu machen, um für seine Sache zu werben.

81 Cioranescu, Un visionario, S. 571-573.

82 All dies geht aus dem Vorwort zu Avontroots drei Jahre später gedrucktem Sendschreiben an den Spanischen König hervor, vgl. Sendbrief van Joan Avontroot tot den Grootmachtigen Coninck van Spaengien. Waer inne cortelick verhaelt wort het misterie van den Oorlogh op de 17 Provintien des Nederlants. Tot Amsterdam Ghedruckt by Paulus van Ravesteyn. Anno 1613, Amsterdam 1613.

83 Ebd. 
Im Jahre 1613 wurde in Amsterdam die erste niederländische Version seines Sendbriefs an den spanischen König gedruck ${ }^{84}$. Dass dieser Brief eine gänzlich andere Qualität hatte als Avontroots frühere Eingaben an den Indienrat oder an den Duque de Lerma, mag man schon daran ermessen, dass Avontroots Schrift noch bis 1966 - dem Jahr seiner offiziellen Abschaffung - auf dem Index der verbotenen Bücher der Katholischen Kirche zu finden war $^{85}$. Der brisante Inhalt des Sendbriefs lässt sich in wenigen Worten zusammenfassen: Avontroot versuchte darin, den spanischen König mit biblischen Argumenten davon zu überzeugen, dass die Doktrin der katholischen Kirche falsch und der Papst der Antichrist sei. Den Krieg gegen die aufständischen niederländischen Provinzen deutet Avontroot im Sinne der Offenbarung des Johannes als ein Zeichen für das herannahende Ende der Herrschaft des Antichristen. Der spanische König solle sich deshalb zum reformierten Glauben bekehren und allen seinen Untertanen die Religionsfreiheit gewähren. Dies sei die einzige Möglichkeit, die aufständischen Provinzen zurückzugewinnen, denn niemals würden ihre Bewohner, nachdem sie zum wahren Glauben gefunden hätten, sich wieder unter das Joch des Antichristen begeben.

Von der niederländischen Fassung seines Briefes gelangten 2000 Exemplare nach Spanien. Im Jahre 1614 entsandte er Johann Coot mit einigen Exemplaren der gerade erschienenen spanischen Übersetzung ${ }^{86}$ und weiteren handschriftlichen Eingaben an den König nach Madrid. Gleichzeitig schickte er 7000 Exemplare der spanischen Version auf dem Seeweg nach Lissabon, wo sie ein Mittelsmann in Empfang nehmen und für ihre Weiterverbreitung sorgen sollte. Die 7000 Flugschriften wurden jedoch noch in Lissabon von der Inquisition beschlagnahmt und auch Coot wurde in Madrid festgenommen und der Inquisition von Toledo übergeben. Nach mehreren Monaten im Inquisitionsgefängnis erklärte er sich bereit, seinen Irrtümern abzuschwören und sich zum Katholizismus zu bekehren, wohl in der Hoffnung, dem Tod auf dem Scheiterhaufen zu entgehen. Tatsächlich sah man trotz der Schwere des Vergehens von der Verhängung der Höchststrafe ab. Am 10. Mai 1615 wurde Coot durch das Tribunal von Toledo zu sechs Jahren Galeere verurteilt ${ }^{87}$.

84 Sendbrief van Joan Avontroot.

85 Jesús Martínez de Bujanda (Hg.), Index librorum prohibitorum 1600-1966, Genf 2002, S. 93.

86 Carta de Ioan Aventrote al poderosísimo Rey de Espania. En el qual brevemente se declara el mysterio de la Guerra sobre las XVII provincias del Pays Baxo. Revista y emendada con vna Exhortacion para los grandes. En Amstredame. En casa de Pablo de Ravesteyne 1614, Amsterdam 1614.

87 AHN, Inq., leg. 2106-15, no 10, zit. nach Thомаs, El hombre, S. 56. Nach LeA, Inquisition, S. 300, sollte auf Anordnung Philipps III. die Galeerenstrafe um zwei Jahre verlängert und dem Verurteilten zusätzlich noch 200 Peitschenhiebe verabreicht werden. Am Tag des »auto de fe« aber wurde die königliche Entscheidung von der »Suprema« widerrufen. 
Johann Avontroot aber war das Schicksal seines Neffen ein zusätzlicher Ansporn, seine Anstrengungen zu verdoppeln, um seine religiösen Überzeugungen der Welt kundzutun, deren nahes Ende er gekommen sah. Kurze Zeit nachdem Avontroot die Nachricht von der Verurteilung seines Neffen erreichte, ließ er eine überarbeitete niederländische Fassung seines Sendbriefs drucken $^{88}$, der noch im selben Jahr Übersetzungen ins Lateische ${ }^{89}$, Deutsche $^{90}$, Italienische und 1616 auch ins Französische folgten. In den folgenden Jahren verfasste er noch weitere Schriften, die er auf eigene Kosten drucken und verbreiten ließ. Dazu gehören ein Brief an den Dogen von Venedig aus dem Jahre $1619^{91}$, in dem er vor der Beeinflussung Venedigs durch den Papst und die spanische Krone warnt, eine an die Fürsten des Heiligen Römischen Reichs adressierte Christiana instructio von $1621^{92}$, in der er den böhmischen Aufstand und die militärische Auseinandersetzung zwischen Friedrich V. von der Pfalz und dem Kaiser als weiteres Zeichen für das Herannahen der Endzeit deutet. Auch ein 1621 erschienener Bericht über die Verbrechen der Spanischen Inquisition wird ihm zugeschrieben ${ }^{93}$.

Von besonderem Interesse im Hinblick auf Avontroots weiteres Schicksal ist aber vor allem seine 1627 zuerst in spanischer Sprache erschienene

88 Sendbrief van Joan Aventroot tot den Grootmachtichsten coninck van Spaengien. Waer inne cortelijck verclaert wort de verborgentheyt des Oorloghs van de 17. Provintien des Nederlants. Hersien ende verbetert met een vermaninghe aen de Grooten. Tot Amsterdam. Ghedruckt by Paulus van Ravesteyn. anno 1615, Amsterdam 1615.

89 Epistola Johannis Aventroti, ad potentissimum regem Hispaniarum. In qua breviter mysterium belli, super XVII Belgii provinciis gesti, exponitur; in Latinam linguam nunc conversa de exemplari Belgico, excuso Amsterodami, Anno MDCXV, Amsterdam 1615; Epistola Ioannis Aventroti, ad potentissimum regem Hispaniae, in qva breviter declaratur mysterium belli XVII. provinciarum Belgicarum. Recognita \& aucta, Cum admonitione ad proceres: Vt fuit Belgice excussa. Amsterodami, apud Paulum Ravesteinum, anno 1615, Amsterdam 1615.

90 Ein sendbrief Johan Aventroots Ahn den Grosmechtigen koenig von Spanien. Darinn kurtzlich vermeldet wird das geheimmsz von dem kriege auf die 17. provintzen des Niderlands. In hochteutsche sprache uebersetzet aus dem Niderlandischen, so gedruckt in Amsterdam. Im jahr MDCXV, Amsterdam 1615; Sendbrief Johan Aventrots Ahn den Grosmechtigen koenig in Spanien: Darin das geheimnis des in den 17. provintzen der Niderlanden gefuehrten kriegs kuertzlich erklaeret wird. Uebersehen und verbessert mit einer vermahnung ahn die Grossen. In hochteutsche sprache uebersetzet aus dem Niderlandischen, so gedruckt in Amsterdam im jahr MDCXV, Amsterdam 1615.

91 Original Van een Italiaenschen Brief ghesonden aen den Doorchluchtichsten Hertoch van Venetien, Op het Houwelyck met der Zee, Amsterdam 1619.

92 Christiana Instructio, Omnibus Romani Imperii Regibus \& Principibus. Super Bello inter Ferdinandvm Caesarem, \& Fredericvm Bohemiae Regem. Per Ioannem Aventrotum. E Belgico Exemplari Amstelodami, Ex Typographia Reavesteniana, Amsterdam 1621.

93 [Johann Bartholomäus AvonTroot], Den grouwel der verwoestinghe, oft grondich bericht ende ontdeckinghe, van de gronden der Spaensche inquisitie, tot waarschouwinghe van alle goede ende oprechte Nederlanders ende evangelische geloofsghenoten, wtghegheven door een vrient ende liefhenbber der selver. Hier is oock noch by ghevoecht de Spaensche inquisitie door Reginaldum Gonsalvum Montanum, s'Gravenhage 1621. 
Epístola a los Peruleros ${ }^{94}$, die 1630 ins Niederländische übersetzt wurde ${ }^{95}$. Den Entstehungshintergrund dieser Schrift erläutert der Verfasser selbst im Vorwort. Im Jahre 1622, kurz nach dem Ende des zwölfjährigen Waffenstillstands mit der spanischen Krone, planten die Vereinigten Niederlande eine militärische Operation an der Pazifikküste unter dem Kommando des Kapitäns Jacques l'Hermite. Avontroot wurde bei der Vorbereitung dieses Unternehmens offenbar zu Rate gezogen, weil er die örtlichen Gegebenheiten gut kannte, und verfasste eine eigene Instruktion für den Oberbefehlshaber der Flottille ${ }^{96}$, die sich im April 1623 auf den Weg machte. Auf Avontroots Bitte erklärte sich letzterer offenbar bereit, eine erste handschriftliche Version des Sendschreibens an die Peruaner mit auf die Expedition zu nehmen, mit dem Avontroot hoffte, die Bewohner Südamerikas zum reformierten Glauben zu bekehren. Obwohl mehrere göttliche Eingebungen und Zeichen Avontroot das Gelingen der Operation vorausgesagt hatten, war deren militärischer Erfolg jedoch gleich Null, sieht man von einer kurzfristigen Blockade des Hafens von Callao ab ${ }^{97}$, und auch Avontroots Schrift erreichte nie ihre Empfänger. Avontroot führte das Scheitern des Unternehmens später darauf zurück, dass er es versäumt hatte, der Flotte neben seinem Sendschreiben auch den reformierten Katechismus mitzugeben. Außerdem war die Expedition gegen seinen Rat viel zu früh aufgebrochen, denn das Jahr, in dem das Reich des Antichristen an seine Ende kommen und die Peruaner die Wahrheit erkennen würden, war nach Avontroots eigenen Berechnungen erst das Jahr $1628^{98}$.

Nach dem Misserfolg der ersten Unternehmung überarbeitet er deshalb die erste, handschriftliche Fassung seines Sendschreibens und gab sie 1627 in den Druck. Wohl zur gleichen Zeit besorgte Avontroot auch eine Übersetzung des Heidelberger Katechismus ins Spanische ${ }^{99} .3000$ Exemplare beider

94 Epistola a los Peruleros, en la qual está comprehendido el catechismo de la verdadera Religion Christiana y una aliança de los Muy Poderosos Señores Estados, de las Provincias Unidas del Pais Baxo, Amsterdam 1627.

95 Sendt-Brief Aen die van Perv Met en Aliance van de Hooghmogende Heeren Staten der Vreenigder Provintien des Nederlands. Getranslaatert uyt de Spaensche Tale, t'Amstelredam, Gedruckt by Paulus Aertsz van Ravesteyn, Anno 1630, Amsterdam 1630.

96 In der offiziellen von den Generalständen erteilten Instruktion für l'Hermite wird auf Avontroots »Instructie voor den Generael« ausdrücklich Bezug genommen, die dieser am 18. April 1623 einreichte, vgl. Instructie vor Jacques l'Hermite, in: Pieter van DAM, Beschryvinge van de Oostindische Compagnie, hg. v. Frederik Willem Stapel, 4 Bde., 's-Gravenhage 1927-1954, Bd. 1, 2, 1929, S. 532-541, hier: S. 535.

97 Vgl. Benjamin Schmidt, Exotic Allies: The Dutch-Chilean Encounter and the (Failed) Conquest of America, in: RenQ 52 (1999), S. 440-473, bes. S. 452-460; Kris E. Lane, Pillaging the Empire. Piracy in the Americas 1550-1750, Armonk, NY 1998, S. 84-87.

98 Sendt-Brief aen die van Peru, S. 3-14.

99 El Catecismo de Heidelberg: enseñanza de la doctrina cristiana redactado por Zacarías Ursino y Gaspar Oleviano, y publicado en 1563, Amsterdam 1628. 
Schriften übergab er dem Kapitän eines Schiffes der wenige Jahre zuvor gegründeten Niederländischen Westindienkompanie, das am 24. Januar 1628 von Texel nach Buenos Aires auslief. Die Untertanen des spanischen Königs auf der anderen Seite des Ozeans waren aber immer noch nicht bereit, sich der >Wahrheit $<$ zu öffnen. Als das Schiff von seine Reise zurückkehrte, bekam Avontroot fast alle 3000 Exemplare wieder ausgehändigt; ganze 75 hatten in Buenos Aires einen Abnehmer gefunden ${ }^{100}$.

Doch auch von diesem neuerlichen Rückschlag ließ sich Avontroot nicht entmutigen. 1632, inzwischen über siebzigjährig, trat er schließlich noch einmal persönlich die Reise nach Madrid an, wiederum mit mehreren tausend Exemplaren seiner Schriften im Gepäck, um einen letzten Versuch zu unternehmen, den spanischen König zu bekehren. Erstaunlicherweise gelangte er mit seiner brisanten Fracht tatsächlich an sein Ziel. Bald nach seiner Ankunft erschien er bei Hof und informierte den Conde-Duque de Olivares von seinen Absichten. Außerdem verlangte er, dass ihm seine inzwischen von der Inquisition beschlagnahmten Güter zurückerstattet würden. Olivares forderte Avontroot auf, sein Anliegen dem König schriftlich zu unterbreiten. Daraufhin übergab er dem Conde-Duque am 24. Oktober 1632 einen an den König adressierten Brief, in dem er Letzteren aufforderte, in seinen Reichen die Predigt des wahren Evangeliums zuzulassen, wie dies in England und in anderen protestantischen Ländern bereits geschehen sei, und die Inquisition abzuschaffen ${ }^{101}$. Olivares stellte Avontroot in Aussicht, die Beschlagnahmung seiner Besitztümer auf den Kanaren zurückzunehmen, jedoch nur unter der Bedingung, dass er seine häretischen Ansichten aufgebe $^{102}$. Da Avontroot sich weigerte, informierte Olivares schließlich die Inquisition von dem Fall. In dem an den Großinquisitor und den Staatsrat gerichteten Schreiben heißt es:

[...] ich glaube, dass dieser [Avontroot] ein häretischer Hund ist, der kommt, weil er gerne als Märtyrer in seinem Glauben sterben möchte, und diesen Wunsch würde ich ihm tatsächlich erfüllen ${ }^{103}$.

100 Sendt-Brief aen die van Peru, S. 13.

101 AHN, Inq., libro 272, fol. 661r.

102 Copye Van't Sententie, S. 4f.

103 »[...] para mí, creo que éste es un perro hereje que viene con ánimo de morir mártir en su Religión, y en verdad que yo le cumpliera el deseo«. AHN, Inq., libro 272, fol. 657, zit. nach Thомаs, El hombre, S. 59. 
IV.

Von Avontroots Ende und Nachleben war eingangs bereits die Rede. Sein Fall ist aber nicht deshalb so ausführlich geschildert worden, weil er so kurios ist, sondern weil er trotz aller Besonderheiten zugleich exemplarisch für die Lebenswirklichkeit und die religiösen Handlungsspielräume einer Personengruppe steht, die gleichsam von Berufs wegen hochmobil war und immer wieder auch die Grenzen zwischen den sich ausdifferenzierenden konfessionellen Räumen innerhalb des frühneuzeitlichen Europas überschritt.

Wie die meisten Fernhandelskaufleute war Avontroot ein Mann, den man selbst gemessen an heutigen Maßstäben als weit gereist bezeichnen würde. Von seiner niederrheinischen Heimat führte ihn sein Weg über die Niederlande auf die Kanaren, schließlich sogar nach Peru und am Ende seines Lebens wieder zurück in die Niederlande. Zwischen Avontroots Mobilität und seiner religiösen Identitätsbildung scheint auf den ersten Blick jedoch kein unmittelbarer Zusammenhang zu bestehen. Um sich eines Tages offen zum reformierten Glauben zu bekennen, hätte er jedenfalls nicht so weite Reisen auf sich nehmen müssen. Die Stationen auf den Kanarischen Inseln und in Südamerika erscheinen, so gesehen, eher als Umwege. Anders als bei der großen Gruppe der protestantischen Glaubensflüchtlinge, die zur gleichen Zeit auf der Suche nach Asyl von Territorium zu Territorium zogen ${ }^{104}$, spielte der Faktor Religion als Movens für Mobilität bei Avontroot zumindest in den ersten Jahrzehnten seines Lebens überhaupt keine Rolle. Wie viele andere Kaufleute dürfte ihn vor allem die Aussicht auf hohe Profite, wie sie im lukrativen Spanienhandel zu erzielen waren, bewogen haben, seine Heimat schon in jungen Jahren zu verlassen und sein Glück auf den Kanaren zu suchen. Unabhängig von den konkreten Motiven für diesen folgenschweren Schritt wird man aber davon ausgehen dürfen, dass die Jahre, die Avontroot im Herrschaftsbereich der spanischen Krone verbrachte, und insbesondere auch seine Erfahrungen mit der Inquisition sein Verhältnis zur Religion entscheidend prägten.

Dies geschah aber offenbar nicht in der Weise, dass die Erfahrung von religiöser Alterität unmittelbar in die Ausformung einer sich von der katholischen Mehrheitskultur abgrenzenden eigenen Identität umschlug. Hier bestand offenbar ein fundamentaler Unterschied zwischen der individuellen Mobilität von Kaufleuten, die in der Regel wirtschaftlich motiviert war, und der Migration von Individuen oder ganzen Gemeinden in Folge religiöser Verfolgung oder Vertreibung. Wechselten Letztere um ihrer religiösen Über-

104 Vgl. dazu die Beiträge von Henning P. Jürgens, Vera von der Osten-Sacken, Susanne Lachenicht und Heinz Schilling in diesem Band. 
zeugungen willen häufig sogar mehrfach ihren jeweiligen Aufenthaltsort, so passten Erstere umgekehrt ihre religiösen Praktiken ihrem wechselnden religiösen Umfeld an; viele legten dabei ein solches Geschick an den Tag, dass man sie nachgerade als »religiöse Chamäleons « bezeichnen könnte ${ }^{105}$. So protestierte etwa der junge Robert Diedon aus Leicester im Jahre 1583 energisch gegen seine Festnahme durch die Inquisition in Bilbao mit dem Argument, dass er in Spanien stets als guter Katholik gelebt und sich den landesüblichen religiösen Gebräuchen angepasst habe. Ebenso freimütig gestand er, bei seinen Aufenthalten in England dem dort üblichen Ritus zu folgen, was er offenbar als gänzlich unproblematisch empfand ${ }^{106}$. Auch der in Spanien ansässige Kaufmann David Quinaloc aus dem schottischen Dundee berichtete im Jahre 1594 zwei durchreisenden Engländern, er besuche regelmäßig die Messe und beichte bei den Mönchen, »um seiner Pflicht genüge zu tun, seine Kreditwürdigkeit nicht zu verlieren und nicht des Landes verwiesen zu werden« (»por cumplir y tener crédito, y por no salir desterrado«). Während die anderen aber beteten, lese er heimlich die Werke Vergils und Ovids in der Kirchenbank ${ }^{107}$. Dies macht zugleich deutlich, dass es bei Wahrung der äuBeren Formen offenbar durchaus Handlungsspielräume für deviantes Verhalten gab. Man durfte es aber nicht zu weit treiben; so warnte Quinaloc seine beiden Gesprächspartner gleich im selben Atemzug, dass man in Spanien nie sicher sei; wenn jemand einem Böses wolle, reichten schon zwei falsche Zeugenaussagen, um den Beschuldigten jedes Vergehens zu überführen ${ }^{108}$ - eine Erfahrung, die auch der junge Johann Avontroot machen musste, aus der er aber offenbar seine Lehren zog. Nach 1589 schien er, dem Beispiel der übrigen protestantischen Kaufleute folgend, alles zu unterlassen, was von seinem katholischen Umfeld als Provokation hätte ausgelegt werden können. Ob er dabei im Geheimen Protestant war oder blieb, ist schwer zu sagen. Religiöse Fragen schienen für ihn bis zu diesem Zeitpunkt keine übergeordnete Rolle zu spielen. Auch in dieser Hinsicht erscheint sein Fall durchaus typisch: Bei den meisten in Spanien ansässigen protestantischen Kaufleuten führte die äußere Anpassung an die katholische Mehrheitskultur wohl tendenziell zu religiöser Indifferenz, also eher zum Verlust als zur Festigung konfessioneller Identität.

Umso erstaunlicher und erklärungsbedürftiger erscheint vor diesem Hintergrund die Wendung, die Avontroots Leben im Jahre 1609 nahm. Betrach-

105 Vgl. mit zahlreichen Beispielen Thомаs, Los protestantes, S. 385-414, das Zitat, ebd., S. 482.

106 AHN Inq., libro 834, fol. 74, relación del auto de fe, Logroño 24 de agosto de 1583, zit. nach Thomas, Los protestantes, S. 392.

107 AHN, Inq. leg. 2105-80: causas despachadas, Toledo 19 de junio 1594 a 1 de junio 1595, zit. nach ebd., S. 389.

108 »[...] que en España no auía seguridad, que quando vno quería haçer mal a otro, con dos testigos falsos le prouauan lo que querían«, zit. nach ebd. 
tet man seinen Lebensweg, zerfällt dieser gleichsam in zwei Teile: Zunächst das in erster Linie dem commercium gewidmete Leben als Kaufmann, dann die paulinische Wende, die das letzte, ganz dem Bibelstudium und der Hinwendung zur Religion gewidmete Lebensdrittel einläutete. Was letztlich den Ausschlag für diese überraschende Entwicklung gegeben hat, wissen wir nicht. Der Tod von Avontroots Frau mag in diesem Zusammenhang ebenso eine Rolle gespielt haben wie das Inkrafttreten des spanisch-niederländischen Waffenstillstands. Beide Ereignisse scheinen jedenfalls die äußeren Anlässe für Avontroots Übersiedlung in die Niederlande gewesen zu sein, wo er in der Folgezeit Gelegenheit hatte, sich intensiver mit religiösen Fragen auseinanderzusetzen und vor allem die Bibel zu studieren. In seinem Sendbrief an den spanischen König schreibt Avontroot Bezug nehmend auf seine früheren Briefe:

In den eersten schreef ic swacklick door dien ic van jongs af in de Eylanden van Canarien gewooont hebbe, daer men de Bijbelsche Schrifture neit en magh ondersoecken: maer comende in vrije landen ondersochte die met de hulpe van God $^{109}$.

Avontroot muss aber schon vor seiner Übersiedlung in die Niederlande begonnen haben, sich mit religiösen Fragen auseinanderzusetzen. Dabei könnten der persönliche Kontakt mit Protestanten und insbesondere auch seine Einbindung in niederländische Handels- und Schmuggelnetzwerke eine Rolle gespielt haben. Möglicherweise verschaffte Avontroot sich auf diesem Wege auch schon vor 1609 Zugang zu indizierten Schriften. Später bediente er sich vermutlich der gleichen Kanäle, um seine eigenen Pamphlete in Spanien zu verbreiten.

Dies macht zugleich deutlich, dass für die Ausbildung religiöser Identität nicht nur die Mobilität von Menschen, sondern nicht zuletzt auch die Zirkulation von Texten eine zentrale Rolle spielte. Diese Texte wiederum folgten dem Weg der Warenströme und der Kaufleute, die sie mit sich führten. Die spanischen Krone stand damit vor dem Problem, den Transfer von Waren und Kapital, auf den sie zwingend angewiesen war, vom Transfer von Ideen abzukoppeln, die man nicht nur als Bedrohung für den wahren Glauben empfand, sondern von denen auch eine erhebliche Gefahr für die Integrität des Herrschafts- und Untertanenverbands auszugehen schien.

Auf lange Sicht erwiesen sich diese Befürchtungen jedoch als unbegründet. Die nach 1558 befürchtete Infiltration der spanischen Bevölkerung mit protestantischem Gedankengut blieb bekanntlich aus. Avontroots vergebliche Bemühungen, den spanischen König und seine Untertanen zum reformierten Glauben zu bekehren, bis hin zu seinem offenbar selbst gewählten Märtyrer-

109 Sendbrief van Joan Aventroot. 
tod auf dem Scheiterhaufen, entbehren aus der Perspektive der Nachgeborenen nicht einer tragischen Ironie.

Auf ganz andere und wesentlich unspektakulärere Weise trug die Mobilität von Kaufleuten aber durchaus dazu bei, die konfessionellen Gegensätze zu überwinden. Gerade weil die allermeisten protestantischen Kaufleute - anders als Avontroot - nicht den geringsten Ehrgeiz zeigten, die Untertanen des spanischen Königs zu bekehren, leisteten sie einen wesentlichen Beitrag zur Entzauberung der von der Inquisition propagierten Feindbilder. Durch den alltäglichen Umgang mit den fremden Kaufleuten verlor die einheimische Bevölkerung, an den großen Handelsumschlagplätzen, nach und nach die Furcht vor den >Ketzern aus dem Norden $<$. Auf diese Weise wurden gleichsam schon im 17. Jahrhundert wesentliche Voraussetzungen für ein friedliches Nebeneinander der Konfessionen geschaffen, auch wenn es bis zur Gewährung der Gewissensfreiheit im Herrschaftsbereich der spanischen Krone noch ein langer Weg war. 


\title{
Almut Bues \\ $»$ Altter gelaube « gegen »newerdachtten glauben« oder wen bewahrt Gott?
}

\author{
Martin Grunewegs interkonfessionelle Kontakte
}

Martin Gruneweg soll in diesem Beitrag als Beispiel für das Erleben interkonfessioneller Kontakte und mögliche daraus folgende Konsequenzen in der zweiten Hälfte des 16. Jahrhunderts dienen. Sein Leben stellt zwar ein Einzelschicksal dar, kann aber, da die Überlieferungslage anhand seiner umfangreichen Aufzeichnungen überaus günstig ist, einige wichtige allgemeine Aspekte beleuchten ${ }^{1}$. Schreiben ist eine Strategie privater Seinsbewältigung; sie ist Selbstdarstellung zur Rechtfertigung menschlichen Verhaltens, also gleichzeitig Legitimationsversuch. Das Schreiben kann dabei die Form einer Neudeutung der Vergangenheit beinhalten; insofern ist eine solche Quelle natürlich immer einseitig.

Gruneweg wurde 1562 in eine lutherische Kaufmannsfamilie in Danzig geboren ${ }^{2}$. Die Familie hatte sich, vielleicht durch den Einfluss des ersten lutherischen Predigers Jakob Knothe, der 1525 in die Familie eingeheiratet hatte, Ende der zwanziger Jahre der Reformation angeschlossen. Das Elternhaus lag neben der seit 1557 den Lutheranern gehörenden Marienkirche, die bis 1572 gemeinsam mit den Katholiken genutzt wurde und durch welche Grunewegs täglicher Schulweg führte ${ }^{3}$. Die Familie hatte auch Kontakte zu größtenteils aus Holland eingewanderten Calvinisten.

Eine friedliche Koexistenz der Konfessionen kennzeichnete die Ostseestadt zu Grunewegs Jugendzeit ${ }^{4}$; das Handelszentrum, dessen Kapital unter anderem in seinem guten Ruf bestand, musste von Anfang an einen Weg des Zusammenlebens von Evangelischen und Katholiken suchen. Wie es da-

1 Vgl. Almut Bues (Hg.), Die Aufzeichnungen des Dominikaners Martin Gruneweg (1562- ca. 1618) über seine Familie in Danzig, seine Handelsreisen in Osteuropa und sein Klosterleben in Polen, Wiesbaden 2008.

2 Zu Danzig siehe Maria BogucKa, Das alte Danzig. Alltagsleben vom 15. bis 17. Jahrhundert, Leipzig 21987.

3 Vgl. auch die Beschreibung der gemeinsamen Nutzung der Johanniskirche in Thorn: Bues, Aufzeichnungen des Dominikaners Martin Gruneweg, S. 573f.

4 Vgl. Irene DingeL, Zwischen römischem Katholizismus, Luthertum und Calvinismus: Aspekte und Strukturen von Konfessionsbildung im späten 16. Jahrhundert, in: Almut BuEs (Hg.), Martin Gruneweg (1562- nach 1615). Ein europäischer Lebensweg/Martin Gruneweg (1562-after 1615). A European Way of Life, Wiesbaden 2009, S. 193-211. 
mals in Handelskreisen üblich war, verbrachte Gruneweg sein dreizehntes Lebensjahr zum Sprachenerwerb bei polnischen Geschäftsfreunden ${ }^{5}$, wo er in Bromberg näher mit dem Katholizismus in Kontakt kam, der das sensible Kind wohl anzog. Denn man empfahl, Gruneweg nach Danzig zurückzuholen, ehe er zum »Papisten« würde ${ }^{6}$.

Mit siebzehn Jahren ging Gruneweg auf die Wanderschaft; seine erste Arbeitsstelle wählte er nicht im benachbarten evangelischen Königsberg, sondern bei dem aus Nürnberg stammenden lutherischen Kaufmann und Hoflieferanten Georg Kersten in Warschau. Die Reformation hatte sich in der masowischen Hauptstadt nicht durchgesetzt, der Stadtrat hatte im Jahre 1574 beschlossen, dass nur Katholiken das Bürgerrecht erhielten; doch kennzeichnete eine weitgehende Tolerierung anderer Glaubensgemeinschaften die Zeit nach der Warschauer Konföderation ${ }^{8}$. Evangelische Gottesdienste wurden am Hofe des Adligen Anzelm Gostomski in der Krakauer Vorstadt durchgeführt. Der junge Gruneweg lebte unter Seinesgleichen in einer anerkannten Minderheit. Er reflektierte an keiner Stelle über sein Verhältnis zur Religion in Warschau, wo er dreißig Jahre später beim Aufbau des Dominikanerklosters helfen sollte.

Im Jahre 1582 fand Gruneweg bei armenischen Kaufleuten in Lemberg Arbeit, was zu einem Wendepunkt in seinem Leben wurde: »Darnach verkaufte ich alle meine deutze kleider unde tzeugte eittel polnische dafuer «? Die Migration erlaubte ihm eine mehrfache Neuorientierung; seine Religion nahm er als »portable Heimat « (Jonathan Rosen) mit ${ }^{10}$. Die Übersiedlung in ein völlig neues Umfeld erlebte er sehr bewusst; er sah hierin, angelehnt an Psalm 18,20 Gottes Willen: Gott zog den Verlorenen aus der Sphäre des Chaos; er sollte in der Ferne zu Gott finden ${ }^{11}$. In Lemberg lebte er innerhalb einer akzeptierten und geschätzten Minderheit, in der sich der junge

5 Vgl. Almut Bues, Sprachenerlernung in den Grenzgebieten der Rzeczpospolita. Deutsch-polnische Gesprächsbücher aus dem 16. und 17. Jahrhundert, in: Christoph Augustynowicz/Andreas Kappeler/Max Demeter Peyfuss (Hg.), Russland, Polen und Österreich in der Frühen Neuzeit. Festschrift für Walter Leitsch, Wien 2003, S. 87-106.

6 Vgl. Bues, Aufzeichnungen des Dominikaners Martin Gruneweg, S. 475.

7 Vgl. Gottfried Schramm, Problem reformacji w Warszawie w XVI wieku, in: PrzHi 54 (1963), S. 557-569. (Evangelische) Hoflieferanten benötigten kein Bürgerrecht und konnten somit in Warschau Handel treiben.

8 Vgl. Tomasz Kempa, Wobec kontrreformacji. Protestanci i prawosławni w obronie swobód wyznaniowych w Rzeczypospolitej w końcu XVI i w pierwszej połowie XVII wieku, Toruń 2007, S. 19-44; vgl. Andrzej SoŁtan, Piotr Klos. Przyczynek do stosunków wyznaniowych w Warszawie na przełomie XVI i XVII w., in: Rocznik Warszawski 27 (1997), S. 5-23.

9 Bues, Aufzeichnungen des Dominikaners Martin Gruneweg, S. 631.

10 Jonathan Rosen, Talmud und Internet. Eine Geschichte von zwei Welten, Frankfurt am Main 2002.

11 Vgl. BuEs, Aufzeichnungen des Dominikaners Martin Gruneweg, S. 639. 
Mann wohl fühlte; seinem Schwager erklärte Gruneweg später, dass er sich jetzt nach armenischer Weise gebe ${ }^{12}$. Die Assimilation betraf jedoch reine Äußerlichkeiten.

In Lemberg existierten noch mehr Konfessionen und Ethnien als in Warschau oder Danzig. Miron Kapral' zählte für den Beginn des 16. Jahrhunderts in der Stadt 50-55 \% Katholiken (Polen und Deutsche), ungefähr 20\% Ruthenen, d.h. Orthodoxe, etwa $15 \%$ Juden und mehr als $10 \%$ Armenier $^{13}$. In Lemberg war das Magdeburger Recht im Jahre 1356 auch »aliis gentibus habitantibus in eadem civitate, videlicet Ormenis, Iudeis, Saracenis, Ruthenis et aliis gentibus « gewährt worden ${ }^{14}$. Schon im 14. Jahrhundert sind drei griechisch-orthodoxe, eine armenische und sechs römisch-katholische Kirchen sowie eine Synagoge belegt. Lemberg war eine »city of uncertain boundaries $\ll^{15}$. Ende des 16 . Jahrhunderts kamen unierte Orthodoxe sowie im 17. Jahrhundert unierte Armenier hinzu' ${ }^{16}$; nur wenige Evangelische siedelten hier: »Dies ist eine Statt, die keinen Ketzer in sich nestelen lest, sondern wierft sie aus wie der Ocean das unreine ${ }^{17}$, wie es bei dem Konvertierten heißt. Von der bunten Vielfalt fühlte sich der mit humanistischem Gedankengut groß gewordene Kaufmannssohn angezogen:

alle tage auch aus aller welt örtter folk beyderr pershoen in ihres landes kleidunge tzusehen, die Ungern in ihren kleinen magerchen, die Kozaken in ihren grossen kutzmen, die Moßkwitter in ihren weyssen ßepken, die Turcken in ihren weyssen tzolmen. Diese in ihrer langen kleidunge, wieder die Deutzen, Welschen, Frantzöser, Hisspanier in ihrer kuertzen. Es sey einer, was tzunge err wolle, er findet hie seine sprache $^{18}$.

Lemberg erweckte in dem Lutheraner, so ist es jedenfalls seinen Aufzeichnungen zu entnehmen, ein Interesse an Religiösem, was aber nicht mit einem Verständnis für Andersgläubige gleichzusetzen ist.

12 Vgl. ebd., S. 847.

13 Angaben bei Miron KAPRAL', Les Orthodoxes et les Catholiques de L'vov (fin du XVIe-première moitié du XVIIe siècle), in: Dix-septième siècle 220 (2003), S. 449-466, hier: S. 449; vgl. auch Мирон КАПрАль, Демографія Львова XV - першої половини XVI ст, in: Ярослав ИсАЕвич I Інші (Нg.), Львів. Історичні нариси, Львів 1996, S. 67-81; Мирон КАПрАль, Національні громади Львова XVI-XVIII ст. Соціально-правові взаємини, Львів 2003.

14 Vgl. Мирон КАПраль (Нg.), Привілеї міста Львова (XIV-XVIII ст.), Львів 1998, S. 27-31, hier: S. 27.

15 Delphine Bechtel, Lemberg/Lwów/Lvov/L'viv. Identities of a »City of Uncertain Boundaries«, in: Diogenes 53 (2006), S. 62-71.

16 Vgl. Михаил В. Дмитриєв, Между Римом и Царьградом. Генезис Брестской церковной унии 1595-1596 гг., Москва 2003; Ирина Я. ГАюк, Вірменська церква в Україні, Львів 2002, S. 46-83.

17 Bues, Aufzeichnungen des Dominikaners Martin Gruneweg, S. 654.

18 Ebd., S. 653. 
Seine Stadtbeschreibung lässt nicht nur für die Kirchenarchitektur breiten Raum, sondern auch für Gebräuche, Zeremonien, z.B. die auf Deutsch gehaltenen Roratemessen ${ }^{19}$. Trotz beginnender Polonisierungsprozesse existierten weiterhin kulturelle Mehrdimensionalitäten in einer multiethnischen und plurikonfessionellen Region ${ }^{20}$. Gruneweg setzte sich nun besonders mit Armeniern und Orthodoxen auseinander ${ }^{21}$. Die in der Diaspora lebenden Armenier, bei denen Ethnie und Konfession übereinstimmten, kannten keine Motive für eine Missionierung ${ }^{22}$. Im Arbeitsumfeld nahmen sie auf andere Konfessionen Rücksicht. Da er mit Armeniern lebte und arbeitete, befragte sie der wissbegierige junge Mann immer wieder zu ihren religiösen Bräuchen $^{23}$; es ist gut möglich, dass er eine Zeit lang mit der armenischen Religion `flirtete<. Dank seiner guten persönlichen Erfahrungen brachte er den Armeniern auch später große Sympathie entgegen. Die orthodoxe Liturgie blieb ihm allerdings fremd: »In der Reussen kirche [...] blieben wir die gantze Liturgia uber und vertrieben die tzeitt mitt hefttigem lachen $\aleph^{24}$; die Zeremonien erschienen ihm $»$ seltzam $\ll^{25}$. Wieweit bei dieser Einschätzung des als katholischer Priester Schreibenden die offizielle katholische Linie mitspielte, entzieht sich unserer Kenntnis, die Distanz zur Orthodoxie wurde jedenfalls auch nach der Kirchenunion gehalten ${ }^{26}$.

In Podolien traf Gruneweg vermehrt auf die seit dem 13. Jahrhundert dort siedelnden Juden, die im 16. Jahrhundert bis zu 25\% der Stadtbevölkerung ausmachen konnten. Das Judenviertel in Lemberg beschrieb er detailliert; in Südosteuropa traf er vermehrt Juden als Zolleinnehmer.

19 Vgl. ebd., S. 666.

20 Vgl. Myron KapraL', Assimilation im frühneuzeitlichen L'viv. Sozialer Aufstieg, Glaubenswechsel und gemischte Ehen, in: Stefan Rohdewald/David Frick/Stefan Wiederkehr (Hg.), Litauen und Ruthenien. Studien zu einer transkulturellen Kommunikationsregion (15.-18. Jahrhundert), Wiesbaden 2007, S. 51-66; Henryk LiTwin, Napływ szlachty polskiej na Ukrainę 1569-1648, Warszawa 2000.

$21 »$ Was belangt diese beiden Secten, die Armenier und Reussen wegen des glaubens, findet man gnug in buechern beschrieben, die mitt solchen dingen ummegehn, dennoch ist tzuwiessen, das die Armenier uns Catholischen sowol im glauben als in ceremonien vor den Reussen, welche sich an die Griechen haltten, neher sein «(BuEs, Aufzeichnungen des Dominikaners Martin Gruneweg, S. 673).

22 »Sie sagen, es wirt ein ider selich, er sey, was sekte er wolle, wen er nur im namen der Heiligen Dreyfaltticheit geteuft ist. Sprechen auch, daß ein unerbar ding sey, die sektte, in welcher er geteuft ist, tzuverwexeln. Meinen auch, das alle sekten Gotte gefallen, nur wegen der wercke, eine vor die ander« (Ebd., S. 674).

23 »Da ich fragte, worume die ungebettnen heren dem kinde folgten, antworte man mir, sie folgetenn nicht so dem kinde als das sie den Heiligen Cresm beleitten, welchen der Priester aufs kindt gelegt hette « (Ebd.).

24 Ebd., S. 675.

25 Ebd., S. 676.

26 Z.B. »Pater Leonardus war so ein skrupulant, das er keinen Reussen grueste noch ansprach und mir deßgleichen nicht tzulies, meidende die, mit welchen die Kirche verbeut gemeinschaft tzuhaben ...« (Ebd., S. 1183f.). Zur orthodoxen Kirche allgemein Antoni Mironowicz, Kościół prawosławny w dziejach dawnej Rzeczypospolitej, Białystok 2001. 
Nachtlagerten im dorfe Zawaliof, 3 meilen, da war der krueger ein Jude, wie dan desselben trents solchs genug ist, das einem auch dunkt, man reyze in Judea. Dan auch die Juden fast allen tzoll einnemen, in suma von Lublin ahn bis tzu den Tattern mus man vor den Judenn das huetlein tzien, und ofte wie vor unserm Herrgotte die hende faltten ${ }^{27}$.

Auf seiner Reise nach Moskau übernahm er die den Russen zugesprochenen Vorurteile den Juden gegenüber ${ }^{28}$. Offensichtlich ging er davon aus, dass die Vorstellung in der traditionellen Orthodoxie sich nicht von derjenigen der Katholiken oder Protestanten unterschied, vielleicht nur noch intoleranter war. Doch differenzierte man damals in Ruthenien eigentlich sehr genau zwischen den biblischen Juden und den jüdischen Mitbürgern ${ }^{29}$.

Zusammen mit den Armeniern unternahm Gruneweg Handelsreisen durch Osteuropa, die seinen kulturellen Horizont überschritten und zahlreiche Risiken in sich bargen; vor dem Aufbruch zu solchen Reisen gingen die Kaufleute in sich und überdachten ihr Leben ${ }^{30}$. Mehrmals gelobte er während der Reisen in gefährlichen Situationen ein gottgefälligeres Leben: Er wollte samstags fasten $^{31}$, den Mönchen Speise geben ${ }^{32}$, nicht mehr tanzen etc. ${ }^{33}$.

Auf den Reisen in das Osmanische Reich kam er das erste Mal mit dem Islam in Berührung. Ohne die bestehenden Vorurteile zu übernehmen, erklärte er die Bauweise der Moscheen ${ }^{34}$, beschrieb die Feste der Muslime ${ }^{35}$, zeichnete ihre Friedhöfe ${ }^{36}$. Doch war auch er nicht frei von der allgemeinen Türkenhysterie im Mitteleuropa des 16. Jahrhunderts ${ }^{37}$; wie andere Reisende

27 Ebd., S. 642. Vgl. Magda Teter, Jews and heretics in Catholic Poland. A beleaguered church in the post-Reformation era, Cambridge 2006, S. 29.

28 »... man wes in der Mosskaw nicht böser folk als die Juden, es wirt auch böser nicht gewunscht, nur das man tzum Juden werde oder eines Judenn kindt sey« (BuEs, Aufzeichnungen des Dominikaners Martin Gruneweg, S. 910).

29 Vgl. Mikhail Dmitriev, What was not understood by Martin Gruneweg in the Orthodox Culture of Eastern Europe?, in: BuEs, Lebensweg, S. 213-239.

30 »Wen die Armenier auff diese reyze wegfertig sein, fasten sie etliche tage, auch eine gantze woche vor dem außtzuege, beichten, comunitzieren gleich goltte es ihnen tzum thotte. Alle mein tage habe ich auch erbarer, fromere, tzuchttigere geselschaft wieder gehört noch gesehn als sie nur auf diesem wege fueren, sowol untter den jungen als altten « (BuEs, Aufzeichnungen des Dominikaners Martin Gruneweg, S. 687).

31 Vgl. ebd., S. 762.

32 Vgl. ebd., S. 841.

33 Vgl. ebd., S. 1027.

34 Vgl. ebd., S. 718.

35 Vgl. ebd., S. 744.

36 Vgl. ebd., S. 745. Die Reisenden nahmen die Speisen von den Gräbern. »Es war sich sonst nichtes tzubeförchten, nur das man die schuesseln und kruege tzufriede lies. Auch haltte ich, das sies den reyzenden nicht wehren und billiger guenen den den Schlangen« (Ebd., S. 745).

37 Es verwundert sehr, dass ein Mensch, der aus persönlicher Erfahrung so viel Gutes über die Menschen im Osmanischen Reich zu berichten wusste, wieder in seine mitteleuropäische Umgebung zurückgekehrt, sich solcher Propagandasprache bediente. In historischem Zusammen- 
hob er Vielweiberei und Homosexualität hervor ${ }^{38}$. Hier, in der eigentlichen Fremde, verwischten sich die Unterschiede der christlichen Konfessionen; Gruneweg suchte Gemeinsamkeiten zwischen katholischer und orthodoxer Kirche, und sei es nur die Kirchensprache, welche die Gläubigen nicht verstanden ${ }^{39}$. Hier standen sich Islam und Christentum immer wieder frontal gegenüber ${ }^{40}$. Individuelle Krisenbewältigungen lassen die existentielle Angst des Einzelnen greifen; die Gemeinschaft der Christen half sich im Osmanischen Reich gegenseitig, der Gedanke der respublica christiana war in diesem Kontext noch lebendig ${ }^{41}$. Als sich Gruneweg allein in einer Notsituation sah, nahm er sich daher vor, »blinder weyze umetzulauffen bis ich etwan tzu Christen keme $\ll^{42}$.

Wie diese Eindrücke den Zwanzigjährigen im Inneren aufwühlten, erfahren wir eigentlich nicht. Hatten die in Südosteuropa tätigen katholischen Missionare ihn >bearbeitet ${ }^{43}$ ? Nachdem er auf seiner fünften Orientreise wohl Opfer einer Vergewaltigung durch Bedros, den Sohn eines armenischen Kaufmanns, geworden war, erkrankte Gruneweg in Edirne schwer. In dieser Situation wählte er, da kein Lutheraner, Zwinglianer oder Calvinist in der Nähe war, zwischen einem italienischen, griechischen oder armenischen Geistlichen den Letzteren als Beichtvater, der ihm die Kommunion gab ${ }^{44}$. Visionen während seiner Krankheit zeigten ihm das Jüngste Gericht, ließen ihn Höllenqualen erleben und führten ihn zur Grabeskirche nach Jerusalem ${ }^{45}$.

hang wurden etwa die »verflucheten heyden« erwähnt oder Sultan Mehmet III. als »der 15. lesterrer Gottes« präsentiert (Ebd., S. 758). Vgl. zuletzt John Viktor ToLAN, Sons of Ishmael. Muslims through European eyes in the Middle Ages, Gainesville 2008.

38 Almut Bues, »die umschnupferten unsere wagen« - Alltagskontakte des Handelsgesellen Martin Gruneweg im Spannungsfeld zwischen Orient und Okzident, in: Marlene Kurz/Martin Scheutz/Karl Vocelka (Hg.), Das Osmanische Reich und die Habsburgermonarchie in der Neuzeit, Wien 2005, S. 427-447.

39 Vgl. Bues, Aufzeichnungen des Dominikaners Martin Gruneweg, S. 704.

40 Siehe Dariusz KoŁodzIEJczyk, Islam a chrześcijaństwo: obcowanie wyznań w bałkańskich prowincjach Porty Otomańskiej w XVI-XVII wieku, in: Marian DYGo/Stanisław Gawlas/Hieronym Grala (Hg.), Stosunki międzywyznaniowe w Europie Środkowej i Wschodniej w XIV-XVII wieku, Warszawa 2002, S. 95-103.

41 Der armenische Karawanenführer zahlte zum Beispiel für die Freilassung eines Griechen und zweier Russen, die wegen Alkoholkonsums von den Türken gefangen genommen worden waren, »etliche hundert hasper«, vgl. BuEs, Aufzeichnungen des Dominikaners Martin Gruneweg, S. 1046.

42 Ebd., S. 771.

43 Vgl. István György Tóтн, The Missionary and the Devil. Ways of Conversion in Catholic Missions in Hungary, in: Eszter Andor/István György Tóтн (Hg.), Frontiers of Faith. Religious Exchange and the Constitution of Religious Identities 1400-1750, Budapest 2001, S. 79-87; ders., Missionaries as cultural intermediaries in religious borderlands. Habsburg Hungary and Ottoman Hungary in the seventeenth century, in: Heinz Schilling/István György Tóth (Hg.), Cultural Exchange in Early Modern Europe. Bd. 1: Religion and Cultural Exchange in Europe, 1400-1700, Cambridge 2006, S. 88-108.

44 Vgl. Bues, Aufzeichnungen des Dominikaners Martin Gruneweg, S. 991.

45 Näheres bei Maria CRĂCIUn, Conversion in the Confessional Age. The Case of Martin Gruneweg, in: Bues, Lebensweg, S. 241-261. 
Durch diese (Wahn-)Vorstellungen reifte bei dem Lutheraner in armenischer Umgebung in einem muslimischen Land der Entschluss zur Konversion zum Katholizismus, den Gruneweg selbst auf den 15. Juni 1586 datierte ${ }^{46}$. Gott, so stellte er es in seinen Aufzeichnungen dar, versuchte ihn in der Ferne, schenkte ihm aber ein neues, reines (gesundes) Leben ${ }^{47}$; er zitierte dazu die Psalmen 81,8; 71,20; 94,17 sowie 10,16. Nach dieser Entrückung soll Gruneweg, wie ihm berichtet wurde, »tzwe stunden lang mitt tzunge und henden $\aleph^{48}$ gepredigt haben und von allen verstanden worden sein. Diese enge Beziehung zwischen Imagination, Predigen und Konversion ist typisch für die Zeit nach dem Konzil von Trient ${ }^{49}$. Hierbei war ihm wohl Vincenz Ferrer Vorbild, was als ein erster Hinweis auf den Predigerorden dienen mag.

Wenig später, am 28. Juni 1586, gelobte Gruneweg in Edirne seinen Eintritt in den Dominikanerorden ${ }^{50}$, der durch seine strikte Haltung Andersgläubigen gegenüber bekannt war. Sein Weg in den Orden verlief nicht geradlinig, er »verhandelte« noch zwei Jahre mit Gott und wiederholte mehrmals sein Gelöbnis des Ordenseintritts, bis ihn die Neujahrspredigt 1588 von Piotr Skarga in der Barbarakirche in Krakau wachrief ${ }^{51}$. Im folgenden Sommer unternahm er eine Wallfahrt nach Tschenstochau; dieses Gemeinschaftserlebnis bestärkte ihn in seinem Entschluss. Er wollte nicht länger als Individuum, sondern in einer Gemeinschaft Gott nahe sein; insofern entschloss er sich nicht nur zur Konversion, sondern auch zum Ordenseintritt. Er entschied sich sozusagen für eine Radikallösung und glaubte auf diese Weise nach dem Zustand extremer Spannungen in einen Zustand der Stabilität und des Gleichgewichts überführt zu werden ${ }^{52}$. Es ist davon auszugehen, dass hierzu nicht nur religiöse, sondern auch rein weltliche Gründe eine Rolle gespielt haben. Die armenischen Freunde wollten den nun sechsundzwanzigjährigen erfahrenen Gehilfen als Geschäftspartner aufnehmen, wozu aber eine standesmäßige Heirat gehörte. Aus diesem sozialen Druck heraus sah der zur Homosexualität neigende Gruneweg den einzigen Ausweg im Klosterleben.

Gruneweg beschreibt seine individuelle Bekehrung, die wohl ohne Druck von außen zustande kam. Schon vor der Konversion dachte er in »katho-

$46 \gg$ Am 15. Junii [...] kam ich recht tzurr altten klaube, von welcher ich durch unfernunft der meinigen geriessen was. Unde erweinte mich von Gotte meine unfruchtbare mutter in fremdem lande unnd nicht tzuhause (BuEs, Aufzeichnungen des Dominikaners Martin Gruneweg, S. 986f.).

47 Vgl. ebd., S. 1011f.

48 Ebd., S. 1005.

49 Vgl. Massimo Leone, Religious Conversion and Identity. The semiotic analysis of texts, London 2004, S. 11-52.

50 Vgl. Bues, Aufzeichnungen des Dominikaners Martin Gruneweg, S. 1027.

51 Vgl. ebd., S. 1097.

52 Vgl. William James, The Varieties of Religious Experience. A Study in Human Nature, New York 1958, S. 198f. 
lischen « Kategorien; dies ist wohl kaum nur auf die Situation des (geistlichen) Autors zurückzuführen. In seiner Jugend erlebte er eine bikonfessionelle Kirche, in der die Heiligenaltäre geblieben waren. Am ersten Schultag hatte der Junge eine Erscheinung am Katharinenaltar ${ }^{53}$, in Bromberg besuchte er mit seinen Gasteltern die Gottesdienste in der Kirche der Bernhardiner ${ }^{54}$, in Warschau beobachtete er die Königin in der Johanniskirche ${ }^{55}$, in Lemberg wohnte er gegenüber der Dominikanerkirche und muss mit den Patres Kontakt gehabt haben ${ }^{56}$. Eine Kategorisierung in entweder evangelisch oder katholisch lässt seine Gedankenwelt nicht erkennen; religiöse Werte und Ideen wie auch das gemeinsame christliche Erbe wurden von Menschen unterschiedlichen Glaubens geteilt ${ }^{57}$. Dass das fremdkonfessionelle Umfeld ihn auf Dauer beeinflusste, ist anzunehmen, aber nicht explizit zu beweisen. Seine persönliche Lebensgeschichte liegt jedenfalls durchaus in der Tendenz seiner Zeit.

Die Zeit nach dem Abschluss des Konzils von Trient brachte in PolenLitauen weitreichende Veränderungen mit sich. In vielen Familien starb die sich in der Mitte des 16. Jahrhunderts zum evangelischen Glauben bekennende Vätergeneration; die nachfolgende Generation der Söhne kehrte zum Katholizismus zurück ${ }^{58}$. Die Einführung des Gregorianischen Kalenders hatte besonders in den Kresy, d.h. den östlichen Gebieten der Rzeczpospolita, erhebliche Auswirkungen für das Zusammenleben der Konfessionen und erzeugte Gehorsam (der römisch-katholischen Kirche nach) und Ungehorsam ${ }^{59}$, was immer wieder zu sichtbaren Gegensätzen führen sollte. Die beginnende Polonisierung zu Ende des 16. Jahrhunderts brachte daher - wie die Kirchenunionen zeigen - auch eine Zuwendung zum Katholizismus mit sich.

Der Übergang aus einer Verteidigungsposition zur Offensive gelang den Orden in den achtziger Jahren; den Kampf um die Gunst der Bevölkerung gewannen oft die Dominikaner. Ein äußeres Zeichen war beispielsweise die Wiederbelebung oder Neuerrichtung der Rosenkranzbruderschaften ${ }^{60}$.

53 Vgl. Bues, Aufzeichnungen des Dominikaners Martin Gruneweg, S. 379.

54 Vgl. ebd., S. 471.

55 Vgl. ebd., S. 585.

56 Vgl. ebd., S. 1017.

57 Vgl. Benjamin J. Kaplan, Divided by Faith. Religious conflict and the practice of toleration in early modern Europe, Cambridge 2007, S. 261.

58 Ein Beispiel hierfür ist die Familie der Radziwiłł, die sich in einen calvinistischen und einen katholischen Zweig spaltete. Damit unterschied sich auch die Erziehung, vgl. Marian СнаснаJ, Zagraniczna edukacja Radziwiłłów od początku XVI do połowy XVII wieku, Lublin 1995.

$59 \gg$... die Griechenn fasten auch noch weitter tzu ihrem Petter nach ihrem ungehorsamen kalender« (BuEs, Aufzeichnungen des Dominikaners Martin Gruneweg, S. 1029).

60 In Krakau traten zwischen 1585 und 1605 3.270 Menschen der Bruderschaft bei, in Lemberg waren es zwischen 1575 und 1596 3.990. Vgl. Stanisław LitaK, Bractwa religijne w Polsce przedrozbiorowej XIII-XVIII wiek. Rozwój i problematyka, in: PrzHi 88 (1997), S. 499-523; Andrzej BRUŹDZIŃSKI, Bractwa religijne w siedemnastowiecznym Krakowie.Zarys problematyki, 
Gleichzeitig mehrten sich die Ordenseintritte. Hatte es in der ersten Hälfte des 16. Jahrhunderts 83 Professe gegeben, so verdreifachte sich deren Zahl in der zweiten Hälfte. Der größte Anstieg fand dabei von den achtziger auf die neunziger Jahre (von 42 auf 72) und zum ersten Jahrzehnt des 17. Jahrhunderts statt ${ }^{61}$. Viele der für die Gegenreformation tätigen Brüder waren Konvertiten wie Abraham Bzowski, Severin Lubomlczyk oder eben Martin Gruneweg.

Als Konvertit zeigte er - wie zu erwarten - keinerlei Verständnis mehr für das Luthertum; nicht nur ein Bruch mit der eigenen Vergangenheit, sondern auch deren negative Stigmatisierung folgten ${ }^{62}$. Den Krieg Danzigs gegen König Stefan Báthory im Jahre 1577 interpretierte er nun als Strafe Gottes ${ }^{63}$. Der Ordensmann hatte es psychisch zu verkraften, dass Mutter und Schwester sowie der Rest seiner Familie lutherisch blieben, wo er sie »wegen irer ketzerye in großer gefehr wuste ${ }^{64}{ }^{64}$ Eigentlich war die Mutter damit schon für den Sohn gestorben, er durfte auch nach ihrem Tod keine Seelenmesse für sie lesen ${ }^{65}$. Die Wut des Konvertiten richtete sich besonders gegen Luther. Er ging in seinen Gedanken so weit, dass »aufs letzte ist grösser sunde ketzereye dan unkeußheit $\ll^{66}$, und er setzte den Namen Luthers mit dem Tier in Offenbarung 13,18 in Verbindung ${ }^{67}$. Grunewegs Urteil über seine alte Konfession ist auch aus der Beschreibung evangelischer Kirchen wie der Pfarre in Łańcut herauszuhören,

welche auch gemewrt ist und die Ketzer Lutherißer Sekte darine leutten. Da waren nur fier wende und in iglichem winckel elende, wieder bield noch schield, nur eittel bancken, und gut, das nicht bette ${ }^{68}$.

in: Włodzimierz BIELAK/Stanisław Tylus (Hg.), Historia świadectwem czasów. Festschrift Marek Tomasz Zahajkiewicz, Lublin 2006, S. 116-120.

61 Vgl. Henryk GAPSKI, Profesi dominikańscy konwentu krakowskiego w latach 1509-1650 (na postawie księgi profesji), in: Jerzy KŁoczowski (Hg.), Studia nad historią dominikanów w Polsce, Bd. 1, Warszawa 1975, S. 647-686, hier: S. 654f.

62 Vgl. Detlef Pollak, Überlegungen zum Begriff von Phänomenen der Konversion aus religionssoziologischer Perspektive, in: Ute Lotz-Heumann/Jan F. Missfelder/Matthias Pohlig (Hg.), Konversion und Konfession in der Frühen Neuzeit, Göttingen 2007, S. 33-55, hier: S. 51.

63 Z.B. Bues, Aufzeichnungen des Dominikaners Martin Gruneweg, S. 512.

64 Ebd., S. 1198.

$65 \gg$ Am 4. Februarii [1594 AB] las ich das erste mal messe auf S. Peters neuen Merters altare, eine selmesse vor verstorbne eltern, den solche andacht helt unser Orden an diesem tage, wiewol sichs mir leidr Gotts nicht gebuert, vor meine elttern tzubitten, dieweile sie auser der kirche gestorben sein « (Ebd., S. 1199f.). Aus konfessionellen Gründen hatte er auch den Kontakt zu seinen ehemaligen armenischen Bekannten abzubrechen, obwohl sie alle direkt bei dem Dominikanerkloster in Lemberg wohnten (Ebd., S. 1192).

66 Ebd., S. 1148.

67 Vgl. ebd., S. 1109; Heiko A. Oberman, Luther. Man between God and the Devil, New Haven 1989, S. 1-15.

68 Bues, Aufzeichnungen des Dominikaners Martin Gruneweg, S. 1282. 
Mit seiner Konversion verbunden war der Versuch einer Rückkehr zum traditionellen, vortridentinischen Katholizismus; die alte Einheit der Kirche wurde hochgehalten ${ }^{69}$. Glaubte Gruneweg, im Orden seinen seelischen Frieden gefunden zu haben, so sollte er sich vorerst täuschen, denn die Zeiten ließen ihn sich in Parteienkämpfe verstricken. Erscheinungen wie Propaganda, Reorganisation des Bildungswesens, Ausschluss Andersgläubiger sowie die Umbildung der Institutionen führten zum Ende des 16. Jahrhunderts nicht nur zu konfessioneller Abgrenzung ${ }^{70}$, sondern zeigten auch Auswirkungen innerhalb der Denominationen oder auch Orden ${ }^{71}$. Ein Teil der Ordensbrüder in Lemberg verfolgte seit Beginn der neunziger Jahre eine Abtrennung der ruthenischen von der polnischen Dominikanerprovinz. Hatte Gruneweg anfangs aktiv auf Seiten der Separatisten gestanden, so wechselte er nach seiner Flucht nach Rom im Sommer 1602 die Provinz ${ }^{72}$. Die Reise zur »Mutterstadt « der römisch-katholischen Kirche ließ ihn, so stellt er es jedenfalls dar, endgültig seinen Platz im polnischen System der Dominikaner finden ${ }^{73}$. Nun konnte er als polnischer katholischer Geistlicher seiner langjährigen hybriden Identität entkommen; er bewegte sich in einem anerkannten Milieu unter seinesgleichen: Gott war im seit alten Zeiten bewährten Glauben bei und mit ihm, was er jetzt auch anderen überzeugend vermitteln konnte. Nach langer Zeit einer inneren Labilität hatte er jetzt zu seinem inneren Gleichgewicht zurückgefunden. Seine Mobilität stellte Gruneweg nun in den Dienst des Ordens; er ist nachweislich in Ratibor, Bochnia, Krakau, Płock, Breslau und Warschau (zumindest bis 1615) zu finden.

Der interessante Lebenslauf und die innere Entwicklung von Martin Gruneweg bieten, wie hier nur angedeutet werden konnte, ein weites Feld gerade für die Frage von interreligiösen Kontakten, wobei neben religiösen auch ethnische, soziale, wirtschaftliche und geschlechtsspezifische Aspekte eine Rolle spielen.

Angesichts des Fehlens mächtiger Territorialfürsten fiel in der Rzeczpospolita die Entscheidung über die Konfession weitgehend den Adelsfamilien zu. Der Adel hatte 1555, also noch vor dem Abschluss des Augsburger Religionsfriedens, auf dem Reichstag in Petrikau das Privileg erhalten, in kirch-

$69 \gg$ Den es ist di gröste gefehr, von der heiligen Kirche tzur seite stehn und sich sondern von der herde des Herren und nicht tzusein in einer heiligen, gemeinen Apostolischen Kirche, one welche nicht ist wieder glaube, hofnunge, liebe oder selicheit, nirgends, niergents « (Ebd., S. 1110).

70 Vgl. Richard Alfred Muller, Post-Reformation reformed dogmatics. The Rise and the development of reformed orthodoxy, ca. 1520 to ca. 1725, Grand Rapids 22003.

71 Vgl. Wolfgang SEIBICH, Gegenreformation als Restauration. Die restaurativen Bemühungen der alten Orden im Deutschen Reich von 1580 bis 1648, Münster 1991.

72 Vgl. Almut Bues, Ein Bruderzwist im Hause des Dominikus, in: Bues, Lebensweg, S. 281-299.

73 Vgl. Jerzy KŁoczowski, Polska prowincja dominikańska w Średniowieczu i Rzeczypospolitej obojga (wielu) narodów, Poznań 2008. 
lichen Dingen selbständig zu entscheiden ${ }^{74}$. Im Großfürstentum Litauen hatten schon seit langer Zeit orthodoxe und armenische Untertanen gelebt; die römisch-katholische Kirche hatte hier keinen Absolutheitsanspruch geltend machen können. Das verstärkte Eindringen der (evangelischen) Reformation um die Mitte des 16. Jahrhunderts - die Stände im königlichen Preußen bekannten sich 1556 zur Reformation -, also in Zeiten einer weitgehenden Toleranz und eines religiösen Nebeneinanders, verband sich mit dem Bestreben nach Ausgleich und Friedenswahrung, was wiederum die Politik beeinflusste. Dieser Kontext ist für Grunewegs Jugend in Danzig wichtig; wäre er zwanzig Jahre später geboren, hätte er eine andere religiöse Umwelt erlebt. Die Konfessionalisierung schuf, wie im Deutschen Reich, neue, aber nicht unbedingt territorialstaatliche Zusammengehörigkeitsgefühle; es bildeten sich konfessionelle Schwerpunkte heraus. Gotthold Rhode zählte für die Rzeczpospolita in dieser Zeit zehn verschiedene Religionsgemeinschaften $^{75}$.

Grunewegs Warschauer Aufenthalt fiel in die Zeit der Interregna und dem damit verbundenen Bedeutungszuwachs dieser Stadt. Die Warschauer Konföderation von 1573 sicherte den Adligen, den dissidentes de religione, die völlige Bekenntnisfreiheit, welche auch in die Wahlkapitulationen der Articuli Henriciani aufgenommen wurde. Gruneweg hatte das Glück, bei seinem ersten Aufenthalt in dieser Stadt von 1579 bis 1582 ein weitgehend friedliches Zusammenleben der Konfessionen und Ethnien zu beobachten. In Warschau sollte sich das religiöse Klima für die evangelischen, meist aus dem Deutschen Reich stammenden Kaufleute im 17. Jahrhundert ändern.

An der Kreuzung mehrerer Handelswege gelegen, lebte Lemberg seit alten Zeiten vom Handel. Hier erlebte Gruneweg in den Jahren 1582 bis 1602 die Blütezeit der dortigen armenischen Kolonie. Bis in das 17. Jahrhundert dominierten die Armenier den Fernhandel mit Luxusgütern; Gruneweg erhielt die Möglichkeit, mit ihnen zu arbeiten und unter ihnen zu leben und somit Informationen aus erster Hand zu sammeln. Neben religiösen und ethnischen spielten hier auch wirtschaftliche Aspekte eine Rolle. Aufkeimende Konflikte innerhalb der Stadt waren eher wirtschaftlich als religiös motiviert. Alle nationes - Armenier, Katholiken, Orthodoxe und Juden - haben in Wirtschaftsunternehmen kooperiert und bei gemeinsamen Verpflichtungen dem Gemeinwesen gegenüber zusammengearbeitet.

Die Menschen dieser Zeit, so ist den Aufzeichnungen Grunewegs zu entnehmen, sahen die Konfessionszugehörigkeit nicht als durch die Geburt ge-

74 In seinen Forderungen nach Freiheit schloß der Adel die Religionsfreiheit mit ein. Jan Tadeusz Lubomirski (Hg.), Dzienniki sejmów walnych koronnych za panowania Zygmunta Augusta króla polskiego, W. X. Litewskiego 1555 i 1558 r. w Piotrkowie złożonych, Kraków 1869, S. 17-31.

75 Gotthold Rhode, Geschichte Polens. Ein Überblick, Darmstadt ${ }^{3} 1980$, S. 245. 
geben an, sie entschieden sich bewusst und individuell für eine Konfession; dieses Konfessionsbekenntnis musste dabei nicht für das ganze Leben gelten. Der litauische Kanzler Lew Sapieha (1557-1633) etwa wechselte zwischen 1570 und 1586 zu vier verschiedenen Konfessionen ${ }^{76}$.

Konversionen waren also etwas Alltägliches und mit keinem >Makek verbunden. Viele höhere (gerade kirchliche) Positionen bekleideten Konvertiten, so war der Erzbischof von Lemberg Jan Dymitr Solikowski (1583-1603) ein lutherischer Konvertit ebenso wie der später an der Kurie tätige Kirchenhistoriker Abraham Bzowski (1567-1637). Der Promotor der Kanonisation des heiligen Hyazinth Odrowąż Severinus aus Luboml (1532-1612), war vor seiner Konversion zum Katholizismus Jude, der Dominikaner Hyacinthus Iudae (ca. 1572-1605) zuvor Rabbiner. Gerade Konvertiten dienten ihrem neu gefundenen Glauben mit Eifer.

Um wählen zu können, muss ein Informationsmarkt vorhanden sein, der sich wiederum nur bei einem breiten Interesse entwickeln kann. Die durch den Buchdruck ermöglichte Kleinpublizistik wie Flugschriften und Flugblätter unterstützte die reformatorische Öffentlichkeit ${ }^{77}$. Die zweite Hälfte des 16. Jahrhunderts ist auch in Polen durch ein Anschwellen der Publizistik gekennzeichnet, sei es im Zuge der Reformation, der Interregna oder der Beschlüsse des Tridentinums ${ }^{78}$. Gruneweg selbst ist ein Beispiel für die Schreibkultur der Zeit.

Sein Leben zur richtigen Zeit am richtigen Ort zeigt die Möglichkeiten, die es während dieser - im Rückblick - schmalen Zeitspanne in der polnischlitauischen Adelsrepublik gegeben hat und die er zu nutzen wusste. Man konnte die Konfessionen wechseln, und es gab auch Wege einer Assimilierung. Gruneweg fühlte sich nicht nur in die armenische Gemeinschaft aufgenommen, er war es auch, wie der Vorschlag zur Heirat mit einer Armenierin beweist. Die Armenier in Lemberg wiederum begannen in dieser Zeit eine vorsichtige Polonisierung. Gruneweg trat zusammen mit seiner Konvertierung voll zum Polentum über, das verdeutlicht seine wiederholte Weigerung, auf Deutsch zu predigen ${ }^{79}$. Dazu wechselte er vom weltlichen in den geistlichen Stand. Seine Konversion besteht also aus einem Bündel

76 Henryk Lulewicz, Art. Sapieha, Lew, in: Polski Słownik Biograficzny 35 (1994), S. 84-104; Natalia JAKovenko, The Conversion of the Ukrainian Nobility - the Socio-Cultural Aspect, in: Hubert Łaszkiewicz (Hg.), Churches and Confessions in East Central Europe in Early Modern Times, Lublin 1999, S. 78-85, hier: S. 79.

77 Vgl. für das Deutsche Reich Johannes Burkhardt, Das Reformationsjahrhundert. Deutsche Geschichte zwischen Medienrevolution und Institutionenbildung 1517-1617, Stuttgart 2002, S. 56-60.

78 Konrad Zawadzki, Prasa ulotna za Zygmunta III, Warszawa 1997; Alodia KaweckA-GrYCzowa/Krystyna Korotajowa (Hg.), Drukarze dawnej Polski od XV do XVIII wieku, 4 Bde., Wrocław 1960-1977.

79 Z.B. Bues, Aufzeichnungen des Dominikaners Martin Gruneweg, S. 803. 
von mindestens drei Komponenten: religiös, ethnisch, sozial und wohl auch geschlechtsspezifisch (seine Homosexualität). Welcher dieser Aspekte die ausschlaggebende Rolle gespielt hat, ist aus Grunewegs Aufzeichnungen nicht zu erkennen.

Während die Identitätsbildung in Europa im 16. Jahrhundert allgemein über Religion und Bildung erfolgte, kam es in der polnisch-litauischen Adelsrepublik infolge der polyzentrischen und egalitären Struktur zu einer Übereinkunft, religiöse Konflikte nicht mit Gewalt lösen zu wollen. Die föderal strukturierte Gesamtstaatlichkeit der Rzeczpospolita ließ Mehrfachbindungen ihrer Mitglieder zu. Dabei gab es unterschiedliche Ebenen und Schichtungen; die Anerkennung der Verschiedenheit bei gemeinsamer Konsensfähigkeit war eine der Voraussetzungen eines Neben- und Miteinanders, das Überschneiden mehrfacher Loyalitäten war möglich.

Kollektive Mentalitäten und regionale Loyalität lagen unter dem Niveau der übergeordneten politischen Einheit, politische Transformationsprozesse konnten jederzeit Veränderungen herbeiführen. Die aktuelle Lage war nicht statisch, sondern man entschied sich für das Staatsgebilde, mit dessen Verfassung man am meisten sympathisierte. Die Anziehungskraft des polnischen Föderationsmodells blieb das ganze 17. Jahrhundert hindurch ungebrochen.

Die Lösung der politischen Herrschaft von der zentralen Funktion der Kirche und des Königs ließ in der Rzeczpospolita im 16. Jahrhundert die Inklusion aller Adligen, also auch die der Peripherie, zu; es gelang, die regionalen Besonderheiten identitätsstiftend zu integrieren. Die machtpolitische Schwäche des Zentrums ersparte Anpassungskonflikte, wie sie in anderen europäischen Ländern der Zeit zu finden sind. Unterschiedliche Sprache und Kultur, verschiedene Zeitrechnungen, konfessionelle Differenzen: all das bildete kein Hindernis einer Kommunikation und eines Zusammenlebens in der Rzeczpospolita. Konfessionsgrenzen hatten sich noch nicht zu Kulturgrenzen verfestigt ${ }^{80}$.

Gerade in den Kresy zeigen sich zahlreiche Variationsmöglichkeiten, welche durch die Kirchenunionen von Brest 1596 und Lemberg 1630 noch erweitert wurden. Man konnte Armenier und armenisch-apostolisch oder Ruthene und Orthodox, aber auch Armenier/Ruthene und Unierter sein, eine Polonisierung war möglich. Die Konfessionszugehörigkeit zeigte auch Auswirkungen auf die Gerichtsbarkeit; bis in die Mitte des 17. Jahrhunderts bestand beispielsweise für Orthodoxe die Möglichkeit einer Appellation an den Patriarchen in Konstantinopel.

80 Vgl. David Tollet, Cohabitation, concurrence et conversion dans la Confédération polonolituanienne au tournant des XVIe et XVIIe siècles, in: Andor/Tóth, Frontiers of Faith, S. 67-78. 
Trotz der ethnischen und religiösen Differenzen ${ }^{81}$ entwickelte sich beim Adel ein gemeinsames politisches Bewusstsein, das der naród polityczny darstellte ${ }^{82}$. Es ist die »goldene Freiheit « (Stanisław Orzechowski), welche die Rechte aller Adligen, einschließlich der Glaubensfreiheit, zusammenfasste. Das Bewusstsein einer gemeinsamen Ethnogenese überwog die partikularen Interessen; man war beispielsweise »natione Polonus, gente Ruthenus, origine Judaeus«.

81 Bevölkerungsschätzungen gehen von $40 \%$ Polen, $20 \%$ Ruthenen, $15 \%$ Litauern, $10 \%$ Deutschen und $5 \%$ Juden aus: Alicja DyBKowska/Jan ŻARYN/Małgorzata Ż̇ArYN (Hg.), Polskie dzieje od czasów najdawniejszych do współczesności, Warszawa ${ }^{2} 1995$, S. 105.

82 Benedykt Zientara, Frühzeit der europäischen Nationen. Die Entstehung von Nationalbewußtsein im nachkarolingischen Europa, Osnabrück 1997, S. 20; Juliusz BARDACH, Od narodu politycznego do narodu etnicznego w Europie Środkowo-Wschodniej, in: Kultura i Społeczeństwo 37 (1993), S. 3-16. 


\title{
Gesine Carl \\ »Ich beschlos zu fliehen. \\ Aber wohin? das wust ich nicht«
}

\author{
Konversionen von Juden zum Christentum und \\ Mobilität im 17. und 18. Jahrhundert
}

\section{Einleitung}

»Ich beschlos zu fliehen. Aber wohin? das wust ich nicht«1. - Mit diesen Worten beschreibt der Konvertit Christian Salomon Duitsch eine Situation zu Beginn seines Konversionsprozesses, als seine Neigung zum Christentum in seinem Wohnort bekannt geworden war und er sich massiven Anfeindungen und Verfolgungsmaßnahmen durch seine jüdischen Noch-Glaubensgenossen ausgesetzt sah, bei denen er kurz zuvor noch als Rabbiner in hohem Ansehen gestanden hatte. Das Gefühl der Ziel- und Orientierungslosigkeit, das in diesem Zitat aus seiner Konversionserzählung zum Ausdruck kommt, sollte bei Duitsch in den folgenden Jahren immer wieder auf kommen. Bevor er im Juni 1767 in Amsterdam zum reformierten Glauben übertrat, hatte er zunächst eine äußerst entbehrungsreiche, jahrelange Odyssee durch halb Europa zu bewältigen, die ihn wiederholt an die Grenzen seiner physischen und psychischen Belastbarkeit brachte. Angesichts dieses Lebensweges verwundert es nicht, dass bereits im Titel seiner 1768 in Amsterdam erschienenen Konversionserzählung von raumbezogener Mobilität die Rede ist: Duitsch bezeichnet sich selbst als einen »Blinden Leiter Der Blinden $\ll^{2}$, der durch die »Bewunderns-Würdige Führung Gottes « auf »dem Wege und Pfaden, die er nicht kennte «, geleitet und schließlich »der Christlichen Reformirten Kirche einverleibet« wurde. Durch diese Gestaltung des Titels wird Gott als entscheidender Akteur in Duitschs Konversionsprozess in den Vordergrund gestellt, während Duitsch sich selbst eine passive Rolle zuschreibt. Dazu passt seine Selbstdarstellung als Blinder, der vor allem in unbekanntem Gelände

1 Christian Salomon Duitsch, Die Bewunderns-Würdige Führung Gottes Bey einem Blinden Leiter Der Blinden/auf dem Wege und Pfaden/die er nicht kennte/durch Christian Salomon Duitsch; ehemals Jüdischen Rabbiner/jetzo aber der Christlichen Reformirten Kirche einverleibet/aus der Holländischen Sprache in die Hochdeutsche übersetzet und vor demselben gedruckt, Amsterdam 1768, S. 52.

2 Die Selbstbezeichnung als ein »Blinder Leiter der Blinden« dürfte auf Mt 15,14 zurückgehen, wo Jesus sich entsprechend über die Pharisäer äußert: »Lasst sie, sie sind blinde Blindenführer! Wenn aber ein Blinder den andern führt, so fallen sie beide in die Grube«. 
auf kundige und hilfsbereite Wegweiser angewiesen ist. Im Titel der niederländischen Ausgabe seiner Konversionserzählung, die ebenfalls 1768 in Amsterdam publiziert wurde, hebt Duitsch zudem die lange Dauer seines Weges zum Christentum hervor, indem er von einem »sechsjährigen Umherirren « spricht ${ }^{3}$. Diesen Prozess des Glaubenswechsels beschreibt er als eine Wanderung »durch die Wüste dieser Welt « ${ }^{4}$, das heißt als einen beschwerlichen Weg, der phasenweise vielleicht sogar zum >Überlebenstraining<wurde.

Im Rahmen des vorliegenden Beitrags soll anhand der Schriften von Duitsch und anderer Konversionserzählungen näher untersucht werden, welche Rolle raumbezogene Mobilität im Konversionsprozess von Juden spielte, die im 17. und 18. Jahrhundert zum Christentum übertraten. Dabei geht es im Einzelnen um folgende Fragen: In welchen Situationen ist von Mobilität die Rede? Und wie wird diese Mobilität von den Schreibenden begründet und bewertet? Wird sie als freiwillig oder erzwungen dargestellt, als selbst- oder fremdgesteuert, als zielgerichtet oder ziellos? Oder ist eine solche eindeutige Zuordnung gar nicht möglich? Außerdem soll betrachtet werden, mit welchen sprachlichen Mitteln Mobilität zum Ausdruck gebracht wird.

Um den Glaubenswechsel und die damit verbundenen Erscheinungsformen raumbezogener Mobilität im Kontext der gesamten Lebensgeschichte besser verorten zu können, sollen auch die Lebensphase vor und nach dem Konversionsprozess in die Analyse einbezogen werden, sofern die Quellen darüber Aufschluss geben.

Als zentrale Quellengrundlage dient ein Korpus aus 36 Konversionserzählungen, in denen insgesamt 41 Konversionsfälle zur Darstellung gelangen. Ein Teil dieser Texte wurde von den Konvertitinnen und Konvertiten selbst verfasst, andere stammen aus der Feder eines Biographen oder es handelt sich um Mischformen. Der älteste dieser Konvertiten trat 1621 zum Christentum über, der jüngste empfing die Taufe im Jahre $1783^{5}$.

Bei der Arbeit mit Konversionserzählungen ist zu berücksichtigen, dass sie stets einen »rekonstruktiven Charakter« besitzen und damit automatisch durch die nachkonversionelle Sichtweise der eigenen Lebensgeschichte ge-

3 Christian Salomon Duitsch, De wonderlyke Leidinge Gods, omtrent eenen blinden Leidsman der Blinden, op Wegen en Paden, die hy niet en kende. Behelzende zyne Roepinge uit het duistere Jodendom; getrokken, en tot het Licht, dat in de Volheid des tyds, in de Waereld verscheenen is, overgebracht; na eene Ses-jaarige omzwervinge, door de Woestyne deezer Waereld. Ondervonden en in 't Hoogduitsch beschreven; door Christiaan Salomon Duitsch, geweezen Joodsche Rabby. Doch nu, door de Goddelyke Voorzienigheid Lidmaat der Gereformeerde Kerke. Tot Verheerlyking van Jehovah, in 't Nederduitsch laaten Vertaalen. Gedrukt voor den Autheur, Amsterdam 1768. - Übersetzung der niederländischen Textstellen durch die Autorin.

4 Auch diese Formulierung fehlt im Titel der deutschen Ausgabe.

5 Eine ausführlichere Auswertung dieser Quellen findet sich in: Gesine CARL, Zwischen zwei Welten? Übertritte von Juden zum Christentum im Spiegel von Konversionserzählungen des 17. und 18. Jahrhunderts, Hannover 2007. 
prägt sind ${ }^{6}$. Hinzu kommt, dass es sich bei der Konversionserzählung um eine »kommunikative Gattung « handelt, die spezifische Erzähl- und Argumentationsmuster sowie eine typische Metaphorik aufweist ${ }^{7}$. Dies bedeutet beispielsweise, dass bestimmte Konversionsmotive wie etwa Aufstiegsambitionen in dieser Quellengattung keine Erwähnung finden, da die Konversionserzählung im Normalfall ja gerade die Funktion haben soll, die Leserschaft davon zu überzeugen, dass der Glaubenswechsel ausschließlich aus religiösen Gründen erfolgt sei. Soziale Mobilität als Triebfeder für Konversionen ist anhand des vorliegenden Quellenmaterials daher kaum erschließbar, so dass sich auch über eventuelle Korrelationen von sozialer und raumbezogener Mobilität in der Regel nichts aussagen lässt.

\section{Die Lebensphase vor dem Konversionsprozess}

Die Schilderung der vorkonversionellen Lebensphase fällt in den meisten Quellen recht knapp aus; es werden jedoch einige Faktoren erkennbar, die bei den späteren Konvertiten eine höhere Mobilitätsbereitschaft ausgelöst haben könnten: So erwähnen zahlreiche Konvertiten den Besuch auswärtiger Schulen, der eine frühzeitige Trennung vom Elternhaus erforderlich machte. Einige Autoren berichten sogar über mehrfache Schulwechsel: Paulus Christian z.B. begann mit acht Jahren an der Synagoge im mährischen Austerlitz zu lernen und setzte seine Studien später in Prag und Lublin fort. AnschlieBend folgte ein zweijähriger Aufenthalt in Konstantinopel, wo er in die Geheimnisse der Kabbala eingeweiht wurde ${ }^{8}$. Auf diese Weise erfolgte nicht nur eine frühe Erziehung zur Selbständigkeit, sondern es wurden vermutlich auch Eigenschaften wie Flexibilität und Kommunikationsfähigkeit gefördert, was spätere Ortswechsel erleichtert haben dürfte. Für Henrietta Wegener und Friederica Paulusin hingegen war der Glaubenswechsel vermutlich ein besonderes Wagnis - beide stammten aus wohlhabenden Verhältnissen und mussten zur Verwirklichung ihrer Konversionsabsichten den Schutz und die

6 David A. Snow/Richard Machalek, The Sociology of Conversion, in: Annual Review of Sociology 10 (1984), S. 167-190, hier: S. 177.

7 Thomas Luckmann, Grundformen der gesellschaftlichen Vermittlung des Wissens. Kommunikative Gattungen, in: Friedhelm Neidhardt (Hg.), Kultur und Gesellschaft. René König, dem Begründer der Sonderhefte, zum 80. Geburtstag gewidmet, Opladen 1986, S. 191-211, hier: S. 205.

8 Paulus Christian, Malachiae Ben-Samuelis Im Jahr nach Christi geburt 1599. zu Brisch in Littaw gebornen und beschnittenen Juden / Nuhmehr aber in der Löblichen Stadt Braunschweig / Anno 1621. wiedergebornen und getaufften Christen. Pauli Christiani Eigen Bekandnüß/von seiner verstockten Blindheit und Wunderbahren gnedigen Erleuchtung und Bekehrung. Sampt Angehengtem Gebet umb bestendigkeit in der einmahl erkandten und bekanten Warheit, Braunschweig 1621, S. 2. 
materielle Sicherheit des Elternhauses aufgeben, ohne in irgendeiner Weise auf die Selbständigkeit vorbereitet worden zu sein'.

Doch auch jene Konvertiten, für die Reisen und Umzüge schon seit ihrer Kindheit zum Alltag gehörten, sahen sich mit dem Beginn ihres Konversionsprozesses vor neue Herausforderungen gestellt, da die raumbezogene Mobilität von da an unter völlig anderen Voraussetzungen stattfand: In der Lebensphase vor der Konversion erfolgte ein Ortswechsel im Normalfall zielgerichtet, das heißt man suchte (aus eigener Initiative oder auf Betreiben der Eltern) einen bestimmten, bewusst ausgewählten Schul- oder Studienort auf. Vor allem aber bewegte man sich innerhalb eines tragfähigen sozialen Netzes, da man, wie auch das folgende Zitat aus der Konversionserzählung Duitschs illustriert, damit rechnen konnte, als reisender Schüler oder Rabbiner überall Unterstützung zu finden: »Ueberhaupt sind die Juden gewohnt an die reisende Rabbinen/aus der maßen grose Liebe und Gütigkeit/und zwar mit äusserster Hochachtung zu beweisen $\aleph^{10}$. Diese große Hilfsbereitschaft gegenüber Gelehrten beziehungsweise Studierenden ist damit zu erklären, dass im Judentum seit der Zerstörung des Tempels das Studium der Opfergesetze als Ersatz für die Darbringung der Opfer gilt. Spenden, die zumindest Einzelnen die Möglichkeit geben, sich ausschließlich religiösen Studien zu widmen, werden daher als besonders verdienstvoll angesehen ${ }^{11}$. Sobald man sich jedoch offen zu seinen Konversionsabsichten bekannte, fiel man automatisch aus diesem innerjüdischen Sozialsystem heraus, was unter Umständen existenzbedrohende Folgen haben konnte. Es verwundert daher nicht, dass der finanziell mittellose Duitsch nach der Flucht aus seinem Wohnort zunächst nach außen hin weiter als Jude lebte, bis sich seine Neigung zum Christentum so gefestigt hatte, dass er sich um die Aufnahme als Taufkandidat bemühen und damit seinen Lebensunterhalt auf andere Weise sichern konnte ${ }^{12}$.

9 Auszug aus: Johann David Cube, Joh. Dav. Cube, Predigers zu Berlin, Reden, welche bey Gelegenheit der Taufe einer gebohrnen Jüdin am 12 Sonnt. nach Trin. 1765 sind gehalten worden, nebst einem Anhange, in: Nachricht von der Ausbreitung der christl. Religion unter dem jüdischen Volke durch einzelne Judenbekehrungen, in: NAHE oder Sammlung zu den neuesten Kirchengeschichten 10 (1771), Th. 75, S. 320-344, hier: S. 321 und Laur. Herold, Gütgen Steinhardin, einer jungen jüdischen Tochter, nun aber nach der durch Gottes Gnade mit Oberherrl. Erlaubniß den 25. Januar 1775. in der Kirche zu den Barfüssern in Nürnberg erlangten heiligen Taufe Friederica, Elisabetha, Maria, Salome, Agnes, Margaretha Paulusin, größtentheils selbst gefertigte Lebensgeschichte und Glaubensbekenntniß zu christlicher Erbauung vorgelegt von dem Täufer Diac. Laur. Herold, in: Justus Israel BEyER (Hg.), Fortgesetzte Nachricht von der zum Heil der Juden errichteten Anstalt, nebst den Auszügen aus den Tagebüchern der reisenden Mitarbeiter. Erstes Stück, herausgegeben von Justus Israel Beyer, Pastor zu St. Cyriaci et Antonii, der St. Moritzkirche Adiunctus, des Königl. Allmosen-Collegii Assessor, und des Orientalischen Instituti Iudaici Director, Halle 1777, S. 43-78, hier: S. 43.

10 Duitsch, Bewunderns-Würdige Führung Gottes, S. 65.

11 Vgl. Günter Stemberger, Jüdische Religion, München 21996, S. 49.

12 Ebd, S. 79. 
Weitere Faktoren, die für die Mobilitätsbereitschaft relevant zu sein scheinen, sind der Familienstand und das Alter: Mindestens 20 der hier betrachteten Konvertiten waren ledig, was darauf hindeuten könnte, dass sich ein unverheirateter Mensch leichter zur Konversion entschloss, da er noch weitgehend unabhängig war und die Interessen von Ehepartner(in) und ggf. Kindern nicht mit berücksichtigen musste. Paulusin erweist sich damit erneut als Ausnahmeerscheinung, da sie sich kurz vor der Hochzeit noch entschied, ihrer Neigung zum Christentum zu folgen und ein tragfähiges soziales Netz gegen eine zunächst sehr unsichere Zukunft einzutauschen ${ }^{13}$. 16 Konvertiten ließen sich im Alter von 21 bis 30 Jahren taufen und damit in einer Lebensphase, in der sie noch relativ gute Chancen hatten, nach der Konversion einen anderen beruflichen Weg einzuschlagen, sich ein neues soziales Umfeld aufzubauen und sich mit den kulturellen Normen ihrer neuen Umgebung vertraut zu machen. Für einen älteren Menschen dürfte dieser Prozess der Neuorientierung und Anpassung erheblich schwieriger gewesen sein.

\section{Der Konversionsprozess}

Als Auslöser des Konversionsprozesses wird in zahlreichen Quellen die intensive Auseinandersetzung mit der Herkunftsreligion genannt, die zur Entdeckung augenscheinlicher Widersprüche und dadurch zu Zweifeln geführt habe. Bei diesem oft jahrelangen, kritisch reflektierenden Studium der Thora und des Talmud ging es jedoch keineswegs von vornherein darum, die eigene Religion auf den Prüfstand zu stellen, vielmehr wurden die aufkommenden Zweifel eher als unerwünschter und erschreckender »Nebeneffekt « erlebt ${ }^{14}$. Am Beginn des Konversionsprozesses stand damit in vielen Fällen eine andere, nicht raumbezogene Art von Mobilität, die Claus J. Tully und Dirk Baier folgendermaßen charakterisieren: »Mobilisierung bedeutet ein In-GangSetzen, das mit dem Hinterfragen beginnt und in eine Neubildung führen kann. Mobilisierung ist somit Auflösung, Flexibilisierung und Pluralisierung zugleich ${ }^{15}$.

13 Herold, Gütgen Steinhardin, S. 46.

14 Vgl. u.a. Friederich Christian Kосн, Sieg der Wahrheit über die Vorurtheile des heutigen Judenthums und dessen Vertheidigers in der Person des nunmehrigen Christen Ernst August Wilhelm Christian Friederici. Nebst einem Anhange von der Größe des Geistes des weyland Durchlauchtigen Fürsten und Herrn, Herrn August Wilhelm, Fürsten zu Hohenlohe, Grafen von Gleichen etc. herausgegeben von M. Friederich Christian Koch, Pastor der Kirche zu S. Trinitatis in Ohrdruff, Hamburg ${ }^{3} 1769$, S. 18.

15 Claus J. Tully/Dirk Baier, Mobiler Alltag. Mobilität zwischen Option und Zwang. Vom Zusammenspiel biographischer Motive und sozialer Vorgaben, Wiesbaden 2006, S. 12. 
Diese »geistige Beweglichkeit « ${ }^{16}$ konnte auch durch Gespräche mit Christen ausgelöst werden, die ebenfalls in vielen Quellen Erwähnung finden. Manchmal wirkten beide Faktoren zusammen, da die zukünftigen Konvertiten einerseits durch die beginnenden Zweifel am Judentum für die Tröstungen und Verheißungen eines Christen empfänglich wurden und andererseits der Austausch mit einem Christen dazu führte, dass sie sich mit ihrer wachsenden inneren Unruhe bewusst konfrontierten, anstatt diese zu unterdrücken oder vor sich selbst zu verleugnen.

Der Kontakt zu Christen ergab sich teils am Wohnort, teils auf beruflich bedingten Reisen, das heißt, die mentale konnte der raumbezogenen Mobilität vorausgehen oder aber diese auf jene folgen: Christian Friderich, Heinrich Friedrich Wentzel und Henrietta Wegener hatten bereits in ihrer Jugend regelmäßig Umgang mit Christenkindern, ebenso Maria Lucia Rehburg, die zeitweilig eine christliche Schule besuchte. So entstand ganz von selbst eine gewisse Vertrautheit mit der anderen Religion und damit das Fundament des späteren Glaubenswechsels ${ }^{17}$. Jacob Abraham Albo dagegen gibt an, die ersten Informationen über das Christentum durch »zwey Hällische Studiosi $\ll$, das heißt reisende Mitarbeiter des Institutum Judaicum, erhalten zu haben, die ihn als Dolmetscher beschäftigten ${ }^{18}$. Auch bei Carol Christian Edzard kam die Begegnung mit einem Christen im Zusammenhang mit seiner

16 Ebd., S. 13.

17 Johann Ludewig Wilcken, Anhang und Bericht/von Bekehrung des ehmaligen Juden/Tschai (oder Jeschia) Salomo/nun bey angenommenem Christenthum/genant: Christian Friderich, in: Ders., Einladungs- und Vorbereitungs-Predigt zur Juden-Tauffe/Als Im Jahr 1698. Dominica Esto mihi, Einem gewesenen Juden/Nahmens Jeschia Salomo, Sonst auch/aus Jüdischem Aberglauben/wegen zugestossener Kranckheit Abraham Selig genant/der Geburt von Berlin / und bey 8. Jahren zu Flatow in Pohlen wohnhafft/allhier zu Züllich im Brandenburg. Lande und Croßnischen Herzogthum belegen/nach geendigter Vesper- oder Nachmittags-Predigt Die Heilige Tauffe offentlich verreichet/und ihm der Nahme Christian Friderich beygeleget wurde/In der ersten Sonntags-Predigt/über die Worte Pauli 1. Cor. I, v. 23. 24. Wir predigen den gekreutzigten Christum/den Juden eine Aergerniß/und den Griechen eine Thorheit / denen aber die beruffen sind/beyde Juden und Griechen/predigen wir Christum Göttliche Krafft/und Göttliche Weißheit. Gehalten/Und auf Begehren wehrter Gönner/Wohlthäter und Freunde/zum Druck gegeben von Joh. Ludewig Wilcken/Diacono in Züllich, Frankfurt/Oder 1698, S. 36-44, hier: S. 37. - Gottfried Berthold, Dreyfaches Jüden-Bekäntnüß Welches Ein Jüdischer Vater/Mutter/und Tochter von Sechs und einem halben Jahre/In Gegenwart Einer sehr Volckreichen Versammlung Zu Barby In der Kloster-Kirchen den 7. Mart. Anno 1708. öffentlich abgeleget/Und darauff Nebst dem Sohne Salomo von drittehalb Jahren die heilige Tauffe empfangen haben: Sowohl denen Getauffen/als auch seiner Christlichen Evangelischen Gemeinde Zum steten Andencken/Zusammt dem darbey gehaltenen Tauff-Sermon Auff Begehren zum Druck überlassen von Gottfried Bertholden/Ober-Pfarrherrn/Consistor. Assessore, und der Schulen Inspectore, Zerbst 1708, S. 28. - CubE, Reden, S. 322f. - Ohne Autorenangabe, [Konversion des Ehepaares Bernhard Abraham/Petronella Moses], in: Fortwährende Bemühung um das Heil des Jüdischen Volks überhaupt erwehnet von D. Joh. Heinrich Callenberg der Theol. u. Phil. Prof. P. Ord., Sechstes Stük, Halle 1753, S. 40-47, hier: S. 41. 
berufsbedingten Mobilität zustande. Er berichtet, dass er »von einem Studioso« ein »Licht empfangen« habe, als er auf dem Weg nach Ostfriesland war, um dort eine Lehrerstelle anzutreten ${ }^{19}$.

Während die oben erwähnten Reisen von Albo und Edzard dem Konversionsprozess vorausgingen (beziehungsweise seine »Initialzündung « erst ermöglichten) ${ }^{20}$, war es in anderen Fällen der Konversionsprozess selbst, der raumbezogene Mobilität erforderlich machte: Viele Konvertiten durchlebten während ihres Konversionsprozesses eine Phase der Wanderschaft, die nicht selten von Unsicherheit und Existenzängsten geprägt war. Diese räumliche Distanzierung vom bisherigen Lebensumfeld wurde häufig dadurch ausgelöst, dass die beginnende Neigung zum Christentum in der Familie und der Nachbarschaft bekannt wurde und der zukünftige Konvertit mit Anfeindungen und Verfolgung konfrontiert wurde oder dies zumindest befürchten musste - Duitsch war in diesem Punkt kein Einzelfall. Geburts- und Taufort der hier betrachteten Konvertiten waren fast nie identisch; zum Teil legten die Taufwilligen enorme Wege zurück, wie etwa der aus Litauen stammende Paulus Christian, der in Braunschweig konvertierte, oder Jacob Abraham Albo, den es von Konstantinopel nach Wittenberg verschlug. Die Wahl eines Tauforts fern der Heimat wird wiederholt explizit mit der Angst begründet, von Familienangehörigen oder anderen Juden unter Druck gesetzt oder verfolgt zu werden ${ }^{21}$.

18 Johann Georg Pfotenhauer, Kurtze Nachricht von dem vorher gegangenen Unterrichte, und dem darauf erfolgten Tauf-Actu eines gebohrnen Judens, Jacob Abraham Albo, aus Belgrad in Ungarn, davon der letztere den 8. Jan. 1750. in der Pfarr-Kirche zu Wittenberg bey volckreicher Versammlung gehalten worden, Auf Begehren und zur Erbauung vieler frommen Hertzen ausgefertiget von M. Joh. George Pfotenhauer, Diac. II. an der Pfarr-Kirche zu Wittenberg, Wittenberg 1750, S. 9.

19 Franciscus Henricus Hoyer, Der Bekehrte Jude/Oder Carol Christian Edzards Vorhin geheissen R. Baruch Ben Jacob, Confession, und Tauff-Actus, Wie Jene in der Pfarrkirchen der Stadt Norden in Ostfrießland den 7. Febr. itzlauffenden Jahres 1678/da zugleich ein allgemeiner Buß-Fast-Bet- wie auch Landtag einfiel/in Gegenwart vieler hundert Zuhörer vor der Canzel von ihme abgeleget; und darauf Dieser von dem Ministerio daselbst im innern Chore verrichtet worden: nachdem derselbe zuvor treulich informiret worden von M. Francisco Henrico Hoyer / Pfarrern daselbst. Auf vielfältig Begehren zum Druck übergeben, Helmstedt 1679, S. 22f.

20 In Bezug auf innerchristliche Konversionen betont auch Heike Bock, dass der Konversionsprozess häufig durch arbeitsbedingte Mobilität ausgelöst worden sei, die zu Kontakten mit Angehörigen einer anderen Konfession geführt habe: Heike Bock, Konversion: Motive, Argumente und Normen. Zur Selbstdarstellung von Proselyten in Zürcher Bittschriften des 17. und 18. Jahrhunderts, in: Thomas Kaufmann u.a. (Hg.), Frühneuzeitliche Konfessionskulturen. 1. Nachwuchstagung des VRG Wittenberg 30.09.-02.10.2004, Gütersloh 2008, S. 153-174, hier: S. 161.

21 Vgl. u.a. Christian, Eigen Bekandnüß, S. 18; Paul Jacob Förtsch, Kurze Nachricht von den Lebensumständen eines zu Christo bekehrten Jüdischen Schulmeisters und Schächters Hirsch Marcus welcher am 13. Sonntage nach Trinitatis in der St. Johannis-Kirche zu Göttingen die H. Taufe empfieng, nebst den dabey gehaltenen geistlichen Reden und von dem Proselyten abgelegtem Glaubensbekenntniß, in: Ders. (Hg.), der Gottesgelahrtheit ordentlichen Lehrer, ersten Prediger zu St. Johannis und im Fürstenthum Göttingen Generalsuperintendenten, Göttingen 
Der Entschluss, die Heimat zu verlassen, erfolgte also nicht freiwillig doch während die meisten Konvertiten zumindest noch die Möglichkeit hatten, ihr Reiseziel selbst zu wählen, wurde Henrietta Wegener und Christian Friderich sogar dieser letzte Handlungsspielraum genommen: Beide wurden von ihren Eltern fortgeschickt, die sie dadurch dem Einfluss ihrer christlichen Bekannten zu entziehen suchten, um so eine Konversion zu verhindern. Wegener musste zu Verwandten reisen und Friderich wurde schon mit 14 Jahren verheiratet ${ }^{22}$.

Ein besonders hohes Maß an selbstgesteuerter und zielgerichteter Mobilität wird in der Konversionserzählung von Friederica Paulusin erkennbar, die ihre Familie bereits verließ, bevor diese etwas von ihren Konversionsgedanken ahnte: Die junge Frau ließ sich »ein erdichtetes Einladungsschreiben« des Rabbiners von Fürth zuschicken, um vor ihren Eltern die Abreise zu legitimieren und sich in sicherer Entfernung von ihrem Heimatort um Taufunterricht bemühen zu können ${ }^{23}$. Einen Sonderfall stellt auch Christian Gottlieb Hirschlein dar, dessen Entschluss zum Wanderleben weniger durch äußere, als vielmehr durch innere Zwänge motiviert gewesen zu sein scheint: Als er sich wegen seiner Neigung zum Christentum wieder einmal mit Selbstvorwürfen peinigte, rieten ihm seine Freunde, drei Jahre lang auf Reisen zu gehen und auf diese Weise ein schon früher abgelegtes Gelübde zu erfüllen. Hirschlein nahm diesen Rat an und fasste den Vorsatz, in dieser Zeit in Armut zu leben, strengste Buße zu tun und sich in keinerlei Überlegungen über Glaubensfragen mehr einzulassen ${ }^{24}$. Wie er in seiner Konversionserzählung weiter ausführt, hatte er etwa dreieinhalb Jahre später einen Traum, der ihm den Anstoß gab, sich endgültig für das Christentum zu entscheiden ${ }^{25}$. Für Hirschlein erwies sich damit der Weg selbst als Ziel - mit anderen Worten: die definitive Entscheidung für eine der beiden Religionen, zwischen denen er sich hin- und hergerissen fühlte, wurde durch diese Phase der bewusst ziellosen Mobilität erst ermöglicht.

Eine Korrelation zwischen raumbezogener Mobilität und einem inneren Klärungsprozess ist auch bei Duitsch festzustellen, der es mehrmals vorzog, seine Konversionsodyssee fortzusetzen, anstatt vorschnell eine Entscheidung zu treffen, die er möglicherweise später bereuen würde. Die folgende Textstelle möge als Beispiel dienen:

1771, S. 10f. Zur Mobilität von Konvertiten vgl. auch Rotraud RIES, »Missionsgeschichte und was dann?« Plädoyer für eine Ablösung des kirchlichen Blicks, in: Jutta BRADEN/Rotraud RiES (Hg.), Themenschwerpunkt: Juden - Christen - Juden-Christen. Konversionen in der Frühen Neuzeit, in: Aschkenas 15 (2005), S. 271-301, hier: S. 294f.

22 Cube, Reden, S. 323f.; Wilcken, Anhang und Bericht, S. 37.

23 Herold, Gütgen Steinhardin, S. 46.

24 Johann Heinrich CAllenberg, Beylage zum Briefwechsel bey dem Jüdischen Instituto 1747. den 11. Jan., Halle 1747, S. $18 f$.

25 Ebd., S. 23f., 45, 61. 
Was sollte ich nun anfangen: zu den Christen überzugehen und mich taufen zu lassen / war mir noch nicht möglich; einige Schwürigkeiten waren zwar aufgelöst/aber die Finsternis in meinem Herzen war auch noch gros genug. Ferner zu welcher Religion oder Sekte der Christen solte ich mich wenden? Wie konnte ich wissen und versichert seyn/welche von ihnen die wahre Religion sey? Ist es nicht besser und vortheiliger noch einige Zeit zu warten/und alles/so viel möglich ist/zu untersuchen / als nachhero von der einen Religion wieder zu der andern zu laufen/und dieser Veränderung wegen/von den Menschen vor einen Betrüger gehalten und ausgescholten zu werden ${ }^{26}$ ?

Duitsch hielt sich damals in Arnheim auf, wo er zunächst unauffällig als Rabbiner gelebt und seine Lektüre des Neuen Testaments verheimlicht hatte, bis ihm die zunehmenden Anfeindungen und Verdächtigungen von jüdischer Seite das Leben irgendwann unerträglich machten. Wie schon bei der Flucht aus seinem Heimatort wusste er auch diesmal nicht, wohin er sich wenden sollte - sein Ziel lässt sich also, um aus Kafkas Erzählung »Der Aufbruch« zu zitieren, lediglich als $» W e g-v o n-h i e r ~ «{ }^{27}$ benennen, aber nicht als ein konkretes $\gg$ Dorthin $\ll$.

Dieses zeitweilige Leben zwischen den Religionen und ohne einen festen räumlichen Bezugspunkt erinnert an die mittlere Phase eines so genannten »Übergangsritus«: Unter den »Übergangsriten«, zu denen er auch den Religionswechsel zählt, versteht Arnold van Gennep alle zeremoniellen Sequenzen, die den Übergang von einem Zustand in einen anderen oder von einer kosmischen beziehungsweise sozialen Welt in eine andere begleiten ${ }^{28}$. Diese Riten lassen sich in eine »Ablösungsphase «, eine »Schwellenphase « beziehungsweise »Umwandlungsphase « und eine »Integrationsphase« unterteilen ${ }^{29}$. In der mittleren Phase, die auch als »liminale Phase « bezeichnet wird, befindet sich das rituelle Subjekt vorübergehend außerhalb der normativen Sozialstruktur und schwebt sowohl räumlich wie magisch-religiös zwischen zwei Welten ${ }^{30}$. Dieser Eindruck eines Schwebens im Undefinierten wird auch dadurch bestätigt, dass zahlreiche Ortswechsel in der Konversionserzählung Duitschs unbegründet bleiben; andere können lediglich mit rational nicht fassbaren Gründen erklärt werden oder erhalten ihre Sinngebung erst im Rückblick: So reiste Duitsch, während er sich in den Niederlanden um die Annahme als Taufkandidat bemühte, wiederholt nach Ams-

26 Duitsch, Bewunderns-Würdige Führung Gottes, S. 135.

27 Franz KAfKA, Der Aufbruch, in: Ders., Sämtliche Erzählungen, hg. von Paul Raabe, Frankfurt am Main 1970, S. 321.

28 Arnold van Gennep, Übergangsriten, Frankfurt am Main 1986, S. 21.

29 Ebd., S. 21, 97.

30 Ebd., S. 27f. und Victor Turner, Vom Ritual zum Theater. Der Ernst des menschlichen Spiels, Frankfurt am Main 1989, S. 39. 
terdam, wurde aber jedes Mal durch eine heftige Abneigung veranlasst, die Stadt geradezu fluchtartig zu verlassen, was er sich nur mit Eingebungen des »Satans « erklären konnte ${ }^{31}$. Ebenso unklar war ihm, weshalb er einige Monate später spontan noch einmal nach Amsterdam zurückkehrte - erst in der schreibenden Retrospektive konnte er diesen Schritt als Werk der göttlichen Vorsehung deuten, die wie ein Zwang erscheint, gegen den der eigene Wille machtlos war:

Doch/gleich ich oben mehrmals gesagt habe/wenn man mich gefragt hätte/warum nach Amsterdam/und was wollt ihr da ausrichten? Weil ihr doch weder der Holländischen Sprache mächtig seyd/noch in der Stadt vor euch einen Freund oder Bekennten finden werdet? Darauf würde ich keine Antwort haben geben können. Siehe / so bin ich als ein Blinder geleitet/auf dem Wege den ich nicht kennte. Hat mir der Satan auch diese Stadt als ein Nazareth vorgestellt/und mich zu dreyen mahlen aus derselben weggeschlept/und in der Wüste umgeführt; gleichwohl mus der Rath des Herrn bestehen/und sein Wille erfüllt werden. Ich muste also wieder/obschon gegen meinen Willen/nach Amsterdam reisen. O wie unbegreiflich/wie wunderbahrlich sind doch die Wege Gottes! doch dieses siehet man/gleich ich gesagt habe/erst von hinten ${ }^{32}$.

Hier begegnet erneut das schon im Titel von Duitschs Konversionserzählung anklingende Leitmotiv einer unmittelbaren Lenkung durch die göttliche Vorsehung, das sich in unterschiedlich intensiver Ausgestaltung auch in vielen anderen Konversionsberichten findet ${ }^{33}$. Duitsch weist diesem Motiv auch insofern einen besonders hohen Stellenwert zu, als er betont, dass er sich in Phasen der Rat- und Orientierungslosigkeit wie etwa zu Beginn seiner Flucht

31 Duitsch, Bewunderns-Würdige Führung Gottes, S. 212.

32 Ebd., S. 234f.

33 Vgl. u.a. Ernst Christian ZARvossi, Danck- und Lob-Gesang/Welchen Bey seiner Bekehrung aus dem finstern Jüdenthumb am Tage Pauli Bekehrung/im Jahr 1668. in der Schloß-Kirche / auff der Hochfürstl. Residentz Frieden-Stein zu Gotha gethan Ernst Christian Zarvossi, vormahls Abraham genant/aus Crakau in Pohlen/und gewesener Rabbi, Wittenberg 1669, S. 4-6. Claus Andreas von OsterodA, Wolgemeintes Sendschreiben/Mein Daniel Jacob Bon/bekehrten Judens/Nunmehr unter dem Namen Claus Andreas von Osteroda/In der SchloßKirche St. Jacobi zu Osterode/Dominica Quasimodogeniti, war der 15. Aprilis des jetztlauffenden 1694. Jahrs/in ungemeiner Volckreicher Versamlung/auf vorergangene treuliche Information, im 23sten Jahr meines Alters/getaufften Christens/abgelassen An meine hertzlich-geehrte Eltern/nahmentlich Jacob Bon/und Sarah Wolff/Auch an meine geliebte fünff Brüdere und zwo Schwestern/samt übrigen Blutsverwandten nach dem Fleisch/wohnhafft zu Wittling unweit Trier/Darin ihnen die Ursach meines Abtrits vom Jüdenthum samt dem ganzen Verlauff meiner Bekehrung zum Christenthum/auch meines jetzigen Ergehens beweglich zur Nachfolge fürgestellet wird, Nordhausen 1694, S. 4f. - Friedrich Albrecht AugusTI, Friedrich Albrecht Augusti, Predigers zu Eschenberga, im Fürstenthum Gotha, Nachricht von dem Leben und Bekehrung eines Jüdischen Studiosi, Nahmens Raphael Joseph, Welcher in der Heil. Taufe Joh. Ludwig Hartmann Immanuel ist genennet worden, und am 3. Heil. Pfingst-Tage, als den 27. May 1749. zu gedachtem Eschenberga die Heil. Taufe empfangen hat, Gotha 1749, S. 10f. 
bewusst der Führung Gottes anvertraute und die Wahl seines nächsten Reiseziels an diese delegierte ${ }^{34}$. Durch diese Bezugnahme auf die Vorsehung erscheint ein Konversionsprozess zum einen stringenter, da in allen Um- und Irrwegen und allen Phasen scheinbar zielloser Mobilität noch immer die göttliche Führung als »roter Faden « erkennbar bleibt. Zum anderen wird, dem christlichen Ideal der Demut entsprechend, der Glaubenswechsel allein als Werk der göttlichen Gnade dargestellt, an dem der in Sünde und Unvollkommenheit verstrickte Konvertit keinen aktiven Anteil hat ${ }^{35}$.

Raumbezogene Mobilität wurde häufig auch dadurch erforderlich, dass sich die Annahme als Taufkandidat schwierig gestaltete. Die Abweisung eines Taufbewerbers war nicht ungewöhnlich, da das Bild der Konvertiten in der Öffentlichkeit stark durch Berichte über so genannte »Taufbetrüger« geprägt war, die sich nur materiell bereichern wollten ${ }^{36}$. Dies bekamen auch David Barchowsky und Simon Frommann zu spüren, die bei ihrem ersten Versuch in Stuttgart beziehungsweise Polen abgewiesen wurden, wobei die Geistlichen in beiden Fällen schlechte Erfahrungen mit angeblich taufwilligen Juden als Grund angaben ${ }^{37}$. Duitsch hingegen fand zwar in Wesel Aufnahme und glaubte sich schon am Ziel seiner Wünsche, musste dann jedoch feststellen, dass die Weseler Prediger untereinander zerstritten waren und niemand sich für seine Betreuung zuständig fühlte, so dass ihm nichts anderes übrig blieb, als erneut auf Wanderschaft zu gehen ${ }^{38}$. In den bisher betrachteten Fällen handelte es sich eindeutig um erzwungene Mobilität, die zunächst wohl auch ziellos gewesen sein dürfte, da die Taufwilligen ja nicht wissen konnten, an welchem Ort sie einen freundlicheren Empfang finden würden. Bei Ernst August Friederici jedoch wird eine Verbindung von Zwang und zielgerichteter Eigeninitiative erkennbar: Anfangs versuchten mehrere Geistliche, sich die anscheinend ungeliebte Aufgabe des Taufunterrichts gegenseitig zuzuschieben, bis Friederici dieses Hin und Her beendete, indem er einen der potentiellen Lehrer noch einmal aufsuchte und ihn ausdrücklich bat, ihn als Taufkandidaten anzunehmen, da er zu ihm ein »besonderes Vertrauen « gefasst habe. Um seiner Bitte mehr Nachdruck zu verleihen, legte er

34 Duitsch, Bewunderns-Würdige Führung Gottes, S. 57f., 229, 241.

35 Zur Berufung auf die göttliche Vorsehung in frühneuzeitlichen Selbstzeugnissen vgl. auch Hans Rudolf Velten, Das selbst geschriebene Leben. Eine Studie zur deutschen Autobiographie im 16. Jahrhundert, Heidelberg 1995, S. 219.

36 Vgl. Johannes Graf (Hg.), Judaeus conversus. Christlich-jüdische Konvertitenautobiographien des 18. Jahrhunderts, Frankfurt am Main 1997, S. 34, 55.

37 Ohne Autorenangabe, [Biographie David Baruchs], in: Fortwährende Bemühung um das Heil des Jüdischen Volks überhaupt erwehnet von D. Joh. Heinrich Callenberg der Theol. u. Phil. Prof. P. Ord., Drittes Stük, Halle 1752, S. 7-27, hier: S. 22f. - Ohne Autorenangabe, Beschluß der Nachricht von der Taufe jüdischer Rabbinen. 3. Zu Zürich. 1. Lebensgeschichte Simon Bar Josephs, nach der Taufe genannt Simon Frommann, in: NAHE oder Sammlung zu den neuesten Kirchengeschichten 3 (1763), Th. 24, S. 815-832, hier: S. 822.

38 Duitsch, Bewunderns-Würdige Führung Gottes, S. 168f., 177f., 194-200. 
ein Empfehlungsschreiben des Generalsuperintendenten vor, was ebenfalls dafür spricht, dass Friederici die ihm verbleibenden Handlungsspielräume effektiv zu nutzen verstand, da eine solche Empfehlung vermutlich nur mit großem Engagement und viel Überzeugungskraft zu bekommen war ${ }^{39}$.

Bei der Untersuchung der sprachlichen Ausdrucksformen raumbezogener Mobilität fällt zunächst auf, dass in den Konversionserzählungen häufig von Wegen beziehungsweise von Übergängen die Rede ist ${ }^{40}$, was erneut für die Auffassung van Genneps spricht, dass der Religionswechsel zu den Übergangsriten gezählt werden kann. Ein Kontext, in dem derartige Formulierungen begegnen, ist das Motiv der göttlichen Leitung, das nicht nur bei Duitsch eng mit der Erfahrung raumbezogener Mobilität verbunden ist. Ernst Christian Zarvossi beispielsweise führt voller Pathos aus, dass er in seinem »Jüdischen Unglauben/als in Finsterniß und Dunckel gefangen « gewesen und »in ungebähnten Sünden-Wegen « umhergeirrt sei, so dass er unweigerlich »im Meer der Verzweiffelung« hätte »verderben« müssen, wenn ihn nicht die »Barmhertzigkeit Gottes [...] zu einer Stadt gebracht« hätte, in der seine »Seele mit dem Wasser des Lebens geträncket « und »mit den Seel-erquickenden Gnaden-Gütern gespeiset worden $\ll \operatorname{sei}^{41}$.

In dieser Textstelle wird zugleich eine Korrelation zwischen raumbezogener Mobilität und einer Finsternis-Licht-Metaphorik erkennbar, die in Konversionserzählungen häufig eingesetzt wird, um einen Kontrast zwischen dem früheren »falschen« und dem neuen »wahren« Glauben zum Ausdruck zu bringen. Die biographische Bruchstelle der Konversion wird dabei, wie Peter L. Berger und Thomas Luckmann erläutern, »zur kognitiven Scheidung von Dunkelheit und Licht $\ll^{42}$. Auch Carl Wilhelm Friedrich versinnbildlicht seine Suche nach dem »wahren « Glauben als Umherirren in der Dunkelheit und bezeichnet sich, ähnlich wie Duitsch, als »verblendet«, weshalb er sich »am hellen Tage in dem Abwege verirrt« habe ${ }^{43}$. Bei Duitsch begegnet

$39 \mathrm{Koch}$, Sieg der Wahrheit über die Vorurtheile, S. 25.

$40 \mathrm{Zu}$ einem ähnlichen Ergebnis gelangt auch Jörg Dünne in Bezug auf frühneuzeitliche Pilgerberichte und -handbücher; an anderer Stelle bezeichnet er die »Begrifflichkeit des Weges« sogar als eine »privilegierte Textmetapher« der Frühen Neuzeit: Jörg DünNE, Pilgerkörper Pilgertexte. Zur Medialität der Raumkonstitution in Mittelalter und früher Neuzeit, in: Ders. u.a. (Hg.), Von Pilgerwegen, Schriftspuren und Blickpunkten. Raumpraktiken in medienhistorischer Perspektive, Würzburg 2004, S. 79-97, hier: S. 89f., 93, 97.

41 Zarvossi, Danck- und Lob-Gesang, S. 4-6.

42 Peter L. Berger/Thomas Luckmann, Die gesellschaftliche Konstruktion der Wirklichkeit. Eine Theorie der Wissenssoziologie, Frankfurt am Main 1994, S. 171f.

43 Carl Wilhelm Friedrich, Les motifs oû les raisons convainquantes d'Isaac Jacob, qu'il a eües d'avoir quitté le Judaïsme \& embrassé le Christianisme. Charles Guillaume Frederic Enseignant de la langue française á Prenzlow. Bewegungsgründe weshalb ich ehemals Isaac Jacob genannt, die Jüdische Religion, worinnen ich gebohren bin, verlassen, und mich zur Christlichen Religion gewendet habe. Carl Wilhelm Friedrich französischer Sprachmeister zu Prenzlow, Stettin 1781, S. 7, 9f. 
diese Selbstdarstellung als ein der Führung bedürftiger Blinder in einer besonders stilisierten Form noch einmal im zweiten Band seiner Konversionserzählung: Duitsch schildert dort, wie er in einer sehr mutlosen Stimmung angeblich einen blinden Bettler auf der Straße traf, der von einem anderen Mann geführt wurde. Beim Anblick des verlässlichen und umsichtigen Blindenführers musste er daran denken, wie sein »großer und gnädiger Führer« Jesus Christus ihn bisher immer treu geleitet und aus allen Gefahren gerettet hatte, und er schämte sich zutiefst, dass er trotzdem immer wieder in Unglauben und Misstrauen verfallen war $^{44}$.

Dem Wortfeld des Weges beziehungsweise des Überganges ist auch die eingangs bereits erwähnte Darstellung des Konversionsprozesses als Wüstenwanderung zuzuordnen, die in der Konversionserzählung Duitschs einen zentralen Stellenwert einnimmt. Eine Schlüsselszene bildet dabei die ausführliche Schilderung eines wegweisenden Traums in der ersten Nacht nach der Flucht aus seinem Heimatort: Duitsch beschreibt, wie er im Traum seit drei Tagen ohne Wasser und Essen in einer »wüsten Einöde« umherirrte, durch die noch nie ein Mensch gekommen war. »Tausend wilde und zerreissende Thiere $\ll^{45}$ machten Anstalten ihn anzufallen, als plötzlich ein Löwe angelaufen kam, der an seine rechte Seite trat und mit ihm durch die wilden Tiere hindurchging:

Dieser Löwe war mein Beschirmer/er brachte mich aus der Wildnis/und da sahe ich einen gebahnten Weg/worauf die Füsse der Menschen noch zu sehen waren. Ich war sehr erfreut/daß ich aus der wüsten Einöde heraus/aus der Todes-Gefahr/auf eine so wunderbahre Weise/befreyt und errettet war $^{46}$.

Der Weg führte ihn zu einem »köstlichen und wundervollen Pallast«, wo Duitsch sehr freundlich empfangen wurde, neue Kleider erhielt und mit den anderen Gästen an einer festlichen Tafel sitzen durfte ${ }^{47}$. Dort legte man ihm die besten Speisen vor, die er jedoch aufgrund seines quälenden Durstes

44 Christian Salomon Duissch, Het twede stuk of Vervolg van de wonderlyke Leidinge Gods, omtrent eenen blinden Leidsman der Blinden, op Wegen en Paden, die hy niet kende. Ondervonden door Christiaan Salomon Duitsch, geweezene Joodsche Rabby; Behelzende zyne werkzaamheden, zo omtrent in en na het doen van zyne Belydenisse; en voor, onder en na zynen $\mathrm{H}$. Doop, als by en onder de bepaling en voltrekking, tot en van zyn Huwelyk, en andere zonderlinge reddinge uit donkere en moejelyke omstandigheden enz. Tot verheerlyking van Jehovah, in het licht gegeven, en gedrukt voor den Autheur, Amsterdam 1771, hier zitiert nach: P. DeETMAN (Hg.), Bloemlezing uit de werken van: Christiaan Salomon Duijtsch, in leven Israëlitisch Rabbijn in Hongarije, en overleden als Predikant der Nederl. Gereformeerde Kerk. Met Portret des Schrijvers. Met een voorwoord van P. Deetman, Predikant te Bennekom, Doesborgh 1870, S. 289-438, hier: S. 388f.

45 Duitsch, Bewunderns-Würdige Führung Gottes, S. 60.

46 Ebd., S. 61.

47 Ebd. 
nicht richtig genießen konnte. Als er dieses Missempfinden äußerte, wurde ihm »ein Glas mit reinen/klahren und hellen Wasser « gereicht, das ihn so »erquickte und sterkte «, als ob er »ein neues Leben erhalten hätte « ${ }^{48}$.

Zu einem Zeitpunkt, zu dem Duitsch die Bibel nach eigener Aussage noch kaum kannte ${ }^{49}$, weist dieser Traum auffallend viele biblische Bezüge auf, was darauf schließen lässt, dass die Traumszene zumindest nachträglich ausgeschmückt wurde. Möglicherweise könnte man sogar noch einen Schritt weiter gehen und den Traum als Parabel betrachten, die im Interesse einer schlüssigen Textkomposition bewusst an dieser Stelle eingefügt wurde, um spätere Ereignisse in der Lebensgeschichte Duitschs in zeichenhafter Form vorwegzunehmen. Dies soll und muss jedoch nicht heißen, dass die Authentizität des Traums völlig in Zweifel zu ziehen ist. Da Duitsch sich immer wieder als phantasiebegabter Autor erweist und zudem durch seine ausgiebige Lektüre der jüdischen Schriften mit Gleichnissen und anderen Formen des bildhaften Sprechens vertraut war, erscheint es durchaus denkbar, dass er auch in Bildern träumte und dieses »Rohmaterial « beim Schreiben lediglich »veredelte «, indem er es zu einer in sich geschlossenen Geschichte ohne logische Brüche zusammenfügte und dabei eventuell einzelne Elemente ergänzte oder ausließ.

Was den Ort des Traumgeschehens betrifft, so fällt ins Auge, dass er nicht eindeutig beschrieben wird, denn Duitsch spricht abwechselnd von einer »Wildnis«, einer »Einöde« und einer »wüsten Einöde « $\aleph^{50}$. Während man bei einer »Wildnis« eher an eine Art Urwald denkt, wird das Wort »Einöde« in der Bibel gelegentlich synonym mit $»$ Wüste « gebraucht $^{51}$, und die Formulierung »wüste Einöde « könnte ein zusätzlicher Hinweis darauf sein, dass eine Wüste gemeint ist. Dafür spricht auch, dass Duitsch seinen Weg zum Christentum ja bereits im Titel der niederländischen Ausgabe seiner Konversionserzählung als eine Wüstenwanderung bezeichnet. Spätere Textstellen machen ebenfalls deutlich, dass Duitsch vor allem bei der schreibenden Vergegenwärtigung besonders schwieriger Phasen seines Konversionsprozesses gern auf diese Metapher der Wüstenwanderung zurückgriff ${ }^{52}$. Zudem ist die Wüste gegenüber der »Wildnis« die weitaus ergiebigere Metapher, denn sie ist in der Bibel ein häufiger Schauplatz, der je nach Situation als Ort des Umherirrens, der Versuchung oder aber der Errettung durch die göttliche Führung erscheint ${ }^{53}$.

\footnotetext{
48 Ebd., S. 62.

49 Ebd., S. 21.

50 Ebd., S. 60f.

51 U.a. Dtn 32,10 und Jes 35,1.

52 Duitsch, Bewunderns-Würdige Führung Gottes, S. 191, 229.

53 U.a. Dtn 8,14-16; Ps 107,4-7 und Mt 4,1.
} 
Dass Duitsch ausgerechnet durch einen Löwen gerettet wurde, dürfte ebenfalls kein Zufall sein, da der Löwe in der Bibel als Symbol der Stärke und Überlegenheit des Volkes Israel oft durchaus positiv konnotiert ist ${ }^{54}$. In der Traumszene symbolisiert der Löwe die Führung und Errettung durch Gott. Er ist damit als das zentrale Element dieser »Traumparabel« anzusehen, da er das Leitmotiv der gesamten Autobiographie verkörpert.

Trotz aller Verzweiflung und Beschwerlichkeit, die eine Odyssee durch die Wüste mit sich bringt, scheint Duitsch sie als notwendigen Bestandteil jedes Konversionsprozesses akzeptiert zu haben. Denn als er im Traum den Palast erreichte und aus Scham über seine schäbige Kleidung den Festsaal nicht zu betreten wagte, sagten ihm die anderen Gäste: »[...] wir waren ehedem so wie ihr gekleidet/und unsern Putz haben wir hier erst empfangen. Wer an diesen Ort will kommen/kan/ja darf nicht anders kommen/denn mit seinen armseligen/schlechten und beschmuzten Kleidern/so wie sie sind $[\ldots] \ll \ll^{55}$. Aber waren die Zustände im lange ersehnten »Palast« wirklich so paradiesisch?

\section{Die nachkonversionelle Lebensphase}

Die meisten Konvertiten standen nach der Taufe vor der Aufgabe, sich beruflich neu zu etablieren, was häufig erneut zu - wohl meist unfreiwilliger raumbezogener Mobilität führte. Über Christian Lebrecht Felß weiß ein späterer Biograph sogar zu berichten, dass dieser nach seiner Taufe noch mehrere Jahre lang ohne festes Einkommen umherzog, bis er zunächst an verschiedenen Gymnasien und Universitäten als Hebräischlehrer tätig werden konnte und später eine Stelle als außerordentlicher Professor in Wittenberg erhielt $^{56}$. Duitsch sah sich in Amsterdam mit so gravierenden Verleumdungen und feindseligen Reaktionen konfrontiert, dass er zeitweilig mit dem Gedanken an eine Rückkehr in die »Wüste « spielte, die ihm gegenüber den Zuständen im »Palast« als das kleinere Übel erschien:

Ach, dass mir jemand Flügel einer Taube gäbe, ich würde hinfliegen, wo ich bleiben möchte, ich würde weit wegschweifen und lieber in der Wüste übernachten, damit ich

54 U.a. Gen 49,9; Num 23,24 und Mi 5,7.

55 Duitsch, Bewunderns-Würdige Führung Gottes, S. 62.

56 Johann Friedrich Alexander DE LE RoI, Die evangelische Christenheit und die Juden unter dem Gesichtspunkte der Mission geschichtlich betrachtet. Erster Band. Die evangelische Christenheit und die Juden in der Zeit der Herrschaft christlicher Lebensanschauungen unter den Völkern. Von der Reformation bis zur Mitte des 18. Jahrhunderts, Karlsruhe 1884, S. 117. 
nur den treibenden Winden und Stürmen entkäme, der Grausamkeit und wütenden Raserei meiner Feinde, die ärger sind als die wilden und reißenden Tiere in der Wüste ${ }^{57}$ !

Damals blieb es bei den bloßen Gedanken, da Duitsch sich bewusst machte, dass seine Gegner sich nur bestätigt fühlen würden, wenn er die Flucht ergriffe. Einige Jahre später bewirkten neue Gerüchte über ihn jedoch tatsächlich einen weiteren - wenn auch nur temporären - Ortswechsel: Duitsch hatte inzwischen in Utrecht Theologie studiert und wollte vor dem dortigen Kirchenrat sein Examen ablegen, musste jedoch feststellen, dass sich das Prüfungsverfahren aufgrund übler Nachrede verzögerte. Er entschied sich daher, sich stattdessen in Schieland prüfen zu lassen ${ }^{58}$. Diese Episode lässt ein hohes $\mathrm{Maß}$ an Entschlossenheit und Eigeninitiative erkennen - Duitsch hatte offenbar aus seinen Erfahrungen als ungeliebter Taufkandidat in Wesel gelernt und ließ sich gar nicht erst auf die Hinhaltepolitik des Utrechter Kirchenrats ein, sondern wurde gleich selbst aktiv.

Zugleich deuten alle hier genannten Beispiele darauf hin, dass sich ein Konvertit nur dann erfolgreich etablieren - und damit dem Zwang zu weiterer räumlicher Mobilität entkommen - konnte, wenn sein neues religiöses Umfeld bereit war, ihn als vollgültiges Mitglied anzuerkennen und zu integrieren. Dieser Eindruck wird auch durch eine spätere Schrift Duitschs bestätigt: Am 7. September 1777 wurde Duitsch als Pfarrer im niederländischen Mijdrecht tätig und hielt dort seine Antrittspredigt, die im folgenden Jahr publiziert wurde. Diese Predigt enthält auch einen autobiographischen Rückblick auf seine allmähliche Hinwendung zum Christentum, der mit der Ankündigung eingeleitet wird, dass Duitsch nunmehr »die Aufschriften der Ebenezers«, die er »auf dem Weg nach Zion, von Sittim bis Gilgal«, durch Gnade habe errichten dürfen, wieder lesen und der Gemeinde zur Andacht mitteilen wolle ${ }^{59}$. Das Wort »Ebenezer«, wörtlich übersetzt »Stein der Hilfe«, ist der Name eines Gedenksteins, den Samuel zwischen Mizpa und Schen zum Dank für einen mit göttlichem Beistand errungenen entscheidenden Sieg über die Philister errichtete (I Sam 7,12) ${ }^{60}$. Den Weg »von Sittim nach Gilgal« legte das Volk Israel auf seinem Einzug in das verheißene Land Kanaan zurück, auf dem es trockenen Fußes den Jordan durchquerte. Zum Gedenken an die wundersame Durchwanderung des Flusses stellte Josua in

57 Duitsch, Het vervolg, S. 413. Diese Textstelle lehnt sich eng an Ps 55,7-9 an.

58 Christian Salomon Duitsch, Intree-Reeden uitgesproken door Christiaan Salomon Duytsch, voor de gemeinte van Mydrecht. Den 7 September 1777. Uit Ephesen III: 8, Amsterdam 1778, zitiert nach: Deetman, Bloemlezing, S. 491-525, hier: S. 517. - Ohne Autorenangabe, Brieven aan R. M. van Goens en onuitgegeven stukken hem betreffende. Tweede Deel, Utrecht 1886, S. 19-22.

59 Duitsch, Intree-Reeden, S. 510; Übersetzung der niederländischen Textstellen durch die Autorin.

60 Vgl. Andreas Evaristus Mader, Art. Eben-Ezer, in: LThK 3 (21931), Sp. 510. 
Gilgal auf Befehl Gottes zwölf Steine auf, die die zwölf Stämme des Volkes Israel symbolisieren sollten (Jos 3 und 4). Duitsch verbindet hier also zwei Bibelstellen miteinander, in denen die Erinnerung an eine besondere göttliche Unterstützung thematisiert wird, und ordnet seine religiöse Neuorientierung beziehungsweise die Gestaltung seines Gedenkens daran so in eine doppelte biblische Traditionslinie ein. Dabei setzt er die Wanderung von Sittim nach Gilgal nicht mit dem sechsjährigen Umherirren während seines Konversionsprozesses gleich, sondern bezeichnet seine Taufe erst als den zweiten von insgesamt vier »Ebenezers«, so dass der Konversionsprozess lediglich als eine Teilstrecke des Weges ins Gelobte Land erscheint. Das beruhigende Gefühl, in »Gilgal« angekommen zu sein, stellte sich erst ein, als Duitsch am 12. August 1777 der Gemeinde von Mijdrecht als Pfarrer zugewiesen wurde, was ihn zur schriftlichen Errichtung seines letzten »Ebenezers « veranlasste:

[...] so dass ich, heute als Euer gesetzmäßiger Lehrer ordiniert, nun zu dieser Stunde gewürdigt werde, um den heiligen Dienst mit dieser Predigt unter Euch zu beginnen und schon wieder ein Ebenezer zum Ruhm der Gnade errichten und ausrufen muss: Bis hierher hat der Herr geholfen ${ }^{61}$ !

Offenbar war ihm zumindest im Rückblick bewusst, dass ein Konvertit mit der Taufe keineswegs automatisch den sicheren Heimathafen erreichte, wo sein Lebensschiff in aller Seelenruhe vor Anker gehen konnte, sondern dass der formelle Übertritt nichts als eine Zwischenlandung markierte, die keine Garantien gab, auf dem Weg zur echten Integration in das neue Lebensumfeld von Schiffbrüchen verschont zu bleiben.

\section{Fazit}

Die Darstellung raumbezogener Mobilität spielt in den hier untersuchten frühneuzeitlichen Konversionserzählungen ehemaliger Juden eine wichtige, zum Teil zentrale Rolle. Dabei ist nicht immer eindeutig erkennbar, aus welchen Gründen beziehungsweise auf wessen Veranlassung ein Ortswechsel erfolgte, da die Grenze zwischen Selbst- und Fremdsteuerung sowie zwischen Freiwilligkeit und Zwang oft fließend ist. In vielen Fällen scheint raumbezogene Mobilität für die Konvertiten eine (oder gar die einzige) Möglichkeit gewesen zu sein, den verbleibenden Handlungsspielraum zu nutzen oder sich überhaupt erst Handlungsspielräume zu erschließen und die Freiheit zu eigenständigen Entscheidungen zurückzuerlangen. Ziellose Mobilität wurde

61 Duitsch, Intree-Reeden, S. 518f. 
offenbar als irritierend erlebt und erweckte das Bedürfnis nach retrospektiver Sinngebung als Teil eines göttlichen Plans.

Diese große Bedeutung von Mobilität wird nicht nur auf der Ebene der erzählten Inhalte, sondern mindestens ebenso sehr in der sprachlichen Gestaltung der Konversionserzählungen fassbar. Bei Duitsch avancieren Mobilitätsmetaphern zum Leitmotiv seiner Schriften. Der gesamte Konversionsprozess wird sogar als »Wüstenwanderung « - und damit als Erfahrung raumbezogener Mobilität - gedeutet.

Zudem hat die Auswertung der Quellen ergeben, dass die konkrete raumbezogene Mobilität der hier betrachteten Konvertitinnen und Konvertiten eng mit einer anderen, mentalen Form von Mobilität im Sinne eines Hinterfragens früherer Überzeugungen und Gewissheiten korreliert ist, wobei die Reihenfolge beider Mobilitätsformen variieren $\mathrm{kann}^{62}$. Dies deutet darauf hin, dass es sich bei einer religiösen Konversion per se um eine Form von Mobilität handeln könnte ${ }^{63}$, die ohne den Rückgriff auf entsprechende Metaphern kaum beschreibbar ist. Für diese Vermutung spricht auch, dass der Terminus »Konversion« ursprünglich eine »Umdrehung«, »Umwandlung« oder »Umkehr « bezeichnet ${ }^{64}$, denn all diese Begriffe bringen eine Bewegung zum Ausdruck - eine Bewegung, die zumindest in den hier ausgewerteten Konversionsfällen eine neue Selbstverortung in mentaler und räumlicher Hinsicht erforderlich machte und mit der offiziellen Annahme des neuen Glaubens in der Taufe durchaus nicht automatisch beendet war.

62 Tully und Baier konstatieren sogar einen generellen Zusammenhang beider Arten von Mobilität: »Die Mobilisierung kultureller Muster und konkrete verkehrserzeugende Mobilität gehen Hand in Hand«. Tully/BAier, Mobiler Alltag, S. 49.

63 Vgl. hierzu auch Günther Hammacher, der die weitaus radikalere These aufstellt, dass es »beim Menschen keine Religion ohne Mobilität« gebe. Günther Hammacher, Philippus als Anhalter. Ein Interview zum Verhältnis von Religion und Mobilität, in: Dieter BeEsE (Hg.), Tatverdächtiger: David. Biblische Geschichten aus polizeilicher Sicht, Bielefeld 1997, S. 129-140, hier: S. 131.

64 Vgl. Hubert Mohr, Art. Konversion/Apostasie, in: HRWG 3 (1993), S. 436-445, hier: S. 437; Dieter Breuer, Konversionen im konfessionellen Zeitalter, in: Friedrich NiEwÖHNER/Fidel RÄDlE (Hg.), Konversionen im Mittelalter und in der Frühneuzeit, Hildesheim 1999, S. 59-69, hier: S. 60; Ute Mennecke-Haustein, Konversionen, in: Wolfgang Reinhard/Heinz Schilling (Hg.), Die katholische Konfessionalisierung. Wissenschaftliches Symposion der Gesellschaft zur Herausgabe des Corpus Catholicorum und des Vereins für Reformationsgeschichte 1993, Münster 1995, S. 242-257, hier: S. 244. 


\title{
Marian Füssel
}

\section{»Als Gefangener in ein ganz fremdes, abergläubisches Land gebracht zu werden, stimmte meine Seele trübe«}

\author{
Kriegsgefangene in fremdkonfessionellem Umfeld und \\ militärische Migration während des Siebenjährigen Krieges
}

Würde man Mobilität allein nach wortwörtlich durchlaufenen Territorien und der Anzahl zurückgelegter Kilometer bestimmen, so zählten die Soldaten sicher zu den mobilsten sozialen Formationen der Frühen Neuzeit ${ }^{1}$. Aber auch wenn man die innere Organisation militärischer Führungseliten betrachtet, ergibt sich ein Bild erstaunlicher Mobilität. So vollzogen sich innerhalb eines transterritorialen Offizierskorps zahlreiche Austauschprozesse jenseits von Nation und Konfession ${ }^{2}$. Irische Offiziere in preußischen und österreichischen Diensten, preußische Offiziere in russischen und französischen Diensten etc. - von einfachen Soldaten ganz zu schweigen - liefern ein komplexes Bild einer auch im Zeitalter der »stehen gebliebenen « Heere extrem mobilen Profession ${ }^{3}$. Räumliche Mobilität war hier eine der wesentlichen Voraussetzungen sozialen Aufstiegs ${ }^{4}$. Gut erforscht sind bislang unter anderem die Kriegsdienste irischer oder hugenottischer Soldaten, wie jüngst etwa

1 Vgl. zuletzt den Überblick bei Matthias Asche u.a. (Hg.), Krieg, Militär und Migration in der Frühen Neuzeit, Münster 2008.

2 Georg Hebbelmann, Das preußische »Offizierskorps« im 18. Jahrhundert. Analyse der Sozialstruktur einer Funktionselite, Münster 1999; Bernhard Kroener, »Des Königs Rock«. Das Offizierskorps in Frankreich, Österreich und Preußen im 18. Jahrhundert - Werkzeug sozialer Militarisierung oder Symbol gesellschaftlicher Integration, in: Peter Baumgart u.a. (Hg.), Die Preußische Armee. Zwischen Ancien Régime und Reichsgründung, Paderborn 2008, S. 72-95; vgl. auch die Dissertation von Carmen Winkel, Offiziere des Königs? Adlige Netzwerke und Patronage im preußischen Offizierskorps 1713-1806, in: Militär und Gesellschaft in der Frühen Neuzeit 1 (2008), S. 81-88, hier: S. 87f.

3 Vgl. z.B. Christopher Duffy, Friedrich der Große und seine Armee, Stuttgart ${ }^{2} 1983$, S. 36f.; Bernhard Kroener, Deutsche Offiziere im Dienst des »allerchristlichsten Königs«(1715-1792). Aspekte einer Sozialgeschichte der Elite deutscher Fremdenregimenter in Frankreich im 18. Jahrhundert, in: Jean Mondot / Jean-Marie Valentin/Jürgen Voss (Hg.), Deutsche in Frankreich, Franzosen in Deutschland 1715-1789. Institutionelle Verbindungen, soziale Gruppen, Stätten des Austausches, Sigmaringen 1992, S. 53-71.

4 Bernhard KroENER, Krieg und Karriere. Geographische Mobilität als Voraussetzung sozialen Aufstiegs in der militärischen Gesellschaft des 17. Jahrhunderts, in: Mathias BEER/Dittmar Dahlmann (Hg.), Über die trockene Grenze und über das offene Meer. Binneneuropäische und transatlantische Migrationen im 18. und 19. Jahrhundert, Essen 2005, S. 45-65. 
ein Sammelband von Matthew Glozier und David Onnekink in europäisch vergleichender Perspektive dokumentiert hat ${ }^{5}$. Neben der mehr oder minder selbst gewählten Mobilität ergaben sich zusätzlich jedoch auch erzwungene interreligiöse beziehungsweise meist interkonfessionelle Transferprozesse etwa durch Kriegsgefangenschaft ${ }^{6}$. Auch die Militärgeschichte hat inzwischen das Konfessionalisierungsparadigma produktiv aufgenommen und gerade für das 17. und 18. Jahrhundert eine verspätete Konfessionalisierung der Streitkräfte aufgezeigt, die sich gegen Ende bereits mit Tendenzen zur »Dekonfessionalisierung « berühren konnte ${ }^{7}$. Ergänzend zu einer traditionell stark auf die obrigkeitlichen Disziplinierungsbemühungen ausgerichteten Sichtweise sind damit inzwischen auch Perspektiven auf die individuell gelebte Frömmigkeitspraxis der Soldaten eröffnet worden, die insgesamt wohl von einem deutlichen Pragmatismus beziehungsweise Synkretismus geprägt war, der beispielsweise auch magische Praktiken zu integrieren wusste ${ }^{8}$. Ein gewiss extremes Beispiel für pragmatische konfessionelle Indifferenz liefert etwa der spektakuläre Fall der lesbischen Soldatin Catharina Margaretha Linck, die zu Beginn des 18. Jahrhunderts unter verschiedenen männlichen Verkleidungen wiederholt auch die Konfession wechselte9.

Im Folgenden soll am Beispiel des Siebenjährigen Krieges ausgehend von ausgewählten Selbstzeugnissen vor allem die Innensicht der beteiligten Soldaten beleuchtet werden. Wie reagierten die Soldaten auf ein fremdkonfessionelles Umfeld und wie nahmen sie die Akteure und Praktiken ihres konfessionellen Gegenübers wahr? Zunächst wird zur Kontextualisierung ein kurzer Überblick über das Verhältnis von Religion und Politik im Siebenjährigen Krieg gegeben (I.), anschließend werden verschiedene, über konfessi-

5 Matthiew Glozier/David OnNekink (Hg.), War, religion and service. Huguenot soldiering 1685-1713, Aldershot 2007.

6 Daniel HонRатн, »In Cartellen wird der Wert eines Feindes bestimmet«. Kriegsgefangenschaft als Teil der Kriegspraxis des Ancien Régime, in: Rüdiger Overmans (Hg.), In der Hand des Feindes. Kriegsgefangenschaft von der Antike bis zum Zweiten Weltkrieg, Köln 1999, S. 141170; Bernhard Kroener, Der Soldat als Ware. Kriegsgefangenenschicksale im 16. und 17. Jahrhundert, in: Heinz Duchhardt/Patrice Veit (Hg.), Krieg und Frieden im Übergang vom Mittelalter zur Neuzeit. Theorie, Praxis, Bilder, Mainz 2000, S. 271-295.

7 Michael Kaiser/Stefan Kroll (Hg.), Militär und Religiosität in der Frühen Neuzeit, Münster 2004.

8 Vgl. Michael KaISER, Zwischen »ars moriendi und »ars mortem evitandi . Der Soldat und der Tod in der Frühen Neuzeit, in: Ders./Kroll, Militär und Religiosität, S. 323-343.

9 Zwischen 1705 und 1712 diente sie in hannoverschen, preußischen, hessischen und polnischen Militärdiensten und gab sich je nach Bedarf als katholisch oder evangelisch aus. Später, als sie verheiratet mit ihrer Frau mittellos durch die Lande zog, machte sie den wiederholten Konfessionswechsel gar zur Einnahmequelle: Ursprünglich im Halleschen Waisenhaus pietistisch erzogen konvertierte sie u.a. in Münster bei den Jesuiten zum Katholizismus, um dann später an der Universität Helmstedt wieder Protestantin zu werden usw. Vgl. Angelika Steidele, In Männerkleidern. Das verwegene Leben der Catharina Margaretha Linck alias Anastasius Rosenstengel, hingerichtet 1721. Biographie und Dokumentation, Wien 2004, S. 57, 68-91. 
onelle Differenzerfahrungen berichtende Selbstzeugnisse vom europäischen Kriegsschauplatz vorgestellt (II.), um dann drittens einen exemplarischen Blick auf die in habsburgischen Diensten stehenden irischen Religionsflüchtlinge zu richten (III.).

\section{Der Kontext: ein inszenierter Religionskrieg}

Der Siebenjährige Krieg gilt gemeinhin nicht als Religionskrieg, doch spielten konfessionelle Motive im Bereich der politischen >Propaganda< hier weiterhin eine zentrale Rolle ${ }^{10}$. Vor allem Friedrich II. versuchte wiederholt, dem Konflikt eine konfessionelle Kontur zu verleihen. Eine protestantischanglikanische Koalition von England und Preußen, wie sie durch die Westminster-Konvention geschaffen wurde, auf der einen, ein katholisches französisch-österreichisches, später noch um Spanien erweitertes Bündnis auf der anderen Seite, schien entsprechende Zuschreibungen zunächst nahezulegen ${ }^{11}$. Aber schon der Kriegseintritt Schwedens machte es Friedrich sehr schwer, sich weiterhin als Verteidiger der protestantischen Sache auszugeben. Manfred Schort hat vor kurzem die Propagandaschlachten in den zeitgenössischen Flugschriften untersucht, die besonders von Friedrich von Beginn an zur Inszenierung eines Religionskrieges genutzt wurden. Einen Anfang machte der Kammergerichtsrat Ludwig Martin Kahle mit seiner anonymen Schrift Unbilliges Verfahren des Ertz-Hauses Oesterreich gegen die Evangelische. Gleich zu Beginn heißt es etwas heuchlerisch:

Es ist gewiss, dass Deutschland Ruhe und Frieden haben kann, imgleichen, dass die darin befindliche verschiedene Religionen den Umsturz des Vaterlandes niemals veranlassen werden, wenn man nicht die Religion zum Deckmantel besonderer, unlauterer Absichten gebrauchet ${ }^{12}$.

10 Vgl. Manfred Schort, Politik und Propaganda. Der Siebenjährige Krieg in den zeitgenössischen Flugschriften, Frankfurt am Main 2006, S. 99-110; Antje Fuchs, Der Siebenjährige Krieg als virtueller Religionskrieg an Beispielen aus Preußen, Österreich, Kurhannover und Großbritannien, in: Franz Brendle/Anton Schindling (Hg.), Religionskriege im alten Reich und in Alteuropa, Münster 2006, S. 313-343; Johannes Burkhardt, Abschied vom Religionskrieg. Der siebenjährige Krieg und die päpstliche Diplomatie, Tübingen 1985; Siegfried FITTE, Religion und Politik vor und während des siebenjährigen Krieges, Berlin 1899.

11 Vgl. Manfred Schlenke, England und das friderizianische Preussen: 1740-1763. Ein Beitrag zum Verhältnis von Politik und öffentlicher Meinung im England des 18. Jahrhunderts, Freiburg i.Br. 1963, S. 220-265.

12 [Ludwig Martin KaHLE], Unbilliges Verfahren des Ertz-Hauses Oesterreich gegen die Evangelische, in: Otto Krauske (Hg.), Preussische Staatsschriften aus der Regierungszeit König Friedrich II, Berlin 1892, S. 256-317, hier: S. 256. 
Diese unlauteren Absichten expliziert Kahle dann anhand der Geschichte der Verfolgung der Protestanten durch die Erzherzöge von Österreich seit der Reformation. Für unseren Zusammenhang bemerkenswert ist unter anderem die angebliche Verweigerung des »jus emigrandi«, also der »traurigen Wohltat emigriren zu dürfen ${ }^{13}$. Auf entsprechende Eingaben der in ihrer freien Religionsausübung behinderten Protestanten habe Maria Theresia sehr ungehalten reagiert und deutlich zu erkennen gegeben, »dass sie denen Protestanten das Beneficium emigrandi nicht verstatten wollte $\ll^{14}$. Die Publikation des Textes wurde vielerorts verboten und führte zu verschiedenen Auseinandersetzungen. Es folgten zahlreiche nicht minder umstrittene Antworten wie etwa die des Franzosen Maubert de Gouvest ${ }^{15}$. Neben der politischen Bündnissituation war aber auch die bekannte, der Religion eher abholde Einstellung des aufgeklärten Preußenkönigs nicht dazu angetan, die These vom Religionskrieg mit großer Glaubwürdigkeit auszustatten. Ein reichspatriotisch gesinnter Autor wunderte sich daher 1757:

Da wir aber bey gegenwärtigen Krieg von keiner Verfolgung weder der einen noch der andern Religion etwas hören; so wüßte ich nicht, warum man die Religion immer in das Spiel mengen, und diesen König zu deren Beschützer aufwerfen will, da man sich von keinem Religions-Krieg etwas zu fürchten ${ }^{16}$.

Wenn sich dann doch einmal religiös motivierte Übergriffe ereigneten, wie etwa das symbolträchtige Bockstehen eines protestantischen Pfarrers für einen französischen Oberst im Vorfeld der Schlacht von Rossbach, wurden diese schnell propagandistisch ausgeschlachtet ${ }^{17}$. Preußen war dabei nicht die einzige Kriegspartei, die den imaginierten Religionskrieg zu instrumentalisieren suchte, auch in England wurde mit dem Antikatholizismus publizistisch Politik wie Geld gemacht, wie sich etwa an den antikatholischen Bildern

13 Ebd., S. 307.

14 Ebd., S. 309.

15 Vgl. Schort, Politik, S. 106-108.

16 Freymüthige Gedanken über die angeblichen Verdienste Sr. Jetzt regierenden Königl. Majestät in Preußen um das gesamte teutsche Reich als ein Antwort-Schreiben eines Schwaben an einen seiner Freunde in Franken. Anno 1757, in: Teutsche Kriegs-Canzley, 3 Bd. Nr. 62, Frankfurt am Main/Leipzig 1757, S. 339-356, hier: 341.

17 Die Episode wurde auch zum Gegenstand eines zeitgenössischen Kupferstichs mit dem Titel »Im Weissenfelschen, an den Ort Weichschütz vor der Schlacht bey Rossbach, hat müssen der dasige Pastor Schren, einen Französischen Obersten, da er hat wollen aufs Pferd steigen, einen so genannten Bock stehen, und er ist von ihm aufs Pferd gestiegen«. Vgl. Schort, Politik, S. 297, 548 (Abbildung); Thomas CARLYLE, History of Friedrich II. of Prussia, called Frederick the Great, Bd. 5, London 1865, S. 219; Grosser Generalstab (Hg.), Die Kriege Friedrichs des Großen. 3. Theil: Der Siebenjährige Krieg 1756-1763, Bd. 5: Hastenbeck und Rossbach, Berlin 1903, S. 124, 251. 
William Hogarths zeigt $t^{18}$. Von Großbritannien und Frankreich aus transferierten sich die konfessionellen Differenzen auch auf die außereuropäischen Kriegsschauplätze vor allem in Neu-England und Kanada, wo ebenfalls versucht wurde, mit dem konfessionellen Gegensatz Politik zu machen ${ }^{19}$. Flugschriften wie The cruel massacre of the protestants, in North America: shewing how the French and Indians join together to scalp the English, and the manner of their scalping waren dazu angetan, die konfessionellen Gemüter von der Wichtigkeit des Krieges auch in Übersee zu überzeugen ${ }^{20}$. Obwohl insgesamt letztlich allenfalls von einem inszenierten beziehungsweise virtuellen Religionskrieg die Rede sein kann, standen sich nichtsdestoweniger sowohl in Europa als auch in Übersee an vielen Fronten Soldaten unterschiedlicher Konfession gegenüber beziehungsweise waren gezwungen, sich in ein fremdkonfessionelles Territorium zu begeben.

\section{Innensichten: peregrinatio bellica und Kriegsgefangenschaft}

Auch ohne Religionskrieg äußerten sich oft genug konfessionelle Wahrnehmungsmuster in den Selbstzeugnissen der Soldaten des Siebenjährigen Krieges vom Gemeinen bis zum Offizier und Feldprediger ${ }^{21}$. Im Rahmen einer Schlacht etwa, wo Tausende binnen weniger Stunden fielen, konnten konfessionelle Abgrenzungen hilfreich sein. So schreibt beispielsweise der Soldat J.S. Liebler nach der Schlacht bei Prag 1757 an seine Familie, er habe die »göttliche Versicherung « in sich: »ob Tausend fallen zu deiner linken und Zehntausend zu deiner rechten, so wird es dich doch nicht treffen. Ja, ich habe mit meinen Augen gesehen, wie es den Feinden des Evangelii vergolten wird $^{22} \ll$.

Die göttliche Vorsehung schützt mithin die Angehörigen des richtigen Bekenntnisses. Mit wie viel Pragmatismus religiöse Differenzen in der Praxis

$18 \mathrm{Zu}$ Hogarth vgl. Fuchs, Religionskrieg, S. 323-340.

19 Vgl. das Kapitel »Who will be Masters of America: The French or the English?« Manhood and Imperial Warfare in the Eighteenth Century, in: Ann M. Little (Hg.), Abraham in Arms. War and Gender in Colonial New England, Philadelphia 2007, S. 166-204.

20 The cruel massacre of the protestants, in North America: shewing how the French and Indians join together to scalp the English, and the manner of their scalping, London 1760.

21 Vgl. bereits Horst CARL, »Die Aufklärung unsers Jahrhunderts ist ein bloßes Nordlicht [...] Konfession und deutsche Nation im Zeitalter der Aufklärung, in: Heinz-Gerhard Haupt/Dieter Langewiesche (Hg.), Nation und Religion in der deutschen Geschichte, Frankfurt am Main 2001, S. 105-141, hier: S. 120f.

22 Briefe Preußischer Soldaten aus den Feldzügen 1756 und 1757, in: Preußische Soldatenbriefe. Mit einer Einleitung von Hans Bleckwenn, Osnabrück 1982, S. 45. Zur religiösen Bewältigung von Kampferfahrungen vgl. Sascha MöBıus, Mehr Angst vor dem Offizier als vor dem Feind? Eine mentalitätsgeschichtliche Studie zur preußischen Taktik im Siebenjährigen Krieg, Saarbrücken 2007, S. 106-110. 
jedoch ebenso überbrückt werden konnten, zeigt das Beispiel des Feldpredigers Christian Täge, der während des Krieges als Protestant in russische Dienste trat. Nachdem die russische Armee unter General Fermor im ostpreußischen Marienwerder einmarschiert war, zählte die russische Generalität bald zu den Zuhörern der Sonntagspredigten des dort ansässigen jungen Diakons Täge ${ }^{23}$. Schon bald befehligte Fermor Täge zu sich und befahl ihm, als Feldprediger in russische Dienste zu treten. Obwohl Täge, wie er in seiner Lebensgeschichte schreibt, schwere Gewissensbisse hatte, fügte er sich dem Befehl des Generals und wurde schon kurze Zeit später in der Hauptkirche vom russischen Erzpriester examiniert und ordiniert. Fermor hatte ein persönliches Interesse daran, denn er hielt laut Täge

sehr viel von Religion, und drang bei der ganzen Armee mit einer gewissen Strenge wenigstens auf das äusserliche Bekenntniß derselben. Jedes Regiment hatte daher auch einen Popen, und über alle war ein Protopop gesetzt. Nur für ihn, der lutherisch war, für viele von dem Generalstabe und für einige vom Unterstabe hatte er bisher keinen Prediger gehabt ${ }^{24}$.

Während Täge im Folgenden mit Erfolg den protestantischen Offizieren predigte, trat bald eine neue Herausforderung an ihn heran: Er sollte nun auch die Kosaken und Kalmüken segnen, die als Vorhut über die Weichsel gehen sollten. Täge inszeniert den entsprechenden Dialog wie folgt:

>Ich? Ein lutherischer Prediger? Soldaten griechischer Religion?< >Der Hetman sagt, wir alle wären Christen, und ihr Segen wäre so gut, wie der Segen des Protopopen, dem sonst dieses Amt obliegt, der aber noch nicht von Königsberg eingetroffen ist.< ,Ich kann nicht ein Wort russisch! > Schadet nichts! Wenn auch niemand sie versteht. Der Russe hält viel auf jeden Prediger, von dem er weiß, dass er zu seinem Amte ordentlich eingesegnet sei. Sprechen sie nur mit Wahrheit und Rührung, und wenn ich mich unterstehen darf, Ihnen einen Rath zu geben, so mischen sie fleißig die Namen Abraham, Isaak und Jakob in ihre Rede. Sie werden den Beifall erfahren, welchen die versammelte Menge Ihnen geben wird ${ }^{25}$.

Täge machte seine Aufgabe gut, die Russen bekreuzigten sich bei Nennung der biblischen Namen, und er war selbst ganz gerührt von seiner eigenen Predigt. »Nach gesprochenem Segen« drückte ihm der Hetman »mit einem gefühlvollen Ausdruck im Gesicht«, den er nie vergessen habe, 40 Rubel in die

23 August Samuel Gerber (Hg.), Christian Täge's ehemaligen russischen Feldpredigers Lebensgeschichte. Nach dessen eigenen Auffsätzen bearbeitet und herausgegeben vom Verfasser der Novellen von Doro Caro, Königsberg 1804, S. 130ff.

24 Ebd., S. 136f.

25 Ebd., S. 139 f. 
Hand $^{26}$. Täges weiteres Schicksal verlief abenteuerlich. Bei Zorndorf geriet er 1758 in preußische Gefangenschaft und wurde dort zu seinem Kummer ausgerechnet von einem Geistlichen besonders schlecht behandelt. Die PreuBen wechselten ihn in der Folge aus, und Täge kehrte zurück nach Marienwerder in russische Dienste. Sein Gönner Fermor fiel alsbald am Zarenhof in Ungnade, und der Feldprediger wurde daraufhin verhaftet und geriet in St. Petersburg für zwei Jahre in russische Gefangenschaft. Noch vor Kriegsende kam Täge frei und erhielt schließlich eine von den Russen finanzierte Pfarrersstelle in Pobethen im Samland.

$\mathrm{Zu}$ den wesentlichen Möglichkeitsbedingungen religiöser Differenzerfahrung zählte die extrem hohe räumliche Mobilität der mit ihren Regimentern ständig in Bewegung befindlichen Soldaten. Ein in dieser Hinsicht typisches, bislang von der Forschung kaum beachtetes Schicksal ist das des Braunschweiger Soldaten Johann Heinrich Ludwig Grotehenn (1734-1786) ${ }^{27}$. In rund 60 Briefen, die eine Art zusammenhängender Erzählung bilden, berichtet der spätere Aeditor der Braunschweiger Garnisonskirche in der für soldatische Selbstzeugnisse der Zeit typischen Itinerarstruktur über seine Erlebnisse auf dem westlichen Kriegstheater ${ }^{28}$. Die Truppen ziehen von Ort zu Ort, von Lager zu Lager und Grotehenn kommentiert die jeweilige materielle Versorgung, das Wetter, die Beschwerlichkeit des Weges. An manchen Orten, an denen er länger verweilte, geht er mitunter sehr ins Detail, berichtet über Land und Leute, Sehenswürdigkeiten und kleine Begebenheiten des Alltags. Sein langer Weg führte ihn zunächst von Braunschweig über Hameln nach Lemgo und von dort unter anderem nach Bielefeld, Minden, Schaumburg, Halle, Hastenbeck, Loccum, Verden, Zeven, Stade, Buxtehude, Celle, Nienburg, Minden, Telgte, Coesfeld, Dülmen, Paderborn, Münster, Winneberg und Fulda. Besonders aufschlussreich für die konfessionellen Wahrnehmungen ist sein längerer Aufenthalt im katholischen Telgte bei Münster.

26 Ebd., S. 142.

27 Vgl. zu ihm Marian Füssel, Ansichten des Krieges: Deutsche Augenzeugenberichte zum 1. August 1759, in: Martin STEFFEn (Hg.), Die Schlacht bei Minden. Weltpolitik und Lokalgeschichte, Minden 2008, S. 97-108, 231-234.

28 [Johann Heinrich Ludwig Grotehenn], Kurzer Entwurf von meiner Geburt und Herkunft, wie auch Ferneres Ergehen, angenehmer und widriger Schicksalen. Auch Briefe und kleine Nachrichten die ich während dem Kriege, welcher sich Anno 1757. im Monat April eraugnete, an meinen Vater geschrieben, woraus theils zu ersehen, wie wir herumgewandert und was sich begeben. Hierinn zusammengetragen von mir Johann Heinrich Ludwig Grotehenn, Aedit. An der Garnison-Kirche in Braunschweig 1767 [Stadtarchiv Braunschweig H III/3-64]. Auszüge aus den Briefen Grotehenns wurden 1991 von Hans Hölscher in einer heimatgeschichtlichen Schriftenreihe der Gemeinde Kirchbrak gedruckt: Johann Heinrich Ludewig GroteHENN, Briefe aus dem Siebenjährigen Krieg: 1757-1763, bearbeitet von Hans Hölscher, 3 Hefte, Kirchbrak 1991/92. Hölscher folgte dabei allerdings nicht wissenschaftlichen Editionsgrundsätzen und ließ zahlreiche Passagen, die ihm redundant oder unwichtig schienen, einfach aus. Im Folgenden wird dabei aus dem Original des Braunschweiger Stadtarchivs zitiert. 
Der bekannte Marienwallfahrtsort war durch eine ausgeprägte katholische Frömmigkeitskultur gekennzeichnet, die nicht ohne Wirkung auf den Braunschweiger blieb ${ }^{29}$. Gleich am ersten Tag, als er einen Freund in Telgte besuchte, wurde er von dessen Wirt sofort zu einer Besichtigung des »Gnadenthrons«, des Marienbildes, geführt. Grotehenn bestaunt höflich die prächtig ausgestattete Wallfahrtsstätte mit den von geheilten Kranken zurückgelassenen Krücken und wird mit einer entsprechenden Legende über die Wunderkraft Marias belehrt. Doch seine Konfrontation mit ihrer besonderen Heilkraft sollte noch massiver werden. In einem Gartenhaus mit kaputten Fenstern einquartiert, zog sich Grotehenn bald eine schwere Erkältung mit »Brust Fieber « zu und ließ sich einen Chirurg kommen, der ihn zur Ader ließ. Seine Wirtin insistierte nun darauf, dass der Kranke doch mit ihrem kranken Pferd zur Maria reiten solle, um sich heilen zu lassen. Grotehenn lehnte jedoch ab und vertraute auf den seiner Ansicht nach medizinisch >rationalen< Aderlass. Endlich geheilt bedankte sich der junge Braunschweiger mit freiwilliger Gartenarbeit. In Münster besichtigte er die Kirchen und bewundert die Wiedertäuferkäfige am Lambertiturm.

Das Beispiel des Braunschweigers ist typisch für die Konfrontation protestantischer Soldaten mit katholischer Volksfrömmigkeit, die in verschiedenen Quellen zur Sprache kommt.

Neben der Stationierung in fremdkonfessionellen Territorien waren es vor allem die Erfahrungen der Kriegsgefangenschaft, die eine Konfrontation mit anderen Glaubensrichtungen herbeiführten ${ }^{30}$. So etwa beim preußischen Musketier Johann Jacob Dominicus (1731-1775), der in Harhausen nördlich von Gummersbach geboren wurde, nach dem frühen Tod seines Vaters bei seinem Stiefvater aufwuchs und eine Kaufmannslehre in Iserlohn machte ${ }^{31}$. Mit neunzehn Jahren wurde er als »Landeskind « in die preußische Armee einberufen und kam zu einem in Hamm und Soest stationierten Regiment. Dominicus durchlebte als Musketier den ganzen Siebenjährigen Krieg und geriet am 21. November 1759 bei Maxen im so genannten »Finckenfang « in österreichische Gefangenschaft, wo er bis Kriegsende verblieb ${ }^{32}$. Der Zusammenhang von Religion und soldatischer Mobilität wird bereits in der Materialität seiner Niederschrift greifbar, denn seine handschriftlichen Aufzeich-

29 Zum Kontext vgl. Werner Freitag, Volks- und Elitenfrömmigkeit in der Frühen Neuzeit. Marienwallfahrten im Fürstbistum Münster, Paderborn 1991.

30 Eine Auswahl an Selbstzeugnissen und Egodokumenten bietet Lutz VoIgTLÄNDER, Vom Leben und Überleben in Gefangenschaft. Selbstzeugnisse von Kriegsgefangenen 1757 bis 1814, Freiburg i.Br. 2005, S. 21-69; vgl. auch ders., Die preußischen Kriegsgefangenen der Reichsarmee 1760/1763, Duisburg 1995, zu den religiösen Belangen vgl. S. 196-200.

31 Dietrich Kerler (Hg.), Aus dem siebenjährigen Krieg. Tagebuch des preußischen Musketiers Dominicus, München 1891 (ND Osnabrück 1972). 
nungen finden sich mit einem gedruckten Psalter und seinem Gesangbuch zusammengebunden, in das er an manchen Stellen Notizen über seinen Weg eingetragen hat ${ }^{33}$. Doch Zeugnisse wie die von Dominicus oder Grotehenn sind leider verhältnismäßig selten.

Erst auf den höheren Ebenen der militärischen Hierarchie werden die Selbstzeugnisse häufiger. So berichtet beispielsweise die Lebensbeschreibung Carl Wilhelms von Hülsen (1734-1810) über ähnliche Erfahrungen mit den Katholiken ${ }^{34}$. Der 1734 geborene Junker von Hülsen, Sohn eines Rittmeisters, genoss eine protestantische religiöse Erziehung und trat 1750 in die Dienste des Infanterieregimentes von Below. Während des Krieges wurde er 1757 unter anderem in Preußisch-Pommern stationiert, wo es zu Zusammenstößen mit der polnischen Bevölkerung kam, die, wie er berichtet, die Preußen für »Ketzer « hielt ${ }^{35}$. Ende November 1759 geriet auch von Hülsen bei Maxen in österreichische Gefangenschaft und wurde zunächst wie die anderen Offiziere nach Dresden transportiert und bei einem ehemaligen Kammerdiener des sächsischen Hofes komfortabel untergebracht. Doch schon nach wenigen Tagen nahte der Aufbruch in die Kriegsgefangenschaft, die insgesamt zwei Jahre dauern sollte. Hülsen notiert: »Welche Aussicht hatte ich vor mir! Als Gefangener in ein ganz fremdes, abergläubisches Land gebracht zu werden, stimmte meine Seele trübe, und dennoch sollte ich die Erfahrung machen, dass Gott überall getreu mit mir sei ${ }^{36} \ll$ !

Dieses fremde, »abergläubische« Land war Österreich. Es folgen zwei Jahre Gefangenschaft in Krems und Umgebung, die Hülsen allerdings nur kurz behandelt, da diese offenbar wenig rühmlich von Alkoholismus und Händeln geprägt waren. Über die Situation der Kriegsgefangenen in Krems besitzen wir jedoch mehrere Zeugnisse preußischer Soldaten, die ihrem Missfallen gegenüber der Kultur der Katholiken in Beschreibungen des allgemeinen Sittenverfalls Ausdruck verleihen. Fähnrich Christian Wilhelm von Prittwitz (1739-1807) etwa beteuert in seiner Lebensbeschreibung zu Beginn seines Berichts über seine Kremser Gefangenenzeit, dass er davon angesichts der begangenen Torheiten lieber gänzlich geschwiegen hätte, liefert dann aber als »aufrichtiger Erzähler« eine detailreiche Beschreibung. So wird das Missver-

32 Vgl. ebd., S. 76ff. Zu Maxen vgl. Georg WinTER, Die kriegsgeschichtliche Überlieferung über Friedrich den Grossen kritisch geprüft an dem Beispiel der Kapitulation von Maxen, Berlin 1888; Ludwig Mollwo, Die Kapitulation von Maxen, Marburg 1893; Grosser Generalstab (Hg.), Die Kriege Friedrich des Großen. Dritter Theil: Der siebenjährige Krieg 1756-1763, Bd. 11: Minden und Maxen, Berlin 1913.

33 Vgl. die Beschreibung bei Kerler, Dominicus.

34 Carl Wilhelm von Hülsen, Unter Friedrich dem Großen. Aus den Memoiren des Aeltervaters 1752-1773, Berlin 1890 (ND Osnabrück 1974).

35 Ebd., S. 60.

36 Ebd., S. 106. 
halten der Kriegsgefangenen schnell mit der allgemeinen Sittenlosigkeit der Katholiken verknüpft und damit zum Teil relativiert:

Wäre die Stadt Krems nicht schon durch ihre üppige und abergläubische Geistlichkeit in einen sittenlosen Zustand versetzt gewesen, so würde ich behaupten, ihre damalige Einquartierung habe denselben herbeigeführt. Aber nun konnte man auf allen Seiten die traurige Bemerkung machen, dass die Schwarzröcke mit den Buntröcken gleichen Schritt hielten und letztere nur das übel vermehrten, das schon vor ihrer Zeit am Gange gewesen ${ }^{37}$.

Dass Prittwitz sich gerade in dieser Situation als besonders aufmerksamer Beobachter erweist, kommt nicht von ungefähr. Der in Schlesien gebürtige Offizierssohn hatte eine pietistisch geprägte, streng-protestantische Erziehung genossen und eigentlich mit einem Studium der Theologie geliebäugelt, sich dann jedoch nicht zuletzt aus Standeskonvention für den Soldatenberuf entschieden ${ }^{38}$. Nach dem Krieg wurde er Mitglied der Herrnhuter Brüdergemeinde, was seine Disposition zur religiös angeleiteten Selbstthematisierung zusätzlich befördert haben dürfte. Aufschlussreich sind etwa von Prittwitz Bemerkungen über die Wahrnehmung des Kultus in Krems:

Reines und unverfälschtes Wort Gottes bekam man hier gar nicht zu hören, auch fehlte es an Bibeln und anderen christlichen Erbauungsbüchern. Dasjenige, was auf den Kanzeln für echte Lehre ausgegeben wurde, war oft das unsinnigste und abgeschmackteste Zeug, das sich nur denken lässt und ohne Widrigkeit und Ekel nicht angehört werden konnte. Daher blieben wir alle ohne Anleitung und Warnung, welches das moralische Übel umso mehr erhöhte.

Die Differenzerfahrung lässt den Preußen die Vorzüge seiner eigenen Konfession umso deutlicher spüren:

37 Christian Wilhelm von PritTwitz, »Ich bin ein Preuße ...«. Jugend und Kriegsleben eines preuBischen Offiziers im Siebenjährigen Krieg. Mit einem Vorwort von Hans Bleckwenn, Paderborn 1989, S. 75.

38 »Da ich da 16, mein Bruder aber 14 1/2 Jahr zurückgelegt hatte, wurden wir gefragt, was für ein Metier wir uns zu widmen gedächten, ob wir studieren oder Soldaten werden wollten? Von diesen beiden Möglichkeiten war nur eine zu wählen: denn für einen jungen Edelmann bleibt keine andere übrig, ob es sich gleich leicht fügen kann, dass er weder zu dem einen noch zu dem anderen - wie es bei uns auch eintraf - eigentlich passt und die dazu erforderlichen Qualitäten besitzt. Freilich hätten wir beide am liebsten das Studium theologicum ergriffen, wozu wir eine große Vorliebe hatten, da aber der Mangel an gehörigen Vorkenntnissen uns nicht unbewußt, wir auch einsahen, welcher Kostenaufwand erforderlich sein dürfte [...] so entschlossen wir uns am Ende, da kein anderer Ausweg übrig blieb, den letzteren Vorschlag einzugehen und den Soldatenstand zu ergreifen«. Ebd., S. 17. 
So wie man die Wohltat einer wohl organisierten Obrigkeit gewöhnlich erst dann nach ihrem wahren Werte zu schätzen weiß, wenn man sich in Ländern befindet, wo sich deren entweder gar keine oder doch nur eine dem Schein nach befindet, ebenso war es auch hier in Betreff der Religion und der davon abhängenden Gottesverehrung. Denn alles, was man mit diesem ehrwürdigen Namen bezeichnete, war nichts denn Trug und Fabel. Dabei lernte man aber auch in der Tat recht einsehen, welche Vorzüge der reelle und unverdorbene Protestantismus vor dem albernen und finsteren Katholizismus voraus hat ${ }^{39}$.

Entsprechende konfessionelle Feindseligkeit konnte mitunter zu handfesten Konflikten führen, wie Prittwitz weiter ausführt:

Wenn das Sanktuarium herumgetragen wurde und uns begegnete, blieben wir gemeiniglich stehen und nahmen die Hüte ab. Da man aber mit dieser Ehrenbezeugung nicht zufrieden war, sondern schlechterdings verlangte, dass wir nieder fallen sollten, wir uns aber dazu nicht bequemen wollten, so entstand darüber ein Zwist, der bis nach Wien zur Kaiserin Maria Theresia gelangte und von ihr dahin entschieden wurde, dass wir entweder die Knie beugen oder uns sogleich entfernen sollten, sobald wir den Schall des dem Hochwürdigen vorausgehenden Glöckchens vernehmen würden. Natürlich wählten wir das letztere, wobei es freilich sehr komisch aussah, wenn jeder, welcher einer dergleichen Prozession nahekam, mit starken Schritten seinem Quartier zueilte. Indessen wurde doch durch diese Prozedur der bisherige Streit beseitigt und die andächtige Bürgerschaft darüber zufrieden gestellt ${ }^{40}$.

Die auf den modernen Beobachter vielleicht übertrieben wirkende Aufmerksamkeit auf das Hutziehen wird verständlicher, wenn man sich etwa das Schicksal des 1766 in Frankreich aufgrund ähnlicher Anschuldigungen hingerichteten Chevaliers de la Barre vergegenwärtigt ${ }^{41}$. Die Vermeidung des Konflikts lässt Prittwitz nun etwas versöhnlichere Töne anschlagen, die bis zu leichter Bewunderung für die Frömmigkeit der Anderen reicht:

Wäre die gottesdienstliche Zeremonie kein bloßes opus operatum gewesen, bei welchem man sich entweder gar nichts oder doch etwas wenig Erbauliches dachte, so würde die ungemeine große Devotion, die man bei jeder darauf Bezug habenden Gelegenheit beobachtete, ganz unstreitig eine wohltätige Sensation bei uns hervorgerufen haben. Denn wenn die Monstranz herumgetragen wurde, fiel alles, Vornehme und Geringe, auf dem steinigen Pflaster nieder, die Wachen traten ins Gewehr, der Offizier

\footnotetext{
39 Ebd., S. 75f.

40 Ebd., S. 76.

41 Vgl. Max Gallo, Que passe la justice du roi. Vie, procès et supplice du chevalier de La Barre, Paris 1987.
} 
kommandierte: >Fallt auf das rechte Knie, nehmt die Hüte ab< und so weiter, welches, da es mit militärischen Tempos verrichtet wurde, einen nicht ungünstigen Anblick gewährte. Gemeiniglich wurde auch der Pater mit einigen wachthabenden Soldaten umgeben, die ihn begleiteten und das Gewehr im rechten Arm trugen ${ }^{42}$.

An dieser Stelle zeigt sich wie das militärische Zeremoniell in der Wahrnehmung konfessionelle Differenzen abschwächen beziehungsweise >ästhetisch ertragbarer machen konnte. Die Grenze zur Lächerlichkeit konnte jedoch in den Augen des Preußen auch leicht überschritten werden, wenn etwa die Jesuiten den militärischen Siegessalut inszenierten: »Possierlich sah es aus, als sich die Jesuiten beikommen ließen, diesen von ihren Völkern abermals errungenen Sieg [bei Breslau 1757, Anm. M.F.] mit Kanonendonner zu publizieren und in ihren schwarzen Mönchs- und Ordenshabit gleich wirklichen Artilleristen das Geschütz zu bedienen ${ }^{43} \ll$.

Situationen, in der die Religiosität in der Fremde besonders zum Problem wurde, waren Tod und Bestattungswesen. Das Läuten des so genannten »Zügen-Glöckchens« etwa, das den nahenden Tod ankündigte, findet Prittwitz von der Absicht her »höchst lobenswert«, doch erreiche es nicht den rechten Zweck: »Es werden nämlich für den in den letzten Zügen liegenden Mitchristen ein paar Ave Maria oder Paternosters stillschweigend heruntergeplappert und dann ist die Sache geschehen «. Prittwitz äußert diesbezüglich dennoch gar den Wunsch, auch in der heimischen Brüdergemeinde ein entsprechendes Geläut zu praktizieren ${ }^{44}$.

Häufig sind es nur indirekte Informationen, die über die konfessionellen Differenzen in der Gefangenschaft Auskunft geben. So etwa im Falle des Tagebuchs des preußischen Leutnants Jakob Friedrich von Lemcke (1738-1810), der nach der Schlacht von Kolin 1757 bei Prag in österreichische Gefangenschaft geriet. In der >goldenen Stadt< trat ihm die Erbitterung der durch die preußische Belagerung in Mitleidenschaft gezogenen tschechischen Zivilbevölkerung entgegen, als er auf einer Bahre durch die Stadt in sein Krankenquartier gebracht wurde: »Als wir über die Moldaubrücke getragen wurden, schrie der Pöbel: >Schmeißt die Kanaillen ins Wasser ${ }^{45}$ ! « Endlich im Quartier angelangt kam er mit einem verwundeten Leutnant von Mar auf eine Stube, der nach drei Tagen an seinen Verletzungen verstarb. Lemcke kommentiert »Vier Tage dauerte es wohl, ehe man die Leiche aus meiner Stube nahm, denn die konnten nicht einig werden, wo sie einen Protestanten begra-

\footnotetext{
42 Prittwitz, Kriegsleben, S. 76.

43 Ebd., S. 77.

44 Ebd., S. $76 f$.

45 R. Walz, Kriegs- und Friedensbilder aus den Jahren 1754-1759. Nach dem Tagebuch des Leutnants Jakob Friedrich v. Lemcke (1738-1810), in: PrJ 138 (1909), S. 19-43, hier: S. 31.
} 
ben sollten $\ll^{46}$. Neben solchen Schwierigkeiten eher praktischer Natur kann wohl davon ausgegangen werden, dass auch die konfessionelle Differenz der Prager das Verhältnis zu den Preußen nicht gerade verbessert haben dürfte. Im katholischen oberschwäbischen Munderkingen löste man die Begräbnisfrage bei den preußischen Kriegsgefangenen, wie dem örtlichen Sterberegister zu entnehmen ist, indem man die zehn verstorbenen Katholiken auf dem gemeindlichen Friedhof bestatte, die fünfundachtzig Protestanten jedoch auf dem »städtischen Zimmerplatz« verscharrte ${ }^{47}$.

Eine besondere Konstellation von konfessionell geprägter Kriegsgefangenschaft hat vor einigen Jahren William Henry Foster an nordamerikanischen Beispielen herausgearbeitet. Denn vielfach unterstanden dort protestantische beziehungsweise präziser gesagt puritanische Männer der Obhut katholischer Frauen, etwa im Gestalt von Nonnen, was neben konfessionellen auch noch geschlechtliche Differenzerfahrungen zeitigen konnte, wie etwa in Montreal, wo zwischen 1759 und 1760 siebenundzwanzig britische Soldaten Zwangsarbeit in einem von Nonnen geführten Hospital beziehungsweise Armenhaus zu leisten hatten ${ }^{48}$.

Auch die Rückkehr in das eigene Land wird in dem meisten Gefangenennarrativen schließlich mit religiösen Markierungen versehen. Prittwitz etwa schildert den Übergang vom »armseligen« habsburgischen Territorium ins $»$ reiche« Schlesien wie folgt:

Erst als wir die österreichisch-schlesische Grenze erreichten wurde es besser, wir trafen wohlhabende Bauern an, und es kam uns vor, als wenn wir aus einer Wüste in das Land Kanaan übergetreten wären, so groß war der Unterschied zwischen diesem Land und den vorhergegangenen Ländern ${ }^{49}$.

Musketier Dominicus schildert, wie er im Mai 1763 in Pressburg (Bratislava) zum ersten Mal nach vier Jahren wieder eine evangelische Kirche besuchen konnte:

Wir kamen um 2 Uhr in Presburg, krigte auch ein evangelisches Wirth. Selbiger sagte, das ietzt 2 Uhr die Resp.[onsorien?] anginge. Wir gleich hinein, war aber eine schlechte Kirche, welche sie nicht besser bauen dörfen, dörfen auch keine Gloken haben. Ich

46 Ebd.

47 Lutz Voigtländer, Sozialgeschichtliche Aspekte der Kriegsgefangenschaft. Die preußischen Kriegsgefangenen der Reichsarmee im siebenjährigen Krieg, in: Overmans, Kriegsgefangenschaft, S. 171-185, hier: S. 179; vgl. ferner auch Haas-Walter VoIGTLÄNDER, Preußische Kriegsgefangene in Memmingen: ein Beitrag zur Geschichte der reichsfreien Stadt während des Siebenjährigen Krieges (1756-1763), Memmingen 2000.

48 William Henry Foster, The captor's narrative. Catholic women and their Puritan men on the early American frontier, Ithaca N.Y. 2003, S. 91-106, 151-155.

49 Prittwitz, Kriegsleben, S. 80. 
fragte auf der Straße, wo die evangelische Kirche wehre; sagte ein Catolischer, da wehre der Luthe Seustal. Ich bin aber recht mit Wemuth in die Kirche komen, und war die erste evangelische Kirche in 4 Jahr. Wir sungen: >Wo sol ich fliehen hin? und wurde das Cap. Joh.1 gelesen, nachgehends Busgebet und Beicht gehalten ${ }^{50}$.

In seinem Gesangbuch notierte der Musketier auf der Seite des Liedes entsprechende Hinweise, die später offenbar in die Reinschrift des Tagebuchs einflossen. Auch in Bösing (heute Pezinok) registriert Dominicus ausführlich die Situation seiner evangelischen Glaubensbrüder ${ }^{51}$. Sein Rückmarsch der ihn von der heutigen Slowakei über Schlesien entlang der Oder bis nach Frankfurt von dort über Berlin und Magdeburg schließlich bis in den Raum Bielefeld / Iserlohn führte, wird immer wieder durch eine kurze Bemerkung über die Anzahl evangelischer Kirchen oder überhaupt das Vorhandensein evangelischer Bevölkerungsteile begleitet. Über Breslau heißt es etwa: »eine schöne wolgebaute Stadt mit 12 evangelischen Kirchen $\ll^{52}$.

Innerhalb der österreichischen Armee dienten offiziell nur wenige Protestanten, wobei allerdings davon ausgegangen werden muss, dass nicht alle »Geheimprotestanten« in den Musterungslisten ihr wahres Bekenntnis angaben $^{53}$. Eine für das Verhältnis konfessioneller gegenüber patriotisch-politischen Differenzen aufschlussreiche Konstellation ergab sich allerdings durch den Dienst der protestantischen sächsischen Soldaten für die österreichische und französische Armee ${ }^{54}$. Nach dem preußischen Einmarsch nach Sachsen und der Kapitulation der sächsischen Armee am Lilienstein am 16. Oktober 1756 flohen zahlreiche sächsische Soldaten nach Österreich, wo sie in einem so genannten »Sammlungswerk « neu aufgestellt wurden ${ }^{55}$. Während des Marsches aus den habsburgischen Territorien zur französischen Armee auf dem westlichen Kriegsschauplatz wurden die Sachsen beispielsweise in Schwaben von der protestantischen Bevölkerung dazu aufgerufen, auf ihr konfessionelles Gewissen zu hören und nicht im Dienste der katholischen

50 Kerler, Dominicus, S. $92 \mathrm{f}$.

51 Ebd., S. 93f. Aus der neueren Forschung zum Protestantismus in den habsburgischen Territorien vgl. Rudolf LeEB u.a. (Hg.), Geheimprotestantismus und evangelische Kirchen in der Habsburgermonarchie und im Erzstift Salzburg (17./ 18. Jahrhundert), Wien 2009.

52 Ebd., S. 96.

53 In der Infanterie waren es den Musterungslisten zufolge jedoch immerhin knapp über 5\% Lutheraner, während sich in der Kavallerie kaum Protestanten fanden, vgl. Christopher Duffy, Sieben Jahre Krieg. 1756-1763. Die Armee Maria Theresias, Wien 2003, S. 217.

54 Vgl. dazu das Kapitel über »Vaterlandsliebe und Gottesfurcht« bei Stefan KrolL, Soldaten im 18. Jahrhundert zwischen Friedensalltag und Kriegserfahrung. Lebenswelten und Kultur in der kursächsischen Armee 1728-1796, Paderborn 2006, S. 331-379.

55 Vgl. dazu jetzt Marcus von SAlisch, Treue Deserteure. Das kursächsische Militär und der Siebenjährige Krieg, München 2009. 
Franzosen »gegen das Evangelium zu kämpfen ${ }^{56}$. Ein punktuelles Ansteigen der Desertionsrate scheint tatsächlich eine entsprechende Wirkung auf die Sachsen zu belegen ${ }^{57}$. Die Feldprediger mahnten jedoch ganz in Sinne der militärischen Bündnispragmatik zu religiöser Toleranz, was mit dazu beigetragen haben dürfte, dass im großen und ganzen die patriotisch-politisch Erwägungen die religiösen Gefühle überwogen ${ }^{58}$. Eines der wenigen überlieferten Selbstzeugnisse eines sächsischen Soldaten, die Militarischen und Litterarischen Briefe des Offizier Hans Carl Heinrich von Trautzschen (1730-1812), repräsentiert ganz in diesem Sinne einen sehr nonchalanten Umgang mit der fremden Konfession ${ }^{59}$. Trautzschen gibt sich ganz als aufgeklärter, galanter und gelehrter Offizier, der nur partiell die moralische und kulturelle Überlegenheit der eigenen protestantischen Konfession durchblicken lässt. Die Franzosen bewundert er aufgrund ihrer Kultur, die gerade gegenüber den habsburgischen Landen herausgestrichen wird ${ }^{60}$. Im Feldlager beim westfälischen Unna räsoniert der Sachse im September 1758: »Vor siebenzehn Jahrhunderten, dachte ich bey mir selbst, sah man hier streitbare Römer, die eine Colonie pflanzten, und itzt eine Menge Ordens- und andrer Geistliche, die auf Unkosten des menschlichen Geschlechts leben ${ }^{61} \ll$.

Im Februar 1760 berichtet Trautzschen aus dem Winterlager in Kitzingen, wo wiederum das Ordenswesen problematisiert wird. Trautzschen schreibt über das Vergnügen des Tanzes und seine Kontakte zum weiblichen Geschlecht, das in diesem Punkt zunächst überkonfessionelle Einigkeit aufweise: »Den obschon ein Theil derselben Ihro Päpstliche Heiligkeit, und der andre D. Martin Luthern, als Oberhäupter ihrer Meynung erkennen, so sind sie doch auf dem Balle ganz einerley Sinnes «.

Gerade deshalb sei es allerdings besonders »schade«, dass sie sich »eines hiesigen großen Frauenzimmermagazins gar nicht bedienen können«, denn es seien in demselben »Urselinernonnen«, die man bloß »durch Gitter sehen

56 Ebd., S. 224f. In einem ähnlichen Sinn sind wohl auch die knappen Ausführungen von Friedrich Schillers Vater Johann Caspar Schiller zu lesen, der 1757 Adjutant beim Prinz Louisischen Regiment war und über den Marsch des württembergischen Korps nach Österreich berichtet: »Sowohl bei Geißlingen, als in dem Lager bei Linz revoltirten viele von General von Spinaßischen und Prinz Louis[ischen] Regiment, aus einer von Übelgesinnten ausgestreuten Furcht, für einem Religions-Kriege«. Johann Caspar Schiller, Meine Lebens-Geschichte. Mit einem Nachwort von Ulrich Ott, Marbach am Neckar 1993, S. 7.

57 Ebd.

58 Kroll, Soldaten, S. 344.

59 [Hans Carl Heinrich von Trautzschen], Militarische und Litterarische Briefe des Herrn von T**, Leipzig 1769; zu Trautzschen vgl. Füssel, Ansichten, S. 105-108.

60 Aus Straßburg schreibt er am 20. Juli 1758: »Von den Gränzen der Muselmänner sind wir endlich bey den gesittetern Franzen angelangt, nachdem wir in einer Weite von hundert Meilen unsern deutschen Herren Landsleuten die Aufwartung gemacht haben«. TRAutzschen, Briefe, S. 77f.

61 Ebd., S. 92. 
und sprechen « könne ${ }^{62}$. Besonders gerührt zeigt sich Trautzschen bei der rituellen Aufnahme einer jungen Novizin. Doch sein Briefpartner solle sich nicht einbilden, dass sie nur Frauenklöster besuchen würden, nein ihre »Neugierde « führe sie in alle Klöster, und diejenigen unter seinen Kameraden, die »den Rebensaft lieben, finden dabey besonders ihre Rechnung «. Schließlich kann sich der sächsische Offizier angesichts klösterlicher Pracht doch nicht einer gewissen Ironie enthalten: »Es ist doch eine herrliche Erfindung, dass man durch das Gelübde der Armuth die größten Reichthümer besitzen kann: allein es scheint, als wenn die heiligen Väter dieses Gelübde ihren Unterthanen überliessen ${ }^{63} \ll$.

Trautzschen folgt damit den Beschreibungstraditionen der protestantischen Aufklärung, wie sie sich vor allem in den Reiseberichten der Spätaufklärung artikulierten ${ }^{64}$.

Die hier vorgestellten Beispiele vermitteln eine gewisse Schieflage in der konfessionellen Differenzerfahrung, thematisierten sie doch vorwiegend Protestanten in katholischen beziehungsweise russisch orthodoxen Territorien. Zweifellos gab es auch das andere Modell von katholischen Franzosen oder Österreichern - auf den außereuropäischen Schauplätzen auch katholischen Spaniern - die sich in ein fremdkonfessionelles, in diesem Fall protestantisches oder anglikanisches Umfeld zu begeben hatten. Die Quellenlage lässt es bei derzeitigem Erschließungsstand jedoch kaum zu, hierzu repräsentative Aussagen zu machen ${ }^{65}$. Einzelne Belege vermitteln jedoch den Eindruck, dass sich die Situation grundsätzlich ähnelte. So erfährt man etwa über die französische Besatzung von Hannover, dass auch hier die Begegnung mit dem Sakrament auf der Straße zu Schwierigkeiten führen konnte, so dass der Bürgermeister die Anweisung gab »man solle der Monstranz, wenn man ihr begegne, entweder beizeiten ausweichen, oder wenn das nicht möglich wäre, den Hut abnehmen $\ll^{66}$. Zumindest scheint es in den französischen Be-

62 Ebd., S. 142.

63 Ebd., S. $143 f$.

64 Vgl. Manuel Frey, Toleranz und Selektion. Konfessionelle Signaturen zwischen 1770 und 1830, in: Olaf Blaschke (Hg.), Konfessionen im Konflikt. Deutschland zwischen 1800 und 1970: Ein zweites konfessionelles Zeitalter, Göttingen 2002, S. 113-153.

65 Ein wesentlicher Faktor hierfür dürfte die geringe Dichte an edierten Quellen auf Seiten der $>$ Kriegsverlierer< des Siebenjährigen Krieges sein, vgl. als knappen Überblick über französische Selbstzeugnisse aus Perspektive der Gewaltwahrnehmung Sven Externbrink, »Que l'homme est cruel et méchant!« Wahrnehmung von Krieg und Gewalt durch französische Offiziere im Siebenjährigen Krieg, in: Historische Mitteilungen 18 (2005), S. 44-57. Um die katholische Perspektive zu beleuchten, wären künftig eingehende Recherchen u.a. in Wiener und Pariser Archiven notwendig, die im Rahmen dieses Aufsatzes nicht geleistet werden konnten.

66 Vgl. Antje Fuchs, »Man suchte den Krieg zu einem Religions-Kriege zu machen«. Beispiele von konfessioneller Propaganda und ihrer Wirkung im Kurfürstentum Hannover während des Siebenjährigen Krieges (1756-1763), in: KaISER/Kroll, Militär und Religiosität, S. 207-224, hier: S. 220. 
satzungsgebieten im Westen zu keinen nachhaltigen konfessionellen Konfrontationen gekommen zu sein.

\section{Karrieren: Die Wildgänse kommen - Browne und die Iren in österreichischen Diensten}

Neben den angeführten Fällen eher temporärer Migration gab es zweifellos auch einige erstaunliche Karrieren von Soldaten mit religiösem >Migrationshintergrund<, wie sich exemplarisch an den >Wildgänsen $<$, den irischen Militärimmigranten des 17. und 18. Jahrhunderts zeigen lässt. Bereits während des Dreißigjährigen Krieges war eine erste Generation irischer Militärimmigranten in habsburgische Dienste getreten und dort zu hohen Würden aufgestiegen. In den zweihundert Jahren von 1630 bis 1830 finden sich dann nicht weniger als 1500 Iren in den Offizierslisten der Habsburger Armee ${ }^{67}$. Die irischen Offiziere heirateten in den österreichischen Hochadel ein, gründeten eigene »hybernische« Klöster - wie das irische Franziskanerkloster in Prag - zur Ausbildung und religiösen Identitätsbildung ihrer Landsleute und knüpften intensive Netzwerke mit ihren Landsleuten.

Einen der spektakulärsten sozialen Aufstiege in Zeiten des Siebenjährigen Krieges dürfte der Ire Maximilian Ulysses Browne (1705-1757) genommen haben $^{68}$. Für den Katholiken Browne brach nach den militärischen Erfolgen der Protestanten zu Beginn der 1690er Jahre eine harte Zeit in Irland an, die viele seiner Landsleute dazu trieb, das Land zu verlassen und in ausländische militärische Dienst zu treten. Während zahlreiche katholische Iren zunächst in Frankreich und Spanien in Dienst traten, findet sich auch eine ganze Reihe, die später in die Armee der Habsburger eintrat ${ }^{69}$. Stellvertretend für diese Generation kann eine Eingabe von Nikolaus von Taaffe (1677-1769) an Maria Theresia gelten, in der er schreibt, dass er Irland verlassen habe,

67 Declan Downey, Die Wildgänse und der Doppeladler. Irische Integration in Österreich von 1630 bis 1918, in: Christoph Hatschek/Michael Kenny (Hg.), Die Wildgänse. Irische Soldaten im Dienste der Habsburger, Wien 2003, S. 43-59, hier: S. 44.

68 Christopher Duffy, Feldmarschall Browne. Irischer Emigrant - Kaiserlicher Heerführer - Gegenspieler Friedrichs II. von Preussen, Wien 1966.

$69 \mathrm{Zu}$ Spanien vgl. Enrique García Hernán/Óscar Recio Morales (Hg.), Extranjeros en el ejército: militares irlandeses en la sociedad española, 1580-1818 (= Essays on the Irish military presence in early modern Spain, 1580-1818), Madrid 2007. Vgl. auch die weiteren Forschungsaktivitäten und Publikationen des spanischen Projektes unter: URL: http://www.irishinspain. org; ferner zur irischen Migration Thomas O'Connor (Hg.), The Irish in Europe 1580-1815, Dublin 2001; ders. / Mary Ann Lyons (Hg.), Irish Migrants in Europe after Kinsale 1602-1820, Dublin 2003; Mary Ann Lyons (Hg.), Irish communities in early modern Europe, Dublin u.a. 2006. 
weil er befürchtete, dass seine Nachkommen unter dem Druck der (gegen die Katholiken gerichteten) Strafgesetze der Versuchung, protestantisch zu werden, nicht hätten widerstehen können. Er suche daher in einem katholischen Land Zuflucht, in dem seine Vorfahren durch die Kriegsdienste, die sie zu verschiedenen Zeiten dem Hause Österreich geleistet hätten, wohl bekannt seien. Er habe seine Verwandtschaft, seinen Grundbesitz, seinen Rang und die Freiheit, die er zu Hause genossen habe, verlassen, um zu verhindern, dass seine Nachkommen einer Religion untreu würden, der ihre Kaiserliche Majestäten so innig ergeben seien ${ }^{70}$.

Der 1705 in Basel geborene Browne, Sohn und Neffe bereits in habsburgischen Diensten stehender Offiziere, trat früh in den Militärdienst ein und erlebte bis zu seinem Tod 1757 nach der Schlacht bei Prag eine beispiellose Karriere, die auch viele irische Landsleute begünstigte. Zu den Protegés von Feldmarschall Browne, die während des Siebenjährigen Krieges für Österreich kämpften, zählten unter anderen Feldmarschall Franz Moritz Graf Lacy, Dauns Nachfolger als Präsident des Hofkriegsrats, General Johann Sigismund Graf McGuire, Stadtkommandant von Dresden, General Karl Graf Kavanagh, Statthalter von Prag, General Heinrich Graf O'Donnell sowie Oberst Thomas Freiherr von Plunkett, Stadtkommandant von Antwerpen ${ }^{71}$. Wie stark die Iren nach der Beendigung des Siebenjährigen Krieges bereits in die militärische Führungselite der Habsburgermonarchie integriert waren, zeigt ein Bericht des Annual Register über die Feier des St. Patrickfestes in Wien im März 1766:

Am 17. dieses Monates gab Seine Exzellenz, Graf Mahony, Botschafter Spaniens am Wiener Hof, einen großen Empfang zu Ehren des hl. Patrick, zu dem alle Personen von Stand irischer Abstammung geladen waren, da auch der Graf selbst aus einer illustren Familie jenes Königreiches stammt. Anwesend waren, unter vielen anderen, Graf Lacy, Präsident des Hofkriegsrates, die Generäle O'Donnel, McGuire, O'Kelly, Browne, Plunkett und McEligot, vier Großkreuzträger, zwei Statthalter, sieben Theresienritter, sechs Stabsoffiziere, vier Geheimräte, außerdem waren die höchsten Würdenträger des Staates zugegen; um der irischen Nation ihren Respekt zu bezeugen trugen sie zu Ehren des Tages Kreuze [ein rotes diagonal gestelltes Kreuz auf weißem Grund], dasselbe trug der ganze $\operatorname{Hof}^{72}$.

Neben der guten Integration in die Wiener Hofgesellschaft verdeutlicht diese Episode vor allem die identitätsstiftende Pflege irischen Brauchtums, die sich

70 Zitiert nach Duffy, Browne, S. 16f.

71 Downey, Wildgänse, S. 49.

72 Zitiert nach Duffy, Browne, S. 23. 
auch in der Pflege der gälischen Sprache unter den kaiserlichen Offizieren ausdrückte.

\section{Fazit}

Die Zeit des Siebenjährigen Krieges diente hier als exemplarischer Untersuchungszeitraum zur Bestimmung der unterschiedlichen Relationen von Religion und Mobilität im 18. Jahrhundert. Anhand der unterschiedlichen Akteure des Krieges vom adeligen Offizier bis zum gemeinen Soldaten konnten sowohl Erfahrungen und Deutungen konfessioneller Differenz als auch Karrieren und Schicksale im Zeichen religiöser wie militärischer Migration aufgezeigt werden. Anders als manche Stereotype von einer gottlosen Soldateska es vielleicht nahe legen, waren die Soldaten des 18. Jahrhunderts meist von einer tiefen Religiosität geprägt, die schon aus pragmatischen Gründen der Lebensbewältigung angesichts ubiquitärer physischer Bedrohung nahe lag. Im Zeitalter einer gerade im Militärwesen anhaltenden oder zum Teil eher nachholenden Konfessionalisierung trug diese Religiosität deutliche konfessionelle Züge, so dass die langfristige Konfrontation mit dem konfessionellen Gegenüber nicht zuletzt in Situationen der Gefangenschaft nachhaltigen Eindruck hinterlassen musste. Ja, man kann in manchen Fällen sicher sogar von einer Stärkung religiöser Identitätsbildung durch die, wenn auch erzwungene, räumliche Mobilität ausgehen. Angesichts der zahlreichen Versuche obrigkeitlicher Religionskriegsinszenierung muss jedoch trotz offenkundiger Distanz zur anderen Konfession ein weitgehend pragmatischer Umgang unter den Soldaten konstatiert werden, der sich kaum nachhaltig durch den Diskurs der Propaganda affizieren ließ. Zwar kam es vereinzelt sowohl zu gewaltsamen Übergriffen gegen die gegnerische Kirche, wie auch zu quer zu den politischen Lagern stehenden Sympathien, etwa im Falle einer katholischen Stadt wie Münster gegenüber ihren französischen Angreifern im Gegensatz zu ihren britischen >Befreiern<, die auf Persistenzen konfessioneller Bindung wie Abstoßung verweisen ${ }^{73}$. Doch zeitigten diese Verhältnisse nicht mehr die zuvor gekannte Dynamik. Der Siebenjährige Krieg erscheint vielmehr als eine Art Laboratorium, in dem sich religiöse wie proto-nationale Semantiken verbreiteten und wirkten, letztlich aber den Logiken eines Staatsbildungs- und Kabinettkriegs wie der transterritorialen Vergesellschaftung unter Militärs untergeordnet blieben.

73 Vgl. Aegidius Huppertz, Münster im siebenjährigen Kriege insbesondere die beiden Belagerungen des Jahres 1759, Münster 1908, S. 64. 


\title{
Von Konfessionseiden und gelehrten Glaubensflüchtlingen, von Konvertiten und heterodoxen Gelehrten
}

\author{
Mobilitätsphänomene konfessionell devianter Professoren zwischen \\ obrigkeitlicher Duldung, Landesverweis und freiwilligem Abzug
}

Professoren an vormodernen Universitäten sind auf den ersten Blick kein besonders naheliegender Untersuchungsgegenstand für den Problemkreis konfessionell bedingter Mobilität, da derartige Phänomene allenfalls in Ausnahmen zu erwarten sind. Die Gründe hierfür sind im genuinen Charakter der vormodernen Institution Universität zu suchen. Anders als heute sollte der Typus der konfessionell gebundenen, vormodernen Landesuniversität, der sich als Ergebnis der Transformationsprozesse im Gefolge von Reformation und katholischer Reform während des Konfessionellen Zeitalters herausgebildet und seine grundsätzliche Erscheinungsform bis zum Ende des 18. Jahrhunderts kaum verändert hatte ${ }^{1}$, gerade keine Gelehrtenmobilität - weder soziale noch räumlich-geographische - generieren. Sie ist vielmehr ein typisches Beispiel für die Wirkweise und das Beharrungsvermögen der »Altständischen Gesellschaft«. Anders als die grundsätzlich hochmobile Gruppe der Studenten ${ }^{2}$ blieben Professoren in aller Regel lebenslang an diejenigen Universitäten gebunden, an denen sie auch selbst studiert hatten. Die-

1 Eine Gesamtcharakterisierung des Universitätswesens im Alten Reich findet sich etwa bei Notker Hammerstein, Zur Geschichte und Bedeutung der Universitäten im Heiligen Römischen Reich Deutscher Nation, in: HZ 241 (1985), S. 287-328; vgl. auch ders./Ulrich HerRmAnN (Hg.), Handbuch der deutschen Bildungsgeschichte, Bde. 1/2, München 1996/2005; Anton Schindling, Bildung und Wissenschaft in der Frühen Neuzeit 1650-1800, München ${ }^{2} 1999$; Notker Hammerstein, Bildung und Wissenschaft vom 15. bis zum 17. Jahrhundert, München 2003.

$2 \mathrm{Zu}$ studentischen Migrations- und Mobilitätsphänomenen in Alteuropa im Übergang vom späten Mittelalter zur Frühen Neuzeit vgl. etwa die Überblicksdarstellungen von Hilde DE RIDDERSymoens, Peregrinatio academica doorheen Europa. 13e $-18^{\mathrm{e}}$ eeuw in vogelvlucht, in: Batavia Academica 1 (1983), S. 3-11; dies., La migration académique des hommes et des idées en Europe, XIII ${ }^{\text {e-XVIII }}{ }^{\mathrm{e}}$ siècles, in: CRE-Information 62 (1983), S. 69-79; dies., Mobilität, in: Walter RüEGG (Hg.), Geschichte der Universität in Europa, Bd. 2, München 1996, S. 335-359; Maria Rosa Di Simone, Storia delle università europee. Consistenza e composizione del corpo studentesco dal 1500 al 1700, in: Clio 12 (1986), S. 349-388; Matthias Asche, »Peregrinatio academica « in Europa im Konfessionellen Zeitalter. Bestandsaufnahme eines unübersichtlichen Forschungsfeldes und Versuch einer Interpretation unter migrationsgeschichtlichen Aspekten, in: Jahrbuch für Europäische Geschichte 6 (2005), S. 3-33. 
se Aussage gilt in besonderer Weise für die protestantischen Hochschulen namentlich für die kleineren und mittelgroßen lutherischen Landesuniversitäten, die in der älteren Historiographie häufig mit dem Negativ-Signum »Familienuniversitäten « belegt und damit pauschal abqualifiziert wurden ${ }^{3}$. Diese hinsichtlich ihrer Immatrikulationsfrequenzen, ihres regionalen Einzugsbereiches und damit verbunden ihrer geistigen Ausstrahlung begrenzten Bildungsanstalten - Tübingen, Marburg, Gießen, Greifswald, Rostock und Kiel, aber auch die reformierte Universität Basel sind dafür typische Beispiele - waren bezüglich horizontaler und vertikaler Mobilitätsphänomene tendenziell beharrliche akademische Korporationen mit spezifisch ständisch konservierenden Strategien und Strukturen des »Obenbleibens«. Hierzu zählte unter anderem die quasi erbliche Weitergabe von Lehrstühlen vom Vater auf den Sohn oder Schwiegersohn und die Praxis der Lehrstuhlexpektanzen, also die Anwartschaft von Professorensöhnen und -schwiegersöhnen auf vorbestimmte Lehrstühle, aber auch die vor allem im 16. und 17. Jahrhundert zahlreich gestifteten Familienstipendien, welche gerade nicht nach dem Kriterium der Bedürftigkeit, sondern nach demjenigen der Verwandt-

3 Zum Typus der protestantischen »Familienuniversitäten « vgl. ders., Über den Nutzen von Landesuniversitäten in der Frühen Neuzeit. Leistung und Grenzen der protestantischen »Familienuniversität«, in: Peter Herde/Anton Schinduing (Hg.), Universität Würzburg und Wissenschaft in der Neuzeit. Beiträge zur Bildungsgeschichte. Gewidmet Peter Baumgart anlässlich seines 65. Geburtstages, Würzburg 1998, S. 133-149; vgl. neuerdings insbesondere die zahlreichen Studien von Julian KÜMmERLE, Profile lutherischer Gelehrtenfamilien. Vergleichende Überlegungen zu einer sozio-konfessionellen und bildungsgeschichtlichen Formation der Frühen Neuzeit, in: Acta Comeniana 17 (2003), S. 33-71; ders., Wissenschaft und Verwandtschaft. Protestantische Theologenausbildung im Zeichen der Familie vom 16. bis zum 18. Jahrhundert, in: Herman J. Selderhuis/Markus Wriedt (Hg.), Bildung und Konfession. Theologenausbildung im Zeitalter der Konfessionalisierung, Tübingen 2006, S. 159-210; ders., Konfessionalität und Gelehrtenkultur im Generationenverband. Protestantische Theologen- und Juristenfamilien im Alten Reich, in Frankreich und der Schweiz, in: Thomas Kaufmann u.a. (Hg.), Frühneuzeitliche Konfessionskulturen, Gütersloh 2008, S. 69-97; ders., »Absinkendes Niveau, fehlende Kritik und geringe Leistung?« Familienuniversitäten und Universitätsfamilien im Alten Reich, in: Daniela Siebe (Hg.), »Orte der Gelahrtheit«. Personen, Prozesse und Reformen an protestantischen deutschen Universitäten des Alten Reiches, Stuttgart 2008, S. 143-157; vgl. auch Friedrich Wilhelm EuLER, Entstehung und Entwicklung deutscher Gelehrtengeschlechter, in: Hellmuth RössLer/Günther Franz (Hg.), Universität und Gelehrtenstand 1400-1800. Büdinger Vorträge 1966, Limburg 1970, S. 183-232; Georg Wieland, Die »Familien-Universität«, in: Uwe Jens Wandel u.a. (Hg.), »... helfen zu graben den Brunnen des Lebens«. 500 Jahre Eberhard-Karls-Universität Tübingen 1477-1977. Ausstellungskatalog, Tübingen 1977, S. 122f.; Dirk Alvermann, Die frühneuzeitliche »Familienuniversität« im Spiegel der Greifswalder Professorenporträts, in: Ders./Birgit DAHLEnBerg, Greifswalder Köpfe. Gelehrtenporträts und Lebensbilder des 16.-18. Jahrhunderts aus der pommerschen Landesuniversität, Rostock 2006, S. 23-30; Nils JöRN, Die Herkunft der Professorenschaft der Greifswalder Universität zwischen 1456 und 1815, in: Dirk Alvermann u.a. (Hg.), Die Universität Greifswald in der Bildungslandschaft des Ostseeraumes, Berlin 2007, S. 155-190; Matthias Asche, Helmstedter Professorenprofile 1576 bis 1810. Skizzen zur Kollektivbiographie einer mitteldeutschen Universität, in: Jens Bruning/Ulrike Gleixner (Hg.), Das Athen der Welfen. Die Reformuniversität Helmstedt 1576-1810. Ausstellungskatalog, Wiesbaden 2010, S. 114-119. 
schaft mit den Professoren oder den oftmals mit diesen verwandtschaftlich verbundenen gelehrten Stifterfamilien verliehen wurden ${ }^{4}$. Die Angehörigen der exklusiven Professoren- und Gelehrtendynastien - eine der wichtigsten sozialgeschichtlichen Konsequenzen der Reformation - waren in aller Regel durch Konnubien mit den Führungsschichten des Trägerterritoriums der jeweiligen Landesuniversität - der Pfarrer- und Beamtenschaft - aufs Engste verbunden $^{5}$. Sie bildeten unter dem Signum einer späthumanistischen Gelehrsamkeit standesspezifische Habitusformen aus ${ }^{6}$ und wiesen alle Formen

4 Exemplarisch ist hinzuweisen auf die reichen württembergischen Familienstiftungen, die ganz überwiegend der Universität Tübingen zugute kamen, vgl. Ferdinand Friedrich FABER (Hg.), Die Württembergischen Familienstiftungen nebst genealogischen Nachrichten über die zu denselben berechtigten Familien. Nachdruck mit Berichtigungen von Adolf Rentschler, 24 Bde., Stuttgart 1940. Eine Analyse dieser wichtigen sozial-, rechts- und personenhistorischen Quelle ist ein Forschungsdesiderat, wie überhaupt die Wirksamkeit des vormodernen Stipendienwesens und die vielfältigen Formen der Studienförderung an Universitäten insgesamt allenfalls punktuell und bruchstückhaft untersucht wurden.

5 Exemplarisch Harald Schieckel, Benedict I. Carpzov (1565-1624) und die Juristen unter seinen Nachkommen. Verwandtschaftliche Verflechtungen bekannter Gelehrtenfamilien, in: ZSRG.G 83 (1966), S. 310-322; Hermann Niebuhr, Zur Sozialgeschichte der Marburger Professoren 1653-1806, Darmstadt 1983; oder Matthias Asche, Von der reichen hansischen Bürgeruniversität zur armen mecklenburgischen Landeshochschule. Das regionale und soziale Besucherprofil der Universitäten Rostock und Bützow in der Frühen Neuzeit (1500-1800), Stuttgart 2000, S. 409ff., 467ff.

6 Die einschlägige Pionierstudie stammt von Erich Trunz, Der deutsche Späthumanismus um 1600 als Standeskultur, in: Zeitschrift für Geschichte der Erziehung und des Unterrichts 21 (1931), S. 17-53 [mehrere Nachdrucke, zuletzt in: Ders., Deutsche Literatur zwischen Späthumanismus und Barock. Acht Studien, München 1995, S. 7-82]. Eine Sozial-, Kultur- und Alltagsgeschichte der deutschen Gelehrten in der Frühen Neuzeit muss zwar noch erst geschrieben werden, aber es liegen mittlerweile einige wichtige Bausteine dafür vor, vgl. etwa Martin GunTau, Zur gesellschaftlichen Stellung und Wirksamkeit deutscher Gelehrter in der Zeit der Aufklärung, in: Bruno Schrage (Hg.), Der bürgerliche Gelehrte und seine Stellung im 18. und 19. Jahrhundert, Rostock 1980, S. 7-31; Gunter E. Grimm, Literatur und Gelehrtentum in Deutschland. Untersuchungen zum Wandel ihres Verhältnisses vom Humanismus zur Frühaufklärung, Tübingen 1983; ders., Vom Schulfuchs zum Menschheitslehrer. Zum Wandel des Gelehrtentums zwischen Barock und Aufklärung, in: Hans Erich BöDEKER/Ulrich HerRmann (Hg.), Über den Prozeß der Aufklärung in Deutschland im 18. Jahrhundert. Personen, Institutionen, Medien, Göttingen 1987, S. 14-38; Siegfried Wollgast, Zur Stellung des Gelehrten in Deutschland im 17. Jahrhundert, Berlin 1984; Otto Gerhard OExLE, Alteuropäische Voraussetzungen des Bildungsbürgertums - Universitäten, Gelehrte und Studierte, in: Werner Conze/Jürgen KockA (Hg.), Bildungsbürgertum im 19. Jahrhundert, Bd. 1, Stuttgart 1985, S. 29-78; Rudolf Vierhaus, Umrisse einer Sozialgeschichte der Gebildeten in Deutschland, in: Ders., Deutschland im 18. Jahrhundert. Politische Verfassung - Soziales Gefüge - Geistige Bewegungen, Göttingen 1987, S. 167-182; Christine TremL, Humanistische Gemeinschaftsbildung. Sozio-kulturelle Untersuchung zur Entstehung eines neuen Gelehrtenstandes in der frühen Neuzeit, Hildesheim 1989; Erhard Wiersing, Kleriker - Beamte - Gelehrte - Erzieher Künstler. Vorüberlegungen zu einer Geschichte und Typologie der Gebildeten im vormodernen Europa, in: Rudolf W. KecK u.a. (Hg.), Literaten - Kleriker - Gelehrte. Zur Geschichte der Gebildeten im vormodernen Europa, Köln 1996, S. 15-56; Roger ChARTIER, Der Gelehrte, in: Michel Vovelle (Hg.), Der Mensch der Aufklärung, Frankfurt am Main 1998, S. 122-168; Marian FüssEL, Gelehrtenkultur als symbolische Praxis. Rang, Ritual und Konflikt an der Universität der Frühen Neuzeit, Darmstadt 2006; ders., Akademische Lebenswelt und gelehrter Ha- 
von Verwandten- und Klientelpatronage auf - nicht nur bei der Besetzung von politischen und kirchlichen Ämtern, sondern auch bei der Berufung auf akademische Lehrstühle?

Obwohl die hier nur knapp angedeuteten Klientelstrukturen sehr zählebig waren, nicht selten bis weit ins 19. Jahrhundert fortwirkten ${ }^{8}$ und maßgeblich zur Genese des Bildungsbürgertums beitrugen, muss zur angemessenen historischen Einordnung dieses aus heutiger Sicht problematisch erscheinenden Phänomens betont werden, dass die primäre Funktion von Universitäten vor der Reformzeit um 1800 die Bewahrung und Tradierung weithin bekannter Wissensbestände war, sie mithin im Dienst des frühmodernen Staates vorrangig Ausbildungs- und Vermittlungsfunktionen wahrzunehmen hatten, wohingegen die wissenschaftliche Innovation durch empirische Forschung allenfalls ein Nebenprodukt der gelehrten Bemühungen darstellte. Somit war die vermeintlich »verfilzte« protestantische »Familienuniversität« durchaus

bitus. Zur Alltagsgeschichte des deutschen Professors im 17. und 18. Jahrhundert, in: Jahrbuch für Universitätsgeschichte 10 (2007), S. 35-51; oder Matthias Asche, Kontinuität des Humanismus. Bildungs- und Lebensentwürfe in gelehrten späthumanistisch-barocken Netzwerken Erträge und Forschungsperspektiven eines Osnabrücker Editionsprojekts für die frühneuzeitliche Kulturgeschichtsforschung, in: HJ 128 (2008), S. 439-468.

7 Nur auf diese Weise konnte etwa der Tübinger Theologieprofessor Dietrich (Theoderich) Schnepf (1525-1586), der Sohn des württembergischen Reformators Erhard Schnepf (14951558), zum Ahnherrn der bedeutenden schwäbischen Gelehrtengeschlechter Heerbrand, Ensslin, Silcher, Hegel, Hauff, Schelling und Baur werden. Regina Burckhardt (1599-1669), die Ehefrau des Tübinger Medizinprofessors Carl Bardili (1600-1647), ist als »Schwäbische Geistesmutter« in die württembergische Gelehrtengeschichte eingegangen, zumal zu ihren Nachkommen unter anderem Geistesgrößen wie Uhland, Hölderlin und Schelling zählen, vgl. die einschlägige genealogische Studie von Hanns Wolfgang RAтн, Regina, die schwäbische Geistesmutter. Die gemeinsame Abstammung Hölderlins, Uhlands, Schellings, Mörikes und anderer bekannter Schwaben, Ludwigsburg/Leipzig 1927 [durch Hansmartin Decker-Hauff neu bearbeiteter, ergänzter und erweiterter ND Limburg 1981]; zudem Rudolf KRAuss, Talentvererbung in der schwäbischen Literatur, in: Kultur und Leben. Monatszeitschrift für kulturgeschichtliche und biologische Familienkunde 2 (1925), S. 358-361; Hans MüLLER, Die Ahnentafel des Dichters Wilhelm Hauff, in: Ahnentafeln berühmter Deutscher N.F. 5/7 (1933/34), S. 65-115; Gerd Wunder, Das Problem der Ahnengemeinschaft namhafter Persönlichkeiten, in: Genealogisches Jahrbuch 2 (1962), S. 5-26; Familienverband Gmelin (Hg.), Die Familie Gmelin. Biographien - Genealogien - Dokumente, Neustadt an der Aisch 1973; Walter BARDILI, Schellings Ahnengemeinschaften mit großen Schwaben, in: Archiv für Sippenforschung 41 (1975), S. 116-119; Hanns Wolfgang Rath u.a., Ahnengeschichte Hölderlins, Limburg 1989; und den Katalogbeitrag von Matthias Asche, Haus der »Schwäbischen Geistesmutter« Regina Bardili (1599-1669), Haaggasse 19, in: Ulrich KöPF u.a. (Hg.), »Brunnen des Lebens « - Orte der Wissenschaft. Ein Rundgang durch 525 Jahre Universität Tübingen, Tübingen ${ }^{3} 2003$, S. 68.

8 Exemplarisch vgl. die Hinweise bei Marita Baumgarten, Vom Gelehrten zum Wissenschaftler. Studien zum Lehrkörper einer kleinen Universität am Beispiel der Ludoviciana Gießen (1815-1914), Gießen 1988; dies., Professoren und Universitäten im 19. Jahrhundert. Zur Sozialgeschichte deutscher Geistes- und Naturwissenschaftler, Göttingen 1997; Olaf WiLlETt, Sozialgeschichte Erlanger Professoren 1743-1933, Göttingen 2001; oder Sylvia PALETscheK, Die permanente Erfindung einer Tradition. Die Universität Tübingen im Kaiserreich und in der Weimarer Republik, Stuttgart 2001. 
dem frühmodernen Staat nützlich, denn ihre Hauptaufgabe - die Ausbildung der »sekundären Führungsschichten $\ll^{9}$ im Trägerterritorium - hat sie stets $\mathrm{zu}$ leisten vermocht ${ }^{10}$. Man muss sogar davon ausgehen, dass akademische »Erbhöfe« in aller Regel ganz im Sinne der Landesherren gewesen sind auch und gerade aus konfessionellen Gründen. Die Weitergabe von Lehrstühlen innerhalb eines exklusiven Kreises der territorialen Eliten gewährleistete - nicht nur im Konfessionellen Zeitalter des 16. und 17. Jahrhunderts die Fortschreibung der Rechtgläubigkeit der Universität als Ganzes, sondern garantierte die unverfälschte Tradierung spezifischer konfessioneller Normen und bekenntnismäßiger Fixierungen über Generationen.

Eine ausgeprägte Berufungskultur, wie sie dann seit dem 19. Jahrhundert charakteristisch und wegweisend für das Hochschulwesen werden sollte, war folglich an vormodernen Universitäten kaum entwickelt, zumal die von auswärts angeworbenen Lehrkräfte zumindest potentiell die Gefahr des Imports heterodoxer Bekenntnisse an die für die territorialen Konfessionalisierungsprozesse so zentral wichtigen Landesuniversitäten ${ }^{11}$ in sich bargen. Sieht man einmal von spezifischen Rahmenbedingungen, wie etwa der Neugründung oder der konfessionellen Neujustierung von Hochschulen ab, gab es konsequenterweise im vormodernen Universitätswesen

9 Begriff nach Gerd HeinRich, Amtsträgerschaft und Geistlichkeit. Zur Problematik der sekundären Führungsschichten in Brandenburg-Preußen 1450-1786, in: Günther Franz (Hg.), Beamtentum und Pfarrerstand 1400-1800. Büdinger Vorträge 1967, Limburg 1972, S. 179-238.

10 Exemplarisch sei verwiesen auf die einschlägigen Studien von Karl E. Demandt, Amt und Familie. Eine soziologisch-genealogische Studie zur hessischen Verwaltungsgeschichte des 16. Jahrhunderts, in: HJLG 2 (1952), S. 79-133; Martin BRECHT, Herkunft und Ausbildung der protestantischen Geistlichen in Württemberg im 16. Jahrhundert, in: ZKG 80 (1969), S. $163-$ 175; Hansmartin Decker-Hauff, Die geistige Führungsschicht Württembergs, in: Franz, Beamtentum und Pfarrerstand, S. 51-80; Bernard VogLer, Le clergé rhénan au siècle de la réforme (1555-1619), Paris 1976; Notker Hammerstein, Universitäten - Territorialstaaten Gelehrte Räte, in: Roman Schnur (Hg.), Die Rolle der Juristen bei der Entstehung des modernen Staates, Berlin 1986, S. 687-735; Gerhard Menk, Die Rekrutierung der Eliten in der Landgrafschaft Hessen bzw. Hessen-Kassel und Waldeck im 16. und 17. Jahrhundert, in: Klaus Malettke/Jürgen Voss (Hg.), Humanismus und höfisch-städtische Eliten im 16. Jahrhundert, Bonn 1989, S. 61-90; Luise Schorn-Schütte, Evangelische Geistlichkeit in der Frühneuzeit. Deren Anteil an der Entfaltung frühmoderner Staatlichkeit und Gesellschaft. Dargestellt am Beispiel des Fürstentums Braunschweig-Wolfenbüttel, der Landgrafschaft Hessen-Kassel und der Stadt Braunschweig, Gütersloh 1996; Asche, Von der reichen hansischen Bürgeruniversität, S. 459ff.; Sabine Holtz, Bildung und Herrschaft. Zur Verwissenschaftlichung politischer Führungsschichten im 17. Jahrhundert, Leinfelden-Echterdingen 2002; Stefan BrakensieK, Juristen in frühneuzeitlichen Territorialstaaten. Familiare Strategien sozialen Aufstiegs und Statuserhalts, in: Günther Schulz (Hg.), Sozialer Aufstieg. Funktionseliten im Spätmittelalter und in der frühen Neuzeit. Büdinger Forschungen zur Sozialgeschichte 2000 und 2001, München 2002, S. 269-289.

11 Dies wurde exemplarisch für die Universität Rostock herausgearbeitet von Thomas KAUFMANN, Universität und lutherische Konfessionalisierung. Die Rostocker Theologieprofessoren und ihr Beitrag zur theologischen Bildung und kirchlichen Gestaltung im Herzogtum Mecklenburg zwischen 1550 und 1675, Gütersloh 1997. 
keine auch nur in Ansätzen mit heutigen Standards vergleichbare Berufungspolitik $^{12}$.

Was bezüglich der Mobilitätsphänomene für das protestantische Hochschulwesen ausgeführt wurde, gilt in weit höherem Maße für katholische Universitäten. Sämtliche Hochschulen in den katholischen Trägerterritorien des Alten Reichs - eine einzige Ausnahme bildete die von einer Kongregation benediktinischer Klöster in Österreich, Franken und Schwaben getragene Universität in Salzburg ${ }^{13}$ - waren mehr oder weniger stark vom Jesuitenorden bestimmt. Zu unterscheiden sind genuine »Jesuitenuniversitäten« mit lediglich zwei Fakultäten - Philosophie und Theologie - von den üblichen Vier-Fakultäten-Universitäten mit unterschiedlich starker Präsenz von Jesuitenpatres als Professoren in den Theologischen und Philosophischen Fakultäten ${ }^{14}$. Die jesuitischen Gelehrten waren grundsätzlich zwar wesentlich

12 Zur Illustration sei auf das Beispiel der Rostocker Professoren hingewiesen: Von den 38 Theologieprofessoren des 17. Jahrhunderts hatten lediglich sieben ihre akademischen Grade nicht in Rostock erworben, und drei von ihnen wurden von auswärtigen Lehrstühlen wegberufen. Rund ein Drittel der Rostocker Rechtsprofessoren wurde außerhalb der mecklenburgischen Hochschule ausgebildet, und nur einer war zuvor Professor an einer anderen Universität. Am auffälligsten ist die akademische Mobilität bei Medizinern, denn hier hatten nur zwei der dreizehn Professoren - die allerdings wie auch ihre Kollegen aus den anderen drei Fakultäten ganz überwiegend aus Rostocker Professorenfamilien stammten - vor der Aufnahme der Lehrtätigkeit in Rostock studiert; von einem auswärtigen Lehrstuhl wegberufen wurde immerhin einer, vgl. Asche, Von der reichen hansischen Bürgeruniversität, S. 467ff. Studien zum vormodernen Berufungswesen sind allerdings noch rar, so dass die für Rostock gewonnenen Zahlen derzeit noch weithin allein stehen müssen, wenngleich auch zu vermuten ist, dass der für Rostock ermittelte Befund zumindest für die protestantischen Universitäten im Reich bestätigt werden würde; vgl. insbesondere Hermann Niebuhr, Zur Sozialgeschichte der Marburger Professoren 1653-1806, Darmstadt 1983; Bernhard ZASchKE, Die Lehrstühle der Universität Tübingen im Dreißigjährigen Krieg. Zur sozialen Wirklichkeit von Professoren im vorklassischen Zeitalter, Tübingen 1993, S. 73ff.; Bernhart JÄHNIG, Zum Geschäftsgang bei der Berufung Königsberger Universitätsprofessoren im frühen 18. Jahrhundert, in: Ders. (Hg.), 450 Jahre Universität Königsberg. Beiträge zur Wissenschaftsgeschichte des Preußenlandes, Marburg 2001, S. 71-82; Simone Giese, Das Spannungsfeld von Politik und Wissenschaft im Spiegel von Berufungsverfahren in den ersten Jahren Schwedisch-Pommerns, in: Dirk Alvermann/Karl-Heinz Spiess (Hg.), Universität und Gesellschaft. Festschrift zur 550-Jahrfeier der Universität Greifswald 1456-2006, Bd. 2, Rostock 2006, S. 215-249; Daniela SieBe, Berufungen zwischen Universität und Landesherrschaft. Das Beispiel Jena 1650-1700, in: Dies., »Orte der Gelahrtheit«, S. $159-191$.

13 Allgemein zur Geschichte der Universität Salzburg vgl. die Sammelbände von Max KaINDLHönIG/Karl-Heinz Ritschel (Hg.), Die Salzburger Universität 1622-1964, Salzburg 1964; Hans WaGner/Barbara Wicha (Hg.), Festschrift Universität Salzburg. 1622-1962-1972, Salzburg 1972; Christian Roнr (Hg.), Barocker Geist und Raum. Die Benediktineruniversität Salzburg, Salzburg 2003.

14 Eine Typologisierung der jesuitisch geprägten Hochschulen im Reich findet sich bei Karl HENGST, Jesuiten an Universitäten und Jesuitenuniversitäten. Zur Geschichte der Universitäten in der Oberdeutschen und Rheinischen Provinz der Gesellschaft Jesu im Zeitalter der konfessionellen Auseinandersetzung, Paderborn 1981; vgl. auch Otto Krammer, Bildungswesen und Gegenreformation. Die hohen Schulen der Jesuiten im katholischen Teil Deutschlands vom 16. bis 18. Jahrhundert, Würzburg 1988. 
mobiler als die Professoren an protestantischen Universitäten, was sich durch das dem Ordenswesen zugrunde gelegte Rotationsprinzip der nicht-fachgebunden unterrichtenden Jesuiten innerhalb der jeweiligen Ordensprovinz erklärt ${ }^{15}$. Aber eine konfessionell bedingte Mobilität oder die bloße Existenz von heterodoxen Professoren ist an katholischen Hochschulen, zumal an genuinen »Jesuitenuniversitäten«, eigentlich gänzlich auszuschließen auch wenn zum Gelehrtenprofil und Berufungswesen an katholischen Universitäten praktisch keine prosopographisch-kollektivbiographischen Studien vorliegen ${ }^{16}$.

Es ist für die Frühe Neuzeit völlig verfehlt, Mobilität und Migration von Professoren - zumal aus konfessionellen Gründen - zum Normalfall zu erklären. Trotz aller grundsätzlichen systemimmanenten Immobilität gab es im vormodernen deutschen Universitätswesen dennoch immer wieder Phasen erhöhter Mobilität der Lehrkräfte, die freilich durch spezifische konfessionelle Rahmenbedingungen determiniert waren und an den verschiedenen Universitäten zeitversetzt und in unterschiedlicher Intensität nachzuweisen sind. Da dies alles noch nicht zusammenhängend untersucht wurde, wird im Folgenden eine erste Zusammenschau solcher konfessionell bedingten Mobilitätsphänomene versucht, die angesichts des ungünstigen Forschungsstandes notgedrungen holzschnittartig bleiben muss. Sie stützt sich auf eine Summe von Einzelbeobachtungen anhand der Durchsicht vorliegender Professoren- und Gelehrtenlexika ${ }^{17}$. Zu fragen ist beim chronologischen Durch-

15 Das allmähliche Nachlassen der Mobilität im Laufe des 17. und im 18. Jahrhundert scheint im Übrigen auch für Professoren an katholischen Universitäten zu gelten, denn obwohl an Jesuitenuniversitäten und Jesuitenkollegs zumindest formal eine Rotation des Lehrpersonals gefordert wurde, zeigen Stichproben vom Lehrkörper der Universität Ingolstadt, dass sich tatsächlich zunehmend die Mobilität der dortigen jesuitischen Professoren auf einen engen Kreis süddeutscher, meist sogar bayerischer Jesuitenkollegs beschränkte; vgl. Laetitia BoEHM u.a. (Hg.), Biographisches Lexikon der Ludwig-Maximilians-Universität München, Bd. 1, Berlin 1998. Ähnliches ist für das jesuitische Lehrpersonal der Universität Heidelberg zwischen 1652 und 1773 festzustellen; vgl. Dagmar DrüLL, Heidelberger Gelehrtenlexikon 1652-1802, Berlin 1991.

16 Zumindest Ansätze einer Kollektivbiographie der Salzburger Professoren aus dem Benediktinerorden am Beispiel der Rhetoriker liegen vor von Dietmar TiLl, Barockrhetorik in Salzburg. Zur Stellung der Benediktiner im frühneuzeitlichen Rhetorikunterricht, in: RoHR, Barocker Geist und Raum, S. 45-72, hier: S. 56ff., insbesondere die tabellarische Übersicht (S. 69) auf Grundlage von Ägidius Kolb, Präsidium und Professorenkollegium der Benediktiner-Universität Salzburg 1617-1743, in: MGSL 102 (1962), S. 117-166; ders., Präsidium und Professorenkollegium der Benediktiner-Universität Salzburg 1734 bis zu deren Ende 1810, in: SMGB 83 (1972), S. 664-716.

17 Die bereits für das 17. und 18. Jahrhundert nachweisbaren, aber erst seit dem 20. Jahrhundert auf wissenschaftlicher Grundlage erstellten Professoren- und Gelehrtenlexika harren noch systematischer prosopographisch-kollektivbiographischer Auswertungen. Auf die Auflistung vorliegender Lexika - auch eine solche dringend notwendige Zusammenstellung ist ein drängendes Desiderat - wird an dieser Stelle verzichtet. Die bibliographischen Nachweise der benutzten Lexika finden sich im Text. 
gang durch die deutsche Universitätsgeschichte der Frühen Neuzeit in erster Linie nach den spezifischen Faktoren und Rahmenbedingungen, die konfessionell bedingte Mobilität von Professoren begünstigen beziehungsweise auslösen konnten. Eine Quantifizierung der ermittelten Phänomene ist beim derzeitigen Forschungsstand freilich noch nicht möglich.

\section{Mobilitätsphänomene im Gefolge der reformatorischen Umbrüche}

Die stürmischen Reformationsjahrzehnte der 1520er bis 1540er Jahre markierten für das Universitätswesen in weiten Teilen Mittel-, Ostmittel- und Nordeuropas die zweifellos gravierendste Existenzkrise seit der Entstehung dieser Institution im Hohen Mittelalter ${ }^{18}$. Frequenzeinbrüche von zuvor nicht gekannten Ausmaßen begleiteten den als allgemeine Legitimations- und Sinnkrise wahrgenommenen Verfall der Universität. Die Umbruchszeit ist nicht nur gekennzeichnet durch die grundlegende Infragestellung des geistlichen Charakters der Universitäten aufgrund der Forderung nach reformatorischem Neubeginn, sondern damit verbunden auch - und dies ist nicht $\mathrm{zu}$ unterschätzen - durch eine tiefgreifende Finanzierungskrise für das akademische Lehrpersonal, deren Ursache das Wegbrechen der regelmäßigen Einkünfte aus dem Pfründenwesen und den Hörergeldern war ${ }^{19}$. Nicht zuletzt daher erklärt sich auch die massive, in quantitativer Hinsicht für die Vormoderne wohl einzigartige Mobilität des akademischen Lehrpersonals, das

18 Zur Krise der deutschen Universitäten in den 1520er bis 1540er Jahre vgl. Matthias Asche, Frequenzeinbrüche und Reformen. Die deutschen Universitäten in den 1520er bis 1560er Jahren zwischen Reformation und humanistischem Neuanfang, in: Walther Ludwig (Hg.), Die Musen im Reformationszeitalter. Akten der Tagung der Stiftung Luthergedenkstätten in der Lutherstadt Wittenberg 14.-16. Oktober 1999, Leipzig 2001, S. 53-96; Beat ImMENHAUSER, Universitätsbesuch zur Reformationszeit. Überlegungen zum Rückgang der Immatrikulationen nach 1521, in: Jahrbuch für Universitätsgeschichte 6 (2003), S. 69-88. Eine Übersicht über die Frequenzentwicklung bietet noch immer das klassische Werk von Franz EulEnBurg, Die Frequenz der deutschen Universitäten von ihrer Gründung bis zur Gegenwart, Leipzig 1904 [ND Berlin 1994], dort besonders der Tabellenanhang S. 284ff. - trotz seiner offenkundigen Mängel; vgl. korrigierend etwa Willem Frijhoff, Surplus ou déficit? Hypothèses sur le nombre réel des étudiants en Allemagne à l'époque moderne (1576-1815), in: Francia 7 (1979), S. 173-218; ders., Grandeur des nombres et misères des réalités. La courbe de Franz Eulenburg et la débat sur le nombre d'intellectuels en Allemagne, 1576-1815, in: Dominique Julia u.a. (Hg.), Les Universités Européennes du XVI ${ }^{\mathrm{e}}$ au XVIII ${ }^{\mathrm{e}}$ siècle. Histoire sociale des populations étudiantes, Bd. 1, Paris 1986, S. 23-63.

19 Zur Finanzierung von Universitäten vor der Reformation vgl. zusammenfassend Jürgen Miethke, Kirchen und Universitäten. Zur wirtschaftlichen Fundierung der deutschen Hochschulen im Spätmittelalter, in: Michael Borgolte/Herrad SpILling (Hg.), Litterae Medii Aevi, Sigmaringen 1988, S. 265-276; Christian Hesse, Pfründen, Herrschaften und Gebühren. Zu Möglichkeiten spätmittelalterlicher Universitätsfinanzierung im Alten Reich, in: Rainer Christoph Schwinges (Hg.), Finanzierung von Universität und Wissenschaft in Vergangenheit und Gegenwart, Basel 2005, S. 57-86, jeweils mit weiterführender Literatur. 
vor die Gewissensentscheidung gestellt, sich der neuen Lehre anzuschließen oder im alten Glauben zu beharren, mit starken Verdrängungsmechanismen innerhalb der Universitäten - gleichermaßen in den Gremien der Konzile und der Fakultäten wie in den Bursen und Studentenhäusern - konfrontiert war. Man darf sich den geistigen und personellen Übergang der älteren Universitäten zur Reformation keineswegs als einen abrupten Vorgang oder gar als einen punktuellen personellen Umbruch vorstellen - nicht einmal in Wittenberg, dem Gravitationszentrum der Reformation ${ }^{20}$. Dies legt schon die Tatsache nahe, dass - mit Ausnahme Greifswalds ${ }^{21}$ - keine deutsche Universität während der 1520er und 1530er Jahre trotz allerorts geringer Immatrikulati-

20 Freilich gerieten die altgläubigen Professoren in Wittenberg seit 1522 in eine zunehmende Defensivposition. Aber auch nach der Neufundierung der Universität im Jahre 1536 wirkte etwa der konfessionell indifferente Physik-Professor Vitus Amerbach (1503-1557), der 1543 die »Leucorea« verließ, sich offen zum Katholizismus bekannte und als Rhetorik-Professor in Ingolstadt starb, vgl. Ludwig FISCHER, Veit Trolmann von Wemding gen. Amerpachius als Professor in Wittenberg 1530-1543, Freiburg 1926; Günter FRANK, Veit Amerbach (1503-1557) - von Wittenberg nach Ingolstadt, in: Heinz Scheible (Hg.), Melanchthon in seinen Schülern, Wiesbaden 1987, S. 103-128.

21 Nach wie vor ist unklar, ob in Greifswald im Jahre 1525 bis zu ihrer Reorganisation als protestantische Universität tatsächlich der Lehrbetrieb eingestellt wurde. Obwohl die Seiten der Matrikeln bis 1539 fehlen, ist es nicht wahrscheinlich, dass es zu einer vollständigen Schließung der Universität Greifswald gekommen ist, wie bereits Johann Gottfried Ludwig KosEGARTEN, Geschichte der Universität Greifswald, Bd. 1, Greifswald 1856 [ND Aalen 1986], S. 180ff., vermutete. Aufgrund der katastrophalen personellen Situation der Universität - bis zum Ende der 1520er Jahre waren nur ein Theologe, drei Juristen und vier Artisten an der noch altgläubigen Hochschule verblieben - hatte allerdings Herzog Philipp I. von Pommern-Wolgast, dem bei der pommerschen Landesteilung (1532) die Rechte an der alten Universität zugesprochen wurden, auf Empfehlung des Wittenberger Theologen Johannes Bugenhagen 1534 ein »Paedagogium« eingerichtet, welches zur Keimzelle der 1539 wiedereröffneten Universität werden sollte, vgl. ebd., S. 188ff. Kurzzeitig wurde von Herzog Barnim IX. von Pommern-Stettin mit der Gründung eines »Paedagogiums « in Stettin (1544) auch ein konkurrierendes Universitätsprojekt im eigenen Landesteil betrieben, vgl. zuletzt Werner Buchнolz, Frühmoderne Staatsbildung, Reformation und Fürstenschule. Das Pädagogium in Stettin und seine Studenten im 16. Jahrhundert, in: Ders. (Hg.), Kindheit und Jugend in der Neuzeit 1500-1900. Interdisziplinäre Annäherungen an die Instanzen sozialer und mentaler Prägung in der Agrargesellschaft und während der Industrialisierung. Das Herzogtum Pommern (seit 1815 preußische Provinz) als Beispiel, Stuttgart 2000, S. 39-54. Zum Frequenzverfall und dem allgemeinen Niedergang der Universität Greifswald während der frühen Reformationsjahre vgl. außerdem Martin WeHRMAnN, Die Neugründung der Universität Greifswald 1539, in: Monatsblätter der Gesellschaft für pommersche Geschichte und Altertumskunde 45 (1931), S. 154-157; Hans Frederichs, Die Universität Greifswald am Vorabend der Reformation, in: Ebd. 47 (1933), S. 169-174; Hellmuth Heyden, Die Erneuerung der Universität Greifswald und ihrer Theologischen Fakultät im 16. Jahrhundert, in: Werner Rothmaler/Wilhelm Braun (Hg.), Festschrift zur 500-Jahrfeier der Universität Greifswald 17.10.1956, Bd. 1, Greifswald 1956, S. 19-33; Manfred HerLing, Die Universität 1539 bis 1815, in: Horst Wernicke (Hg.), Greifswald. Geschichte der Stadt, Schwerin 2000, S. 191-208, hier: S. 191ff.; Dirk AlvermanN, Reformatorischer Neubeginn und akademischer Aufbruch. Die Greifswalder hohe Schule auf dem Weg zur pommerschen Landesuniversität, in: Henning Rischer/Martin Schoebel (Hg.), Verfassung und Verwaltung Pommerns in der Neuzeit. Vorträge des 19. Demminer Kolloquiums zum 75. Geburtstag von Joachim Wächter am 12. Mai 2001, Bremen 2004, S. 29-101. 
onszahlen geschlossen wurde. Vielmehr muss eine mehr oder weniger lange Übergangsphase angenommen werden, in welcher die meist erst später wirksamen Reformentwürfe ausgearbeitet wurden, die dann ihrerseits zu einer grundlegenden konfessionellen Neuausrichtung und finanziellen Neufundierung der Hochschule führten. In dieser Phase lehrten in aller Regel altgläubige und evangelische Professoren und Magister nebeneinander beziehungsweise in Konkurrenz zueinander, wobei sich freilich durch gezielte landesherrliche Neuberufungen oder innerakademische Kooptationsmaßnahmen die konfessionellen Mehrheiten allmählich zugunsten einer Seite verschoben, so dass erst in der Schlussphase des Transformations- und Reformprozesses konfessionell bedingte Verdrängungsmechanismen wirksam wurden. Bei den Universitäten, an denen sich die evangelische Bewegung schließlich Bahn brach, sind in dieser Phase insbesondere zwei Phänomene zu beobachten: einerseits der mehr oder weniger freiwillige Rückzug der älteren, in aller Regel reformkatholisch, aber nicht reformatorisch gesinnten Professorengeneration von ihren Lehrämtern auf ihre noch nicht säkularisierten geistlichen Pfründen, andererseits das gezielte Eindringen von jungen, aus den Zentren der Reformation gezielt angeworbenen, evangelischen Lehrkräften. Dennoch wurden bisweilen auch nach der definitiven Umgestaltung der Universitäten einzelne altgläubige Professoren geduldet, zumal wenn für deren Lehrgegenstand zunächst noch keine passende personelle Alternative gefunden werden konnte ${ }^{22}$. Mancherorts hat sich dieser faktisch bikonfessionelle Zustand der Reformationsjahrzehnte bis weit ins 16. Jahrhundert gehalten, etwa an der Universität Wien, die - anders als die bayerische Landesuniversität Ingolstadt - wegen ihres überproportional hohen Anteils an evangelischen Professoren und Magistern überzeugten Katholiken außerhalb der habsburgischen Erblande noch gegen Ende des 16. Jahrhunderts als konfessionell unzuverlässig galt ${ }^{23}$.

22 An der Universität Rostock wurde beispielsweise dem letzten Rektor des erst 1559 endgültig säkularisierten und vier Jahre später der Universität als »Convictorium« übertragenen Hauses der Brüder vom Gemeinsamen Leben, Heinrich Pauli (genannt Arsenius), noch bis zu seinem Tode (1575) erlaubt, Unterricht in griechischer Sprache zu geben, vgl. Georg Christian Friedrich Lisch, Buchdruckerei der Brüder vom gemeinsamen Leben zu St. Michael in Rostock, in: Jahrbücher des Vereins für mecklenburgische Geschichte und Altertumskunde 4 (1839), S. 1-62, hier: S. 26ff. Zum langwierigen Transformationsprozess der Universität Rostock vgl. zusammenfassend die Hinweise bei Asche, Von der reichen hansischen Bürgeruniversität, S. 45ff.; neuerdings ausführlicher Marko A. Pluns, Die Universität Rostock 1418-1563. Eine Hochschule im Spannungsfeld zwischen Stadt, Landesherren und wendischen Hansestädten, Köln 2007, S. 282ff.

23 Obwohl an der Universität Wien im Jahre 1537 die Lehrtätigkeit von in Wittenberg promovierten Professoren verboten wurden und 1546 von den Lehrkräften ein Eid auf die katholische Kirche vor der Theologischen Fakultät, dem Bischof und dem Universitätskanzler verlangt wurde, mussten im Lehrkörper noch lange verheiratete - wohl mehrheitlich lutherische - Magister geduldet werden, vgl. Rudolf KINK, Geschichte der kaiserlichen Universität zu Wien, Bd. 1, Wien 1854, S. 257ff., 271, 302f. Zum Charakter der Universität Wien im 16. Jahrhundert vgl. insbesondere die Hinweise bei Wenzel Hartl/Karl Schrauf, Nachträge zum dritten Ban- 
Weitgehend gemieden wurde auch die nach dem Abzug der Humanisten in den 1520er Jahren dauerhaft frequenzschwache kurmainzische Universität Erfurt, an welcher nach der Reformation beständig katholische und protestantische Lehrkräfte nebeneinander unterrichteten. Letztere wurden freilich durch den lutherischen Erfurter Rat berufen und vom Mainzer Kurfürsten nur geduldet. Die evangelischen Professoren waren allerdings nicht in die Gremien der korporativen akademischen Selbstverwaltung eingebunden und durften keine akademischen Grade verleihen, denn die Hochschule behielt offiziell den Charakter als katholische kurmainzische Universität ${ }^{24}$.

\section{Mobilitätsphänomene im Konfessionellen Zeitalter}

Die in konfessioneller Hinsicht günstigsten Bedingungen und personellen Strukturen, mithin die Schaffung entweder eines homogen protestantischen oder eines homogen katholischen Lehrkörpers, konnten lediglich an denjenigen Universitäten umgesetzt werden, die aus dem Geist der Reformation und der katholischen Reform gänzlich neu gegründet wurden. Das Konfessionel-

de von Joseph Ritter von Aschbachs Geschichte der Wiener Universität. Die Wiener Universität und ihre Gelehrten 1520-1565, Bd. 1/I, Wien 1898; aus neuerer Zeit in den Studien von Kurt MüHLberger, Zu den Krisen der Universität Wien im Zeitalter der konfessionellen Auseinandersetzungen, in: Lorenz MiкоLетzкy (Hg.), Bericht über den achtzehnten österreichischen Historikertag in Linz, in der Zeit vom 24. bis 29. September 1990, Wien 1991, S. 269-277; ders., Bildung und Wissenschaft. Kaiser Maximilian II. und die Universität Wien, in: Friedrich Edelmayer/Alfred Kohler (Hg.), Kaiser Maximilian II. Kultur und Politik im 16. Jahrhundert, Wien 1992, S. 203-230; ders., Zwischen Reform und Tradition. Die Universität Wien in der Zeit des Renaissance-Humanismus und der Reformation, in: Mitteilungen der Österreichischen Gesellschaft für Wissenschaftsgeschichte 15 (1995), S. 13-42 [wiederabgedruckt in: Walter Leitsch/Stanislaw Trawkowski (Hg.), Polen und Österreich im 16. Jahrhundert, Wien 1997, S. 113-149].

24 Die Universität Erfurt behielt ihren bikonfessionellen Charakter durchgehend bis zu ihrer Schließung im Jahre 1816, vgl. Erich KLEINEIDAM, Universitas studii Erffordensis. Überblick über die Geschichte der Universität Erfurt, Bd. 3, Leipzig 1983, S. 79ff.; Almuth Märker, Geschichte der Universität Erfurt 1392-1816, Weimar 1993, S. 61ff. Dabei war in den Reformationsjahrzehnten bis auf die Theologen die überwiegende Zahl der Lehrkräfte trotz der Bemühungen des Mainzer Erzbischofs protestantisch, vgl. KLEINEIDAM, Universitas studii Erffordensis, S. 93ff. Erstmals 1563 wurde ein Protestant zum Rektor gewählt, vgl. ebd., S. 94. Im Jahre 1566 stiftete der Erfurter Rat sogar eine evangelische Theologieprofessur und einen Lehrstuhl für Hebräisch, welche allerdings beide nicht dem Personenverband der Universität angehörten, vgl. ebd., S. 95ff. Bis zum Ende des 16. Jahrhunderts waren die katholischen Kräfte, deren personeller Rückhalt das 1575 gegründete Jesuitenkolleg in Heiligenstadt war, an der Hochschule bereits so weit marginalisiert, dass nur noch ein katholischer Theologe in Erfurt lehrte, wo im Übrigen bis 1623 für über hundert Jahre keine Promotionen an der Theologischen Fakultät stattfanden, vgl. ebd., S. 181ff. Durch die Gründung der Universitäten Marburg (1527), Jena (1548/58), Helmstedt (1574/76) und Würzburg (1582) in der näheren Umgebung hatte sich der regionale Einzugsbereich Erfurts zudem auf ein Minimum reduziert. Die Studenten entschieden sich wegen des unklaren konfessionellen Status der Hochschule zum Studium an in konfessioneller Hinsicht eindeutig positionierten Landesuniversitäten, vgl. ebd., S. 97f. 
le Zeitalter war aus naheliegenden Gründen eine Phase sowohl der Expansion, als auch der konfessionellen Segmentierung des Universitätswesens im Reich $^{25}$. Auf protestantischer Seite folgten auf die vom hessischen Landgrafen Philipp mit Hilfe von jungen, evangelisch gesinnten Humanisten - zumeist aus Erfurt - gegründeten Universität Marburg (1527) ${ }^{26}$ gemäß reichsrechtlicher Grundlage des Augsburger Religionsfriedens die Neugründungen der wesentlich durch Wittenberger Absolventen bestimmten Hochschulen in Jena (1548/58) und Helmstedt (1574/76).

Die Vorstellung von einer konfessionellen Homogenität des Lehrkörpers an protestantischen Universitäten ist freilich insofern zu relativieren, als gerade an lutherischen Hochschulen um die Mitte des 16. Jahrhunderts die theologisch-dogmatischen Auseinandersetzungen um das Erbe Luthers und Melanchthons offen ausbrachen. Der Gegensatz zwischen Gnesiolutheranern

25 Gesamtcharakterisierungen der deutschen Universitäten im Konfessionellen Zeitalter finden sich etwa bei Anton Schinduing, Schulen und Universitäten im 16. Jahrhundert. Bildungsexpansion und Laienbildung im Dienste der Konfessionen. Eine Problemskizze in zehn Punkten, in: Norbert Richard Wolf (Hg.), Wissensorganisierende und wissensvermittelnde Literatur im Mittelalter. Perspektiven ihrer Erforschung. Kolloquium 5.-7. Dezember 1985, Wiesbaden 1987, S. 278-288; ders., Schulen und Universitäten im 16. und 17. Jahrhundert. Zehn Thesen zu Bildungsexpansion, Laienbildung und Konfessionalisierung nach der Reformation, in: Walter BRANDMÜLleR u.a. (Hg.), Ecclesia militans. Studien zur Konzilien- und Reformationsgeschichte. Festschrift für Remigius Bäumer, Bd. 2, Paderborn 1988, S. 561-570; ders., Universität im 16. und 17. Jahrhundert. Bildungsexpansion, Laienbildung und Konfessionalisierung nach der Reformation, in: Carl August LüCKERATH (Hg.), Von den Generalstudien zur spezialisierten Universität. Vier Kolloquiumsvorträge zur deutschen Bildungs- und Wissenschaftsgeschichte, Köln 1990, S. 29-52; Peter Baumgart, Die deutschen Universitäten im Zeichen des Konfessionalismus, in: Alexander Patschovsky/Horst Rabe (Hg.), Die Universität in Alteuropa, Koblenz 1994, S. 147-168; Notker Hammerstein, Die historische und bildungsgeschichtliche Physiognomie des konfessionellen Zeitalters, in: Ders., Handbuch der deutschen Bildungsgeschichte, Bd. 1, S. 57-101; Arno SEIFERT, Das höhere Schulwesen. Universitäten und Gymnasien, in: Ebd., S. 197-374; Asche, Frequenzeinbrüche und Reformen; oder ders., Humanistische Distanz gegenüber dem »Konfessionalisierungsparadigma«. Kritische Bemerkungen aus der Sicht der deutschen Bildungs- und Universitätsgeschichte, in: Jahrbuch für Historische Bildungsforschung 7 (2001), S. 261-282.

26 Marburg wurde regelrecht zu einem Sammelpunkt ehemaliger Erfurter Humanisten. Landgraf Philipp der Großmütige von Hessen berief gleich zur Eröffnung im Jahre 1527 die Theologen Adam Krafft und Erhard Schnepf sowie den Mediziner Euricius Cordus nach Marburg. Wenige Jahre später kamen noch Antonius Niger (1533 als Professor für Physik), Johannes Draconites (1534 Nachfolger Schnepfs) und Eobanus Hessus (1536 als Professor für Geschichte) aus Erfurt dorthin; vgl. die Nachweise bei Franz GundLach, Catalogus Professorum Academiae Marburgensis. Die akademischen Lehrer der Philipps-Universität Marburg von 1527 bis 1910, Marburg 1927, Nr. 1f., 5, 291, 539, 682. Zum Gründungszusammenhang der Universität Marburg vgl. Heinrich Hermelink/Siegfried A. KaeHLer, Die Philipps-Universität zu Marburg 1527-1927. Fünf Kapitel aus ihrer Geschichte (1527-1866), Marburg 1927, S. 5ff.; Walter HeinemeYer, Die Bildungspolitik Landgraf Philipps des Großmütigen von Hessen, in: HJLG 21 (1971), S. 100-128; ders., Zur Gründung des »universale studium Marpurgense«, in: Ders. u.a. (Hg.), Academia Marburgensis. Beiträge zur Geschichte der Philipps-Universität Marburg, Marburg 1977, S. 49-92; Peter Baumgart, Die deutsche Universität des 16. Jahrhunderts. Das Beispiel Marburg, in: HJLG 28 (1978), S. 50-79. 
und Philippisten generierte bekanntlich die Konkordienbemühungen innerhalb des Luthertums und begleitete die von der Kurpfalz ausgehende Ausformung des (deutsch-)reformierten Bekenntnisses. Diese innerprotestantischen Verwerfungen im Zeichen der Konfessionsbildungsprozesse brachten praktisch an allen protestantischen Universitäten erneut zahlreiche Mobilitätsphänomene hervor. Aufsehenerregend war zweifellos der Sturz und die Ausweisung der Philippisten unter Kurfürst August, der nach 1574 zu einem nachhaltigen Elitenaustausch in Kursachsen führte und insbesondere auch die beiden Landesuniversitäten in Wittenberg und Leipzig betraf ${ }^{27}$. Ver-

27 An der Universität Wittenberg fielen den Säuberungen zum Opfer: der Mediziner und Schwiegersohn Melanchthons Caspar Peucer (ging nach seiner Freilassung aus der Gefangenschaft als fürstlicher Leibarzt nach Dessau), die Theologen Caspar Cruciger der Jüngere (ging als Hofprediger nach Kassel), Heinrich Moeller (ging als Pfarrer nach Hamburg), Christoph Pezel (ging als Professor an die reformierte »Hohe Schule « Bremen) und Friedrich Widebram (ging zunächst als Pfarrer ins Nassauische und später ebenfalls als Professor nach Bremen) sowie der Ethiker Wolfgang Krell und der Gräzist Esrom Rüdinger (ging als Professor an das Kolleg der Mährischen Brüderunität in Eibenschitz bei Brünn). Außerdem verließen die drei Schwiegersöhne des Hauptangeklagten Peucer - der Jurist Joachim Eger, der Mediziner Hieronymus Schaller und der kurfürstliche Leibarzt Johann Hermann - freiwillig das Land. An der Universität Leipzig wurde nach langen Prozessen im Jahre 1576 der Theologe Andreas Freyhub entlassen; vgl. Robert Calinich, Kampf und Untergang des Melanchthonismus in Kursachsen in den Jahren 1570-1574 und die Schicksale ihrer vornehmsten Häupter. Aus den Quellen des königlichen Hauptstaatsarchivs zu Dresden, Leipzig 1866; August KLuckhoнn, Der Sturz der Kryptocalvinisten in Sachsen 1574, in: HZ 18 (1867), S. 77-127; Paul ZINCK, Die Universität Leipzig in den kryptocalvinistischen Wirren zur Zeit des Kurfürsten August, in: BSKG 16 (1902), S. 71-119; Ernst KocH, Der kursächsische Philippismus und seine Krise in den 1560er und 1570er Jahren, in: Heinz Schilling (Hg.), Die reformierte Konfessionalisierung in Deutschland. Das Problem der »Zweiten Reformation«, Gütersloh 1986, S. 60-77; ders., Auseinandersetzungen um die Autorität von Philipp Melanchthon und Martin Luther in Kursachsen im Vorfeld der Konkordienformel von 1577, in: LuJ 59 (1992), S. 128-159; HansPeter Hasse, Bildungspolitik im 16. Jahrhundert. Kurfürst August und die Universität Wittenberg, in: Peter Freybe (Hg.), Wittenberg als Bildungszentrum 1502-2002, Lutherstadt Wittenberg 2002, S. 127-156; ders., Paul Krell (1531-1579). Melanchthons »Enarratio Symboli Nicaeni« (1550) und der Sturz der Philippisten in Kursachsen 1574, in: Scheible, Melanchthon in seinen Schülern, S. 427-463; ders., Caspar Peucers Prozeß und die »Historia carcerum«, in: Ders./Günther Wartenberg (Hg.), Caspar Peucer (1525-1602). Wissenschaft, Glaube und Politik im konfessionellen Zeitalter, Leipzig 2004, S. 135-155; Theodor Mahlmann, Melanchthon als Vorläufer des Wittenberger Kryptocalvinismus, in: Günter Frank/Herman J. SELDERHuis (Hg.), Melanchthon und der Calvinismus, Stuttgart 2005, S. 173-230; Ulrike Ludwig, Philippismus und orthodoxes Luthertum an der Universität Wittenberg. Die Rolle Jakob Andreäs im lutherischen Konfessionalisierungsprozeß Kursachsens (1576-1580), Münster 2009, S. 78ff. Nach dem Tod des Kurfürsten August folgte dessen Sohn Christian I., der während seiner kurzen Regierungszeit (1586-1591) unter dem Einfluss seiner Räte eine politische Annäherung an die reformierte Kurpfalz suchte und die gnesiolutherischen Kräfte im Lande zurückdrängte. Nach 1588 wurden die unter Kurfürst August wortführenden Theologieprofessoren Georg Mylius in Wittenberg (ging an die Universität Jena) und Nikolaus Selnecker in Leipzig (ging als Superintendent nach Hildesheim) ausgewiesen und deren Stellen durch die reformierten Professoren Heinrich Maius (Nachfolger von Mylius), Urban Pierius (Nachfolger des verstorbenen David Voit in Wittenberg) und Christoph Gundermann (Nachfolger von Selnecker) ersetzt, die ihrerseits nach dem frühen Tod Kurfürst Christians I. von dessen Nachfolger Christian II. 
gleichbar, aber weniger spektakulär als die kursächsischen Maßnahmen, die zur Ausweisung einer großen Zahl von Pfarrern ${ }^{28}$ und mehrerer Wittenberger und Leipziger Professoren führten, gab es im letzten Drittel des 16. Jahrhunderts auch andernorts Fälle, wo konfessionell verdächtige oder offenkundig deviante Professoren aufgrund ihrer Verweigerung des obligatorischen Konfessionseides $^{29}$ teils erzwungen, teils freiwillig ihre Universität verließen und insbesondere an einer der zahlreich entstandenen reformierten »Hohen Schulen« dauerhaft einen neuen Wirkungsort fanden ${ }^{30}$. Dennoch ist zu beto-

ausgewiesen wurden. Selnecker und Mylius kehrten 1592 beziehungsweise 1603 wieder an ihre Universitäten zurück, vgl. Franz Dibelius, Zur Geschichte und Charakteristik Nikolaus Selnecker's, Leipzig 1888; Erich BAYreuther (Hg.), Nikolaus Selnecker 1530-1592, Hersbruck 1980; Helmut Süss, Zum 400. Todestag von Nikolaus Selnecker, in: Mitteilungen der Altnürnberger Landschaft e.V. 41 (1992), S. 46-49; Hans Meyer-Roscher, Nicolaus Selnecker 1590-1591. Superintendent in Hildesheim, in: Hildesheimer Heimat-Kalender (1998), S. 72 74; Kenneth Appold, Der Fall Georg Mylius, in: Irene Dingel/Günter Wartenberg (Hg.), Die Theologische Fakultät Wittenberg 1502 bis 1602, Leipzig 2002, S. 155-172. Der Streit um das wahre Luthertum in Kursachsen, der stets auch eine innerdynastische Komponente des Gegensatzes der beiden wettinischen Linien besaß, wurde erst in den frühen 1590er Jahren beigelegt, als die gegenseitigen Vormundschaftsregierungen der Ernestiner und Albertiner zu einem einheitlichen orthodox lutherischen Bekenntnis an den drei wettinischen Universitäten Wittenberg, Leipzig und Jena führten. Zu den philippistischen Wirren in Kursachsen der 1570er und 1580er Jahre vgl. zusammenfassend Ernst Ludwig Theodor Henke, Caspar Peucer und Nikolaus Krell. Zur Geschichte des Luthertums und der Union am Ende des 16. Jahrhunderts, Marburg 1865; Thomas Klein, Der Kampf um die zweite Reformation in Kursachsen 1586-1591, Köln 1962; Franz LAU, Die zweite Reformation in Kursachsen. Neue Forschungen zum so genannten sächsischen Kryptocalvinismus, in: Verantwortung. Untersuchungen über Fragen aus Theologie und Geschichte. Zum sechzigsten Geburtstag von Landesbischof D. Gottfried Noth DD, Berlin 1964, S. 137-154; Ernst Косн, Ausbau, Gefährdung und Festigung der lutherischen Landeskirche von 1553 bis 1601, in: Helmar Junghans (Hg.), Das Jahrhundert der Reformation in Sachsen, Leipzig 2005, S. 195-223; Karlheinz BlaschKe, Religion und Politik in Kursachsen, in: SchiLling, Die reformierte Konfessionalisierung, S. 79-97; Andreas GössNeR, Die kursächsische Universitätspolitik, in: Helmar Junghans (Hg.), Die sächsischen Kurfürsten während des Religionsfriedens von 1555 bis 1618, Leipzig 2007, S. 115-126.

28 Einzelnachweise bei Reinhold GrünBERG, Sächsisches Pfarrerbuch. Die Parochien und Pfarrer der Ev.-luth. Landeskirche Sachsens (1539-1939), 2 Bde., Freiberg 1939/40, passim.

29 Zur Funktion von Konfessionseiden vgl. insbesondere die Studien von Klaus SchreIner, Rechtgläubigkeit als »Band der Gesellschaft« und »Grundlage des Staates«. Zur eidlichen Verpflichtung von Staats- und Kirchendienern auf die »Formula Concordiae« und das »Konkordienbuch «, in: Martin Brecht/Reinhard Schwarz (Hg.), Bekenntnis und Einheit der Kirche. Studien zum Konkordienbuch, Stuttgart 1980, S. 351-379; ders., Iuramentum Religionis. Entstehung, Geschichte und Funktion des Konfessionseides der Staats- und Kirchendiener im Territorialstaat der frühen Neuzeit, in: Der Staat 24 (1985), S. 211-246. Die Wirksamkeit und Durchsetzung von Konfessionseiden ist hingegen allenfalls in Ansätzen untersucht, vgl. für die Universität Tübingen ders., Disziplinierte Wissenschaftsfreiheit. Gedankliche Begründung und geschichtliche Praxis freien Forschens, Lehrens und Lernens an der Universität Tübingen (1477-1945), Tübingen 1981, S. 8ff.

30 Exemplarisch sei hingewiesen auf die beiden maßgeblichen Initiatoren der reformierten »Hohen Schule in Bremen, Christoph Pezel und Nathan Chytraeus. Zum ehemaligen Wittenberger Theologie-Professor Pezel vgl. Johann Friedrich Iken, Die Wirksamkeit des Christoph Pezelius in Bremen 1580 bis 1604, in: BrJ 9 (1877), S. 1-54; Jürgen Moltmann, Christoph Pezel (1539-1604) und der Calvinismus in Bremen, Bremen 1958; zum ehemaligen Rosto- 
nen, dass besonders bei renommierten Juristen und Medizinern nicht selten auch stillschweigend auf die vorgeschriebene Ableistung des Konfessionseides vor dem Antritt ihrer Lehrtätigkeit verzichtet wurde, um sie für die jeweilige Universität gewinnen zu können. Echte Heterodoxie an deutschen Universitäten war hingegen offenbar ganz selten ${ }^{31}$. Allerdings konnte durchaus die persönliche Konfessionalität oder auch nur ein in Ansätzen ungünstiger Leumund einer Anstellung als akademischer Lehrer im Wege stehen ${ }^{32}$.

Die personellen Veränderungen, die mit dem Übergang lutherischer Universitäten zum reformierten Bekenntnis verbunden waren - hinzuweisen ist vor allem auf die Verhältnisse in Heidelberg und Marburg -, führten dagegen zu einem nachhaltigen Austausch des älteren Lehrpersonals. Der Elitenaus-

cker Poesie-Professor Chytraeus vgl. die beiden Sammelbände von Thomas Elsmann u.a. (Hg.), Nathan Chytraeus 1543-1598. Ein Humanist in Rostock und Bremen, Bremen 1991; Karl-Heinz Glaser u.a. (Hg.), David und Nathan Chytraeus. Humanismus im konfessionellen Zeitalter, Ubstadt-Weiher 1993; zudem Thomas Fuchs, Nathan Chytraeus (1543-1598). Zum 450. Geburtstag eines Kraichgauer Humanisten, in: BadHei 74 (1994), S. 113-120; sowie die Edition von Sabine Pettke (Hg.), Nathan Chytraeus. Quellen zur zweiten Reformation in Norddeutschland, Köln 1994. Die auffällig zahlreich seit den späten 1570er Jahren gegründeten »Hohen Schulen « - am bedeutendsten waren diejenigen Anstalten in Neustadt an der Haardt (1578/85), Zerbst (1582), Herborn (1584), Bremen (1584), Burgsteinfurt (1591) und Hanau (1607) -, deren philippistisch gesinnten beziehungsweise dezidiert reformierten Professoren häufig längere Phasen der Vertreibung und konfessionell bedingter Migration erlebt hatten, waren freilich auch ein Ausdruck der Suche nach einem theologisch-dogmatischen Mittelweg zwischen den sich verfestigenden protestantischen Konfessionen; vgl. die instruktive Übersicht bei Gerhard Menk, Die kalvinistischen Hochschulen und ihre Städte im konfessionellen Zeitalter, in: Heinz Duchhardt (Hg.), Stadt und Universität, Köln 1993, S. 83-106.

31 Eines der wenigen Beispiele ist der Altdorfer Medizinprofessor Ernst Soner (1572-1612), der gewisse Sympathien für den Sozinianismus hegte und aus diesem Grund ein Anziehungspunkt für antitrinitarisch gesinnte Studenten - namentlich aus dem Polnisch-Litauischen Reich und aus den Ländern der Stephanskrone - gewesen ist, vgl. Karl Braun, Der Socinianismus in Altdorf 1616, in: ZBKG 8 (1933), S. 65-81, 129-150; Domenico CACCAMo, Ernest Soner i kryptosocynianizm w Altdorfie [= Ernst Soner und der Kryptosozinianismus in Altdorf], in: ORP 9 (1964), S. 85-104; ders., Sozinianer in Altdorf und Danzig im Zeitalter der Orthodoxie, in: ZOF 19 (1970), S. 42-78; Bálint KesERÜ, Peregrinatio academica dissidentium der Siebenbürger Unitarier, in: László SzÖGI/Júlia VARGA (Hg.), Universitas Budensis 1395-1995. International Conference for the History of Universities on the Occasion of the $600^{\text {th }}$ Anniversary of the Foundation of the University of Buda, Budapest 1997, S. 189-198, hier: S. 195; instruktiv auch der Tagungsbericht von Klaus Birnstiel/Martin Schmeisser, Antitrinitarismus in Altdorf um 1600, in: Mitteilungen des Sonderforschungsbereichs 573 »Pluralisierung und Autorität in der Frühen Neuzeit« I (2009), S. 55-58 [auch als Online-Ressource verfügbar unter: URL: http://www.sfb-frueheneuzeit.uni-muenchen.de/mitteilungen/index.html].

32 So gelang es etwa dem zeitweiligen mecklenburgischen Herzog Albrecht von Wallenstein nicht, Johannes Kepler (1571-1630) wegen seiner verdächtigen Vergangenheit als Hofmathematiker Kaiser Rudolfs II. in Prag trotz seiner eindeutig lutherischen familiären Sozialisation und akademischen Ausbildung am Tübinger Stift mit einem Mathematik-Lehrstuhl an der Universität Rostock zu versorgen; vgl. Bernhard WANDT, Die geplante Berufung von Johannes Kepler an die Universität Rostock (1629/30), in: NTM. Zeitschrift für Geschichte der Wissenschaften, Technik und Medizin 19 (1982), S. 77-84; ders., Die Universität Rostock und Johannes Kepler (1571-1630), in: Beiträge zur Geschichte der Wilhelm-Pieck-Universität Rostock 3 (1983), S. 50-55. 
tausch vollzog sich in Marburg unter Landgraf Moritz von Hessen-Kassel (reg. 1592-1627) relativ abrupt und zerbrach so endgültig den ohnehin fragilen Grundkonsens der drei hessischen Erhalter der Samtuniversität Marburg (Hessen-Kassel, Hessen-Darmstadt, Hessen-Marburg) ${ }^{33}$. Mit der gewaltsamen Okkupation des oberhessischen Landesteils nach dem Tod des Marburger Landgrafen Ludwig IV. (1604) durch den Kasseler Landgrafen und den an dessen Konversion (1605) anschließenden Bemühungen zur Durchsetzung des reformierten Bekenntnisses im Marburger Landesteil und an der Landesuniversität kam es zur Abwanderung der lutherischen Professoren an das 1605 vom Darmstädter Landgrafen Ludwig V. (reg. 1596-1626) gegründete »Akademische Gymnasium « in Gießen, das zwei Jahre später ebenfalls kaiserliche Universitätsprivilegien erhielt ${ }^{34}$. In Heidelberg hingegen vollzog sich der personelle Austausch seit dem Regierungsantritt von Kurfürst Ottheinrich (reg. 1556-1559) und forciert während der Regierungszeit des Kur-

33 Zum Marburger Erbstreit vgl. ausführlich Kurt BECK, Der hessische Bruderzwist zwischen Hessen-Kassel und Hessen-Darmstadt, Frankfurt am Main 1978; Manfred Rudersdorf, Ludwig IV. Landgraf von Hessen-Marburg 1537-1604. Landesteilung und Luthertum in Hessen, Mainz 1991.

34 Zum Entstehungszusammenhang der Universität Gießen vgl. Peter Moraw, Kleine Geschichte der Universität Gießen 1607-1982, Gießen 1982, S. 9ff.; sowie den Sammelband von dems./Volker Press (Hg.), Academia Gissensis. Beiträge zur älteren Gießener Universitätsgeschichte. Zum 375-jährigen Jubiläum dargebracht vom Historischen Institut der Justus-Liebig-Universität Gießen, Marburg 1982, darin insbesondere die Beiträge von Manfred RuDERSDORF, Der Weg zur Universitätsgründung in Gießen. Das geistige und politische Erbe Landgraf Ludwigs IV. von Hessen-Marburg, S. 45-82; Anton Schinduing, Die Universität Gießen als Typus einer Hochschulgründung, S. 83-113; außerdem Ernst Schering, Gießen und Marburg. Universitäts- und Fakultätsgeschichte im Kontext konfessioneller Auseinandersetzungen, in: Bernhard JendorfF u.a. (Hg.), Theologie im Kontext der Geschichte der Alma mater Ludoviciana, Gießen 1983, S. 11-53. Insgesamt wurden sechs orthodox lutherisch gesinnte Professoren wegen ihrer Weigerung, die Unterschrift unter die so genannten »Verbesserungspunkte« des Kasseler Landgrafen Moritz zu leisten - vgl. hierzu Theodor Griewank, Das »Christliche Verbesserungswerk « des Landgrafen Moritz und seine Bedeutung für die Bekenntnisentwicklung der kurhessischen Kirche, in: JHKGV 4 (1953), S. 38-73; Gerhard MenK, Die "Zweite Reformation« in Hessen-Kassel. Landgraf Moritz und die Einführung der Verbesserungspunkte, in: Schilling, Die reformierte Konfessionalisierung, S. 154-183; Manfred RUDERSDORF, Lutherische Erneuerung oder Zweite Reformation? Die Beispiele Württemberg und Hessen, in: Ebd., S. 130-156 - im Jahre 1605 ihres Amtes enthoben: die Theologen Johannes Winckelmann (ging nach Gießen; seine Nachfolger wurden 1606 Gregorius Schönfeld der Ältere, der Kasseler Superintendent und Professor am dortigen »Collegium Mauritianum«, und Raphael Egli, ein Professor aus Zürich) und Balthasar Mentzer (ging nach Gießen; sein Nachfolger würde 1605 Caspar Sturm, ein Pfarrer aus Gudensberg) sowie der Hebraist Johannes Scholl (ging als Pfarrer nach Friedberg; sein Nachfolger wurde 1605 Johannes Molther der Ältere, ein Pfarrer aus Friedberg). Einige verließen später - mehr oder weniger freiwillig die Universität Marburg: die Juristen Hermann Lersner (ging 1605 nach Lengsfeld; vakante Stelle wurde erst 1625 wieder besetzt) und Gothofredus Antonii (ging 1605 nach Gießen; sein Nachfolger wurde 1605 Christoph Deichmann aus Burgsteinfurt) sowie der Mediziner Heinrich Ellenberger (ging 1607 als Physicus nach Friedberg; sein Nachfolger wurde 1608 der vorherige Physik-Professor Nicolaus Braun); vgl. die Nachweise bei GundLach, Catalogus Professorum, Nr. 20-26, 133, 140f., 304, 306. 
fürsten Friedrich III. (reg. 1559-1576), der bekanntlich eine dezidierte Politik der Öffnung gegenüber Einflüssen aus dem westeuropäischen Calvinismus betrieb ${ }^{35}$. Schon vor Kurfürst Ottheinrich begann jedoch die Berufung einer großen Zahl evangelischer Gelehrter unterschiedlichster theologischer Provenienz an die Heidelberger Universität, deren Gemisch nicht ohne Brisanz war und stets allerlei Konflikte in sich barg ${ }^{36}$. Hinzuweisen ist in diesem Zusammenhang insbesondere auf die zahlreichen Glaubensflüchtlinge und Exulanten aus Italien, Frankreich und den Niederlanden, die an der Universität Heidelberg - im Selbstverständnis das »Deutsche« beziehungsweise das »Dritte Genf « - Aufnahme fanden ${ }^{37}$. Anders als in Heidelberg und

35 Einen Eindruck von der großen Ausstrahlung der Universität Heidelberg in der Zeit um 1600 vermittelt die Matrikelanalyse von Armin KoHnle, Die Universität Heidelberg als Zentrum des reformierten Protestantismus im 16. und frühen 17. Jahrhundert, in: Márta FonT/László SzÖGI (Hg.), Die ungarische Universitätsbildung und Europa, Pécs 2001, S. 141-161.

36 Einzelnachweise bei Dagmar DrÜLl-ZimmERmanN, Heidelberger Gelehrtenlexikon 1386-1651, Berlin 2002, dort vor allem instruktiv die nach konfessioneller Verortung erstellte Liste der Professoren nach der Reformation, S. 593ff.

37 Nachzuweisen sind für die Regierungszeiten der Kurfürsten Ottheinrich, Friedrich III. und Friedrich IV. (reg. 1583-1610) die Berufungen von immerhin sieben Exulanten aus den Niederlanden (1556 Jurist François Baudoin, 1563 Philosoph Lambert Ludolf Pithopoeus, 1567 Jurist Peter Alst, 1571 Philosoph Matthaeus Lannoius der Ältere, 1589 Theologe Jacob Kimedoncius, 1593 Philosoph Janus Gruterus, 1602 Philosoph Abraham Kimedoncius), sechs Glaubensflüchtlinge aus Frankreich (1557 Theologe Pierre Bouquin, 1560 Jurist Jacob Concenatius, 1569 Petrus Ramus, 1573 Jurist Hugo Donellus, 1584 Theologe François de Jon der Ältere, 1600 Denis Godefroy) und vier protestantische Gelehrte aus Italien (1561 Theologe Immanuel Tremellius, 1567 Theologe Hieronymus Zanchi, 1585 Jurist Julius Pacius, 1596 Philosoph Aemilius Portus). Allgemein zum - nicht nur in Heidelberg signifikant auftretenden - Phänomen der Gelehrten mit Exulantenhintergrund vgl. Delio CANTIMORI, Italienische Häretiker der Spätrenaissance, Basel 1949; Robert von RoosBroeck, Die Beziehungen der Niederländer und der niederländischen Emigranten zur deutschen Gelehrtenwelt im XVI. Jahrhundert. Eine Übersicht, in: RössLER/Franz, Universität und Gelehrtenstand, S. 107-125. Darüber hinaus war Heidelberg ohnehin ein Sammelpunkt für aus konfessionellen Gründen ausgewiesene und ausgewanderte Professoren von orthodox lutherischen Universitäten. So wirkte beispielsweise der Philosoph Victorinus Strigel vor seiner Heidelberger Berufung (1567) an der Leipziger und der Theologe Georg Sohn bis 1584 an der Marburger Universität. Nach dem Tod Kurfürst Friedrichs III. kam es unter seinem Nachfolger Ludwig VI. (reg. 1576-1583) zumindest kurzzeitig zu einer konfessionellen Neuausrichtung im Sinne des orthodoxen Luthertums, die für zahlreiche reformierte Heidelberger Professoren den Verlust ihres Lehramts bedeutete (1577 Tremellius, Alst und Zanchi, 1579 Donellus, die Mediziner Albert Blaurer und Ludwig Graff der Jüngere sowie der Jurist Nikolaus Dobbin, 1580 Pithopoeus und Lannoius, die Mediziner Thomas Erastus und Theophil Mader sowie die Philosophen Hermann Witekind, Ulrich Faber, Timotheus Mader und Theophil Mader). Einige der entlassenen reformierten Heidelberger Professoren fanden während der kurzen orthodox lutherischen Phase unter Kurfürst Ludwig VI. Aufnahme an der vom Simmerner Pfalzgrafen Johann Casimir 1578 gegründeten reformierten »Hohen Schule« in Neustadt an der Haardt, vgl. Jakob Anton LEISER, Die Neustadter Hochschule. Collegium Casimirianum, Neustadt an der Haardt 1886 [ND Neustadt an der Weinstraße 1978]; Karl TAVERnier, Das Casimirianum zu Neustadt a. d. H. Urkundliche Beiträge zu seiner Geschichte, Erlangen 1922 [ND Neustadt an der Weinstraße 1978]; Gustav Breith, Das Casimirianum zu Neustadt an der Haardt. Zur 550jährigen Jubelfeier der Ruprecht-Karls-Universität zu Heidelberg, o.O. 1936; Peter Moraw/Theodor Karst, Die 
Marburg, wo die konfessionellen Neuausrichtungen zum Teil heftige theologische Auseinandersetzungen auslösten, vollzog sich die Berufung einiger weniger gemäßigt reformierter Professoren an die kurbrandenburgische Landesuniversität Frankfurt an der Oder nach der Konversion des Kurfürsten Johann Sigismund (1613) relativ geräuschlos ${ }^{38}$. Phänomene von heterodoxen Professoren und konfessionellen Verwerfungen wie die für die protestantischen Hochschulen skizzierten gab es an katholischen nicht, auch wenn insbesondere an den älteren katholischen Universitäten in den Jahrzehnten um 1600 durchaus personelle Verdrängungsmechanismen wirksam waren. Diese resultierten allerdings nicht aus theologischen, sondern zumeist aus rechtlichen Bedingtheiten, mithin aus den zuweilen zähen Kämpfen um die Inkorporation von exemten Jesuitenkollegs in den akademischen Rechtsverband ${ }^{39}$.

Universität Heidelberg und Neustadt an der Haardt, Speyer 1963; Gustav Adolf BenRath, Das Casimirianum, die reformierte Hohe Schule in Neustadt an der Haardt (1578-1584), in: RupertoCarola 38 (1986), S. 31-37; Otto Böcher, Das Casimirianum in Neustadt a.d. Weinstraße, in: Ärzteblatt Rheinland-Pfalz 43 (1990), S. 90-97; ders., Das Casimirianum in Neustadt an der Weinstraße, Speyer 1995. Einige von diesen kehrten nach dem Regierungsantritt des anfangs noch unter Vormundschaft des Pfalzgrafen Johann Casimir stehenden Kurfürsten Friedrich IV. wieder nach Heidelberg zurück (1584 Pithopoeus, 1585 Witekind, 1588 Theophil Mader); vgl. die Einzelnachweise bei DrüLl-Zimmermann, Heidelberger Gelehrtenlexikon 1386-1651, passim.

38 Die »Viadrina« gehört trotz ihrer stets hohen Besucherfrequenzen und ihres enormen regionalen Ausstrahlungsbereiches in den polnisch-litauischen, preußischen und baltischen Raum zu den am schlechtesten untersuchten Universitäten im Alten Reich. Die personellen Veränderungen im Lehrkörper, die sich aus dem Konfessionswechsel Kurfürst Johann Sigismunds ergeben haben, sind nicht erforscht. Hinzuweisen ist lediglich auf die wenigen Angaben in den Gesamtdarstellungen von Günter MüHLPFORDT, Die Oder-Universität 1506-1811. Eine deutsche Hochschule in der Geschichte Brandenburg-Preußens und der europäischen Wissenschaft, in: Günther HAASE/Joachim Winkler (Hg.), Die Oder-Universität Frankfurt. Beiträge zu ihrer Geschichte, Weimar 1993, S. 19-72, neuerdings auch bei Irina MoDRow, Wonach in Frankfurt »jeder, der nur wollte, gute Studien machen konnte [...]«. Eine kleine Geschichte der Viadrina anlässlich ihres 500. Jubiläums, Schöneiche bei Berlin 2006; vgl. außerdem das noch immer maßgebliche, materialreiche Werk von Carl Renatus HAusEn, Geschichte der Universität und Stadt Frankfurt an der Oder seit ihrer Stiftung bis zum Schluß des 18. Jahrhunderts, Frankfurt a.d. Oder 1800; Siegfried RHODE, Studien zur Geschichte der theologischen Fakultät der Universität Frankfurt an der Oder, Diss., Berlin 1945. Auch fehlt ein modernes Professorenlexikon, weshalb bislang lediglich auf die Biographien-Sammlung von Lothar NoAck/Jürgen Splett (Hg.), Bio-Bibliographien. Brandenburgische Gelehrte der Frühen Neuzeit. Mark Brandenburg mit Berlin-Cölln 1506-1640, Berlin 2009, zurückgegriffen werden muss. Kurfürst Johann Sigismund hatte offenbar nicht nur bei seiner Religions- und Kirchenpolitik in der Mark Brandenburg, sondern auch an der Landesuniversität starke Rücksichten auf die lutherischen Stände zu nehmen. Immerhin konnte er durchsetzen, dass im Jahre 1616 der bis dahin obligatorische Eid der Professoren und Studenten auf die orthodox lutherische »Konkordienformel « abgeschafft wurde. Alle brandenburgischen Hohenzollern achteten stets peinlich genau darauf, dass die theologischen Kontroversen an der »Viadrina « nicht eskalierten.

39 Das Nebeneinander von Jesuitenpatres mit ihrem kostenlosen, universitätsähnlichen Unterricht und den ordentlichen Professoren an den Philosophischen und Theologischen Fakultäten war in aller Regel durch starke Konkurrenzen geprägt. Zudem stemmten sich die Universitätsprofessoren gegen die Forderung des Jesuitenordens nach vollständiger Übernahme dieser 


\title{
Mobilitätsphänomene während des Dreißigjährigen Krieges
}

\begin{abstract}
Der Dreißigjährige Krieg, der von den Zeitgenossen in erster Linie als Religionskrieg erfahren, wahrgenommen und retrospektiv gedeutet wurde, schädigte das deutsche Universitätswesen nachhaltig. Vor dem Hintergrund der sich oftmals innerhalb weniger Jahre abwechselnden militärischen Besatzungen in den Kriegsjahrzehnten der 1620er, 1630er und frühen 1640er Jahre ist eine letzte Phase erhöhter konfessionell bedingter Mobilität bei den Professoren feststellbar. Obwohl einige Universitäten durchaus auch vom Krieg profitieren konnten, mithin im Windschatten der militärischen Operationen zu Zufluchtsstätten für Lehrende und Studierende werden konnten - so etwa Straßburg, Königsberg oder die niederländischen und skandinavischen Universitäten ${ }^{40}$ - überwogen doch die vielfältigen negativen Auswir-
\end{abstract}

Fakultäten, zumal damit massive Einschnitte in die akademische Rechtskorporation verbunden waren. Wegen der Inkorporations- und Kompetenzstreitigkeiten musste der Jesuitenorden in Ingolstadt sogar zweimal - zwischen 1552 und 1556 sowie zwischen 1573 und 1576 - wieder die Universitätsstadt verlassen. Erst im Jahre 1585 wurden den Jesuiten alle Lehrstühle der Philosophischen Fakultät übertragen, vgl. Hengst, Jesuiten an Universitäten, S. 86ff. mit weiterführender Literatur. An der Universität Köln war der Einfluss des Jesuitenordens vergleichsweise gering, denn ihm wurde lediglich eines von drei der Universität inkorporierten Gymnasien, das »Tricoronatum«, übertragen. An der Theologischen Fakultät fielen die Jesuitenpatres als Professoren praktisch kaum ins Gewicht, vgl. ebd., S. 99ff. mit weiterführender Literatur. Die Jesuitenkollegs in Prag (1555), Wien (1558) und Freiburg (1582) wurden erst sehr spät den Universitäten inkorporiert: In Wien wurden 1623 dauerhaft drei Theologie- und zehn Philosophieprofessuren an den Orden übertragen, vgl. KINK, Geschichte der kaiserlichen Universität, Bd. 1, S. 349ff., 357ff. In Prag wurde das jesuitische Clemens-Kolleg sogar erst 1654 mit der bis 1620 von utraquistischen und protestantischen Professoren dominierten »Carolina« vereinigt, vgl. Wenzel Wladiwoj Томек, Geschichte der Prager Universität. Zur Feier der fünfhundertjährigen Gründung derselben, Prag 1849 [ND Osnabrück 1968], S. 69ff. In Freiburg schließlich gelang den Jesuiten die Übernahme der meisten Lehrstühle in der Philosophischen und Theologischen Fakultät im Jahre 1620, vgl. HeNGST, Jesuiten an Universitäten, S. 143ff. mit weiterführender Literatur. In Erfurt konnte wegen des erbitterten Widerstandes der ganz überwiegend lutherischen Bürger erst im Jahre 1611 ein Jesuitengymnasium als Konkurrenz zum evangelischen Ratsgymnasium eröffnet werden, das acht Jahre später zum Kolleg erhoben wurde, vgl. ebd., S. 148ff.; KLeIneIDam, Universitas studii Erffordensis, Bd. 3, S. 125ff., jeweils mit weiterführender Literatur. Wegen der schwachen personellen Besetzung in den Philosophischen und Theologischen Fakultäten gestaltete sich dagegen die Rezeption jesuitischer Professoren an den Universitäten Trier (1561) und Mainz (1562) relativ problemlos. Hier wurde dem Orden jeweils auch die Leitung der gesamten Fakultäten übertragen, vgl. ebd., S. 110ff., 116ff.

40 Explizit thematisiert wurde das Phänomen von »Ausweichuniversitäten« während des DreiBigjährigen Krieges lediglich für die mehrheitlich auf die während des Krieges geschlossene Universität Heidelberg ausgerichtete Besuchergruppe der pfälzischen Landeskinder, vgl. Alexander Persijn, Pfälzische Studenten und ihre Ausweichuniversitäten während des Dreißigjährigen Krieges. Studien zu einem Pfälzischen Akademikerbuch, Diss., Mainz 1959; zudem die Hinweise bei August SCHRICKER, Zur Geschichte der Universität Straßburg. Festschrift zur Eröffnung der Universität Straßburg am 1. Mai 1872, Straßburg 1872, S. 37. Zu den erweiterten regionalen Einzugsbereichen der vom Krieg weitgehend verschonten Universitäten vgl. die Hinweise in den einschlägigen Matrikelanalysen von Herman T. ColendRANDER, De herkomst der Leidse studenten, in: Pallas Leidensis, Leiden 1925, S. 273-303; Arthur Schulze, Die ört- 
kungen des Krieges, unter denen praktisch alle deutschen Hochschulen zu leiden hatten ${ }^{41}$.

Hier muss in erster Linie die Universität Heidelberg genannt werden, die aufgrund der exponierten Politik des reformierten pfälzischen Kurfürsten

liche und soziale Herkunft der Straßburger Studenten 1621-1793, Frankfurt am Main 1926; Johannes Lehmann, Die örtliche und soziale Herkunft der Königsberger Studenten 1544-1649, Diss., Leipzig 1929; Thomas Otto Achelis, Deutsche Studenten auf nordischen Universitäten während des Dreißigjährigen Krieges, in: AKuG 39 (1957), S. 189-208; ders., Deutsche Studenten als Hofmeister in Skandinavien während des Dreißigjährigen Krieges, in: Zeitschrift für Niederdeutsche Familienkunde 32 (1957), S. 129-139; Heinz SCHNEPPEN, Niederländische Universitäten und deutsches Geistesleben von der Gründung der Universität Leiden bis ins späte 18. Jahrhundert, Münster 1960; Hans Bots/Willem T. M. FrijhofF, De studentenpopulatie van de Franeker academie. En kwantitatief onderzoek (1585-1811), in: Goffe T. JENSMA u.a. (Hg.), Universiteit te Franeker 1585-1811. Bijdragen tot de geschiedenis van de Friese hogeschool, Leeuwarden 1985, S. 56-72.

41 Die Thematik »Universität und Krieg« ist bislang allenfalls in Ansätzen in den Blick der Forschung genommen worden, vgl. etwa Georg MüLLER, Die Visitationen der Universität Leipzig zur Zeit des Dreißigjährigen Krieges, in: NASG 27 (1906), S. 18-59; Hermann Hofmeister, Die Universität Helmstedt zur Zeit des 30jährigen Krieges, in: ZHVNS 72 (1907), S. 241-277; Otto Bock, Die Reform der Erfurter Universität während des Dreißigjährigen Krieges, Halle 1908; Hermann MAYER, Freiburg i. Br. und seine Universität im Dreißigjährigen Krieg, in: Zeitschrift der Gesellschaft für Beförderung der Geschichts-, Altertums- und Volkskunde von Freiburg, dem Breisgau und den angrenzenden Landschaften 26 (1910), S. 121-188; ebd., 27 (1911), S. 35-90; Arthur Werner, Die Studenten-Legionen der Prager Universität vom 30jährigen Krieg bis 1848, Prag 1934; Karl-Hans ARndT, Stadt und Universität Erfurt im Kampf gegen die Pest während des dreißigjährigen Krieges, in: Beiträge zur Hochschul- und Wissenschaftsgeschichte Erfurts 12 (1965/66), S. 11-50; Anton ERnstBerger, Die Universität Nürnberg-Altdorf während des Dreißigjährigen Krieges in ihrem Bestande bedroht, München 1966; Ulrich SIEBER, Professor Johann Martin Rauscher 1592-1655. Studien zur Geschichte der Universität Tübingen im Dreißigjährigen Krieg, Diss., Tübingen 1968; Reinhard Rudolf Heinisch, Salzburg im Dreißigjährigen Krieg, Wien 1968; Volker Press, Kurfürst Maximilian I. von Bayern, die Jesuiten und die Universität Heidelberg im Dreißigjährigen Krieg 1622-1649, in: Wilhelm Doerr (Hg.), Semper Apertus. 600 Jahre Ruprecht-Karls-Universität Heidelberg. Festschrift in sechs Bänden, Bd. 1, Berlin 1985, S. 314-370; Bernhard ZAschKA, Die Lehrstühle der Universität Tübingen im Dreißigjährigen Krieg. Zur sozialen Wirklichkeit im vorklassischen Zeitalter, Tübingen 1993; zur Bedeutung der Kriegsereignisse für die Universitäten im Ostseeraum vgl. auch Howard Hotson, A Dark Golden Age. The Thirty Years War and the Universities of Northern Europe, in: Allan I. Macinnes u.a. (Hg.), Ships, Guns and Bibles in the North Sea and Baltic States, c. 1350-c. 1700, East Linton 2000, S. 235-270. Derzeit sind allerdings mehrere einschlägige Dissertationsprojekte in Arbeit zur Universität Leipzig von Wenke Richter (Leipzig), zur Universitätsstadt Erfurt von Thomas Kossert (Osnabrück) sowie in komparatistischer Ausrichtung zu den südwestdeutschen Universitäten Heidelberg, Tübingen und Freiburg von Susanne Häcker (Tübingen), vgl. dazu die ersten Vorabstudien: Wenke Richter, Der Dreißigjährige Krieg und die Alma Mater. Vergleich der Immatrikulationen, in: Journal der Universität Leipzig VII (2006), S. 39-41; Susanne Häcker, Universität und Krieg. Die Auswirkung des Dreißigjährigen Krieges auf die Universitäten Heidelberg, Tübingen und Freiburg, in: Militär und Gesellschaft in der Frühen Neuzeit. Bulletin 11 (2007), S. 163-173 [Projektskizze]; dies., »[...] sogar Kriegskameraden trifft man unter euch an«. Die Verteidigung von Stadt, Lehre und Glauben durch Heidelberger, Tübinger und Freiburger Universitätstheologen im Dreißigjährigen Krieg, in: Franz Brendef/Anton Schindling (Hg.), Geistliche im Krieg, Münster 2008, S. 89-100; dies., Mediziner auf der Flucht? Die Rolle der akademischen Medizin während der Pestzüge des Dreißigjährigen Krieges am Beispiel der vorderösterreichischen Universität Frei- 
und späteren Kriegsverlierers Friedrich V. durchaus so etwas wie ein zeitgenössischer »Symbol-« oder »Erinnerungsort« des Protestantismus war und welcher der bayerische Herzog Maximilian mit der Verschleppung des wertvollen Bücherschatzes der Bibliotheca Palatina nach Rom gewissermaBen auch das »kulturelle Kapital« raubte $^{42}$. Mit jedem Besatzungswechsel 1620 bis 1633 stand Heidelberg unter spanischer und bayerischer, 1633 bis 1634/35 unter schwedischer und schließlich unter kaiserlicher Besatzung veränderte sich auch die Konfession der Universität insgesamt und damit auch die personelle Zusammensetzung des Heidelberger Professorenkollegiums. Schließlich stellte sie 1631 für den langen Zeitraum von 22 Jahren - als einzige im Reich - ihren Lehrbetrieb völlig ein, ohne verlegt zu werden ${ }^{43}$.

Die Professoren entwickelten angesichts der unsicheren Zeitläufte bezüglich der oftmals auch in konfessioneller Hinsicht wechselnden Besatzungen unterschiedliche Strategien: Sehr verbreitet war die Flucht vor drohender Ausweisung durch die Besatzungstruppen ${ }^{44}$. Allerdings zog eine fremdkonfessionelle militärische Besatzung nur in wenigen Fällen den Konfessionswechsel der Universität und den Austausch des Lehrpersonals nach sich. Der Konfessionsstand einer Universität wurde nur dort angetastet, wo sich die Machtverhältnisse grundlegend verändert hatten und die Besatzungsmächte erwarteten, dass dies auch nach dem Krieg so bleiben würde. Neben Heidelberg, das nach der Ächtung des reformierten Kurfürsten ursprünglich unter die dauerhafte Verfügungsgewalt des bayerischen Herzogs gelangen soll-

burg, in: Virus. Beiträge zur Sozialgeschichte der Medizin 7 (2008), S. 185-194; Andreas KosSERT, Zwischen Schweden, Mainz und Sachsen. Erfurt als kulturelles Zentrum im Dreißigjährigen Krieg, demnächst in: Militär und Gesellschaft in der Frühen Neuzeit. Bulletin 13 (2009), S. 263-267 [Projektskizze].

42 Karl Preisendanz, Aus den Schicksalen der Bibliotheca Palatina, in: BadHei 26 (1939), S. $207-$ 218; Hans-Otto Keunecke, Maximilian von Bayern und die Entführung der Bibliotheca Palatina nach Rom, in: Archiv für Geschichte des Buchwesens 19 (1978), S. 1401-1446; Elmar Mittler, Raub oder Rettung?, in: Ders. (Hg.), Bibliotheca Palatina. Ausstellungskatalog, Heidelberg 1986, S. 458-493; zudem die Hinweise bei Walter Berschin, Die Palatina in der Vaticana. Eine deutsche Bibliothek in Rom, Darmstadt 1992.

43 Zur Universität Heidelberg im Dreißigjährigen Krieg vgl. Press, Kurfürst Maximilian I. von Bayern; zudem Eike Wolgast, Die Universität Heidelberg 1386-1986, Berlin 1986, S. 52ff.; Notker Hammerstein, Vom »Dritten Genf« zur Jesuiten-Universität. Heidelberg in der frühen Neuzeit, in: Geschichte der Universität Heidelberg. Vorträge im Wintersemester 1985/86, Heidelberg 1986, S. 34-44.

44 In Heidelberg etwa wurden alle noch nicht geflohenen Professoren vom bayerischen Statthalter in der Kurpfalz bis 1626, als die Universität ein erstes Mal für drei Jahre geschlossen wurde, entlassen und ausgewiesen. Ausnahmen waren der Physiker Christoph Jungnitz und der Jurist Reinhard Bachoven. Beide waren reformierten Bekenntnisses, konvertierten allerdings und erhielten nach der Wiedereröffnung der Universität durch den bayerischen Kurfürsten Maximilian (1629) wieder Professuren; vgl. die Einzelnachweise bei DrüLL-ZIMMERMANN, Heidelberger Gelehrtenlexikon 1386-1651. Den Lehrbetrieb Heidelbergs übernahmen zwischen 1629 und 1631 katholische Professoren - in der Theologischen und Philosophischen Fakultät Jesuitenpatres -, bevor unter schwedischer Besatzung die Universität gänzlich ihre Tore schloss. 
te, galt dies insbesondere für Marburg und Erfurt, wo die vormaligen Landesherren als Universitätserhalter ebenfalls zeitweise durch andere ersetzt wurden - in Marburg der reformierte Kasseler Landgraf durch den lutherischen Darmstädter Landgrafen ${ }^{45}$, in Erfurt der Mainzer Erzbischof durch den schwedischen König ${ }^{46}$.

45 Oberhessen mit Marburg wurde nach der kaiserlichen Eroberung im Jahre 1624 dem lutherischen Landgrafen von Darmstadt zugeschlagen. Da die Gießener Universität nach Marburg verlegt wurde - vgl. Moraw, Kleine Geschichte der Universität Gießen, S. 22ff. wich ein großer Teil der entlassenen reformierten Marburger Professoren an das bereits 1599 vom Landgrafen Moritz gegründete, sukzessiv von einer »Hofschule« (Pagenanstalt, Ritterakademie) zu einer »Hohen Schule« ausgebauten »Collegium Adelphicum Mauritianum« in Kassel aus, vgl. Theodor Hartwig, Die Hofschule zu Cassel unter Landgraf Moritz dem Gelehrten, Diss., Marburg 1864; Norbert ConRads, Ritterakademien der Frühen Neuzeit. Bildung als Standesprivileg im 16. und 17. Jahrhundert, Göttingen 1982, S. 115ff., 157ff.; Holger Thomas GräF, The Collegium Mauritianum in Hesse-Kassel and the Making of calvinist Diplomacy, in: The Sixteenth Century Journal 28 (1997), S. 1167-1180; ders., Die Kasseler Hofschule als Schnittstelle zwischen Gelehrtenrepublik und internationalem Calvinismus. Ein Beitrag zu den institutionen- und sozialgeschichtlichen Grundlagen frühneuzeitlicher Diplomatie, in: ZVHG 105 (2000), S. 17-32; außerdem die Hinweise bei ScHERING, Gießen und Marburg, S. 11-53. Insgesamt sind neun Marburger Professoren im Jahre 1624 entlassen worden - alle drei Theologen Johannes Crocius, Georg Cruciger und Caspar Sturm, der Jurist Antonius Matthaeus, der Mediziner Johannes Molther der Jüngere, der Logiker Johannes Combach, der Rhetoriker Gregor Schönefeld der Jüngere, der Mathematiker Christian Sturm sowie der französische und italienische Sprachmeister Catharinus Dulcis (Cathérin le Doux), von denen wiederum drei am Kasseler »Mauritianum « (Crocius, Cruciger, Combach) Aufnahme fanden -, aber nur vier vom Darmstädter Landgrafen übernommen worden (der Jurist Johannes Goddaeus, der Mediziner Nicolaus Braun, der Ethiker Rudolf Goclenius der Ältere und der Gräzist Theodor Vietor); vgl. die Nachweise bei GundLach, Catalogus Professorum, Nr. 24, 28f., 126, 153, 304, 308, 534, 555, 642, 686, 690, 708.

46 Obwohl der Mainzer Kurfürst Träger und Erhalter der Universität war, muss Erfurt seit der Mitte des 16. Jahrhunderts faktisch als bikonfessionelle Hochschule bezeichnet werden, vgl. Anm. 24 in diesem Beitrag. Dieser ungeklärte konfessionelle Status hatte dazu geführt, dass die Erfurter Universität sich nach der Frequenzkrise der Reformationsjahrzehnte nicht mehr erholen und an die Glanzzeiten des Hochhumanismus um 1500 anschließen konnte. Erst durch die schwedische Eroberung der Stadt im Jahre 1631 trat kurzzeitig eine Besserung ein. Der Stadt wurde von König Gustav II. Adolf der Reichsstadtstatus in Aussicht gestellt, zudem rasch mit einer durchgreifenden Universitätsreform begonnen, an deren Ende eine eindeutig lutherische Hochschule stehen sollte. Die Grundlage hierfür bildete die Vertreibung der katholischen Professoren und die Neufundierung der Universität durch säkularisiertes Kirchengut, vgl. Kleineidam, Universitas studii Erffordensis, Bd. 3, S. 132ff.; ebd., Bd. 4, Erfurt ${ }^{2}$ 1988, S. 2ff.; MÄrker, Geschichte der Universität Erfurt, S. 63ff.; auch Franz Schauerte, Gustav Adolf und die Katholiken in Erfurt, Köln 1887 und Bock, Die Reform der Erfurter Universität. Im Jahre 1633 konnte die evangelische Theologische Fakultät eröffnet werden, die allerdings nur bis zum Prager Frieden (1635) Bestand hatte. Die für nur wenige Jahre erreichte eindeutige konfessionelle Profilierung Erfurts als lutherische Universität - verbunden mit der hohen schwedischen Militärpräsenz in der Stadt als nicht zu unterschätzender Sicherheitsfaktor - führte tatsächlich zu einem bemerkenswerten Anstieg der Immatrikulationen. Der Westfälische Frieden mit seinen Restitutionsregelungen auf der Grundlage des »Normaljahres« von 1624 stellte jedoch den bikonfessionellen Charakter der Universität vor dem 
So wurde also noch während des Krieges das dem Augsburger Religionsfrieden zugrundeliegende Prinzip »cuius regio eius religio« praktisch angewendet. An allen anderen Universitäten im Reich - sogar in Rostock unter dem katholischen Herzog Albrecht von Wallenstein ${ }^{47}$ - wurde der ältere Konfessionsstand beibehalten und bis auf wenige Ausnahmen, die - wie etwa in Erfurt oder Freiburg - in der Regel lediglich die Ausweisung der Jesuitenpatres betrafen ${ }^{48}$, der vorgefundene Lehrkörper nicht angetastet. Weniger verbreitet als Flucht oder Ausweisung war die Konversion als das einzige probate Mittel für Professoren, um unter den Bedingungen der fremdkonfessionellen Besatzung weiterhin lehren zu können. Dieser Konfessionswechsel musste jedoch vom Konvertiten glaubhaft erklärt werden ${ }^{49}$.

Krieg wieder her: die Wiedererrichtung der katholischen Theologischen Fakultät, aber auch die Beibehaltung der bereits 1566 eingerichteten Professur für die Augsburger Konfession, vgl. Kleineidam, Universitas studii Erffordensis, Bd. 4, S. 8f.; vgl. auch ders., Augustinus Gibbon de Burgo OESA und die Wiedererrichtung des theologischen Studiums der Augustinereremiten an der Universität Erfurt, in: AAug 41 (1978), S. 65-112.

47 Zusammenfassend vgl. Otto Karsten KraBBE, Aus dem kirchlichen und wissenschaftlichen Leben Rostocks. Zur Geschichte Wallensteins und des Dreißigjährigen Krieges, Berlin 1863 und Wilhelm Stieda, Die Universität Rostock und Wallenstein, in: Jahrbücher des Vereins für mecklenburgische Geschichte und Altertumskunde 81 (1917), S. 75-88; außerdem die Hinweise bei Georg Christian Friedrich Lisch, Wallensteins Kirchen- und Schul-Regierung in Meklenburg, in: Ebd. 37 (1872), S. 3-39.

$48 \mathrm{Zu}$ Erfurt, wo die kurzzeitige Transformation der bikonfessionellen zu einer lutherischen Universität unter schwedischer Besatzung auf der Konstruktion beruhte, dass die Stadt nach der Ablösung der Herrschaft des Mainzer Kurfürsten eine Reichsstadt werden, mithin hier konsequent das Prinzip »cuius regio eius religio« des Augsburger Religionsfriedens Anwendung finden sollte, vgl. Anm. 24 und 46 in diesem Beitrag. Zu Freiburg, wo von den schwedischen Besatzungstruppen durchaus zeitweise versucht wurde, protestantische Professoren zu berufen, vgl. Theodor Kurrus, Die Jesuiten an der Universität Freiburg i. Br. 1620-1773, Bd. 1, 1963, S. 27ff.; auch MAYER, Freiburg i. Br. und seine Universität.

49 Dies geschah im Idealfalle mit einem ausführlichen Rechtfertigungsschreiben, wie es etwa gedruckt vom Tübinger Rechtsprofessor Christoph Besold (1577-1638) vorliegt. Die Konversion Besolds, der übrigens im vorauseilenden Gehorsam dem habsburgischen Statthalter im Herzogtum Württemberg vorschlug, die verwaiste Ritterakademie vor Ort in ein Jesuitenkolleg umzuwandeln, hat gerade in jüngster Zeit das Interesse der Forschung gefunden, vgl. Matthias Pohlig, Gelehrter Frömmigkeitsstil und das Problem der Konfessionswahl. Christoph Besolds Konversion zum Katholizismus, in: Ute Lotz-Heumann u.a. (Hg.), Konversion und Konfession in der Frühen Neuzeit, Gütersloh 2007, S. 323-352; auch die Hinweise bei Emil NiETHAMMER, Christoph Besold, in: SLB 2 (1941), S. 11-34; Barbara Zeller-Lorenz/Wolfgang Zeller, Christoph Besold 1577-1638. Polyhistor, gefragter Consiliator und umstrittener Konvertit, in: Ferdinand Elsener (Hg.), Lebensbilder zur Geschichte der Tübinger Juristenfakultät, Tübingen 1977, S. 9-18; Barbara ZelLer-LorenZ, Christoph Besold (1577-1638) und die Klosterfrage, Tübingen 1986. 


\begin{abstract}
Ausblick
Das spätere 17. und das 18. Jahrhundert führten zu einer Konsolidierung des bi- beziehungsweise trikonfessionellen Universitätswesens im Reich, für das an protestantischen Universitäten zumeist das bereits skizzierte Phänomen von »Familienuniversitäten«, an katholischen dasjenige der fortdauernden jesuitischen Dominanz typisch war. Tiefgreifende Konflikte unter den Professoren um das »richtige « Bekenntnis traten zugunsten von oftmals nicht minder leidenschaftlich geführten Auseinandersetzungen über wissenschaftliche Methoden oder Denkschulen deutlich zurück. In der zweiten Hälfte des 17. Jahrhunderts gehörten konfessionell bedingte Mobilitätsphänomene bei Professoren jedenfalls bereits der Vergangenheit an - sieht man einmal von den an nahezu allen protestantischen Universitäten sehr heftig geführten Disputen um die Aufnahme pietistisch gesinnter Lehrkräfte ab. Die zuweilen unerbittlichen Streitigkeiten zwischen einem mehrheitlich orthodox lutherischen Professorenkollegium und einigen wenigen Pietisten, die so manchen akademischen Lehrer zum mehr oder weniger freiwilligen Abzug bewogen haben ${ }^{50}$, trugen jedoch im Kern den Charakter von Gelehrtendisputen um die »richtige « wissenschaftliche Methode und sollten auch auf diese Weise eingeordnet werden.
\end{abstract}

Auch wenn der Staatsrechtler Joseph von Sonnenfels seinen Wiener Rechtsstudenten empfahl: »Wer echte freie Politik hören will, müsse nach Göttingen gehen $\aleph^{51}$, bleibt dennoch festzuhalten, dass noch bis zur Reformzeit um 1800 das deutsche Universitätswesen konfessionsgebunden blieb und zumindest von Theologieprofessoren Konfessionseide verbindlich gefordert wurden. Die beiden faktisch bikonfessionellen Hochschulen im Reich Erfurt und nach dem Dynastiewechsel in der Kurpfalz seit 1685 auch Heidelberg, wo außer in der Theologischen Fakultät alle Lehrstühle alternierend mit reformierten und katholischen Professoren besetzt wurden und seit 1706 auch Jesuitenpatres Theologieprofessuren bekleideten ${ }^{52}$ - erfuhren nur

50 Exemplarisch sei verwiesen auf den - freilich gravierenden, da einzigartigen - Fall des Auszugs der herzoglichen Professoren an die vom Schweriner Herzog Friedrich in Bützow neugegründete pietistische Universität, vgl. hierzu ausführlich Asche, Von der reichen hansischen Bürgeruniversität, S. 70ff.; vgl. auch ders., Die mecklenburgische Hochschule Bützow (17601789) - nur ein Kuriosum der deutschen Universitätsgeschichte? Versuch einer historischen Neubewertung, in: Jahrbuch für Universitätsgeschichte 9 (2006), S. 133-147, jeweils mit weiterführender Literatur.

51 Zitiert nach Notker Hammerstein, Die deutschen Universitäten im Zeitalter der Aufklärung, in: ZHF 10 (1983), S. 73-89.

52 Nach der Übersicht zur konfessionellen Zugehörigkeit der Professoren bei DRÜLL, Heidelberger Gelehrtenlexikon 1652-1802, S. 197ff., gestaltete sich die Praxis der Berufungspolitik der kurpfälzischen Landesherren in konfessioneller Hinsicht jedoch eindeutig zugunsten der Katholiken, insbesondere nach dem Dynastiewechsel von 1685: In der Theologischen Fakultät amtierten zwischen 1652 und 180218 reformierte, aber 71 katholische Professoren, in der Ju- 
sehr wenig Zuspruch seitens der Studenten, was auch an den heftigen konfessionellen Polemiken vor Ort lag. Erst mit dem Verbot des Jesuitenordens durch das Breve Dominus ac Redemptor noster Papst Clemens' XIV. im Jahre $1773^{53}$, das freilich keineswegs zu einem abrupten Abzug der nunmehr zu Säkularklerikern gewordenen Jesuitenpatres aus den Universitäten führte ${ }^{54}$, und dem geistig-personellen Neuanfang im Zeichen der Aufklärung konnten an einigen traditionell katholischen Universitäten (Mainz, Trier) und Neugründungen des späten 18. Jahrhunderts [Münster (1780-1818), Bonn (1786-

ristischen Fakultät 18 protestantische (davon vier Lutheraner) und 37 katholische, in der Medizinischen Fakultät fünfzehn protestantische (davon zwei Lutheraner) und 23 katholische sowie in der Philosophischen Fakultät 35 protestantische (davon acht Lutheraner) und 95 katholische Professoren.

53 Zur Aufhebung des Jesuitenordens vgl. Joachim Karl Friedrich KnaAke, Das Breve Papst Clemens XIV. betr. Die Aufhebung des Jesuiten-Ordens, Leipzig 1903; Félix Sánchez VALLEJo, Die Aufhebung der Gesellschaft Jesu vor 200 Jahren, in: Jesuiten. Jahrbuch der Gesellschaft Jesu 1973/74, S. 18-26; Winfried Müller, Die Aufhebung des Jesuitenordens in Bayern. Vorgeschichte, Durchführung, administrative Bewältigung, in: ZBLG 48 (1985), S. 285-352; ders., Die Aufhebung des Jesuitenordens in Deutschland, in: Bernard Plongeron (Hg.), Aufklärung, Revolution, Restauration (1750-1830), Freiburg i. Br. 2000, S. 173-178; Paul Shore, The Suppression of the Society of Jesus in Bohemia, in: AHSJ 65 (1996), S. 139-156; Rita HAUB, »Ich habe euch nie gekannt, weicht alle von mir [...]«. Die päpstliche Aufhebung des Jesuitenordens 1773, in: Hans Ulrich Rudolf (Hg.), Alte Klöster - Neue Herren. Die Säkularisation im deutschen Südwesten 1803. Begleitbücher zur großen Landesausstellung Baden-Württemberg 2003 in Bad Schussenried. Aufsätze, Bd. 2/I, Ostfildern 2003, S. 77-88.

54 Vielmehr waren die Universitätserhalter auch nach 1773 noch dringend auf die ehemaligen Jesuitenpatres angewiesen, denn ohne diese wäre der theologische und philosophische Unterricht sofort zusammengebrochen, vgl. Helmut KRöLl, Die Auswirkungen der Aufhebung des Jesuitenordens in Wien und Niederösterreich. Ein Beitrag zur Geschichte des Josephinismus in Österreich, in: ZBLG 34 (1971), S. 547-617; Hermann HalberZETTL, Die Stellung der Exjesuiten in Politik und Kulturleben Österreichs zu Ende des 18. Jahrhunderts, Wien 1973; Michael Schaich, »Religionis defensor acerrimus«. Joseph Anton Weissenbach und der Kreis der Augsburger Exjesuiten, in: Christoph WeIss (Hg.), Von »Obscuranten« und »Eudämonisten«. Gegenaufklärerische, konservative und antirevolutionäre Publizisten im späten 18. Jahrhundert, St. Ingbert 1997, S. 77-125; Winfried MüLlER, Die Exjesuiten. Eine Funktionselite ohne Aufgabe?, in: Rudolf Schieffer (Hg.), Beiträge der Sektion Geschichte. Kirche und Bildung vom Mittelalter bis zur Gegenwart. Generalversammlung der Görres-Gesellschaft in Eichstätt vom 23. bis 27.09.2000, München 2001, S. 43-52. So wurden beispielsweise an der Universität Paderborn die jesuitischen Professoren nach 1773 mangels personeller Alternativen bruchlos weiterbeschäftigt - freilich nunmehr als Weltpriester -, sogar der Kirchenrechtler Anton Wennecker, der zwischen 1765 und 1784 ununterbrochen das Amt des Universitätskanzlers innehatte. Bis zum Jahre 1797 wurden noch zahlreiche ehemalige Jesuitenpatres zu Professoren berufen, und noch 1808 bestand der Lehrkörper der Universität fast ausschließlich aus ehemaligen Paderborner Jesuitenzöglingen, vgl. Hubertus R. DrobnER, Die Professoren der Kirchengeschichte und Patrologie in Paderborn 1777-1989, in: ThGl 79 (1989), S. 403-445; ders., Die Professoren der Theologischen Fakultät Paderborn 1773-1989, in: Ebd. 80 (1990), S. 419-441. Das Beispiel der »Theodoriana« in Paderborn zeigt, dass die Aufhebung des Jesuitenordens weder zu einem personellen Schnitt, noch zu einem wissenschaftlichen Neuanfang geführt hatte, zumal sich auch die alte jesuitische Lehrstuhlsystematik mit ihrer starken Betonung der scholastischen Methode bis zur Schließung der Universität im Jahre 1818 erhielt, vgl. Karl Hengst, Die Academia Theodoriana zu Paderborn. Westfalens älteste Universität, in: Ebd., S. 350-378, hier: S. 366ff. 
1798) und Aschaffenburg (1808-1814) $]^{55}$ auch einige wenige protestantische Professoren berufen werden ${ }^{56}$. Es bleibt jedoch festzuhalten, dass, solange die deutschen Universitäten prinzipiell konfessionsgebunden blieben, mithin bis zum Beginn des 19. Jahrhunderts, generell die Mobilität von Professoren notgedrungen stets eingeschränkt blieb.

55 Zur alten Universität Münster vgl. Anton PIEPER, Die alte Universität Münster 1773-1818. Ein geschichtlicher Überblick. Mit einem Verzeichnis der Universitätslehrer, Münster 1902; Alwin Hanschmidt, Die erste münstersche Universität 1773/80-1818. Vorgeschichte, Gründung und Grundzüge ihrer Struktur und Entwicklung, in: Heinz Doldinger (Hg.), Die Universität Münster 1780-1980, Münster ${ }^{2}$ 1980, S. 3-27 [wiederabgedruckt in: Franz BöLsKER (Hg.), Schule, Lehrerausbildung, Universität. Festgabe zur Emeritierung von Alwin Hanschmidt, Vechta 2004, S. 111-136]; Wilhelm RibHEgGe, Geschichte der Universität Münster. Europa in Westfalen, Münster 1985. Zur ersten Universität Bonn vgl. noch immer die Studien von Max BRAUBACH, Die erste Bonner Universität und ihre Professoren. Ein Beitrag zur rheinischen Geistesgeschichte im Zeitalter der Aufklärung, Bonn 1947; ders., Die erste Bonner Hochschule. Maxische Akademie und kurfürstliche Universität 1774/77 bis 1798, Bonn 1966; außerdem Adolf Arens, Die kurfürstliche Universität zu Bonn, Bonn 1888 und den Ausstellungskatalog: Bonn und seine kurfürstliche Universität, Bonn 1988. Zur Universität Aschaffenburg vgl. Theodor Josef Scherg, Dalbergs Hochschulstadt Aschaffenburg, Bd. 1, Aschaffenburg 1954.

56 Das Phänomen der Berufung evangelischer Professoren an katholische Universitäten in den Umbruchsjahren um 1800 ist noch nicht gezielt untersucht worden - nicht einmal ihr quantitativer Umfang. Vermutlich war der Mediziner und Naturforscher Samuel Thomas Sömmerring in Mainz (1784) der erste Protestant, der an eine katholische Universität berufen wurde, vgl. über ihn zuletzt Gunter Mann/Franz Dumont (Hg.), Samuel Thomas Sömmerring und die Gelehrten der Goethezeit. Beiträge eines Symposions in Mainz vom 19. bis 21. Mai 1983, Stuttgart 1985; Manfred Wenzel, Samuel Thomas Sömmerring, Naturforscher der Goethezeit in Kassel, Kassel 1988; ders. (Hg.), Samuel Thomas Sömmerring in Kassel (1779-1784). Beiträge zur Wissenschaftsgeschichte der Goethezeit, Stuttgart 1994; Rolf Simon (Hg.), Samuel Thomas Sömmerring (1755-1830). Mediziner und Naturwissenschaftler aus Thorn. Ausstellungskata$\log$, Münster-Wolbeck 2001. Seit der Mitte des 18. Jahrhunderts nahm an katholischen Universitäten auch allmählich die Zahl der (katholischen) Rechtsprofessoren zu, die an der protestantischen Universität Göttingen studiert hatten, vgl. zusammenfassend die Hinweise bei Robert HAAss, Die geistige Haltung der katholischen Universitäten Deutschlands im 18. Jahrhundert, Freiburg 1952. Die nach dem Vorbild Göttingens im Geist der (katholischen) Aufklärung neugegründeten Universitäten ließen zudem durchaus Raum für aufgeklärte Exoten, wie etwa den späteren Radikalaufklärer Eulogius Schneider, der kurzzeitig an der Universität Bonn wirkte, vgl. Braubach, Die erste Bonner Hochschule, S. 116ff.; zudem die Hinweise in der jüngsten Biographie von Claude Betzinger, Vie et mort d'Euloge Schneider, ci-devant franciscain. Des lumières à la terreur 1756-1794, Strasbourg 1997. 


\section{Autorenverzeichnis}

Prof. Dr. Matthias Asche, Historisches Seminar - Abteilung für Neuere Geschichte, Universität Tübingen, Wilhelmstraße 36, 72074 Tübingen

PD Dr. Bettina Braun, Institut für Europäische Geschichte, Alte Universitätsstr. 19, 55116 Mainz

PD Dr. Almut Bues, Deutsches Historisches Institut, Aleje Ujazdowskie 39, 00-540 Warszawa, Polen

Dr. Gesine Carl, Historisches Seminar, DFG-Forschergruppe >Selbstzeugnisse in transkultureller Perspektive<, Universität Hamburg, Von-Melle-Park 6/IX, 20146 Hamburg

Dr. Manuel F. Fernández Chaves, Departamento de Historia Moderna, Universidad de Sevilla, C/Doña María de Padilla, 41004 Sevilla, Spanien

Prof. Dr. Marian Füssel, Juniorprofessor für Frühe Neuzeit mit Schwerpunkt außereuropäische Geschichte, Universität Göttingen, Platz der Göttinger Sieben 5, 37073 Göttingen

Dr. Henning P. Jürgens, Institut für Europäische Geschichte, Alte Universitätsstr. 19, 55116 Mainz

Prof. Dr. Margit Kern, Theologische Fakultät, Kunstgeschichte der Frühen Neuzeit, Humboldt-Universität zu Berlin, Sitz: Burgstr. 26, 10099 Berlin

Prof. Dr. Felix Konrad, Juniorprofessor für Außereuropäische Geschichte (Schwerpunkt Naher Osten), Historisches Seminar, Universität Kiel, Leibnizstraße 8, 24118 Kiel

Prof. Dr. Susanne Lachenicht, Lehrstuhl für Geschichte der Frühen Neuzeit, Universität Bayreuth, Universitätsstraße 30 / GW II, 95440 Bayreuth

Prof. Dr. Matthias Morgenstern, Evangelisch-theologische Fakultät, Universität Tübingen, Liebermeisterstr. 12, 72076 Tübingen

Dr. des. Vera von der Osten-Sacken, Institut für Europäische Geschichte, Alte Universitätsstr. 19, 55116 Mainz 
Dr. Rafael M. Pérez García, Departamento de Historia Moderna, Universidad de Sevilla, C/Doña María de Padilla, 41004 Sevilla, Spanien

Prof. Dr. phil. Dr. theol. h.c. Heinz Schilling, Institut für Geschichtswissenschaften, Humboldt-Universität zu Berlin, Unter den Linden 6, 10099 Berlin

Dr. Klaus Weber, The Rothschild Archive, New Court, St. Swithin's Lane, London EC4P 4DU

Dr. Thomas Weller, Institut für Europäische Geschichte, Alte Universitätsstr. 19, 55116 Mainz

Prof. Dr. Christian Windler, Historisches Institut, Ordentliche Professur für Neuere Geschichte, Universität Bern, Unitobler, Länggassstrasse 49, 3000 Bern 9, Schweiz 


\section{Register}

\section{Ortsregister $^{1}$}

Aachen $89,120,122$

Aalter 295

Afrika 115, 118, 140f., 215, 219, 230, 237, 239-242, $262 \mathrm{f}$.

Agde 261

Ägypten 224, 256, 257

Aire 98

Alcalá la Real 247

Aleppo 192, 197, 202

Algier 213, 215, 240

Alicante 238

Almagro 239, 249f., 256

Altenburg 48

Altona 63, 119, 122, 140, 146-149, 152f., $158,162,165$

Ampleforth 100

Amsterdam 62, 70, 119-121, 123, 125, $130-133,140,142-145,148,155,159$, 161, 164f., 293, 313f., 337f., 346, 351

Anatolien 222, 224, 227

Ancona 222

Andalusien $\quad 243,249,261$

Antequera 247

Antillen 159, 163, 165, 167

Antwerpen 79, 96, 98, 101f., 104, 117, 127, 140f., 144, 297, 313, 372

Aragonien 118, 235, 238, 240

Arica 311

Arnheim 345

Arnshaugk 43, 48

Aschaffenburg 400

Augsburg 271

Austerlitz 339
Ávila 251, 253, 258

Bahia 141f.

Balearen 253

Bandar Abbas 187, 195, 209

Barbados 156

Barcelona 238

Basel 25, 28, 30, 163, 372, 376

Basra 190, $195 \mathrm{f}$.

Baur 378

Bayern 381,384

Bedburg 124

Belgrad 223

Bengalen 198

Berlin $62,66,153,155,177-179,368$

Bern 78

Bielefeld 361, 368

Bilbao 319

Bochnia 332

Bockenheim 122

Böhmen 117, 166

Bonn 399, 400

Bordeaux 127, 153-155, 159

Bösing 368

Bosnien 226, 227

Boston 177

Boulogne 97

Brandenburg 117, 155, 164, 175, 392

Brandenburg-Preußen 148, 150, 172, 176, 178, 180f.

Brasilien 142f., 156f., 163, 165

Braunschweig 50,161,343, 361

Bremen $31,148,162,293,387-389$

1 Kursiv gesetzte Seitenzahlen verweisen auf Erwähnungen in den Anmerkungen, recte gesetzte auf den laufenden Text. 
Bremen (Hochstift) 122

Breslau 332, 366, 368

Bretagne 86

Britische Inseln 76, 80, 88, 105, 109, 155, 158

Bromberg 324, 330

Brügge $79,97,100,101,103,295$

Brünn 272, 387

Brüssel 79, 95, 97, 100, 101f., 104, $108 \mathrm{f}$

Budapest 60

Buenos Aires 317

Burg (bei Magdeburg) 178

Burgsteinfurt $389 f$.

Burtscheid 132

Bützow 398

Buxtehude 361

Callao 311, 316

Cambrai 97, 110

Cambridge 101

Campo de Calatrava 238, 249f.

Capranica 89

Caracas 161

Cájar de la Vega 248

Celle 361

Chalcedon 88

Charleville 89

Château d'Oex 78

China 200

Coesfeld 361

Córdoba $243,245,249,250$

Crngrob 277

Črni Kal (Slowenien) 277

Cuautitlán 270-272, 276, 279

Cuenca 299

Curaçao 156

Dänemark 13, 17f., 20, 22, 24, 28, 30, 3133, 35, 39f., 109, 163

Danzig $80,166,323-325,331,333$

Darlington 100

Delft 171
Den Haag 152, 205

Dessau 387

Deutschland 19f., 22, 39, 73, 79, 113, 117, $121,137,154,162,357$

Dieulouard 97, 100

Dillenburg 32

Dordrecht 124

Douai 81, 83, 88, 96, 97-99, 100, 101, 103-105, 106, 109, 111

Downside 100, 106

Dresden 363

Dülmen 361

Dundee 319

Dünkirchen 97, 98, 100

Edirne 328f.

Eibenschitz 387

Eisfeld 49

Eisleben 41

El Hierro 307

Emden 18, 20-24, 31, 33, 37, 124,129, 134, 310

England 15f., 18, 23, 27-29, 31f., 79f., 81, 83, 88, 94-97, 99f., 101, 102, 104-112, 117, 121, 155f., 159, 160, 164f., 172, 174, 176, 178-181, 304, 305, 317, 319, 357f.

Erfurt 88, 385f., 393, 394, 396-398

Erzurum 198

EU 103

Europa 1f., 4-6, 8, 10, 31, 33, 60-63, 75120, 127, 138f., 141, 143, 155f., 158, 160, $162,165,174,176,186,189,195-199$, 202, 213-215, 217, 276f., 294, 304, 318, $326-328,335,337,359,375,382$

Fez 262

Fiume 160

Flandern $\quad 14,91,102,108 \mathrm{f}$

Franken 380

Frankenthal 120, 122, 155

Frankfurt (Main) 18, 21-40, 63, 120, 122f., 134,150 
Frankfurt (Oder) 179, 368, 392

Frankreich 7, 62, 82f., 89f., 100, 111, 117f., 153-156, 159f., 162-167, 170-176, 192, 194, 205, 302, 303, 359, 365, 371, 391

Freiburg 78, 383, 393, 394, 397

Friedberg 390

Fulda 361

Fürth 344

Galata 225, 226

Geißlingen 369

Genf 19, 22, 30, 186, 190f., 193-196

Gent $14,79,97,109,117,295$

Genua 197

Gera 41,49

Gibraltar 237, 239

Gießen 376, 390, 396

Glastonbury 23

Glückstadt 143

Gombroon 197

Gotha 47

Göttingen 398, 400

Gran Canaria 299, 310

Granada 235-245, 247f., 250-255, 260

Gravelines 95, 97

Gravesend 13

Graz 222

Greifswald 376, 383

Greyerz 78

Großbritannien 359

Guadalajara 255

Guadeloupe 155-158

Gudensberg 390

Guinea 162

Haldern 295f., 318

Halle (Saale) 76, 356

Halle (Westf.) 361

Haltern 296

Hamburg 18, 37f., 62f., 67, 119-122, 124$126,130,133,137-167,310-312,387$
Hameln $\quad 67,361$

Hamm 362

Hanau 122, 389

Hannover 68, 370

Hastenbeck 361

Heidelberg 381, 389-391, 393, 394f., 398

Heiligenstadt 385

Heiliges Römisches Reich deutscher Nation 9, 77, 78, 100, 121, 165, 315, $333,334,375,380,382,386,392,395$, $397 f$.

Heldburg 49

Helmstedt $\quad 50,356,385,386$

Helsingborg 17

Herborn 32, 389

s'Hertogenbosch 33

Hessen 77, 148, 150, 161, 390, 396

Hildesheim 67, 97, 387

Hispaniola 155

Holland (niederländische Provinz) 79, $143,155,160,310,323$

Hormuz 187

Hornachos 251, 261

Huelva 250

Iberische Halbinsel 82, 115f., 125, 139, 164, 235, 238, 240, 251, 254, 261, 262, $303 f$.

Ingolstadt $381,383,384,393$

Irland $81-83,105,106,109,117,176,178$, 371

Iserlohn $\quad 362,368$

Isfahan 184, 186-206, $208 \mathrm{f}$

Iskenderun 197

Istanbul s.a. Konstantinopel 214f., 20f., 224-227, 232

Italien $\quad 89,118,391,391$

Jamaika 156

Jena $\quad 43-46,49,385,386,387$

Jerusalem 1,328

Jütland $17 f$. 
Kalisz 29

Kanaan 352, 367

Kanada 156, 177, 359

Kanarische Inseln 293, 295f., 304f., 307, 309, 312f., 317f., 320

Karibik 155-157, 165

Karlshafen 155

Kassel 387, 390, 396

Kastamonu 227

Kastilien 118, 235-237, 241f., 249, 251, 258-261

Katalonien 238, 240

Kattegat 17

Kayseri 222

Kiel 376

Kirchenstaat 118

Kitzingen 369

Kleve 178, 293, 295f.

Kolding 17, $33 \mathrm{f}$.

Köln 79, 108, 109, 120, 122, 296f., 393

Königsberg 324, 360, 393

Konstantinopel s.a. Istanbul 185f., 191, $224,335,339,343$

Kopenhagen 17f., 22, 34f., 36, 62

Krakau 324, 329, 330, 332

Krefeld 120, $132 \mathrm{f}$.

Krems (Donau) 363f.

Kreta 225

Kuba 163, 312

Kurbrandenburg 392

Kurpfalz $\quad 387,395,398$

Kursachsen $44,48,49,387,388$

La Gomera 307, 311

La Mancha 256

La Palma 297, 299, 307-311

La Rochelle 89, 153-155, 192

Lamspringe 97, 106

Łańcut 331

Languedoc 153

Lar 209

Las Palmas de Gran Canaria 299, 308f.
Leicester 319

Leiden 130,157

Leipzig $\quad 69,387,387,388,391,394$

Lemberg 324-326, 330, 331, 332-335

Lemgo 205, 361

Lengsfeld 390

Levante 118

Libyen 183

Lissa 62

Lissabon $82,89,141,144,314$

Litauen 330, 333, 343

Livorno 140

Loccum 361

London 13-40, 62, 98, 100, 101, 102, 120f., 125f., 131, 133f., 141, 142, 143, 155, 163f., 177-179, 313

Lorient 162

Löwen $14,89,95,98,101,111$

Lübeck 18, 37f., 148

Lublin 327, 339

Lucca 118

Madrid 83, 144, 293, 300, 304, 305, 309, 312-314, 317

Magdeburg 19, 20,27, 117, 368

Maghreb 184, 197, 215

Mainz 5, 19, 393, 399, 400

Mansfeld 50

Marburg 376, 385, 386, 389f., 390, 391, 392, 396

Marie-Galante 158

Marokko 215, 262

Martinique 155-158

Maxen 362f.

Mecheln 94, 111

Mecklenburg 379

Meißen 48

Mekka 2

Messina 221

Metz 62f., 175

Mexiko 265f., 270

Middelburg 310 
Mijdrecht 352f.

Minden 361

Mirabeau $173 f$.

Mitteleuropa 61f., 118, 141, 156, 162, 165f., 217, 304, 327

Monschau 120, 132

Moskau 327

Munderkingen 367

Münster (Westfalen) 117, 151, 296, 356, 361f., 373, 399, 400

Murcia 242, 261

Nancy 97

Nantes 161

Nassau 387

Nazareth 346

Neapel 253

Neu-Djulfa $184,186-192,195,197,201-$ 203, 206, 208f

Neu-England 359

Neuspanien 265-291

Neustadt (Haardt) 389, 391

New Paltz 179

New Rochelle 179

New York 177, $179 f$.

Niederlande $15,23,77,79,81-84,86,89$, 91-112, 117f., 121, 124, 140, 142f., 152, $155,159,164,171,225,271,293,296,305$, $308,310-313,316,318,320,323,345,391$

Nienburg 361

Nieuport 97

Nijmegen 33

Niš 223

Nordamerika $155,158,176,178,216$

Normandie 149

Norwegen 109

Norwich 120

Nürnberg 324,340

Oberursel 25f., 28

Osmanisches Reich 6, 119, 140, 183-185, 197, 200, 213-234, 327f
Ostende 97

Österreich $60,117,144,214,362 f ., 366-$ $368,369,372,380$

Österreichische Niederlande 100

Ostfriesland $18,38,343$

Ostpreußen 166

Osuna 250

Otumba 272f., 276

Oxford 101

Paderborn 361, 399

Paris $62,83,97,102,195,211$

Paros 220

Pays de Gex 191

Peloponnes 225

Persien 183, 186, 188f., 191, 193f., 197200, 202, 204-206, 212

Peru 293, 311, 318

Petrikau 332

Płock 332

Pobethen 361

Podolien 326

Polen 14, 17, 28, 31, 80, 83, 89, 334, 347

Polen-Litauen 330, 332f., 335

Pontoise 97

Portarlington 179

Portugal 115, 118-120, 140-142, 144, 155, $166,173,187$

Prag 89, 339, 359, 366, 371f., 389, 393

Pressburg 367

Preußen 163, 166, 174, 333, 357f.

Preußisch-Pommern 363

Quito 253

Ratibor 332

Recife $142 \mathrm{f}$

Rees 295

Regensburg 83,88

Reims 102

Riga 161

Rochefort 228 
Rom 80, 89, 98, 100, 102, 105, 106, $108,109-112,118,184,189,192$, 194, 198, 202, 207, 210-212, 265, 332, 395

Rossbach 358

Rossinière 78

Rostock 18, 36-38, 166, 376, 379, 380, 384, 389, 397

Rotterdam 157, 159

Rouen 98, 102f., 155, 163, 175

Rougemont 78

Rudolstadt 50

Ruppiner Land 179

Russland, Zarenreich $\quad 138,166$

Ruthenien 327

Saanen 78

Sachsen s. a. Kursachsen 41, 42, 43, 48, 49, 77, 148, 368f.

Sachsenburg 43, 48

Safavidenreich 8, 183-212

Saint Christophe $156 f$.

Saint-Domingue 155f., 158, 163

Saint-Germain-en-Laye 83

Saint-Jean d'Angély 192

Salzburg 5, 85, 117, 380

Samland 361

Sanlúcar de Barrameda 250

Santiago de Compostela 96

Schauenburg-Pinneberg 119, 122

Schaumburg 361

Schelling 378

Schieland 352

Schlesien 161, 364, 367f.

Schottland 82f., 88, 109

Schwaben 368,380

Schweden $80,83,86,120,357$

Schweiz 14,16

Sedan 175

Seeland (niederländische Provinz) 79, 310

Serbien 223
Sevilla $81,105,141,144,239,242,243$, 245f., 248-251, 253, 256-258, 261, 303f., 304 309, 313

Shiraz 189, 197

Silcher 378

Skagerrak 17

Skandinavien 117, 120f., 166

Slowakei 368

Soest 362

South Carolina 181

Spanien 81-83, 87, 89, 94-96, 98-100, 102, 104, 109, 115, 119f., 140-142, 144, 155f., 161, 165f., 173, 250, 251, 260, 293295, 305f., 311-314, 318-320, 357, 371

Spanische Niederlande 79, 81, 83, 89, 91, 94-96, 97, 109, 164

St. Gallen 161

St. Kitts 156

St. Lawrence 100

St. Malo 97

St. Omer 101-104

St. Petersburg 361

St. Sébastien 161

Stade 122, 361

Stenglin 161

Stettin 383

Stockholm 161

Stolberg 120, 132

Straßburg $14,25,369,393$

Stuttgart 26, 347

Südamerika 160f., 294, 311, 316, 318

Syrien 212

Tarragona 302

Tazacorte 297, 308

Teignmouth 100

Telgte $361 \mathrm{f}$.

Temesvar 223

Tepeapulco 273,276

Texel 317

Thessaloniki 119, 140

Thorpe-le-Soken 178 
Thüringen 51,56

Tizayuca $271,276,278$

Toledo 243, 250f., 293, 295, 296, 302, 314

Trier 393, 399

Triest 160

Tripolis 183,215

Tschenstochau 329

Tübingen 376, 377, 394

Tunis 215,223

Uhland 378

Ungarn 191, 217, 223

Unna 369

Untergreyerz 78

Utrecht 296, 352

Valencia $236-241,243,251,260 f$.

Valladolid $81,105,106,303$

Venedig $126,217,225,315$

Venetien 185, 220, 223

Verden 361

Vereinigte Staaten von Amerika 181

Vivarais 153

Vlissingen 157,310

Warschau 324f., 330, 332f.

Weichschütz 358
Weida 43,48

Weimar 43, 45, 48

Wesel 18, 21-29, 347, 352

Westfalen 296

Wieluń 89

Wien 60, 62, 144, 197, 365, 372, 384, 393

Winchester 100, 101

Winneberg 361

Wismar 18, 36-38

Wittenberg $25,28,30,33,44,46,75,343$, $383,384,387$

Worms 27, 28

Wuppertal 132f.

Württemberg 397

Würzburg $78,88,385$

Yorkshire 93

Ypern 79, 97

Zanigrad 277

Zerbst 389

Zeulenroda 49

Zeven 361

Ziegenrück 43, 48

Zorndorf 361

Zürich 19, 300, 390

\section{Personenregister $^{2}$}

Abbas I. (Schah von Persien) [15861628] 187,200

Ağa, Ġażanfer [ 1550-1603] 219-223, 233

Ağa, Mehmed 223, 233

Aguilar, Ambrosio Pablo de 248

Ahmed III. (Sultan) [1703-1730] 224, 227
Aḥmed Paşa s. Bonneval, Claude-Alexandre de

Albo, Jacob Abraham [geb. 1721] 342f.

Albrecht VII. (Erzherzog von Österreich) [1559-1621] 96, 108

Albrecht von Brandenburg (Kurfürst von Mainz) [1490-1545] 385, 396, 397

2 Kursiv gesetzte Seitenzahlen verweisen auf Erwähnungen in den Anmerkungen; Geburtsdaten von lebenden Personen werden nicht angegeben. 
Aldobrandini, Pietro [1571-1621] 108

Allen, William [1532-1594] 81, 102, 105, 109f., 111

Alst, Peter [1535-1595] 391

Alvares, Manoel 142

Alvares, Ximenes 142

Ahmad al-Wansarisi [ 1430/1-1508] 237

Amerbach, Vitus [1503-1557] 383

Amsdorf, Nikolaus von [1483-1565] 42, 45f., 50, 53, 54, $55 \mathrm{f}$.

Amsinck, Zimbert [1696-1762] 161

Angelus a Sancto Ioseph 193, 202, 205

Angers, Valentin d' 203, 207

Annas 277

Anna von Oldenburg [1501-1575] 18

Anquin, Rogal 304

Antonii, Gothofredus [1571-1618] 390

Armas, Joseph de 309

aš-Šahrastānī, Tāă ad-Dīn Abū 'l-Fatḥ Muhammad ibn 'Abd al-Karīm [ 10861153] 224

August (Kurfürst von Sachsen) [15261586] 43, 48f., 52, 387

Augustin von Hippo [354-430] 10

Ávila, Alonso de [1539-1566] 271

Ávila, Gil Gonzáles de [gest. 1543] 271

Avontroot, Johann [1559-1633] 293-321

Bachoven, Reinhard 395

Backereel, Hermen 34, 36

Bade, Klaus J. 4

Baffo, Violante 220

Baier, Dirk 341

Bailey, Gauvin Alexander 268f.

Balguerie, Isaac 153

Barchowsky, David [geb. 1713] 347

Bardili, Carl [1600-1647] 378

Barnim IX. (Herzog von Pommern) [15011573] 383

Báthory, Stefan (König von Polen-Litauen) [1533-1586] 331

Baudoin, François [1520-1573] 391
Benoist, Elie [1640-1728] 171

Berenberg, Johann 161

Berenberg, Rudolf 161

Berger, Peter L. 348

Berghe, Nicolaus von den 17

Berliner, Rudolf 277

Beyer, Hartmann [1516-1577] 23, 26

Bhabha, Homi K. 267, 269, 278

Bialik, Chaim Nachman [1873-1934] 65

Bishop, William [1554-1624] 88

Blaurer, Albert [1543-1592] 391

Bleda, Jaime [gest. 1634] 261, 263

Bodeck, Johann von [1555-1631] 122

Boeglin, Michel 239

Bonneval, Claude-Alexandre de / Aḥmed Paşa [1675-1747] 226-228, 232f.

Boué, Anne-Marie 153

Boué, Jacques 162

Boué, Jean-Alexandre [1706-1781] 153

Boué, Pierre [1677-1745] 153, 161-163

Boué, Pierre [1738-1802] 158f.

Bouquin, Pierre [ 1515-1582] 391

Boyer, Jean 161

Braubach, Peter [ 1500-1567] 23-25, 28

Braun, Nicolaus [1558-1639] 390, 396

Brenz, Johannes [1499-1570] 26

Browne, Maximilian Ulysses [17051757] 371-373

Bruchsal, Alexander 20

Bruguier, Alexandre 161

Bucer, Martin [1491-1551] 10, 15

Bugenhagen, Johannes [1485-1558] 20, $24,33,383$

Bullens, Hans 296

Bulliet, Richard 228

Bullinger, Heinrich [1504-1575] 16, 19, $21,25,39$

Burckhardt, Regina [1599-1669] 378

Burkhart, Louise M. 275

Büsch, Johann Georg [1728-1800] 162

Buscoducensis, Heinrich [gest. 1576] 24, 33 
Bustamante, Francisco de 271

Butler, Charles [1750-1832] 101

Bzowski, Abraham [1567-1637] 331, 334

Caesar, Philipp 51

Calvin, Johannes [1509-1564] 10, 19, 20, 21f., 23, 24-28, 30, 31, 39, 124, 300

Cardaillac, Louis 253

Cardona, Sancho de [geb. 1474] 240

Cassander, Georg [1513-1566] 14, 23

Castro, Benedikt de [1597-1684] 145

Castro, Rodrigo de [1546-1627/30] 145

Çelebizāde, İsmā $\overline{1}^{\mathrm{i}}{ }^{\mathrm{c}}{ }^{\mathrm{A}} \mathrm{s}$ ı̣m [gest. 1760/6] $225 f$.

Cervantes, Miguel de [1547-1616] 256

Chajim Hameln 61f., 72

Chamberlain, George [1576-1634] 109

Chardin, Jean [1643-1713] 204f.

Chaunu, Pierre [1923-2009] 174

Chaussinand-Nogaret, Guy 174

Chemnitz, Martin [1522-1586] 50

Chevalier de la Barre s. Lefèbvre, JeanFrançois

Chézaud, Aimé [gest. 1664] 192, 202, 208

Chinon, Gabriel de [1610-1670] 204

Christian, Paulus [geb. 1599] 339, 343

Christian I. (Kurfürst von Sachsen) [15601591] 387

Christian II. (Kurfürst von Sachsen) [15831611] 387

Christian III. (König von Dänemark und Norwegen) [1503-1559] 17, 34, 36, 39

Christian IV. (König von Dänemark und Norwegen) [1577-1648] 145

Christian V. (König von Dänemark und Norwegen) [1646-1699] 152

Christian VI. (König von Dänemark und Norwegen) [1699-1746] 163

Christina von Schweden (Königin) [16261689] $80,121,123,144,151 f$.

Chytraeus, Nathan [1543-1598] 388
Cicala, Carlo 221

Cicala, Scipione [1545-1605] 218, 221, 230

Çı̆̆ālazāde, Yūsuf Sinān Paşa s. Cicala, Scipione

Clayesen, Gaspar Nicolás 305, 309f

Clemens VIII. (Papst) [1536-1605] 108, 111

Clemens IX. (Papst) [1600-1669] 152

Clemens XIV (Papst) [1705-1774] 399

Cohen de Lara, David [1602-1674] 145

Colbert, Jean-Baptiste [1619-1683] 153, $157,164,166$

Colford, Gabriel 102

Combach, Johannes [1585-1651] 396

Connok, Edward 200

Conseilleire, Pierre Emerence de la [16451699] 149

Concenatius, Jacob 391

Coot, Johann $313 \mathrm{f}$.

Cordus, Euricius [1486-1535] 386

Cornelius a Sancto Cypriano 207

Cortés, Hernán [1485-1547] 270

Cranmer, Thomas [1489-1556] 14, 15f.

Crespin, Jean [ 1520-1572] 30, 32, 293

Creswell, Joseph [1557-1623] 86, 100

Crocius, Johannes [1590-1659] 396

Cromwell, Oliver [1599-1658] 82

Cruciger, Caspar der Jüngere [15251597] 387

Cruciger, Georg [1575-1637] 396

Curiel, Jacob s. Nunes da Costa, Duarte

Dale, María van 297f., 308, 320

Dale, Paul van 297

Daun, Leopold Joseph Maria [17051766] 372

Davis, Natalie Zemon 70

Dean, Carolyn 267, 278

Deichmann, Christoph [1676-1648] 390

Desvignes, Michel Raymond [17041757] 189f. 
Diedon, Robert 319

Dillon, Anne 106f.

Dingel, Irene 56

Dobbin, Nikolaus [1536-1614] 391

Domínguez Ortiz, Antonio [19091972] 250

Dominicus, Johann Jacob [1731-1775] 362f., 367f.

Donellus, Hugo [1527-1591] 391

Dorothea Susanna (Herzogin von Sachsen Weimar) [1544-1592] 41, 50, 51

Draconites, Johannes [1494-1566] 386

Dubin, Lois C. 166

Duitsch, Christian Salomon [1734-1795] 337f., 340, 343-354

Dulcis, Catharinus [1540-1626] 396

Edward VI. (König von England und Irland) [1537-1553] 15-17, 32

Edzard, Carol Christian [geb. 1651] 342f.

Efendi, ${ }^{\mathrm{c}} \mathrm{Al} \overline{1} \quad 224$

Efendi, Nūḥ [gest. 1707] 223-225, 227

Efendi, Süleymān 224

Egenolff, Christian [1502-1555] 24

Eger, Joachim 387

Egli, Raphael [1559-1622] 390

el-Hāacc, Beşīr Ağa [gest. 1746] 227

Elias Gomperz von Kleve 62

Elisabeth I. (Königin von England) [15331603] 32, 106, 108, 305

Eliseus a Sancto Andrea 197

Ellenberger, Heinrich [ 1570-1624] 390

Emden, Jacob [1697-1776] 64

Englefield, Francis [1520-1596] 95

Erasmus von Rotterdam [1466/9-1536] 10

Erastus, Thomas [1524-1583] 391

Erve / Ctematius, Gellius van der [gest. nach 1566] 17, 24

Esther von Hameln 62

Étoile, Angela de l' 193

Étoile, François de 1' 193

Étoile, Isaac Boutet de l' 192f., 208
Étoile, Louis de l' 193

Étoile, Reine de l' 191-193, 195

Faber, Ulrich 391

Fabritius, Ludwig 205

Farel, Guillaume [1489-1565] 25

Farnese, Alessandro [1545-1592] 79

Farnese, Ottavio [1524-1586] 101

Fedeli da Milano, Barnaba [16631731] 188, 193f., 208-210, 212

Feilchenfeld, Alfred [1860-1923] 60, 72

Felß, Christian Lebrecht [1640-1719] 351

Fénelon, François de Salignac de la Mothe [1651-1715] 154

Ferdinand II. (Kaiser) [1578-1637] 315

Fermor, Wilhelm Graf von [nach 17001771] 360f.

Fernández de Granada, Miguel 250

Ferrer, Vincenz [1350-1419] 329

Flacius Illyricus, Matthias [1520-1575] $20,43,44-47,53$

Floor, Willem 189

Foster, William Henry 367

Franciscus Maria a Sancto Siro 197

François, Etienne $\quad 176,182$

Frangipani, Ottavio Mirto [gest. 1612] 108, 109

Frank, Walter [1905-1945] 138

Freud, Siegmund [1856-1939] 60

Freyhub, Andreas [gest. 1576] 387

Friderich, Christian [geb. 1672] 342, 344

Friederici, Ernst August [geb. 1744] 346348

Friedrich (Herzog von MecklenburgSchwerin) [1717-1785] 398

Friedrich, Carl Wilhelm [geb. ca. 1760] 348

Friedrich II. (König von Preußen) [17121786] 357f.

Friedrich III. (Kurfürst von der Pfalz) [1515-1576] 391 
Friedrich III. (Herzog von Schleswig-Holstein-Gottorf) [1597-1659] 199

Friedrich IV. (König von Dänemark und Norwegen) [1671-1730] 165

Friedrich IV. (Kurfürst von der Pfalz) [1574-1610] 391

Friedrich V. (Kurfürst von der Pfalz) [15961632] 315,395

Friedrich Wilhelm I. (Herzog von SachsenWeimar) [1562-1602] 48

Friedrich Wilhelm III. (König von Preußen) [1770-1840] 181

Frommann, Simon [geb. 1761] 347

Frost, John 208

Fryer, John [ 1650-1733] 187, 197, 205f.

Gante, Pedro de [ 1486-1572] 271, 273

Gaspar, George 305

Gaubisch, Urban [1527-1592] 41

Ġāzī, Aḥmed Paşa 227

Geer, Louis de [1587-1652] 120

Gennep, Arnold van [1873-1957] 345, 348

Gerçek, Dāvud Ağa [gest. 1733/4] 225f., $232 \mathrm{f}$.

Gernhard, Bartholomäus [1525-1600] 41-58

Girardin, Stanislas de [1762-1827] 196

Glikl bas Juda Leib / Glückel von Hameln [1646/7-1724] 59-73

Glozier, Matthew 356

Goclenius, Rudolf, der Ältere [15471628] 396

Goddaeus, Johannes [1555-1632] 396

Godefroy, Denis [1549-1622] 391

Godske, Peter 35

Goethe, Johann Wolfgang von [17491832] $122 \mathrm{f}$.

Gómez Aco, Ernesto 272

Gómez de Sandoval y Rojas, Francisco, Duque de Lerma [1598-1635] 312, 314

Gostomski, Anzelm [ca. 1508-1588] 324
Gouvest, Maubert de [1721-1767] 358

Graff, Ludwig d. J. [1547-1615] 391

Gregor XIII. (Papst) [1502-1585] 110f.

Groenenberg, Jakob 297, 308, 310

Grotehenn, Johann Heinrich Ludwig [17341786] 361-363

Gruneweg, Martin [1562- ca. 1618] 9, 323-336

Gruterus, Janus [1560-1627] 391

Guidi di Bagno, Giovanni Francesco [15781641] 109

Guilday, Peter [1884-1947] 84, 94

Guise, Heinrich von [1550-1588] 103

Gundermann, Christoph [gest. 1592] 387

Gustav II. Adolf (König von Schweden) [1594-1632] 396

Gutiérrez, Alonso 257, 258

Guzmán de Pimentel, Gaspar, Conde-duque de Olivares [1587-1645] 317

Gwynn, Robin 172

Haemstede, Adrian von [1525-1562] 130, 131

Harboe, Ludwig [1709-1783] 32

Hedges, William [1632-1701] 198f.

Heer, Friedrich [1913-1983] 113

Heinrich VIII. (König von England) [14911547] 106

Hekīmoğlu 'Alī Paşa [1689-1758] 227

Hennin, Pierre-Michel [1728-1807] 196

Hermann, Johann [1527-1605] 387

Hermite, Jacques 1' [1582-1624] 311, 316

Herodes 271, 277, 278

Heshusius, Tilemann [1527-1588] 49f.

Hessus, Eobanus [1488-1540] 386

Heyberger, Bernard 185, 212

Hintze, Otto [1861-1940] 123

Hirschlein, Christian Gottlieb [gest. nach 1768] 344

His, Louise Madeleine 163

His, Pierre François [1692-1760] 158, 161, 163 
Hoca İbrāhīm [gest. 1713] 226

Hoerder, Dirk 169

Hogarth, William [1697-1764] 359

Hölderlin, Johann Christian Friedrich [1770-1843] 378

Holert, Tom 266

Horb, Johann Heinrich [1645-1695] 147

Hügel, Andreas [1500-1578] 44

Hülsen, Carl Wilhelm von [1734-1810] 363

Husain, Sultan [1668-1726] 189, 191

ibn Muștafāa, Nūḥ [gest. 1659] 224

İbrāhīm Paşa 225, 226

Idiáquez, Juan 256

Innozenz XII. (Papst) [1615-1700] 90

Israel, Jonathan Irvine 141

Itzcoatl [1380-1440] 272, 286

Iudae, Hyacinthus [ca. 1572-1605] 334

Iudex, Matthäus [1528-1564] 47

Jakob I. (König von England) [15661625] $81,100,106,110$

Jellinek, Georg [1851-1911] 123

Johann IV. (Herzog von Sachsen-Lauenburg / Bischof von Hildesheim) [gest. 1547] 50

Johann Casimir (Pfalzgraf von Pfalz-Simmern), [1543-1592] 391

Johann Friedrich von Schleswig-HolsteinGottorf (Erzbischof von Bremen) [15791634] 199

Johann Friedrich II. (Herzog von Sachsen) [1529-1595] 44-49, 55

Johann Sigismund (Kurfürst von Brandenburg) [1572-1619] 392

Johann Wilhelm (Herzog von Sachsen Weimar) [1530-1573] 43, 48-50, 55

Johanna I. (Königin von Kastilien) [14791555] 235, 237

Jon, François de, der Ältere [15451602] 391
Joseph II. (Kaiser) [1741-1790] 97

Joutard, Philippe 175

Judas 271f., 274, 277, 278, 281

Julius (Herzog von Braunschweig-Wolfenbüttel) [1528-1589] 50

Jungnitz, Christoph [gest. 1540] 395

Jurieu, Pierre [1637-1713] 171

Kaempfer, Engelbert [1651-1716] 205

Kafka, Franz [1883-1924] 345

Kāḩyā, İbrāhīm Paşa 226

Kahle, Ludwig Martin [1712-1775] 357f.

Kaiphas 271, 277, 278

Kaplan, Yosef 131-133

Kapral', Miron 325

Karim Khan Zand [ 1700-1779] 189

Karl IX. (König von Schweden, Herzog von Södermannland) [1550-1611] 80

Karl I. (König von England) [16001649] 98,106

Karl II. (König von England) [16301685] 106

Karl V. (Kaiser) [1500-1558] 15, 235, 237

Kaufmann, David [1852-1899] 60f.

Kavanagh, Karl Graf von 372

Kellenbenz, Hermann [1913-1990] 138

Kemper, Engelbert s. Kaempfer, Engelbert

Kepler, Johannes [1571-1630] 389

Kersten, Georg 324

Kilıç, 'Alī Paşa [ 1496-1578/87] 213

Kimedoncius, Abraham [gest. 1625] 391

Kimedoncius, Jacob [1554-1596] 391

Knab, Sebastian [1628-1690/91] 188

Knothe, Jakob [ca. 1490-1564] 323

Knox, John [1514-1572] 82

Krafft, Adam [1493-1558] 386

Krell, Wolfgang [1535-1593] 387

Kretzenbacher, Leopold [1912-2007] 276

Krusinski, Tadeusz Juda [1675-1756/7] 191, 194 
Kubler, George [1912-1996] $268 f$.

Lacy, Franz Moritz von [1725-1801] 372

Lannoius, Matthaeus, der Ältere [15411586] 391

Lapeyre, Henri 262

Lara, Jaime 270

Lasco, Johannes a (Laski, Jan) [14991560] $14,15-33,39,124,134 \mathrm{f}$.

Laud, William [1573-1645] 172

Laymann, Paul [1575-1635] 208

Leander a Sancta Caecilia 199

Lefèbvre, Jean-François [1647-1766] 365

Leibsohn, Dana 267, 278

Lemcke, Jakob Friedrich von [17381810] 366

Léonard, Emile Guillaume [1891-1961] 175

Leonart, Felipe 302

Le Roy Ladurie, Emmanuel 174

Lerma, Herzog von s. Gómez de Sandoval y Rojas, Francisco

Lersner, Hermann [1534-1618] 390

Lewis, Owen [1533-1595] 110

Lievent, Hieronymus 307

Linck, Catharina Margaretha [1687-1721] 356

Lion, Claude du 157

Lockhart, James 274

López Madera, Gregorio [1574-1640] 241, 261

Lorenzo, Tobias 305

Lubomlczyk, Severin [1532-1612] 331, 334

Luckmann, Thomas 348

Ludwig IV. (Landgraf von Hessen-Marburg) [1537-1604] 390

Ludwig V. (Landgraf von Hessen-Darmstadt) [1577-1626] 390

Ludwig VI. (Kurfürst von der Pfalz) [15391583] 391
Ludwig XIII. (König von Frankreich) [1601-1643] 187

Ludwig XIV. (König von Frankreich) [1638-1715] 163,153,156, 160, 164, $166,171,174,187$

Luther, Martin [1483-1546] 17, 19, 20, 28, 41, 43, 44f., 46, 47-49, 52f., 54, 55, 57f., 75, 135f., 299, 308, 331, 369, 386

Madaleno, Francisco 308

Mader, Theophil [1541-1604] 391

Mader, Timotheus [ca. 1545-nach 1592] 391

Maius, Heinrich [1545-1607] 387

Mangon, Abraham [ 1666-1734] 31

Manrique, Andrés 310

Mans, Raphaël du [gest. 1696] 192, 203-206

Maria 300, 362

Maria I. (Königin von England) [15161558] 16f., 32, 80, 112, 118, 134

Maria I. (Königin von Schottland) [15421587] 99

Maria Theresia (Erzherzogin von Österreich, Königin von Ungarn) [17171780] $358,365,371$

Martell, Karl [ 688-741] 114

Martínez, Fernando (Erzdiakon von Écija) [gest. 1404] 116

Matthaeus, Antonius [1564-1637] 396

Maximilian I. (Kurfürst von Bayern) [15731651] 395

Mayer, Johann Friedrich [1650-1712] 146

Mayne, Cuthbert [1543/44-1577] 106

McGuire, Johann Sigismund Graf von [1711-1767] 372

Mehmed III. (Sultan) [1566-1603] 220, 328

Mehmed IV. (Sultan) [1642-1693] 224

Meir (Rabbi) [2. Jhd.] 66

Melanchthon, Philipp [1497-1560] 23, 27f, 30, 43, 44, 49, 55, 75, 386, 387

Mendizábal, Juan Álvarez [1790-1853] 312 
Meschinet, Pierre Samuel de [gest. 1807] 153

Mentzer, Balthasar I. [1565-1627] 390

Menzel, Hieronymus [1527-1590] 50

Mercier, Claude-Ignace [gest. 1674] 198, 202

Mersmann, Birgit 266

Messerschmidt, Johann 47

Messía Lobo, Gonzalo 306

Meyer, Jean 162

Michael (Graf von Greyerz) [15391575] 78

Michelet, Jules [1798-1874] 174

Micron, Marten [1523-1559] 17f., 21, 33, 36, 37f., 39

Milano, Barnaba Fedeli da [gest. 1731] 193f., 208

Milner, John [1752-1826] 101

Moeller, Heinrich [1530-1589] 387

Molther, Johannes der Ältere [1561-1618] 390

Molther, Johannes der Jüngere [geb. 1591] 396

Monterrosa, Mariano 271, 278

Montesquieu, Charles Louis de [16891755] $173 f$.

Monteverde, Ana de 297

Monteverde, Melchor de 297, 308

Morgado, Alonso 248

Moritz (Landgraf von Hessen-Kassel) [1572-1632] 390, 396

Moritz (Kurfürst von Sachsen) [15211553] 43,46

Mörlin, Maximilian [1516-1584] 47

Morray, Juan 304

Mose 256, 257

Müller, Johannes [1590-1673] 145f

Murād III. (Sultan) [1546-1595] $220 \mathrm{f}$

Musaeus, Simon [1521-1576] 47

Mușțafā II. (Sultan) [1664-1703] 224

Mylius, Georg [1548-1607] 387
Nairac, Guillaume [1705-1793] 153

Nehemias, Baruch s. Castro, Benedikt de Neumeister, Erdmann [1671-1756] 152

Nevşehirli, Dāmād İbrāhīm Paşa [ 16601730] 226, 231

Niger, Antonius [1500-1555] 386

Noviomagus, Paul [gest. 1571] 17, 33

Nunes da Costa, Duarte [1585-1664] 143f.

Oberman, Heiko Augustinus [1930-2001] $38,134 \mathrm{f}$.

Ochino, Bernardino [1487-1564] 25

Ochs, Albrecht [1716-1780] 163

O'Donnell, Heinrich, Graf von [1726-1789] 372

O’Mahony, Demetrius, Graf von [gest. 1777] 372

Odrowąż, Severinus aus Luboml s. Lubomlczik, Severin

Olearius, Adam [1603-1671] 199

Olivares, Herzog von s. Guzmán de Pimentel, Gaspar

Onnekink, David 356

Oporinus, Johannes [1507-1568] 25, 30f.

Orzechowski, Stanisław [1513-1566] 336

Otter, Jean [1707-1748] 189

Ottheinrich (Kurfürst von der Pfalz) [15021559] 390f.

Overschie, Nicolaas Jacobsz [gest. nach 1638] 194

Ovid [43 v. Chr. $-\sim 17$ n. Chr.] 319

Pacius, Julius [1550-1635] 391

Padilla, Luis de 304

Palladius, Peder [1503-1560] 34

Pallu, François [1625-1702] 192

Pantoja, Gutierre 223, 230, 233

Pappenheim, Bertha [1859-1936] 60f., 70, $72 \mathrm{f}$.

Pappenheim, Wolf [gest. 1881] 60

Pauli, Heinrich (Arsenius) [gest. 1575] 384 
Paulus 2

Paulusin, Friederica [geb. 1752] 339, 341, 344

Paz, Sebastián de 299

Pech, Sebastian 30f.

Peraza de Ayala y Castilla Rojas, Antonio [1568-1626] 311

Percy, Mary [gest. 1572] 95

Persons, Robert [1546-1610] 81, 95, 101, $102 \mathrm{f}$.

Perussel, François [1542-1565] 21

Peterson, Jeanette Favrot 268

Petrus 107, 271, 277, 278

Peucer, Caspar [1525-1602] 387

Pezel, Christoph [1539-1604] 387, 388

Philipp I. (Landgraf von Hessen) [15041567] 386

Philipp I. (Herzog von Pommern-Wolgast) [1515-1560] 383

Philipp II. (König von Spanien) [15271598] 95, 111, 236, 241-243, 246f., $255,260,263$

Philipp III. (König von Spanien) [15781621] $187,261,312,313,314$

Philipp IV. (König von Spanien) [16051665] 293, 317

Philippus Maria a Sancto Augustino 199

Pierius, Urban [1546-1616] 387

Pithopoeus, Lambert Ludolf [15351596] 391

Pius V. (Papst) [1504-1572] 93, 111, 300

Plunket, Oliver [1625/29-1681] 106

Plunkett, Thomas Freiherr von [17161779] 372

Pontius Pilatus 271, 277, 278

Portus, Aemilius [1550-1614/15] 391

Poullain, Valerand [1515-1558/60] 23, 27

Poynter, William [1762-1827] 101

Prada, Andrés de [gest. 1611] 313

Prittwitz, Christian Wilhelm von [17391807] 363-367
Priuli, Antonio (Doge von Venedig) [15481623] 315

Quinaloc, David 319

Quiroga, Gaspar de [1514-1594] 305

Rab, Christoph [1552-1620] 32

Ramus, Petrus [1515-1572] 391

Rāşid, Meḥmed [1660-1735] 223, 224

Redondo, Alonso 308f.

Rehburg, Maria Lucia [geb. 1723/24] 342

Reiss, Athene 277

Rhode, Gotthold [1916-1990] 333

Rhoding, Bartholomäus [ 1550-1626] 32

Ribera, Juan de [1532-1611] 260

Rojas, Pedro [1919-1984] 270f.

Rosales, Jacob [vor 1593-nach 1662] 144

Rosen, Jonathan 324

Rousseau, Isaac [1672-1747] 191

Rousseau, Jacques [1679-1753] 190f., 193-195, 197

Rousseau, Jean-François-Xavier [1738nach 1773] 193, 195f.

Rousseau, Jean-Jacques [1712-1778] 191

Rousseau, Maria-Theresia-Regina 195

Rousseau, Marie 191

Rousseau, Théodore 196

Rowlands, Richard s. Verstegan, Richard

Rüdinger, Esrom [1523-1590] 387

Rudolf II. (Kaiser) [1552-1612] 389

Ruymbeke, Bertrand Van 155

Sabbatai Zwi [1626-1676] 67, 68

Sagnac, Philippe [1868-1954] 174

Sahid, Anne-Marie [1751-1816] 195

Sahid, Elias 210

Salazar, Graf von s. Velasco, Bernardino de

Salazar de Mendoza, Pedro [15491629] 251

Salgado de Faria, Andrés 297-299

Salvatierra, Martín de [1525-1604] 260

Samuel 352 
Sánchez Doria, Rodrigo 258

Sapieha, Lew [1557-1633] 334

Savoyen-Carignan, Eugen von [16631736] 227

Schaller, Hieronymus [gest. 1581] 387

Schiller, Friedrich von [1759-1805] 369

Schiller, Johann Caspar [1723-1796] 369

Schilling, Heinz 35, 38, 76, 85, 102

Schipano, Mario [gest. vor 1650] 200

Schmedenstede, Heinrich [gest. 1554] 38

Schneider, Eulogius [1756-1794] 400

Schnepf, Dietrich [1525-1586] 378

Schnepf, Erhard [1495-1558] 44, 378, 386

Scholl, Johannes 390

Schönefeld, Gregor der Jüngere [gest. 1625] 396

Schönfeld, Gregor der Ältere [15591628] 390

Schorer, Nicolaas 194,208

Schort, Manfred 357

Schrader, Fred 153

Scoville, Warren [1913-1969] 153, 160, $173 f$.

Sebastián, Santiago 271

Seignelay, Jean Baptiste [1651-1690] 154

Selānikī, Muștafā [1563-1599] 222

Selīm II. (Sultan) [1524-1574] 219f.

Selnecker, Nikolaus [1530-1592] 387

Semüz, Aḥmed Paşa [ 1527-1580] 222

Şeyhī, Meḥmed [1666-1717] 224

Seymour, Edward, Duke of Somerset [ 1500-1552] 15

Sigismund II. August (König von Polen) [1520-1572] 24f.

Sigismund III. Wasa (König von Polen) [1566-1632] 80,86

Sılıḥār, Halīl Ağa $221 f$.

Simons, Menno [1496-1561] 36, 36, 37

Sixtus V. (Papst) [1521-1590] 111

Skarga, Piotr [1536-1612] 329

Sohn, Georg [1551-1589] 391

Solikowski, Jan Dymitr [1583-1603] 334
Sömmerring, Samuel Thomas [1755-1830] 400

Soner, Ernst [1572-1612] 389

Sonnenfels, Joseph von [1732/33-1817] 398

Spangenberg, Cyriacus [1528-1604] 51

Spinoza, Baruch de [1632-1677] 130

Stanley, William [1548-1630] 94

Story, John [1504-1571] 81

Stössel, Johann [1524-1576] 46f.

Strigel, Victorinus [1524-1569] 44-47, 391

Stuart, Maria s. Maria I. von Schottland

Studemund-Halévy, Michael 164

Sturm, Caspar [1550-1625] 390,396

Sturm, Christian [1597-1628] 396

Sulțān, Fāṭma 221, 222

Sulțān, Nūr Bānū [ 1525-1583] 220

Süreyyā, Meḥmed [1845-1908] 222, 224

Taaffe, Nikolaus von [1677-1769] 371

Täge, Christian [1724-1807] 360f.

Tapia Sánchez, Serafín de 237, 248, 259

Tavernier, Jean-Baptiste [1605-1684/9] 204

Terán, José Antonio 271, 278

Texeira, Diego [1581-1666] 143f.

Texeira, Manoel [1625-1705] 144-146

Texier, Bernard 161

Thadden, Rudolf von 182

Thévenot, Jean de [1633-1667] 209

Thompson, James 104

Tilhac, Jacques 201, 206

Timann, Johann [vor 1500-1557] 24, 24

Țopal, ' Ossmān Paşa [1663-1733/4] 227

Toussaint y Ritter, Manuel [1890-1955] 271

Trautzschen, Hans Carl Heinrich von [1730-1812] 369f.

Tremellius, Immanuel [1510-1580] 391

Tudor, Maria s. Maria I. von England

Tully, Claus J. 341 
Utenhove, Jan [1520-1565] 13-40

Valadés, Diego [1533-1582] 272f.

Valle, Pietro della [1586-1652] 200

Vauban, Sébastien [1633-1707] 173

Velasco, Bernardino de, Conde de Salazar [gest. 1621] 262

Venedikli, Hasan Paşa 213

Venier, Nicolo [ca. 1483-1530] 220

Vergil [70-19 v. Chr.] 319

Vermigli, Pietro Martyr [1500-1562] 15

Verstegan, Richard [1548-1640] 81, 101f., 104, 111

Vietor, Theodor [1560-1645] 396

Villotte, Jacques [1656-1743] 198, 211

Vincent, Bernard 250

Voit, David [1530-1589] 387

Volckmar, Johannes [1666-1715] 147

Voltaire [1694-1778] 173-175

Wallenstein, Albrecht von [15831634] 389, 397

Ward, Maria [1585-1645] 97, 104

Weber, Max [1846-1920] 123, 133, 174

Wegener, Henrietta [geb. 1748] 339, 342, 344
Weideman, Melchior [gest. nach 1562] 47

Wennecker, Anton [gest. nach 1784] 399

Wentzel, Heinrich Friedrich [geb. 1666/67] 342

Wesenbeck, Matthias [1531-1586] 45f.

Westphal, Joachim [1510-1574] 19-21, $23-28,30-32,38$

Widebram, Friedrich [1532-1585] 387

Wigand, Johannes [1523-1587] 41, 43, 46, $49,53,54,56 f ., 58$

Winckelmann, Johannes [1551-1621] 390

Winckler, Johann [1642-1705] 147

Winter, Balthasar [gest. nach 1560] $45 f$.

Witekind, Hermann [1522-1603] 391

Wolrad II. (Graf von Waldeck-Eisenberg) [1509-1575] 51

Yardeni, Myriam $\quad$ 173, 175, 181

Ybáñez, Francisco 309

Yeğen, Meḥmed Paşa [gest. 1745] 227

Zanchi, Hieronymus [1516-1590] 391

Zarvossi, Ernst Christian [ca. 1620-1681] 348

Zippora von Hameln $\quad 62,68$

Zwingli, Ulrich [1484-1531] 25, 28 


\section{Vandenhoeck \& Ruprecht}

Veröffentlichungen des Instituts für Europäische Geschichte Mainz Beiheft 81

Ein Kennzeichen des frühneuzeitlichen Europa ist die enorme Zunahme von Mobilität, ermöglicht durch bessere Verkehrswege und technische Neuerungen. Religion konnte sich hemmend wie befördernd auf Mobilitätsprozesse auswirken. So lösten etwa die konfessionelle Spaltung und die nachfolgende Konfessionalisierung die Auswanderung ganzer Claubensgemeinschaften innerhalb Europas und nach Öbersee aus.

Die Beiträger möchten religions-und migrationsgeschichtliche Fragestellungen zusammenführen. Im Mittelpunkt steht die Frage nach dem Stellenwert von Mobilität für die Ausbildung oder Auflösung religiös-konfessioneller Identitäten im frühneuzeitlichen Europa.

Mit Beiträgen von Matthias Asche, Bettina Braun, Almut Bues, Cesine Carl, Manuel F. Fernández Chaves, Marian Füssel, Rafael M. Pérez García, Henning P. Jürgens, Margit Kern, Felix Konrad, Susanne Lachenicht, Matthias Morgenstern, Vera von der Osten-Sacken, Heinz Schilling, Klaus Weber, Thomas Weller und Christian Windler.

\section{Die Herausgeber}

Dr. phil. Henning P. Jürgens ist Wissenschaftlicher Mitarbeiter am Institut für Europäische Geschichte Mainz.

Dr. phil. Thomas Weller ist Wissenschaftlicher Mitarbeiter am Institut für Europäische Ceschichte Mainz. 